\title{
STRUCTURAL BEHAVIOUR OF ULTRA HIGH PERFROMANCE FIBRE REINFORCED CONCRETE COMPOSITE MEMBERS
}

\author{
By: \\ Luaay Hussein \\ B. Sc. in Civil Engineering, University of Baghdad, 1989 \\ MASc. in Civil Engineering, Ryerson University, 2011
}

\author{
A dissertation \\ presented to Ryerson University \\ in partial fulfillment of the \\ requirements for the degree of \\ (Doctor of Philosophy) \\ in the Program of \\ (Civil Engineering)
}

Toronto, Canada, 2015

(C) Luaay Hussein, 2015 


\section{AUTHOR'S DECLARATION FOR ELECTRONIC SUBMISSION OF A DISSERTATION}

I hereby declare that I am the sole author of this dissertation. This is a true copy of the dissertation, including any required final revisions, as accepted by my examiners.

I authorize Ryerson University to lend this dissertation to other institutions or individuals for the purpose of scholarly research

I further authorize Ryerson University to reproduce this dissertation by photocopying or by other means, in total or in part, at the request of other institutions or individuals for the purpose of scholarly research.

I understand that my dissertation may be made electronically available to the public. 


\title{
STRUCTURAL BEHAVIOUR OF ULTRA HIGH PERFROMANCE FIBRE REINFORCED CONCRETE COMPOSITE MEMBERS
}

\section{Luaay Hussein}

PhD, Department of Civil Engineering, Ryerson University, 2015

\begin{abstract}
The aging and deterioration of reinforced concrete infrastructures in North America present major technical and economical challenges to infrastructure owners. To effectively address some of the challenges, there is a need to develop innovative and cost-effective systems. The main objective of this research was to develop composite members of ultra-high performance fibre reinforced concrete and normal strength concrete or high strength concrete (UHPFRCNSC/HSC). In order to achieve this objective, the first phase of this research investigates the structural behaviour of UHPFRC with varying fibre content beams without web reinforcement. Test results indicated that the addition of $1 \%$ of steel fibres effectively improves the shear strength of UHPC beams by $77 \%$ due to the crack-bridging stress that develops across the crack surface. In the second phase, experimental studies were carried out on UHPFRC-NSC/HSC prisms and beams without stirrups to investigate the flexural and shear capacity of those composite members. Each beam specimen was designed to have the UHPFRC layer in tension and the NSC/HSC layer in compression. Additional varied parameters included fibre volume content, and shear connectors were investigated. Test results showed that the performance of the proposed composite system in terms of the flexural and shear capacity was successfully enhanced. All composite beams failed in shear at a force that is 1.6 to 2.0 times higher than that of the NSC/HSC beam's resistance. Test results showed that the effect of using HSC versus NSC in the composite beam was negligible, and the bond strength between the two concrete material layers (UHPFRC and NSC/HSC) was significantly high that the addition of shear connectors was unnecessary. In the third phase, an analytical and finite element models to predict the ultimate shear capacity of UHPFRC composite beams were proposed and validated with the experimental results. The results of the finite element analysis showed that the size effect in structures made of UHPFRC material has little influence on the shear capacity. Finally a comparison between the finite element model and the analytical model indicated that both
\end{abstract}


models developed in this research are capable of predicting the shear behaviour of UHPFRC and UHPFRC-NSC/HSC beams. 


\section{Acknowledgment}

The author would like to express his deepest appreciation to his supervisor Dr. Lamya Amleh, for her invaluable advice, guidance, suggestion, patient and encouragement throughout the execution of this research program. Her unfailing optimism and constant encouragement always prompted the author to overcome the difficulties in completing this research.

The author would like to express his sincerely thanks to the Civil Engineering Department in Ryerson University, and to the technicians in the structural, and concrete labs for their invaluable assistance throughout the execution of this research program.

The author also would like to thank, and acknowledge Lafarge Canada Inc. for providing the UHPC and expertise of Mr. Gaston Doiron.

Finally, the author is grateful to his family, colleagues, and all friends for their support, and encouragement throughout this work. 


\section{Table of Contents}

AUTHOR'S DECLARATION FOR ELECTRONIC SUBMISSION OF A DISSERTATION ..... ii

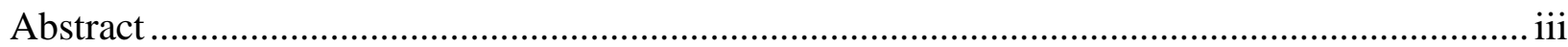

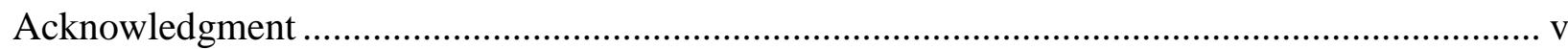

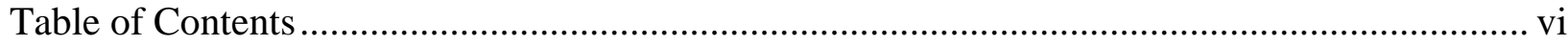

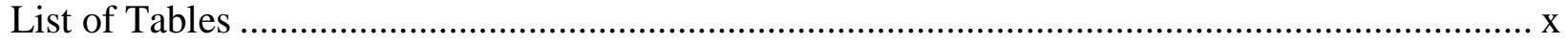

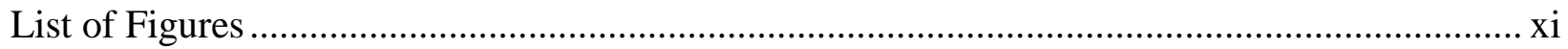

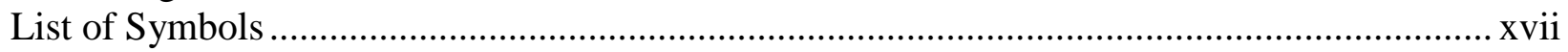

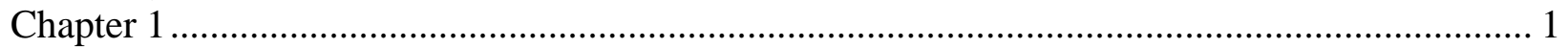

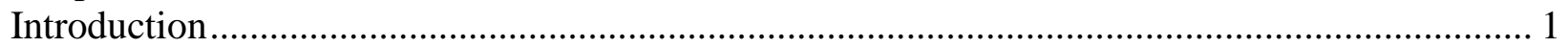

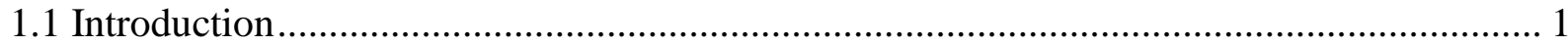

1.2 Objectives and Scope of the research ................................................................. 2

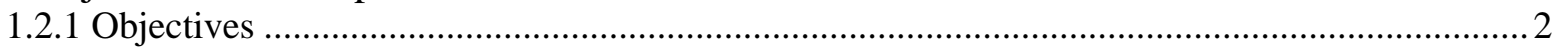

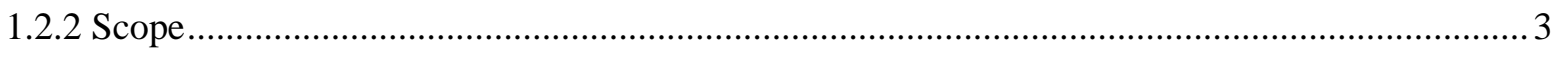

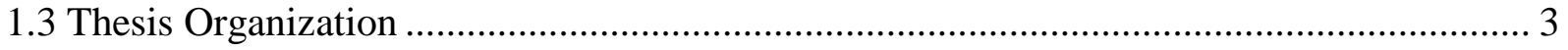

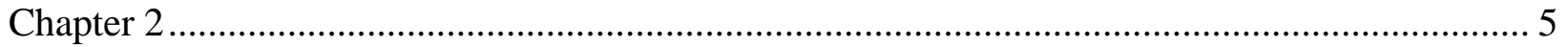

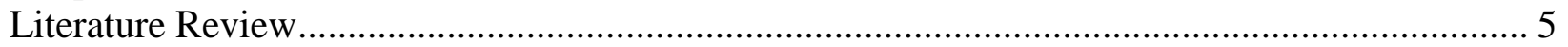

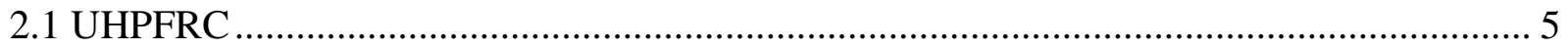

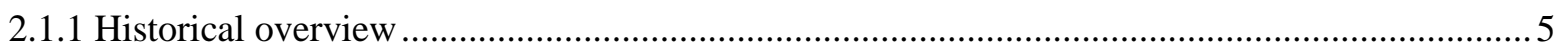

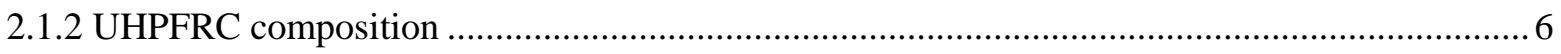

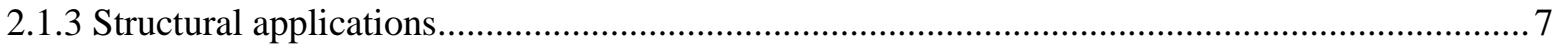

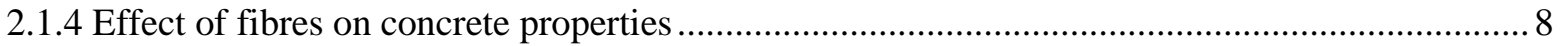

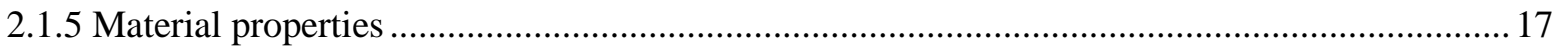

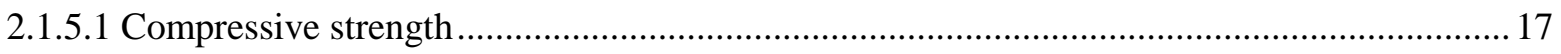

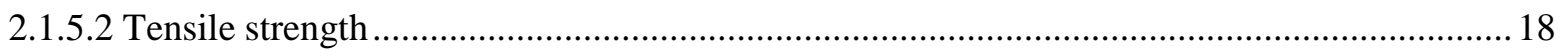

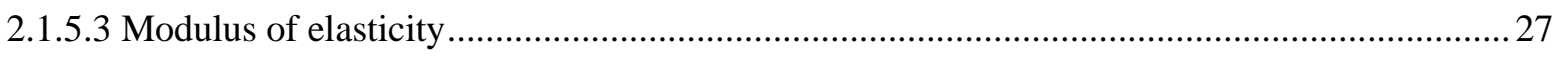

2.2 Shear behaviour of reinforced concrete beams ...................................................... 27

2.2.1 Shear stresses distribution and failure of plain concrete beams ........................................... 27

2.2.2 Shear in reinforced concrete beams without shear reinforcement ..........................................29

2.2.2.1 Inclined cracking pattern and modes of shear failure .......................................................29

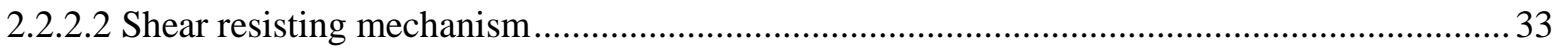

2.2.3 Shear in reinforced concrete beams with shear reinforcement .............................................. 34

2.2.4 Shear in steel fibre reinforced concrete beams without shear reinforcement............................ 35

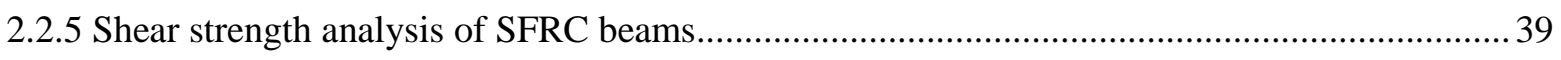

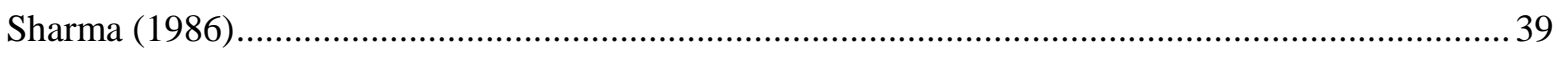

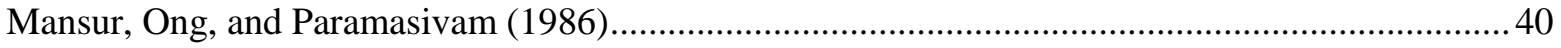

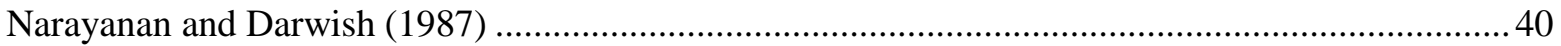




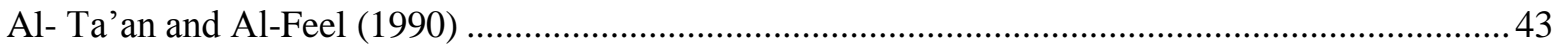

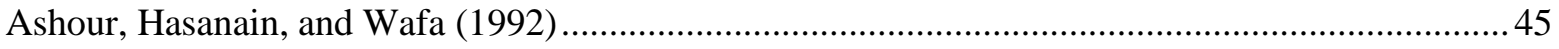

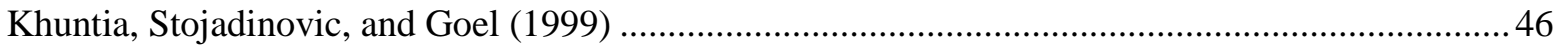

Kwak, Eberhard, Woo-Suk Kim, and Jubum Kim (2002) ........................................................... 47

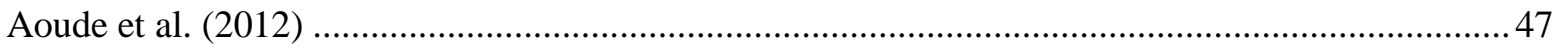

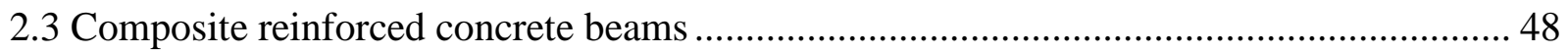

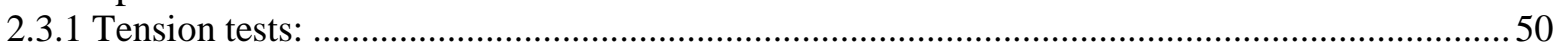

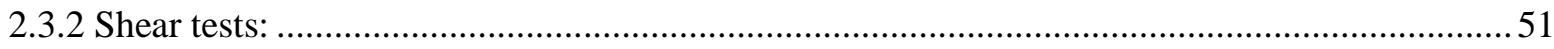

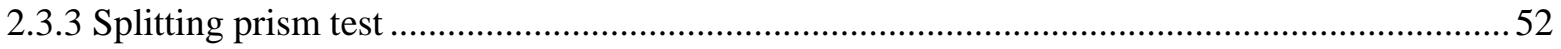

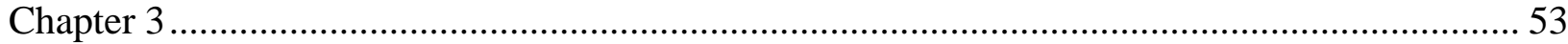

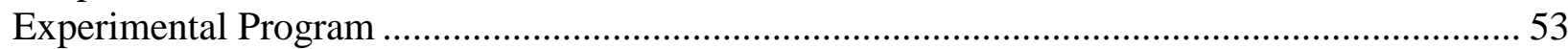

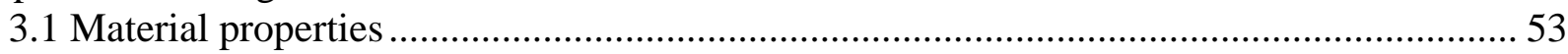

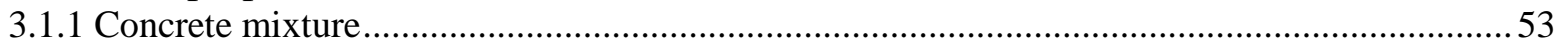

3.1.2 Selection of fibres type and volume content ....................................................................5

3.1.3 Selection of longitudinal steel reinforcement …..................................................................5

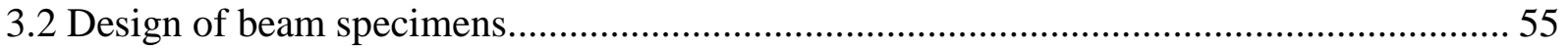

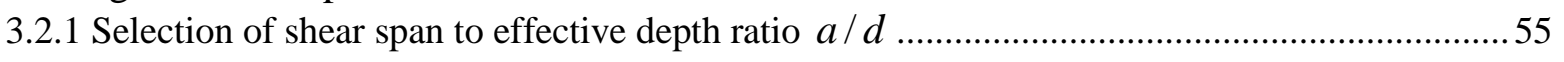

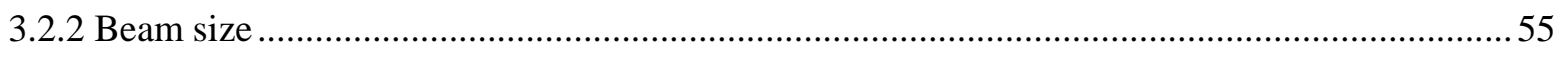

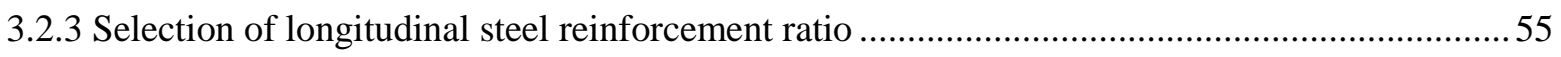

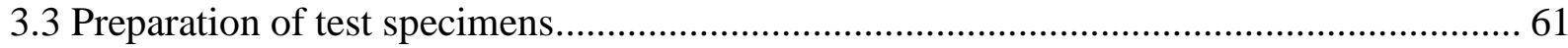

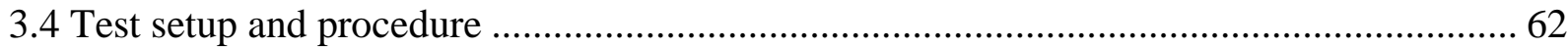

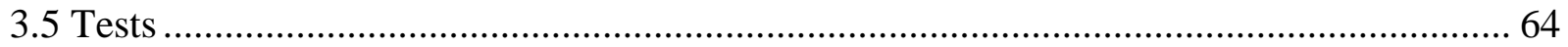

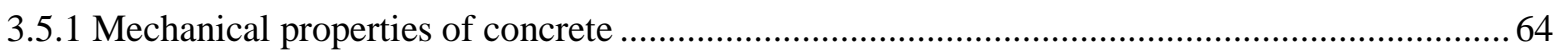

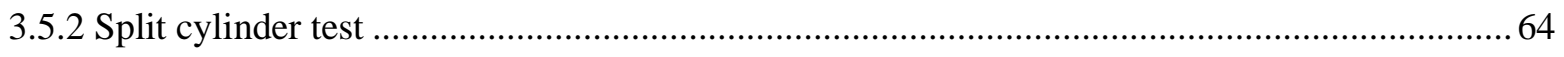

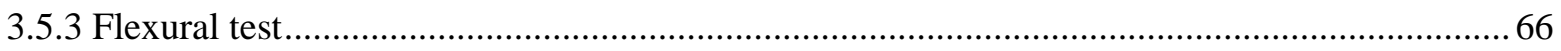

3.5.4 Bond strength between UHPFRC and NSC/HSC layers ...................................................6 66

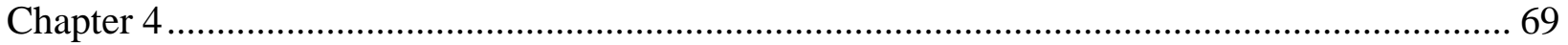

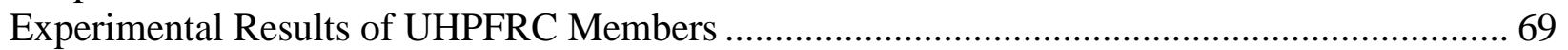

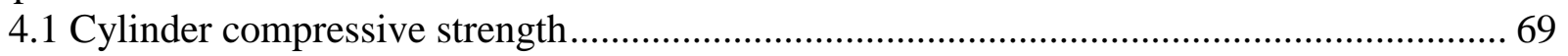

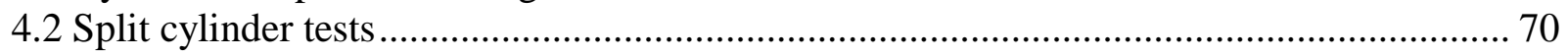

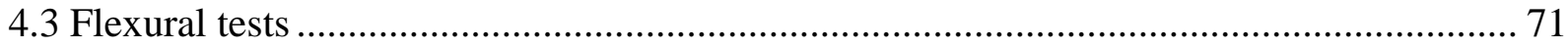

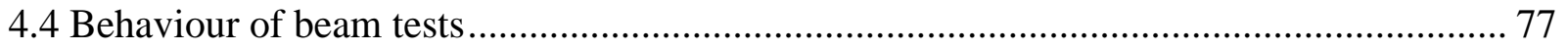

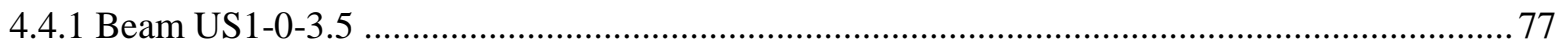

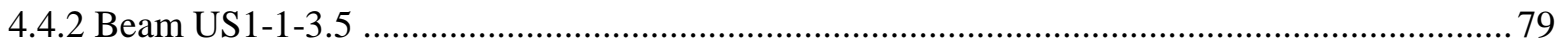

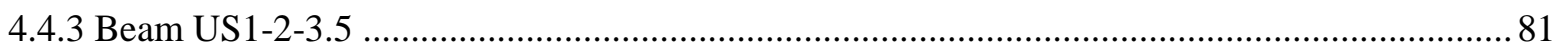

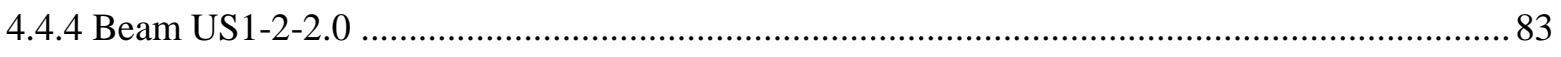

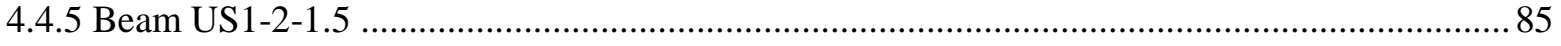




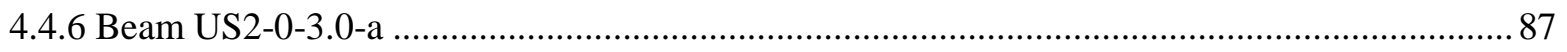

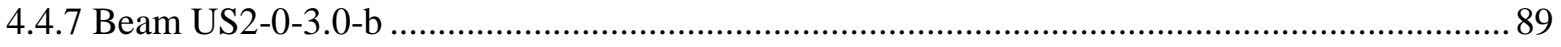

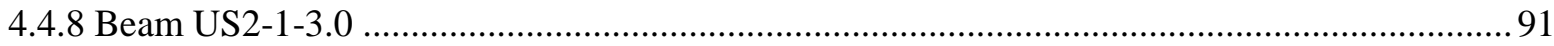

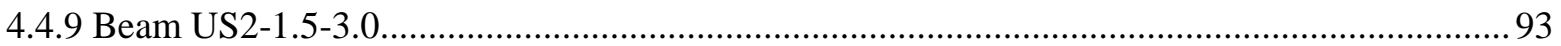

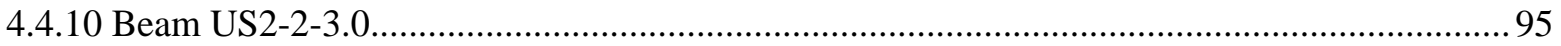

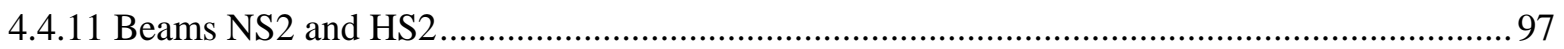

4.5 Comparison of response of UHPFRC beams....................................................... 101

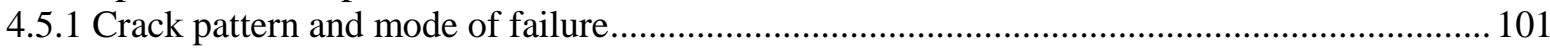

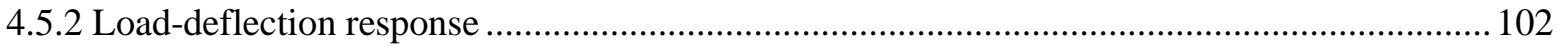

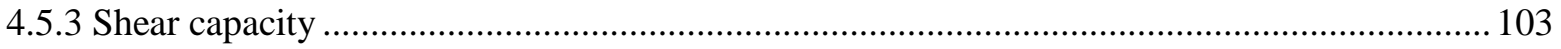

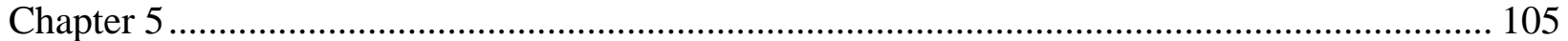

Experimental Results of UHPFRC- NSC/HSC Members ...................................................... 105

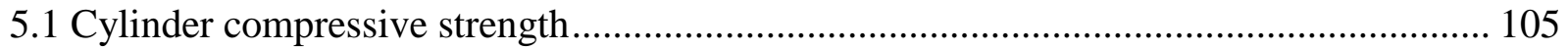

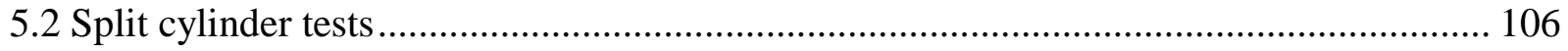

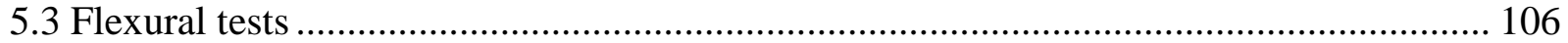

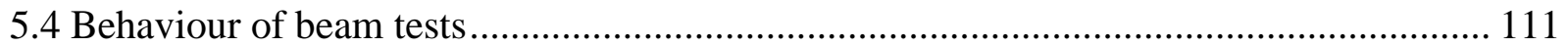

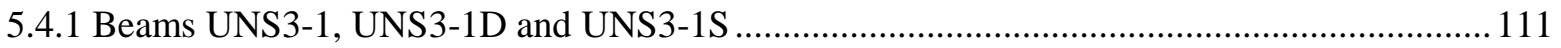

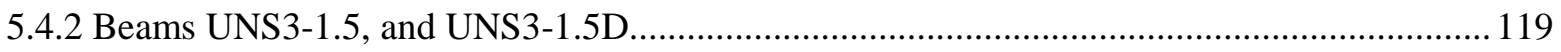

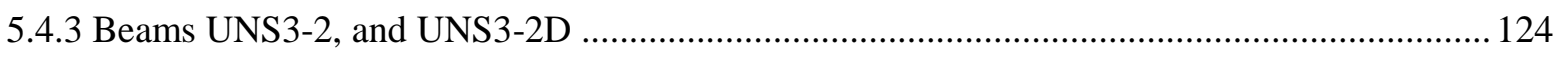

5.4.4 Beams UHS3-1, UHS3-1D, UHS3-1S, UHS3-1.5, UHS3-1.5D, UHS3-2, and UHS3-2D ..... 128

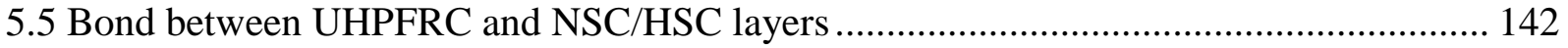

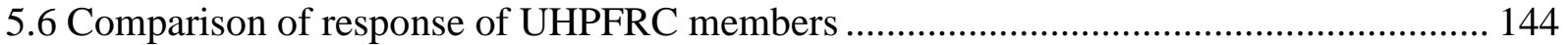

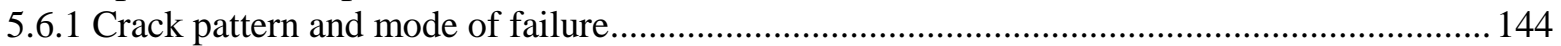

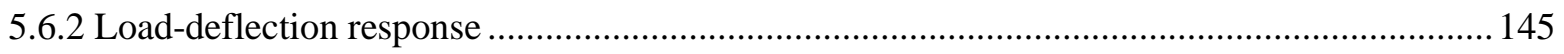

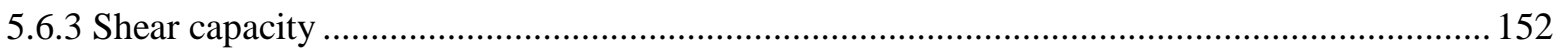

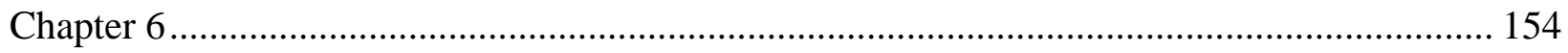

Analytical Modeling of UHPFRC \& UHPFRC- NSC/HSC Members................................. 154

6.1 Comparisons with previous models and recommendations ........................................ 154

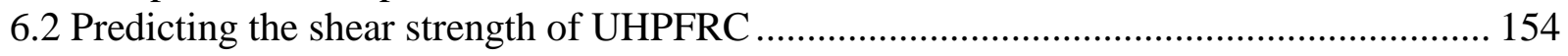

6.3 Predicting the flexural strength of UHPFRC ........................................................ 161

6.4 Predicting the shear strength of UHPFRC - NSC/HST composite beams ..................... 163

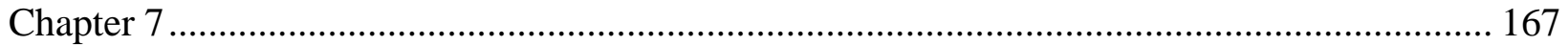

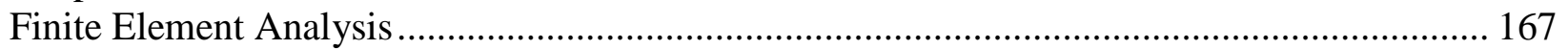

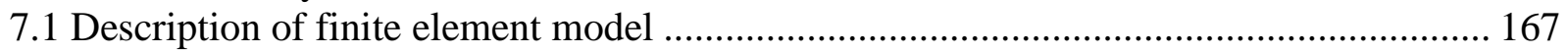

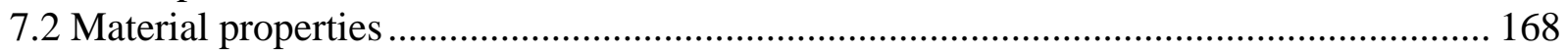

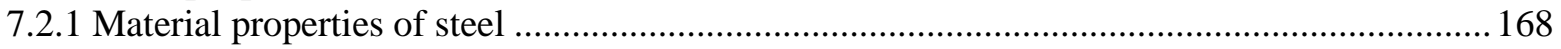

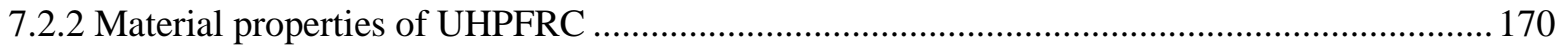

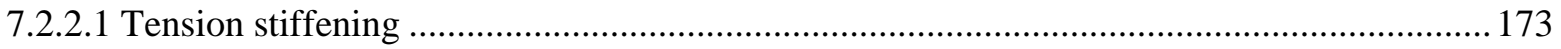

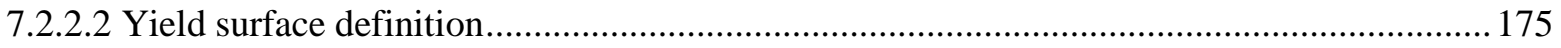




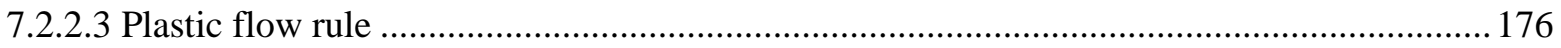

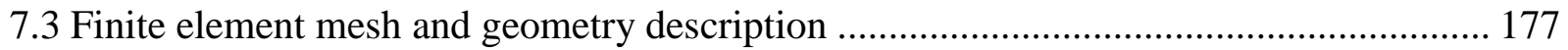

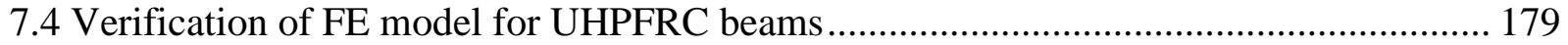

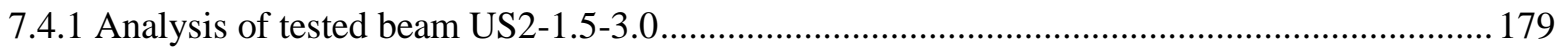

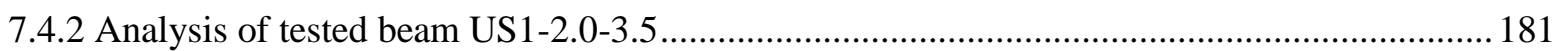

7.4.3 Verification with experimental results of beam Yang et al. (2012) ...................................... 181

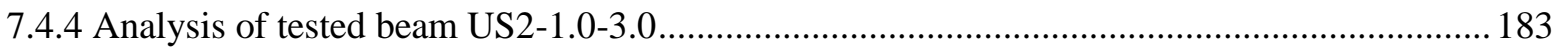

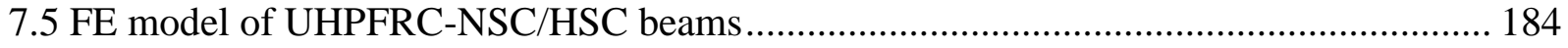

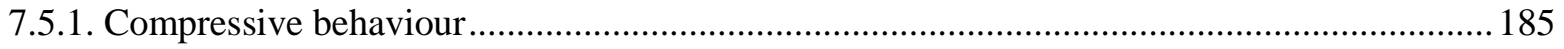

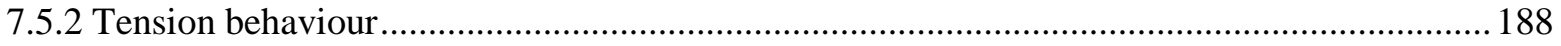

7.6 Verification of FE model for UHPFRC-NSC/HSC beams ........................................... 189

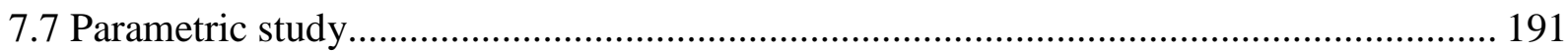

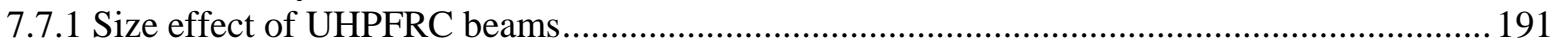

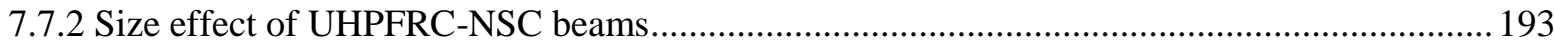

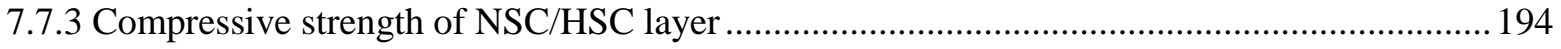

7.8 Comparison between FE analysis and analytical model ............................................. 195

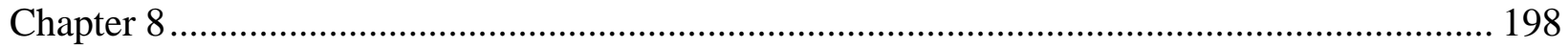

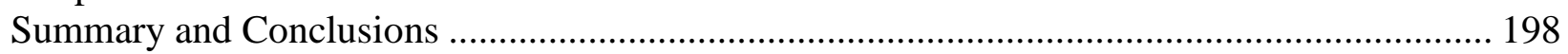

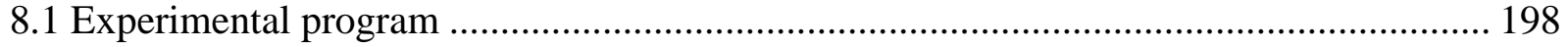

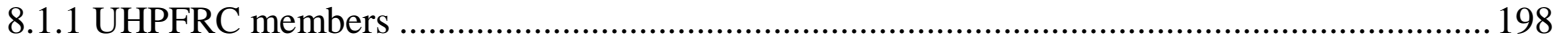

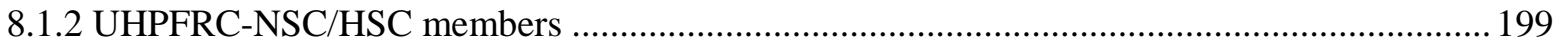

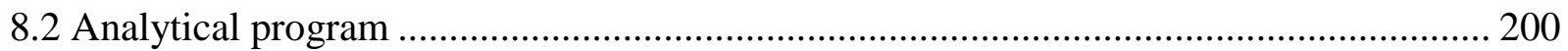

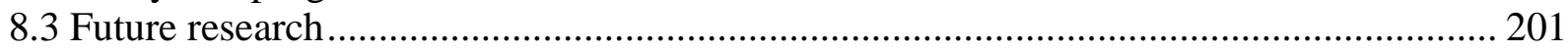

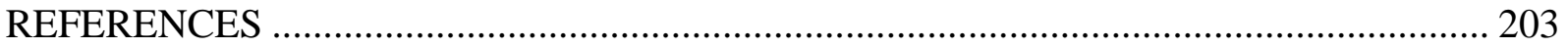




\section{List of Tables}

Table 2.1: Models for predicting the shear strength of FRC beams 49

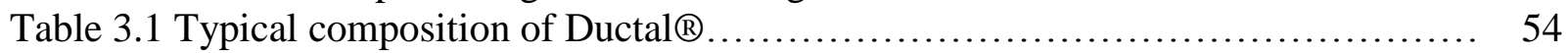

Table 3.2 Calculation of beam shear and flexural strength.......................... 57

Table 3.3 Experimental parameters of specimens of phase 1 ....................... 58

Table 3.4 Experimental parameters of test beams of phase $2 \ldots \ldots \ldots \ldots \ldots \ldots \ldots \ldots \ldots \ldots . \ldots \ldots$

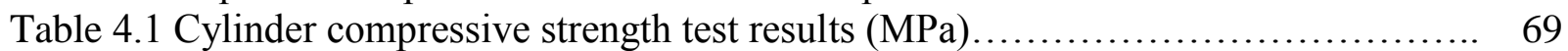

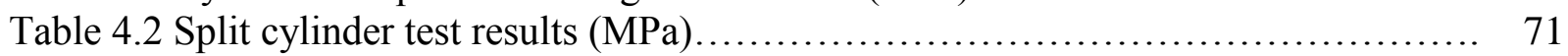

Table 4.3 Flexural properties and test results of UHPC mixtures..................... 73

Table 4.4 Flexural toughness and modulus of rupture of beams....................... 74

Table 4.5 Material properties and experimental parameters of specimens................ 102

Table 4.6 Shear capacity of UHPFRC beams................................... 104

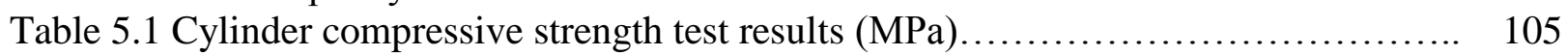

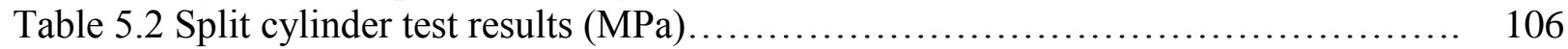

Table 5.3 Flexural test results of UHPFRC-NSC/HSC ............................... 107

Table 5.4 Flexural toughness and modulus of rupture of beams........................ 107

Table 5.5 Experimental results of test beams.................................... 112

Table 5.6 Shear capacity of UHPFRC-NSC test specimens......................... 152

Table 5.7 Shear capacity of UHPFRC-HSC test specimens........................ 153

Table 6.1 Comparison with previous Investigators and recommendations............... 155

Table 6.2 Comparison with experimental results................................... 163

Table 6.3 Material properties and experimental parameters of test beams............... 166

Table 7.1 Material properties of FE model for reinforcing steel........................ 176

Table 7.2 Material properties of FE model for UHPFRC ............................ 177

Table 7.3 Shear capacity for UHPFRC for different beam sizes....................... 192

Table 7.4 Shear capacity for UHPFRC-NSC for different beam sizes..................... 193

Table 7.5 Comparison between FE Analysis and Analytical Model for different UHPFRC beam sizes................................................................ 196

Table 7.6 Comparison between FE Analysis and Analytical Model for different UHPFRC-NSC beam sizes.................................................... 196

Table 7.7 Comparison between FE Analysis and Analytical Model for UHPFRC-

NSC/HSC with 2\% fibre volume content......................................... 197

Table 8.1 Summary of proposed models..................................... 201 


\section{List of Figures}

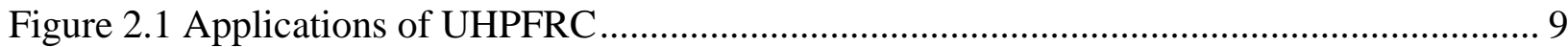

Figure 2.2 Different types of steel fibres grouped according to their bond characteristics (Wille

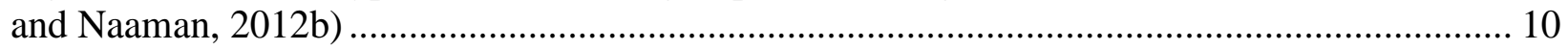

Figure 2.3 Different types of steel fibres (Wille and Naaman, 2012b)................................... 10

Figure 2.4 Shear stress slip relationship of smooth (S) and deformed (T2, H) steel fibres

embedded in HSC (60 MPa) and UHPC A (194 MPa) (Wille and Naaman, 2012a) ................. 12

Figure 2.5 Comparison of pullout response of high-strength straight, hooked-end, and twisted

fibres embedded in high-strength concrete (Wille and Naaman, 2012b) ............................... 12

Figure 2.6 Effect of fibre geometry on pullout behaviour of steel fibres embedded in UHPC-A

(Wille and Naaman, 2012b) ........................................................................................... 13

Figure 2.7 Effect of fibre inclination for hooked steel fibre in high strength concrete (Banthia and

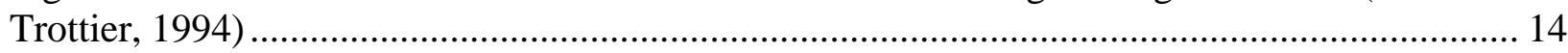

Figure 2.8 Different stress-strain curve for brittle matrix composites (Dinh, 2009) .................. 17

Figure 2.9 Tension tests: (a) direct tension test; (b) bending or modulus of rupture test; (c) double punch test; (d) split cylinder test (Kaufmann, W., 1998)....................................................... 19

Figure 2.10 Direct tensile stress-strain curves for different types of SFRC (ACI Committee 544,

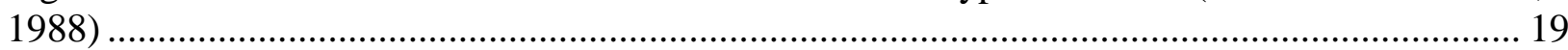

Figure 2.11 Tensile stress-crack opening relationship for different Concrete Mixtures (Noghabai,

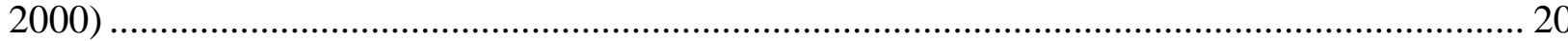

Figure 2.12 - Response of UHPFRC in uniaxial tensile stress state compared to conventional (CC), fibre- reinforced normal or high-strength concrete (FRC, HSFRC), as well as engineered cementitious composites (ECC) with short polymeric (PE, PVA) fibres (adapted from

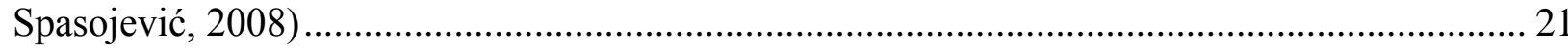

Figure 2.13 Idealized simplified response of strain-hardening FRC composites in tension (Wille

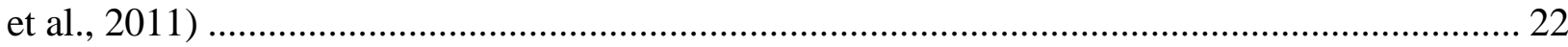

Figure 2.14 Influence of fibre volume fraction on tensile behaviour. (a) Smooth (S) fibres and (b) twisted (T) fibres (Wille et al., 2011) ............................................................................... 22 Figure 2.15 Average fibre tensile stress $\sigma_{f p c}$ within the composite at peak strength $\sigma_{p c}$ (Wille et

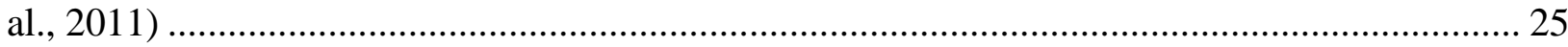

Figure 2.16 UHPFRC bending beam tests according to ASTM 1609 (a) Test setup and (b) influence of fibre geometry (Wille et al., 2012a) ............................................................... 27

Figure 2.17 Plain concrete beam subjected to a concentrated load ........................................ 29

Figure 2.18 Flexural and diagonal tension cracks (Winter and Nilson, 1979) .......................... 30

Figure 2.19 Effect of shear span to depth ratio (a/d) on shear strength of beams without stirrups

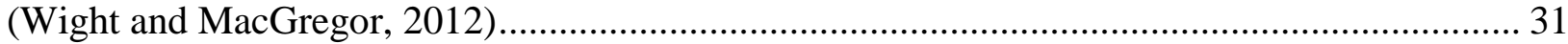

Figure 2.20 Beams failure mode (ACI- ASCE, 1973) (adapted from Dinh, 2009)................... 32

Figure 2.21 modes of failure of short spans with a/d ranging from 1 to 2.5 (ACI- ASCE, 1973) 33

Figure 2.22 Shear resistance components in a cracked concrete beam without shear

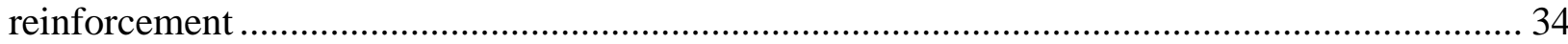

Figure 2.23 Internal forces in a cracked concrete beam with stirrups (ACI- ASCE, 1973) ........ 36

Figure 2.24 Beam cross-section area (Yang et al., 2012) .................................................... 38

Figure 2.25 (a) Patterns of shear failure in specimens with $a / d \geq 3$ (b) patterns of shear failure in specimens with $a / d \leq 2.5$ (Narayanan and Darwish, 1987) ............................................. 42 
Figure 2.26 Forces within fibre reinforced concrete beam with diagonal tension crack (Al- Ta'an

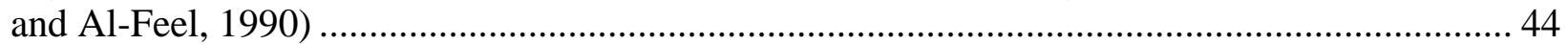

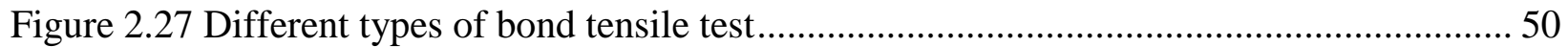

Figure 2.28 Different types of bond shear test............................................................ 51

Figure 2.29 Bond strength test methods (Momayez et. al., 2005) ......................................... 52

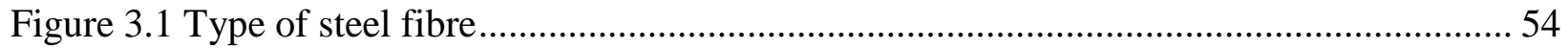

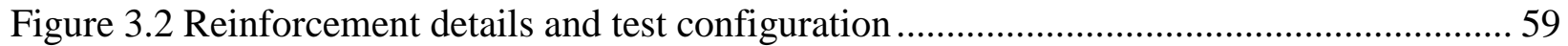

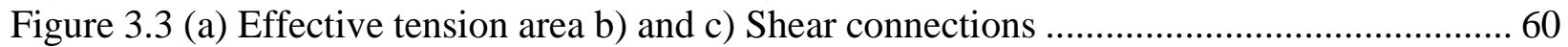

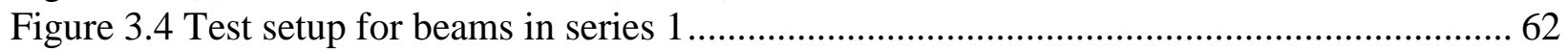

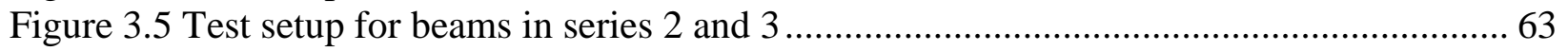

Figure 3.6 Split cylinder test (Wight and MacGregor, 2012) .............................................. 65

Figure 3.7 Four-point bending test (a) dimensions, and (b) instrumentation ASTM C 1609 (2006)

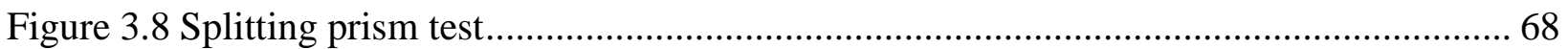

Figure 4.1 Failure modes of concrete cylindrical specimens under compression loading test ..... 70

Figure 4.2 Failure modes of concrete cylindrical specimens under split cylinder tests ............. 71

Figure 4.3 Flexural behaviour of UHPFRC prisms ....................................................... 73

Figure 4.4 Load versus net deflection relationship for UHPFRC prisms ................................ 74

Figure 4.5 Comparison between flexural strength of series $0 \%, 1 \%, 1.5 \%$ and $2 \%$ fibre content 74

Figure 4.6 First-crack stress relationship with fibre volume content $\%$................................ 75

Figure 4.7 Post-cracking peak stress relationship with fibre volume content \% ....................... 76

Figure 4.8 Stress at net deflection values (L/600) relationship with fibre volume content \% ..... 76

Figure 4.9 Stress at net deflection values (L/150) relationship with fibre volume content \% ..... 77

Figure 4.10 Load versus central deflection relationship - Beam US1-0-3.5 .......................... 78

Figure 4.11 Crack pattern after failure - Beam US1-0-3.5 ............................................ 78

Figure 4.12 Load versus reinforcement strain - Beam US1-0-3.5 …................................ 79

Figure 4.13 Load versus central deflection relationship - Beam US1-1-3.5 ........................... 80

Figure 4.14 Crack pattern after failure - Beam US1-1-3.5 .............................................. 80

Figure 4.15 Load versus reinforcement strain - Beam US1-1-3.5 ..................................... 81

Figure 4.16 Load versus central deflection relationship - Beam US1-2-3.5 ......................... 82

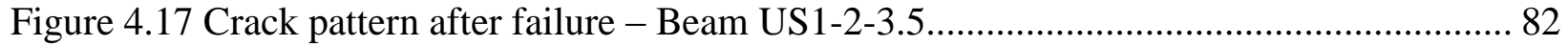

Figure 4.18 Load versus reinforcement strain - Beam US1-2-3.5 ...................................... 83

Figure 4.19 Load versus central deflection relationship - Beam US1-2-2.0 ........................... 84

Figure 4.20 Crack pattern after failure - Beam US1-2-2.0 ............................................ 84

Figure 4.21 Load versus reinforcement strain - Beam US1-2-2.0 …................................... 85

Figure 4.22 Load versus central deflection relationship - Beam US1-2-1.5 ......................... 86

Figure 4.23 Crack pattern after failure - Beam US1-2-1.5 .............................................. 86

Figure 4.24 Load versus reinforcement strain - Beam US1-2-1.5 ...................................... 87

Figure 4.25 Load versus central deflection relationship - Beam US2-0-3.0-a........................ 88

Figure 4.26 Crack pattern after failure - Beam US2-0-3.0-a ............................................. 88

Figure 4.27 Load versus reinforcement strain - Beam US2-0-3.0-a .................................... 89

Figure 4.28 Load versus central deflection relationship - Beam US2-0-3.0-b ....................... 90

Figure 4.29 Crack pattern after failure - Beam US2-0-3.0-b .......................................... 90

Figure 4.30 Load versus reinforcement strain - Beam US2-0-3.0-b ................................... 91

Figure 4.31 Load versus central deflection relationship - Beam US2-1-3.0 ......................... 92

Figure 4.32 Crack pattern after failure - Beam US2-1-3.0............................................ 92 
Figure 4.33 Load versus reinforcement strain - Beam US2-1-3.0 .................................... 93

Figure 4.34 Load versus central deflection relationship - Beam US2-1.5-3.0 ........................ 94

Figure 4.35 Crack pattern after failure - Beam US2-1.5-3.0 ............................................ 94

Figure 4.36 Load versus reinforcement strain - Beam US2-1.5-3.0 .................................... 95

Figure 4.37 Load versus central deflection relationship - Beam US2-2-3.0 .......................... 96

Figure 4.38 Crack pattern after failure - Beam US2-2-3.0 .............................................. 96

Figure 4.39 Load versus reinforcement strain - Beam US2-2-3.0 ...................................... 97

Figure 4.40 Load versus central deflection relationship - Beam NS2 ................................. 98

Figure 4.41 Crack pattern after failure - Beam NS2 ...................................................... 98

Figure 4.42 Load versus reinforcement strain - Beam NS2-0-3 ........................................ 99

Figure 4.43 Load versus central deflection relationship - Beam HS2-0-3 ............................ 100

Figure 4.44 Crack pattern after failure - Beam HS2-0-3 ............................................... 100

Figure 4.45 Load versus reinforcement strain - Beam HS2-0-3 ....................................... 101

Figure 4.46 Load versus central deflection relationship for a/d ratio for Series 1 with $2 \%$ fibre

volume content................................................................................................. 103

Figure 4.47 Load versus central deflection relationship for different fibre volume contents for

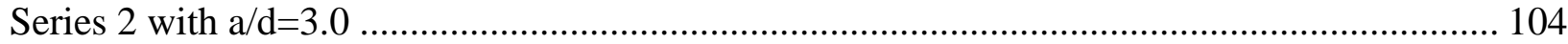

Table 4.6 Shear capacity of UHPFRC beams ..................................................................... 104

Figure 5.1 Flexural behaviour of UHPFRC/NSC prisms ................................................... 109

Figure 5.2 Flexural behaviour of UHPFRC/HSC prisms ................................................ 110

Figure 5.3 Load versus net deflection relationship for UHPFRC-NSC prisms ....................... 110

Figure 5.4 Load versus net deflection relationship for UHPFRC-HSC prisms ....................... 111

Figure 5.5 Load versus central deflection relationship - Beam UNS3-1 ............................. 113

Figure 5.6 Crack pattern after failure - Beam UNS3-1 ............................................. 113

Figure 5.7 Load versus central deflection relationship - Beam UNS3-1D ............................ 114

Figure 5.8 Crack pattern after failure - Beam UNS3-1D ............................................... 114

Figure 5.9 Load versus central deflection relationship - Beam UNS3-1S ............................ 115

Figure 5.10 Crack pattern after failure - Beam UNS3-1S ............................................... 115

Figure 5.11 Load versus crack width relationship - Beam UNS3-1 .................................. 116

Figure 5.12 Load versus crack width relationship - Beam UNS3-1D ................................. 116

Figure 5.13 Load versus crack width relationship - Beam UNS3-1S ................................. 117

Figure 5.14 Load versus reinforcement strain - Beam UNS3-1 ........................................ 118

Figure 5.15 Load versus reinforcement strain - Beam UNS3-1D ........................................ 118

Figure 5.16 Load versus reinforcement strain - Beam UNS3-1S ....................................... 119

Figure 5.17 Load versus central deflection relationship - Beam UNS3-1.5 ........................ 120

Figure 5.18 Crack pattern after failure - Beam UNS3-1.5 .......................................... 120

Figure 5.19 Load versus central deflection relationship - Beam UNS3-1.5D ....................... 121

Figure 5.20 Crack pattern after failure - Beam UNS3-1.5D ........................................... 121

Figure 5.21 Load versus crack width relationship - Beam UNS3-1.5 ................................ 122

Figure 5.22 Load versus crack width relationship - Beam UNS3-1.5D ............................... 122

Figure 5.23 Load versus reinforcement strain - Beam UNS3-1.5 ..................................... 123

Figure 5.24 Load versus reinforcement strain - Beam UNS3-1.5D ................................... 123

Figure 5.25 Load versus central deflection relationship - Beam UNS3-2 ........................... 124

Figure 5.26 Crack pattern after failure - Beam UNS3-2 ................................................. 124

Figure 5.27 Load versus central deflection relationship - Beam UNS3-2D ......................... 125

Figure 5.28 Crack pattern after failure - Beam UNS3-2D .............................................. 125 
Figure 5.29 Load versus crack width relationship - Beam UNS3-2 ................................. 126

Figure 5.30 Load versus crack width relationship - Beam UNS3-2D .................................. 126

Figure 5.31 Load versus reinforcement strain - Beam UNS3-2 ........................................ 127

Figure 5.32 Load versus reinforcement strain - Beam UNS3-2D ...................................... 127

Figure 5.33 Load versus central deflection relationship - Beam UHS3-1 ........................... 128

Figure 5.34 Crack pattern after failure - Beam UHS3-1 .............................................. 128

Figure 5.35 Load versus central deflection relationship - Beam UHS3-1D .......................... 129

Figure 5.36 Crack pattern after failure - Beam UHS3-1D ............................................... 129

Figure 5.37 Load versus central deflection relationship - Beam UHS3-1S ........................... 130

Figure 5.38 Crack pattern after failure - Beam UHS3-1S .............................................. 130

Figure 5.39 Load versus central deflection relationship - Beam UHS3-1.5 ........................ 131

Figure 5.40 Crack pattern after failure - Beam UHS3-1.5 …....................................... 131

Figure 5.41 Load versus central deflection relationship - Beam UHS3-1.5D ....................... 132

Figure 5.42 Crack pattern after failure - Beam UHS3-1.5D .............................................. 132

Figure 5.43 Load versus central deflection relationship - Beam UHS3-2 ........................... 133

Figure 5.44 Crack pattern after failure - Beam UHS3-2 ................................................ 133

Figure 5.45 Load versus central deflection relationship - Beam UHS3-2D ......................... 134

Figure 5.46 Crack pattern after failure - Beam UHS3-2D ............................................... 134

Figure 5.47 Load versus crack width relationship - Beam UHS3-1 ................................... 135

Figure 5.48 Load versus crack width relationship - Beam UHS3-1D ................................. 136

Figure 5.49 Load versus crack width relationship - Beam UHS3-1S .................................. 136

Figure 5.50 Load versus crack width relationship - Beam UHS3-1.5 ................................ 137

Figure 5.51 Load versus crack width relationship - Beam UHS3-1.5D ............................... 137

Figure 5.52 Load versus crack width relationship - Beam UHS3-2 .................................. 138

Figure 5.53 Load versus crack width relationship - Beam UHS3-2D .................................. 138

Figure 5.54 Load versus reinforcement strain - Beam UHS3-1 ....................................... 139

Figure 5.55 Load versus reinforcement strain - Beam UHS3-1D ........................................ 139

Figure 5.56 Load versus reinforcement strain - Beam UHS3-1S ........................................ 140

Figure 5.57 Load versus reinforcement strain - Beam UHS3-1.5 ...................................... 140

Figure 5.58 Load versus reinforcement strain - Beam UHS3-1.5D ...................................... 141

Figure 5.59 Load versus reinforcement strain - Beam UHS3-2 ........................................ 141

Figure 5.60 Load versus reinforcement strain - Beam UHS3-2D ........................................ 142

Figure 5.61 Splitting tensile tests of composite cubes ..................................................... 143

Figure 5.62 Load versus central deflection relationship comparison for UHPFRC-NSC beams

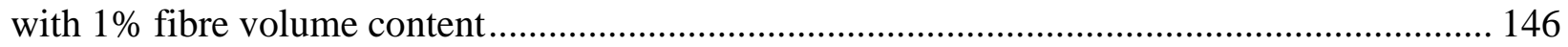

Figure 5.63 Load versus central deflection relationship comparison for UHPFRC-NSC beams

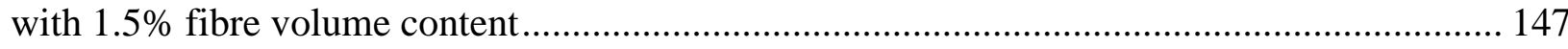

Figure 5.64 Load versus central deflection relationship comparison for UHPFRC-NSC beams

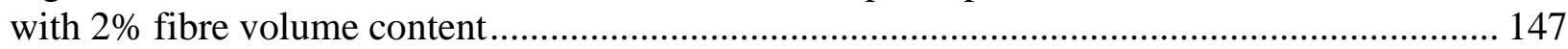

Figure 5.65 Load versus central deflection relationship comparison for UHPFRC-NSC beams

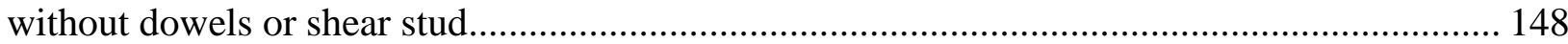

Figure 5.66 Load versus central deflection relationship comparison for UHPFRC-HSC beams

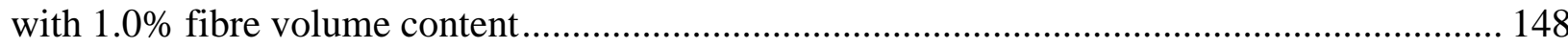
Figure 5.67 Load versus central deflection relationship comparison for UHPFRC-HSC beams

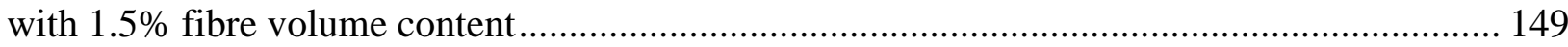


Figure 5.68 Load versus central deflection relationship comparison for UHPFRC-HSC beams

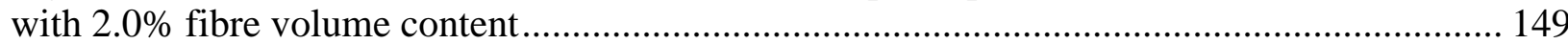

Figure 5.69 Load versus central deflection relationship comparison for UHPFRC-HSC beams

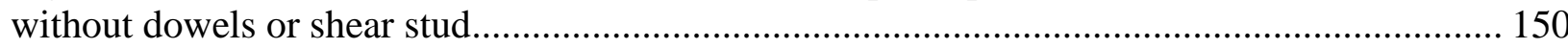

Figure 5.70 Load versus central deflection relationship comparison for beams with $1 \%$ fibre volume content .......................................................................................................... 150 Figure 5.71 Load versus central deflection relationship comparison for beams with $1.5 \%$ fibre

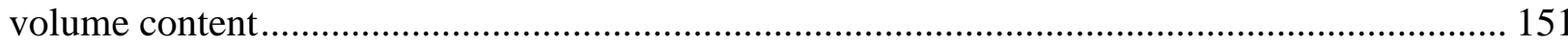

Figure 5.72 Load versus central deflection relationship comparison for beams with $2 \%$ fibre

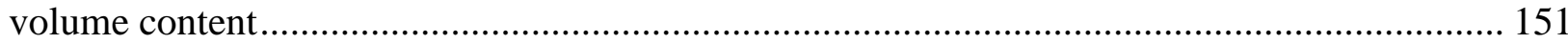

Figure 6.1 Fibre contributions to shear resistance ................................................................ 157

Figure 6.2 Load versus central deflection relationship for NSC, HSC and UHPC without fibre

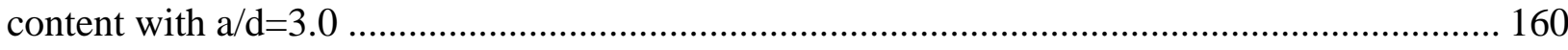
Figure 6.3 Vertical stress and strain distribution: (a) typical reinforced concrete beam section;(b) strain distribution; (c) actual concrete stresses with fibres; (d) equivalent concrete stresses with

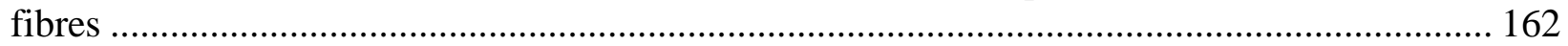

Figure 6.4 Fibre contributions to shear resistance ……………….......................................... 164

Figure 7.1 Nominal and true stress strain curve for steel reinforcement .................................. 169

Figure 7.2 Plastic Strain- True Stress behaviour for Classical metal plasticity model............... 171

Figure 7.3 nominal compression stress-strain curve for UHPFRC............................................ 171

Figure 7.4 CDP model input for inelastic compression behaviour for UHPFRC........................ 172

Figure 7.5 Compression damage parameter input for UHPFRC ……………………............ 172

Figure 7.6 CDP model input for inelastic tension behaviour for UHPFRC for different fibre

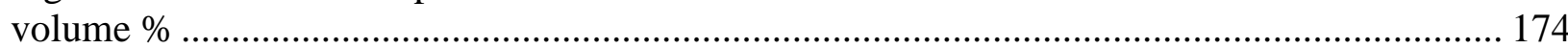

Figure 7.7 Tension damage parameter input for UHPFRC for different fibre volume \% .......... 174

Figure 7.8 Drucker-Prager yield criteria for different values of ${ }^{K_{c}}$, (Hibbitt et al., 2011) ........ 175

Figure 7.9 Generated FE mesh of beam US2-1.5-3.0 with element size $30 \mathrm{~mm}$....................... 178

Figure 7.10 Load and boundary condition for FE model..................................................... 178

Figure 7.11 Load versus central deflection for different mesh sizes for beam US2-1.5-3 ......... 179

Figure 7.12 Load versus strain for beam US2-1.5-3 ............................................................ 180

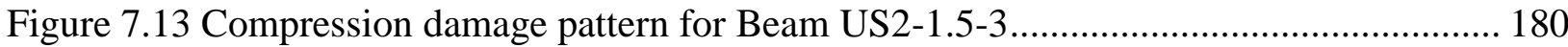

Figure 7.14 Load versus central deflection for beam US1-2.0-3.5 .......................................... 181

Figure 7.15 Load versus central deflection for beam S34-F15-P0 (Yang et al., 2012) .............. 182

Figure 7.16 Load versus central deflection for beam S34-F20-P0 (Yang et al., 2012) .............. 182

Figure 7.17 Compression damage pattern for beam S34-F20-P0 (Yang et al., 2012)................ 183

Figure 7.18 Load versus central deflection for beam US2-1.0-3.0 ........................................... 184

Figure 7.19 nominal compression stress-strain curves for NSC and HSC ............................... 186

Figure 7.20 CDP model input for inelastic compression behaviour for NSC and HSC ............. 187

Figure 7.21 Compression damage parameter input for NSC and HSC .................................... 187

Figure 7.22 Nominal tensile stress-strain curves for NSC and HSC ……................................. 188

Figure 7.23 CDP model input for inelastic tension behaviour for NSC and HSC...................... 189

Figure 7.24 Load versus central deflection for beam UNS3-2 …………………………........ 190

Figure 7.25 Compression damage pattern for Beam UNS3-2 …………………………......... 191

Figure 7.26 Load versus central deflection for UHPFRC for different beam sizes.................... 192

Figure 7.27 Load versus central deflection for UHPFRC-NSC for different beam sizes............ 194 
Figure 7.28 Load versus central deflection for UHPFRC-NSC/HSC beams for different

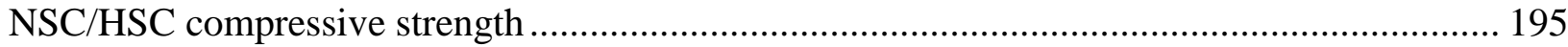




\section{List of Symbols}

a

$a_{c}$

A

$A_{s f}$

$A_{s t}$

$b$

$b_{w}$

$c$

$d$

$d_{f}$

$d_{c y l}$

$d^{\prime}$

$d_{v}$

$E_{c}$

$E_{f}$

$E_{m}$

$E_{s}$

$\mathrm{F}$

$f$

$f_{r}$

$f_{s p}$

$f_{y}$

$f_{f t}$

$f_{c}^{\prime}$

$f_{f i b}$

$h$

$h_{u}$

$h_{n}$

$l_{c y l}$

I

$K_{c}$ shear span

depth of equivalent compression stress block

area of bond plane

cross-sectional area of the fibre

area of tensile steel reinforcement

width of the member

beam width or web width for I beam,

depth of neutral axis measured from the top face of the beam

effective depth of beam

diameter of the fibre

diameter of the cylinder

depth of compression steel reinforcement

effective shear depth

elastic modulus of concrete

fibre modulus

matrix modulus

elastic modulus of steel

fibre factor

flexural strength

modulus of rupture

split tensile strength

steel yield strength,

uniform fibre reinforced concrete stress in tension

concrete compressive strength

average fibre pull-out force per fibre

height of the member

thickness of UHPFRC layer.

thickness of NSC/HSC layer

length of the cylinder

moment of inertia of the cross section

ratio of the second stress invariant on the tensile meridian to that on the compressive meridian 


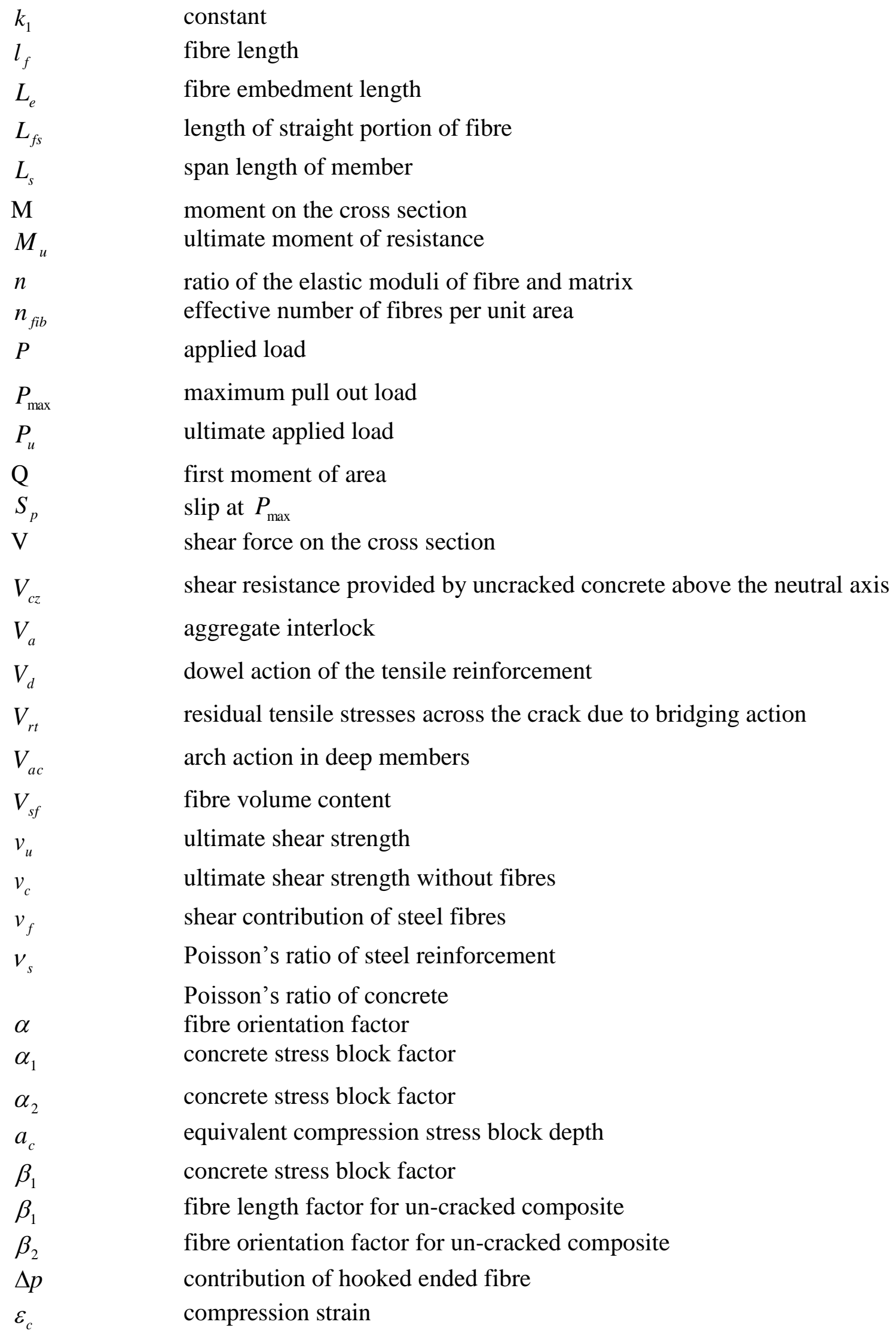




$\begin{array}{ll}\varepsilon_{t} & \text { tensile strains } \\ \varepsilon_{c}^{i n} & \text { inelastic strain in compression } \\ \varepsilon_{c}^{c r} & \text { cracking strain in tension } \\ \theta & \text { angel of crack inclination } \\ \phi & \text { flexural reduction factor } \\ \sigma_{c} & \text { compression stress } \\ \sigma_{t} & \text { tensile stress } \\ \sigma_{c c} & \text { fibre composite tensile strength } \\ \sigma_{p c} & \text { post-cracking tensile strength } \\ \sigma_{f} & \text { fibre tensile strength } \\ \sigma_{s p} & \text { splitting tensile strength of plane } \\ \sigma_{m u} & \text { ultimate matrix tensile strength of matrix } \\ \sigma_{c u} & \text { ultimate tensile strength of the composite } \\ \sigma_{f u} & \text { ultimate tensile strength of fibre } \\ \sigma_{f p c} & \text { average tensile stress of the fibres } \\ \eta & \text { efficiency of a single fibre } \\ \eta_{1} & \text { fibre length factor } \\ \lambda_{1} & \text { effective bond length } \\ \lambda_{2} & \text { fibre orientation factor } \\ \lambda_{3} & \text { group factor } \\ \rho & \text { longitudinal steel reinforcement ratio } \\ \rho_{w} & \text { utilization factor } \\ \chi_{u} & \\ \tau_{1} & \text { longitudinal steel reinforcement ratio } \\ & \end{array}$




\section{Chapter 1}

\section{Introduction}

\subsection{Introduction}

The aging and deterioration of highway bridge structures in North America present major technical and economic challenges to bridge owners regarding when and how to upgrade these damaged structures and extend their service lives at the minimum life cycle cost. These problems are further compounded by the budgetary constraints that face most highway agencies. Highway bridge girders are approaching the end of their service life and some of them present serious structural deficiencies due to the effects of corrosion, overload, inadequate original design, poor construction, and lack of reliable inspection and effective maintenance. To effectively address some of the above challenges, there is a need to develop effective management tools as well as innovative and cost-effective materials, construction techniques and structural systems to build the next generation of high-performance bridges.

Ultra-high performance fibre-reinforced concrete (UHPFRC) represents a major step forward when compared to conventional normal strength concrete (NSC) and high strength concrete (HSC), due to the achievement of very high strength and very low permeability. The UHPC is a concrete with a compressive strength above $150 \mathrm{MPa}$, pre-and post-cracking tensile strengths above $5 \mathrm{MPa}$, and has enhanced durability via its discontinuous pore structure (Graybeal, 2005). This "ultra" high strength is achieved through different techniques such as the use of improved materials, ultra-fine pozzolans (e.g. silica fume), low water-cement ratio, improved quality and higher dosage of superplasticizer, use of fibres (metallic or synthetic) to increase energy absorption capacity and decrease brittleness, high cementitious material content, longer mixing time and heat treatment (Rahman et al., 2005). UHPFRC tensile strength varies from 10 to 30 $\mathrm{MPa}$, and the modulus of elasticity varies between 60 and $100 \mathrm{GPa}$ (Buitelaar et al., 2004). Using UHPFRC in the construction of new bridges and in the renewal of existing highway bridge networks could minimize maintenance requirements in the construction of new long lasting 
bridges and result in lower life cycle costs (Almansour and Lounis, 2010).

UHPC's initial construction cost is significantly higher than that of normal strength concrete (NSC), which has limited its use in North America and elsewhere. The structural efficiency and cost-effectiveness of using UHPFRC in composite construction is investigated in this study, to address some of the challenges faced by bridge owners. Therefore, to strengthen the bridge zones that are most exposed to severe environmental deterioration and high mechanical loading, a system combining NSC/HSC with UHPFRC in a composite construction is intended to optimize the use of the properties of both materials. In this composite construction, UHPFRC was used in the parts of the structure that require high mechanical loading and/or low permeability to detrimental substances, whereas, the other parts were made using NSC/HSC. The proposed system of composite "UHPFRC-NSC/HSC" structures can be used for the effective construction of new structures and the rehabilitation of existing structures. Such a composite system will enable structures (e.g. bridges) with longer service lives, longer spans, lighter weights, and lower maintenance costs over their life cycle.

\subsection{Objectives and Scope of the research}

\subsubsection{Objectives}

The commonly used design codes in North America, ACI-318-11 and CSA A23.3-04 and in Europe EN 1992-1-1:2004 could not predict the shear capacity of reinforced concrete beams with a compressive strength exceeding $150 \mathrm{MPa}(22 \mathrm{ksi})$. In addition, the experimental studies of the shear characteristic for UHPFRC beams are extremely limited. Thus, the primary objectives of this research are:

1. Investigate the performance and structural behaviour of new composite UHPFRC-NSC, and UHPFRC-HSC members subjected to shear and bending.

2. Develop an analytical model to predict the shear strength of new composite elements UHPFRC-NSC, and UHPFRC-HSC beams.

3. Develop a finite element model to predict the shear strength of new composite elements UHPFRC-NSC, and UHPFRC-HSC beams. 
In order to understand shear behaviour of composite UHPFRC-NSC, and UHPFRC-HSC members, the following objectives were investigated:

4. Investigate the shear behaviour of ultra-high performance concrete UHPC beams without web reinforcement, and ultra-high performance steel fibre reinforced concrete UHPFRC without web reinforcement.

5. Investigate the concrete contribution to shear strength, and the contribution of steel fibres to shear strength of UHPC beams and UHPFRC beams without web reinforcement.

6. Investigate the shear failure mechanism, and the ultimate shear strength of UHPFRC beams.

7. Develop an analytical model to predict the shear strength of UHPFRC beams.

8. Develop an analytical model to predict the flexural strength of UHPFRC beams.

\subsubsection{Scope}

This investigation was limited to simply supported beams subjected to concentrate monotonic loading. Other loading schemes such as cyclic, reversed cyclic and dynamic loading, which are substantially different than monotonic loading were not investigated.

This research is also limited to concrete compressive strength between 150 and $200 \mathrm{MPa}$, without and with straight steel fibres. However, the results of this investigation can be applicable to FRC beams constructed with other deformed steel fibres that exhibit bond stress versus slip response similar to that of straight steel fibres used in this investigation.

\subsection{Thesis Organization}

This thesis has eight chapters. Following this introductory chapter is Chapter 2, which presents background information and reviews the various topics that are treated in the thesis. Thereafter, the thesis is divided into three main phases including experimental, analytical and numerical investigations:

1. The first phase of the research program investigates the behaviour of UHPFRC members and UHPFRC composite members: 
a. Chapter 3 discusses the experimental program including the choice of studied parameters and the design and testing of beam specimens and determines the mechanical properties of the materials used in the beam specimens

b. Chapter 4 presents the test results of UHPFRC beams

c. Chapter 5 discusses the test results of UHPFRC composite beams

2. The second phase of the research program presents an analytical models that can be used to predict the flexural and shear behaviour of UHPFRC beams and an analytical model to predict the shear behaviour of UHPFRC-NSC/HSC composite beams (Chapter 6)

3. The third phase of the research program presents a finite element model to predict the shear behaviour of UHPFRC beams and UHPFRC-NSC/HSC composite beams to investigate the effect of studied parameter on the composite behaviour (Chapter 7)

Chapter 8 provides concluding remarks about the implications of the experimental and analytical study. Finally, recommendation of future study is presented. 


\section{Chapter 2}

\section{Literature Review}

This chapter presents a comprehensive review of the literature regarding the various topics that were studied in this thesis. The literature review begins with the concept of using UHPFRC as a structural material and will summarize some of the mechanical properties. Section 2.1 describes the characteristic of UHPFRC material. Section 2.2 summarizes some of the methods that can be used to predict the shear behaviour of fibre reinforced concrete beams and presents a summary of some of the past research that has focussed on the use of steel fibres in Reinforced concrete (RC) beams. Section 2.3 introduces the concept of composite concrete members and summarizes the past research that has focussed on composite concrete members.

\subsection{UHPFRC}

\subsubsection{Historical overview}

The term ultra-high performance concrete was first used in a publication by de Larrard and Sedran (1994). Although no precise definition could be found in the reviewed technical literature to ultra-high performance concrete (UHPC), UHPC is defined as the concrete or cementitious composites with compressive strength over $150 \mathrm{MPa}(22 \mathrm{ksi})$ and with water to cementitious ratio (w/c) less than 0.2 (Wille and Naaman, 2012). When steel fibres are added to UHPC to increase the energy absorption capacity and decrease brittleness, the term ultra-high performance fibre reinforced concrete (UHPFRC) is used.

UHPFRC development found its origin in early 1970s, Yudenfreund et al. (1972) investigated high strength pastes with low w/c ratios $(\mathrm{w} / \mathrm{c}=0.2$ to 0.3$)$. They achieved $230 \mathrm{MPa}$ by using vacuum mixing process to reduce the porosity of the cement paste. Hot temperature and pressure technique was first applied by Roy et al. (1972), and resulted in high strength cement pastes with compressive strengths up to $680 \mathrm{MPa}$. With the development of superplasticizers and pozzolanic 
admixtures such as silica fume, Birchall et al. (1981) developed polymer modified cementitious materials called Macro-Defect-Free (MDF) cements, and Bache (1987) developed the densified small particles (DSP) which use the interaction of superplasticizers and silica fume to decrease the porosity of the material and to increase the strengths. This led to compressive strengths between 120 and $250 \mathrm{MPa}$. This matrix was theoretically investigated and optimized by DeLarrard and Sedran (1994). Richard and Cheyrezy (1995) introduced reactive powder concrete (RPC) and reported compressive strengths up to $800 \mathrm{MPa}$ using a temperature of up to 400C, pressure of $50 \mathrm{MPa}, 10 \%$ volume content of steel fibres, and steel aggregates. However, these high strength cement pastes and mortars are very brittle. Consequently, the addition of fibres is necessary to enhance ductility. Compact reinforced composite (CRC) was developed by Aalborg Portland (1986) in Denmark. This type of UHPC contains 5 to 10\% of steel fibres (6 mm length and $0.15 \mathrm{~mm}$ of diameter) to improve the tensile strength of the material without improving the ductility of a structure (Bache, 1987). Reactive powder concrete (RPC) was further developed by Bouygues, France in 1995 which contains maximum $2.5 \%$ of steel fibres by volume (13 mm length and $0.16 \mathrm{~mm}$ of diameter) (Richard and Cheyrezy 1995, Orange et al. 2000). The length of the fibre in RPC is twice longer than CRC. This low fibre content of RPC doesn't increase the tensile strength of the matrix, which is around $8 \mathrm{MPa}$; however, the bond between fibres and the matrix was found to be improved compared to CRC. The multi-scale cement composite (MSCC) using a mixture of short and long steel fibres were developed at the LCPC in France and are known under the name CEMTECmultiscal ® (Rossi 1997, Rossi, 2002)

\subsubsection{UHPFRC composition}

UHPFRC consists of cement, silica fume, fine sand, fibres, water and superplasticizer. Typical water/cement ratio is $0.15-0.20$.

Cement: The cement content is very high, more than two times higher than that of the normal strength concrete $\geq 700 \mathrm{~kg} / \mathrm{m}^{3}$. The cement used in UHPFRC usually has low alkali content, low to medium fineness and low $\mathrm{C} 3 \mathrm{~A}$-content, thus, reducing water need, ettringite formation and heat of hydration. The homogeneity of the mix was improved by eliminating the coarse aggregate, and optimizing the packing density. Some researchers used quartz powder of $25 \%$ of cement content as a filler to optimize the packing density (Wille and Naaman, 2012). 
Silica fume: Silica fume is used in UHPFRC to fill the voids between cement grains. It improves rheological properties, and it forms hydration products. Silica fume of $25 \%$ of cement content is found to be the optimum filling capacity (Wille and Naaman, 2012). However, the use of silica fume increases the shrinkage of the mix to be more than that of the conventional concrete with similar water to binder ratio (Loukili, 1999).

Sand: Sand with a mean particle size smaller than $1 \mathrm{~mm}$ is used to produce UHPFRC mix. Quartz sand is more suitable for UHPFRC due to its high hardness property and its good interface with the cement paste.

Superplasticizer: Superplasticizers are essential to ensure a good workability of UHPFRC. They improve rheology of the fresh material and reduce the need for water. Polycarboxylates and polycarboxylatethers are very efficient superplasticizers .

Fibres: UHPC is a brittle material; therefore, fibres with different geometries and lengths are added to UHPC to increase the energy absorption capacity and decrease brittleness. Steel fibres are mostly adapted due its high strength and stiffness. Steel and organic fibres are used in UHPFRC. Steel fibres in UHPFRC are generally pulled out; therefore, fibre ductility is less important than it strength. Naaman (2008) developed curves for strain hardening under bending and uniaxial tension as a function of the fibre properties. Rossi (2002) developed UHPFRC on the basis of the multiscale concept with several kinds of steel fibres to increase the tensile strength of the material and the deformation capacity of the structure.

\subsubsection{Structural applications}

Application of UHPC has been used internationally in the construction of a limited number of bridges in Canada, the United States, Europe, Asia, and Australia. The first application for a footbridge was realized with a use of RPC, in Sherbrooke, Canada in 1997 (Fig. 2.1(a)). It is 60 $\mathrm{m}$ long and $3.3 \mathrm{~m}$ wide post-tensioned truss with $30 \mathrm{~mm}$ thick slab. Deck and truss members are made from UHPFRC, no passive reinforcement was used. Amongst this type of the UHPC applications are Seonyu footbridge in Seoul, South Korea (Fig. 2.1(b)); the Sakata Maria footbridge in Sakata city, Japan (Fig. 2.1(c)); the Yokemuri footbridge in Yagamata, Japan; and 
the Papatoetoe and Penrose footbridges in Auckland, New Zealand (Ahlborn et al., 2008, Suleiman et al., 2008, Schmidt and Fehling, 2004, Buitelaar, 2004)

The first UHPC highway bridge was opened to traffic in France in 2001 (Hajar et al. 2004), and at the same time, another UHPC bridge was constructed in Italy with $11.8 \mathrm{~m}$ span. (Meda and Rosati, 2003). In late 2005, a $33.8 \mathrm{~m}$ span UHPC bridge was designed and opened to traffic in Iowa (Bierwagen and Abu-Hawash, 2005).

Other application of UHPC include piles lining in oil production platform in the lake of Maracaibo in Venezuela in 1992 and 1993 (Buitelaar, 2004), as a rehabilitation material in the Kinzua Dam Stilling Basin in 1983 (Buitelaar, 2004), and as an architectural shape in tollgate of Millau Viaduct in France (Fig. 2.1(d)) (Schmidt and Fehling, 2004).

\subsubsection{Effect of fibres on concrete properties}

The incorporation of steel fibres in the mix design overcomes the brittle behaviour of plain UHPC under tensile loading, and significantly improves its post-cracking tensile resistance and toughness. The performance of UHPFRC depends greatly on the bond between steel fibres and concrete, fibres distribution in the concrete matrix, and the fibre content. The primary role of steel fibres is bridging the cracks. As cracks open, the fibres can either fracture or pull out from the concrete depending on the bond strength between the fibres and the concrete. Pull out failure is more often due to the amount of energy absorbed in the concrete matrix. Therefore, improving the bond characteristic between the steel fibres and concrete is desirable to increase the bridging affect. 


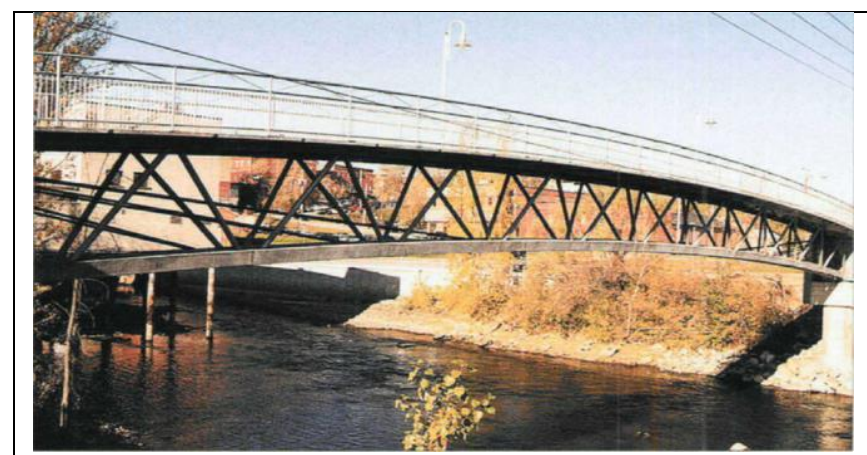

(a) Footbridge in Sherbrooke, Canada, 1997

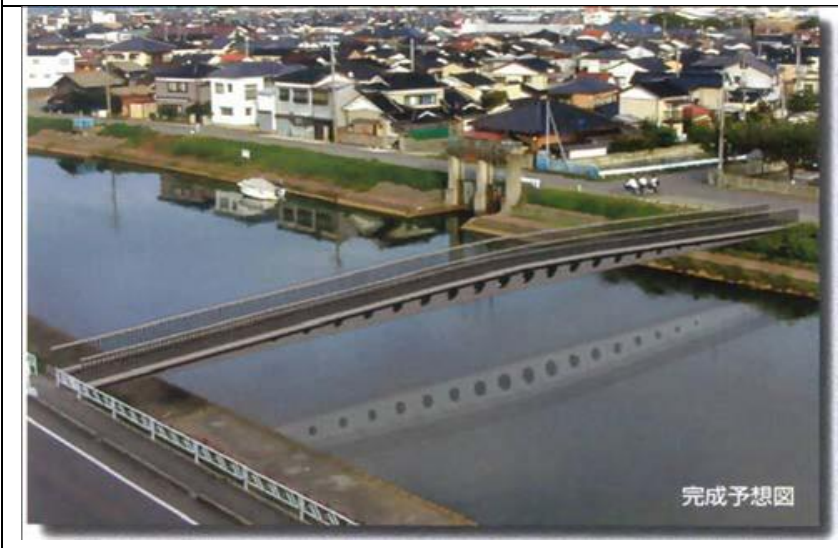

(c) Sakata Mirai footbridge, Japan, 2000

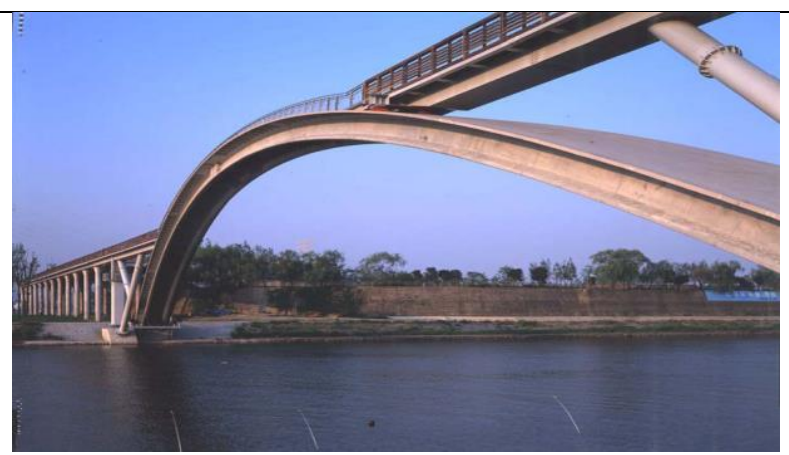

(b) Footbridge in Seoul, South Korea, 2002

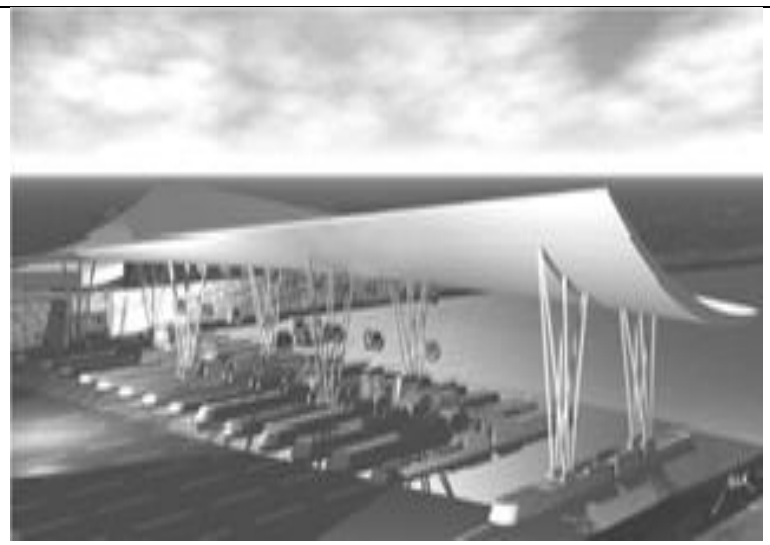

(d) Roof of the Millau toll-gate

Figure 2.1 Applications of UHPFRC

Different types of fibres were used in the concrete industry; the common types are shown in Figures 2.2 and 2.3. Straight fibre was the first type of steel fibres used in concrete and its bond strength depends on the friction between the fibre and the concrete. Therefore, higher surface area to volume ratio of fibres has high bond strength. Also, the bond strength depends on the aspect ratio, which is the length of fibre to diameter ratio. The deformation of fibres significantly improves the bond strength between fibres and concrete. However, increasing fibre aspect ratio, introducing mechanical anchorage, and changing fibre cross section may decrease the bond strength due to inadequate workability and fibre distribution (ACI Committee 544, 1988). 


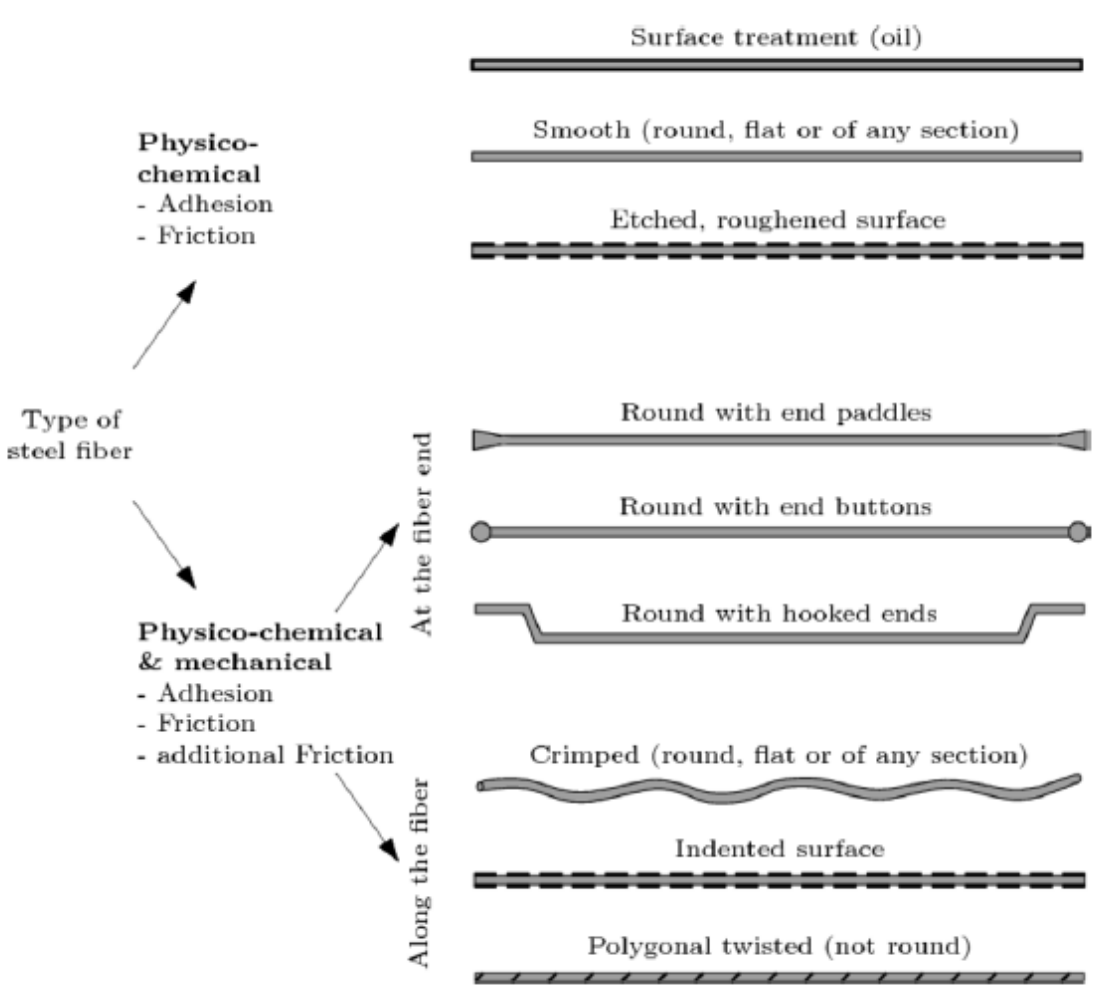

Figure 2.2 Different types of steel fibres grouped according to their bond characteristics (Wille and Naaman, 2012b)

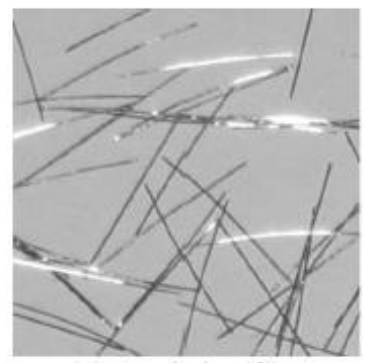

(a) straight (S)

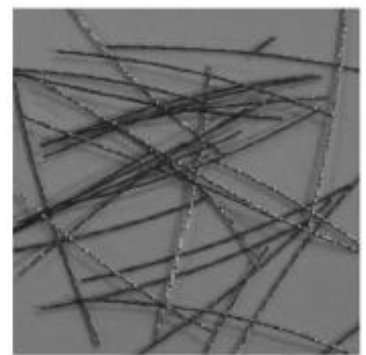

(d) high twisted (T1)

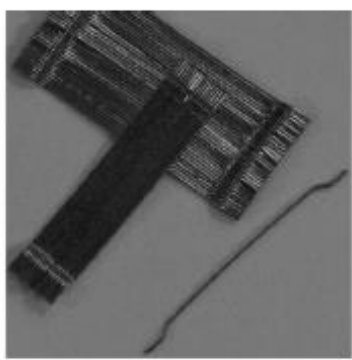

(b) hooked (H1)

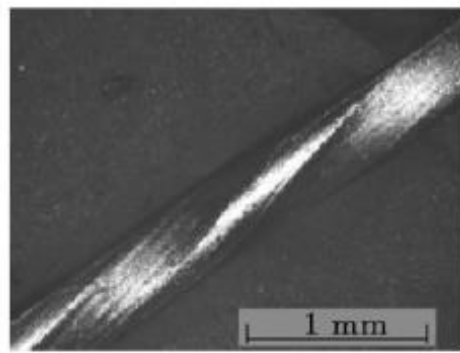

(e) high twisted (T1)

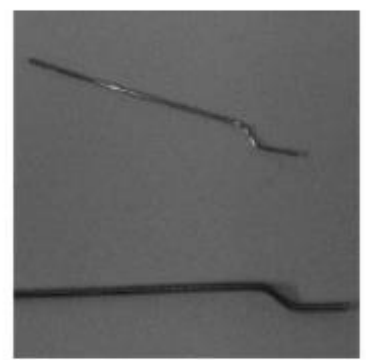

(c) hooked $(\mathrm{H} 2)+(\mathrm{H} 1)$

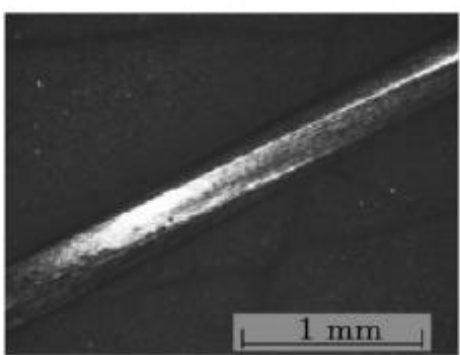

(f) low twisted (T2)

Figure 2.3 Different types of steel fibres (Wille and Naaman, 2012b) 
The fibre matrix bond mechanism depends on physico-chemical bond that is based on the adhesive and frictional forces, and mechanical bond due to fibre deformation (Wille and Naaman, 2012a). Fig. 2.4 shows comparison between smooth fibres and deformed fibres, such as end hooked or twisted fibres. It can be noted from Fig. 2.4 that mechanical contribution of deformed fibres increases the bond component, which leads to the increase in the pull out resistance. The mechanical bond properties are affected by the geometric deformation of the fibre and the matrix tensile stress resistance. The deformation along fibre length provide a mechanical bond contribution along the fibre such as in crimped, indented or polygonal twisted fibres whereas the deformation at the fibre end increases the mechanical bond such as paddles, buttons or hooks fibres.

Chan and Chu (2004), Markovic (2006), and Stengel (2009) studied the behaviour of steel fibres embedded in UHPC. Wille and Naaman (2012b) developed Fig. 2.5 to illustrate fibre tensile stress-slip behaviour of straight $(\mathrm{S})$, hooked-end $(\mathrm{H})$, and twisted $(\mathrm{T})$ fibres based on pullout tests of fibres embedded in high-strength cementitious matrix by Sujiravorakul (2001), Kim et al. (2008), Naaman and Najm (1991), Robins et al. (2002), and Cunha et al. (2010).

It can be noted from Fig. 2.5 that the pullout response of one single S-fibre is characterized by a rapid increase of fibre stress followed by a decrease of tensile stress with an increase of pullout slip due to fibre debonding. The bond strength between S-fibre surface and the matrix is predominantly controlled by the physicochemical bond properties; while in hooked-end fibre, the pullout induces pressure on the cement matrix at the end of the hook which increases the frictional force and thus increases the pullout resistance. However, this mechanical contribution decreases with an increase in slip due to straighten of the end hook. For Polygonal-shaped Tfibres, the mechanical contribution along the fibre length provided by the un-twist torque resistance increases the pressure on the cement matrix along the fibre length and thus increases the pullout resistance and the amount of dissipated energy up to very high slips. 


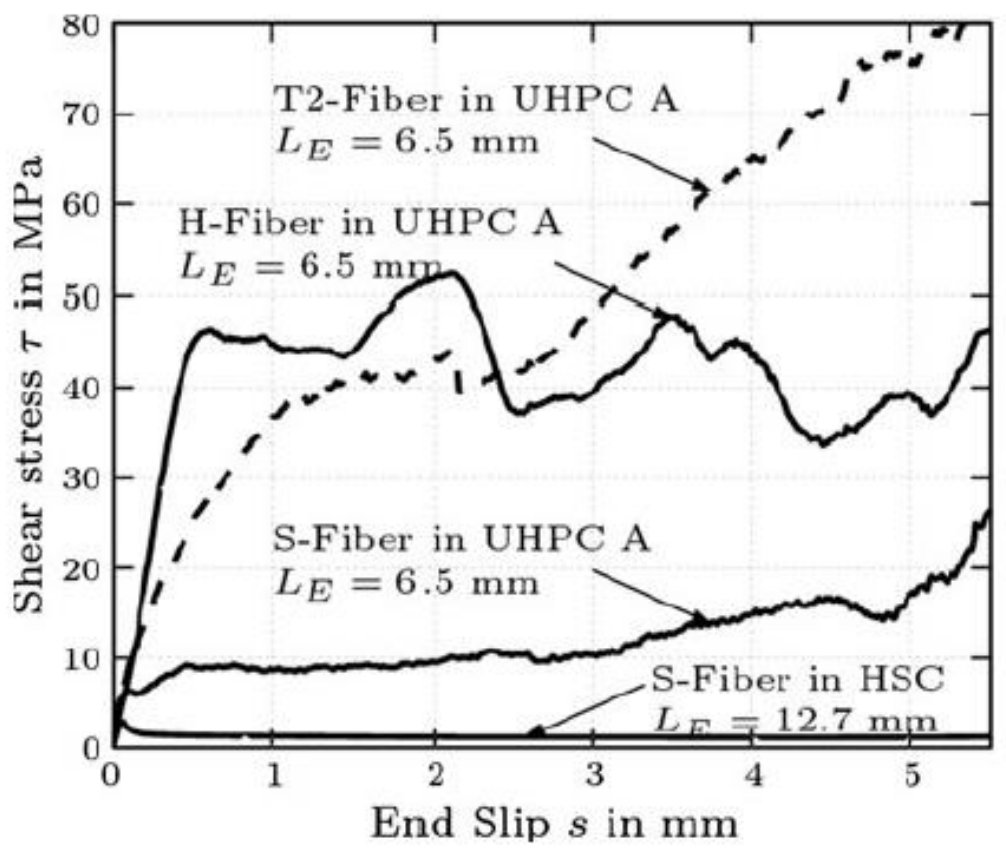

Figure 2.4 Shear stress slip relationship of smooth (S) and deformed (T2, H) steel fibres embedded in HSC (60 MPa) and UHPC A (194 MPa) (Wille and Naaman, 2012a)

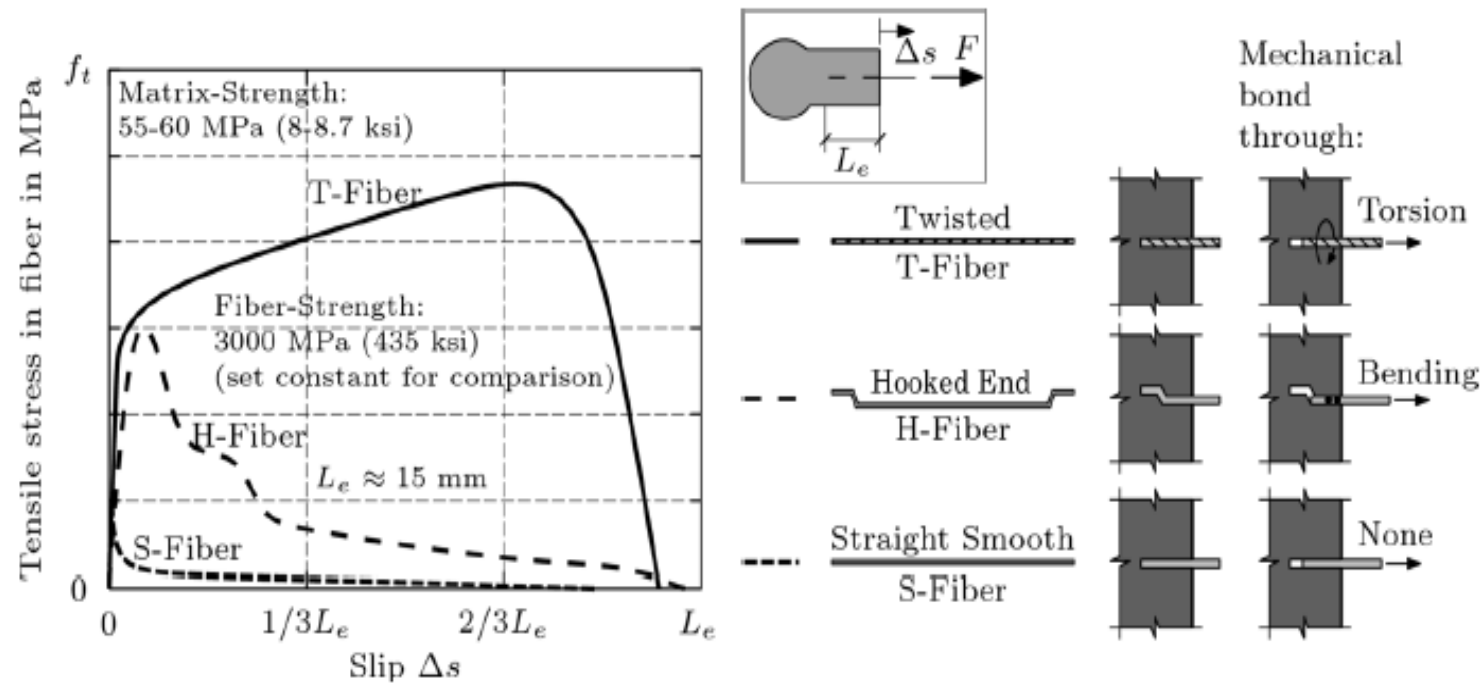

Figure 2.5 Comparison of pullout response of high-strength straight, hooked-end, and twisted fibres embedded in high-strength concrete (Wille and Naaman, 2012b) 
The average pullout load-versus-slip curves of the S-, H-, and T-fibres are shown in Fig. 2.6(a). Fig. 2.6(b) shows the mechanical bond contribution of the deformed fibres in comparison to Sfibres. It can be noted from Fig. 2.6(b) that the maximum fibre stress for the pulled-out deformed fibres (T1 and T2) is approximately three times the stress achieved by the S-fibres. The material use factor which is defined as the maximum tensile stress achieved through pullout divided by the material tensile strength was between 0.9 and 1.0 for deformed fibres which is more than twice the value of 0.44 for the $S$-fibre.

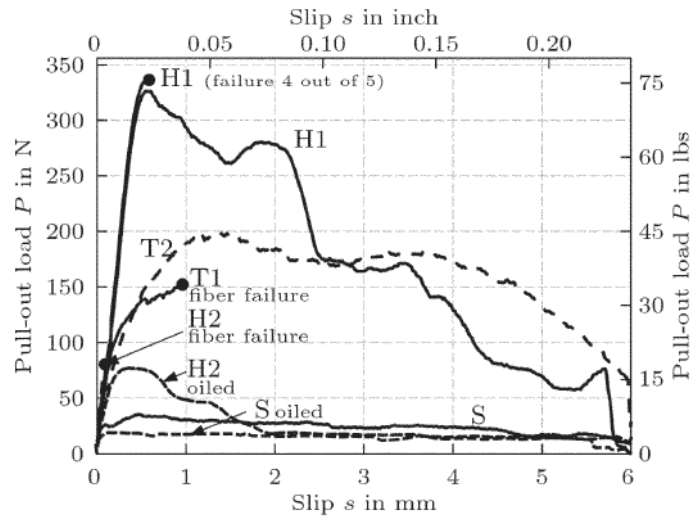

(a) Pull out load versus slip

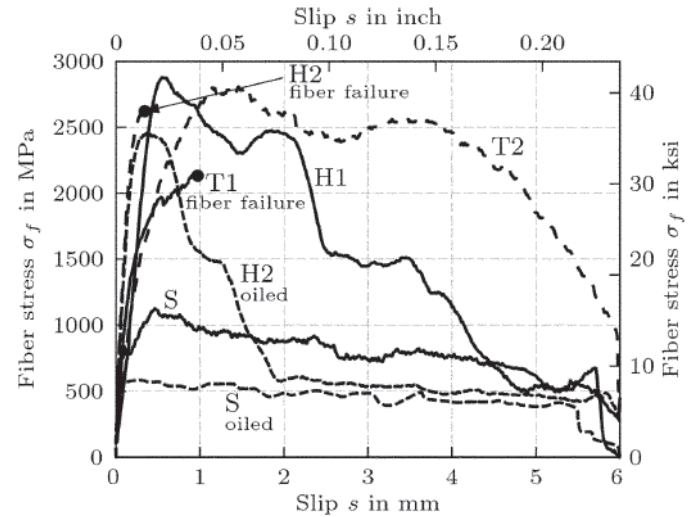

(b) Fiber stress versus slip

Figure 2.6 Effect of fibre geometry on pullout behaviour of steel fibres embedded in UHPC-A (Wille and Naaman, 2012b)

Banthia and Trottier (1994) studied the effect of inclination angle with respect to loading direction for hooked steel fibre in normal, mid and high strength concrete. They found that the load-slip curve was not significantly affected by changing the inclination angle that ranged between 0 and 15 degrees, while at an angle higher than 30 degrees, the effect of fibre inclination was more pronounced up to a slip of $3.5 \mathrm{~mm}$ as shown in Fig. 2.7. 


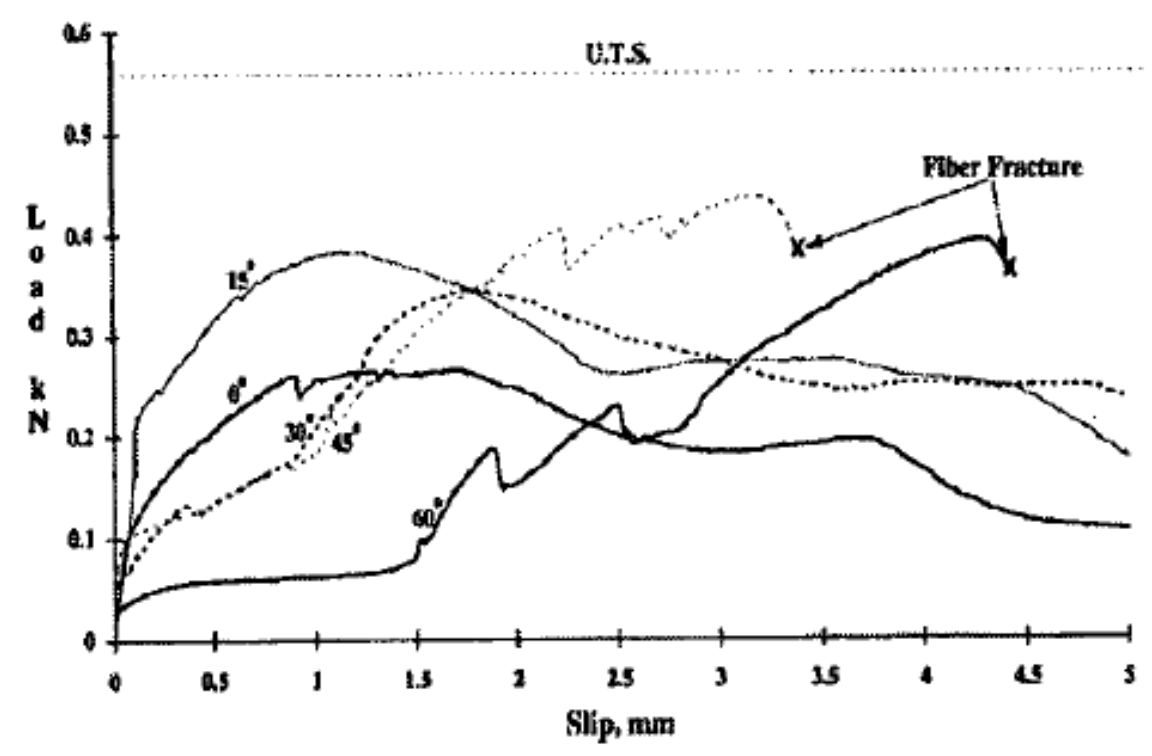

Figure 2.7 Effect of fibre inclination for hooked steel fibre in high strength concrete (Banthia and Trottier, 1994)

According to Hannant (1978), the fibre composite tensile strength, $\sigma_{c c}$, and elastic modulus, $E_{c}$, are:

$$
\begin{aligned}
& \sigma_{c c}=\sigma_{f} * V_{s f}+\sigma_{m u}\left(1-V_{s f}\right) \\
& E_{c}=E_{f} * V_{s f}+E_{m}\left(1-V_{s f}\right)
\end{aligned}
$$

where, $\sigma_{f}=$ fibre tensile strength,

$\sigma_{m u}=$ matrix tensile strength at first crack

$E_{f}=$ fibre modulus,

$E_{m}=$ matrix modulus, and

$V_{s f}=$ fibre volume content 
To account for fibre length factor, $\eta_{1}$, and fibre orientation factor, $\alpha$, the composite tensile strength, $\sigma_{c c}$, and elastic modulus, $E_{c}$, can be calculated as follows:

$$
\begin{gathered}
\sigma_{c c}=\eta_{1} \alpha \sigma_{f} * V_{s f}+\sigma_{m u}\left(1-V_{s f}\right) \\
E_{c}=\eta_{1} \alpha E_{f} * V_{s f}+E_{m}\left(1-V_{s f}\right)
\end{gathered}
$$

Allen (1972) proposed a fibre length factor takes into consideration the ability to develop the bond along the fibres as follows:

$$
\eta_{1}=\left\{\begin{array}{l}
\frac{l_{f}}{2 l_{c}} i f l_{f} \leq l_{c} \\
1-\frac{l_{f}}{2 l_{c}} i f l_{f}>l_{c}
\end{array}\right.
$$

Where, $l_{f}$ is the fibre length and $l_{c}$ is the two times the length of the fibre embedment length required to induce fibre fracture as opposed to fibre pullout. The fibre embedment length can vary between $l_{f} / 2$ and 0 . If pullout occurs from the side with the smaller embedment length, the average effective embedment length is $l_{f} / 4$ (Narayanan and Darwish, 1987, Aoude, 2007); therefore the factor $\eta_{1}=0.5$. The fibre orientation factor $\alpha$ for one, two and three dimensional fibre orientations is $1,2 / \pi$, and 0.5 respectively (Naaman, 2008).

The "effective" number of fibres per unit area, $n_{f i b}$, can be calculated using equation (2.6) for fibres randomly oriented in three dimensions (Hannant, 1978):

$$
n_{f i b}=\frac{V_{s f}}{A_{s f}} * \alpha * \eta_{1}
$$

where, $A_{s f}$ is the cross-sectional area of the fibre. 
The post-cracking tensile strength, $\sigma_{p c}$, can be calculated on the basis of the average bond strength, the number of fibres per unit area, and the effective bond length (Naaman and Reinhardt, 1995):

$$
\sigma_{p c}=\lambda_{1} \lambda_{2} \lambda_{3} \tau V_{s f} \frac{l_{f}}{d_{f}}
$$

where, $\lambda_{1}, \lambda_{2}$, and $\lambda_{3}$ are the effective bond length, fibre orientation factor and group factor associated with number of factors crossing a unit area for post-cracking state, $d_{f}$ is the diameter of the fibre, and $\tau$ is bond between the fibre and the matrix

The critical fibre volume content can be defined as the volume content where the composite can carry additional stress after the matrix cracked $\left(\sigma_{p c} \geq \sigma_{c c}\right)$ as shown in Fig. 2.8. Naaman and Reinhardt (1995) derived an expression for critical fibre volume content taking into account the fibre distribution and the bond between the fibre and the matrix as follows:

$$
V_{f c}=\frac{1}{1+\frac{\tau}{\sigma_{m u}} \frac{l_{f}}{d_{f}}\left(\lambda_{1} \lambda_{2} \lambda_{3}-\beta_{1} \beta_{2}\right)}
$$

where, $\beta_{1}$ and $\beta_{2}$ are fibre length and fibre orientation factor for uncracked composite. For hooked steel fibres, Naaman and Reinhardt predicted a volume content factor of $2 \%$. 


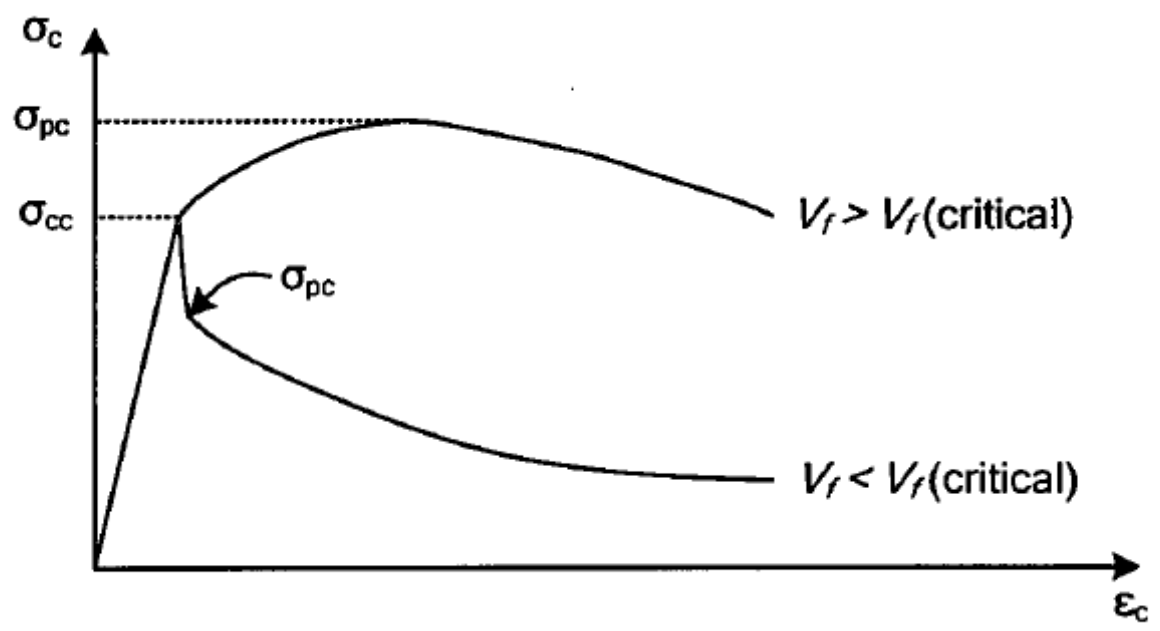

Figure 2.8 Different stress-strain curve for brittle matrix composites (Dinh, 2009)

\subsubsection{Material properties}

\subsubsection{Compressive strength}

Several authors reported that the effect of fibres on the compressive strength was not significantly increased (Minelli, 2005, Dupont, 2003, Nataraja et al., 1999). Tomas and Ramaswamy (2007) reported that the increase in the peak compressive strength was less than $10 \%$ when fibres with $1.5 \%$ volume content was added to the concrete. However, the addition of fibres significantly reduced the rate of strength loss after the peak stress. Johnston (2001) showed that lateral swelling of the concrete takes place during the uniaxial compressive test resulting in a combination of shear and tensile stresses in the concrete section due to the improved postcracking resistance of the steel fibre reinforced concrete. Several investigators have proposed models for the characterization of the compressive stress-strain behaviour of SFRC (Nataraja et al., 1999, Mansur et al., 1999).

Graybeal and Davis (2008) investigated the relationship between the measured compressive strength of cylinder specimens and cube specimens of UHPFRC in the strengths that ranged from 80 to $200 \mathrm{MPa}$. They found the followings:

1. A factor of 0.96 should be applied to convert the $70.7 \mathrm{~mm}$ (2.78 in.) cube strength result into an equivalent $76 \mathrm{~mm}$ ( 3 in.) diameter cylinder result 
2. The $102 \mathrm{~mm}$ (4 in.) diameter cylinders, $76 \mathrm{~mm}$ (3 in.) diameter cylinders, and $100 \mathrm{~mm}(4$ in.) cubes are acceptable and interchangeable test specimens for the determination of the compressive strength of UHPFRC

\subsubsection{Tensile strength}

It is difficult to experimentally evaluate the direct tensile behaviour of steel fibre reinforced concrete (SFRC). The problem arises from the need for specimens that have sufficiently large cross section area such that the fibre distribution will be similar to that in real structural members. Therefore, this size of specimen often poses difficulty in the design of fixtures to grip the end of the specimen. The average strain is hard to interpret because after cracking the average strain is due to local crack opening. In addition, the length of the strain gauge affects the average strain. Recent research by Graybeal and Baby (2013) presented a direct tension test method applicable to UHPC based on a concept of a standard tension test applied to metals. They investigated different fibre percentage contents and curing conditions of UHPC. The results showed that the uniaxial tensile strength of UHPFRC was higher than $9 \mathrm{MPa}$.

Usually, the concrete tensile strength is obtained from indirect tests due to the difficulties to achieve truly axial tension without secondary stresses induced by the holding devices in the direct tension test as shown in Fig. 2.9(a). Indirect tests such as the bending or modulus of rupture test, Fig. 2.9(b), the double punch test, Fig. 2.9(c), or the split cylinder test, Fig. 2.9(d).

While indirect tests are easier to perform, they require assumptions about the state of stress within the specimen in order to determine the tensile strength from the measured failure load.

Shah (1978) performed direct tensile test with straight, hooked and standard steel fibres as shown in Fig. 2.10 (ACI Committee 544, 1988) 
(a)

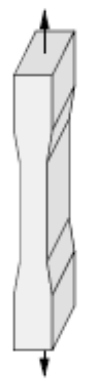

(b)

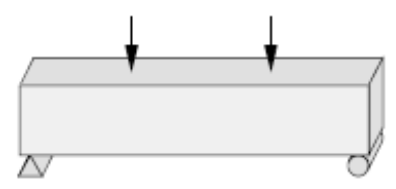

(c)

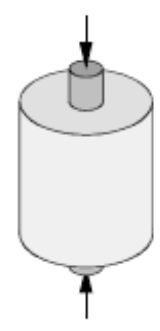

(d)

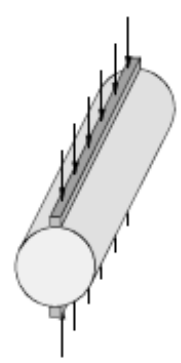

Figure 2.9 Tension tests: (a) direct tension test; (b) bending or modulus of rupture test; (c) double punch test; (d) split cylinder test (Kaufmann, W., 1998)

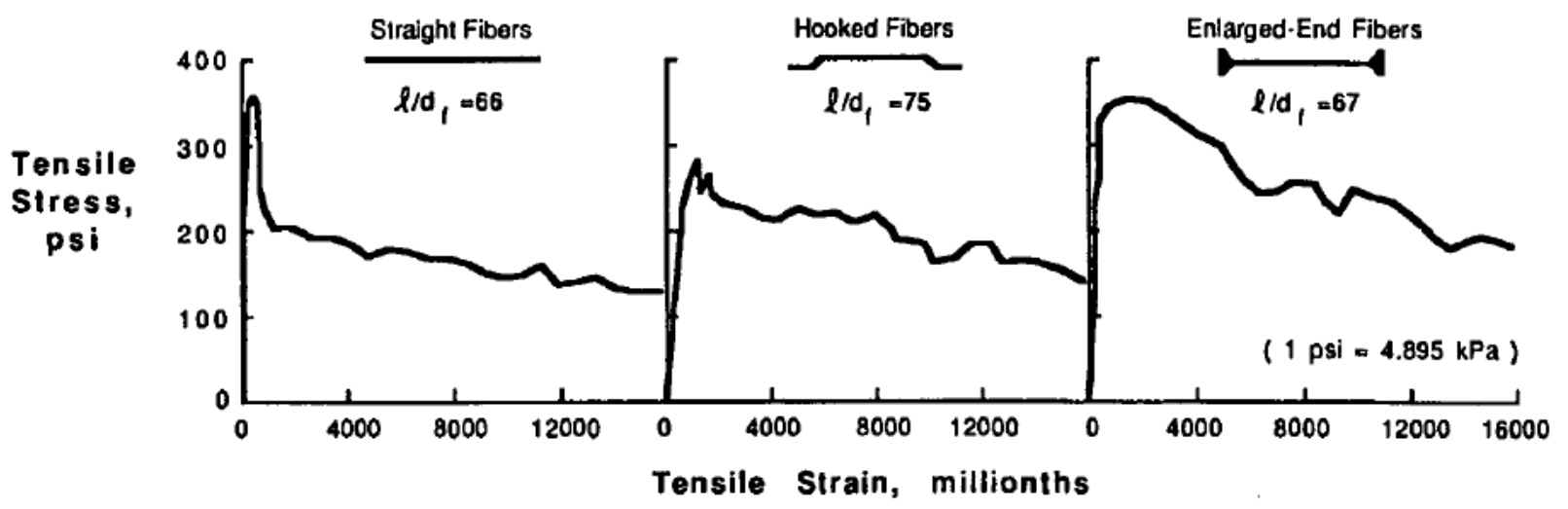

Figure 2.10 Direct tensile stress-strain curves for different types of SFRC (ACI Committee 544, 1988)

Noghabai (2000) studied the tensile characteristics of the concrete by testing notched concrete cylinder specimen under uniaxial tension loads. The advantage of this test method is it's applicability to any type of concrete, regardless of type of fibre used taking into account fibre orientation. However, when larger fibres are used, the small cross section of the specimen may not represent the material adequately. Noghabai (2000) found that the use of high strength concrete increases both the first crack and the post-cracking tensile strength of SFRC (Fig. 2.11). 

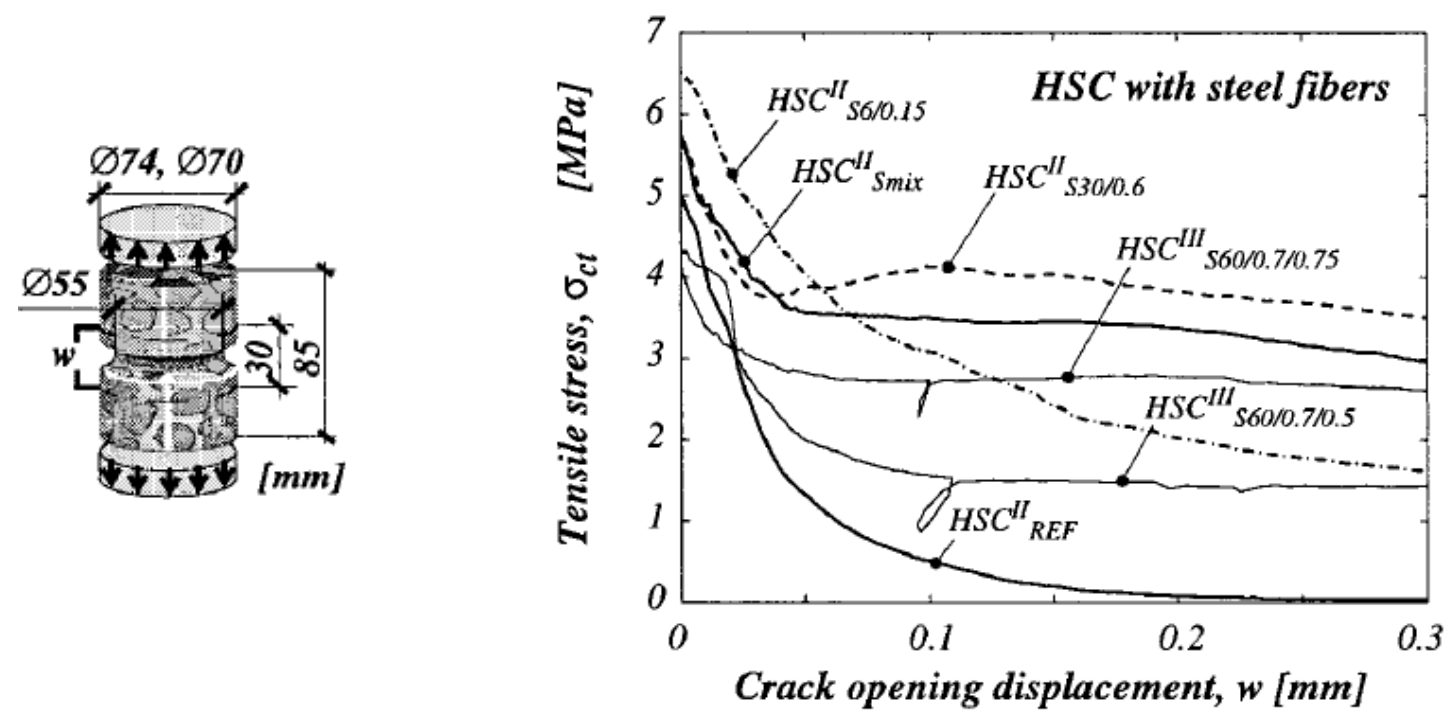

(a) Test Setup

(b) Tensile stress-crack opening relationship

Figure 2.11 Tensile stress-crack opening relationship for different Concrete Mixtures (Noghabai, 2000)

As mentioned earlier, incorporating steel fibres will increase the fracture energy, ductility, compressive and tensile strength while the cracking reducing tendency of the concrete matrix. In general, UHPFRC mixture tensile behaviour has three main stages as shown in Fig. 2.12 (Spasojevic, 2008):

1. Linear-elastic response stage - The response of the UHPFRC concrete under increasing strain is essentially linear-elastic until the applied load induces a stress level in the UHPFRC mixture that matches the concrete tensile strength and a first microcrack appears.

2. Pseudo strain hardening stage - This stage is also referred to as "pseudo plastic" because there is no real plastic microstructural changes occur. In fact, deformations continue to increase strongly as a result of formation of the several microcracks (Spasojevic, 2008), while the uniaxial tensile stress does not change considerably, or increases considerably slower compared to the linear-elastic stage. The development of multiple microcracking with uniformly distributed openings secured together by the fibres within the UHPFRC is similar to strain hardening or plastic deformation. 
3. Strain softening stage - This stage occurs at the onset of any of the UHPFRC mixture sections fails to transfer the average stress of the same intensity, resulting in reaching the strain hardening capacity of UHPFRC mixture. Then the formation of macrocracks occurs and will start opening further until eventually reach the deformation capacity, normally addressed as half the length of the longest fibre (Spasojevic, 2008).

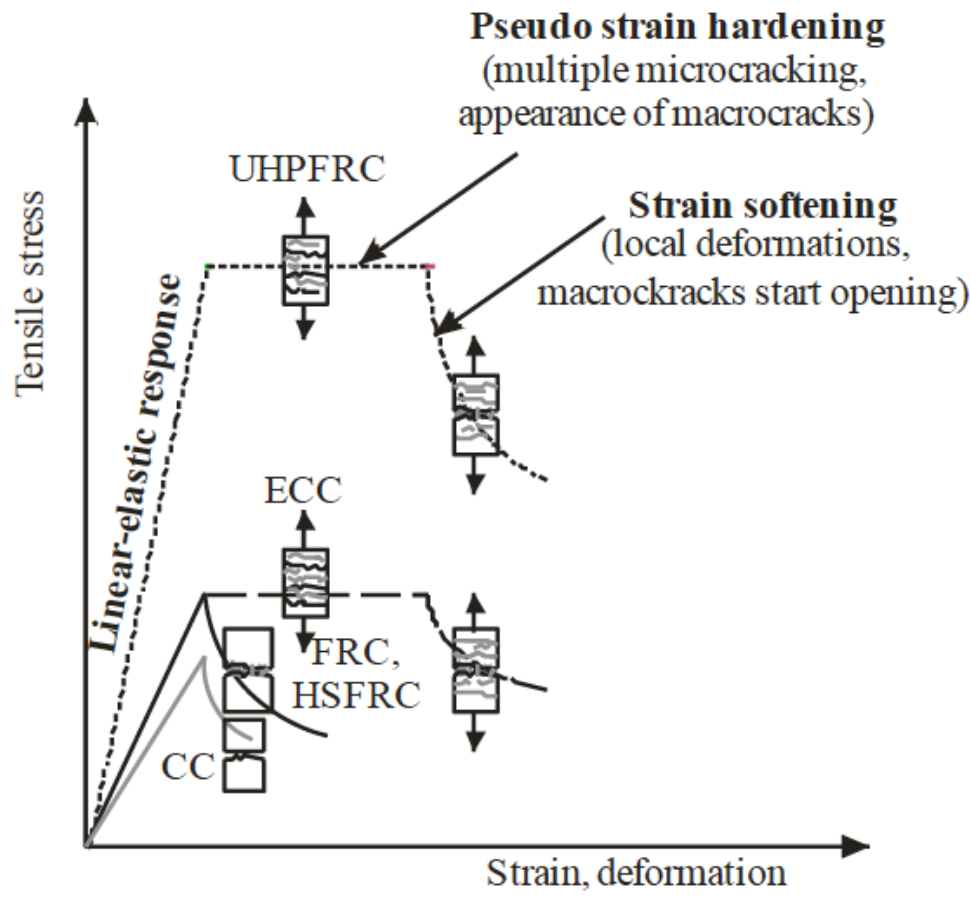

Figure 2.12 - Response of UHPFRC in uniaxial tensile stress state compared to conventional (CC), fibre- reinforced normal or high-strength concrete (FRC, HSFRC), as well as engineered cementitious composites (ECC) with short polymeric (PE, PVA) fibres (adapted from Spasojević, 2008)

Similarly, Wille and Naaman, (2011) studied the tensile behaviour of the UHPFRC, Fig. 2.13 illustrates a simplified response of strain-hardening FRC composites in tension where stress is defined as the obtained tensile load, when the first percolation crack occurs, divided by the specimen cross sectional area, and the maximum post-cracking stress is defined as the maximum tensile load divided by the specimen cross sectional area. The elastic behaviour (Part I) up to 9095\% of cracking strength followed by development of micro cracks and activation of fibres; the 
strain hardening behaviour when, multiple cracks will form with small crack width and inelastic strain (Part II); and the strain softening behaviour (Part III).

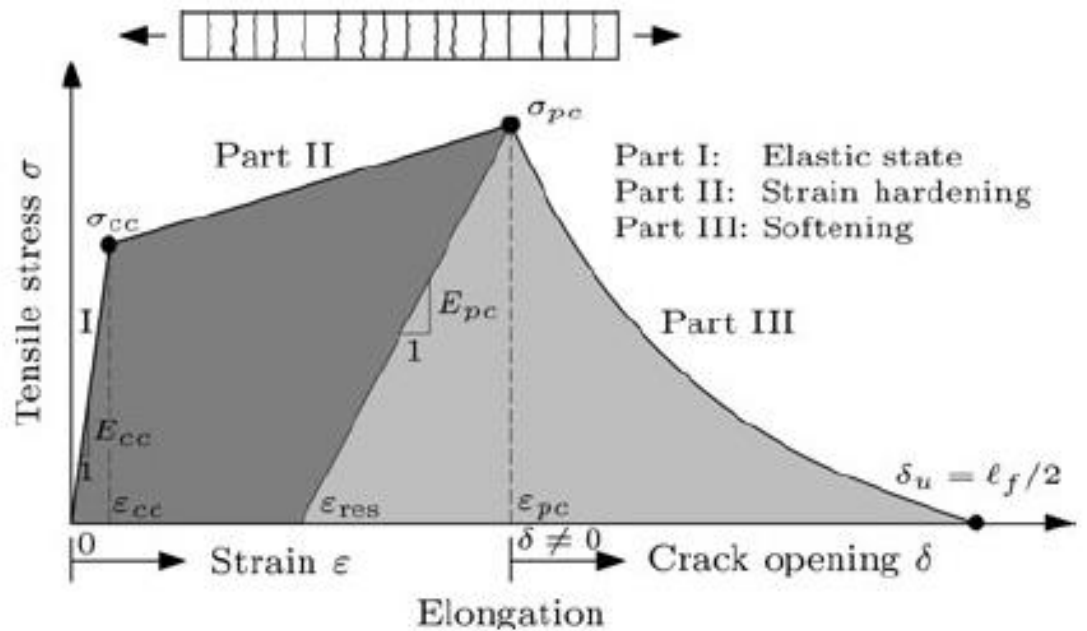

Figure 2.13 Idealized simplified response of strain-hardening FRC composites in tension (Wille et al., 2011)

Increasing the fibre volume content within a certain range increases the tensile strength as well as the tensile strain at peak stress as shown in Fig. 2.14. Naaman and Wille (2010) recommended a fibre factor in order to preserve a suitable workability of UHPFRC without fibre clumping.
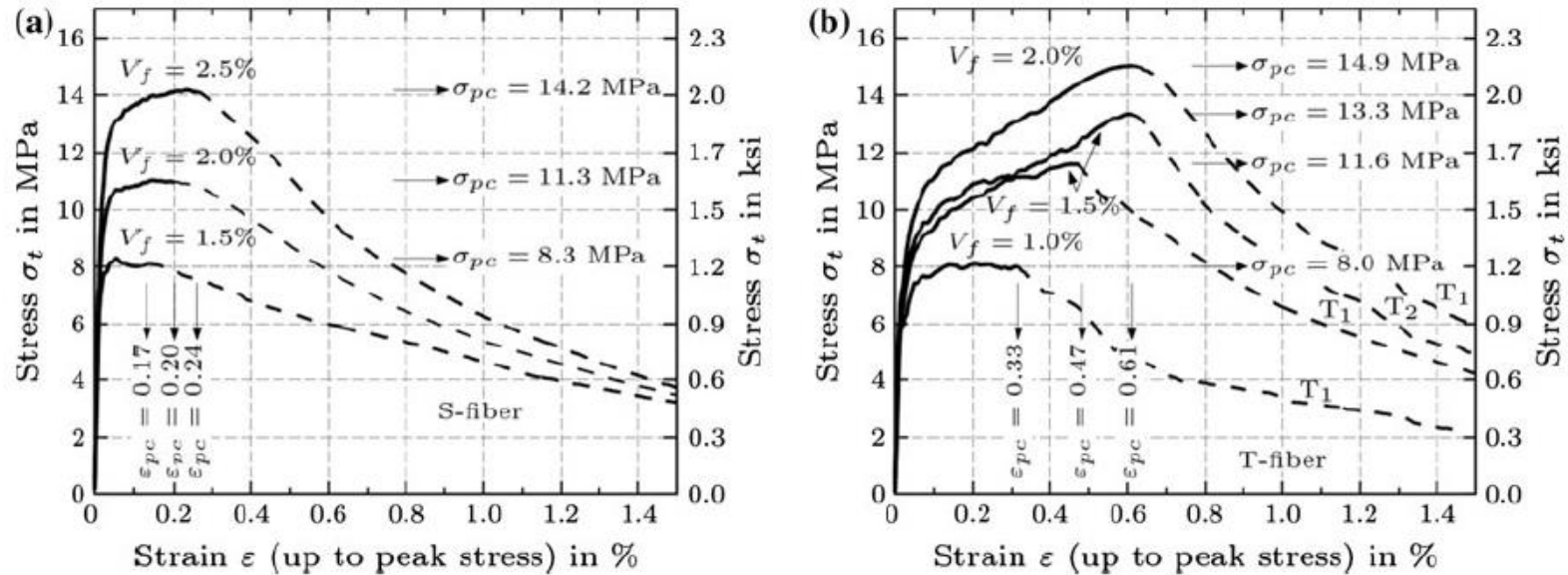

Figure 2.14 Influence of fibre volume fraction on tensile behaviour. (a) Smooth (S) fibres and (b) twisted (T) fibres (Wille et al., 2011) 
Naaman (2008) introduced the utilization factor to evaluate the utilization of the fibre material. The utilization factor, $\chi_{u}$, is defined as the ratio of maximum post-cracking stress to the ultimate tensile strength of the composite, assuming all fibres fail simultaneously.

$$
\chi_{u}=\frac{\sigma_{p c}}{\sigma_{c u}}
$$

The ultimate tensile strength of the composite $\sigma_{c u}$ can be obtained from equation (2.10)

$$
\sigma_{c u}=\alpha * V_{s f} * \sigma_{f u}
$$

where, $\alpha=$ orientation factor, $\sigma_{f u}=$ the ultimate tensile strength of fibre. The maximum postcracking stress $\sigma_{p c}$ can be obtained from equation (2.11)

$$
\sigma_{p c}=\lambda * \tau * \frac{l_{f}}{d_{f}} * V_{s f} \leq \sigma_{c u}
$$

where, $\tau$ is the equivalent bond strength between fibre and matrix, $l_{f} / d_{f}$ the fibre aspect ratio and $\lambda$ is the product of several coefficients, taking into account the influence of embedded length, orientation effect, group reduction effect and spalling effect by large inclination of the fibre. The value of maximum post-cracking stress $\sigma_{p c}$ can be obtained from direct tensile test. Naaman (2008) also suggested equation (2.12) for calculating the first cracking strength of the composite $\left(\sigma_{c c}\right)$ :

$$
\sigma_{c c}=\sigma_{m u}\left(1-V_{s f}\right)+\lambda \tau V_{s f} \frac{l_{f}}{d_{f}} \leq \sigma_{m u}\left[1+(n-1) V_{s f}\right]
$$

where, $\sigma_{m u}$ is the ultimate tensile strength of the matrix and $\lambda$ is the product of several coefficients, taking into account the influence of average contribution of bond at the onset of matrix cracking, fibre orientation and reduction of fibre-matrix bond stress due to external stress 
radial or normal to the interface, and $n=E_{f} / E_{m}$ is the ratio of the elastic moduli of fibre and matrix.

Wille et al. (2011) improved the strain hardening capacity from 0.3 to $0.6 \%$ of UHPFRC composites. They used different types of steel fibres as shown in Fig. 2.3. The test results are shown in Fig. 2.14. They evaluated the utilization of fibre material, $\chi_{u}$, using equations (2.9) and (2.10), and was in the range of 28 to $51 \%$. This range concluded that it's possible for a further improvement in the bond behaviour in order to increase the fibre utilization which leads to a higher tensile strength for a given fibre volume content. The average tensile stress of the fibres, $\sigma_{f p c}$ within the composite at peak strength $\sigma_{p c}$ was calculated from equation (2.13), which was derived from equation (2.10).

$$
\sigma_{f p c}=\frac{\sigma_{p c}}{\alpha V_{s f}}
$$

By assuming $\alpha=0.75$, the maximum average fibre tensile stress $\sigma_{f p c}$ within different UHPFRC is shown in Fig. 2.15.

It can be noted from Fig. 2.15 that the fibre tensile stress $\sigma_{f p c}$ of straight fibres is not significantly affected by the different fibre volume content, while the $\sigma_{f p c}$ of hooked fibres is significantly affected by the fibre volume content. They attributed that to the group effect which was affected by the localized mechanical bond anchorage at the end of the hook that leads to peak stress concentrations in the matrix causing micro cracks which in turn reduce the proportional increase in the tensile strength when fibre volume content was increased. While for the twisted fibres, the fibre tensile stress $\sigma_{f p c}$ was not significantly affected by the fibre volume content due to the distribution of mechanical bond over the entire length of the fibre. 


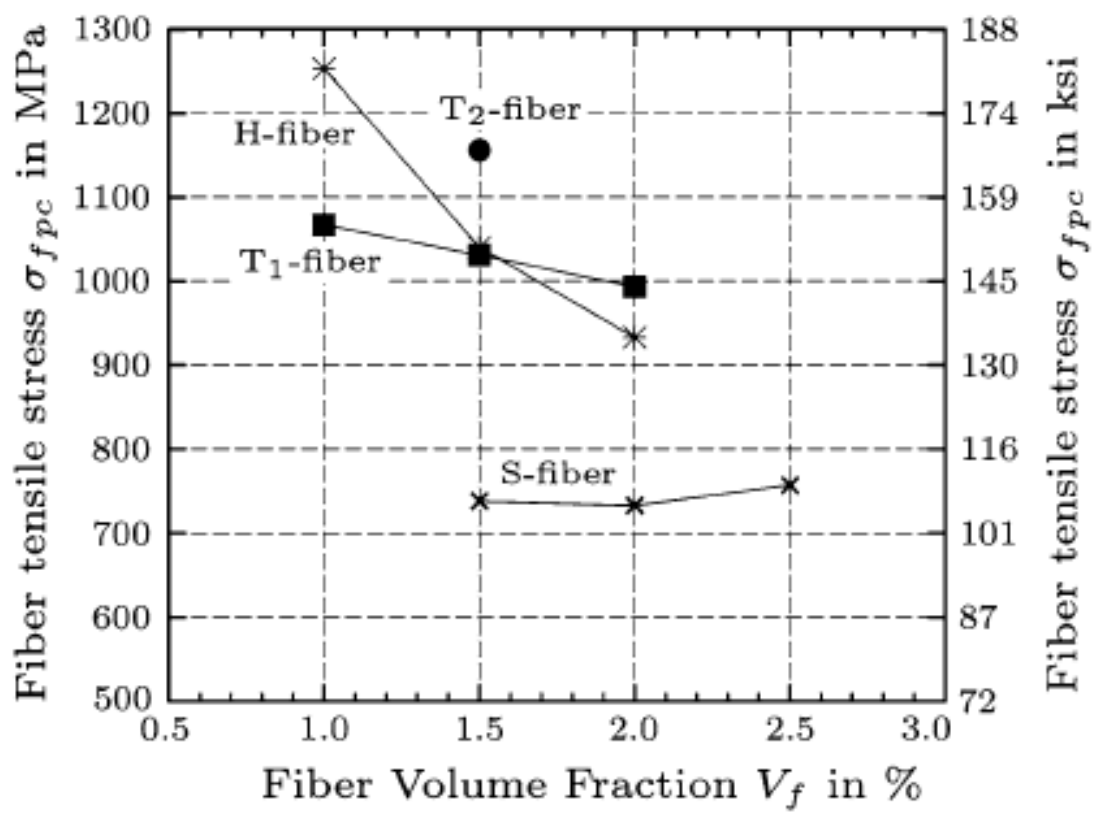

Figure 2.15 Average fibre tensile stress $\sigma_{f p c}$ within the composite at peak strength $\sigma_{p c}$ (Wille et al., 2011)

The parameter $\lambda$ was estimated using equations (2.10) and (2.11), and by obtaining the tensile strength $\sigma_{p c}$ from the tensile test results, and the equivalent bond strength $\tau$ was obtained from tests on single fibre pull out as follows:

$$
\tau=\frac{P_{\max }}{\pi d_{f}\left(L_{e}-S_{p}\right)}
$$

where, $P_{\max }$ is the maximum pull out load, $L_{e}$ the embedment length, and $S_{p}$ slip at $P_{\max }$. Wille et al. (2011) found out the value of $\lambda$ for straight fibres is 0.95 , and for deformed fibres is 0.24 which represent the group effect of fibres in the composite by considering constant fibre orientation, and neglecting the spalling effect. These results show a significant difference between straight fibres and deformed fibres. They attributed the low values of $\lambda$ for deformed bars to the strong mechanical bond that causes high stress concentration and damages the matrix 
locally, and the smaller crack spacing less than fibre length that reduces the mean embedment length, leading to a decrease in pull out resistance

ACI Committee 544 (1988) commented that the first-crack flexural strength and the peak postcracking flexural strength should be reported from the flexural test which can be calculated by assuming linear stress distribution.

Wafa and Ashour (1992) found that 1.5\% volume content of fibres with an aspect ratio of 80 increased the first-crack flexural strength by 67\%. Tomas and Ramaswamy (2007) found that adding 0.5 to $1.5 \%$ by volume of hooked steel fibres with an aspect ratio of 60 increased the first-crack flexural strength by $40 \%$.

Wille et al. (2011) performed bending tests on UHPFRC to confirm the effectiveness of fibre geometry observed in the direct tensile tests as shown in Fig. 2.16. They noted that the ratio of equivalent bending strength to direct tensile strength ranged between 2.4 and 2.65 .

The effect of specimen size on the flexural and axial tensile strengths was investigated by Reineck and Frettlohr (Reineck and Frettlohr, 2010). The results show that strength decreased with increasing size of test specimens

Wille and Parra-Montesinos (2012) investigated the effects of beam size, casting method, and support conditions on UHPC flexure test results. The results show that large discrepancies in equivalent bending strengths using the same UHPFRC mixture design, depending on the test setup and specimen characteristics. They noted that that the equivalent bending strengths was ranged between $10 \mathrm{MPa}$ and $29 \mathrm{MPa}$ depend on various casting methods, and support conditions. 


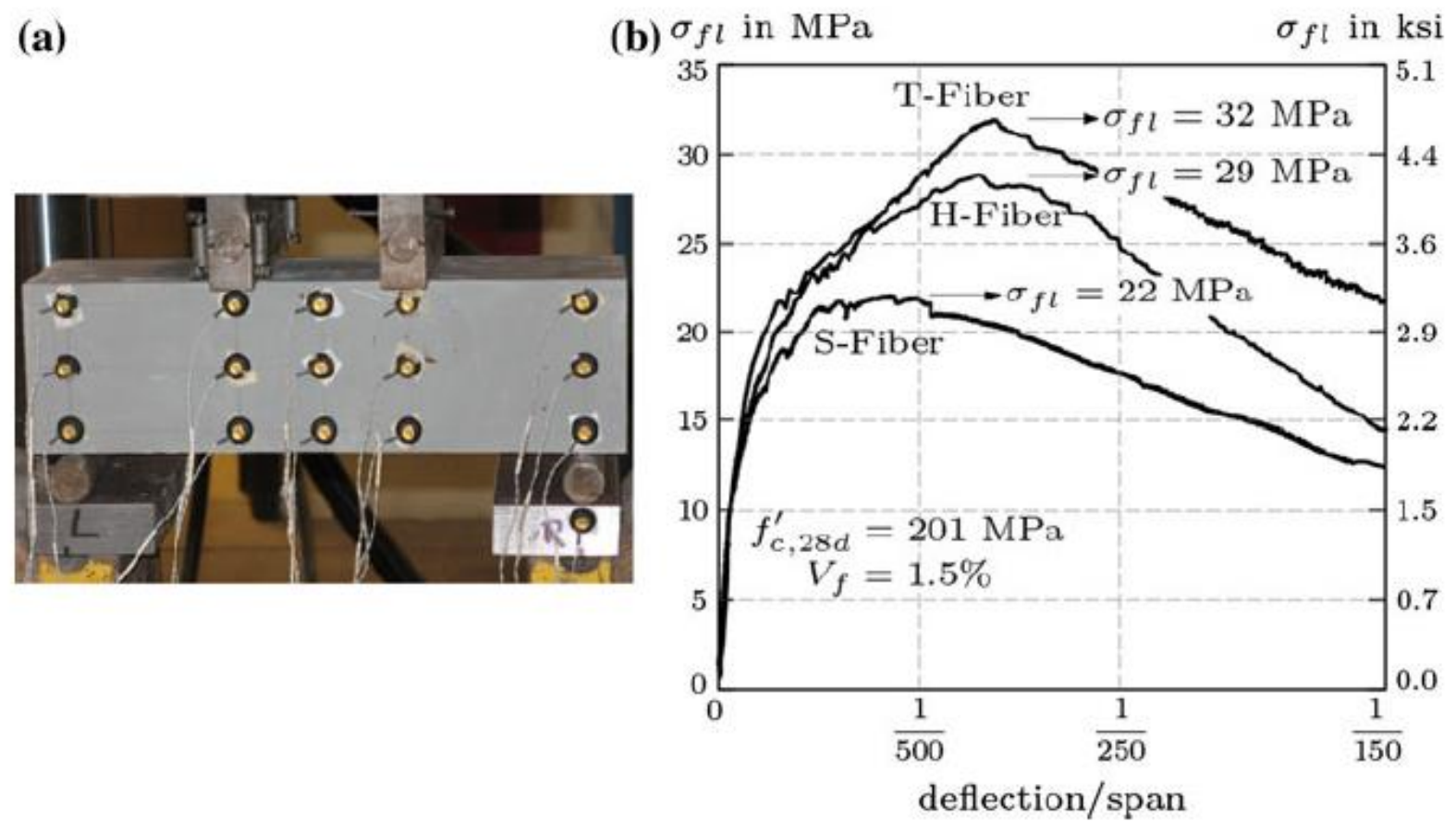

Figure 2.16 UHPFRC bending beam tests according to ASTM 1609 (a) Test setup and (b) influence of fibre geometry (Wille et al., 2012a)

\subsubsection{Modulus of elasticity}

Graybeal (2005) measured the modulus of elasticity of UHPFRC material by testing compression cylinders according to the ASTM C469 test method. The results from these tests show that the modulus of elasticity for air treated cylinders was $42.7 \mathrm{GPa}$. The results show that the specimens continued to gain strength for at least 8 weeks after casting. Graybeal also measured the modulus of elasticity using direct tension tests. The average measured value was 47.6 GPa.

\subsection{Shear behaviour of reinforced concrete beams}

\subsubsection{Shear stresses distribution and failure of plain concrete beams}

For simply supported rectangular beams with no stirrups and no longitudinal reinforcement subjected to a concentrated load at mid span as shown in Fig. 2.17, the normal and shear stresses for $x \leq a$ are determined from beam theory as follows: 


$$
\begin{aligned}
& f(x, y)=-\frac{M y}{I}=-\frac{12 V x y}{b h^{3}} \\
& v(y)=\frac{V Q}{I b}=\frac{6 V}{b h^{3}}\left(\frac{h^{2}}{4}-y^{2}\right)
\end{aligned}
$$

where, $\mathrm{V}=$ Shear force on the cross section

$$
\begin{aligned}
& \mathrm{M}=\text { Moment on the cross section } \\
& \mathrm{I}=\text { moment of inertia of the cross section } \\
& \mathrm{Q}=\text { first moment about the centroidal axis of the part of the cross-sectional area lying } \\
& \text { farther from the centroidal axis than the point where the shear stresses are being } \\
& \quad \text { calculated } \\
& \mathrm{b}=\text { width of the member at the section where the stresses are being calculated } \\
& \mathrm{h}=\text { height of the member at the section where the stresses are being calculated }
\end{aligned}
$$

As shown in Fig. 2.17 which illustrates the normal and shear distribution of stresses at the top and bottom surfaces, the shear stress is zero and the beam is subjected to a pure tension or compression stress state, while at the mid-depth level of the beam, the shear stress is maximum, which is determined as follows:

$$
v_{\max }(y=0)=\frac{3 V}{2 b h}
$$

The shear stress in equation (2.17) is pure shear stress, leads to principal tension and compression stresses with the same magnitude. When the principal tensile stress exceeds the tensile strength of concrete, crack forms at the mid-depth level of the beam usually perpendicular to the direction of the principal tensile stress know as diagonal tension cracks. For plain concrete, 
flexural cracking will likely precede diagonal cracking leading to immediate collapse of the beam.

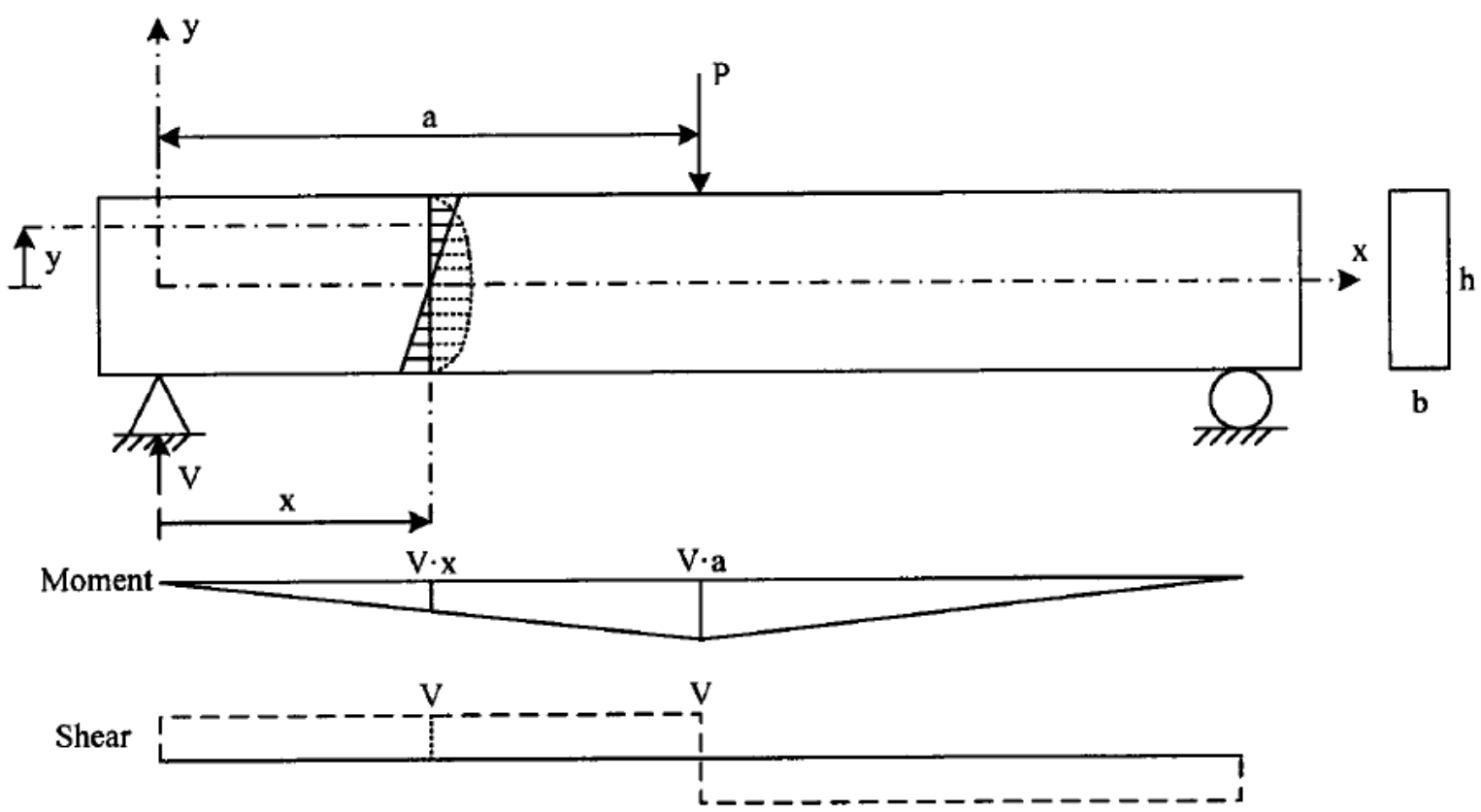

Figure 2.17 Plain concrete beam subjected to a concentrated load

\subsubsection{Shear in reinforced concrete beams without shear reinforcement}

\subsubsection{Inclined cracking pattern and modes of shear failure}

When longitudinal reinforcement is added to the beam, flexural cracks form due to the ability of longitudinal reinforcement to bridge cracks and transfer stresses to concrete by bond action. Reinforced concrete beams without stirrups may fail in shear. Two different modes of shear cracks were specified by Winter and Nilson (1979): web-shear cracks and flexure shear cracks as shown in Fig. 2.18. When the flexural stresses are small at the particular location, the diagonal tension stresses are inclined at an angle about $45^{\circ}$ and equal in magnitude to the shear stress with a maximum at the neutral axis. These diagonal web-shear cracks start mostly near the neutral axis and propagate in both directions as shown in Fig. 2.18(a). While when both the shear forces and bending moments have large values, the flexural tension cracks form first and their width are 
controlled by the presence of longitudinal reinforcement. However, when the principal tension stress at the upper end of one or more of these cracks exceeds the tensile strength of the concrete, diagonal tension crack form and propagates known as flexural-shear cracks as shown in Fig. 2.18(b). These flexural-shear cracks are more common than web-shear cracks.

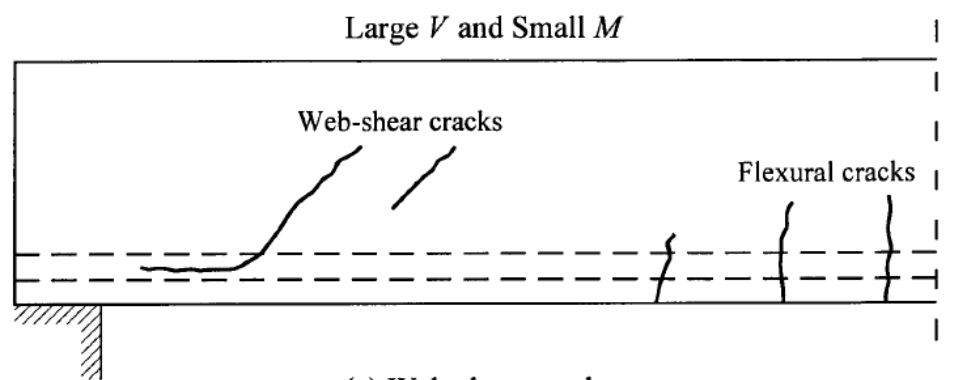

(a) Web-shear cracks

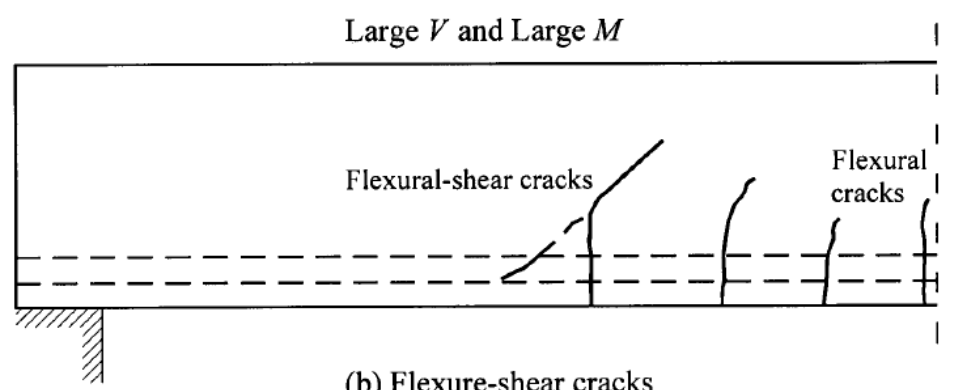

(b) Flexure-shear cracks

Figure 2.18 Flexural and diagonal tension cracks (Winter and Nilson, 1979)

In reinforced concrete beams, shear is transferred by two mechanisms: beam action and arch action; depending on the shear span $a$ to depth $d$ ratio ( $a / d$ ratio). The contribution of beam action and arch action and the amount of shear reinforcement affects the behaviour of beams failing in shear (Wight and MacGregor, 2012). The moments and shears at inclined cracking and failure of a rectangular beam without shear reinforcement are shown in Fig. 2.19. The shaded areas in Fig. 2.19 show the reduction in strength due to shear. Therefore, web reinforcement is provided to achieve the full flexural capacity. 


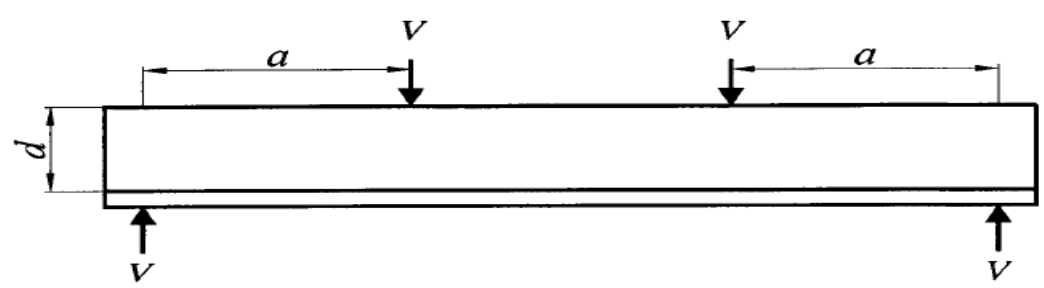

(a) Beam

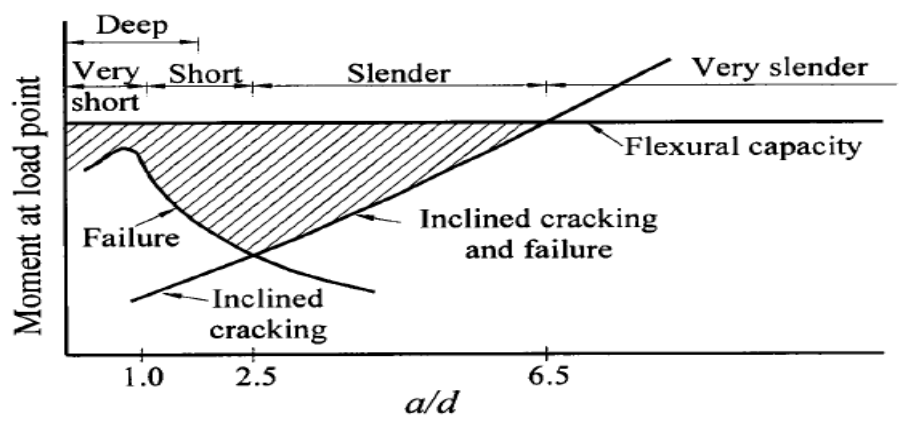

(b) Moment at cracking and failure

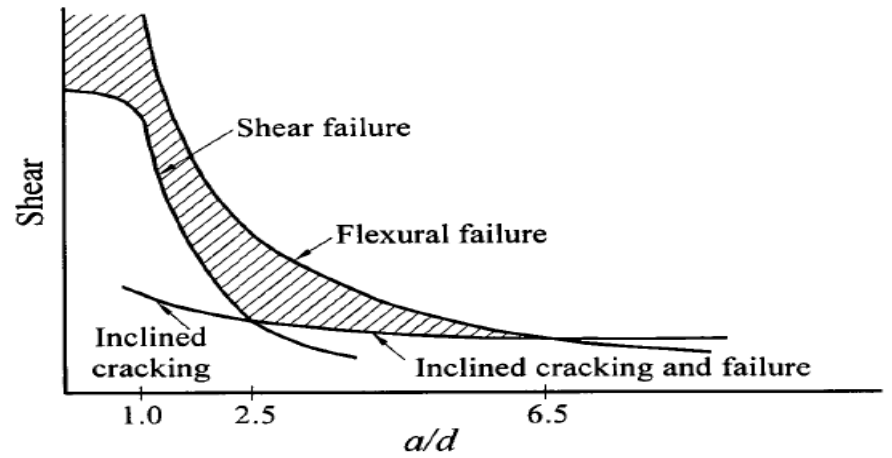

(c) Shear at cracking and failure

Figure 2.19 Effect of shear span to depth ratio (a/d) on shear strength of beams without stirrups (Wight and MacGregor, 2012)

According to Wight and MacGregor (2012), beams can be classified based on shear span to depth ratio $(\mathrm{a} / \mathrm{d})$, into four types:

1. Very short: when the shear span to depth ratio between 0 and 1 . These beams develop inclined cracks between the load and the support which in turn destroy the horizontal shear flow from the longitudinal reinforcement to the compression zone, changing the behaviour from beam action to arch action. In this case, the reinforcement serves as the 
tension tie between the supports, and the failure occurs due to anchorage failure at the ends of the tension tie as shown in Fig. 2.20.

2. Short: when the shear span to depth ratio between 1 and 2.5. These beams develop inclined cracks and are able to carry additional load after the redistribution of internal forces. Failure in these beams usually due to bond failure, a splitting failure or a dowel failure along the tension reinforcement as shown in Fig. 2.21(a) or by crushing of concrete in the compression zone over the shear crack know as shear-compression failure as shown in Fig. 2.21(b).

3. Slender: when the shear span to depth ratio between 2.5 and 6. These beams develop inclined cracks that disrupt the equilibrium to such an extent that the beam fails at the inclined cracking load.

4. Very slender: when the shear span to depth ratio greater than 6 . These beams will fail in flexure prior to the formation of inclined cracks.

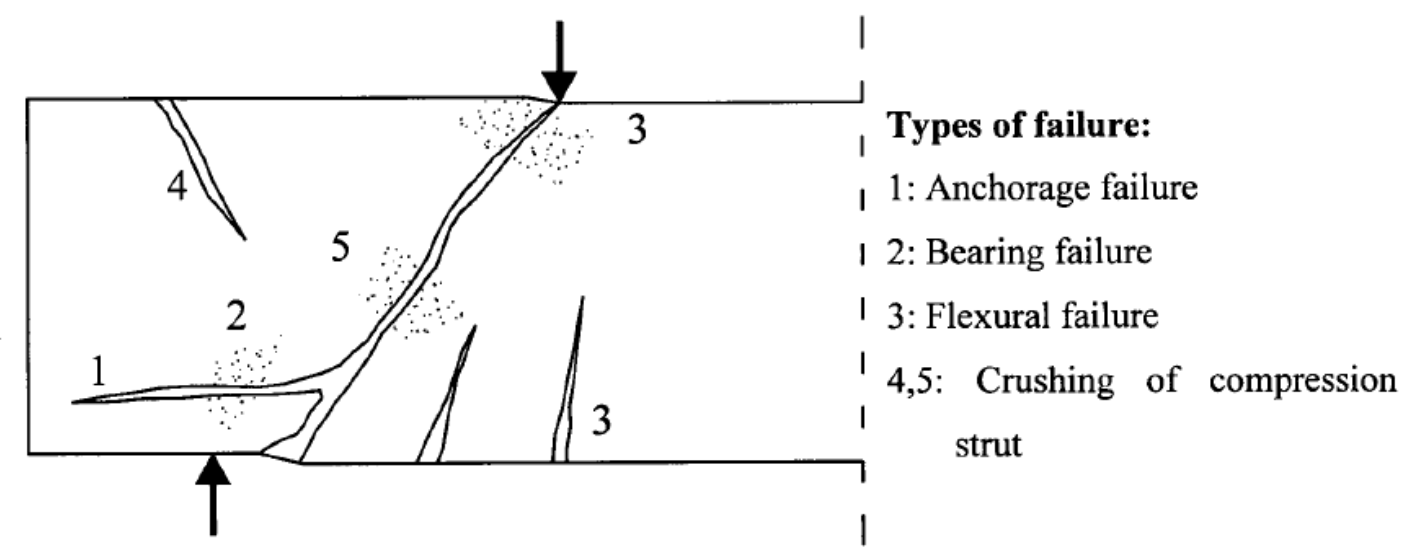

Figure 2.20 Beams failure mode (ACI- ASCE, 1973) 


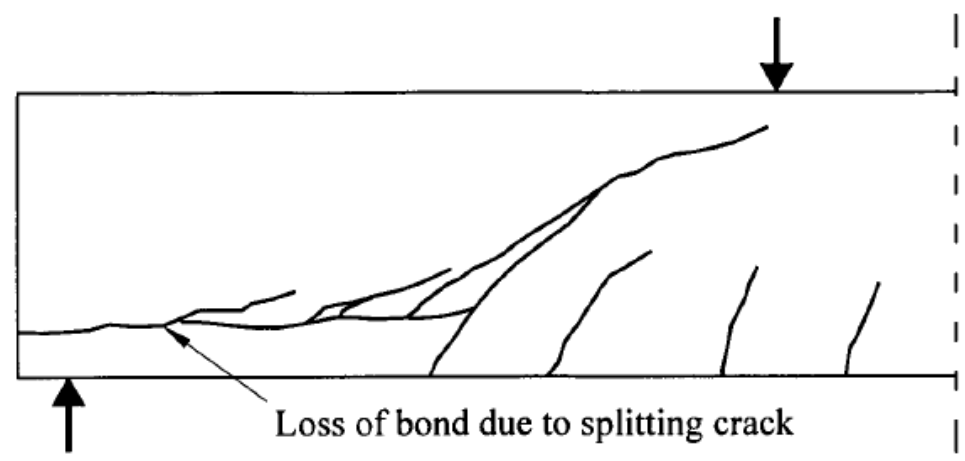

(a) Shear-tension failure

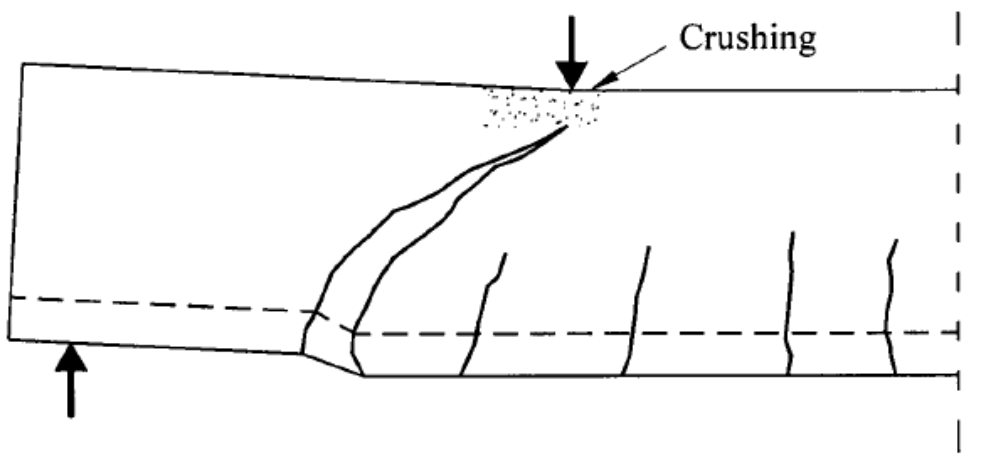

(b) Shear-compression failure

Figure 2.21 modes of failure of short spans with a/d ranging from 1 to 2.5 (ACI- ASCE, 1973)

\subsubsection{Shear resisting mechanism}

According to ACI- ASCE committee 445 (1998), five components for shear transfer in cracked concrete beams are identified as shown in Fig. 2.22:

1- Shear resistance provided by uncracked concrete above the neutral axis $V_{c z}$

2- Shear transfer along interface of the two faces of the shear cracks known as aggregate interlock $V_{a}$

3- Dowel action of the tensile reinforcement $V_{d}$

4- Residual tensile stresses across the crack due to bridging action $V_{r t}$

5- Arch action $V_{a c}$ in deep members 
These components are generally lumped together and referred to as the concrete contribution to shear strength $V_{c}$.

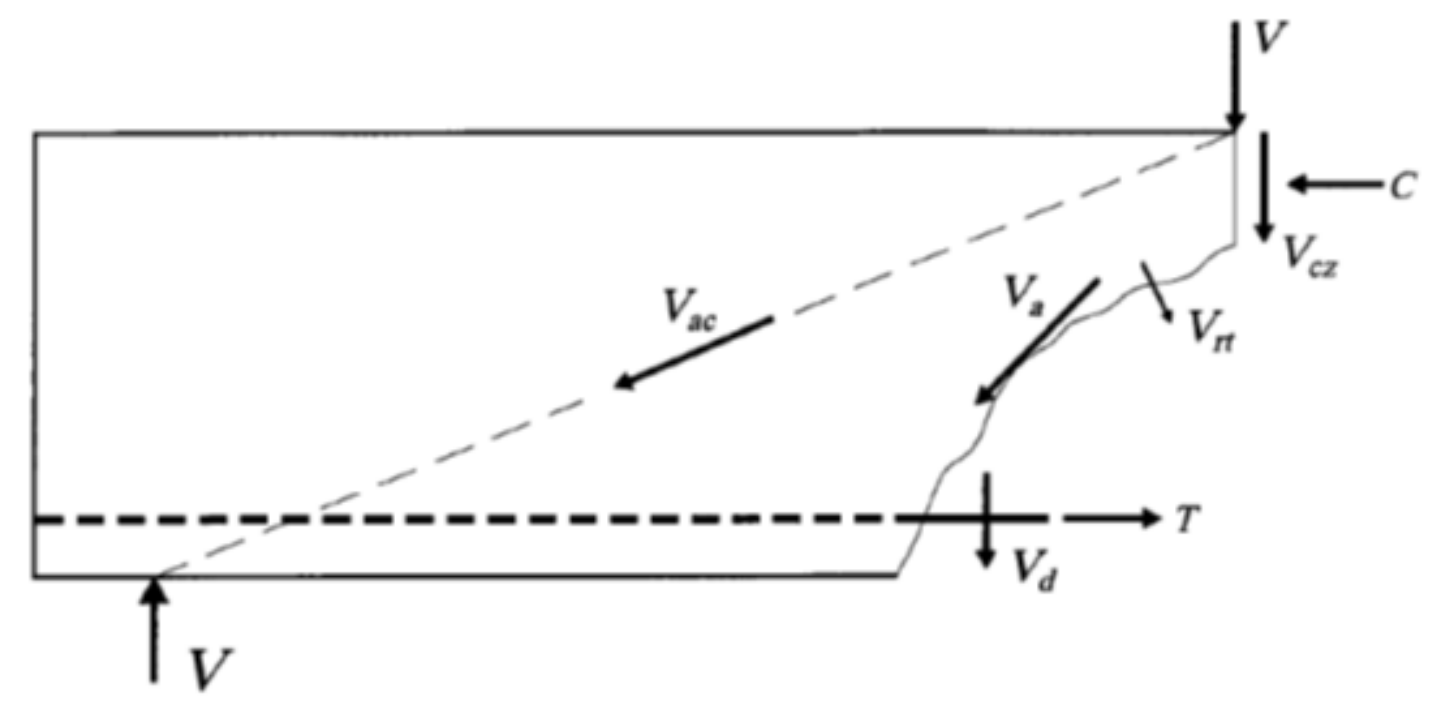

Figure 2.22 Shear resistance components in a cracked concrete beam without shear reinforcement

The concrete contribution for beams with shear reinforcement is influenced by the concrete tensile strength, longitudinal reinforcement ratio, shear span to effective depth ratio, axial forces, and the depth of concrete member (ASCE-ACI committee 445, 1998)

\subsubsection{Shear in reinforced concrete beams with shear reinforcement}

Shear failure in reinforced concrete beams is frequently sudden and without any warning due to the brittle nature of plain concrete behaviour in tension. Therefore, concrete beams are generally reinforced with shear reinforcement to ensure the flexural failure will occur rather than shear failure. Richart (1927) and Moretto (1945) showed experimentally that stirrups in reinforced concrete beams are only effective after the formation of diagonal cracks. Winter and Nilson (1979) reported that the effect of stirrups prior to formation of diagonal cracks was not noticeable and the presence of shear reinforcement will not prevent the formation of diagonal cracks; therefore, the main role of stirrup reinforcement is to carry the redistributed shear stresses through tension after the formation of the diagonal cracks. However, stirrups slow down the propagation of diagonal cracks through their contribution to shear performance of reinforced 
concrete beams. In addition, stirrup reinforcement controls the crack opening, in turn, helps aggregate interlock resist shear, increase the confinement of the cross section, which increases the compressive strength of the concrete, enhance the bond and prevent a premature splitting failure of longitudinal tensile reinforcement.

After formation of diagonal cracks, the internal forces in a typical reinforced concrete beam reinforced with steel stirrups are shown in Fig. 2.23(a). The shear resisting components are: the shear in compression zone $V_{c z}$; the vertical component of shear transfer across the crack by aggregate interlock $V_{a y}$; the dowel action of longitudinal reinforcement $V_{d}$; shear transferred by tension in stirrups $V_{s}$. Fig. 2.23(b) shows the loading history of such a beam. Prior to flexural cracking, the uncracked concrete carries the entire shear, and as soon as the inclined cracks appear, stirrups contribute and resist a portion of the applied shear. When the applied shear increases, the stirrups yield and their contribution remain constant, which lead to widen the inclined crack, results in decreasing the contribution of aggregate interlock, and increasing the dowel action and uncracked concrete contributions until either a splitting (dowel) failure occurs, or the compression zone crushes due to combined shear and compression stresses.

\subsubsection{Shear in steel fibre reinforced concrete beams without shear reinforcement}

In steel fibre reinforced concrete SFRC beams without stirrup reinforcement, steel fibres play a similar role to that of stirrups in RC beams. Steel fibres carry the redistributed tensile stresses and slow down the propagation of diagonal cracks through their contribution to shear performance of SFRC beams. In addition, steel fibres control crack opening, foster the formation of multiple diagonal cracks, and prevent a premature splitting failure along the tensile reinforcement. However, in shear strength analysis of SFRC beams without stirrups present several challenges due to uncertain distribution of fibres in concrete that lead to non-uniform mechanical properties, and the widening of diagonal cracks in SFRC which are due to fibre pullout instead of stirrups yielding in RC beams. This makes the problem more complicated due to complex behaviour of fibres pullout and bond between fibres and concrete. 


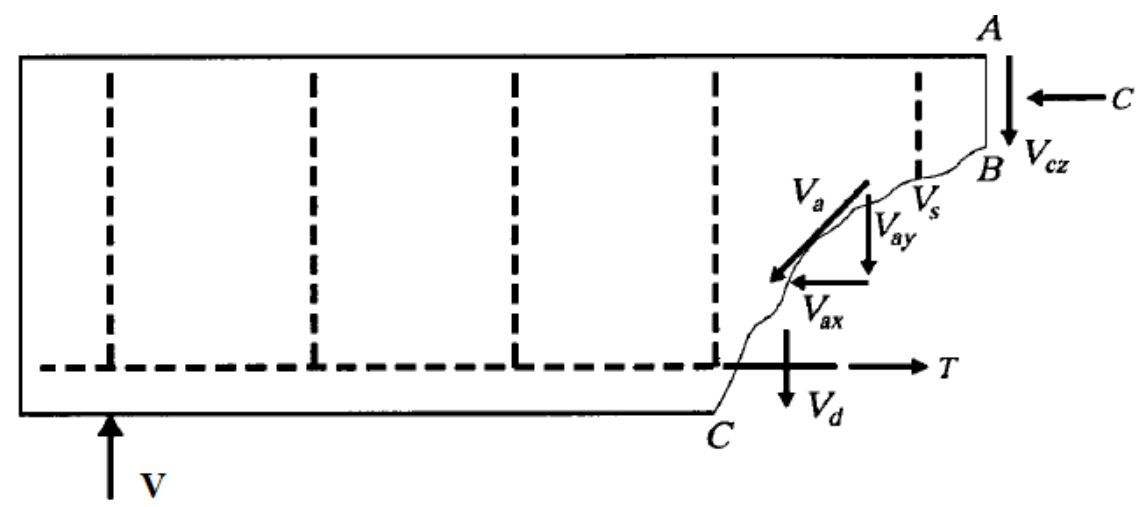

(a) Shear resisting components after formation of diagonal cracks

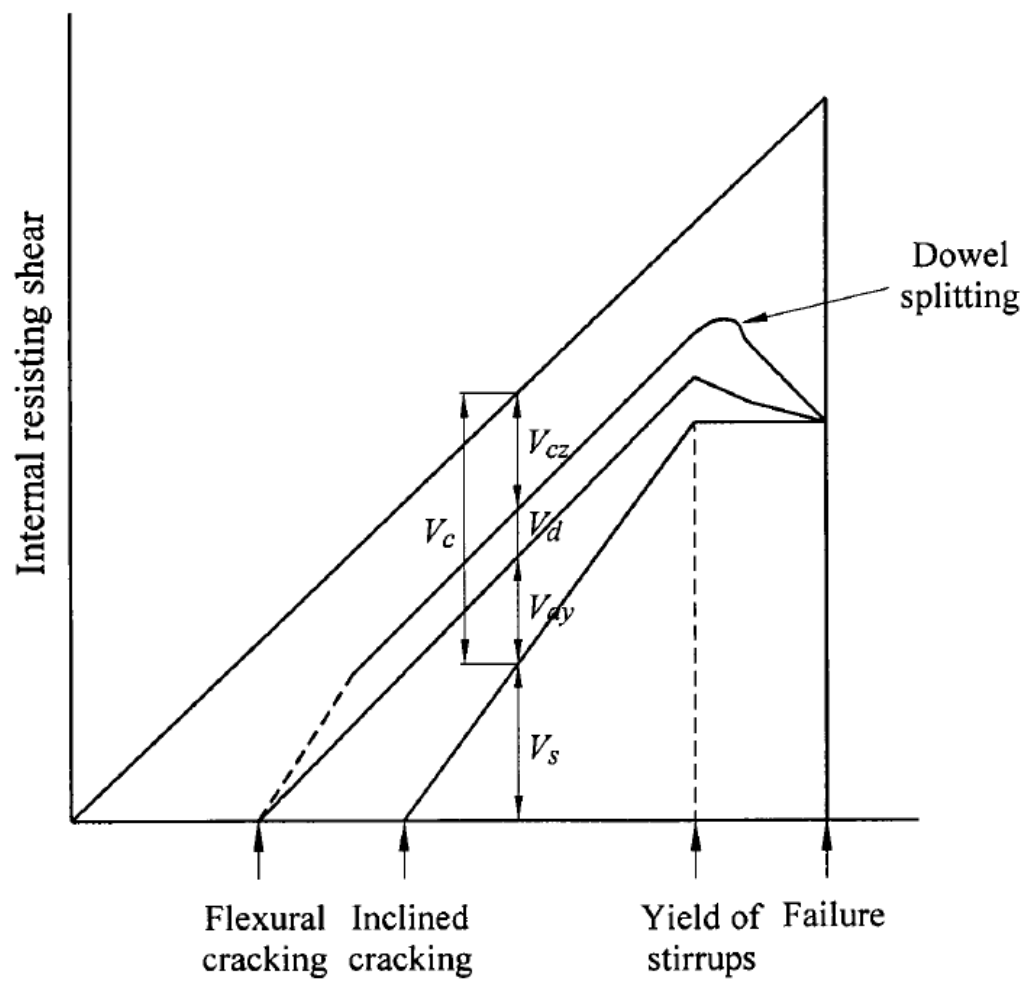

Applied shear

(b) Distribution of internal shear

Figure 2.23 Internal forces in a cracked concrete beam with stirrups (ACI- ASCE, 1973)

Many researchers investigated the shear behaviour of SFRC beams without stirrups. They investigated the following parameters: cross section shape, beam size, tensile reinforcement ratio, beam slenderness, aggregate size, concrete tensile strength and ductility. 
Swamy and Bahia (1985), and Rosenbusch and Teutsch (2002) studied the effect of beam cross sectional shape by comparing the shear behaviour of rectangular beams with that of T-beams. Swamy and Bahia showed that T-beams with flange thickness equal to one fifth of the beam depth and flange width equal to three times the web width results in $30 \%$ increase in the ultimate shear strength compared to rectangular beams. Rosenbusch and Teutsch showed that the load deflection response not significantly influenced by changing the flange width from 20 to 40 inches, while changing the flange thickness from 6 in to 8 in led to $54 \%$ increase in the ultimate shear strength compared to rectangular beam with the same height.

Schanzt (1993), Adebar et al. (1997), Noghabai (2000), Rosenbusch and Teutsch (2002), and Dinh et al. (2010) investigated the size effect of shear behaviour of SFRC beams, Noghabai showed that increase in the effective depth from $409 \mathrm{~mm}$ to $569 \mathrm{~mm}$ results a $15 \%$ decrease in average shear stress at failure. While Dinh et al. (2010) showed that increase the effective depth from $457 \mathrm{~mm}$ to $686 \mathrm{~mm}$ resulted in a $7 \%$ decrease in the shear stress, and concluded that size effect is negligible for beam depths up to $686 \mathrm{~mm}$.

The effect of shear span to effective depth ratio on shear behaviour of SFRC beams has been extensively investigated by researchers. Batson et al. (1972) proposed a critical value of 3 of shear span to effective depth ratio for SFRC beams to distinguish between deep and slender beams. Ashour et al. (1992), Swamy et al. (1993), and Dina et al. (2010) investigated the effect of longitudinal tensile reinforcement ratio on the beam strength. They concluded that higher tensile reinforcement ratio resulted in higher shear strength due to increase dowel action and deeper compression zone.

Kwak et al. (2002) studied the effect of SFRC compressive strength on the shear strength of reinforced SFRC beams. They found the shear strength increased $20 \%$ when the concrete compressive strength doubled. 
Dina et al. (2010) showed that minimum fibre volume content greater than or equal to $0.75 \%$ led to multiple diagonal cracking and a substantial increase in shear strength compared to reinforced concrete beams without stirrup reinforcement. Susetyo et al. (2011) showed that $0.5 \%$ fibre content was incapable of controlling crack propagation in reinforced concrete panels.

The safety margins of the shear design provisions of the AFGC (Association Française de Génie Civil) were investigated by Baby et al. (2010) on nine $3 \mathrm{~m}$ long I-shaped girders with various types of shear reinforcement (stirrups only, fibres only, and stirrups/fibres). They found that the ratio between the ultimate predicted and experimentally applied loads for beams without stirrups was around 0.52. Yang et al. (2012) investigated the shear behaviour of UHPFRC beams. UHPFRC I beam specimens with a depth $700 \mathrm{~mm}$ were casted as shown in Fig. 2.24. They investigated the shear span to effective depth ratio, the volume content of steel fibres, and the presence or absence of pre-stress. Test results showed that the ultimate shear strength decreases as the shear span to effective depth ratio increases due to the arch action at the low shear span to effective depth ratio.

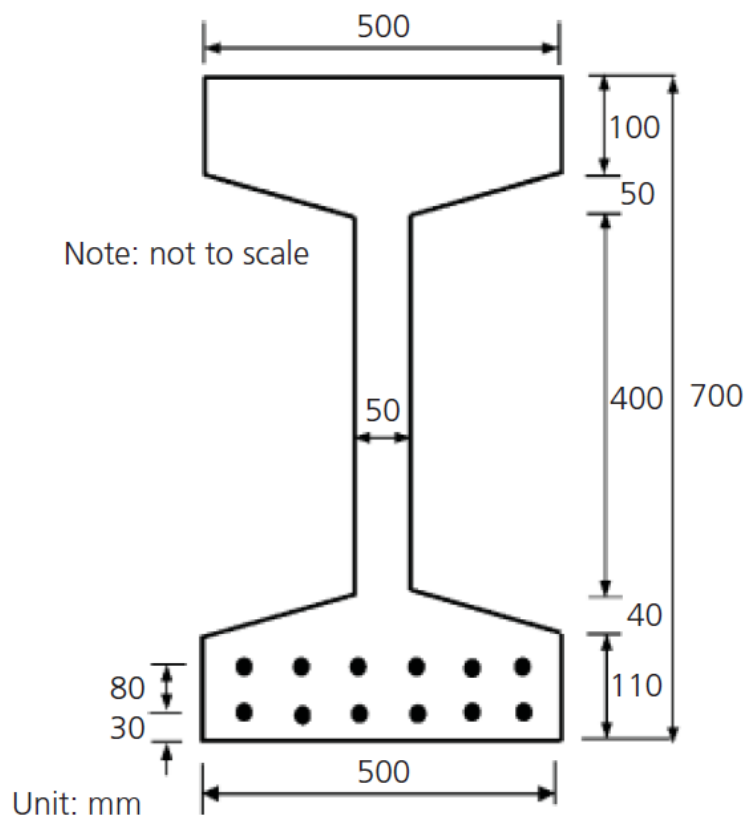

Figure 2.24 Beam cross-section area (Yang et al., 2012) 


\subsubsection{Shear strength analysis of SFRC beams}

Shear behaviour of SFRC beams is complicated due to many factors affecting shear strength. The primary controlling factors are the tensile strength of fibre reinforced concrete, shear span to effective depth ratio, and longitudinal reinforcement ratio. The tensile strength of SFRC beams are affected by fibre aspect ratio, fibre geometry, fibre content, and fibre tensile strength. In this section, some of the main methods that were developed to predict the shear behaviour of SFRC beams are presented.

\section{Sharma (1986)}

Sharma studied the shear behaviour of SFRC beams by testing seven normal and SFRC beams subjected to bending and shear. The beams were $150 \mathrm{~mm}$ x $300 \mathrm{~mm}$ in cross section with concrete compressive strength between 42.3 MPa and 48.6 MPa. Stirrups were provided only at load points and supports. Based on the splitting tensile strength $f_{s p}$, and shear span to effective depth ratio $a / d$, Sharma proposed the ultimate shear strength as follows:

$$
v_{u}=\left(k_{1} f_{s p}\right) \frac{d^{0.25}}{a}
$$

where, $v_{u}$ is shear stress of fibrous concrete, $k_{1}$ is a constant equal to $2 / 3$ as suggested by Wright (1955), who found out that direct tensile stress of the order of $2 / 3$ of the splitting tensile strength. It can be noted from equation (2.18) that the contribution of fibres and longitudinal reinforcement ratio were not introduced in the expression. To determine the tensile strength of concrete $f_{s p}$, Sharma used the following equation that was adopted from European Concrete Committee (1993):

$$
f_{s p}=9.5 \sqrt{f_{c}^{\prime}}(\mathrm{psi})
$$

Sharma validated the expression with 41 SFRC beams and showed good estimates. 


\section{Mansur, Ong, and Paramasivam (1986)}

Mansur et al. adopted the ACI-ASCE Committee 426 equation for shear that takes into account the contribution of shear strength in compression region, aggregate interlock and dowel action, and include the contribution of fibres to shear strength by calculating the post-cracking tensile strength, $\sigma_{p c}$, that can be obtained from direct tensile test of dog-bone specimens.

$$
v_{u}=0.167 \sqrt{f_{c}^{\prime}}+17.2 \frac{\rho V d}{M}+\sigma_{p c} \quad \mathrm{MPa}
$$

To include the effect of arch action, the ratio $M / V$ was defined as:

$$
\begin{array}{ll}
\frac{M}{V}=\frac{M_{\text {max }}}{V}-\frac{a}{2} & \text { for } a / d \leq 2.0 \\
\frac{M}{V}=\frac{M_{\text {max }}}{V}-d & \text { for } a / d>2.0
\end{array}
$$

They used the post-cracking tensile strength, $\sigma_{p c}$, that proposed by Swamy and Al-Taan (1981), and assuming that this stress is uniformly distributed over the critical diagonal crack, and assuming that the horizontal projection of this critical crack is equal to the effective depth of the beam d.

\section{Narayanan and Darwish (1987)}

Narayanan and Darwish investigated the behaviour of SFRC beams subjected to shear. They tested 49 beams simply supported rectangular beams under symmetrical concentrated loads, 10 beams contained conventional stirrups and 33 were reinforced with crimped steel fibres as web reinforcement. Test results showed that shear cracks in SFRC beams were similar to that in conventional RC beams. However, the spacings between cracks in the SFRC beams were closer than that in conventional RC beams. They attributed that to the redistribution of stresses beyond cracking, and fibres become more effective after shear cracking by resisting the principal tensile stresses until the complete pullout of all fibres occurred at one critical crack. In addition, the inclusion of steel fibres eliminated the spalling of concrete even at very late stages of failure compared with some spalling occurred at the ultimate stages in beams reinforced with 
conventional stirrups. They showed that the shear failure in specimens with shear span to effective depth ratio $a / d \geq 3$ was due to splitting failure or failure in the compression zone as shown in Fig. 2.25(a), while for specimens with shear span to effective depth ratio $a / d \leq 2.5$ was due to compression splitting failure, flexural failure or crushing of concrete zone as shown in Fig. 2.25(b).

To consider the shear contribution of steel fibres, $v_{f}$, they assumed the diagonal crack angle is 45 , and the average bond strength of fibre, $\tau$, was assumed to be the average pullout length $l_{f} / 4$ , and the number of fibres over a unit area $n_{f i b}$ was adopted from the work of Romualdi et al. (1964) as follows:

$$
n_{f i b}=\frac{1.64 V_{s f}}{\pi d_{f}^{2}}
$$

Thus, the shear contribution of steel fibres, $v_{f}$, counted on a diagonal crack that has vertical projection equal to the distance between the center of tension reinforcement to the upper tip of diagonal crack is:

$$
v_{f}=0.41 \tau V_{s f} \frac{l_{f}}{d_{f}}
$$

where, $\tau=$ average bond strength of fibre taken as $4.15 \mathrm{MPa}$ based on flexural strength results by Swamy et al. (1974). Equation (2.25) was modified to account for the effect of fibre geometry on bond, $\beta$, as follows:

$$
v_{f}=0.41 \tau F
$$

where, $F=V_{s f} \frac{l_{f}}{d_{f}} \beta$ is the fibre factor, and the bond factor, $\beta$, was adopted from Narayanan and Kareem-Palanjian (1984), is approximately 0.5, 0.75, and 1 for round, crimped, and indented fibres respectively. 

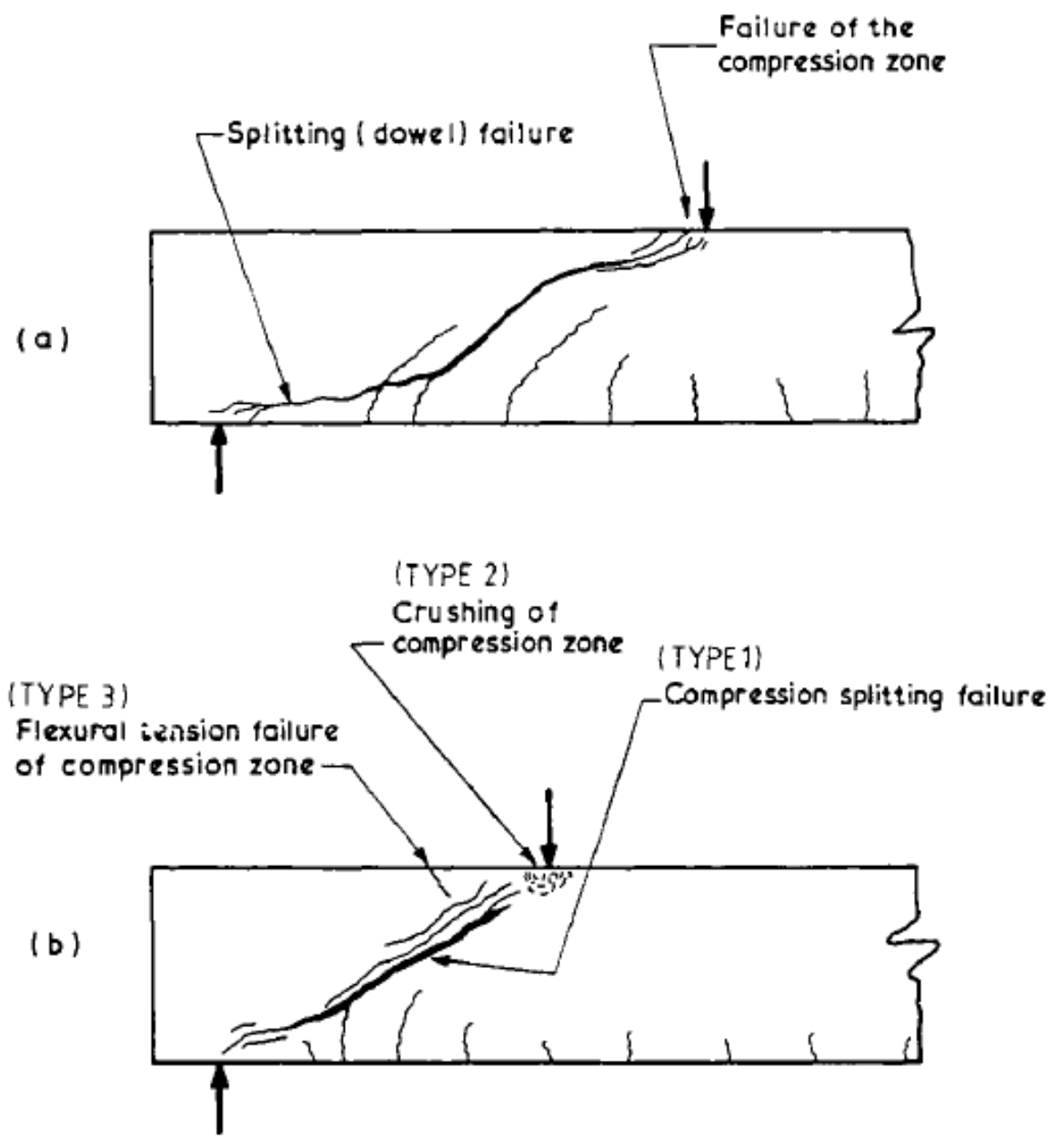

Figure 2.25 (a) Patterns of shear failure in specimens with $a / d \geq 3$ (b) patterns of shear failure in specimens with $a / d \leq 2.5$ (Narayanan and Darwish, 1987)

Based on, regression analysis for 91 test results, and taking into account the fibre contribution to the total shear strength in terms of split tensile strength, $f_{s p}$, dowel action, and the shear span to effective depth ratio $a / d$, the ultimate shear strength is:

$$
v_{u}=e\left[A^{\prime} f_{s p}+B^{\prime} \rho \frac{d}{a}\right]+v_{f}
$$

where, e is a non-dimensional factor that takes into account the effect of arch action and is equal to 1 for slender beams $a / d>2.8$, and is equal to $2.8 d / a$ for shorter beams $a / d \leq 2.8$; 
$A^{\prime}=0.24, B^{\prime}=80 M P a$, and $\rho$ is the longitudinal steel reinforcement ratio. It can be noted in this model that the contribution of shear in the compression region was not directly specified. In addition, the authors neglect the contribution of aggregate interlock.

\section{Al- Ta'an and Al-Feel (1990)}

Al- Ta'an and Al-Feel proposed a method to calculated the ultimate shear strength of SFRC beams based on an equation developed by Zsutty (1971), and Places and Regan (1971) that takes into account the contribution of uncracked compression zone, aggregate interlock, and dowel action, $v_{c}$, as shown in equations (2.27), and (2.28)

$$
\begin{array}{ll}
v_{c}=\left(10 \rho f_{c}^{\prime} \frac{d}{a}\right)^{1 / 3} & \text { for } a / d>2.5 \\
v_{c}=\left(160 \rho f_{c}^{\prime}\right)^{1 / 3}\left(\frac{d}{a}\right)^{4 / 3} & \text { for } a / d \leq 2.5
\end{array}
$$

The contribution of fibre was obtained by considering the post cracking tensile stress along the diagonal crack. To estimate the contribution of fibres to the shear resistance, the depth of neutral axis was calculated by equating the external moment to the internal resisting moment as shown in Fig. 2.26 and equation (2.29):

$$
M_{u}=V_{u} * a=v_{c} b d a=\phi 0.85 f_{c}^{\prime} a_{c} b\left(d-\frac{a_{c}}{2}\right)+A_{s}^{\prime} f_{y}\left(d-d^{\prime}\right)
$$

where, $v_{c}=$ ultimate shear strength without fibres $(\mathrm{MPa})$

$$
\begin{aligned}
& \mathrm{d}=\text { effective depth of beam }(\mathrm{m}) \\
& \mathrm{a}=\text { shear span }(\mathrm{m}) \\
& a_{c}=\text { equivalent compression stress block depth } \\
& \phi=\text { Flexural reduction factor }
\end{aligned}
$$


$d^{\prime}=$ depth of compression steel reinforcement $(\mathrm{m})$

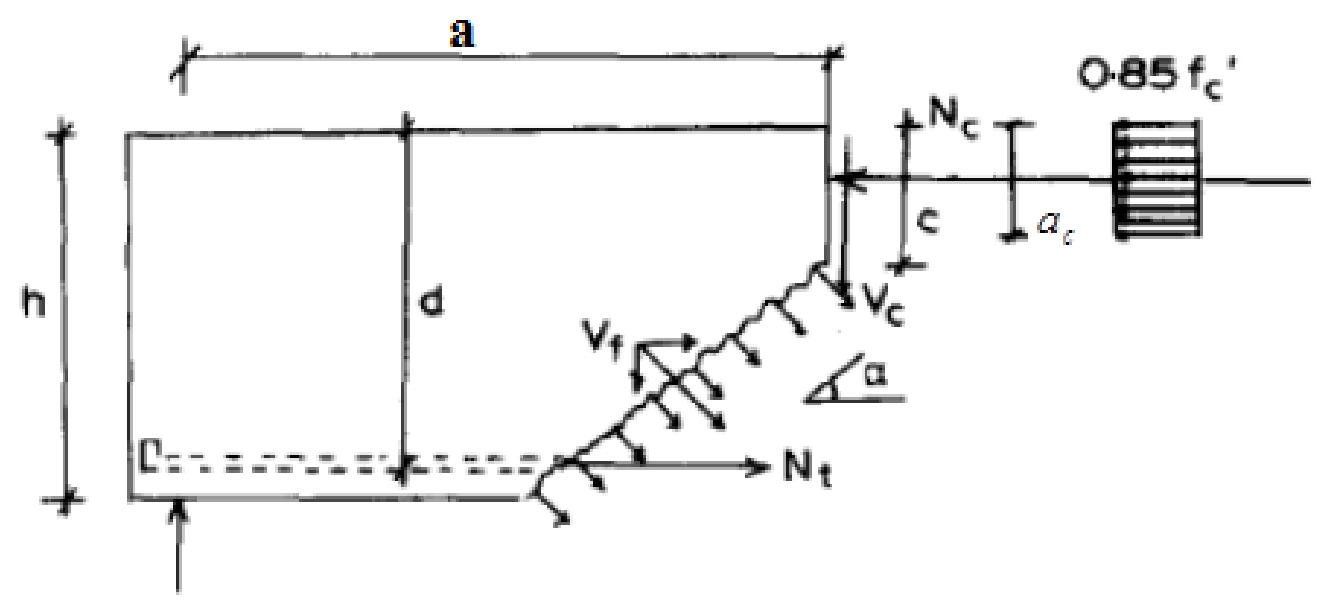

Figure 2.26 Forces within fibre reinforced concrete beam with diagonal tension crack (Al- Ta'an and Al-Feel, 1990)

It was observed that the effect of steel fibres on flexural strength is small and not more that $10 \%$ (Al- Ta'an and Al-Feel, 1990); therefore, this increase in the moment resistance was used to eliminate the flexural reduction factor. To determine the contribution of steel fibre to ultimate shear strength, they calculated the post-cracking strength, $\sigma_{p c}$, as follows:

$$
\sigma_{p c}=n_{f i b} \cdot f_{f i b}
$$

Where $n_{f i b}$ is the number of fibres crossing a unit area, and can be obtained from a proposal by Aveston et al. (1974):

$$
n_{f i b}=\frac{2 V_{s f}}{\pi d_{f}^{2}}
$$

and $f_{f i b}=$ average fibre pull-out force per fibre can be determined from equation (2.32) assuming the average fibre pull-out length is $l_{f} / 4$

$$
f_{f i b}=\tau \pi d_{f} l_{f} / 4
$$


where, $\tau=$ average bond strength of fibre taken as $4.15 \mathrm{MPa}$ based on flexural strength results by Swamy and Mangat (1976). This leads to a post-cracking strength, $\sigma_{p c}$, as follows:

$$
\sigma_{p c}=0.5 \tau F
$$

Therefore, the unit stress provided by the fibre is:

$$
v_{f}=\sigma_{p c} b(h-c) / d
$$

where, $\mathrm{c}=$ depth of compression region. Thus the total ultimate shear strength of SFRC beams is:

$$
v_{u}=v_{c}+v_{f}
$$

This method compared with experimental data of 89 SFRC beams by other researches, and gave acceptable results.

\section{Ashour, Hasanain, and Wafa (1992)}

Ashour et al. tested 18 rectangular high strength fibre reinforced concrete beams subjected to combined shear and flexure. All beam were singly reinforced and without shear reinforcement. Test results showed that steel fibres increased the shear strengths, stiffness, and ductility of beams. They modified the ACI committee 318 equation on shear by incorporating the effect of shear span to effective depth ratio $a / d$ from a regression analysis to the parameters $\sqrt{f_{c}^{\prime}}$ and $\rho \frac{d}{a}$ as follows:

$$
v_{u}=\left(0.7 \sqrt{f_{c}^{\prime}}+7 F+17.2 \rho\right) \frac{d}{a} \quad(\mathrm{MPa})
$$

They modified Zsutty (1968) equation to include the contribution of fibre through the factor $\mathrm{F}$ as follows:

$$
v_{u}=\left(2.11 \sqrt[3]{f_{c}^{\prime}}+7 F\right)\left(\rho \frac{d}{a}\right)^{0.333} \quad \text { for } a / d>2.5
$$




$$
v_{u}=\left[\left(2.11 \sqrt[3]{f_{c}^{\prime}}+7 F\right)\left(\rho \frac{d}{a}\right)^{0.333}\right]\left(2.5 \frac{d}{a}\right)+v_{f}\left(2.5-\frac{a}{d}\right) \text { for } a / d \leq 2.5
$$

The shear strength of fibre, $v_{f}$, can be calculated form equation (2.25) similar to Narayanan and Darwish (1987). The above equations showed good agreement with the test results by the author.

\section{Khuntia, Stojadinovic, and Goel (1999)}

Khuntia et al. adopted the ACI Committee 318 equation for shear equation (2.39) that takes into account the contribution of shear strength in compression region, aggregate interlock and dowel action, and include the contribution of fibres to shear strength by using equation (2.25).

$$
v_{c}=0.167 \sqrt{f_{c}^{\prime}} \quad \mathrm{MPa}
$$

Based on suggestion by Naaman (1987) that the fibre bond stress for hooked steel fibres is about 2 times the tensile strength of plain concrete, they assumed the bond stress of fibres as follows:

$$
\tau=0.68 \sqrt{f_{c}^{\prime}} \quad \mathrm{MPa}
$$

By applying equation (2.40) into (2.25), and assuming the vertical projection of the diagonal crack equal to $0.9 \mathrm{~d}$, the shear strength of fibres, ${ }^{v_{f}}$, becomes:

$$
v_{f}=0.25 F \sqrt{f_{c}^{\prime}} \quad \mathrm{MPa}
$$

To include the arch action, they multiplied the total shear strength by the arch action factor $A$, equal to $2.5 \mathrm{~d} / \mathrm{a}$. Therefore, the ultimate shear strength is:

$$
v_{u}=(0.167 A+0.25 F) \sqrt{f_{c}^{\prime}} \quad \mathrm{MPa}
$$

Equation (2.42) was validated with tested beams from different researches and showed good results. 


\section{Kwak, Eberhard, Woo-Suk Kim, and Jubum Kim (2002)}

Kwak et al. developed an equation to predict the shear strength of fiber reinforced concrete beams based on an equation developed by Zsutty's (1971) that takes into account the influence of tensile strength on arching action with additional fibre term as proposed by Narayanan and Darwish as shown in equation (2.24). Therefore, the ultimate shear strength is:

$$
v_{u}=3.7 e f_{s p}^{2 / 3}\left(\rho \frac{d}{a}\right)^{1 / 3}+0.8(0.41 \tau F)
$$

where $\mathrm{e}$ is a function of the $a / d$ ratio which is equal to 1 for $a / d>3.4$, and equal to $\frac{3.4 d}{a}$ for $a / d \leq 3.4$. Equation (2.43) was validated with 139 tested beams from different researches and showed good results for concrete with a compressive strength between 31 and $65 \mathrm{MPa}$.

\section{Aoude et al. (2012)}

Aoude et al. proposed a model to predict the shear behaviour of SFRC beams. They assumed the shear resistance of SFRC beam is equivalent to the expected shear strength of a traditional reinforced concrete beam plus additional shear resistance provided by fibres and can be calculated from equation (2.35). They obtained the shear strength $v_{c}$ for a traditional reinforced concrete beam from Modified compression field theory (Collins et al., 1996), and the fibre contribution to shear resistance from equation (2.43):

$$
V_{f}=n_{f i b} * 0.83 f_{\text {fib }} * b_{w} * d_{v} * \cot \theta
$$

where, $n_{\text {fib }}$ is the effective number of fibres per unit area, and can be obtained from equation (2.31), $\theta$ is the crack inclination, and $f_{f i b}$ is the fibre pullout strength that can be calculated from equation (2.44)

$$
f_{f i b}=\tau * \pi * d_{f} * \frac{L_{f s}}{2}+\Delta p
$$


Where, $L_{f s}$ is the length of straight portion of fibre, and $\Delta p$ is the contribution of hooked ended fibre that can be obtained from equation (2.45) (Alwan et al., 1999):

$$
\Delta p=\frac{3.05}{\cos \left(45^{0} * \pi / 180\right)}\left(f_{f y} * \frac{\pi *\left(d_{f} / 2\right)^{2}}{6}\right)
$$

The proposed model validated with the experiment results by the author and other researches and showed good estimates.

A summary of the relationships that have been proposed in the literature for predicting the shear resistance of fibre reinforced concrete beams is shown in Table 2.1.

\subsection{Composite reinforced concrete beams}

UHPFRC material is a new material that needs to be investigated in order to better characterize its properties and optimize its use in structural applications. A few works have been dedicated to study the behaviour of composite "UHPFRC- concrete" elements for slender beams with $a / d$ between 3 and 4. Structural applications with the concept of composite concrete-concrete elements were studied by Habel et al. (2006), and Martinola et al. (2010). They investigated the compatibility of two materials of different ages, their long term behaviour, transverse cracking and debonding risk. They proposed a model to add a layer of UHPFRC with steel bars as an external tensile flexural reinforcement. The early age material properties appeared important for successful structural interventions. Kamen et al. (2008) performed analysis of thermomechanical behaviour at early age of UHPFRC. They studied hydration, shrinkage under different temperatures, and performed first creep tests in tension. Noshiravani and Bruhwiler (2010) investigated the structural response of composite UHPFRC-RC beams subjected to bending and shear. The results show that the UHPFRC layer increases the member shear strength without impairing the deformation capacity. They used the Critical Shear Crack Theory to show the enhanced response of the composite beams. 
Table 2.1: Models for predicting the shear strength of FRC beams

\begin{tabular}{|c|c|}
\hline Author & Model \\
\hline Sharma (1986) & $\begin{array}{l}v_{u}=\left(k_{1} f_{s p}\right) \frac{d^{0.25}}{a} \\
k_{1} \text { is a function of the test that is used to determine the tensile resistance of the } \\
\text { concrete. }\end{array}$ \\
\hline $\begin{array}{l}\text { Narayanan and Darwish } \\
\text { (1987) }\end{array}$ & $\begin{array}{l}v_{u}=e\left[A^{\prime} f_{s p}+B^{\prime} \rho \frac{d}{a}\right]+0.41 \tau F \\
F=V_{s f} \frac{l_{f}}{d_{f}} \beta \\
\text { e is a function of the } a / d \text { ratio }\end{array}$ \\
\hline $\begin{array}{l}\text { Al- Ta' an and Al-Feel } \\
\text { (1990) }\end{array}$ & $\begin{array}{ll}v_{u}=v_{c}+v_{f} & \\
v_{c}=\left(10 \rho f_{c}^{\prime} \frac{d}{a}\right)^{1 / 3} & \text { for } a / d>2.5 \\
v_{c}=\left(160 \rho f_{c}^{\prime}\right)^{1 / 3}\left(\frac{d}{a}\right)^{4 / 3} & \text { for } a / d \leq 2.5 \\
v_{f}=0.5 \tau F b(h-c) / d & \end{array}$ \\
\hline Ashour et al. (1992) & $\begin{array}{l}v_{u}=\left(2.11 \sqrt[3]{f_{c}^{\prime}}+7 F\right)\left(\rho \frac{d}{a}\right)^{0.333} \text { for } a / d>2.5 \\
v_{u}=\left[\left(2.11 \sqrt[3]{f_{c}^{\prime}}+7 F\right)\left(\rho \frac{d}{a}\right)^{0.333}\right]\left(2.5 \frac{d}{a}\right)+v_{f}\left(2.5-\frac{a}{d}\right) \text { for } a / d \leq 2.5\end{array}$ \\
\hline Khuntia et al. (1999) & $v_{u}=\left(0.167\left(2.5 \frac{d}{a}\right)+0.25 F\right) \sqrt{f_{c}^{\prime}}$ \\
\hline Kwak et al. (2002) & $v_{u}=3.7 e f_{s p}^{2 / 3}\left(\rho \frac{d}{a}\right)^{1 / 3}+0.8(0.41 \tau F)$ \\
\hline Aoude et al. (2012) & $\begin{array}{l}v_{u}=v_{c}+v_{f} \\
V_{f}=n_{f i b} * 0.83 f_{f i b} * b_{w} * d_{v} * \cot \theta \\
v_{c} \text { is calculated according to Modified Compression Field Theory }\end{array}$ \\
\hline
\end{tabular}


Bond characteristics at the interface zone are one of the most difficult phenomena to predict due to difference in composition, and material property. Different test methods have been proposed to assess the bond strength between the two different concrete materials. The basic types of bond tests are direct tension tests, direct shear tests, indirect tension tests, shear and compression tests, and pull off test (Saucier et al., 1991)

\subsubsection{Tension tests:}

Tension tests can be classified into direct and indirect tests. In a direct tension test as shown in Fig. 2.27(a), the tensile force is transmitted to the concrete either by glued metal or by special grips. In this test, the alignment of the specimen is essential; therefore the test consumes a lot of time to get good results (Saucier et al., 1991). However, the indirect tension tests include flexural tests and splitting tests as shown in Fig. 2.27(c) are much easier to perform. In flexural test, the area of the bonded surface subjected to loading is small compared to the specimen volume, leads to only a small part of the bonded plane is subjected to the maximum stress; therefore, the efficiency of this test is low compared to direct tension test (Momayez et. al., 2005). The splitting test is more efficient in this regard, and the method was later adopted as a standard test ASTM C496.

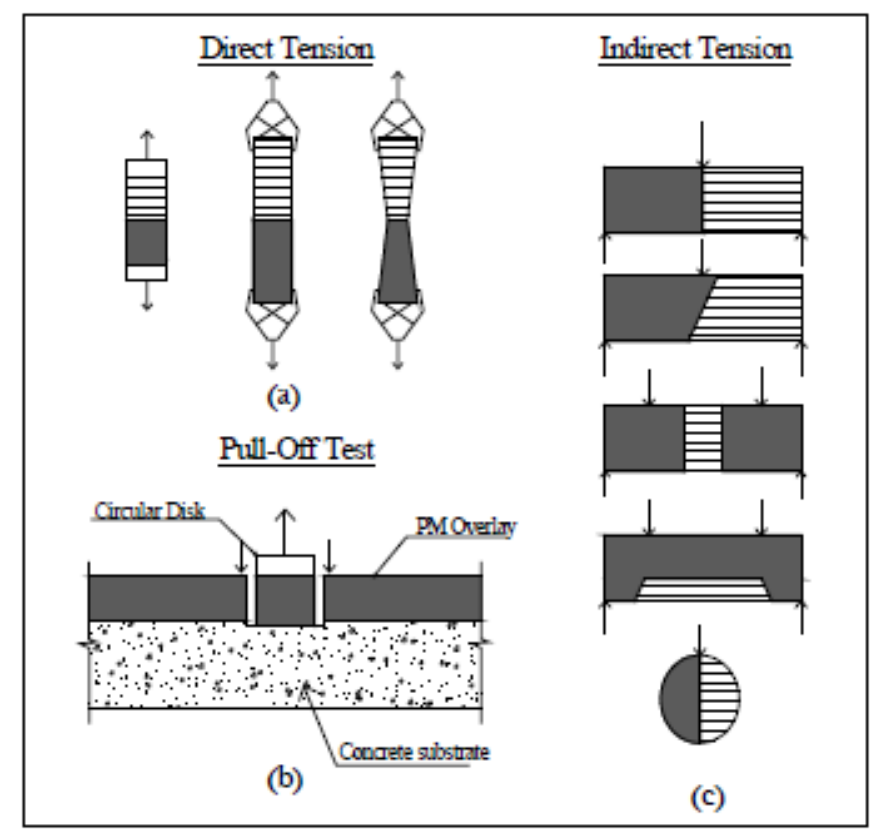

Figure 2.27 Different types of bond tensile test 
The pull-off test as shown in Fig. 2.27(b) is a relatively new bond test. In this test, the preparation of the specimen involved preparation of the concrete surface, gluing on a disc using a fast curing epoxy, partial coring around the disc perpendicular to the planed surface, and pulling the disc using a calibrated hydraulic pull machine reacting against a centered counter pressure resting on the planed surface. The results of this method are more accurate in predicting the tensile bond strength.

\subsubsection{Shear tests:}

In a direct shear test as shown in Fig. 2.28(a), the bonded surface is subjected to shear stress and a small bending stress due to some stress concentrations at the edge of the bonding planes leading to scatter in the test results (Saucier et al., 1991, Momayez et. al., 2005). The shear stress is combined with a compression stress in the axis perpendicular to the bonding plane in the slant shear test as shown in Fig. 2.28(b). The composite cylinder in slant test is loaded as in a standard compression test. This test was modified by Wall and Shrive (1988) by using a prism with a length three times the cross sectional dimension. The results of the modified test showed that a slight misalignment of the two halves of the prism specimen has negligible effects on the capacity of the composite specimens.
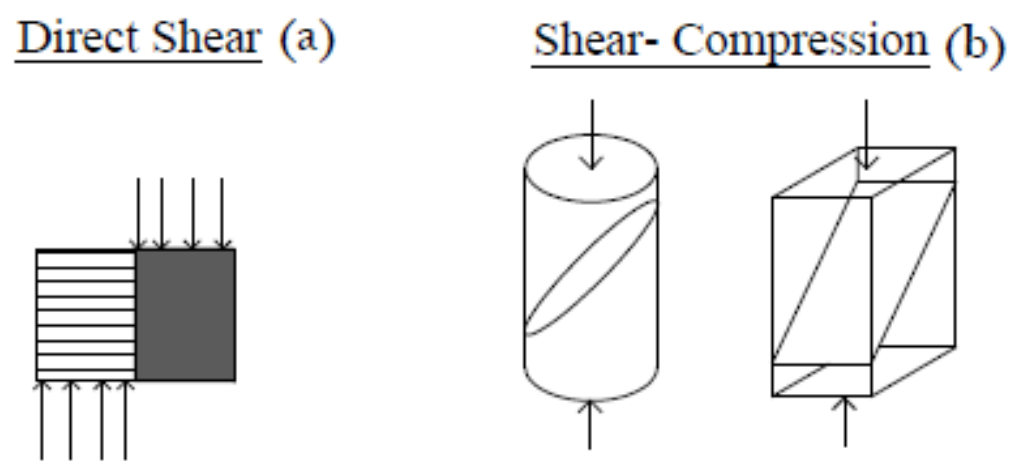

Figure 2.28 Different types of bond shear test 


\subsubsection{Splitting prism test}

Momayez et al. (2005) investigated the effect of different test methods on bond strength between concrete substrate and repair material. In their study, four test methods pull-off, slant shear, splitting prism and a new direct shear named Bi-Surface shear test as shown in Fig. 2.29 with cementitious or modified-cementitious repair materials, and two surface roughness's were studied. They found that the bond strength dependent on the test method used. They observed from test results that the measured bond strength decreases with the test method in the following order: slant shear, Bi-Surface shear, splitting, and pull-off.

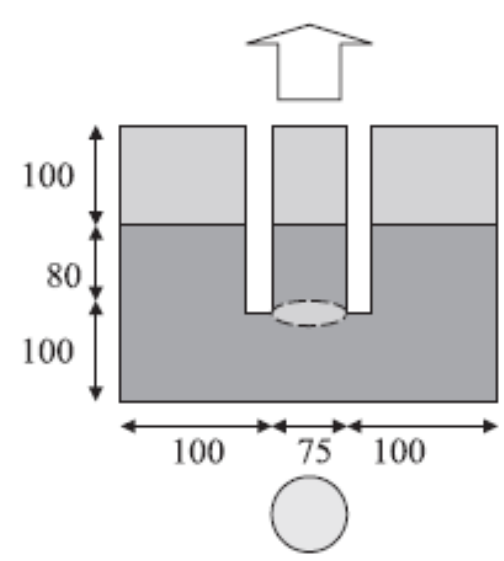

a) Pull-off

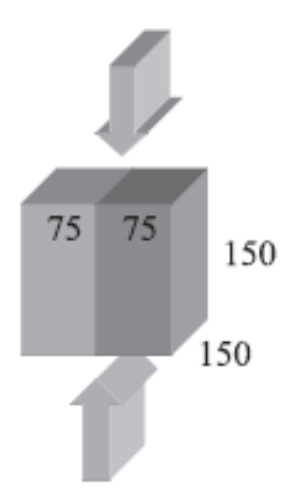

b) Splitting Prism

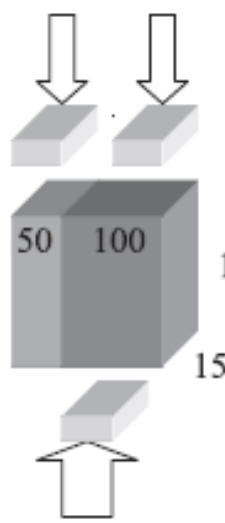

c) Direct Shear (Bi-Surface)

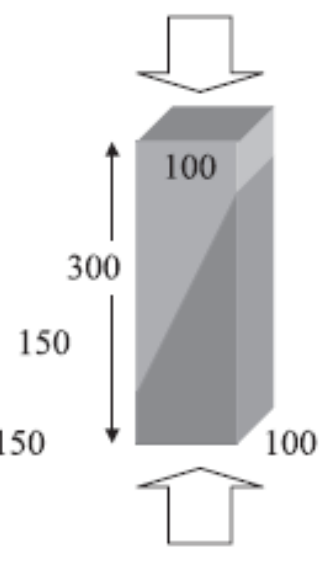

d) Slant Shear

Figure 2.29 Bond strength test methods (Momayez et. al., 2005) 


\section{Chapter 3}

\section{Experimental Program}

The experimental study consists of two main phases: the first phase of the experimental program was to investigate the shear and flexural behaviour of ultra-high performance reinforced concrete, UHPFRC, and ultra-high performance fibre reinforced concrete, UHPFRC, without web reinforcement. The second phase of the experimental program focused on the development of new composite beams build with the combination of ultra-high performance fibre reinforced concrete and conventional normal strength concrete, NSC, and high strength concrete, HSC, and on investigating the shear and flexural behaviour of UHPFRC-NSC and UHPFRC-HSC composite beams.

This chapter presents the details of test specimens, test setup, test procedure, and the properties of different material used in this experimental program. A total of twenty eight beams were tested. In addition, tests to obtain the mechanical properties of the materials (cylinder tests, split tensile tests, four points bending tests, splitting prism tests) were performed. The following sections provide details of the experimental program.

\subsection{Material properties}

\subsubsection{Concrete mixture}

The UHPC mixture that was used in this study is a commercial product, Ductal@, which is composed of premix powder, water, superplasticizer. The premix powder includes cement, silica fume, ground quartz, and sand. Table 3.1 shows the typical composition of this material. The NSC mixture used in this study is a commercial product provided by Dufferin concrete while the HSC mixture is a commercial product provided by Innocon concrete. Both mixtures have a maximum aggregate size $19 \mathrm{~mm}$. 
Table 3.1 Typical composition of Ductal ${ }^{\circledR}$

\begin{tabular}{|l|c|c|}
\hline \multicolumn{1}{|c|}{ Material } & $\mathrm{kg} / \mathrm{m}^{3}$ & Percentage by weight \\
\hline Portland Cement & 712 & 28.5 \\
\hline Fine Sand & 1020 & 40.8 \\
\hline Silica Fume & 231 & 9.3 \\
\hline Ground Quartz & 211 & 8.4 \\
\hline Superplasticizer & 30.7 & 1.2 \\
\hline Water & 109 & 4.4 \\
\hline
\end{tabular}

\subsubsection{Selection of fibres type and volume content}

One type and three quantities of fibres were incorporated in this study. Ductal ${ }^{\circledR}$ UHPFRC suggested the use of straight steel fibres geometry (13 mm length $\mathrm{x} 0.2 \mathrm{~mm}$ diameter) with a tensile strength above $2500 \mathrm{MPa}$ as shown in Fig. 3.1. This is in agreement with the recommendations of the Japanese code for UHPFRC. Previous research conducted by Dina et al. (2010) and Susetyo et al. (2011) has shown that $0.5 \%$ fibre volume content is incapable of controlling crack propagation in reinforced concrete panels. Therefore, to determine the effect of fibre volume content on the shear behaviour of UHPFRC beams, three volume content ratios of steel fibres were used in the present study, $1 \%, 1.5 \%$, and $2 \%$.

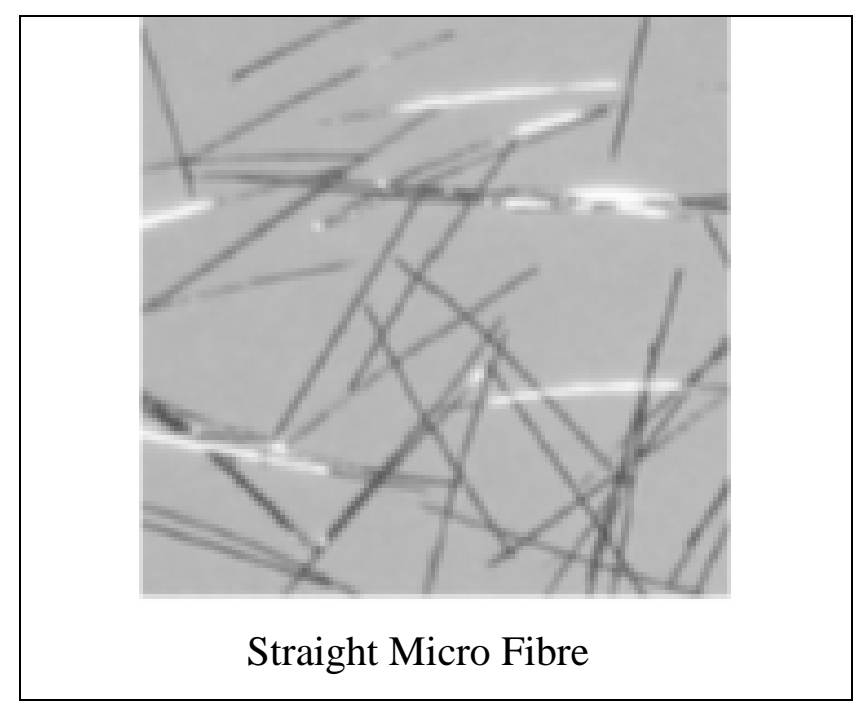

Figure 3.1 Type of steel fibre 


\subsubsection{Selection of longitudinal steel reinforcement}

The longitudinal steel reinforcements used in this study were obtained locally, conforming to the Canadian Standard Association (CSA) Standard G30.14-M83. To determine the mechanical properties of the reinforcing steel, tension tests were performed on six randomly obtained deformed from each batch of the $25 \mathrm{M}, 30 \mathrm{M}$ reinforcing bars. All of the coupons exhibited a yield plateau, with average experimental yield strengths of $474 \mathrm{MPa}$, and $468 \mathrm{MPa}$ and ultimate strength of $590 \mathrm{MPa}$, and $688 \mathrm{MPa}$ respectively.

\subsection{Design of beam specimens}

\subsubsection{Selection of shear span to effective depth ratio $a / d$}

As discussed in chapter two, deep beam classified when $a / d \leq 2.5$ and slender beam when $a / d>2.5$. Different $a / d$ ratios were investigated to examine the effect of arch action on shear behaviour of UHPFRC beams. For series 2 and 3, all the beams were having $a / d$ ratio of 3 to minimize the effect of arch action.

\subsubsection{Beam size}

According to ACI specification 11.4.6.1, no minimum area of shear reinforcement is required for reinforced concrete flexural members for beams with height not greater than $250 \mathrm{~mm}$. Thus, the minimum beam depth in this test program was designed to be $300 \mathrm{~mm}$. All the beams had cross section of 150 wide and $300 \mathrm{~mm}$ deep.

\subsubsection{Selection of longitudinal steel reinforcement ratio}

As previously mentioned, UHPFRC is a new material without any design guidelines for shear. The elementary calculations of the shear strength of the beams were based on Parra-Montesinos recommendation (2006), the shear strength for steel fibre reinforced concrete (SFRC) with a

fibre volume content of $1 \%$ is $0.3 \sqrt{f_{c}^{\prime}}(M P a)$, which was considered adequate for the purpose of evaluating the use of deformed steel fibres as minimum shear regardless of concrete compressive strength and the effective span depth, while the shear strength for SFRC concrete 
with a fibre volume content greater than $1 \%$ is $0.4 \sqrt{f_{c}^{\prime}}(M P a)$. These assumptions based on a concrete compressive strength of up to $103 \mathrm{MPa}$; it should be noted that these assumptions were used in the present program as elementary calculations for the shear strength of the beams. For example to determine the shear load required of beam with shear span to effective depth ratio $a / d=3.5$, and fibre volume content $1 \%$ is:

$$
\begin{gathered}
P_{s}=\frac{L}{(L-a)}=2.5 * V_{c}=2.5 * 0.3 * \sqrt{f_{c}^{\prime}} * b * d \\
P_{s}=2.5 * 0.3 * \sqrt{200} * 150 * 210=467751 \mathrm{~N}=334.11 \mathrm{kN}
\end{gathered}
$$

To calculate the beam flexural strength using 4- 25M reinforcing bars in two layers

$$
\begin{aligned}
& A_{s}=4 * 500=2000 \\
& a_{c}=\frac{A_{s} f_{y}}{0.85 f_{c}^{\prime} b}=\frac{2000 * 430}{0.85 * 200 * 150}=33.725 \mathrm{~mm} \\
& M_{n}=A_{s} f_{y}\left(d-\frac{a_{c}}{2}\right)=2000 * 430 *\left(210-\frac{33.725}{2}\right)=166098039 \mathrm{~N} . \mathrm{mm} \\
& P_{m}=2.5 * \frac{M_{n}}{a}=2.5 * \frac{166098039}{735 * 1000}=564.96 \mathrm{kN}
\end{aligned}
$$

where $a=$ the shear span, $L=$ the length of the beam, $b=$ width of the beam, $d=$ the effective depth of the beam, and $a_{c}=$ the depth of the equivalent concrete stresses block measured from the top of the compression concrete zone

Table 3.2 shows the calculation of shear strength based on these assumptions. However, all of the fibre reinforced beams in series 1 failed in flexure. Therefore, the flexural capacity of the beams was increased in series by using 4-30M in order to investigate the shear behaviour of the 
beams. Experimental results of series 1 showed that both beams with $1 \%$ and $2 \%$ fibre volume content failed in flexure, and testing another beam with $1.5 \%$ fibre volume content will not contribute to the study. Therefore, the beam with $1.5 \%$ fibre volume content in series 1 was omitted.

Table 3.2 Calculation of beam shear and flexural strength

\begin{tabular}{|l|c|c|c|c|c|c|c|c|}
\hline Beam & $v_{u} / \sqrt{f_{f}}$ & $\begin{array}{c}d_{b} \\
(\mathbf{m m})\end{array}$ & $\begin{array}{c}\mathbf{d} \\
\mathbf{( m m})\end{array}$ & $\begin{array}{c}P_{s} \\
(\mathbf{k N})\end{array}$ & $\begin{array}{c}\rho \\
(\mathbf{m m})\end{array}$ & $\begin{array}{c}P_{m} \\
(\mathbf{k N})\end{array}$ & $P_{s}<P_{m}$ \\
\hline US1-1 & 0.3 & 25 & 210 & 334.11 & 0.063 & 33.725 & 564.96 & 230.85 \\
\hline US1-2 & 0.4 & 25 & 210 & 445.48 & 0.063 & 33.725 & 564.96 & 119.48 \\
\hline
\end{tabular}

Based on the experimental results in series 1, the test beams in phase 1 were classified according to their steel reinforcement ratio as shown in Fig. 3.2. Beams in series 1 were $1275 \mathrm{~mm}$ long with a cross section of $150 \mathrm{~mm}$ wide by $300 \mathrm{~mm}$ deep, and beams in series 2 were $1284 \mathrm{~mm}$ long with a cross section of $150 \mathrm{~mm}$ wide by $300 \mathrm{~mm}$ deep. The experimental parameters of the test beams in both series are summarized in Table 3.3. The length of the beams was designed to provide a left shear span to effective depth ratio between 1.5 and 3.5 in series 1 and 3.0 in series 2. The end reinforcing bars were bended to prevent anchorage failure as shown in Fig 3.2. In addition, the right span was reinforced with enough stirrups to ensure shear failure in the left span. Four longitudinal bars were used as the main reinforcement, and $15 \mathrm{M}$ bars were used as compression reinforcement in all beams with concrete cover thickness of $20 \mathrm{~mm}$.

The specimen nomenclature was derived as follows: the first and second letters indicate the type of concrete strength (concrete mixture) used in the specimen followed by the series number of the specimen, the following number indicates the volume of fibre content used and the last number indicates the shear span to effective depth ratio. For example, specimen US1-1-3.5 is a specimen cast using UHPC strength with a series 1 configuration which has a $1 \%$ fibre volume content and shear span to effective depth ratio of 3.5. In series 2, two UHPC beams without fibre content (US2-0-3.0-a and US2-0-3.0-b) were tested to act as control specimens. 
In the second phase the composite beam combining UHPFRC-NSC and UHPFRC-HSC materials were developed and investigated. The length of the beam was designed to provide a left shear span to effective depth of 3.0 and no anchorage failure will occur as shown in Fig 3.2. In addition, the shorter span was reinforced with enough stirrups to ensure shear failure in the longer span.

Table 3.3 Experimental parameters of specimens of phase 1

\begin{tabular}{|l|c|c|c|}
\hline \multicolumn{1}{|c|}{ Beam } & $a / d$ & $\begin{array}{c}\rho \\
\boldsymbol{\%}\end{array}$ & $\begin{array}{c}v_{f} \\
\boldsymbol{\%}\end{array}$ \\
\hline US1-0-3.5 & 3.5 & 0.063 & 0 \\
\hline US1-1-3.5 & 3.5 & 0.063 & 1 \\
\hline US1-2-3.5 & 3.5 & 0.063 & 2 \\
\hline US1-2-2.0 & 2.0 & 0.063 & 2 \\
\hline US1-2-1.5 & 1.5 & 0.063 & 2 \\
\hline US2-0-3.0-a & 3.0 & 0.081 & 0 \\
\hline US2-0-3.0-b & 3.0 & 0.081 & 0 \\
\hline US2-1-3.0 & 3.0 & 0.081 & 1 \\
\hline US2-1.5-3.0 & 3.0 & 0.081 & 1.5 \\
\hline US2-2-3.0 & 3.0 & 0.081 & 2 \\
\hline
\end{tabular}

According to ACI code (ACI, 2011), which states that the steel reinforcement should be well distributed over the zone of maximum concrete tension, the total effective tension area of the concrete surrounding the reinforcement is double the distance from the face of outside tension fibre to the centroid of the tension reinforcement, y, multiplied by the beam width as shown in Fig. 3.3a. The NSC and HSC were bonded to the UHPFRC using either shear stud connectors or dowels as shown in Fig. 3.3b. Two dowels of $10 \mathrm{M}$ bars were installed $200 \mathrm{~mm}$, and $400 \mathrm{~mm}$ from the left support and used as a shear connector with the beams reinforced with dowels. For the beams reinforced with shear studs, three shear studs with $10 \mathrm{~mm}$ diameter and $100 \mathrm{MPa}$ 
tensile strength were placed $150 \mathrm{~mm}$ spacing from the left support and used as a shear connector for the beams. Series 3 test variables are summarized in Table 3.4

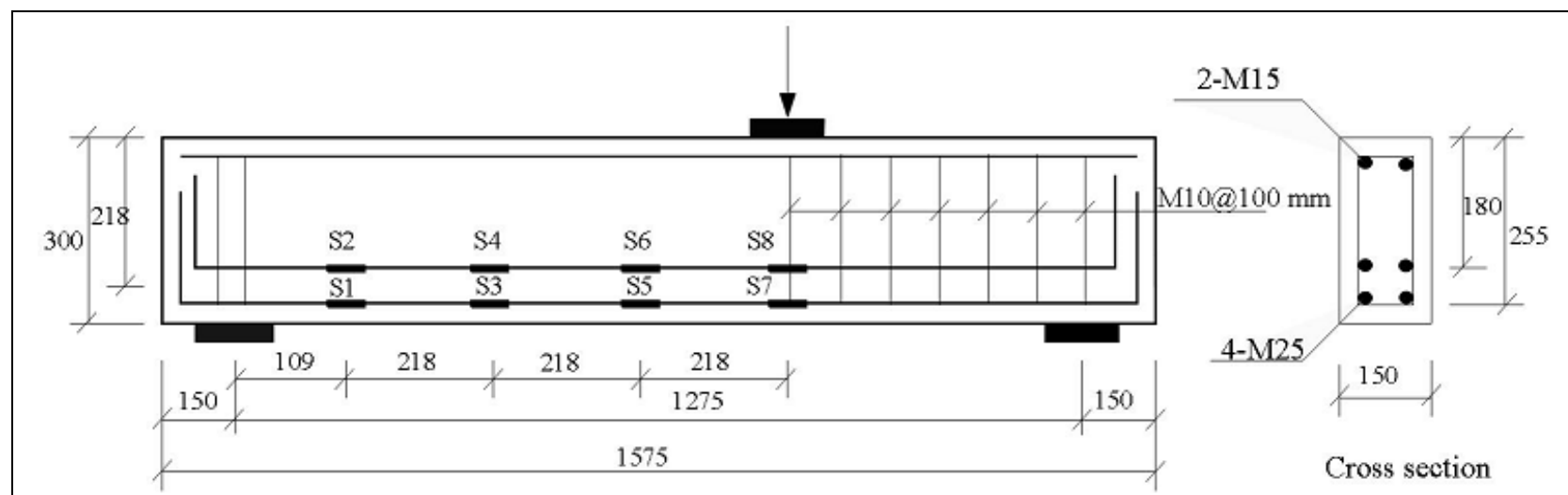

a) Series 1

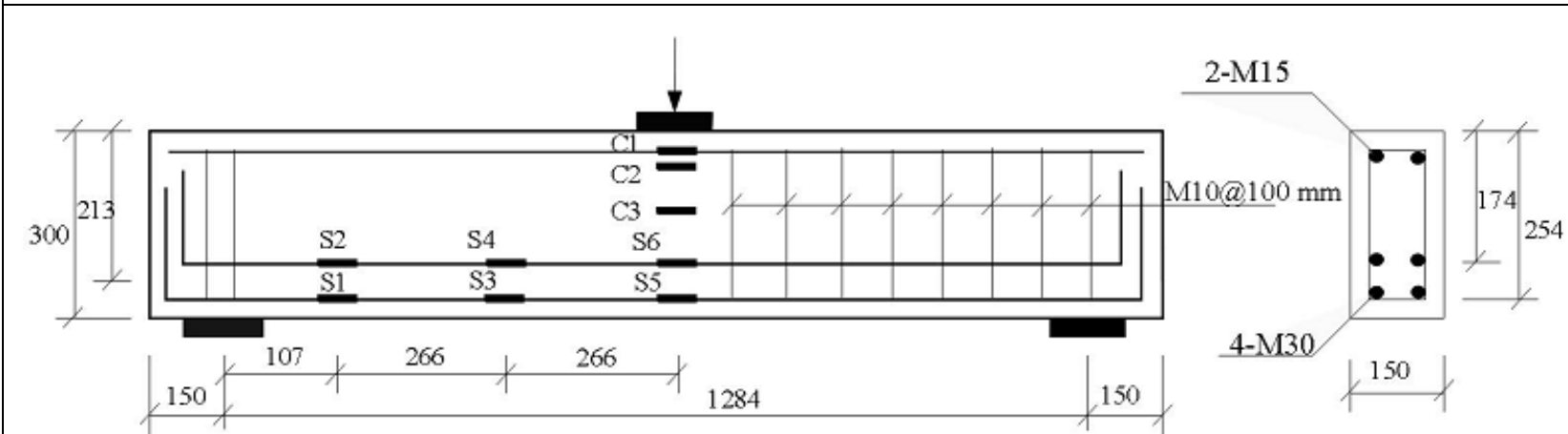

Cross section

b) Series 2

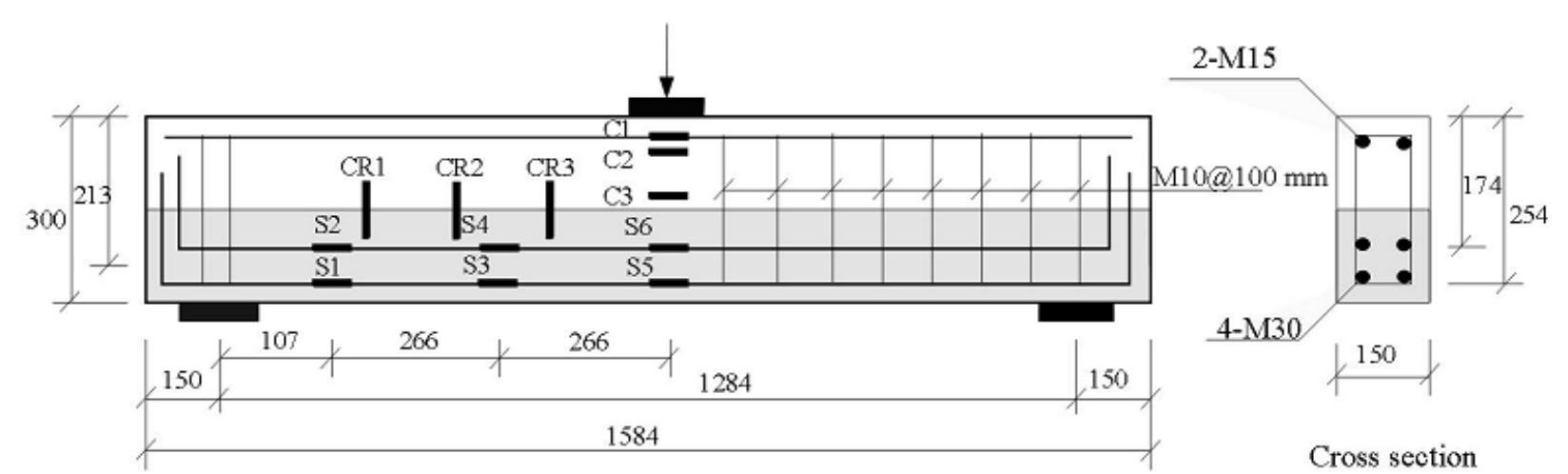

(c) Series 3

Figure 3.2 Reinforcement details and test configuration 


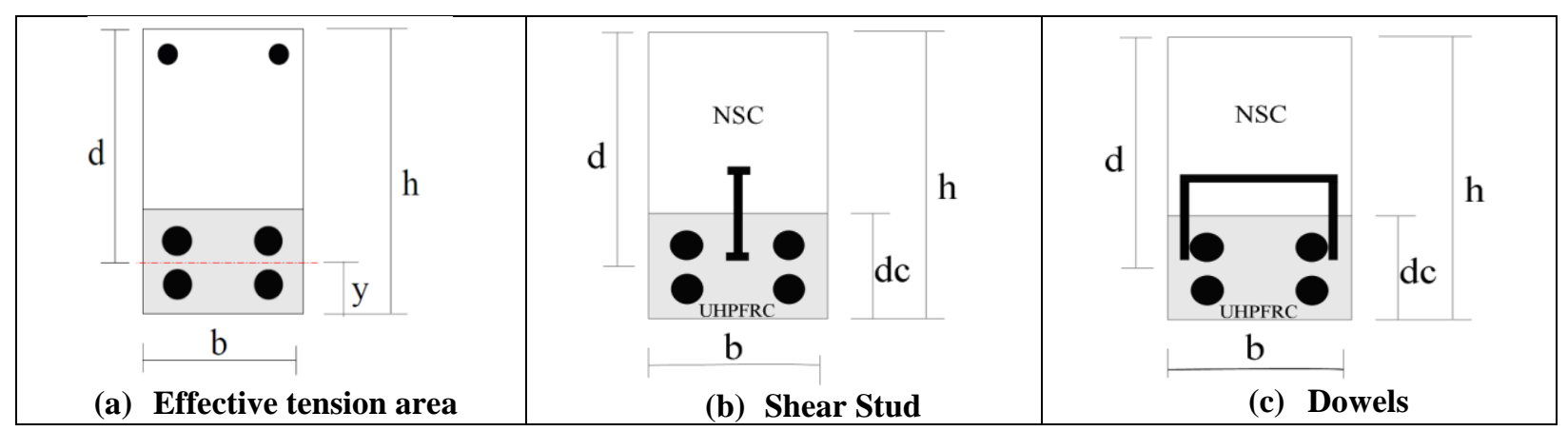

Figure 3.3 (a) Effective tension area b) and c) Shear connections

Table 3.4 Experimental parameters of test beams of phase 2

\begin{tabular}{|c|c|c|c|}
\hline Beam & $a / d$ & $\begin{array}{l}\rho \\
\%\end{array}$ & $\begin{array}{l}v_{f} \\
\text { \% }\end{array}$ \\
\hline NS2-0 & \multirow{16}{*}{3.0} & \multirow{16}{*}{0.081} & \multirow[t]{2}{*}{0} \\
\hline HS2-0 & & & \\
\hline UNS3-1 & & & \multirow{3}{*}{1} \\
\hline UNS3-1D & & & \\
\hline UNS3-1S & & & \\
\hline UNS3-1.5 & & & \multirow[t]{2}{*}{1.5} \\
\hline UNS3-1.5D & & & \\
\hline UNS3-2 & & & \multirow[t]{2}{*}{2} \\
\hline UNS3-2D & & & \\
\hline UHS3-1 & & & \multirow[t]{3}{*}{1} \\
\hline UHS3-1D & & & \\
\hline UHS3-1S & & & \\
\hline UHS3-1.5 & & & \multirow[t]{2}{*}{1.5} \\
\hline UHS3-1.5D & & & \\
\hline UHS3-2 & & & \multirow[t]{2}{*}{2} \\
\hline UHS3-2D & & & \\
\hline
\end{tabular}

The shear span to effective depth ratio in all beams in series 3 was 3.0. Therefore, the specimen nomenclature of series 3 was derived as follows without indicating the shear span to effective depth ratio: the first and second letters indicate the type of concrete strength (concrete mixture) used in the specimen followed by the series number of the specimen, the following number indicates the volume of fibre used and the last number indicates the shear connector. For 
example, specimen UN3-1D is a specimen cast using UHPFRC-NSC strength with a series 3 configuration which has $1 \%$ fibre volume content and dowels as the shear connector.

\subsection{Preparation of test specimens}

Wooden forms were used to cast the beam test specimens. A thin layer of grease was applied to the internal surfaces to ensure easy stripping and to prevent water absorption. The reinforcements were placed inside the forms, providing a minimum clear concrete cover of $20 \mathrm{~mm}$. The UHPFRC was mixed in a 250 L capacity shear mixer. After casting, the UHPC specimens were sprayed with water and covered with plastic sheets and were stored at room temperature until the day of testing.

When casting composite members, the setting time for UHPFRC is longer than NSC, HSC, and the UHPC premix provided by Lafarge Inc. without an accelerator. For this reason, the beams were casted upside down. The NSC/HSC layer was casted first and then the UHPFRC layer was casted on top of the NSC/HSC layer without any surface preparation of the NSC or HSC layers prior to casting. After casting, the composite specimens were sprayed with water and covered with plastic sheets and were stored at room temperature until the day of testing. However, the NSC and HSC specimen were cured for 28 days. All the beams in phase 1 were tested after 28 days of casting. The composite beams in phase 2 with NSC were tested after 28 days and the composite beams with HSC were tested after 90 days.

It should be noted that the NSC/HSC layer need vibration to consolidate the concrete by removing the entrapped air to the surface and allowing concrete to flow into corners, around the reinforcement rebar and flush against the form face. Therefore, the NSC/HSC layer must cast first then the UHPFRC layer which is self-consolidated. Thus, the proposed composite system is applicable to precast concrete. 


\subsection{Test setup and procedure}

The simply supported beam specimens were subjected to a concentrated load that was applied at a distance from the left support according to the shear span to effective depth ratios for series 1 and at the mid-span for series 2 and 3. The test setup is shown in Fig. 3.4. In this system, the force of the hydraulic actuator machine was measured by a load cell with $1340 \mathrm{kN}$ loading capacity. During the testing procedure, loading was incrementally increased by $20 \mathrm{kN}$. Between loading increments, the beams were inspected for the initiation of any cracks and marked. In series 1 , two potentiometers were installed under the loading point at the mid span on each beam to measure the deflection as shown in Fig. 3.4.

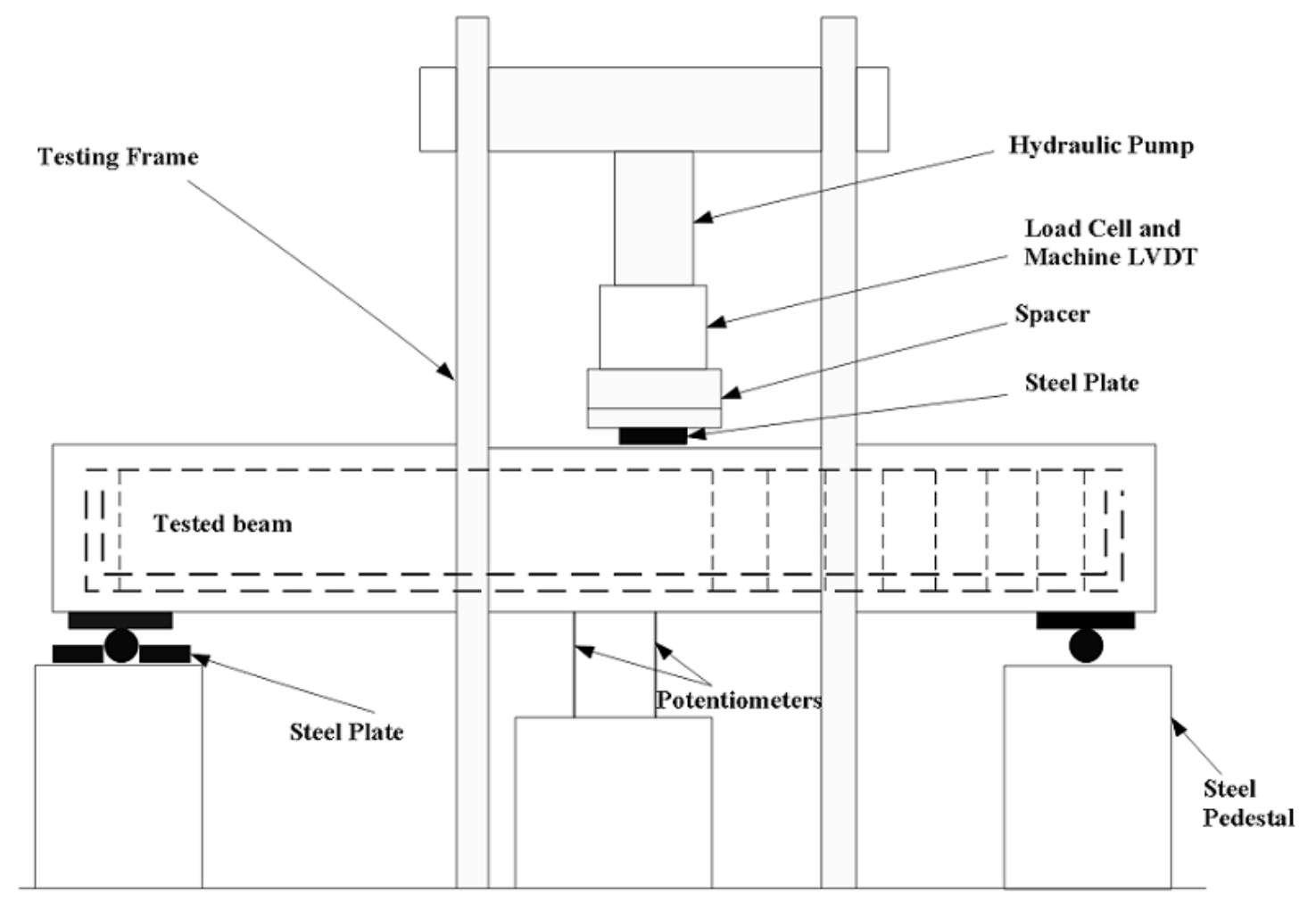

Figure 3.4 Test setup for beams in series 1

For series 2 and 3, two potentiometers were installed under the loading point at the mid span of each beam on each side to measure the deflection as shown in Fig. 3.5. For series 1, eight strain 
gauges labelled S1 to S8 were attached to the bottom reinforcing bars. For series 2 and3, six strain gauges labelled S1 to S6 were attached to the bottom reinforcing bars to measure the strain of the reinforcement and three $60 \mathrm{~mm}$ concrete strain gauges labelled C1 to C3 were mounted onto the concrete surface along the height of the mid-span of the beam at distances $20 \mathrm{~mm}, 70$ $\mathrm{mm}$ and $150 \mathrm{~mm}$ from the top layer as shown in Fig. 3.2. In addition, three crack gauges were used for series 3 to measure the crack width at the interface between the UHPFRC and NSC/HSC layers. The crack gauges were mounted on the concrete surface at a distance $150 \mathrm{~mm}$, $300 \mathrm{~mm}$, and $450 \mathrm{~mm}$ from the left support as shown in Fig. 3.2. Gauge readings were recorded until they became unreliable due to the cracking in the underlying concrete. These gauges were capable of detecting strain due to small crack openings in each location. However, the readings of concrete strain gauges were unreliable when a localised macro crack developed and hence were not considered.

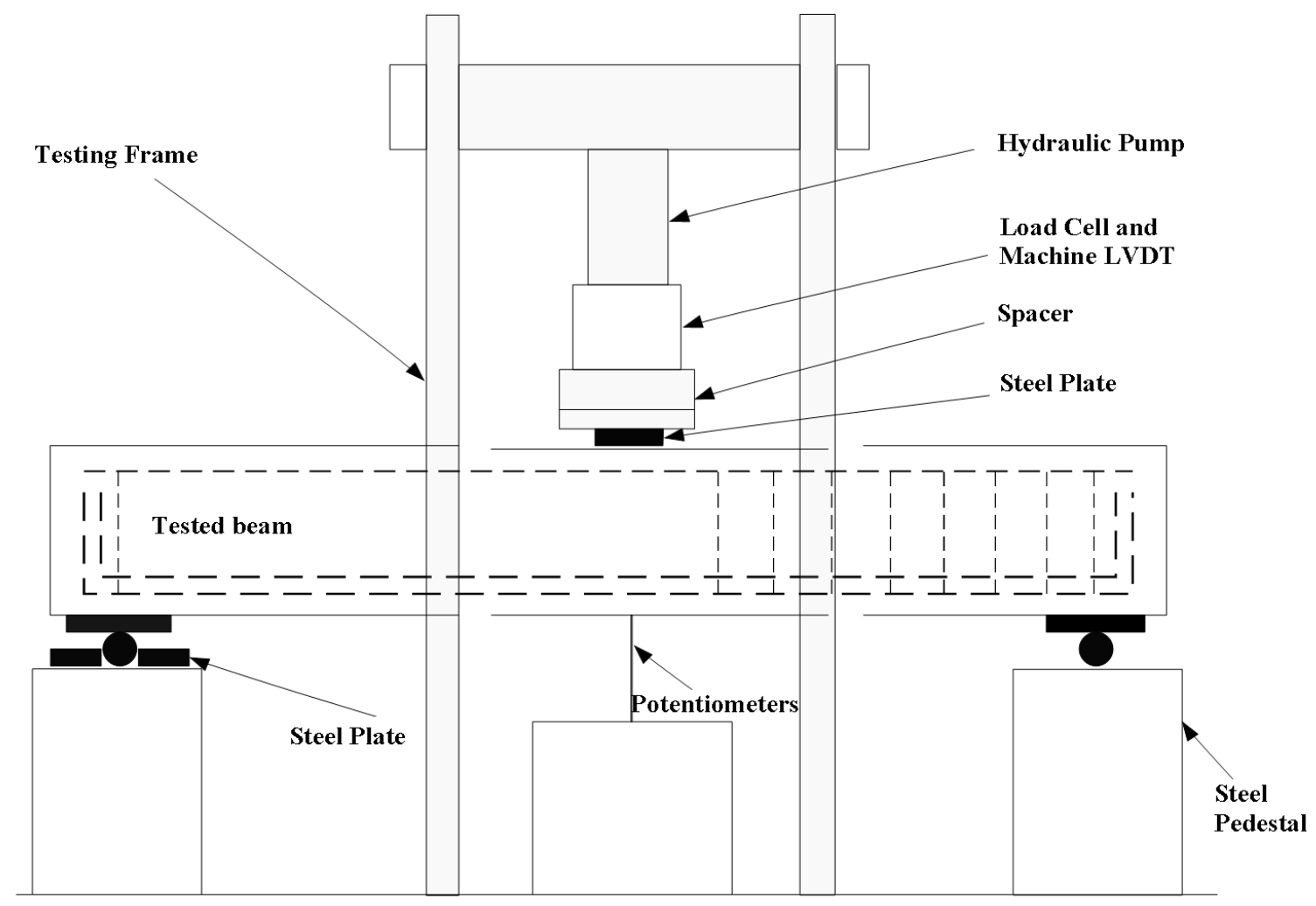

Figure 3.5 Test setup for beams in series 2 and 3 


\subsection{Tests}

\subsubsection{Mechanical properties of concrete}

The compressive strength, $f_{c}^{\prime}$, of the UHPFRC, NSC and HSC was obtained through compressive testing of cylindrical specimens with a diameter of $100 \mathrm{~mm}$ and height of $200 \mathrm{~mm}$ in accordance with ASTM C39/C39M. The cylindrical specimens were cast at the same time as the test beams. After casting, the UHPFRC specimens were covered with plastic sheets and were stored at room temperature for 28 days, while the NSC and HSC specimens were cured for 28 days. The ends of the cylinder were ground to remove the weak paste layers, and to ensure that the cylinders were uniformly and axially loaded. All specimens were tested at the same day as the beams.

\subsubsection{Split cylinder test}

The tensile strength of the UHPC and the UHPFRC was obtained through spilt cylinder testing, $f_{s p}$, of specimens in accordance with ASTM C496 "Standard Test Method for Splitting Tensile Strength of Cylindrical Concrete Specimens". The same concrete cylinder used in the compression test was placed on its side and a compression force was applied along the diameter of the concrete cylinder, as shown in Fig. 3.6(a), (Wight and MacGregor, 2012). Fig. 3.6(c) shows an element on the vertical diameter subjected to biaxial tension and compression stresses, and Fig. 3.6(d) shows the distribution of both compression and tension stresses along the vertical circular face. There are two areas of high transverse compression on the far ends of the top and bottom of the vertical circular face of the concrete cylinder, but on the rest of the diameter, there is almost a uniform tension. The ends of the cylinder were ground flat to remove the weak paste layers. All specimens were tested at the same day of testing the beams. 


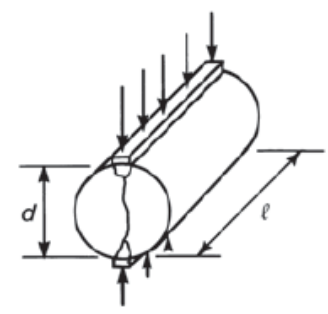

(a) Test procedure.

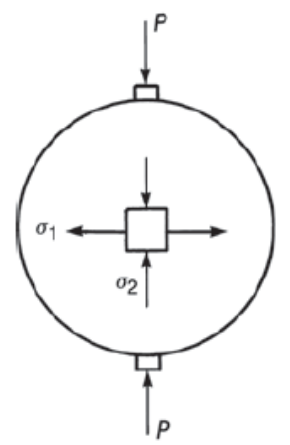

(c) Stresses on element.

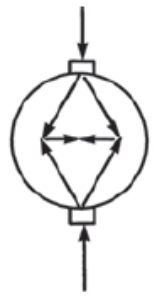

(b) Simplified force system

Figure 3.6 Split cylinder test (Wight and MacGregor, 2012)

The values of the splitting tensile strength $f_{s p}$, were calculated using the equation outlined in the CAN/CSA Standard A23.3-13C (2004), as follows:

$$
f_{s p}=\frac{2 P}{\pi \cdot l_{c y l} \cdot d_{c y l}}
$$

where:

$$
\begin{gathered}
\mathrm{P}=\text { maximum applied load, } \mathrm{N}, \\
l_{c y l}=\text { length of the cylinder, } \mathrm{mm}, \\
d_{c y l}=\text { diameter of the cylinder, } \mathrm{mm} .
\end{gathered}
$$




\subsubsection{Flexural test}

In order to determine the flexural tensile strength of UHPFRC, bending tests were performed on concrete prisms $152 \times 152 \times 457 \mathrm{~mm}$ in size. The composite UHPFRC-NSC/HSC prisms were made up of a $101 \mathrm{~mm} \mathrm{NSC/HSC}$ layer at the top, and a $51 \mathrm{~mm}$ UHPC layer at the bottom. The NSC/HSC and UHPFRC layers were cast at the same time; the NSC/HSC layer was cast first and then the UHPFRC layer was cast on the top. In order to allow for better visualization, the NSC and HSC layers were painted white and the UHPFRC layer was painted grey. For each composite type, a minimum of three four-point un-notched bending tests were performed while loaded at a rate of $0.05 \mathrm{~mm} / \mathrm{min}$ in accordance with ASTM C 1609 (2006). Measurements were obtained from a set of four potentiometers, one at each support to measure the support displacement and two at mid-span to measure the mid-span displacement. The net mid-span deflections were determined using these measurements and the load-deflection curve was drawn. In addition, the first-cracking load, and the ultimate load of the concrete were registered during the tests. The first-cracking strength and the ultimate cracking strength were calculated according to eq. (3.8).

$$
f=\frac{P L_{s}}{b h^{2}}
$$

where,

$f=$ the flexural strength, MPa

$\mathrm{P}=$ the load, $\mathrm{N}$

$L_{s}=$ the span length, $\mathrm{mm}$

$\mathrm{b}=$ the average width of the specimen at the fracture, $\mathrm{mm}$, and

$\mathrm{h}=$ the average depth of the specimen at the fracture, $\mathrm{mm}$.

\subsubsection{Bond strength between UHPFRC and NSC/HSC layers}

To evaluate the bond characteristics between the UHPFRC, NSC/HSC materials, splitting test were performed with $150 \mathrm{~mm}$ cube specimens. The specimens were loaded along an interface plane to simulate a tensile load perpendicular to the plane as shown in Fig. 3.8. This test followed a similar procedure as the ASTM C496 test used for splitting tensile strength of 
cylindrical concrete specimens. Three samples of each UHPFRC-NSC/HSC composite were tested using this method and the average values of the three specimens were evaluated for each combination.

Bond stress is defined as the shear stress along the interface surface between the two materials, and can be calculated by the following equation (Momayez et al., 2005):

$$
\sigma_{s p}=\frac{2 P}{\pi A}
$$

where $\sigma_{s p}=$ splitting tensile strength of plane, $\mathrm{MPa}(\mathrm{psi}) ; \mathrm{P}=$ applied load, $\mathrm{N}$ (lbf); and $\mathrm{A}=$ area of bond plane along the interface surface between UHPFRC and NSC or HSC materials, $\mathrm{mm}^{2}$ ( $\left.i n^{2}\right)$.

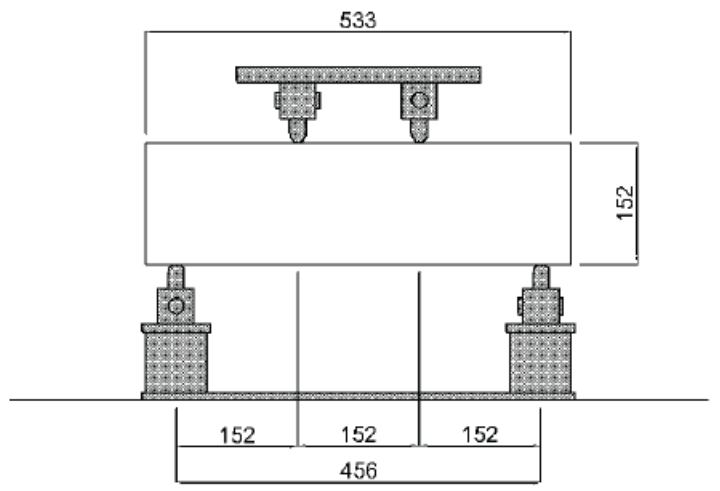

(a)
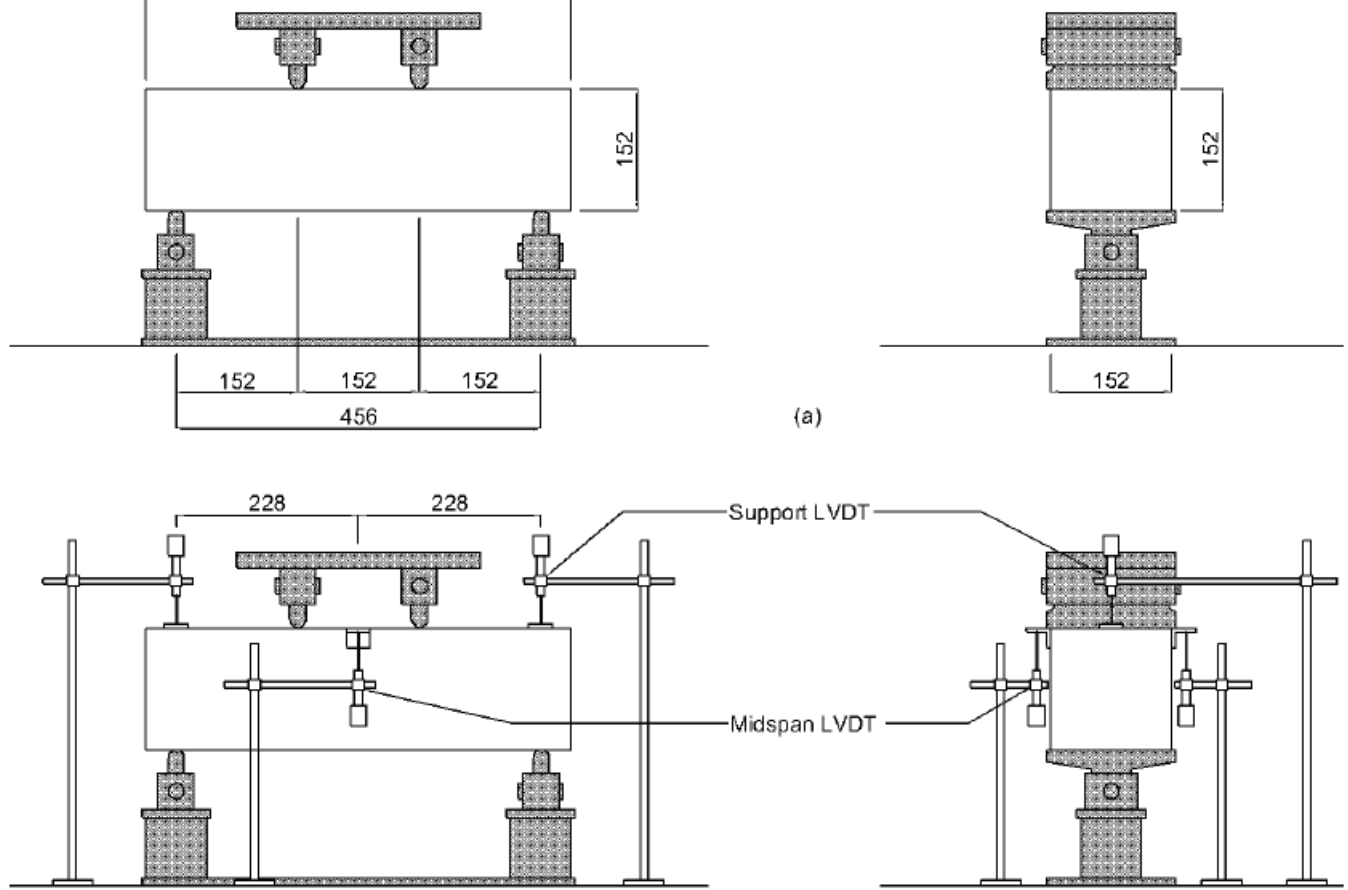

(b)

Figure 3.7 Four-point bending test (a) dimensions, and (b) instrumentation ASTM C 1609 (2006) 


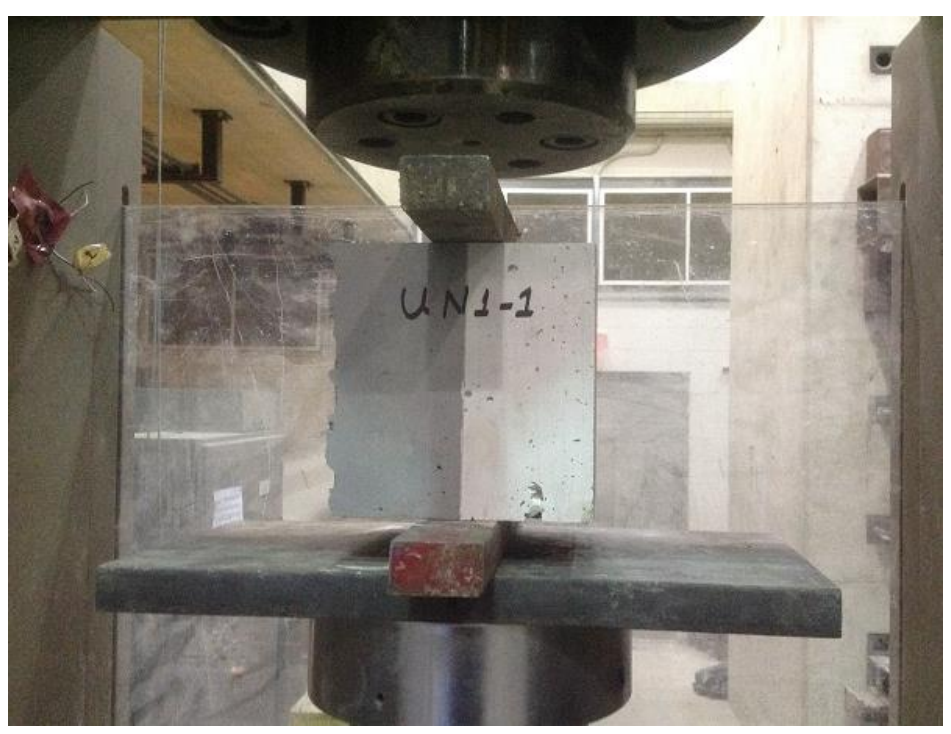

Figure 3.8 Splitting prism test 


\section{Chapter 4}

\section{Experimental Results of UHPFRC Members}

This chapter describes the material tests conducted in this experimental program and provides details on the analytical procedure used to study the structural behaviour of the UHPFRC tested beams. To study the specimens' structural behaviour, including, its load - deflection relationship, reinforcement strains, crack pattern, and concrete strains in the critical shear span, each beam was analysed separately. In addition, this chapter compares the responses of UHPFRC specimens with that of the UHPC specimens to better understand the benefits associated with the use of steel fibres in UHPC members.

\subsection{Cylinder compressive strength}

Results from the concrete cylinder compressive strength tests are shown in Table 4.1. The results summarized in Table 4.1 indicate that fibre addition didn't significantly affect the compressive strength of the concrete. It was observed from the tests that the UHPC without fibres addition exhibit explosive failures during compression tests while UHPFRC did not exhibit explosive failures during compression tests. This can be attributed to the restraining and confining effects of the fibres. Fig. 4.1 shows the different failure modes of UHPC and UHPFRC cylinders under the compression-loading test.

Table 4.1 Cylinder compressive strength test results (MPa)

\begin{tabular}{|l|c|c|c|c|c|c|c|}
\hline \multicolumn{1}{|c|}{ Beam } & $\mathbf{C ~ \# 1 ~}$ & $\mathbf{C ~ \# 2}$ & $\mathbf{C ~ \# 3}$ & $\mathbf{C ~ \# 4}$ & $\mathbf{C ~ \# 5}$ & Mean & CV \\
\hline US1-0-3.5 & 142.095 & 141.139 & 127.199 & 124.595 & & 133.038 & 0.077 \\
\hline US1-1-3.5 & 151.719 & 148.929 & 145.859 & 159.098 & 158.836 & 152.888 & 0.034 \\
\hline US1-2-3.5 & 142.543 & 180.051 & 180.359 & 155.351 & & 158.593 & 0.098 \\
\hline US1-2-2.0 & 154.419 & 161.636 & 152.375 & 157.047 & 156.770 & 155.436 & .071 \\
\hline US1-2-1.5 & 145.938 & 146.435 & 157.233 & 159.105 & 151.338 & 152.010 & 0.034 \\
\hline NS2 & 46.385 & 53.512 & 59.129 & 43.241 & 52.718 & 51.197 & 0.130 \\
\hline HS2 & 68.041 & 67.529 & 73.601 & 68.618 & 72.595 & 70.078 & 0.036 \\
\hline US2-0-3.0-A & 120.017 & 124.643 & 126.064 & 119.552 & & 133.580 & 0.023 \\
\hline US2-0-3.0-B & 173.054 & 163.931 & 174.777 & 166.611 & 157.220 & 167.118 & 0.038 \\
\hline US2-1-3.0 & 162.668 & 158.574 & 146.562 & 152.727 & 143.301 & 152.750 & 0.047 \\
\hline US2-1.5-3.0 & 159.487 & 161.322 & 150.792 & 145.001 & 152.759 & 153.872 & 0.038 \\
\hline US2-2-3.0 & 150.969 & 157.135 & 156.409 & 155.328 & 152.212 & 154.410 & 0.015 \\
\hline
\end{tabular}




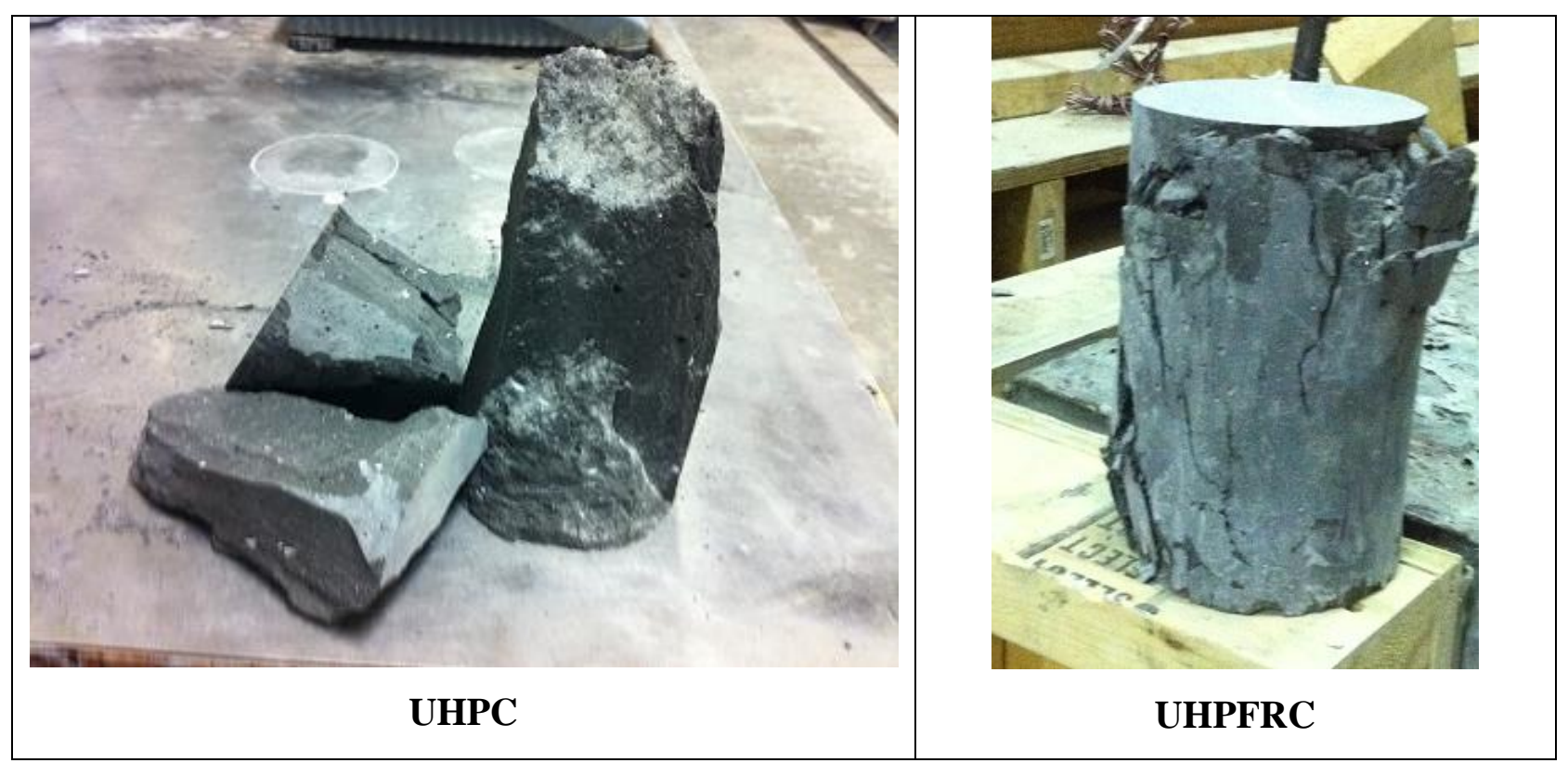

Figure 4.1 Failure modes of concrete cylindrical specimens under compression loading test

\subsection{Split cylinder tests}

As was mentioned earlier, cracking is a form of tension failure. Hence, the purpose of tensile strength of concrete is necessary to determine the load at which the concrete members may crack. The results of the splitting tensile strength tests, $f_{s p}$, for each cylinder were calculated according to equation (3.1), and summarised in Table 4.2. The results indicate that fibre addition enhanced the splitting tensile strength of the concrete. It was also observed that the addition of the fibres altered the failure mode of the cylinders tested. A brittle splitting failure mode was observed in the non-fibre reinforced concrete cylinders, while the fibre reinforced concrete cylinders remained intact with indications of hairline crack fracture across the length of the cylinders. It was noted that the fibres increased the splitting resistance of the concrete by limiting and controlling the transverse tensile stresses and strains in the concrete. Fig. 4.2 shows the different cylinder splitting failure modes of UHPC and UHPFRC cylinders. 
Table 4.2 Split cylinder test results (MPa)

\begin{tabular}{|l|c|c|c|c|}
\hline \multicolumn{1}{|c|}{ Beam } & $V_{f} \%$ & $f_{c}^{\prime}$ & $f_{s p}$ & $f_{s p} / \sqrt{f_{c}^{\prime}}$ \\
\hline US1-0-3.5 & 0.0 & 133.043 & 6.179 & 0.520 \\
\hline US1-1-3.5 & 1.0 & 152.884 & 12.617 & 1.056 \\
\hline US1-2-3.5 & 2.0 & 158.593 & 16.081 & 1.277 \\
\hline US1-2-2.0 & 2.0 & 155.436 & 15.118 & 1.212 \\
\hline US1-2-1.5 & 2.0 & 152.010 & 15.708 & 1.274 \\
\hline NS2 & 0.0 & 51.197 & 3.029 & 0.423 \\
\hline HS2 & 0.0 & 70.078 & 4.216 & 0.503 \\
\hline US2-0-3.0-a & 0.0 & 133.580 & 7.945 & 0.717 \\
\hline US2-0-3.0-b & 0.0 & 167.118 & 5.805 & 0.449 \\
\hline US2-1-3.0 & 1.0 & 152.750 & 9.339 & 0.755 \\
\hline US2-1.5-3.0 & 1.5 & 153.872 & 12.864 & 1.037 \\
\hline US2-2-3.0 & 2.0 & 154.410 & 15.698 & 1.263 \\
\hline
\end{tabular}

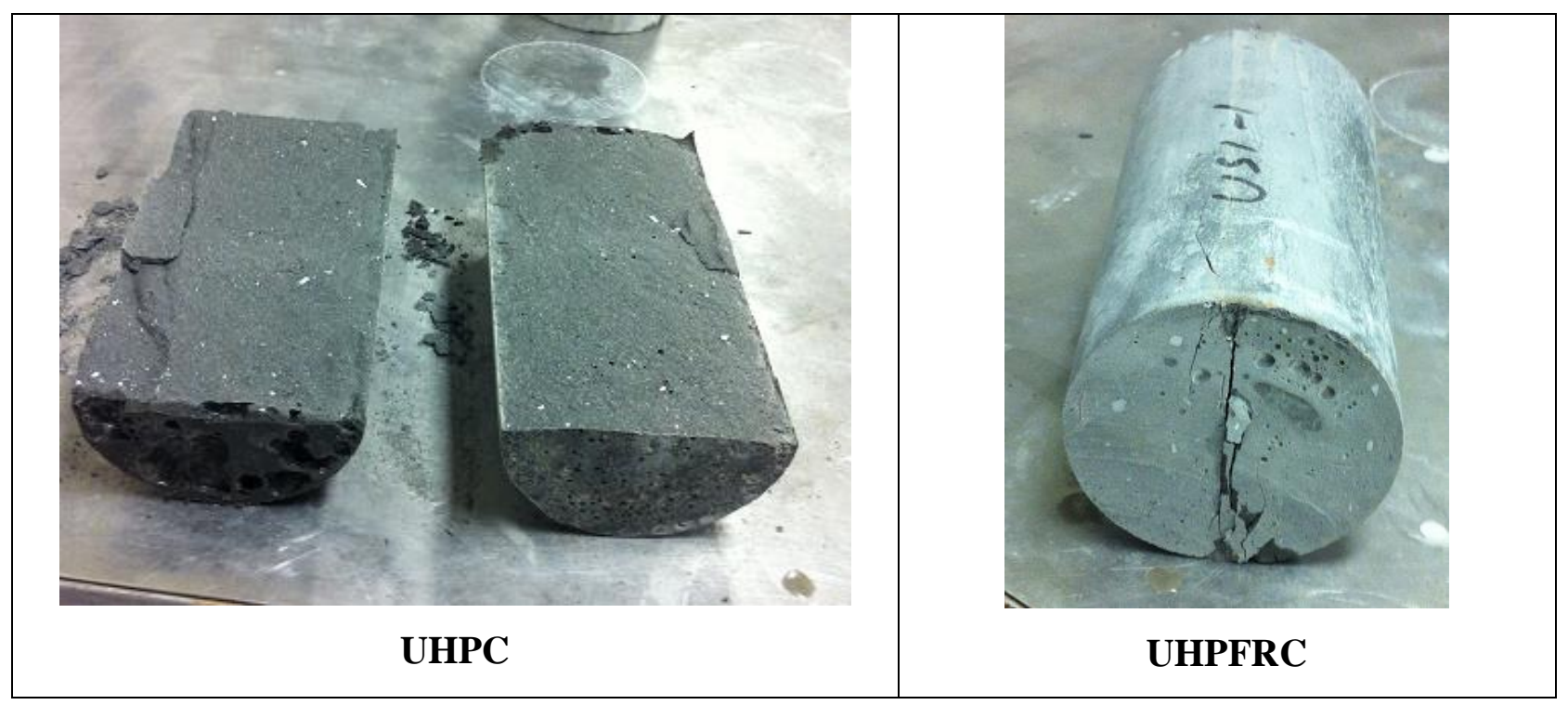

Figure 4.2 Failure modes of concrete cylindrical specimens under split cylinder tests

\subsection{Flexural tests}

The flexural behaviour of UHPC and UHPFRC prism specimens differed significantly. The prism specimens without the addition of fibre underwent brittle failure and the first crack propagated quickly after initiation, leading to a sudden drop in load carrying capacity after reaching the peak load. For the fibre prisms, the first crack propagated slowly until failure. The prisms were also able to carry the load after failure. This demonstrates that the fibres have the 
ability to redistribute stresses across the crack until fibres pull out from the matrix. The addition of fibres enhanced the flexural strength and ductility of the concrete prisms.

The average first crack load and the average peak crack load were calculated according to equation (3.2), and summarized in Table 4.3. The first crack load and the first crack deflection are the loads where the first crack initiated and its corresponding deflection while the peak load and peak deflection are the peak load and its corresponding deflection. The average first crack load was calculated by obtaining the mean of all deflections at first crack loads. The average first crack load is the load corresponding to average deflection that was calculated by interpolating the two nearest points on the load-deflection curves. Similar procedure used to calculate the average peak load and its corresponding deflection. Fig. 4.3 shows the cracking behaviour of UHPFRC prisms. After first crack initiated in the prisms with $0 \%$ fibre content (US0), the crack propagated very fast and the prisms suddenly collapsed, while crack propagated slowly after initiation in the prisms with $1 \%$ (US1), $1.5 \%$ (US1.5), and 2\% (US2) fibre content. Therefore, adding fibres to the UHPC changed the failure mode from brittle mode to ductile mode. Fig. 4.4 shows the load versus net deflection relationship for series US0, US1, US1.5, and US2 respectively.

The average first crack load, first crack deflection, peak load, and peak deflection are shown in Table 4.3. The addition of fibres enhanced the flexural strength and ductility of the concrete prisms as shown in Table 4.3 and Fig. 4.5. The average ultimate load for UHPFRC (US) prisms with $0 \%, 1 \%, 1.5 \%$ and $2 \%$ fibres volume content were $43.88,66.09,76.93$ and $85.45 \mathrm{kN}$ respectively. It can be noted from Table 4.3 that the addition of steel fibres enhanced the flexural capacity by $83 \%, 127 \%$, and $136 \%$ for US1, US1.5, and US2 respectively. 
Table 4.3 Flexural properties and test results of UHPC mixtures

\begin{tabular}{|c|c|c|c|c|c|c|}
\hline Series & $\begin{array}{c}\text { Average } \\
\text { Compressive } \\
\text { Strength } \\
(\mathbf{M P a}) \\
(\mathbf{C V})\end{array}$ & $\begin{array}{c}\text { Average } \\
\text { Splitting } \\
\text { Tensile } \\
\text { Strength } \\
(\mathbf{M P a}) \\
(\mathbf{C V})\end{array}$ & $\begin{array}{c}\text { Average } \\
\text { Deflection } \\
\text { at First } \\
\text { Crack } \\
(\mathbf{m m}) \\
(\mathbf{C V})\end{array}$ & $\begin{array}{c}\text { Average } \\
\text { Load at } \\
\text { First } \\
\text { Crack } \\
(\mathbf{k N})\end{array}$ & $\begin{array}{c}\text { Average } \\
\text { Deflection } \\
\text { at Peak } \\
\text { Load } \\
(\mathbf{m m}) \\
(\mathbf{C V})\end{array}$ & $\begin{array}{c}\text { Average } \\
\text { Peak } \\
\text { Load } \\
(\mathbf{k N})\end{array}$ \\
\hline $0 \%$ & 144.579 & $\begin{array}{c}6.645 \\
(0.140)\end{array}$ & & & 0.260 & 38.380 \\
& $(0.110)$ & 10.980 & 0.361 & 63.535 & 0.489 & 66.089 \\
\hline $1 \%$ & 152.820 & $(0.149)$ & $(0.019)$ & & $(0.034)$ & \\
\hline $1.5 \%$ & $10.001)$ & 12.860 & 0.520 & 74.540 & 0.608 & 76.930 \\
& $(0.038)$ & $(0.083)$ & $(0.308)$ & & & \\
\hline $2 \%$ & 155.120 & 15.668 & 0.596 & 82.896 & 0.712 & 85.445 \\
& $(0.015)$ & $(0.020)$ & $(0.052)$ & & \\
\hline
\end{tabular}

$\mathrm{CV}=$ Coefficient of Variation

The toughness of concrete prisms was calculated by estimating the area under the load-deflection curve up to a net deflection of 1/150 of the span length. Table 4.4 shows the flexural toughness number rounded to the nearest Joule, and the modulus of rupture $f_{r}$, which was determined by flexural members that had dimensions of $152 \times 152 \times 457 \mathrm{~mm}$. It was observed that the addition of steel fibres significantly improved the toughness of the prisms (as shown in Table 4.4). For instance, concrete prisms with $1 \%$ fibres were approximately 27 times tougher than concrete prisms without fibres.

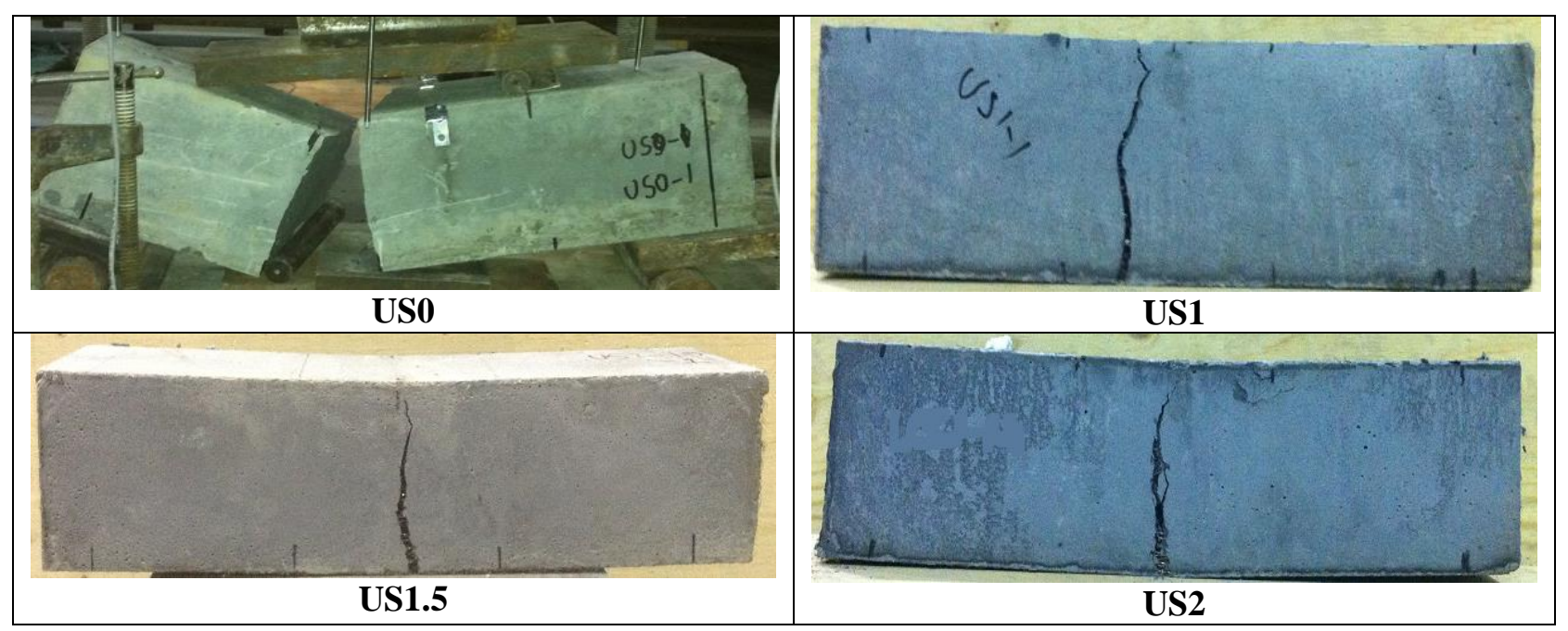

Figure 4.3 Flexural behaviour of UHPFRC prisms 


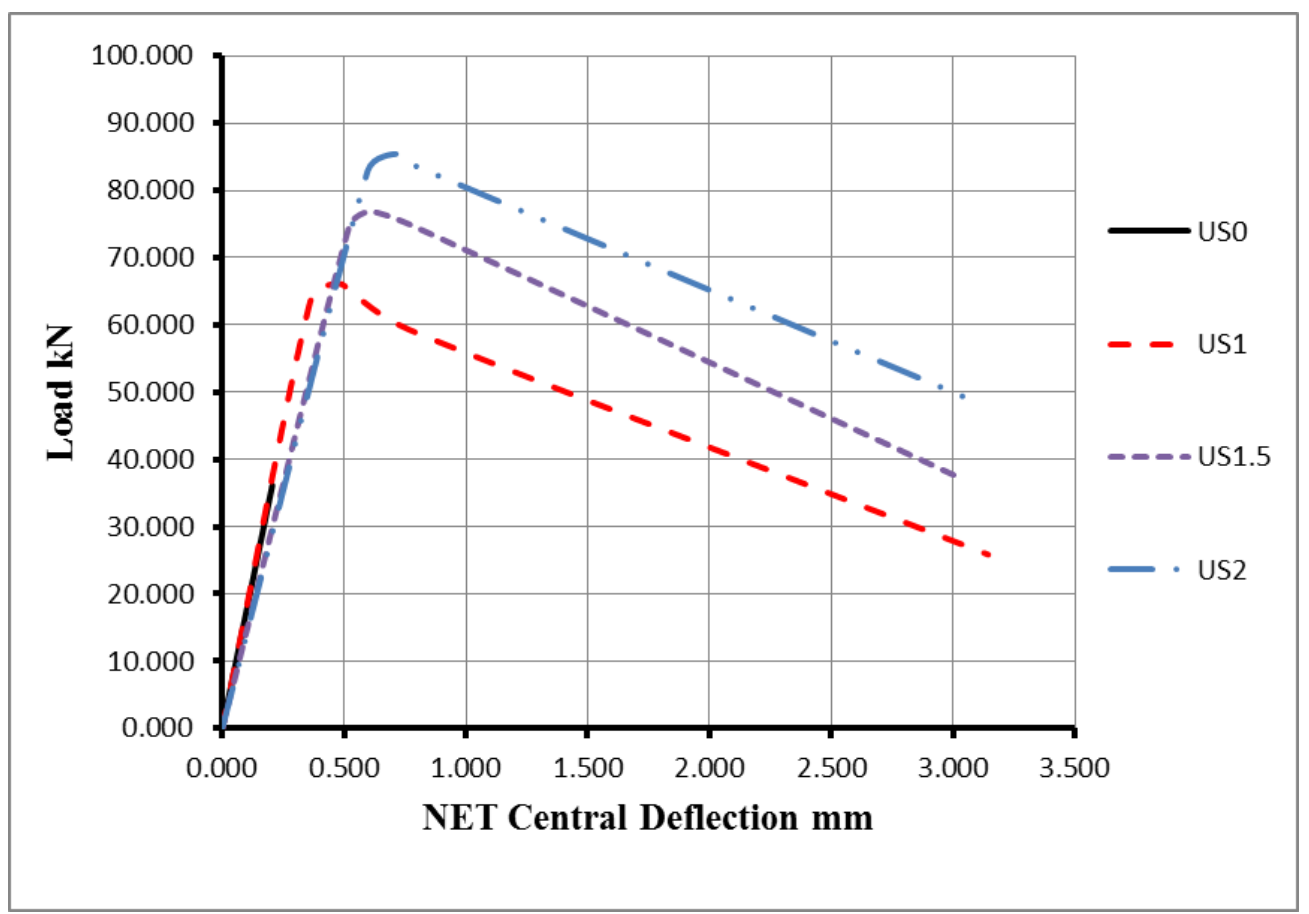

Figure 4.4 Load versus net deflection relationship for UHPFRC prisms

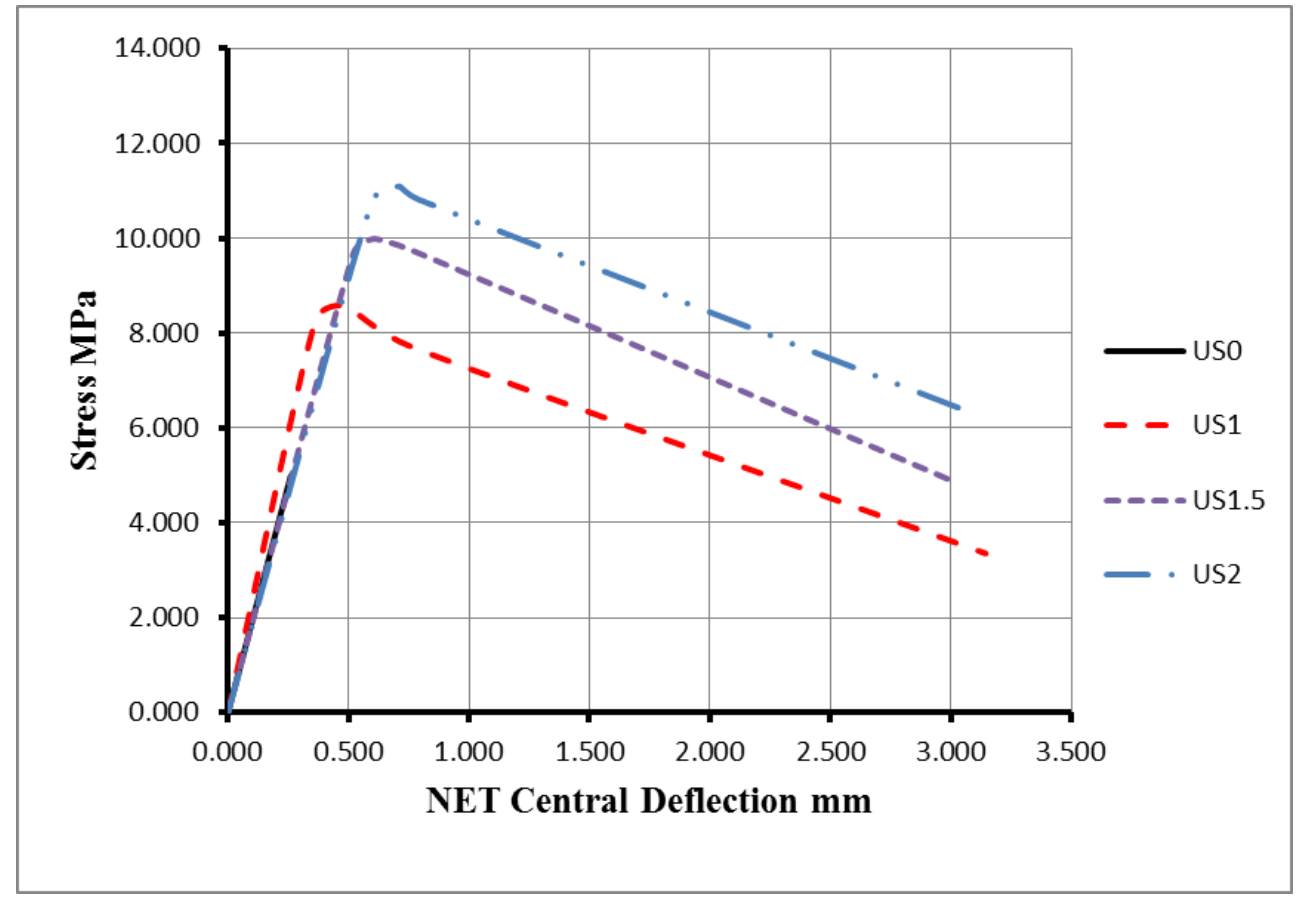

Figure 4.5 Comparison between flexural strength of series $0 \%, 1 \%, 1.5 \%$ and $2 \%$ fibre content 
Table 4.4 Flexural toughness and modulus of rupture of beams

\begin{tabular}{|c|c|c|}
\hline Series & $\begin{array}{c}f_{r} \\
(\mathbf{M P a})\end{array}$ & $\begin{array}{c}\text { Flexural Toughness } \\
(\text { Joule) }\end{array}$ \\
\hline $0 \%$ & 4.984 & 4.989 \\
\hline $1 \%$ & 8.581 & 138.355 \\
\hline $1.5 \%$ & 9.989 & 164.319 \\
\hline $2 \%$ & 11.095 & 192.240 \\
\hline
\end{tabular}

Figures 4.6 to 4.9 show the relationship between the fibre volume content $\%$ and the first-crack stress $\left(\sigma_{c}\right)$, post-cracking peak stress $\left({ }^{\sigma_{p c}}\right)$, stress at net deflection values $(\mathrm{L} / 600)\left({ }^{\sigma_{600}}\right)$, and stress at net deflection values $(\mathrm{L} / 150)\left({ }^{\sigma_{150}}\right)$. It can be noted that the bending stress after first crack increased to a peak point then followed by gradual dropping in strength after this peak point.

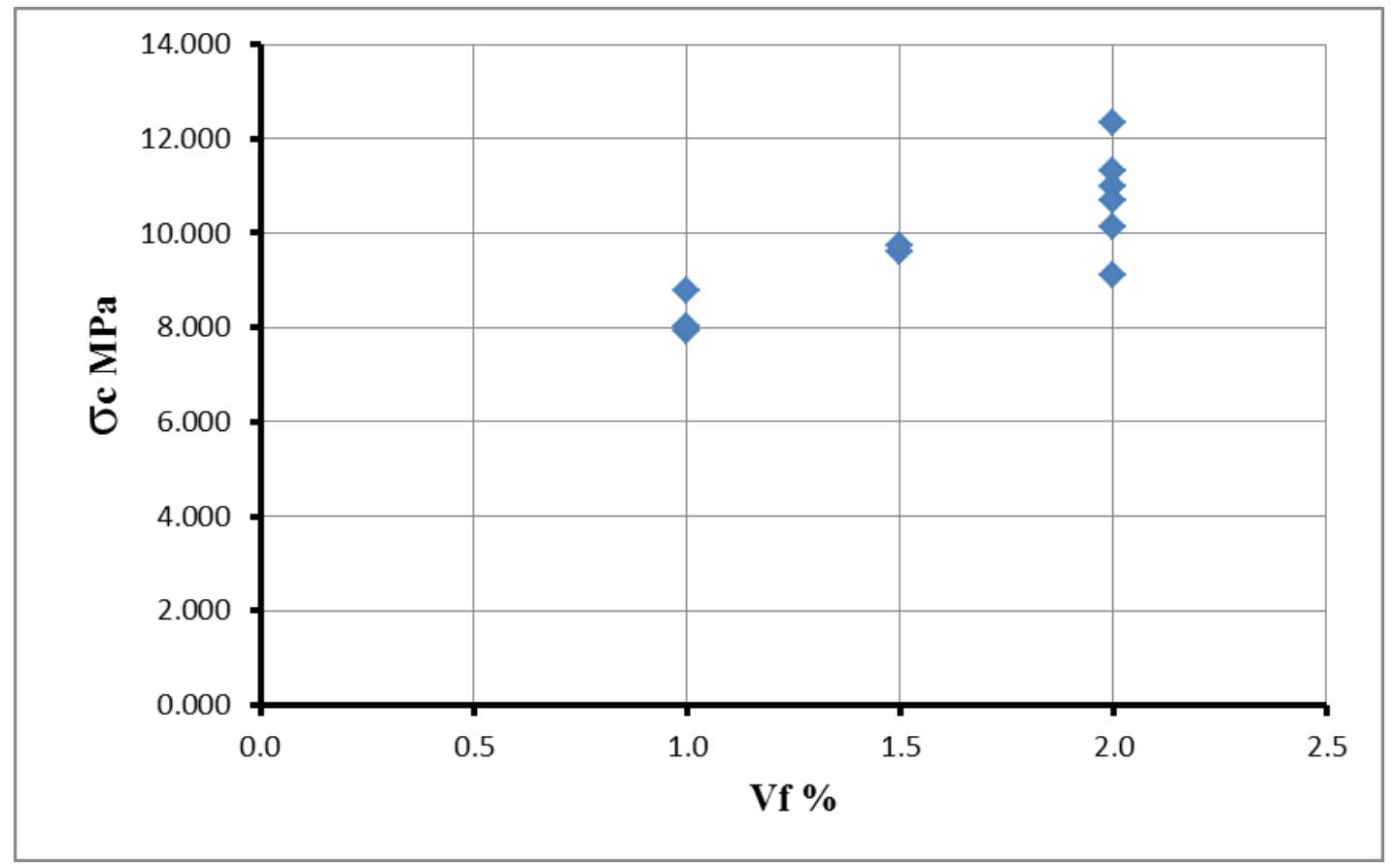

Figure 4.6 First-crack stress relationship with fibre volume content $\%$ 


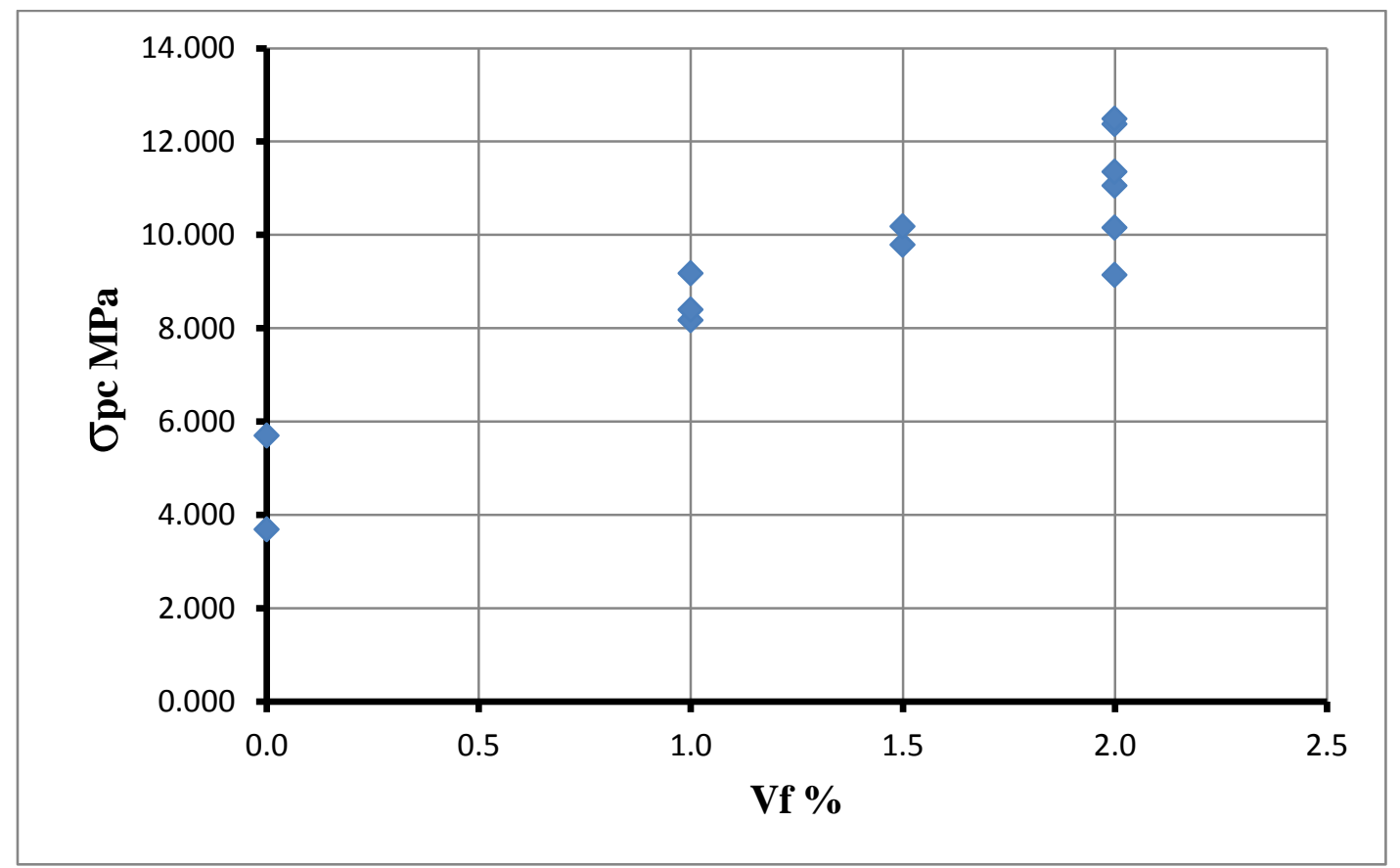

Figure 4.7 Post-cracking peak stress relationship with fibre volume content \%

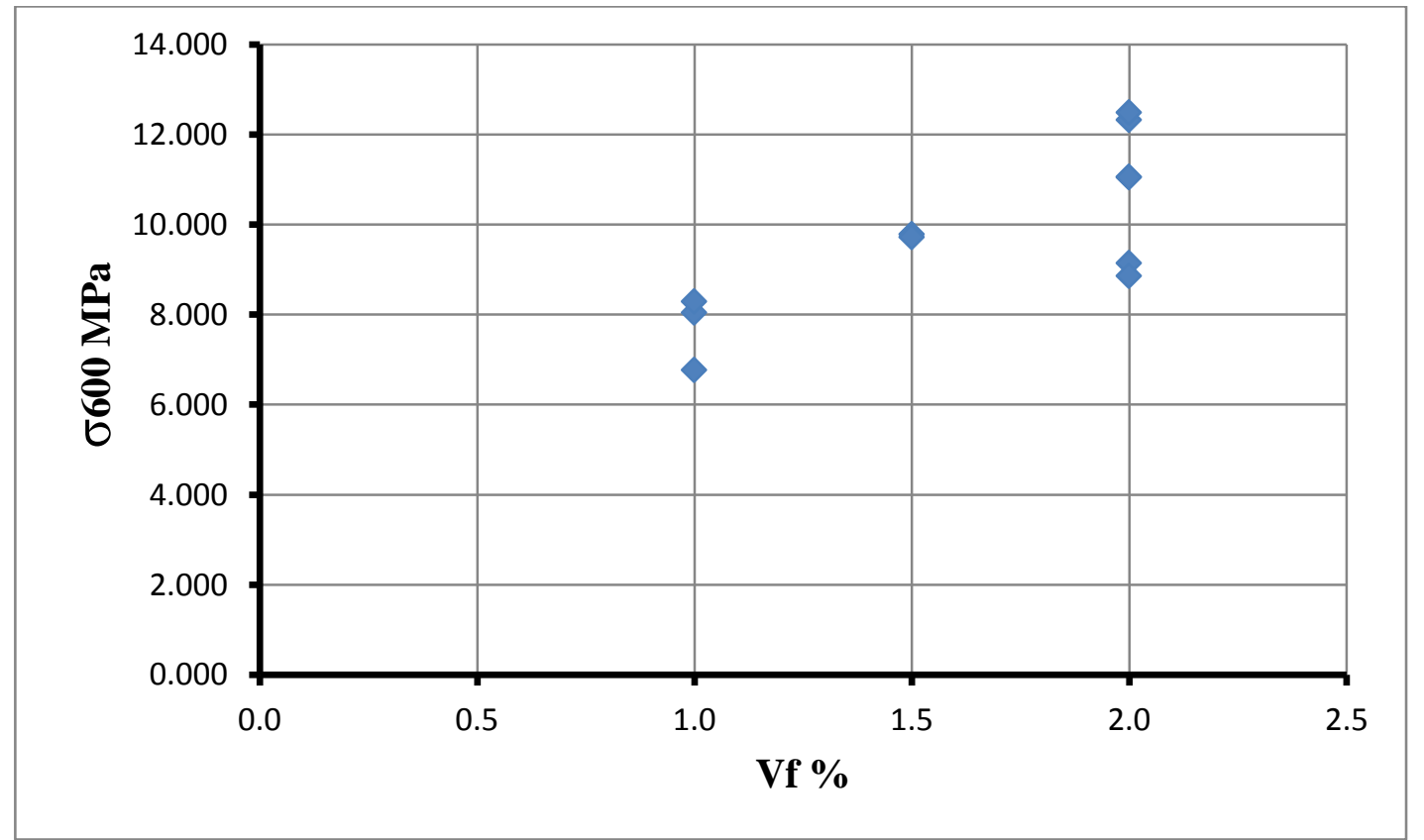

Figure 4.8 Stress at net deflection values $(\mathrm{L} / 600)$ relationship with fibre volume content \% 


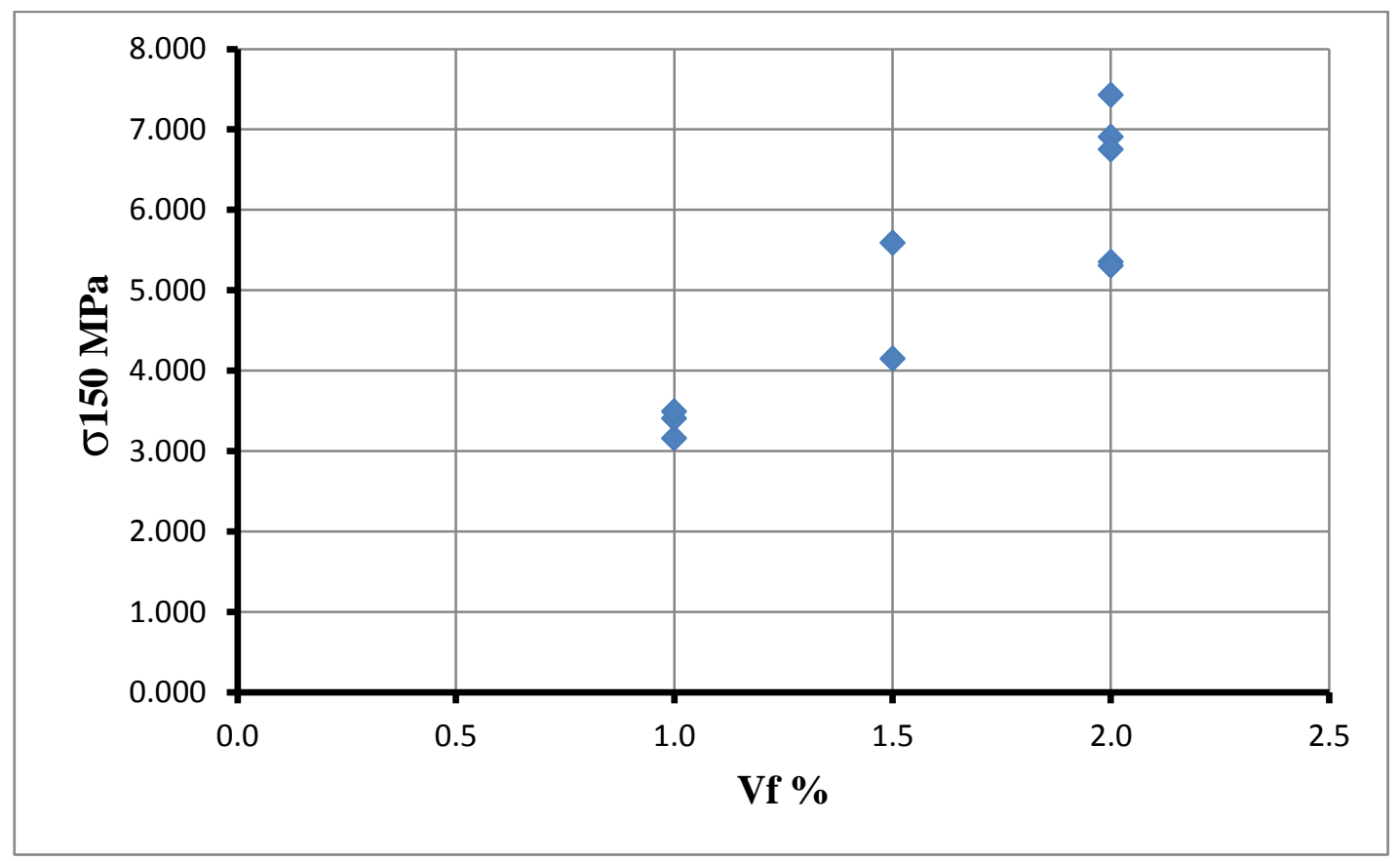

Figure 4.9 Stress at net deflection values (L/150) relationship with fibre volume content \%

\subsection{Behaviour of beam tests}

\subsubsection{Beam US1-0-3.5}

Figures 4.10 and 4.11 show the load versus central deflection relationship and crack pattern after failure respectively. Inclined cracks began to develop in the left span at the mid depth of the beam at an applied load $190 \mathrm{kN}$. As the load increased, the cracks began to propagate to the bottom surface of the beam and to the loading point simultaneously. Additional cracks developed at the shear span before the crack width increased and the beam failed at an applied load of 240 $\mathrm{kN}$. It can be seen from Fig. 4.11 that the crack propagated along the top and lower layer of the reinforcing bars at the lower end of the inclined crack. This can be attributed to lower dowel action mechanism combined with bond failure at the steel concrete interface. From Fig. 4.10, it can be seen that the central deflection increased linearly and it was proportional with the applied load up to a load of $200 \mathrm{kN}$ where the first crack developed in the left span. Beyond this point, the relationship between the load and central deflection was nonlinear. The deflection at ultimate load was $3.15 \mathrm{~mm}$ and the maximum deflection of the beam was $4.79 \mathrm{~mm}$. 


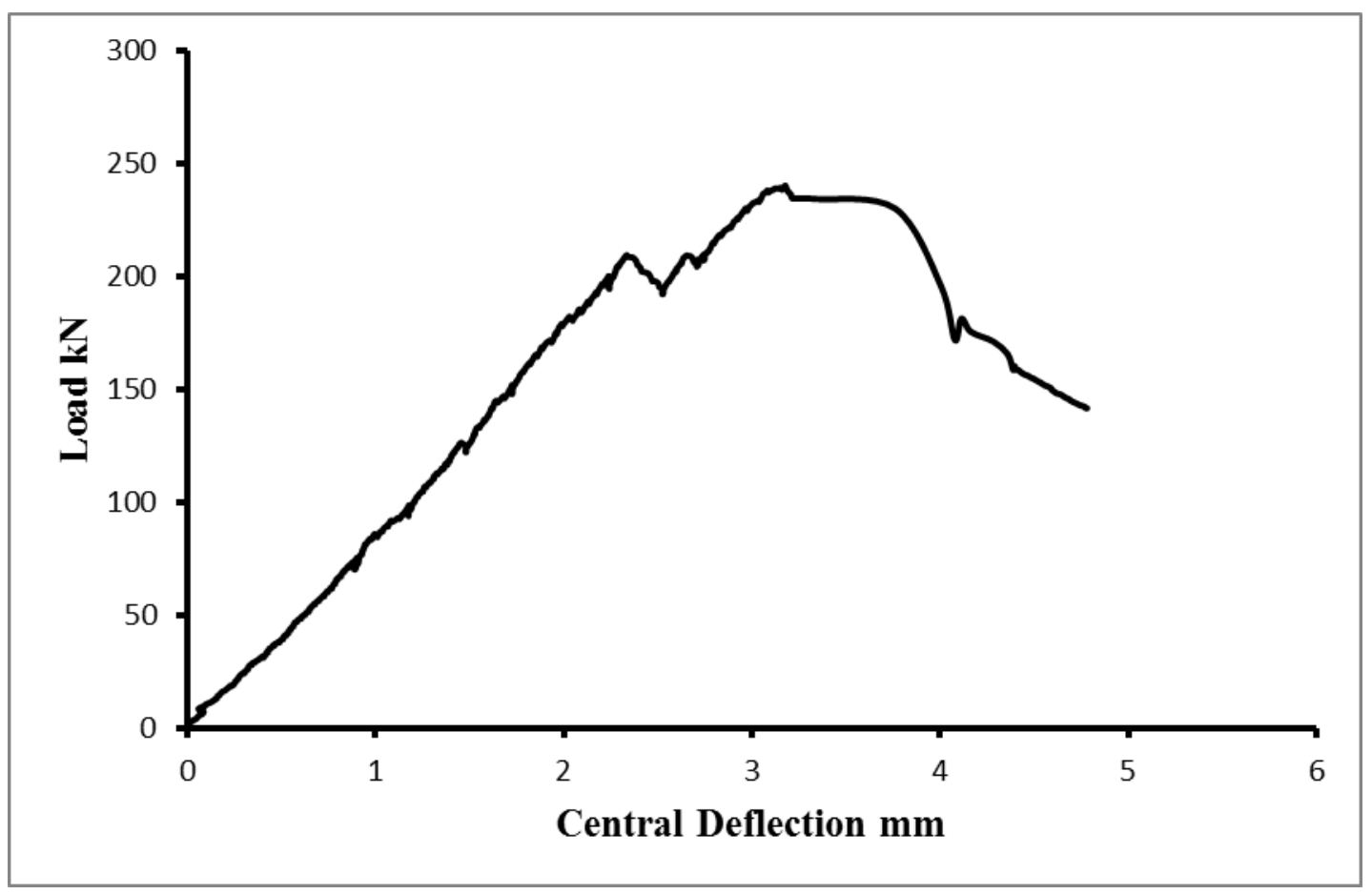

Figure 4.10 Load versus central deflection relationship - Beam US1-0-3.5

Fig. 4.12 shows the load versus the reinforcement strain relationship for beam US1-0-3.5. It can be noted from Fig. 4.12 that the strains at S2 and S3 gauges were very small up to the load at first diagonal crack $(190 \mathrm{kN})$. Then the strains at these gauges started to increase due to the inclined cracks that developed in the vicinity of the gauges. At the peak load the strain at S1 through S8 were still in the linear range of the reinforcement stress-strain curve.

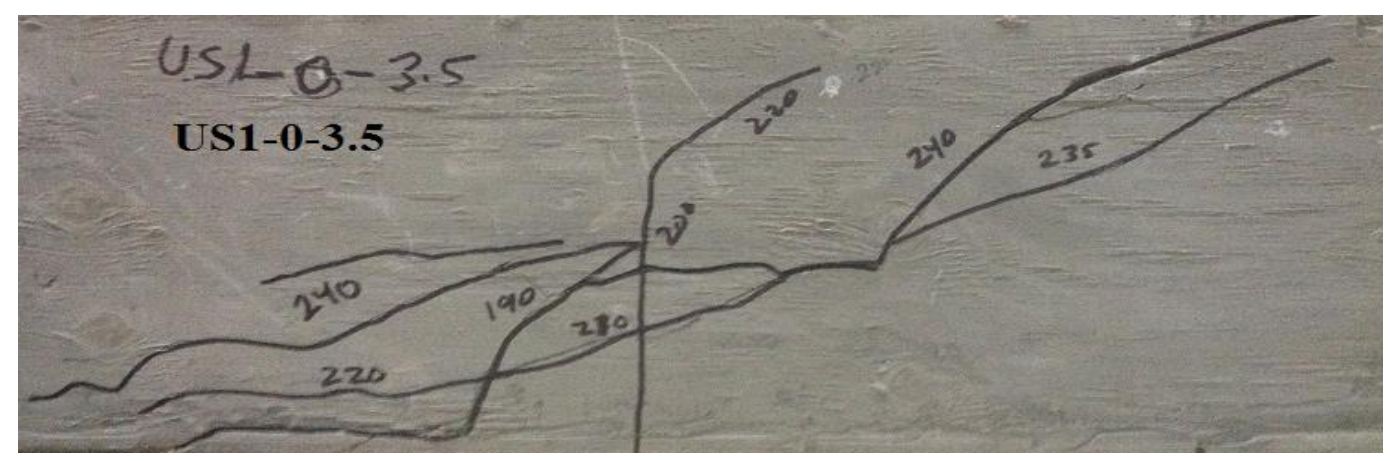

Figure 4.11 Crack pattern after failure - Beam US1-0-3.5 


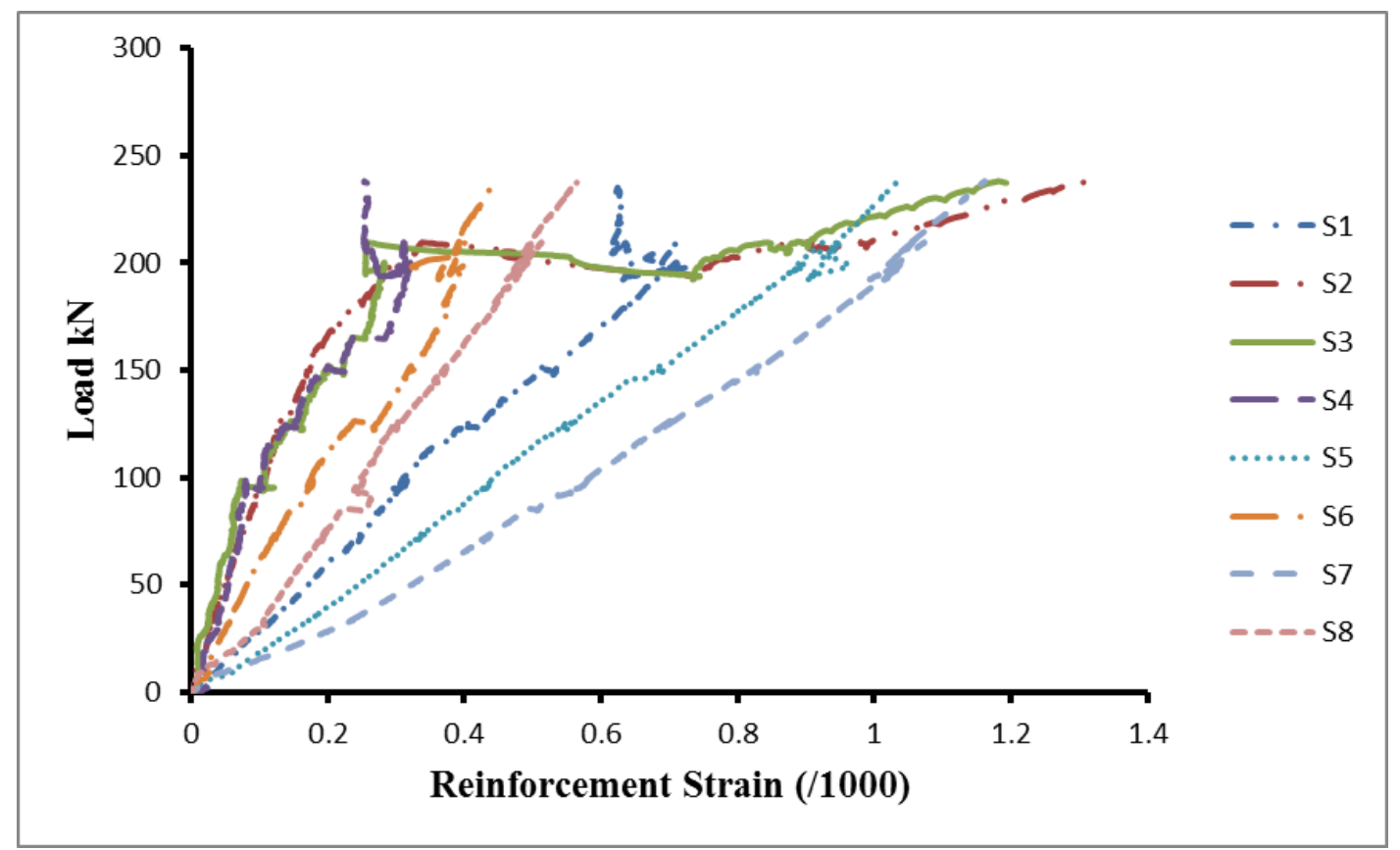

Figure 4.12 Load versus reinforcement strain - Beam US1-0-3.5

\subsubsection{Beam US1-1-3.5}

Figures 4.13 and 4.14 show the load versus deflection relationship and crack pattern after failure respectively. Flexural cracks began to develop from the bottom surface of the beam in the region below the loading point at applied load $430 \mathrm{kN}$. As the applied load increased to $600 \mathrm{kN}$, another cracks developed in the mid depth of the beam below the loading point where the maximum moment occurred. At the same time, cracks at bottom surface of the beam developed below the loading point. As the applied load increased to $667 \mathrm{kN}$, these cracks were connected together and the beam failed as shown in Fig. 4.14. It can be noted from Fig. 4.13 that the central deflection increased linearly with the applied load up to a load of $560 \mathrm{kN}$ even after the initiation of the first flexural crack. The addition of steel fibres significantly increased the ductility of the UHPC beams as shown in Fig. 4.13. The deflection at the ultimate load was $10.559 \mathrm{~mm}$ and the maximum deflection at failure was $14.418 \mathrm{~mm}$. 


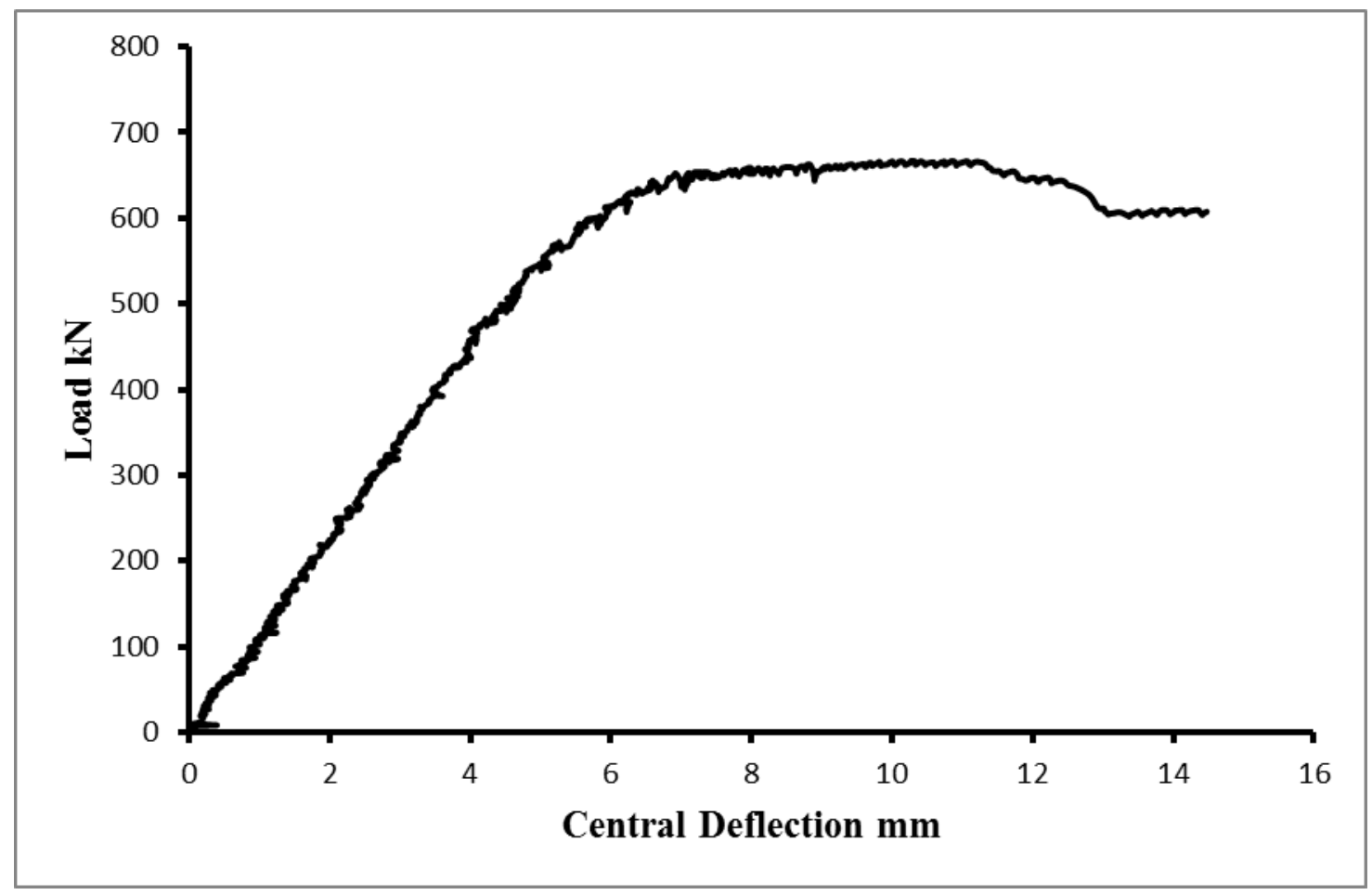

Figure 4.13 Load versus central deflection relationship - Beam US1-1-3.5

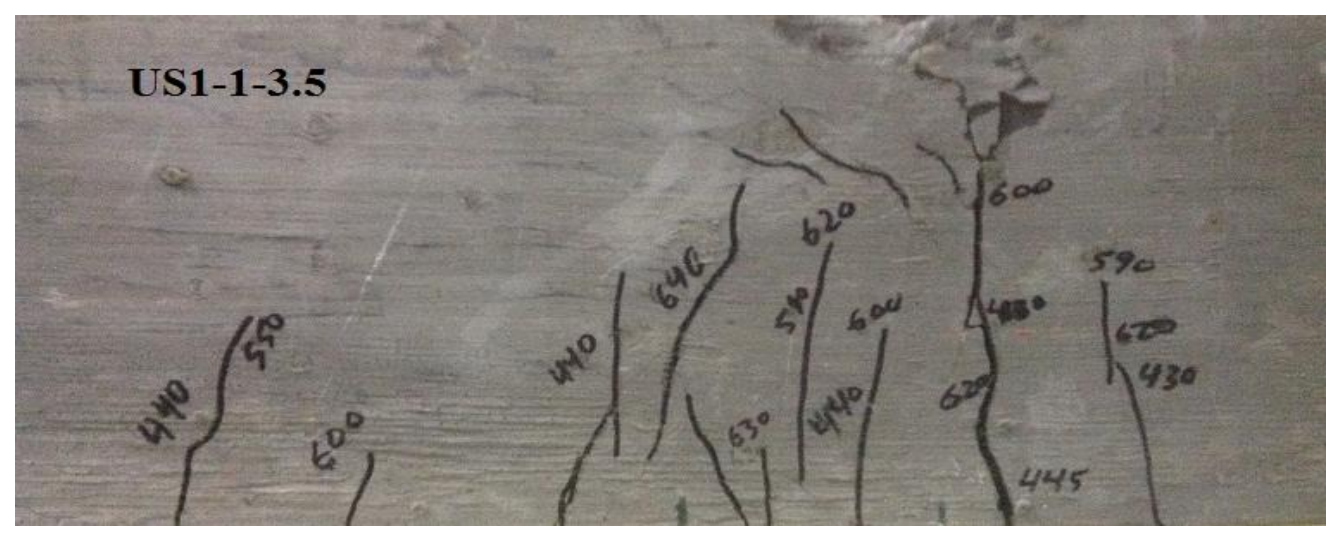

Figure 4.14 Crack pattern after failure - Beam US1-1-3.5

Fig. 4.15 shows the load versus the reinforcement strain relationship for beam US1-1-3.5. It can be noted from Fig. 4.15 that the strain gauge S8 was very small up to $520 \mathrm{kN}$ load, then the flexural cracks started to propagate toward the loading point while the strains at S1, S2 and S3 gauges were very small due to the fact that no cracks were developed at the region close the left support. The strains at most of the gauges were proportionally linear up to a load which depends 
of the location of the strain gauges then the strains at these gauges started to increase rapidly due to the cracks that developed in the vicinity of the gauges. The lower layer reinforcing steel bar yielded at S7, S5, and S8 at an applied load 440, 530, $617 \mathrm{kN}$ respectively.

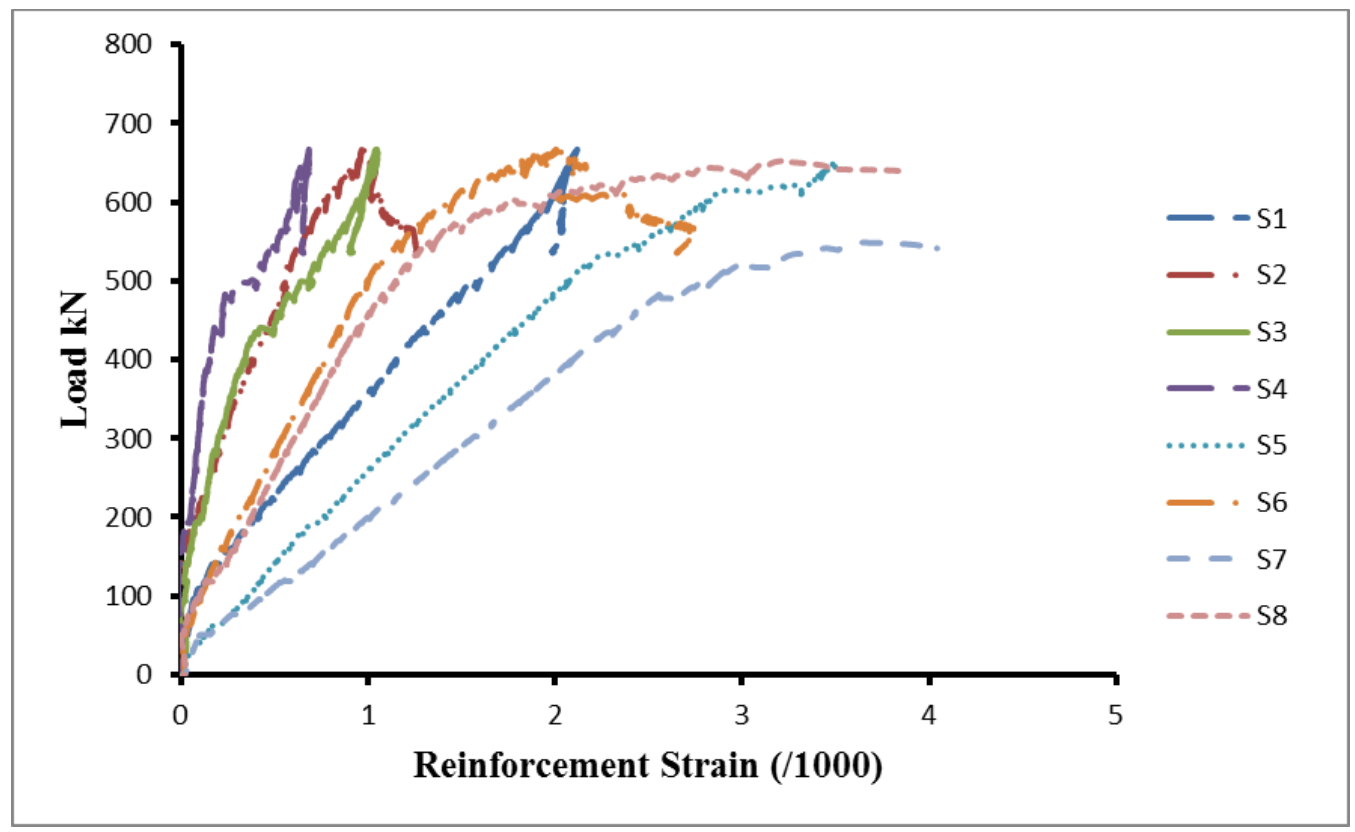

Figure 4.15 Load versus reinforcement strain - Beam US1-1-3.5

\subsubsection{Beam US1-2-3.5}

Figures 4.16 and 4.17 show the load versus deflection relationship and crack pattern after failure respectively. Flexural cracks started to develop from the bottom surface of the beam in the region below the loading point at applied load $650 \mathrm{kN}$. As the applied load increased to $690 \mathrm{kN}$, another cracks developed, below the loading point where the maximum moment occurred. As the applied load increased to $724 \mathrm{kN}$, the crack width increased and the beam failed as shown in Fig. 4.17. It can be noted from Fig. 4.16 that the central deflection at the ultimate load was $8.78 \mathrm{~mm}$ and the maximum deflection at failure, was $10.05 \mathrm{~mm}$. It can be noted from Fig. 4.18 that the central deflection increased linearly with the applied load up to a load of $600 \mathrm{kN}$ where the flexural cracks started to propagate to the loading point. 


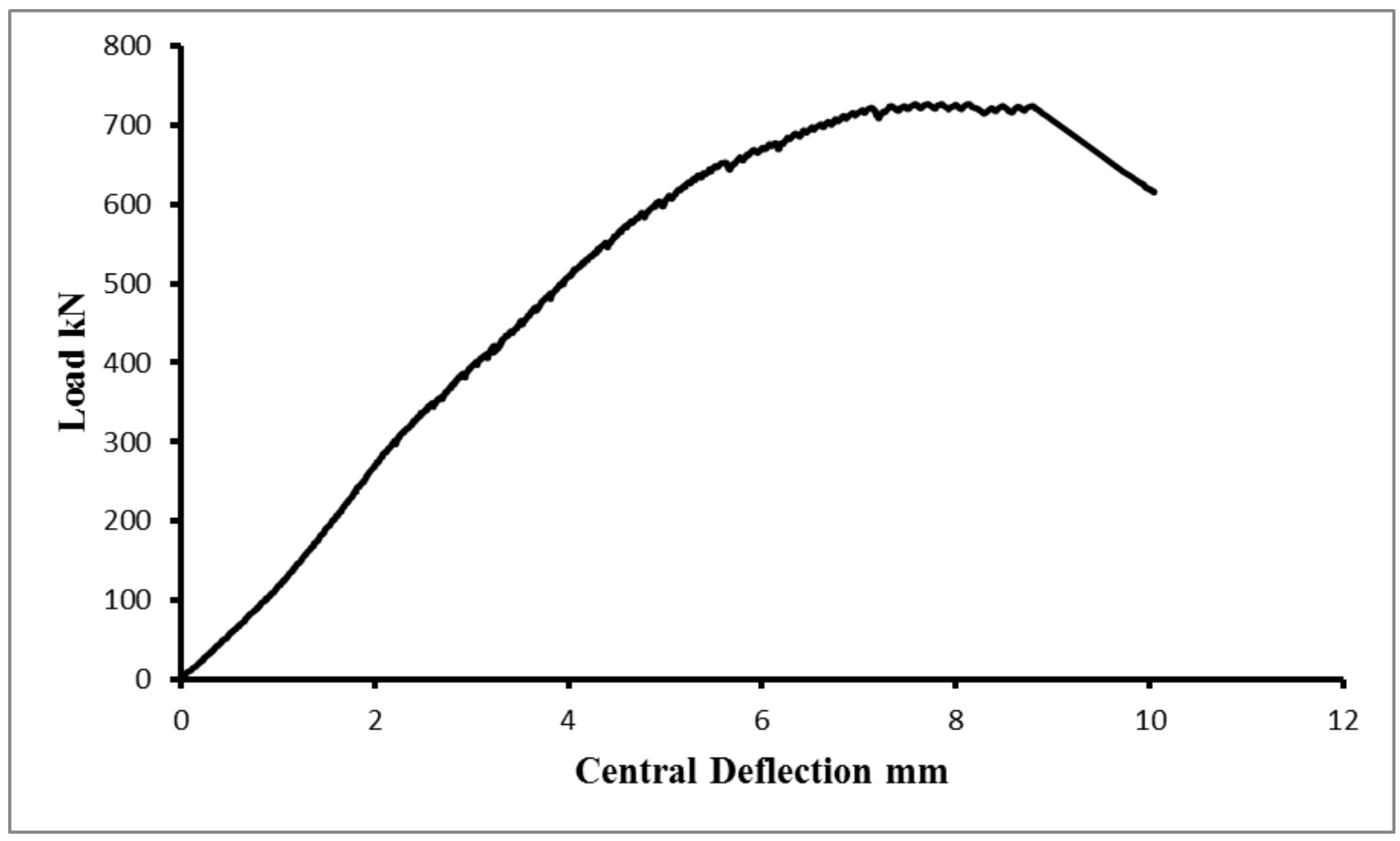

Figure 4.16 Load versus central deflection relationship - Beam US1-2-3.5

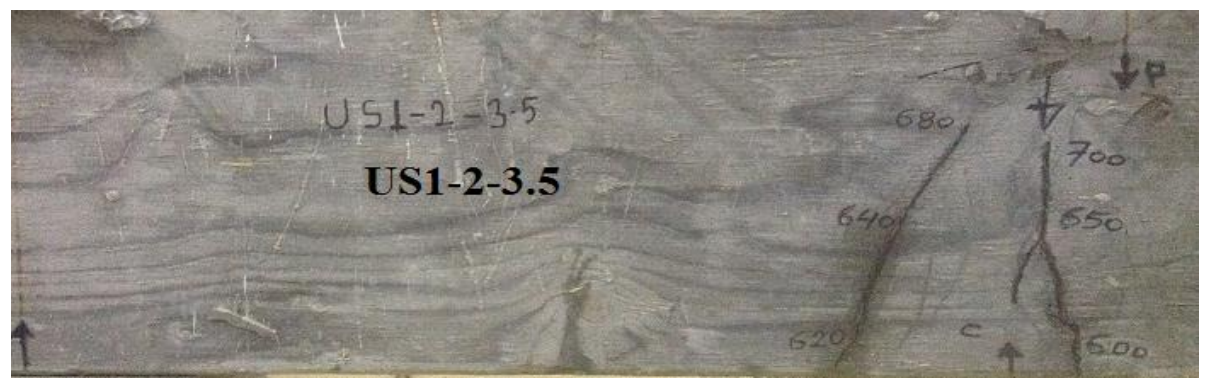

Figure 4.17 Crack pattern after failure - Beam US1-2-3.5

Fig. 4.18 shows the load versus the reinforcement strain relationship for beam US1-2-3.5. It can be noted from Fig. 4.18 that the strain at S3, S7 and S8 were increased linearly with the applied load increased. The upper layer of steel reinforcing bar was yielded at S8 at an applied load 640 $\mathrm{kN}$. At this applied load $(640 \mathrm{kN})$, the flexural crack started to propagate upward in this region. The lower layer reinforcing bar yielded at S5 at an applied load $700 \mathrm{kN}$. Strain gauges S5, and 
S6 were unstable beyond $700 \mathrm{kN}$ applied load. In addition, the strain gauge S2 was defective at the beginning of the test.

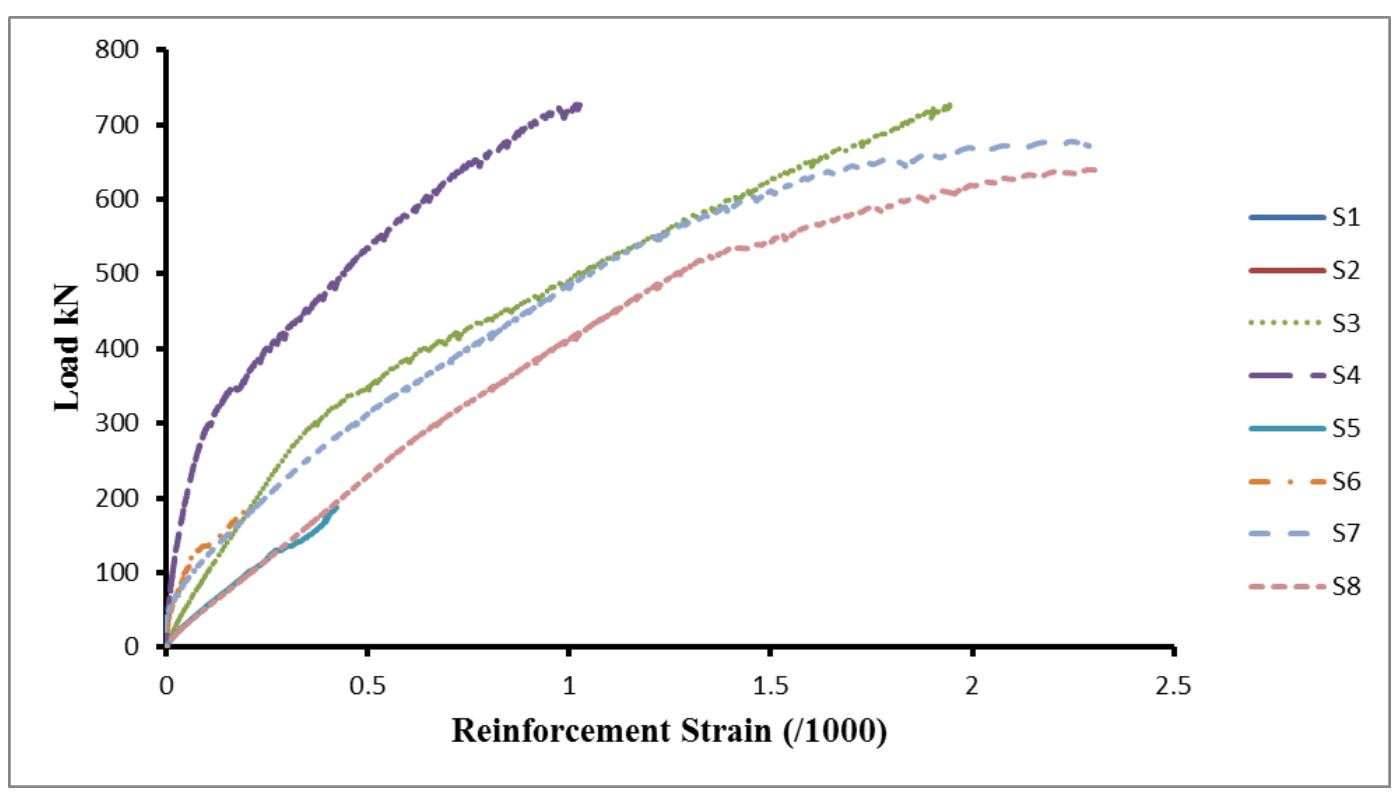

Figure 4.18 Load versus reinforcement strain - Beam US1-2-3.5

\subsubsection{Beam US1-2-2.0}

The load versus central deflection relationship and crack pattern after failure are shown in Figures 4.19 and 4.20 respectively. Flexural cracks started to develop from the bottom surface of the beam in the region below the loading point at applied load $550 \mathrm{kN}$. As the applied load increased to $600 \mathrm{kN}$, the crack started to propagate upward. Then the crack width increased with increasing the applied load. Another cracks to the right of the loading point developed at an applied load of $750 \mathrm{kN}$ and the beam failed at an applied load $780 \mathrm{kN}$. It can be seen from Fig. 4.20 that only one single major flexural crack developed, below the loading point where the maximum moment occurred. It can be seen from Fig. 4.19 that the central deflection at the ultimate load was $6.15 \mathrm{~mm}$ and the maximum deflection at failure, was $9.27 \mathrm{~mm}$. 


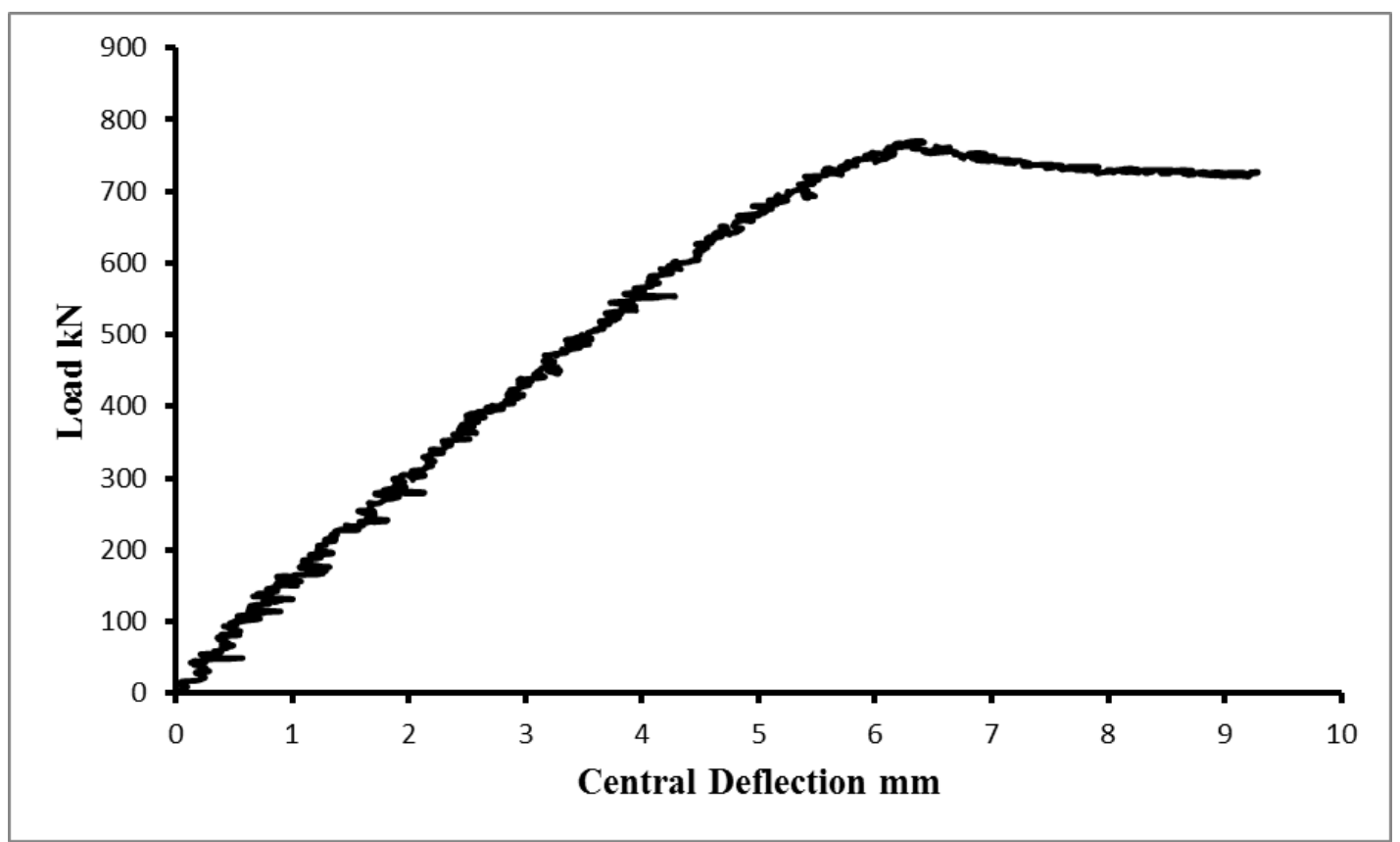

Figure 4.19 Load versus central deflection relationship - Beam US1-2-2.0

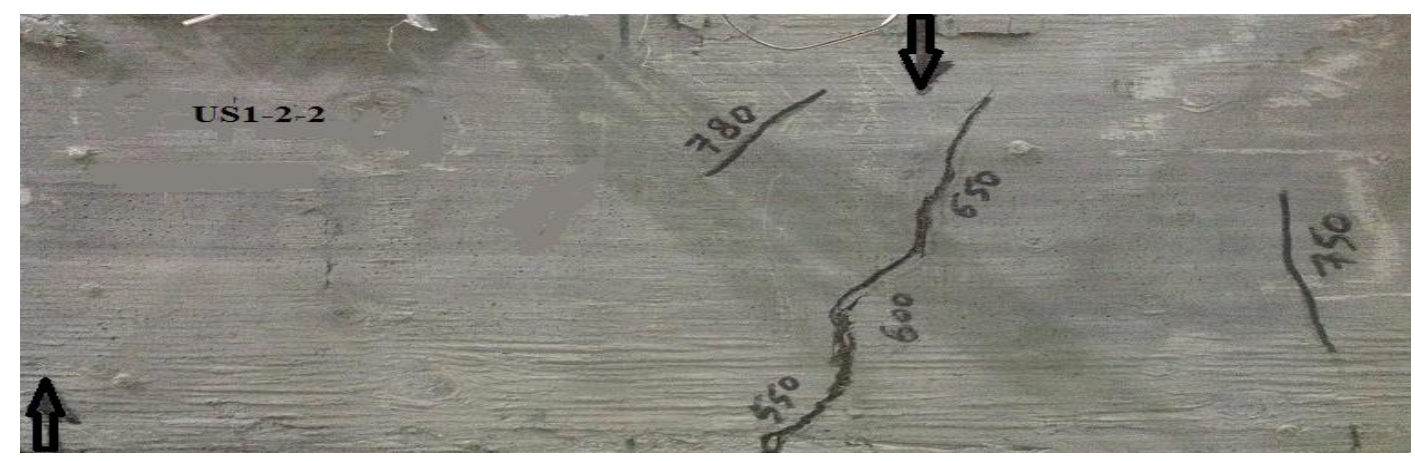

Figure 4.20 Crack pattern after failure - Beam US1-2-2.0

Fig. 4.21 shows the load versus the reinforcement strain relationship for beam US1-2-2.0. The strains at most of the gauges were proportionally linear with the applied load. The strain gauges $\mathrm{S} 1$ and S5 were higher than S7 due to the crack that developed in the vicinity of the gauges. The reinforcing steel bar yielded at S5, S1, S6, and S7 with applied loads of 601, 693, 732, and 736 $\mathrm{kN}$ respectively. 


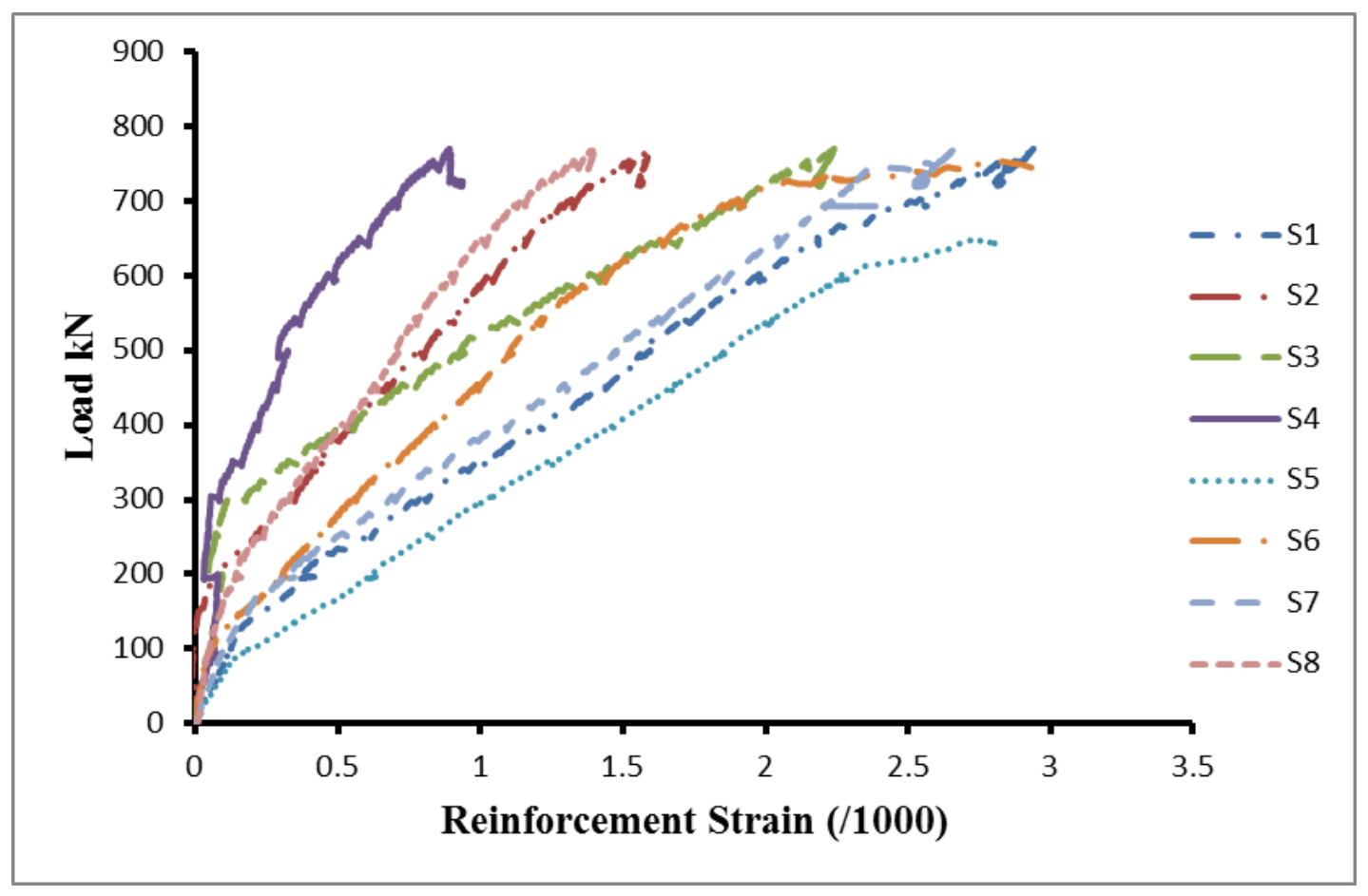

Figure 4.21 Load versus reinforcement strain - Beam US1-2-2.0

\subsubsection{Beam US1-2-1.5}

The load versus central deflection relationship and crack pattern after failure are shown in Figures 4.22 and 4.23 respectively. Flexural cracks started to develop from the bottom surface of the beam in the region below the loading point at applied load $600 \mathrm{kN}$. As the applied load increased to $680 \mathrm{kN}$, the crack started to propagate upward. Then the crack width increased with increasing the applied load to $800 \mathrm{kN}$. Another cracks started to develop at the mid depth between the support and the loading point at applied load between 780 and $820 \mathrm{kN}$. The beam failed at an applied load $882 \mathrm{kN}$. It can be seen from Fig. 4.21 that only one single major flexural crack developed, below the loading point where the maximum moment occurred. It can be noted from Fig. 4.22 that the central deflection at the ultimate load was $4.96 \mathrm{~mm}$ and the maximum deflection at failure was $7.79 \mathrm{~mm}$. In addition, the load versus central deflection was proportionally linear up to applied load $800 \mathrm{kN}$. 


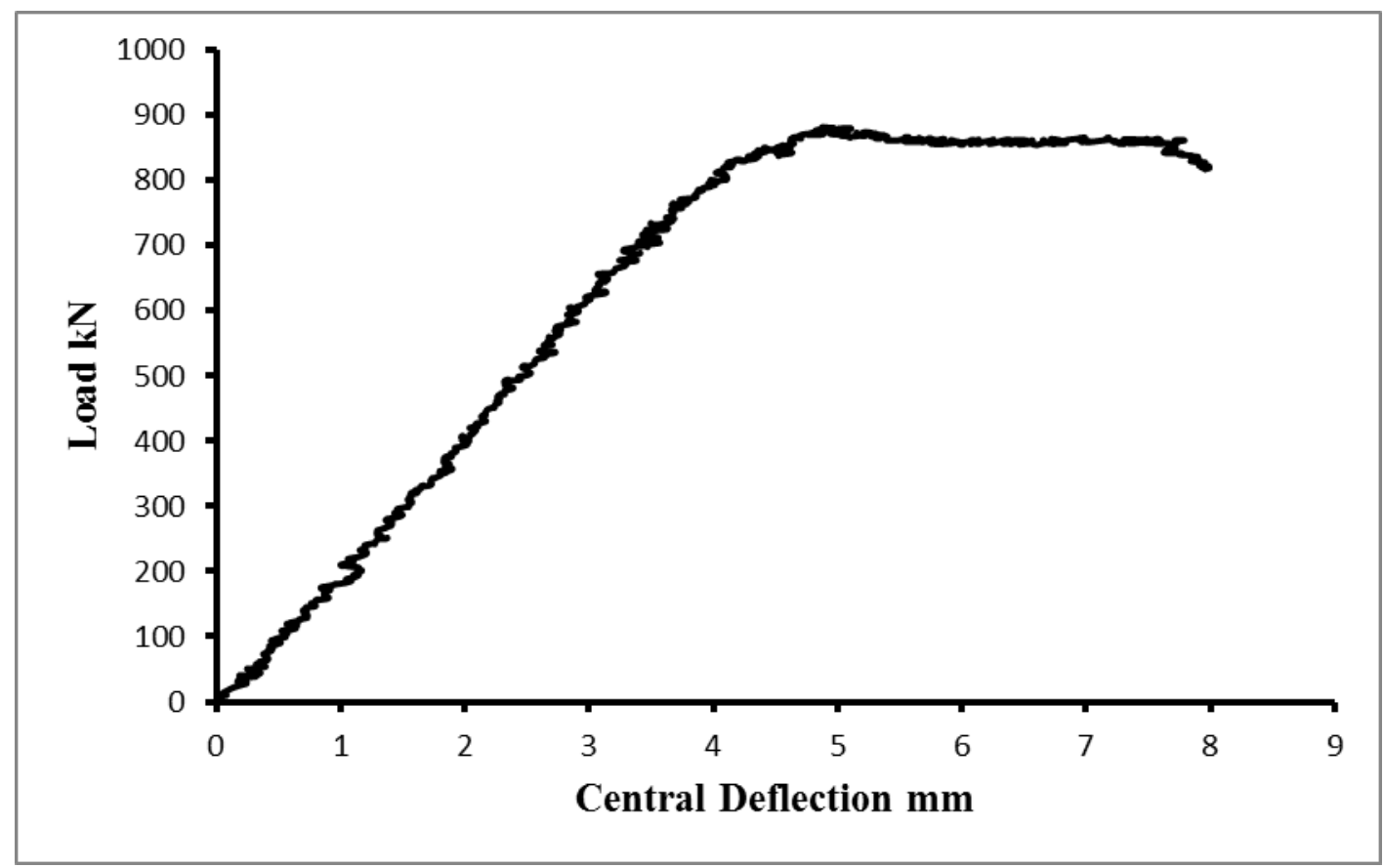

Figure 4.22 Load versus central deflection relationship - Beam US1-2-1.5

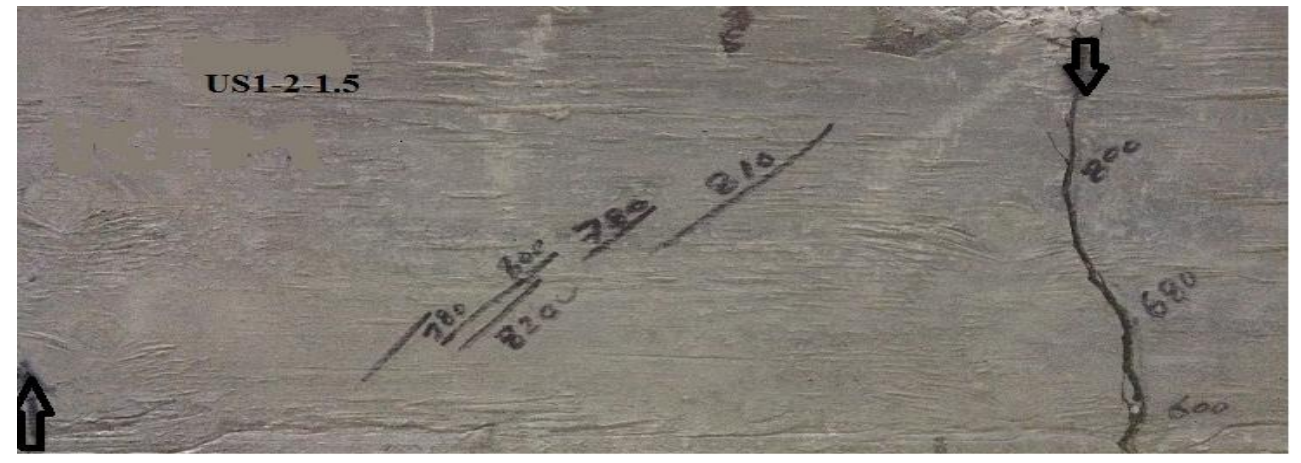

Figure 4.23 Crack pattern after failure - Beam US1-2-1.5

The load versus the reinforcement strain relationship for beam US1-2-1.5 is shown in Fig. 4.24. Most of the strain gauge readings were proportionally linear up to an applied load of $700 \mathrm{kN}$. The strain gauge S5 was higher than the others due to the crack that developed in the vicinity of the gauge. The reinforcing steel bar yielded at S5, S1, and S2 at applied loads of 775, 796 and $874 \mathrm{kN}$ respectively. 


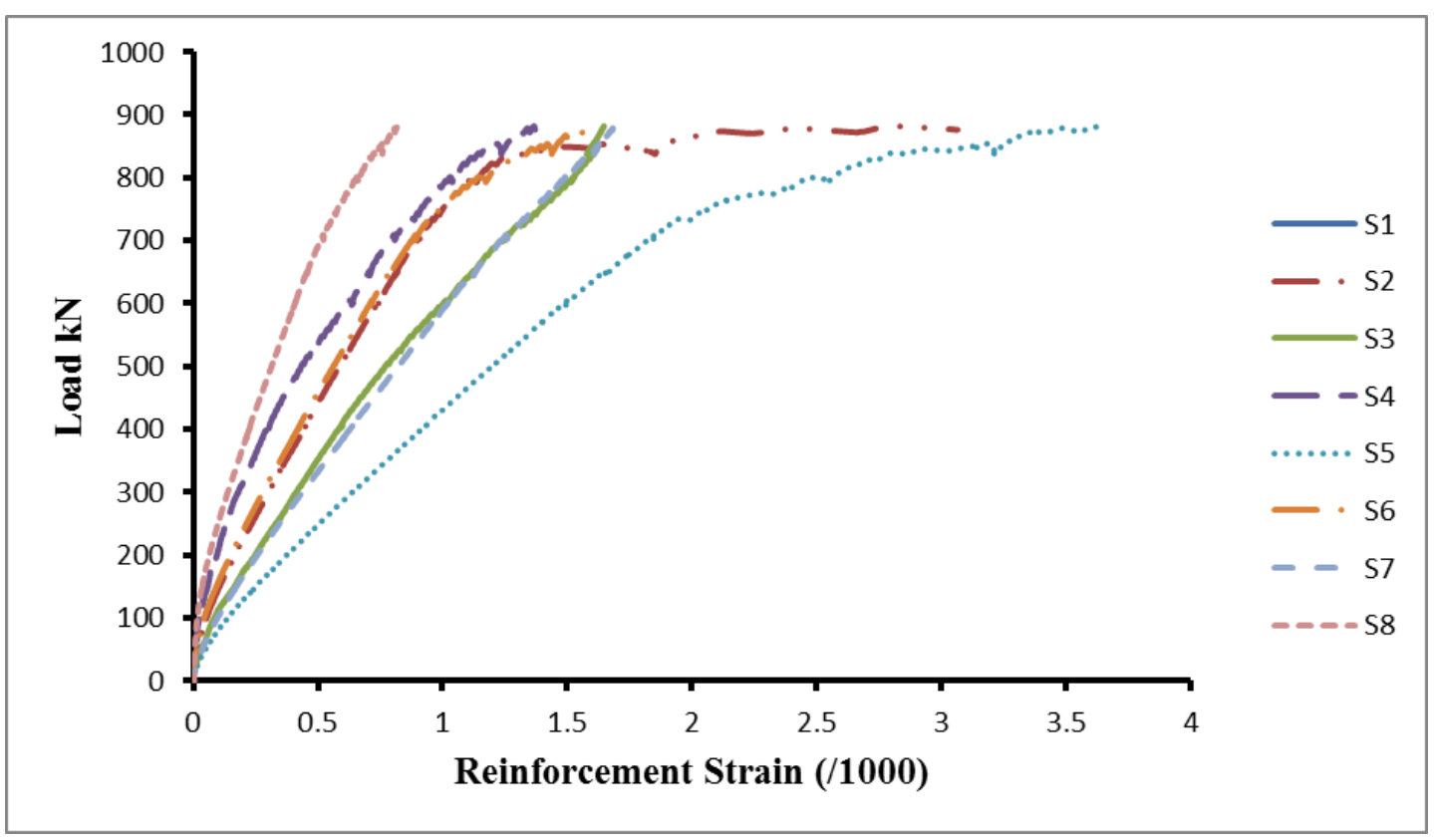

Figure 4.24 Load versus reinforcement strain - Beam US1-2-1.5

\subsubsection{Beam US2-0-3.0-a}

Figures 4.25 and 4.26 show the load versus deflection relationship and crack pattern after failure respectively. Inclined cracks started to develop in the left span at the mid depth of the beam at applied load $170 \mathrm{kN}$. As the applied load increased, another crack started to develop in the left span at load $200 \mathrm{kN}$ as shown in the Fig. 4.26. These cracks began to propagate to the bottom surface of the beam and to the loading point at the same time. The crack width increased and the beam failed in shear at applied load $284 \mathrm{kN}$. The central deflection increased linearly with applied load up to $279.42 \mathrm{kN}$ even after the cracks formed and propagated to the loading point, and to the bottom of the beam. Then a sudden drop in the deflection at load $279.42 \mathrm{kN}$ followed by increasing the load up to $284.05 \mathrm{kN}$ at which the beam failed. The maximum deflection at failure was $4.63 \mathrm{~mm}$. 


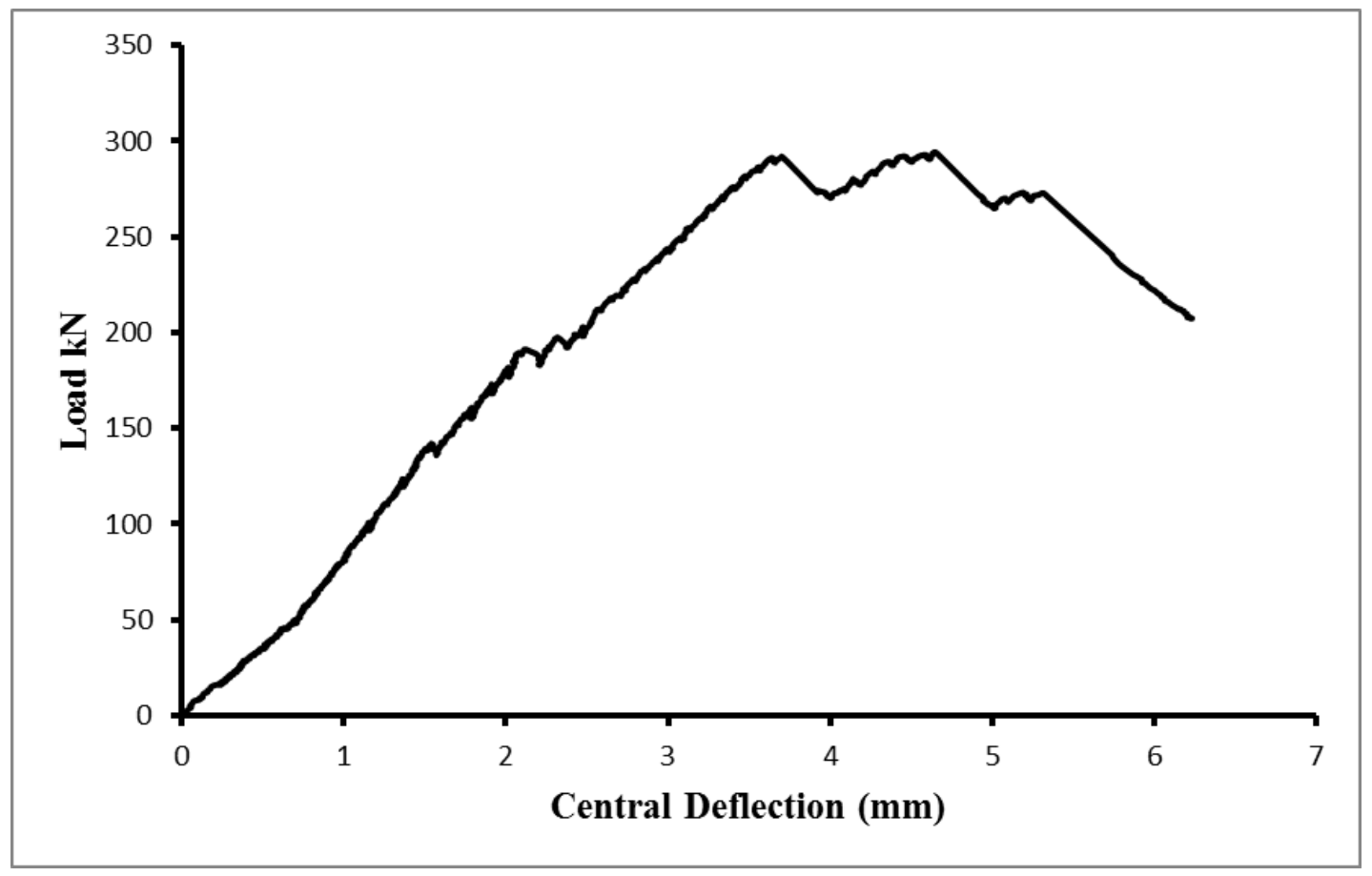

Figure 4.25 Load versus central deflection relationship - Beam US2-0-3.0-a

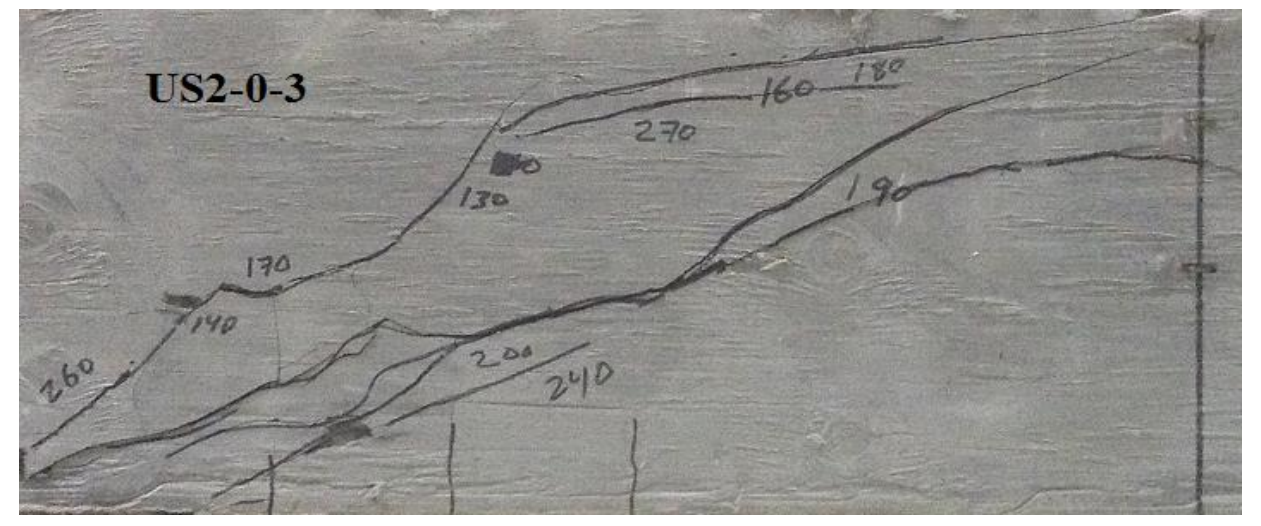

Figure 4.26 Crack pattern after failure - Beam US2-0-3.0-a

Fig. 4.27 show the load versus the reinforcement strain relationship for beam US2-0-3.0-a. Most of the strain gauges readings were proportionally linear up to an applied load of $280 \mathrm{kN}$. The strain gauge S1 significantly increased at an applied load of $195 \mathrm{kN}$ due to the inclined crack that developed in the vicinity of the gauge. It can be observed from Fig. 4.27 that the reinforcing steel 
bar did not reach the yield point at all gauges. In addition, the reading of strain gauge $\mathrm{C} 3$, which is at the mid-depth of the beam, was almost zero. This indicates that the neutral axis was at the mid depth of the beam.

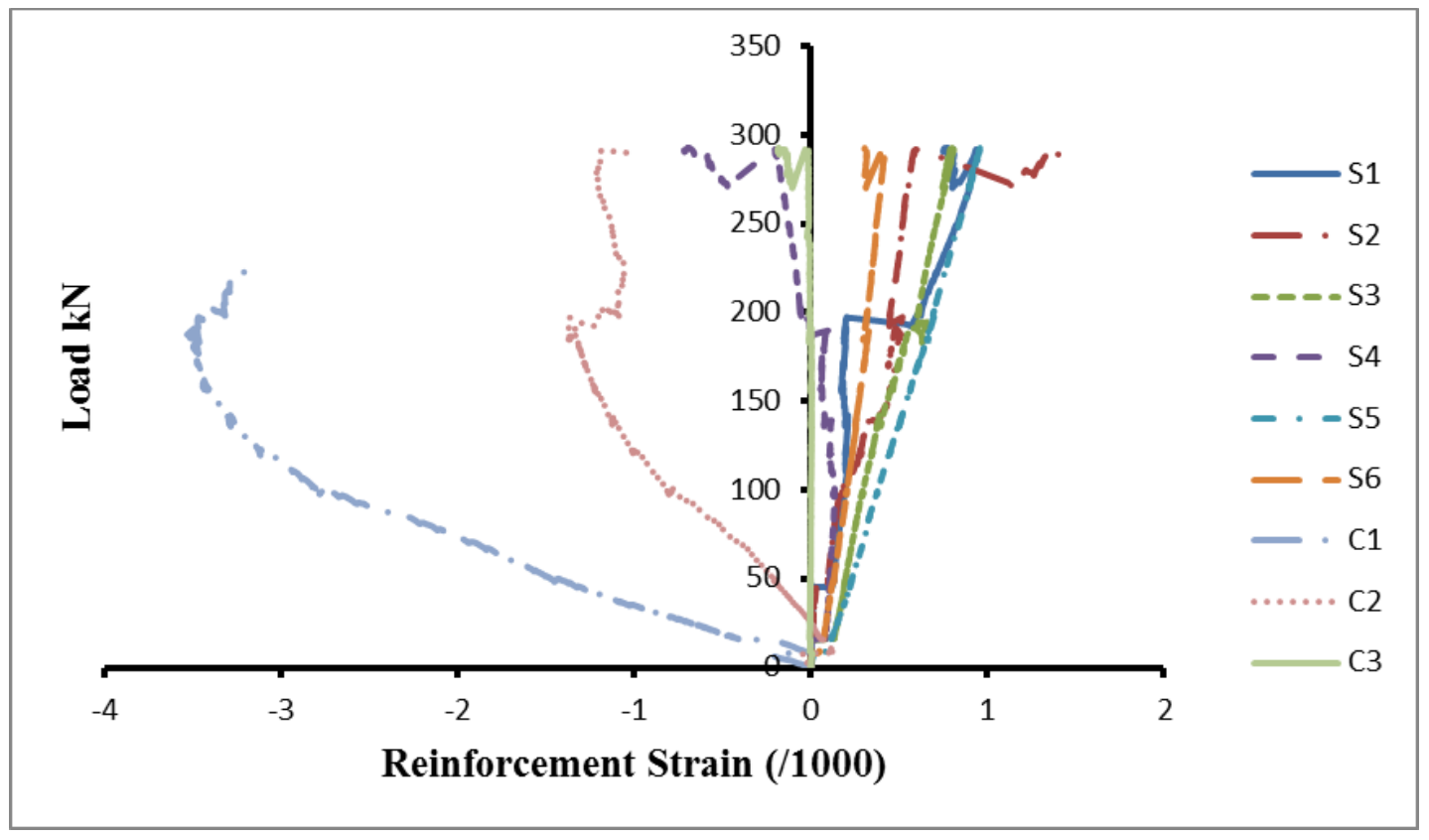

Figure 4.27 Load versus reinforcement strain - Beam US2-0-3.0-a

\subsubsection{Beam US2-0-3.0-b}

The behaviour of beam US2-0-3.0-b was similar to beam US2-0-3.0-a as shown in Figures 4.28 and 4.29. The beam failed at an applied load $294.5 \mathrm{kN}$. The load versus the reinforcement strain relationship for beam US2-0-3.0-b is shown in Fig. 4.30. It can noted that the strain gauge S2 significantly started to increase at applied load $100 \mathrm{kN}$ due to the inclined cracks that formed in the vicinity of the gauge, and the steel bar yielded at an applied load of $256 \mathrm{kN}$. 


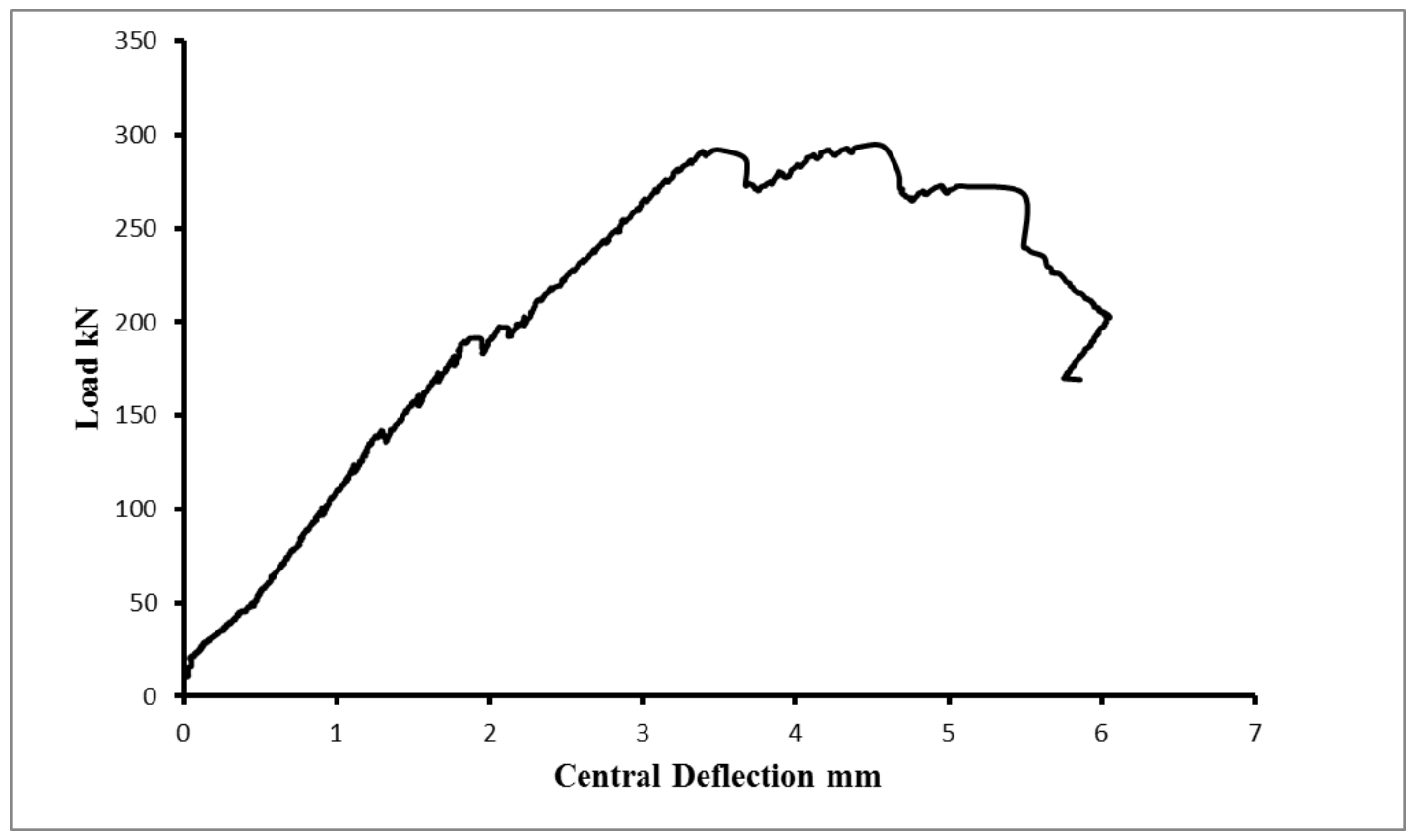

Figure 4.28 Load versus central deflection relationship - Beam US2-0-3.0-b

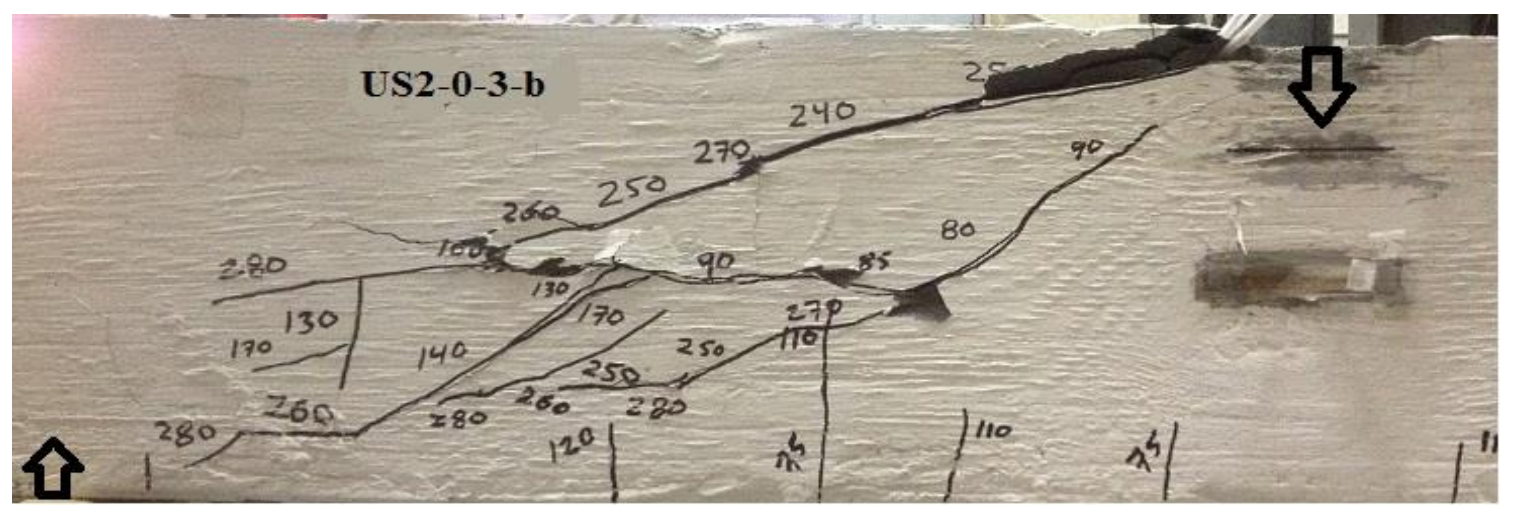

Figure 4.29 Crack pattern after failure - Beam US2-0-3.0-b 


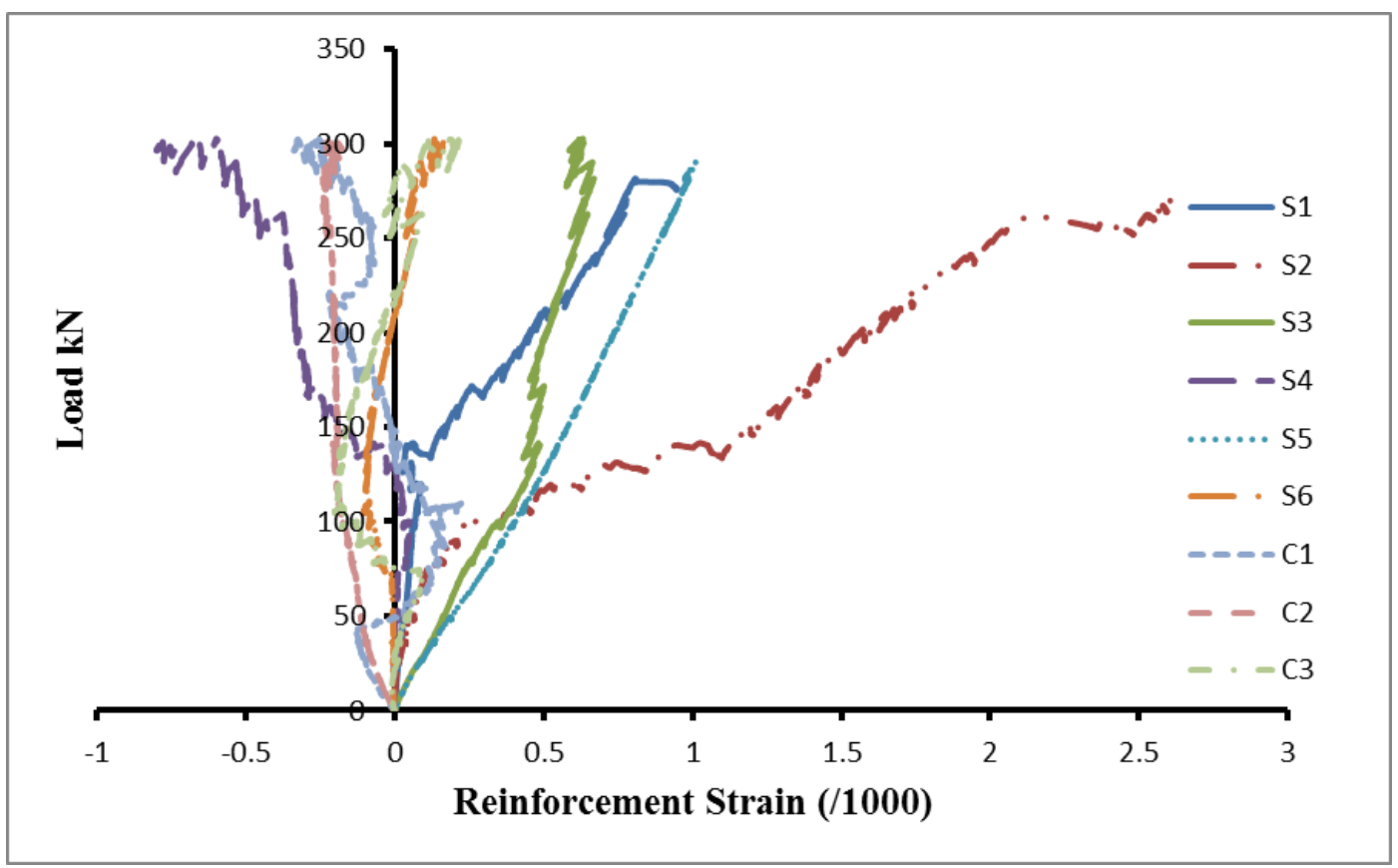

Figure 4.30 Load versus reinforcement strain - Beam US2-0-3.0-b

\subsubsection{Beam US2-1-3.0}

The load versus deflection relationship and crack pattern after failure are shown in Figures 4.31 and 4.32 respectively. Diagonal tension crack started to develop in the left span at the mid depth of the beam at applied load $580 \mathrm{kN}$. This crack started to propagate to the loading point, and to the bottom of the beam as the applied load increased to $650 \mathrm{kN}$. At the same time, another crack started to develop at the mid depth of the beam, and to the right of first crack. These cracks connected together at applied load $680 \mathrm{kN}$. The crack width started to increase as the applied load increased until the beam failed in shear at applied load $789.72 \mathrm{kN}$ as shown in Fig. 4.32. The load versus deflection relationship was almost linear up to an applied load of $680 \mathrm{kN}$. However, when the width of shear cracks started to increase, the load versus deflection relationship became nonlinear. The maximum deflection at failure was $8.22 \mathrm{~mm}$. 


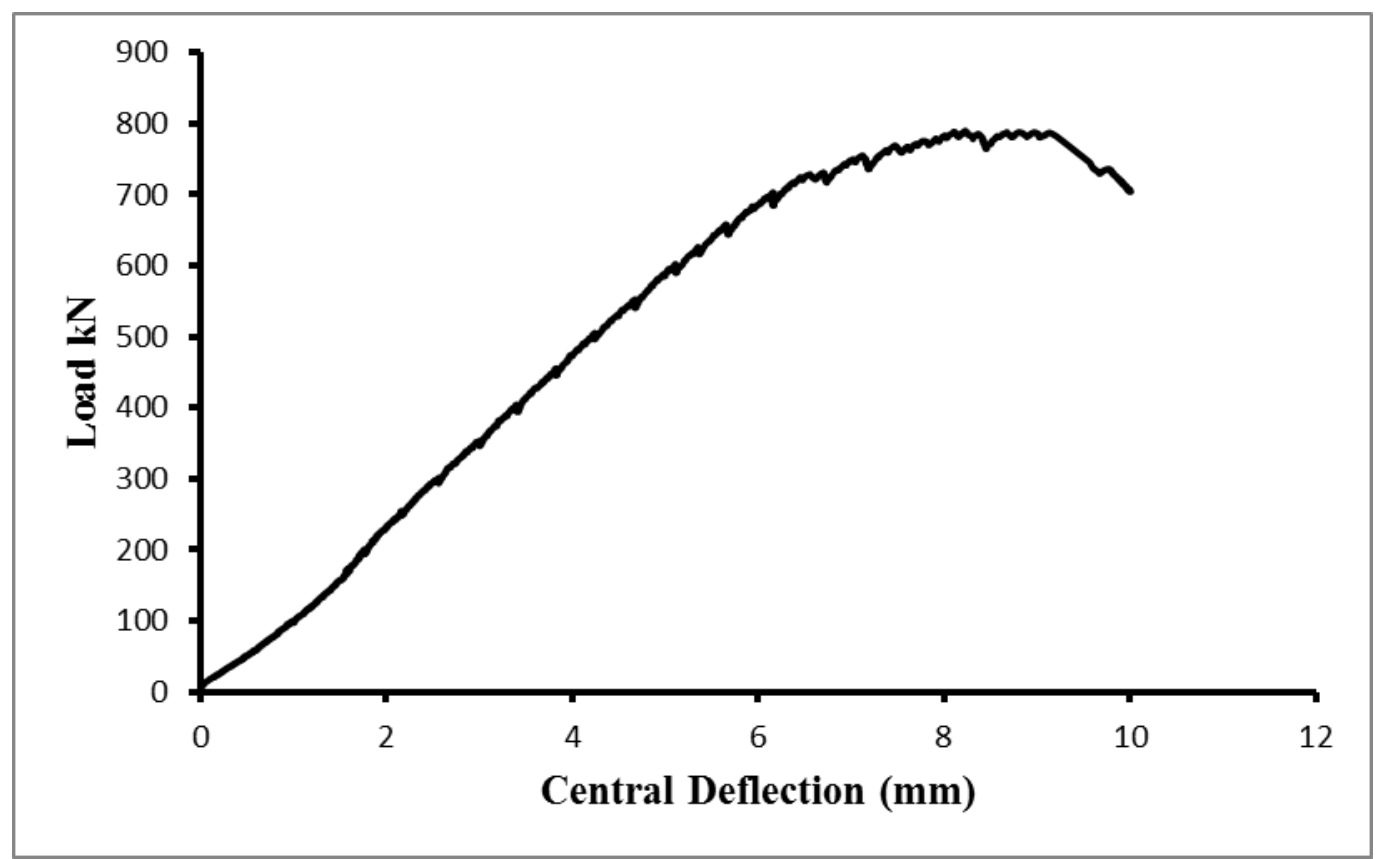

Figure 4.31 Load versus central deflection relationship - Beam US2-1-3.0

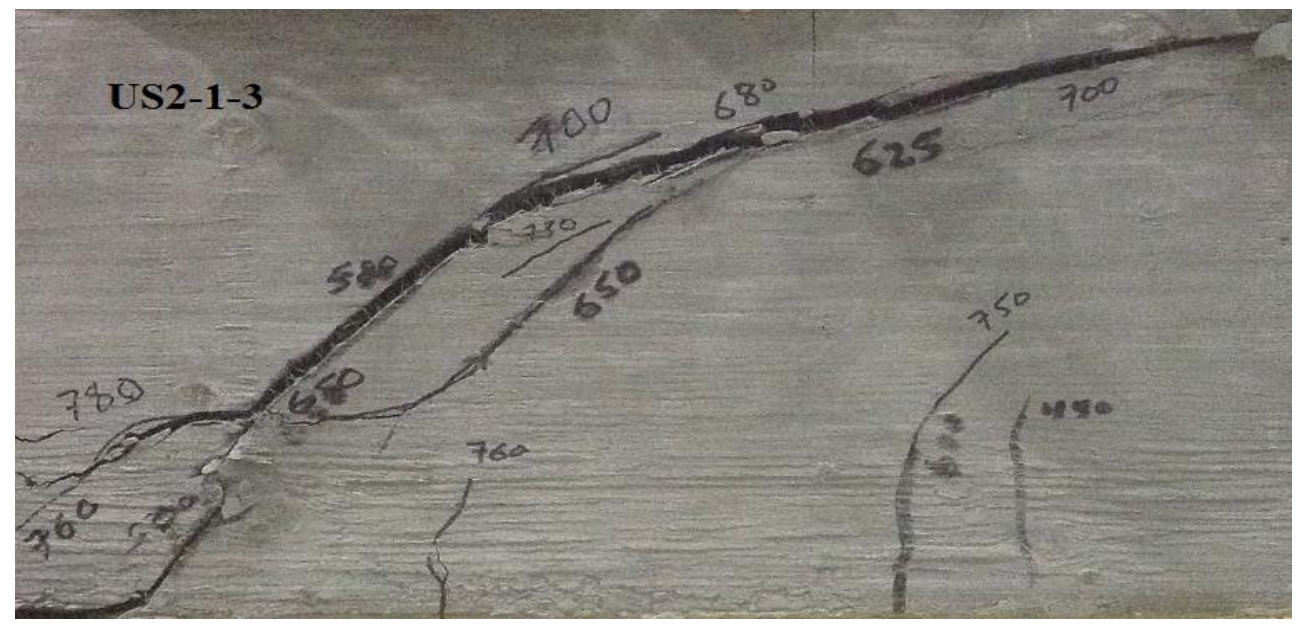

Figure 4.32 Crack pattern after failure - Beam US2-1-3.0

The load versus the reinforcement strain relationship for beam US2-1-3.0 is shown in Figure 4.33. Similarly to previous beams, the strains at most of the gauges were proportionally linear up to an applied load of $680 \mathrm{kN}$. The strain gauges S5 and S6 reached the yield point at applied load 679 and $735 \mathrm{kN}$ respectively. The strain gauge $\mathrm{C} 1$ was lower than $\mathrm{C} 2$ due to the crushing of the 
concrete surface at $\mathrm{C} 1$. Therefore, the reading of $\mathrm{C} 1$ was not reflecting the actual concrete strain and was disregarded.

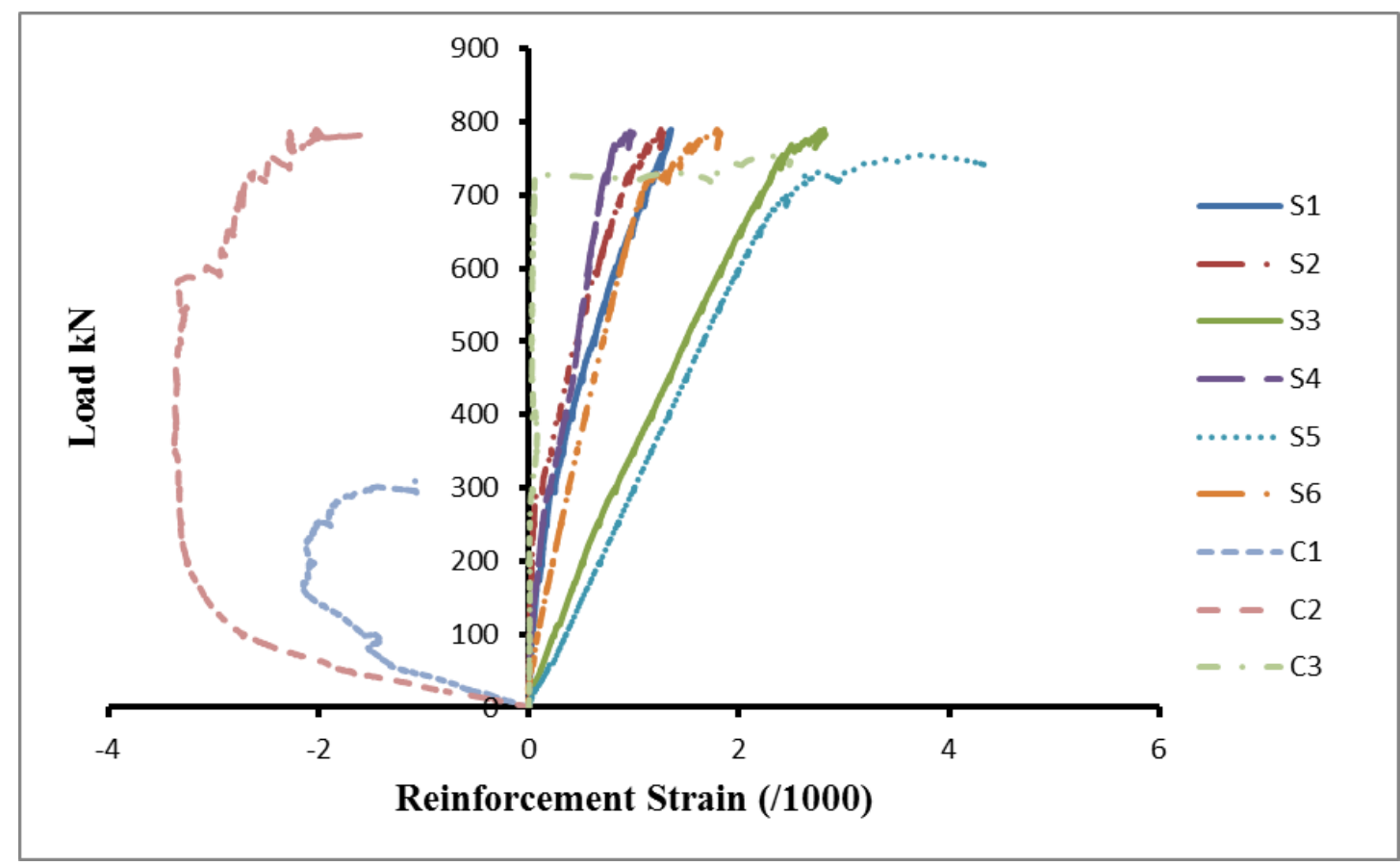

Figure 4.33 Load versus reinforcement strain - Beam US2-1-3.0

\subsubsection{Beam US2-1.5-3.0}

The crack behaviour of beam US2-1.5-3.0 was different from US2-1-3.0. Flexural cracks started to develop at applied load $550 \mathrm{kN}$ at the center region of the beam as shown in Fig. 4.35. As the applied load increased to $700 \mathrm{kN}$, diagonal shear crack started to develop at the mid depth of the beam in left span. This shear crack propagated upward and downward diagonally. Another shear crack formed between the first inclined crack and the loading point when the applied load reached $860 \mathrm{kN}$. At this point, the width of the flexural cracks started to increase. As the applied load increased the second shear crack started to propagate rapidly to the loading point and to the bottom of the beam until the beam failed in shear at applied load $911.58 \mathrm{kN}$. The location of shear crack in beam US2-1.5-3.0 was close to the loading point and different from beam US2-13.0. This can be attributed to the high shear capacity in this beam due to high percentage of steel 
fibres compared to beam US2-1-3.0. The load versus deflection relationship was similar to previous beams. It was almost linear up to an applied load of $780 \mathrm{kN}$ as shown in Fig. 4.34. The maximum deflection at failure was $10.64 \mathrm{~mm}$.

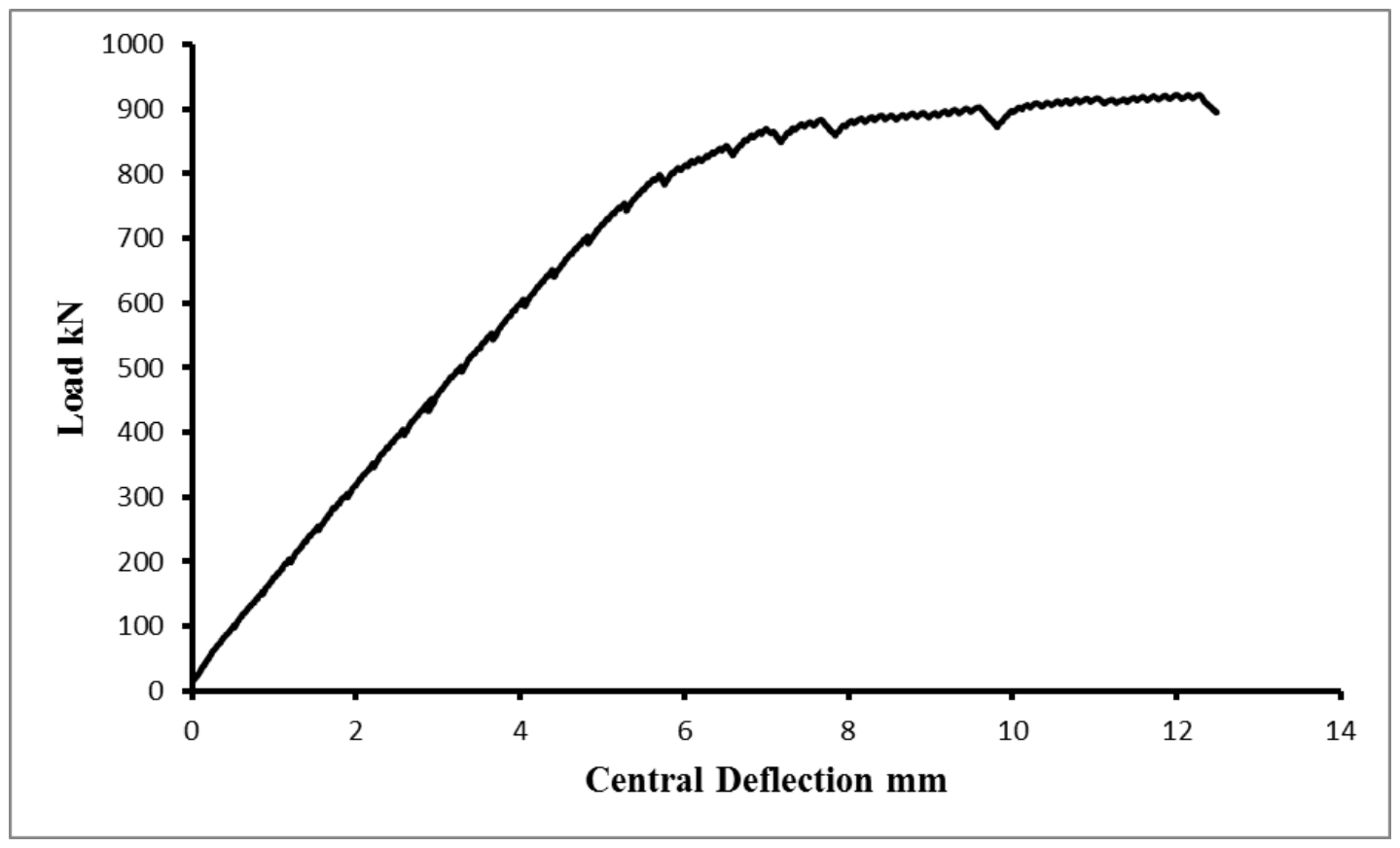

Figure 4.34 Load versus central deflection relationship - Beam US2-1.5-3.0

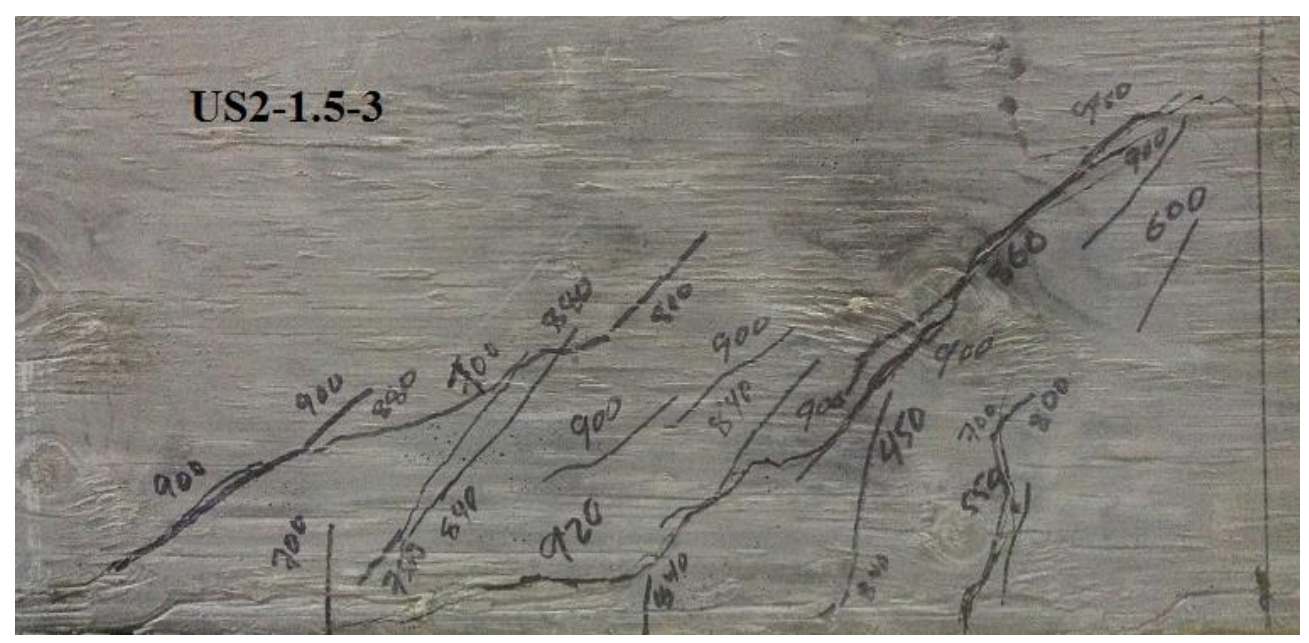

Figure 4.35 Crack pattern after failure - Beam US2-1.5-3.0 
The load versus the reinforcement strain relationship for beam US2-1.5-3.0 is shown in Fig. 4.36. Similarly to previous beams, the strains at most of the gauges were proportionally linear up to an applied load of $780 \mathrm{kN}$. The strain gauges S5 and S3 reached the yield point at applied load 768 , and $827 \mathrm{kN}$ respectively. The strain gauge $\mathrm{C} 1$ was damaged at the beginning of the test due to crushing of the concrete surface at the gauge location.

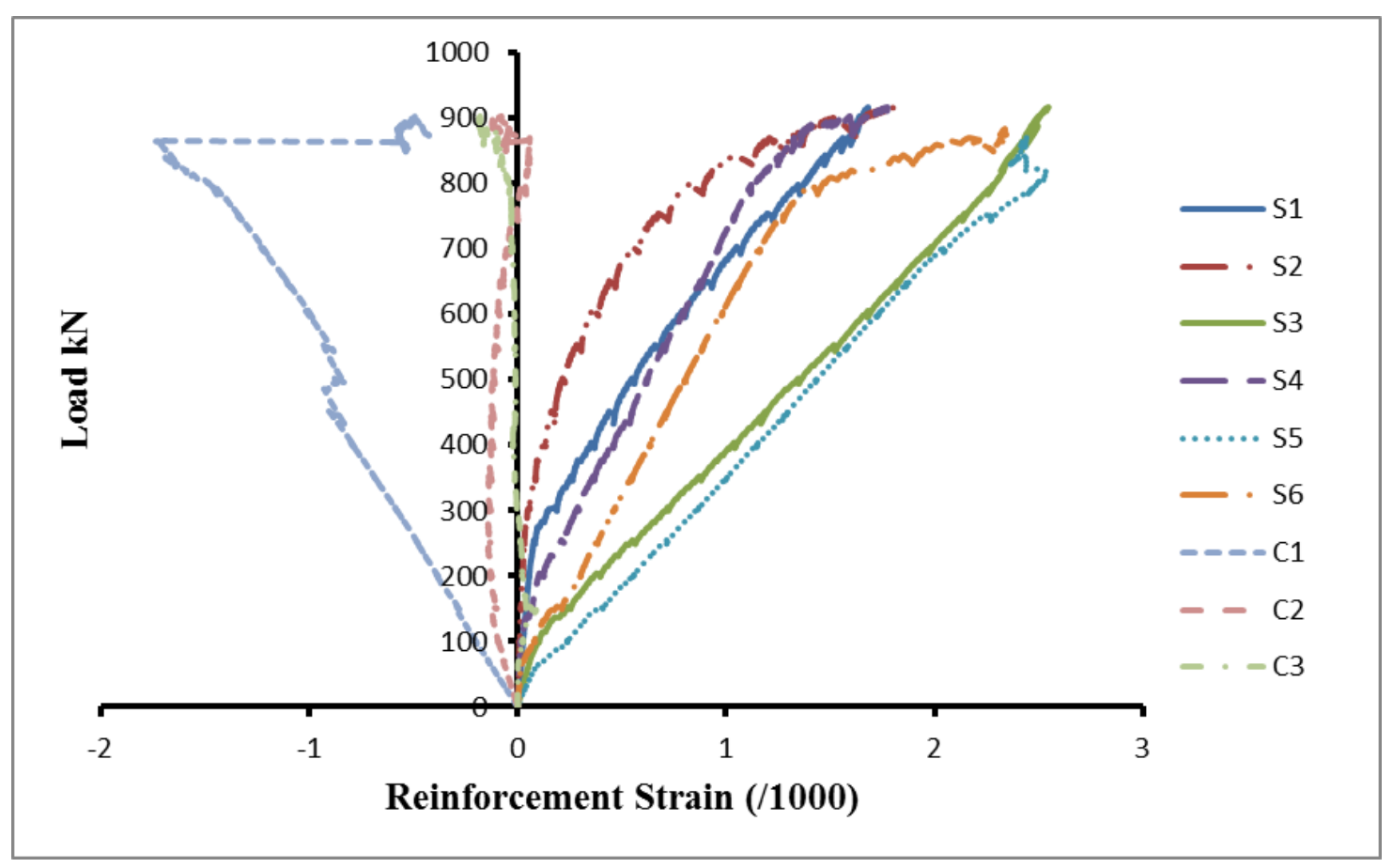

Figure 4.36 Load versus reinforcement strain - Beam US2-1.5-3.0

\subsubsection{Beam US2-2-3.0}

The load versus deflection relationship and crack pattern after failure are shown in Figures 4.37 and 4.38 respectively. Flexural cracks started to develop at the mid span of the beam under the loading point at applied load $450 \mathrm{kN}$. As the applied load increased, the flexural cracks started to propagate upward and crack width increased until the beam failed in flexural at applied load $950.13 \mathrm{kN}$. There was no evidence of forming shear cracks in this beam. It can be observed that increasing the fibre volume percentage to $2 \%$ significantly increase the shear capacity; however, the flexural capacity was slightly increased. Similar to beam US2-1.5-3, the load versus 
deflection relationship was almost linear up to an applied load of $680 \mathrm{kN}$. The maximum deflection at failure was $10.15 \mathrm{~mm}$.

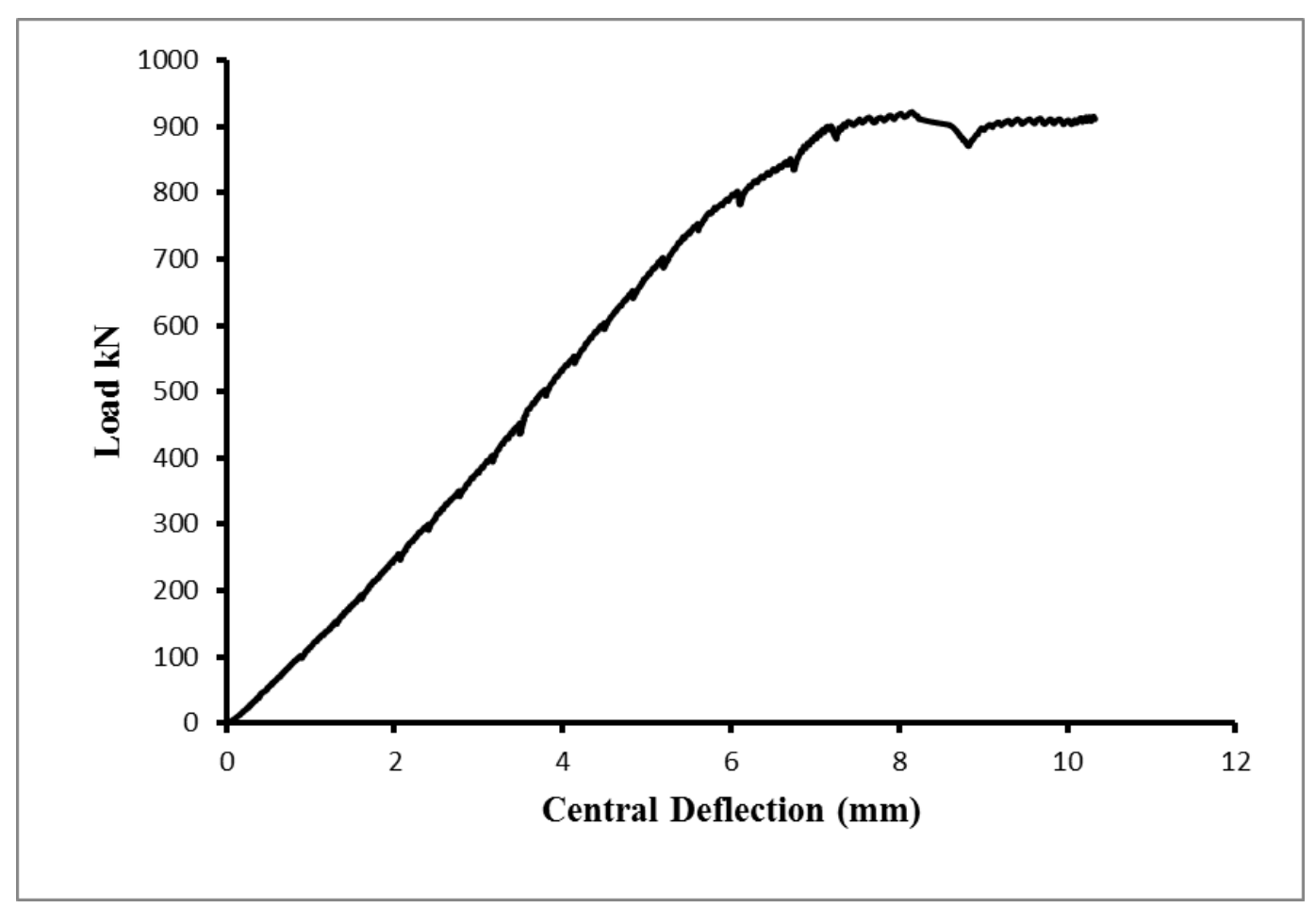

Figure 4.37 Load versus central deflection relationship - Beam US2-2-3.0

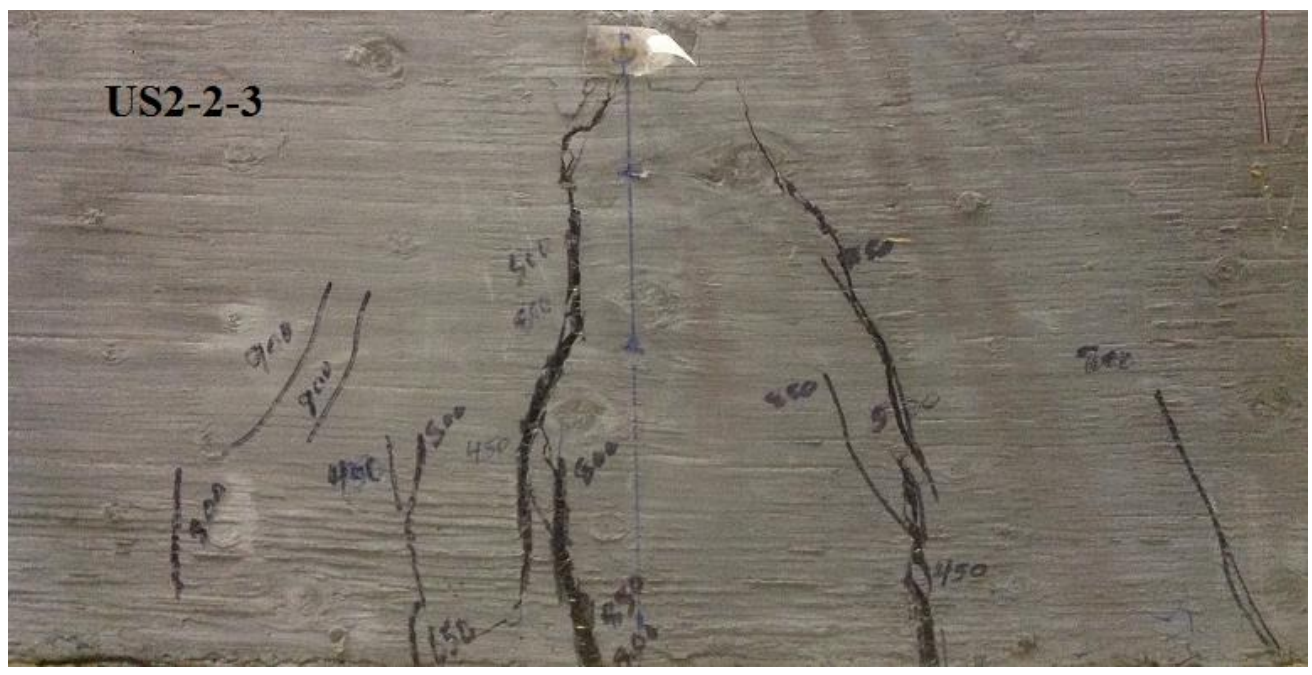

Figure 4.38 Crack pattern after failure - Beam US2-2-3.0 
The load versus the reinforcement strain relationship for beam US2-2-3.0 is shown in Figure 4.39. Similarly to previous beams, the strain readings of most of the gauges were proportionally linear up to an applied load of $780 \mathrm{kN}$. The strain gauges S5 and S3 reached the yield point at an applied load of 702, and $945 \mathrm{kN}$ respectively. The strain gauge $\mathrm{C} 1$ was damaged at the beginning of the test due to crushing of the concrete surface at the gauge location.

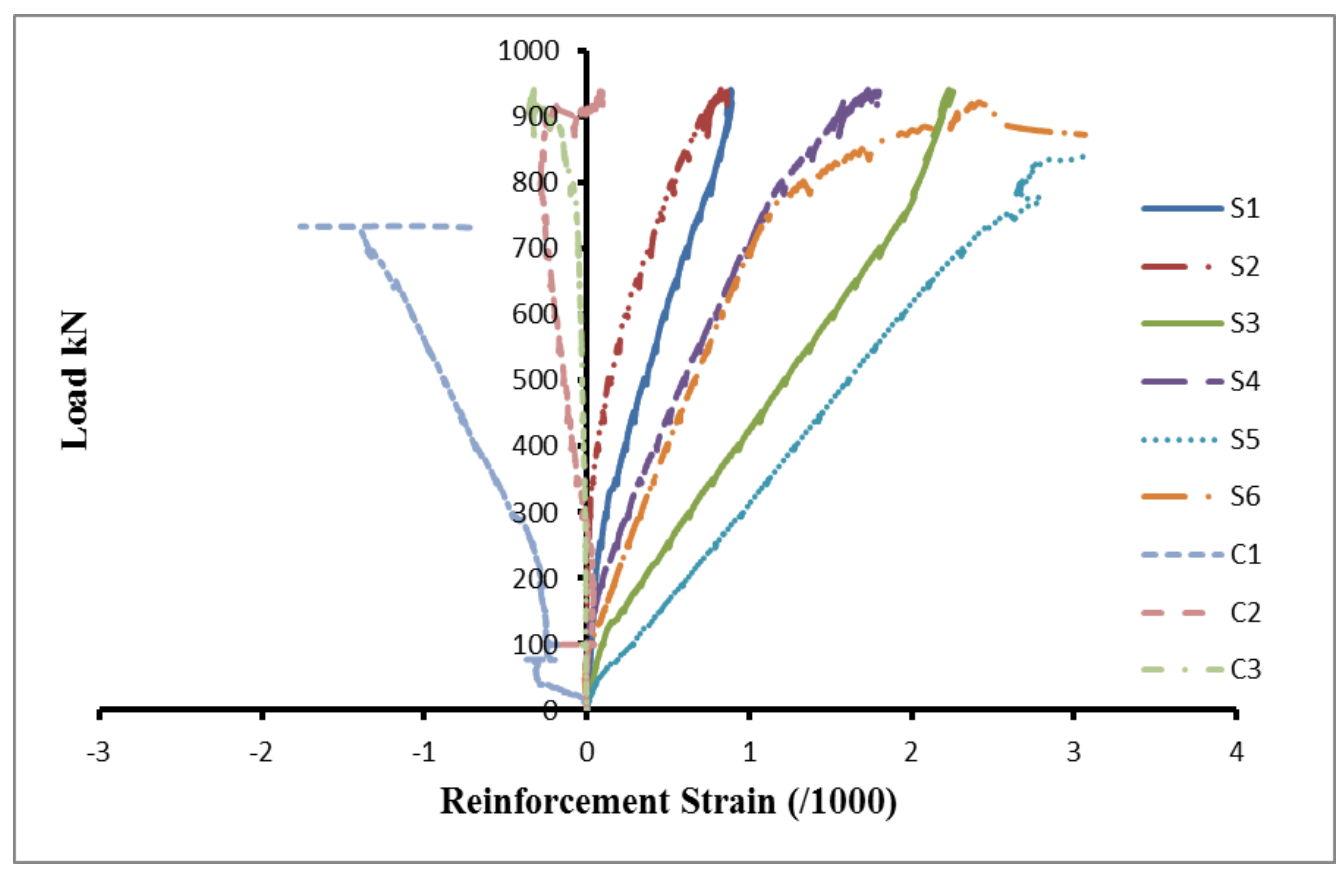

Figure 4.39 Load versus reinforcement strain - Beam US2-2-3.0

\subsubsection{Beams NS2 and HS2}

Figures 4.40 and 4.41 show the load versus central deflection relationship and crack pattern after failure respectively for beam NS2-0-3. Inclined cracks started to develop in the left span at the mid depth of the beam at an applied load of $165 \mathrm{kN}$. In addition, cracks began to develop along the lower layer of reinforcing bars due to dowel action mechanism combined with bond failure at the steel concrete interface. As the load increased, the crack started to propagate to the bottom surface of the beam and the loading point at the same time. Additional cracks developed in the shear span before the crack width increased and the beam failed at applied load $250 \mathrm{kN}$. From Fig. 4.40, it can be seen that the central deflection increased linearly, and it was proportional to 
the load up to a load of $165 \mathrm{kN}$ where the first crack developed in the left span. Beyond this point, the relationship between the load and central deflection was nonlinear. At failure, the maximum deflection of the beam was $5.01 \mathrm{~mm}$. It was observed from the Fig. 4.40 that the failure mode is brittle.

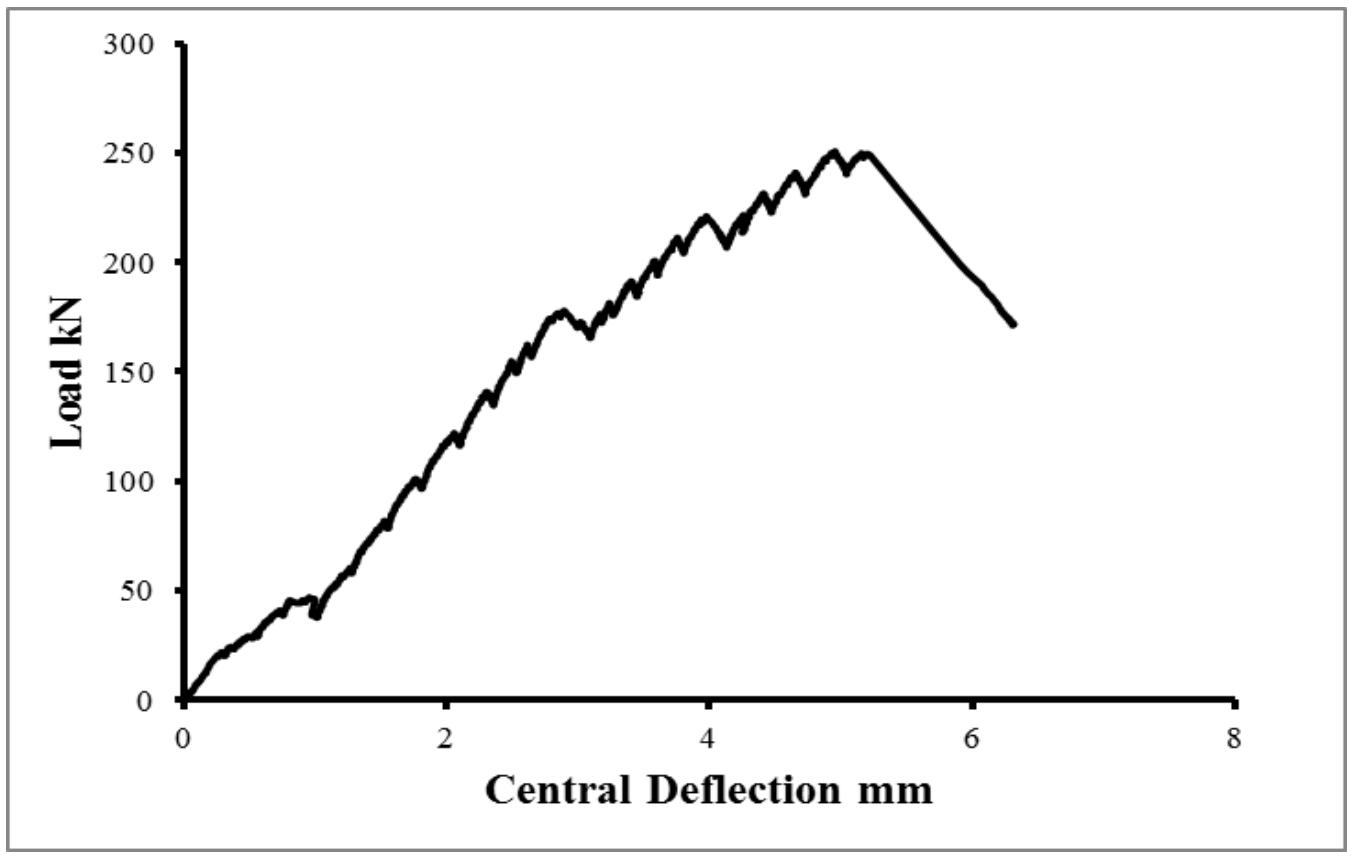

Figure 4.40 Load versus central deflection relationship - Beam NS2-0-3

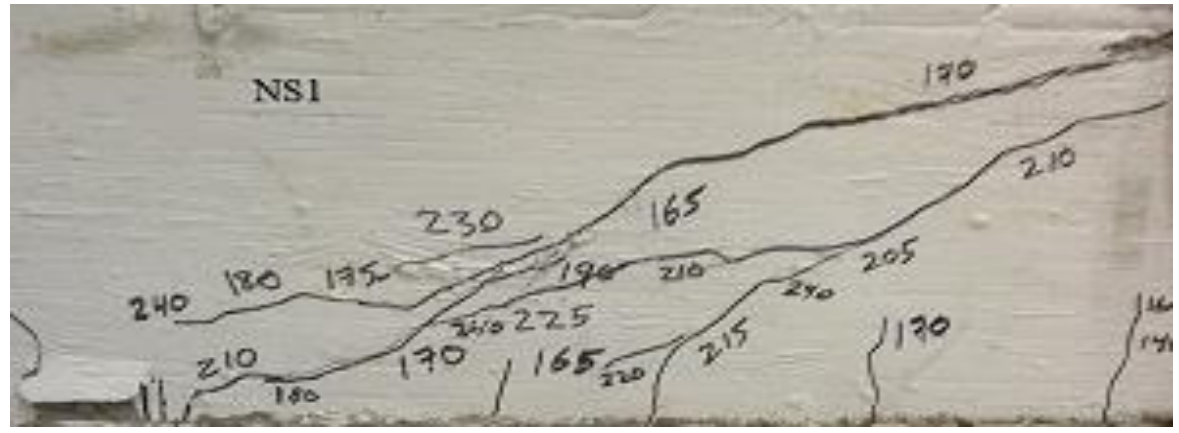

Figure 4.41 Crack pattern after failure - Beam NS2-0-3 
Figure 4.42 shows the load versus the reinforcement strain relationship for beam NS2. It can be noted from Fig. 4.42 that the strains gauge S2 was very high due to the inclined cracks that developed in the vicinity of the gauge.

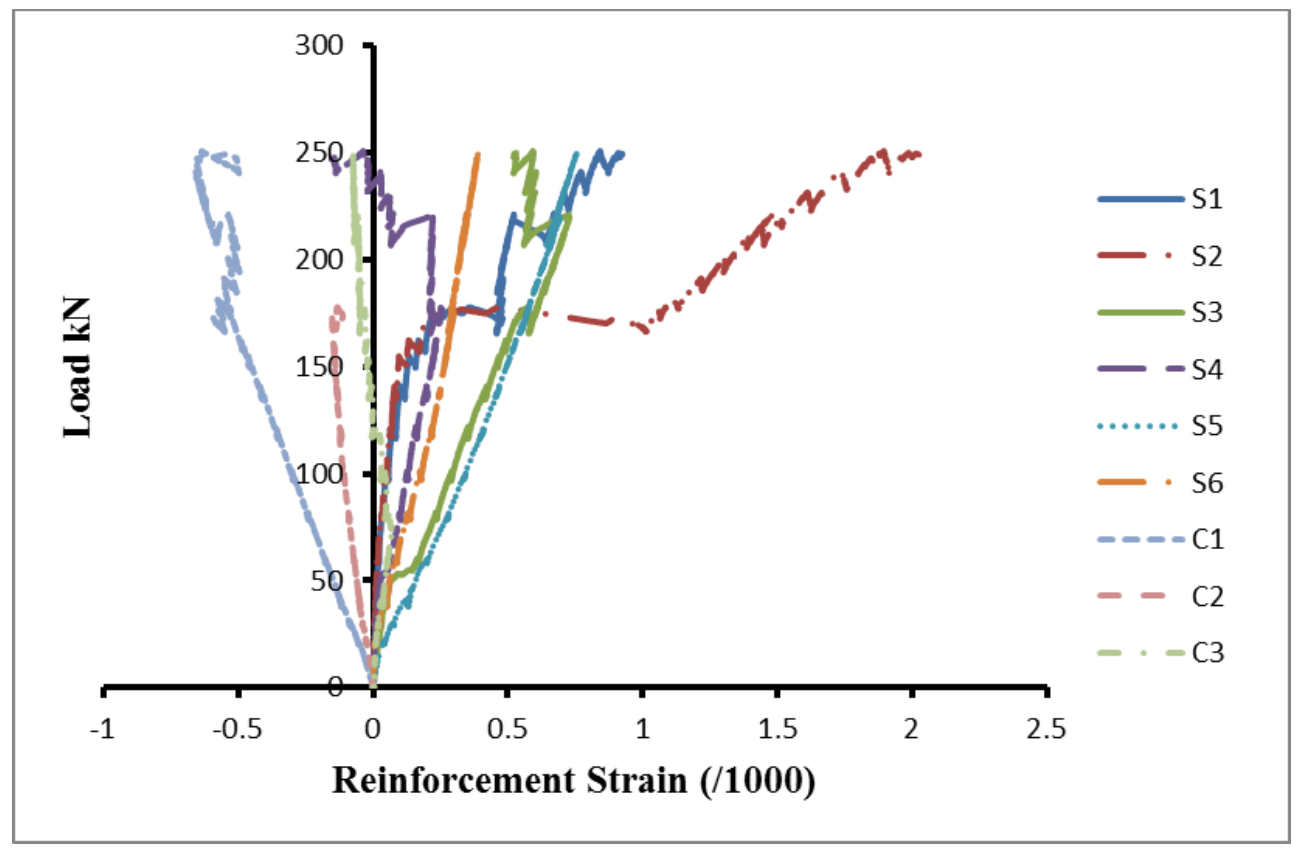

Figure 4.42 Load versus reinforcement strain - Beam NS2-0-3

The load versus central deflection relationship and crack pattern after failure for beam HS2 are shown in Figures 4.43 and 4.44 respectively. The load versus central deflection relationship of beam HS2 was similar to that of beam NS2. However, the crack pattern of beam HS2 was slightly different from that of beam NS2, the inclined cracks were closer in beam HS2 than that of beam NS2.

The load versus the reinforcement strain relationship for beam HS2 is shown in Fig. 4.45. It can be noted from Fig. 4.45 that the strains gauges S1 and S2 started to increase rapidly when the applied load reached $145 \mathrm{kN}$ due to the inclined cracks that began to form in the vicinity of the gauges. 


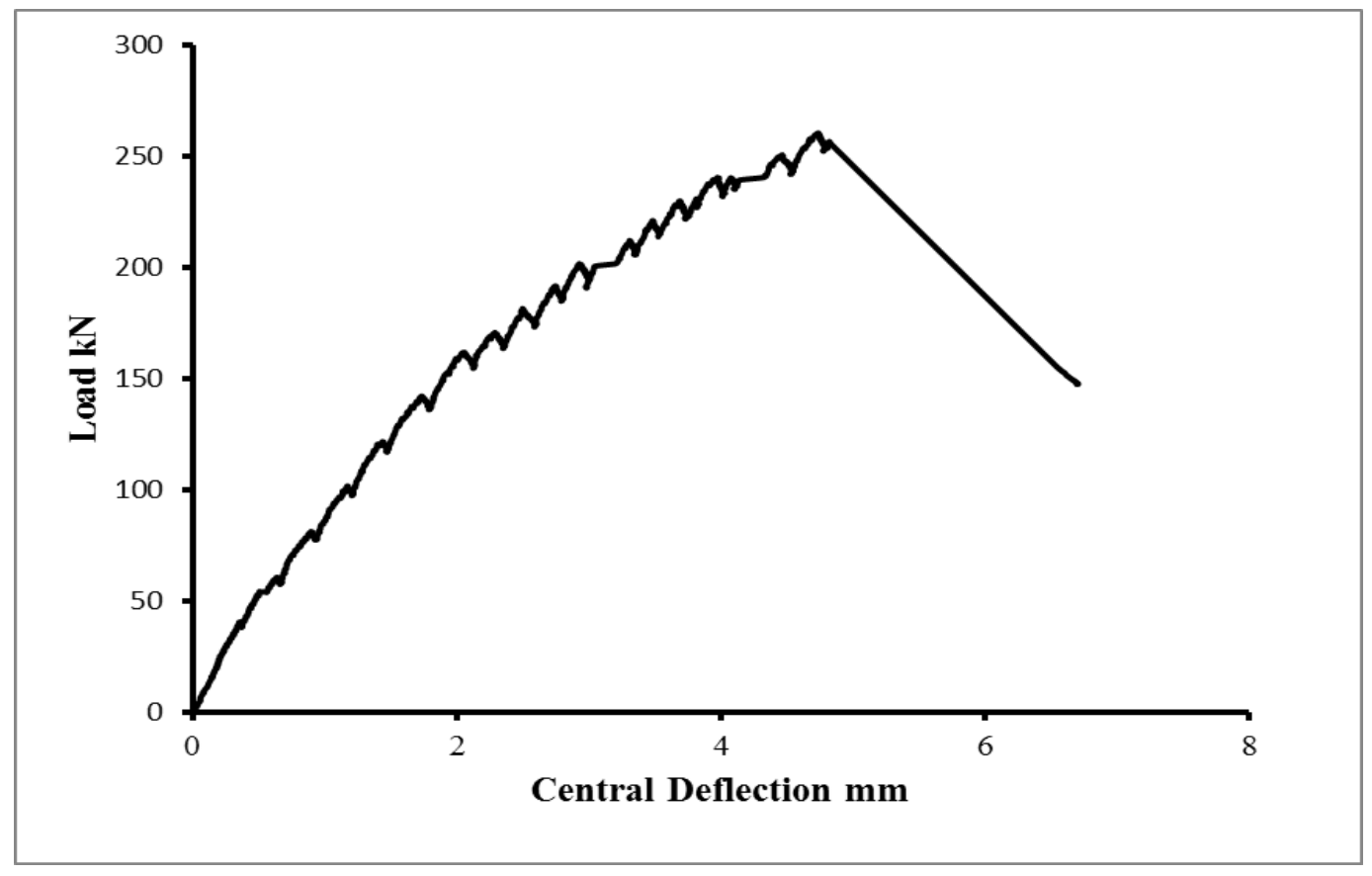

Figure 4.43 Load versus central deflection relationship - Beam HS2-0-3

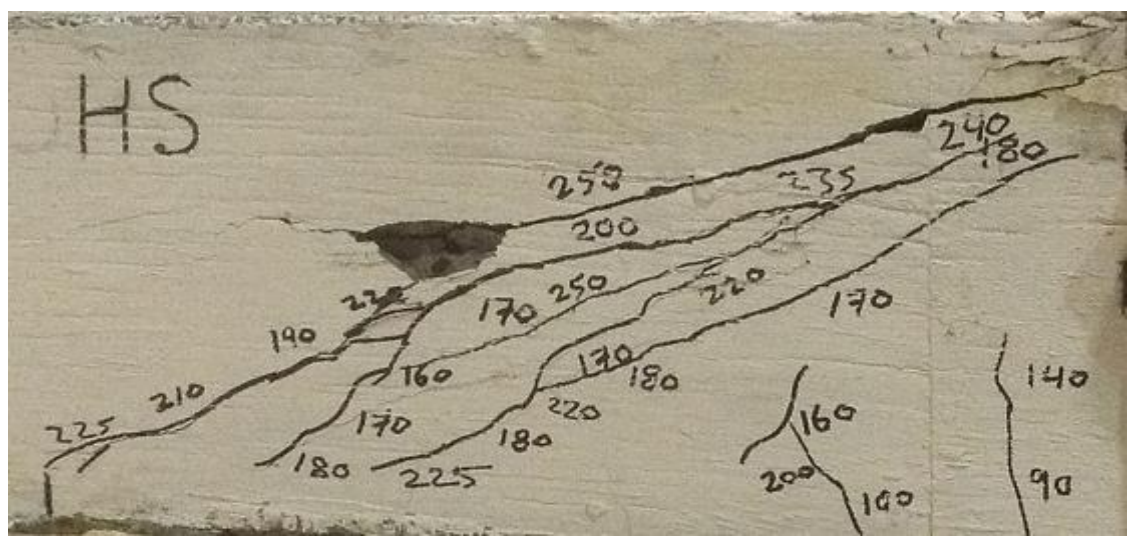

Figure 4.44 Crack pattern after failure - Beam HS2-0-3 


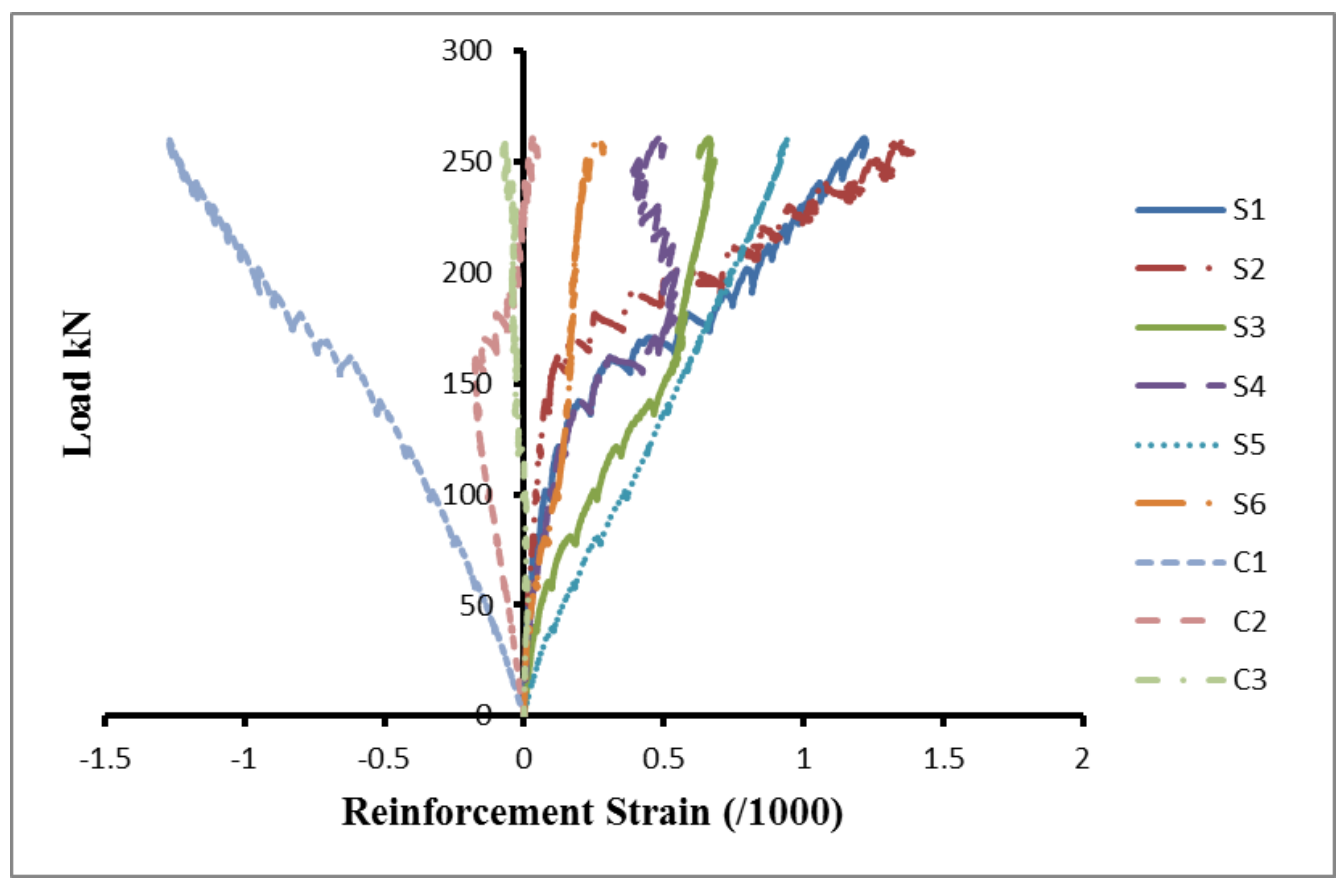

Figure 4.45 Load versus reinforcement strain - Beam HS2-0-3

\subsection{Comparison of response of UHPFRC beams}

\subsubsection{Crack pattern and mode of failure}

All of the beams in series 1 failed in flexure, except the beam without fibre content failed in shear. Flexural cracks began to develop from the bottom surface of the beam in the region below the loading point. As the applied load increased, more cracks developed in the region below the loading point where the maximum moment occurred. These cracks became connected as the load increased and the beam failed. Table 4.5 shows the initial cracking load, ultimate failure load, and the mode of failure for all beams in series 1 and 2. Beams in series 2 failed in shear except beam US2-2-3 failed in flexure. For beams failed in shear, inclined cracks began to develop in the left span at the mid depth of the beam. As the load increased, another crack began to develop in the left span. These cracks began to propagate to the bottom surface of the beam and to the loading point simultaneously. The crack width increased and the beam failed in shear. 
Table 4.5 Material properties and experimental parameters of specimens

\begin{tabular}{|l|c|c|c|c|c|c|c|c|}
\hline \multicolumn{1}{|c|}{ Beam } & $a / d$ & $\rho$ & $v_{f}$ & $f_{c}^{\prime}$ & $f_{s p}$ & $\begin{array}{c}\text { Initial } \\
\text { Cracking } \\
\mathbf{\text { LPad }}\end{array}$ & $\begin{array}{c}\text { Ultimate } \\
\mathbf{M P a} \\
\mathbf{\text { Failure }} \\
\text { Load } \\
\mathbf{k N}\end{array}$ & $\begin{array}{c}\text { Mode of } \\
\text { Failure }\end{array}$ \\
\hline US1-0-3.5 & 3.5 & 0.063 & 0 & 133.04 & 6.18 & 210 & 240 & Shear \\
\hline US1-1-3.5 & 3.5 & 0.063 & 1 & 152.89 & 12.62 & 430 & 667 & Flexure \\
\hline US1-2-3.5 & 3.5 & 0.063 & 2 & 158.59 & 16.08 & 650 & 724 & Flexure \\
\hline US1-2-2.0 & 2.0 & 0.063 & 2 & 155.47 & 15.19 & 500 & 780 & Flexure \\
\hline US1-2-1.5 & 1.5 & 0.063 & 2 & 152.01 & 15.71 & 800 & 882 & Flexure \\
\hline NS2-0-3.0 & 3.0 & 0.081 & 0 & 51.19 & 3.03 & 165 & 250 & Shear \\
\hline HS2-0-3.0 & 3.0 & 0.081 & 0 & 70.08 & 4.22 & 160 & 256 & Shear \\
\hline US2-0-3.0-a & 3.0 & 0.081 & 0 & 133.58 & 7.95 & 170 & 284 & Shear \\
\hline US2-0-3.0-b & 3.0 & 0.081 & 0 & 167.12 & 5.81 & 210 & 294 & Shear \\
\hline US2-1-3.0 & 3.0 & 0.081 & 1 & 152.75 & 9.34 & 440 & 790 & Shear \\
\hline US2-1.5-3.0 & 3.0 & 0.081 & 1.5 & 153.89 & 12.86 & 450 & 912 & Shear \\
\hline US2-2-3.0 & 3.0 & 0.081 & 2 & 154.41 & 15.69 & 650 & 950 & Flexure \\
\hline
\end{tabular}

\subsubsection{Load-deflection response}

At each loading step, the deflections were measured by one potentiometer installed at the midspan of the beams in series 1 and two potentiometers installed on each side of the beams in series 2. These measured deflections were then compared. The central deflection curves of the beams with $2 \%$ fibre volume fraction in series 1 can be seen in Fig. 4.46. Figure 4.47 illustrates the central deflection curves of the beams in series 2 . These figures show that the deflection of the beams increased linearly, and was proportional to the applied load, even after the initiation of cracks. The addition of steel fibres increased the ductility of the UHPC beams. The maximum deflection of beams US2-0-3-a, US2-0-3-b, US2-1-3, US2-1.5-3, and US2-2-3 at failure were $4.65,5.23,8.22,10.64$, and $10.15 \mathrm{~mm}$ respectively. It can be seen from Fig. 4.47 that the behaviour of UHPC beam without addition of fibre was similar to the behaviour of NSC and HSC beams with slightly higher strength due to the high compressive strength of UHPC material compared to NSC and HSC materials. This demonstrates that UHPC without fibres is a brittle 
material, and that increasing the compressive strength of the concrete will not enhance the shear capacity of reinforced concrete beams. It was noted from Fig. 4.47 that beams US2-2-3 and US21.5-3 showed similar behaviour. This behaviour can be attributed to maximum flexural capacity of the beams in series 2 .

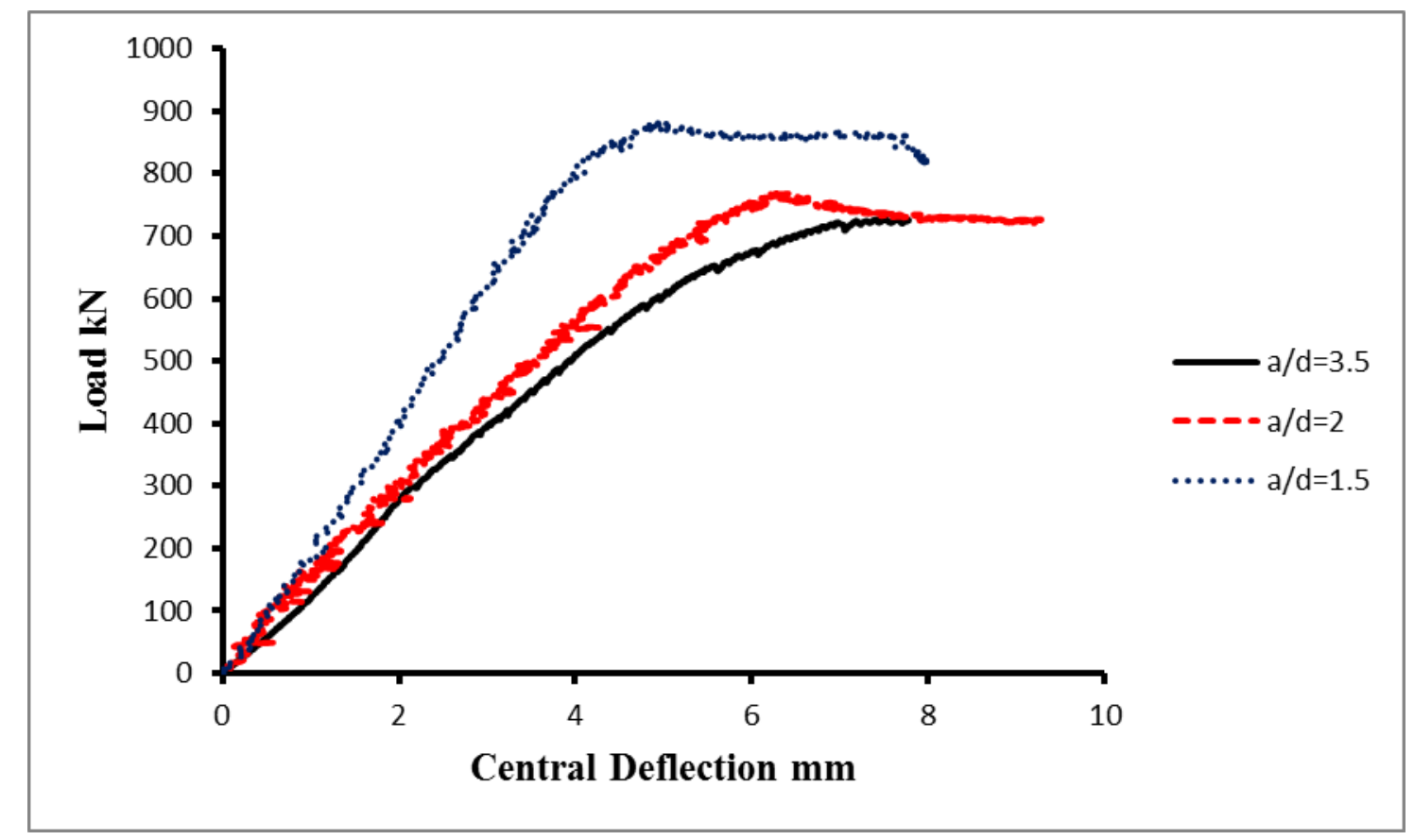

Figure 4.46 Load versus central deflection relationship for a/d ratio for Series 1 with $2 \%$ fibre volume content

\subsubsection{Shear capacity}

Table 4.6 show that the shear capacity of UHPFRC was significantly increased by increases in fibre volume percentage. It can be noted that that the ultimate shear capacity of UHPFRC beams with $1 \%$ and $1.5 \%$ fibre volume content is 1.7 , and 2.13 times higher than the shear capacity of the UHPC without fibre content. 


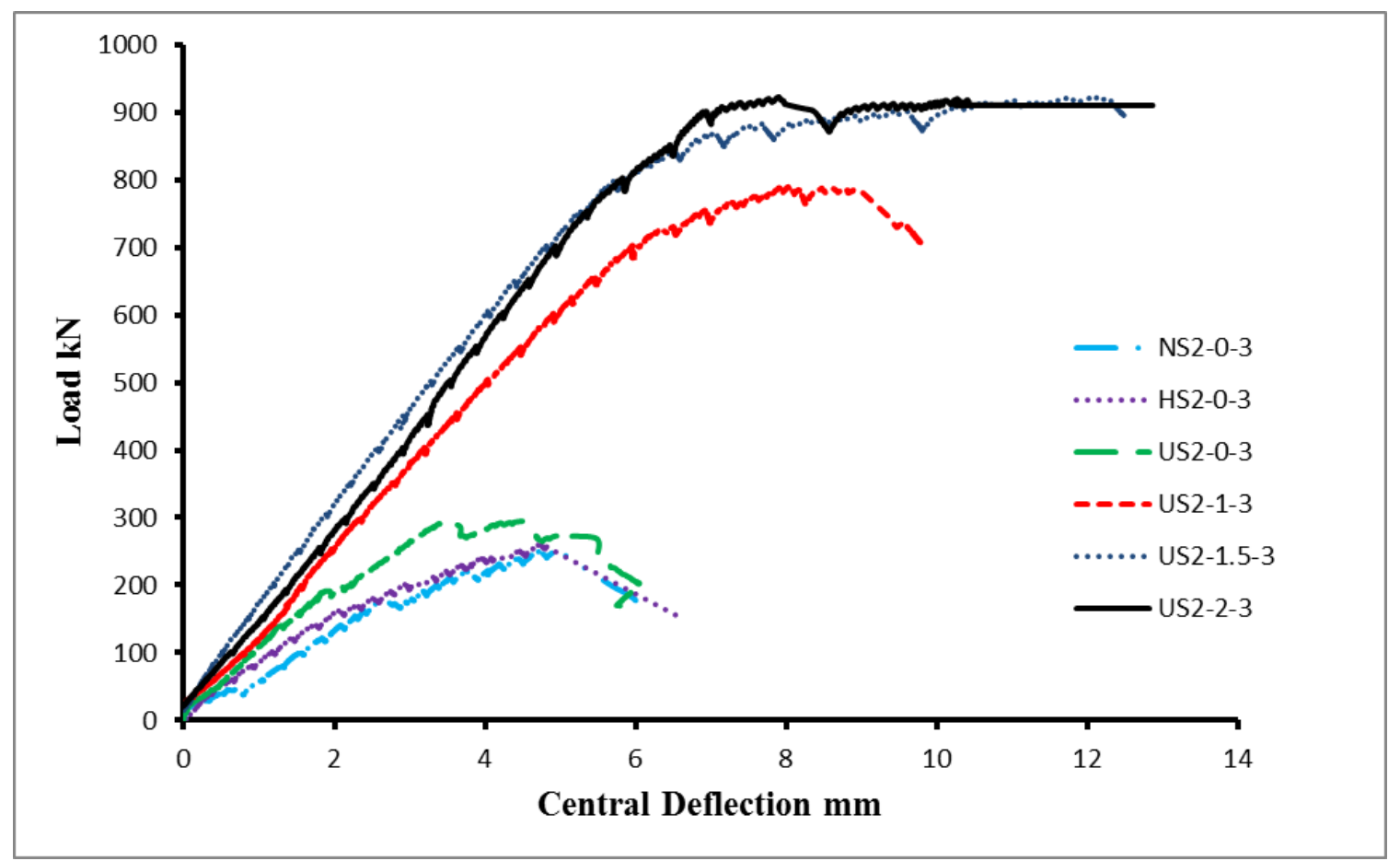

Figure 4.47 Load versus central deflection relationship for different fibre volume contents for Series 2 with $\mathbf{a} / \mathbf{d}=\mathbf{3 . 0}$

Table 4.6 Shear capacity of UHPFRC beams

\begin{tabular}{|l|c|c|c|c|c|}
\hline $\begin{array}{c}\text { Beam } \\
\text { specimen }\end{array}$ & \% Fibres & $\begin{array}{c}\text { Maximum } \\
\text { Shear } \\
\text { capacity } \\
V \exp \\
(\mathbf{k N})\end{array}$ & $\begin{array}{c}\text { Increase in } \\
\text { Resistance } \\
\left(\frac{V \exp -V \exp 0}{V \exp 0}\right.\end{array}$ & $\begin{array}{c}\text { Deflection at } \\
\text { Maximum } \\
\text { Resistance } \\
\Delta \exp \\
(\mathbf{m m})\end{array}$ & $\begin{array}{c}\text { Maximum } \\
\text { Deflection } \\
\Delta \max \end{array}$ \\
\hline US2-0-3-a & 0 & 142.03 & --- & 4.65 & 6.30 \\
\hline US2-0-3-b & 0 & 147.25 & ---- & 5.23 & 7.20 \\
\hline US2-1-3 & 1 & 394.86 & $77 \%$ & 8.22 & 14.02 \\
\hline US2-1.5-3 & 1.5 & 455.29 & $120 \%$ & 10.64 & 16.03 \\
\hline US2-2-3 & 2 & $>475.1$ & $>134 \%$ & 10.15 & 17.32 \\
\hline
\end{tabular}




\section{Chapter 5}

\section{Experimental Results of UHPFRC- NSC/HSC Members}

This chapter describes the material tests conducted in this experimental program and provides details on the analytical procedure used to study the structural behaviour of the UHPFRC composite members. To study the specimen's structural behaviour, including, its load deflection relationship, reinforcement strains, crack pattern, and concrete strains in the critical shear span, each beam was analysed separately. In addition, this chapter compares the responses of UHPFRC-NSC/HSC specimens with that of the UHPFRC specimens to better understand the composite action between UHPFRC material and NSC/HSC material.

\subsection{Cylinder compressive strength}

Results from the concrete cylinder compressive strength tests are shown in Table 5.1. For composite beams, the letters $\mathrm{N}$ and $\mathrm{H}$ indicate the result for NSC and HSC layer respectively, and the letter $U$ indicates the result of UHPFRC layer.

Table 5.1 Cylinder compressive strength test results (MPa)

\begin{tabular}{|c|c|c|c|c|c|c|c|c|}
\hline Beam & Layer & C \#1 & $\mathrm{C} \# 2$ & $\mathrm{C} \# \mathbf{3}$ & $\mathrm{C \# 4}$ & C \#5 & Mean & CV \\
\hline NS2 & $\mathrm{N}$ & 46.385 & 53.512 & 59.129 & 43.241 & 52.718 & 51.197 & 0.130 \\
\hline HS2 & $\mathrm{H}$ & 68.041 & 67.529 & 73.601 & 68.618 & 72.595 & 70.078 & 0.036 \\
\hline UNS3-1 & \multirow{3}{*}{$\begin{array}{l}\mathrm{N} \\
\mathrm{U}\end{array}$} & \multirow{3}{*}{$\begin{array}{c}46.385 \\
148.390\end{array}$} & \multirow{3}{*}{$\begin{array}{c}53.512 \\
174.187\end{array}$} & \multirow{3}{*}{$\begin{array}{c}59.129 \\
141.908\end{array}$} & 43.241 & 52.718 & 51.197 & 0.130 \\
\hline UNS3-1D & & & & & \multirow[t]{2}{*}{148.161} & \multirow{2}{*}{187.280} & \multirow{2}{*}{159.985} & \multirow[t]{2}{*}{0.101} \\
\hline UNS3-1S & & & & & & & & \\
\hline UNS3-1.5 & $\mathrm{N}$ & 46.385 & 53.512 & 59.129 & 43.241 & 52.718 & 51.197 & 0.130 \\
\hline UNS3-1.5D & $\mathrm{U}$ & 156.784 & 181.707 & 177.072 & 173.138 & 160.488 & 169.838 & 0.056 \\
\hline UNS3-2 & $\mathrm{N}$ & 46.385 & 53.512 & 59.129 & 43.241 & 52.718 & 51.197 & 0.130 \\
\hline UNS3-2D & U & 187.331 & 168.827 & 158.421 & 174.052 & 166.631 & 168.001 & 0.065 \\
\hline UHS3-1 & \multirow{3}{*}{$\mathrm{U}$} & \multirow{3}{*}{$\begin{array}{c}68.041 \\
174.933\end{array}$} & \multirow{3}{*}{$\begin{array}{c}67.529 \\
192.698\end{array}$} & \multirow{3}{*}{$\begin{array}{c}73.601 \\
174.793\end{array}$} & \multirow{3}{*}{$\begin{array}{c}68.618 \\
201.997\end{array}$} & \multirow{3}{*}{$\begin{array}{l}72.595 \\
165.135\end{array}$} & \multirow{3}{*}{$\begin{array}{c}70.078 \\
181.907\end{array}$} & \multirow{3}{*}{$\begin{array}{l}0.036 \\
0.073\end{array}$} \\
\hline UHS3-1D & & & & & & & & \\
\hline UHS3-1S & & & & & & & & \\
\hline UHS3-1.5 & $\mathrm{H}$ & 68.041 & 67.529 & 73.601 & 68.618 & 72.595 & 70.078 & 0.036 \\
\hline UHS3-1.5D & U & 158.172 & 182.038 & 159.235 & 194.701 & 156.803 & 170.189 & 0.090 \\
\hline UHS3-2 & $\mathrm{H}$ & 68.041 & 67.529 & 73.601 & 68.618 & 72.595 & 70.078 & 0.036 \\
\hline UHS3-2D & $\mathrm{U}$ & 185.407 & 191.683 & 188.864 & 200.387 & 192.849 & 191.838 & 0.025 \\
\hline
\end{tabular}

$\mathrm{CV}=$ Coefficient of Variation 


\subsection{Split cylinder tests}

The results of the splitting tensile strength tests $f_{s p}$, for each cylinder were calculated according to equation (3.1), and summarised in Table 5.2.

Table 5.2 Split cylinder test results (MPa)

\begin{tabular}{|c|c|c|c|c|c|}
\hline Beam & $V_{f} \%$ & Layer & $f_{c}^{\prime}$ & $f_{s p}$ & $f_{s p} / \sqrt{f_{c}^{\prime}}$ \\
\hline NS2 & 0.0 & $\mathrm{~N}$ & 51.197 & 3.029 & 0.423 \\
\hline HS2 & 0.0 & $\mathrm{H}$ & 70.078 & 4.216 & 0.503 \\
\hline UNS3-1 & \multirow{3}{*}{1.0} & $\mathrm{~N}$ & 51.197 & N3.029 & N0.423 \\
\hline UNS3-1D & & \multirow[t]{2}{*}{ U } & \multirow[t]{2}{*}{159.985} & \multirow[t]{2}{*}{ U11.169 } & \multirow[t]{2}{*}{ U0.883 } \\
\hline UNS3-1S & & & & & \\
\hline UNS3-1.5 & \multirow[t]{2}{*}{1.5} & $\mathrm{~N}$ & 51.197 & N3.029 & N0.423 \\
\hline UNS3-1.5D & & $\mathrm{U}$ & 169.838 & U14.768 & U1.133 \\
\hline UNS3-2-A & \multirow[t]{2}{*}{2.0} & $\mathrm{~N}$ & 51.197 & N3.029 & N0.423 \\
\hline UNS3-2D & & $\mathrm{U}$ & 168.001 & U15.534 & U1.198 \\
\hline UHS3-1 & \multirow{3}{*}{1.0} & \multirow{3}{*}{$\begin{array}{l}\mathrm{H} \\
\mathrm{U}\end{array}$} & \multirow{3}{*}{$\begin{array}{c}70.078 \\
181.907\end{array}$} & \multirow{3}{*}{$\begin{array}{c}\mathrm{H} 4.216 \\
\mathrm{U} 13.002\end{array}$} & \multirow{3}{*}{$\begin{array}{l}\text { H0.503 } \\
\text { U0.964 }\end{array}$} \\
\hline UHS3-1D & & & & & \\
\hline UHS3-1S & & & & & \\
\hline UHS3-1.5 & \multirow[t]{2}{*}{1.5} & $\mathrm{H}$ & 70.078 & H4.216 & $\mathrm{H} 0.503$ \\
\hline UHS3-1.5D & & $\mathrm{U}$ & 170.189 & U15.635 & U1.198 \\
\hline UHS3-2 & \multirow[t]{2}{*}{2.0} & $\mathrm{H}$ & 70.078 & H4.216 & H0.503 \\
\hline UHS3-2D & & $\mathrm{U}$ & 191.838 & U16.275 & U1.175 \\
\hline
\end{tabular}

\subsection{Flexural tests}

The average peak load and average failure load for UHPFRC/NSC (UN) and UHPFRC/HSC (UH) prisms were calculated according to equation (3.2) and summarized in Table 5.3. The peak load and peak deflection are the peak load and its corresponding deflection while the failure load and the failure deflection are the loads where the prism failed and its corresponding deflection. The average peak load was calculated by obtaining the mean of all deflections at peak loads. The average peak load is the load corresponding to average deflection that was calculated by interpolating the two nearest points on the load-deflection curves. Similar procedure was used to calculate the average failure load and its corresponding deflection. 
The flexural toughness is the total area under the load-deflection curve up to failure. Table 5.4 shows the flexural toughness number rounded to the nearest Joule, and the modulus of rupture $f_{r}$ , which was determined by flexural members that had dimensions of $152 \times 152 \times 456 \mathrm{~mm}$. It can be noted from Table 5.4 that the flexural toughness increased with the addition of steel fibres to UHPFRC layer.

Table 5.3 Flexural test results of UHPFRC-NSC/HSC

\begin{tabular}{|c|c|c|c|c|c|c|c|}
\hline Series & Layer & $\begin{array}{c}\text { Average } \\
\text { Compressive } \\
\text { Strength } \\
\text { (MPa) }\end{array}$ & $\begin{array}{c}\text { Average } \\
\text { Splitting } \\
\text { Tensile } \\
\text { Strength } \\
\text { (MPa) }\end{array}$ & $\begin{array}{c}\text { Average } \\
\text { Deflection } \\
\text { at Peak } \\
\text { Load } \\
(\mathbf{m m}) \\
(\mathrm{CV})\end{array}$ & $\begin{array}{c}\text { Average } \\
\text { Peak } \\
\text { Load } \\
(\mathbf{k N})\end{array}$ & $\begin{array}{c}\text { Average } \\
\text { Deflection } \\
\text { at Failure } \\
(\mathbf{m m}) \\
(\mathrm{CV})\end{array}$ & $\begin{array}{c}\text { Average } \\
\text { Failure } \\
\text { Load } \\
(\mathrm{kN})\end{array}$ \\
\hline NS & $\mathrm{N}$ & 51.197 & 3.029 & $\begin{array}{c}0.220 \\
(0.140)\end{array}$ & 40.843 & & \\
\hline $\mathrm{HS}$ & $\mathrm{H}$ & 70.078 & 4.216 & $\begin{array}{c}0.257 \\
(0.051)\end{array}$ & 37.587 & & \\
\hline UN1 & $\begin{array}{l}\mathrm{N} \\
\mathrm{U}\end{array}$ & $\begin{array}{c}51.197 \\
159.985\end{array}$ & $\begin{array}{c}3.029 \\
11.169\end{array}$ & $\begin{array}{c}0.748 \\
(0.250)\end{array}$ & 50.323 & $\begin{array}{c}1.145 \\
(0.030)\end{array}$ & 41.730 \\
\hline UN1.5 & $\begin{array}{l}\mathrm{N} \\
\mathrm{U}\end{array}$ & $\begin{array}{c}51.197 \\
169.838 \\
\end{array}$ & $\begin{array}{c}3.029 \\
14.768 \\
\end{array}$ & $\begin{array}{c}0.982 \\
(0.345) \\
\end{array}$ & 68.393 & $\begin{array}{c}1.195 \\
(0.026) \\
\end{array}$ & 60.693 \\
\hline UN2 & $\begin{array}{l}\mathrm{N} \\
\mathrm{U}\end{array}$ & $\begin{array}{c}51.197 \\
168.001\end{array}$ & $\begin{array}{c}3.029 \\
15.534\end{array}$ & $\begin{array}{c}1.163 \\
(0.130)\end{array}$ & 77.760 & $\begin{array}{c}1.418 \\
(0.118)\end{array}$ & 68.133 \\
\hline UH1 & $\begin{array}{l}\mathrm{H} \\
\mathrm{U}\end{array}$ & $\begin{array}{c}70.078 \\
181.907\end{array}$ & $\begin{array}{c}4.216 \\
13.002\end{array}$ & $\begin{array}{c}0.763 \\
(0.338)\end{array}$ & 54.490 & $\begin{array}{c}2.143 \\
(0.144)\end{array}$ & 28.160 \\
\hline UH1.5 & $\begin{array}{l}\mathrm{H} \\
\mathrm{U}\end{array}$ & $\begin{array}{c}70.078 \\
170.189\end{array}$ & $\begin{array}{c}4.216 \\
15.635\end{array}$ & $\begin{array}{c}1.010 \\
(0.161)\end{array}$ & 57.765 & $\begin{array}{c}2.178 \\
(0.218)\end{array}$ & 44.880 \\
\hline UH2 & $\begin{array}{l}\mathrm{H} \\
\mathrm{U}\end{array}$ & $\begin{array}{c}70.078 \\
191.838 \\
\end{array}$ & $\begin{array}{c}4.216 \\
16.275 \\
\end{array}$ & $\begin{array}{c}1.113 \\
(0.237)\end{array}$ & 66.393 & $\begin{array}{c}2.268 \\
(0.040)\end{array}$ & 45.030 \\
\hline
\end{tabular}

$\mathrm{CV}=$ Coefficient of Variation

Table 5.4 Flexural toughness and modulus of rupture of beams

\begin{tabular}{|c|c|c|}
\hline Series & $\begin{array}{c}f_{r} \\
(\mathbf{M P a})\end{array}$ & $\begin{array}{c}\text { Flexural Toughness } \\
(\mathbf{k N}-\mathbf{m m})\end{array}$ \\
\hline NS & 5.503 & 4.992 \\
\hline HS & 4.881 & 4.823 \\
\hline $\mathrm{UN} 1$ & 7.398 & 37.086 \\
\hline $\mathrm{UN} 1.5$ & 10.054 & 40.884 \\
\hline $\mathrm{UN2}$ & 11.431 & 63.832 \\
\hline $\mathrm{UH} 1$ & 7.792 & 77.909 \\
\hline $\mathrm{UH} 1.5$ & 8.260 & 88.602 \\
\hline $\mathrm{UH} 2$ & 9.494 & 103.679 \\
\hline
\end{tabular}


The cracking behaviour of UHPFRC/NSC (UN) and UHPFRC/HSC (UH) prisms are shown in Figures 5.1 and 5.2 respectively. Figures 5.3 and 5.4 show the load versus net deflection relationship for the UN, and $\mathrm{UH}$, series respectively. The average peak load for UN prisms with $1 \%, 1.5 \%$ and $2 \%$ fibres volume content were $50.32,68.39$ and $77.76 \mathrm{kN}$ respectively, while for the average peak load for UH prisms with $1 \%, 1.5 \%$ and $2 \%$ fibres volume content were 54.49, 57.76 and $66.39 \mathrm{kN}$ respectively. The average peak load for NSC prisms was $40.84 \mathrm{kN}$ and for HSC prisms was $37.58 \mathrm{kN}$. It can be noted that the average ultimate load for NSC prisms was slightly higher than the average ultimate load for HSC prisms. This can be attributed to high brittleness of HSC prisms compared to NSC prisms that made the cracks to propagate faster in HSC prisms compared to NSC prisms. The results show (Fig. 5.3) that the addition of UHPFRC layer with $1 \%, 1.5 \%$ and $2 \%$ fibres volume content at the bottom of the UN prisms increased the flexural capacity by $23 \%, 68 \%$, and $90 \%$ respectively. While for UH prisms, the addition of UHPFRC layer with $1 \%, 1.5 \%$ and $2 \%$ fibres volume content at the bottom of the UH prisms increased the flexural capacity by $45 \%, 54 \%$, and $77 \%$ respectively.

A comparison between UN and UH prism specimens show that the compressive strength of the NSC or HSC layer had no significant effect on the flexural capacity of composite prisms. However, increasing the steel fibre percentage in the UHPFRC layer significantly improved the flexural strength of the concrete prisms. This can be attributed to the fact that when the fibre percentage increased, the fibre concentration in the vicinity of the crack increased, providing effective stress transfer across the crack. It was noted during the tests of composite prisms that the crack propagated very fast when reached the NSC or HSC layer. This can be attributed to the effect of fibres that bridging the crack, delay the propagation of the macro cracks in the UHPFRC layer.

Furthermore, the addition of UHPFRC layer with $1 \%, 1.5 \%$ and $2 \%$ fibres volume content at the bottom of the UN prisms significantly enhanced the ductility by 3.4, 4.6, and 5.3 times respectively compared to NS prism respectively. While for UH prism specimens, the addition of 
UHPFRC layer with $1 \%, 1.5 \%$ and $2 \%$ fibre volume content at the bottom of the UH prisms enhanced the ductility by $3.8,3.9$, and 4.3 times respectively compared to HS prism.

It was observed that addition of steel fibres significantly improved the toughness of the prisms as shown in Table 5.4. For instance, UN and UH prisms with $1 \%$ fibres showed approximately 8 and 16 times higher toughness than that of NS and HS prisms respectively.

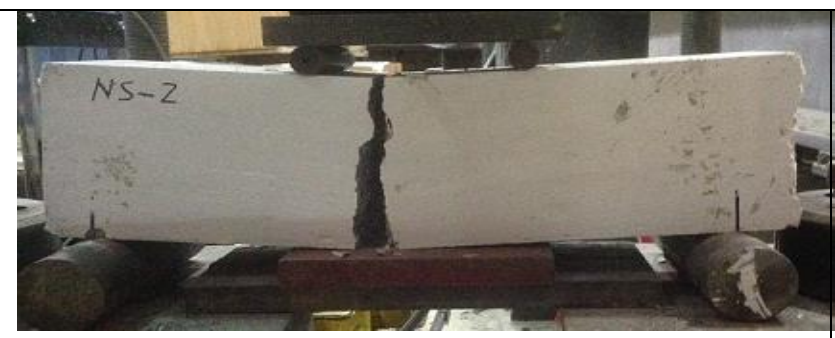

(a) NSC

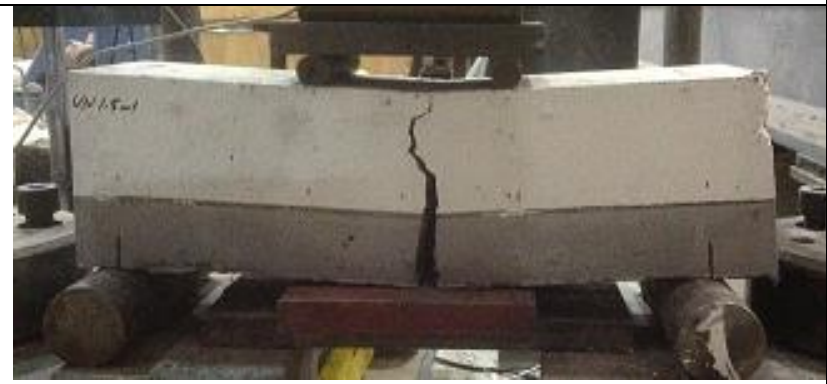

(c) UN1.5

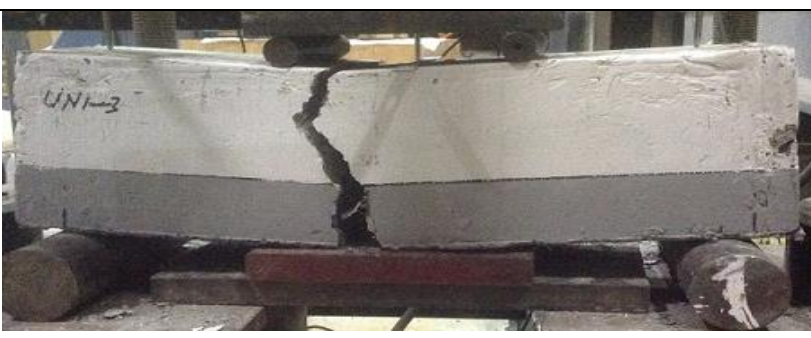

(b) UN1

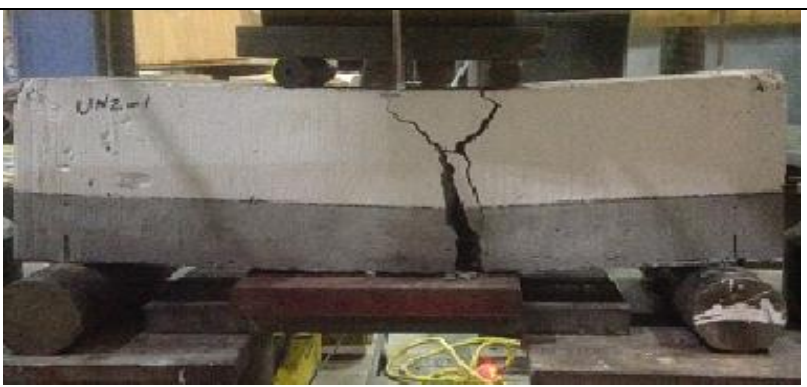

(d) UN2

Figure 5.1 Flexural behaviour of UHPFRC/NSC prisms 


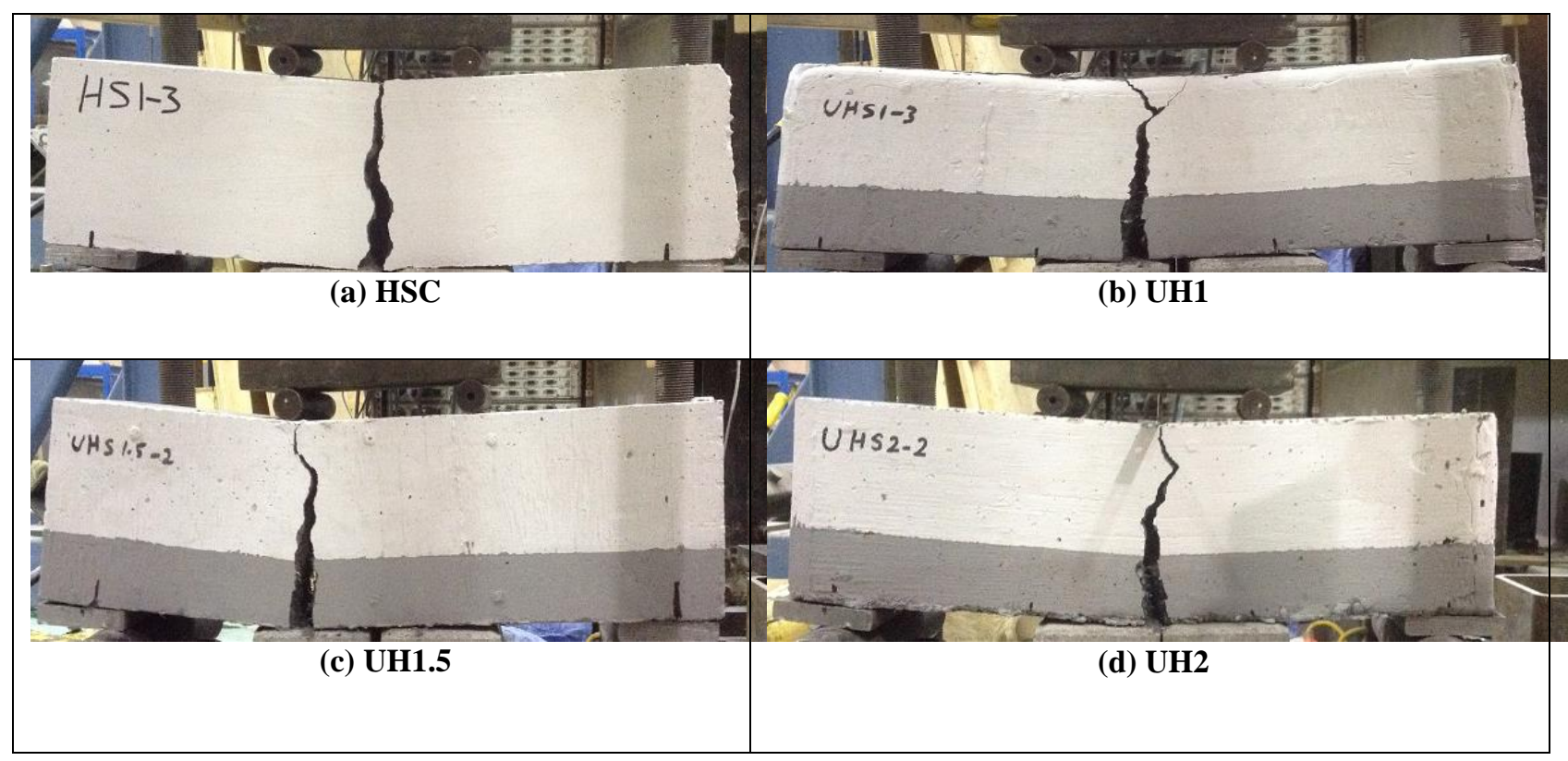

Figure 5.2 Flexural behaviour of UHPFRC/HSC prisms

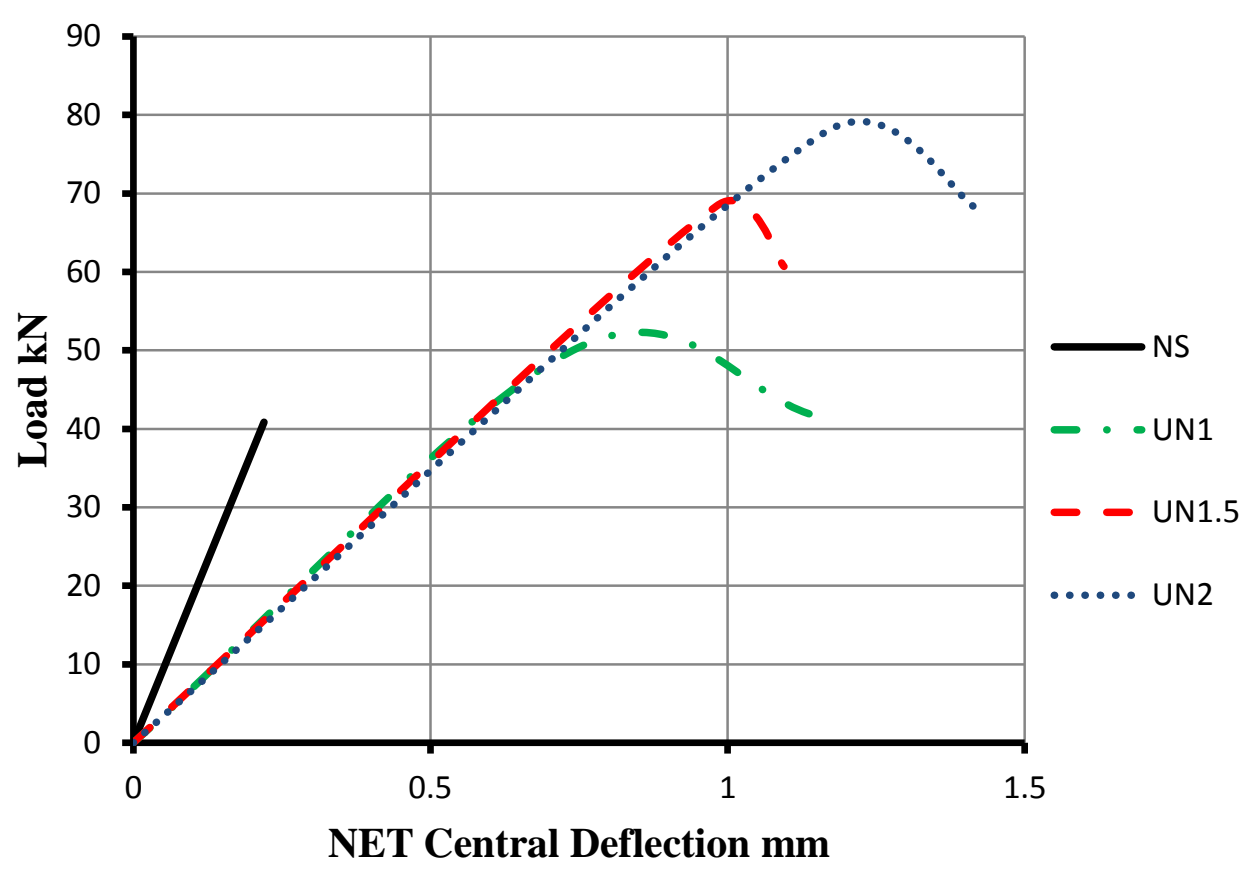

Figure 5.3 Load versus net deflection relationship for UHPFRC-NSC prisms 


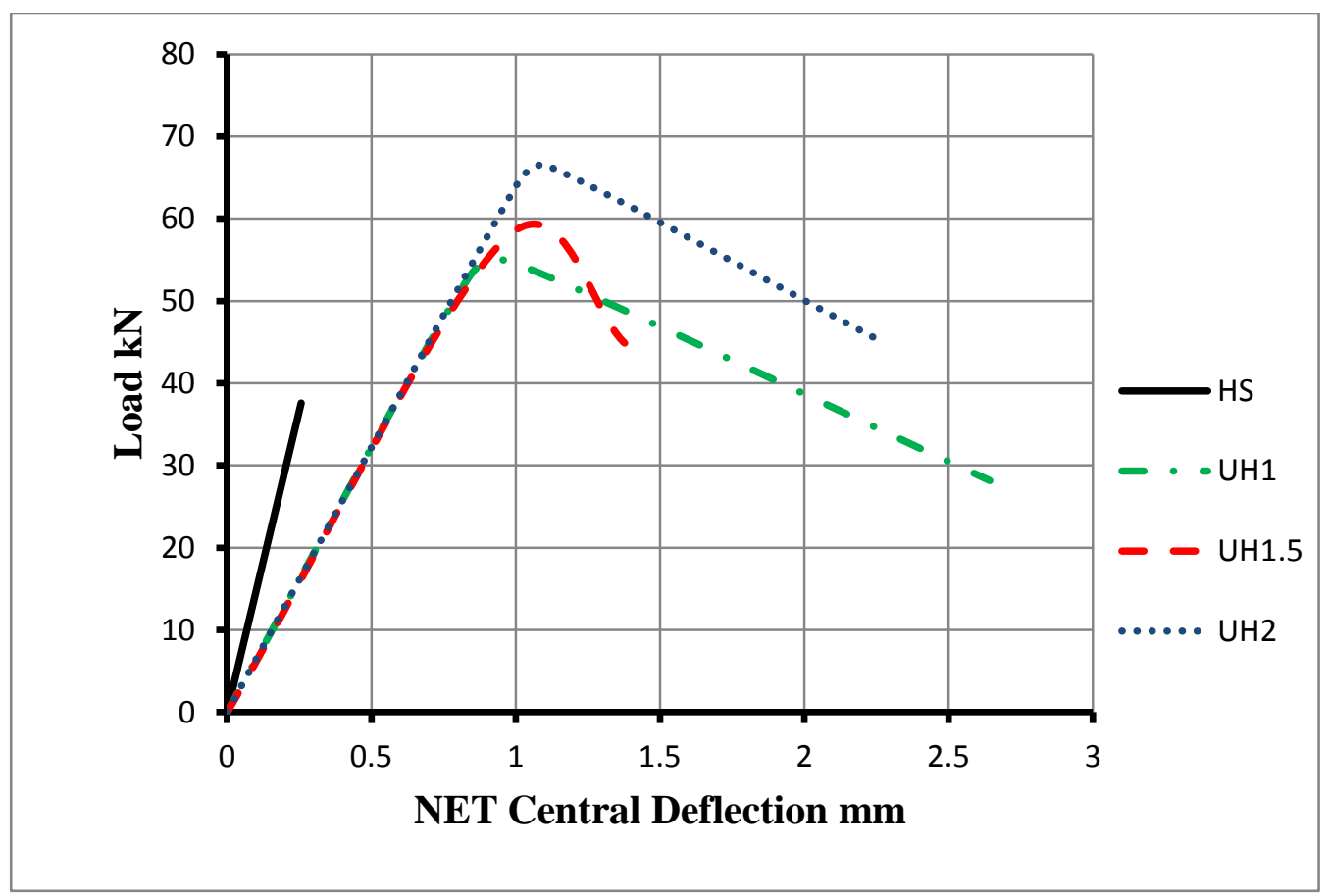

Figure 5.4 Load versus net deflection relationship for UHPFRC-HSC prisms

\subsection{Behaviour of beam tests}

The initial cracking load, ultimate failure load, and deflection at peak load are summarized in Table 5.5.

\subsubsection{Beams UNS3-1, UNS3-1D and UNS3-1S}

For Beams UNS3-1, UNS3-1D and UNS3-1S, the load versus central deflection relationship and crack pattern after failure are shown in Figures 5. 5 - 5.10 respectively. All beams failed in shear due to concrete crushing in the compression zone in the NSC portion. Inclined crack was initiated in the left span at the bottom of the NSC layer (mid depth of the beam), and as the applied load increased, the crack propagated to the loading point. As the applied load further increased, another inclined crack started to develop in the left span at the bottom of the NSC layer, and the cracks width increased, and fibres were pulled out of the matrix. Failure occurred as one major diagonal crack in the NSC layer resulted in tensile failure of the beam. 
The UNS3-1, UNS3-1D and UNS3-1S beams failed at applied loads 436, 402 and $430 \mathrm{kN}$ respectively. The shear capacity of the composite beam was not improved by the presence of dowels and shear stud. This can be attributed to the high bond strength between the UHPFRC and NSC layer because the inclined cracks were did not propagate through the interface between the UHPFRC, and NSC layer. The initial cracking load, the ultimate load, and the maximum deflection at ultimate load for UNS3-1, UNS3-1D and UNS3-1S are shown in Table 5.5.

Table 5.5 Experimental results of test beams

\begin{tabular}{|c|c|c|c|c|}
\hline Beam & $V_{f} \%$ & $\begin{array}{c}\text { Initial } \\
\text { Cracking } \\
\text { load } \\
\text { kN }\end{array}$ & $\begin{array}{c}\text { Ultimate } \\
\text { Failure } \\
\text { Load } \\
\text { kN }\end{array}$ & $\begin{array}{c}\text { Deflection at } \\
\text { Maximum } \\
\text { Resistance } \\
\Delta \exp \\
(\mathbf{m m})\end{array}$ \\
\hline UNS3-1 & \multirow{3}{*}{1.0} & 295 & 436.24 & 6.15 \\
\hline UNS3-1D & & 300 & 402.25 & 5.55 \\
\hline UNS3-1S & & 300 & 430.24 & 6.46 \\
\hline UNS3-1.5 & \multirow[t]{2}{*}{1.5} & 310 & 439.15 & 7.66 \\
\hline UNS3-1.5D & & 280 & 503.56 & 6.41 \\
\hline UNS3-2 & \multirow[t]{2}{*}{2.0} & 350 & 521.56 & 6.63 \\
\hline UNS3-2D & & 310 & 502.45 & 7.24 \\
\hline UHS3-1 & \multirow{3}{*}{1.0} & 280 & 528.41 & 8.57 \\
\hline UHS3-1D & & 280 & 439.22 & 9.52 \\
\hline UHS3-1S & & 290 & 433.02 & 6.19 \\
\hline UHS3-1.5 & \multirow[t]{2}{*}{1.5} & 245 & 403.59 & 5.15 \\
\hline UHS3-1.5D & & 290 & 465.79 & 6.52 \\
\hline UHS3-2 & \multirow[t]{2}{*}{2.0} & 300 & 522.89 & 6.45 \\
\hline UHS3-2D & & 370 & 521.45 & 10.92 \\
\hline
\end{tabular}




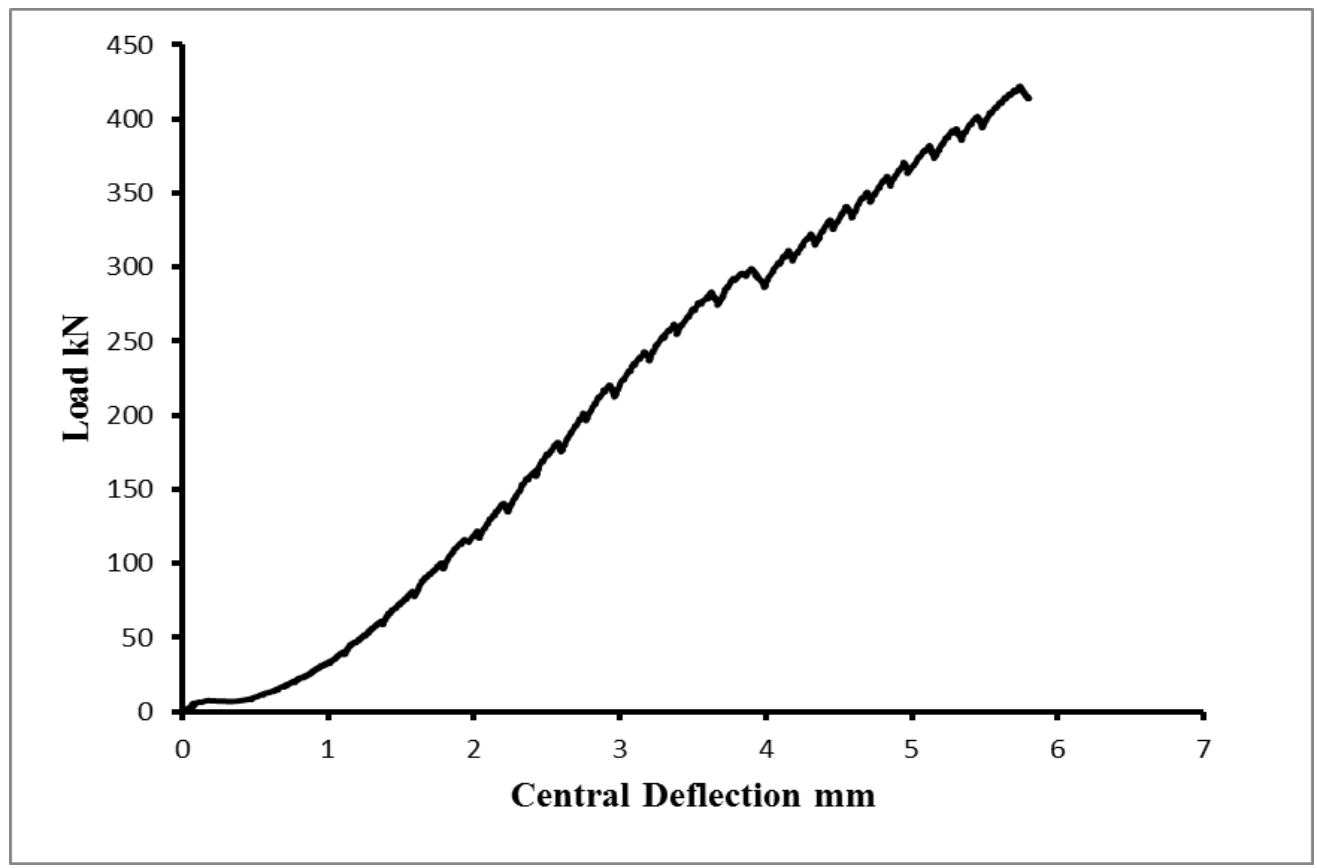

Figure 5.5 Load versus central deflection relationship - Beam UNS3-1

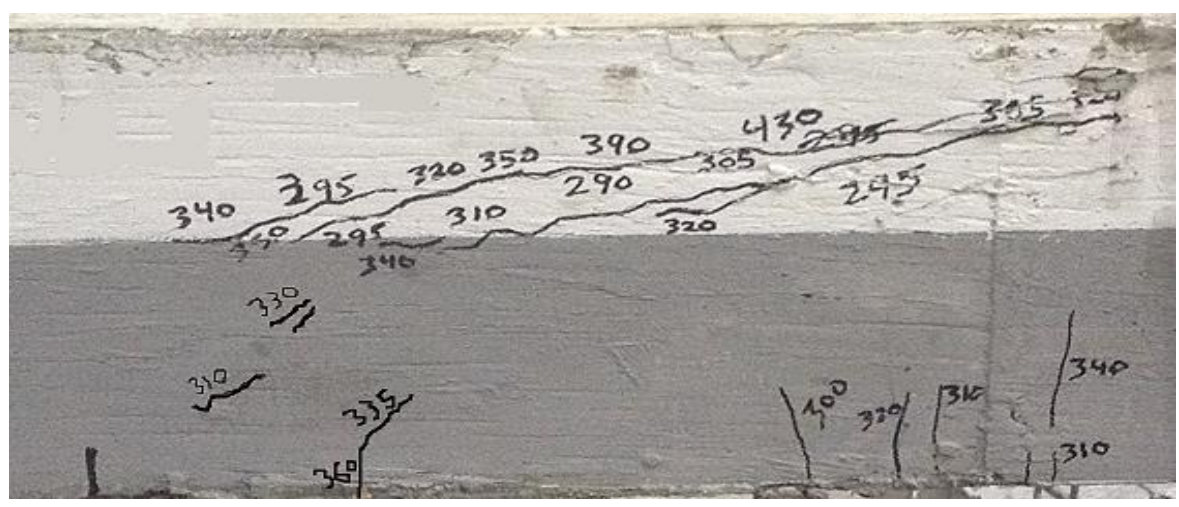

Figure 5.6 Crack pattern after failure - Beam UNS3-1 


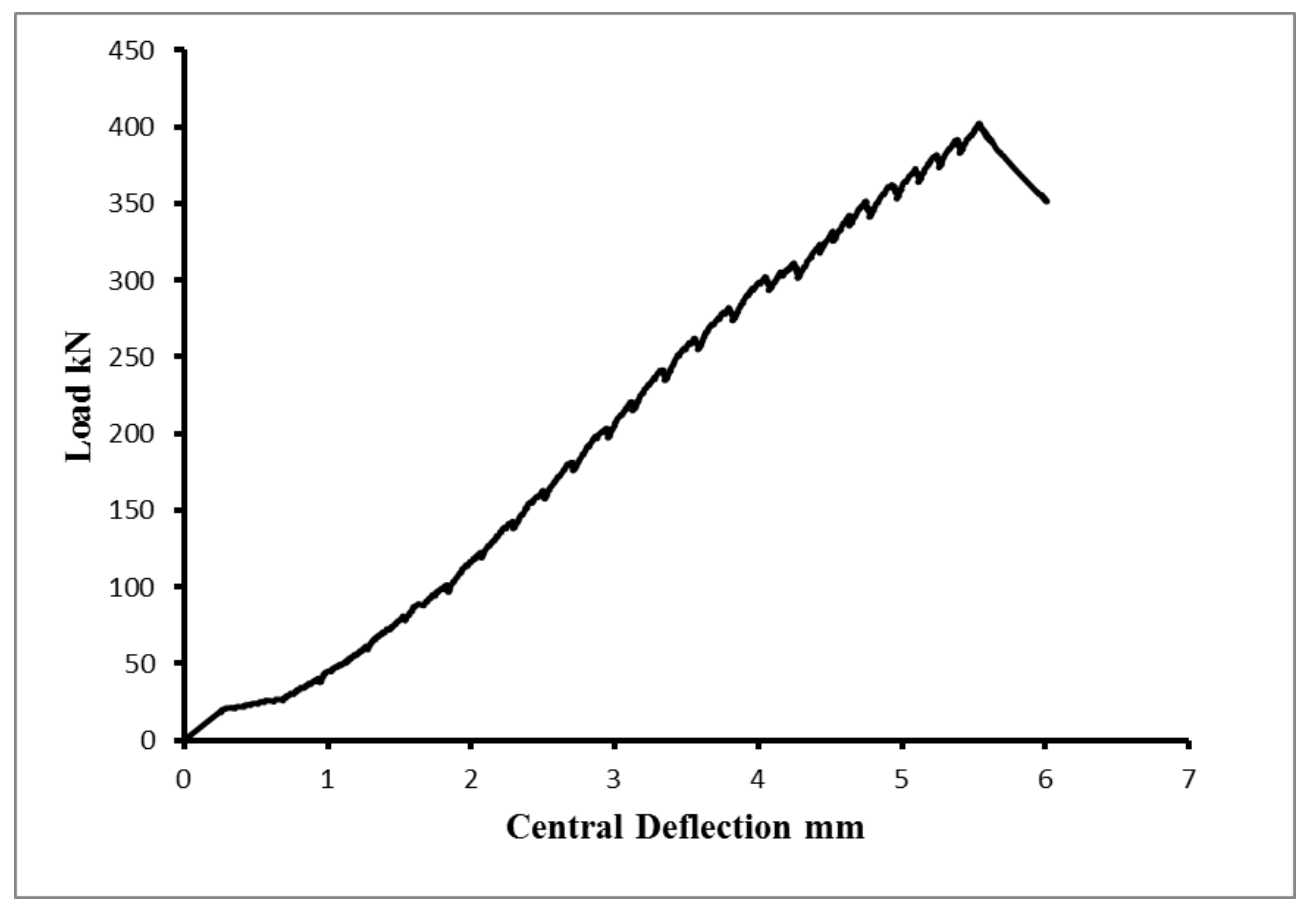

Figure 5.7 Load versus central deflection relationship - Beam UNS3-1D

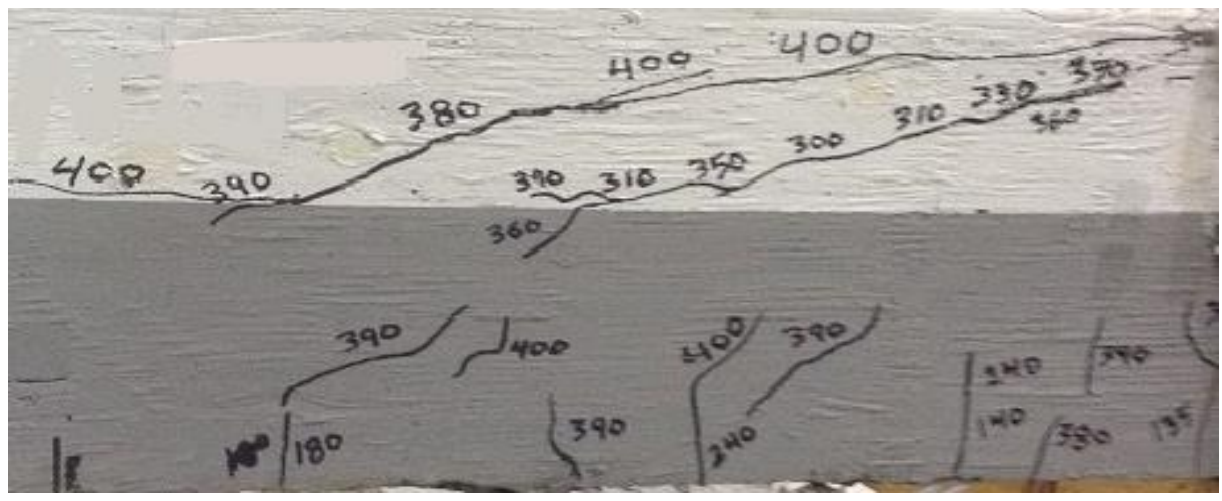

Figure 5.8 Crack pattern after failure - Beam UNS3-1D 


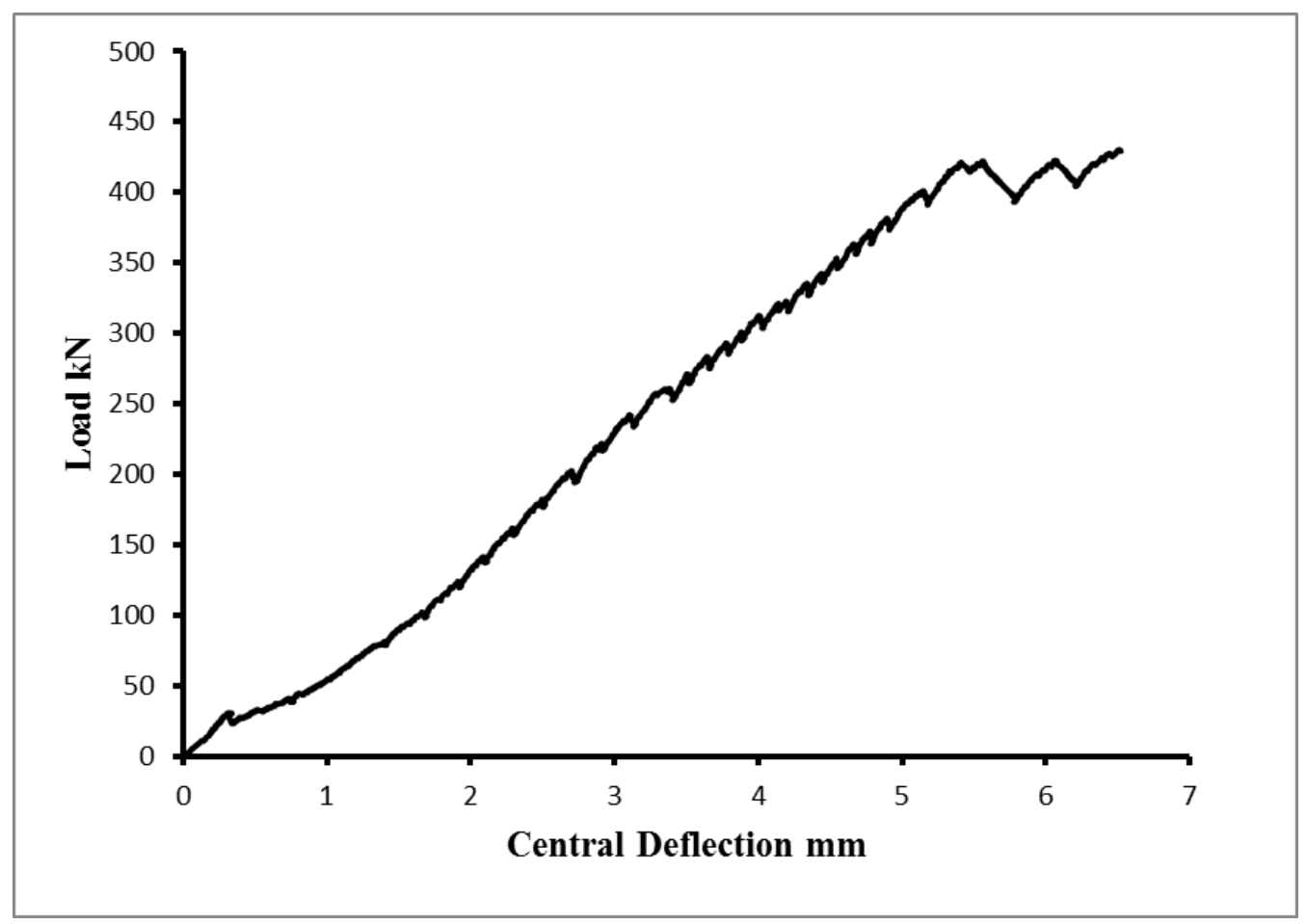

Figure 5.9 Load versus central deflection relationship - Beam UNS3-1S

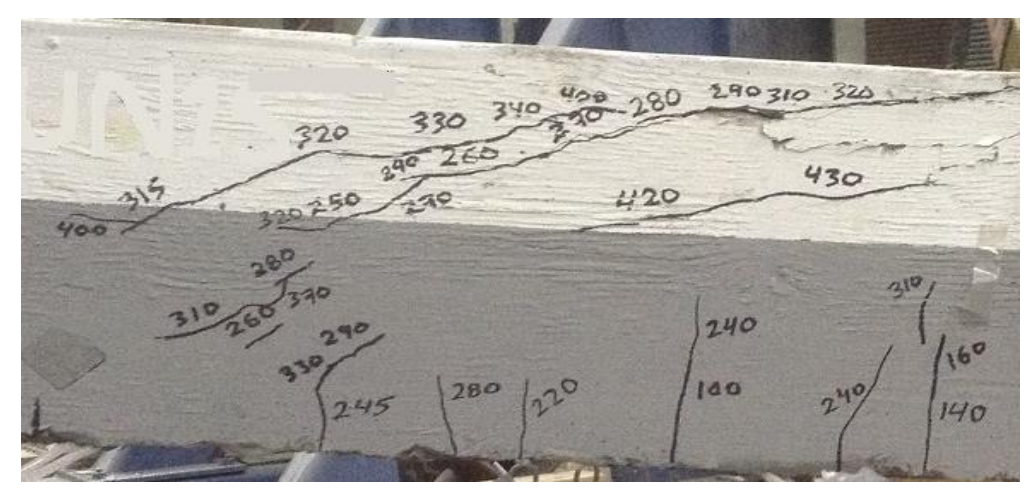

Figure 5.10 Crack pattern after failure - Beam UNS3-1S

Figures 5.11 - 5.13 show the load - crack width relationships for beams UNS3-1, UNS3-1D and UNS3-1S respectively. It can be noted from Figures $5.11-5.13$ that the widths of the crack were significantly smaller in all beams between the UHPFRC, and NSC/HSC layers, and when the inclined cracks started to propagate through the NSC/HSC layer, the crack width increased due to forming of diagonal cracks in NSC or HSC layer. For example, Beam UNS3-1, the crack 
widths at crack gauges were almost zero up to applied $200 \mathrm{kN}$, then when the inclined cracks started to develop in the NSC layer, the crack widths started to increase.

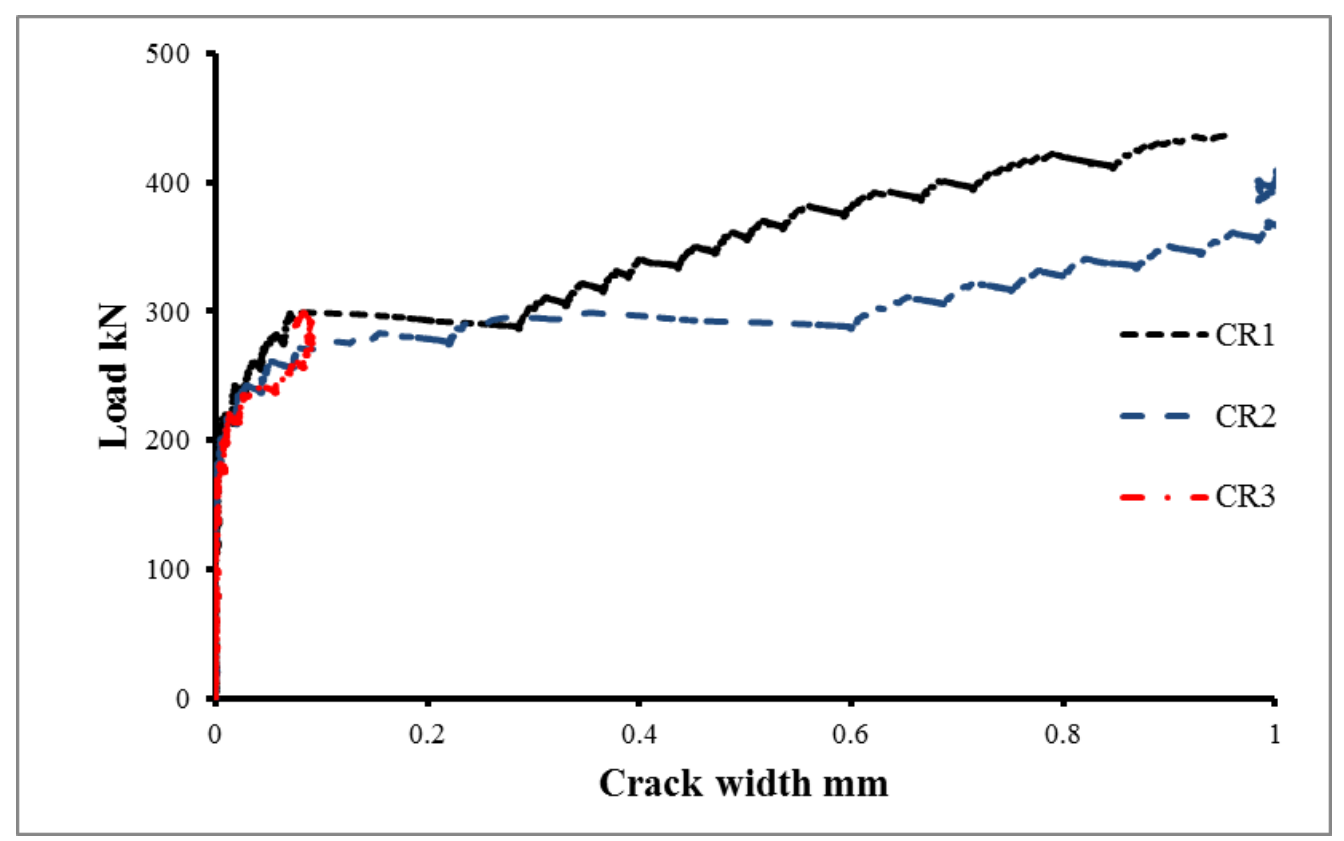

Figure 5.11 Load versus crack width relationship - Beam UNS3-1

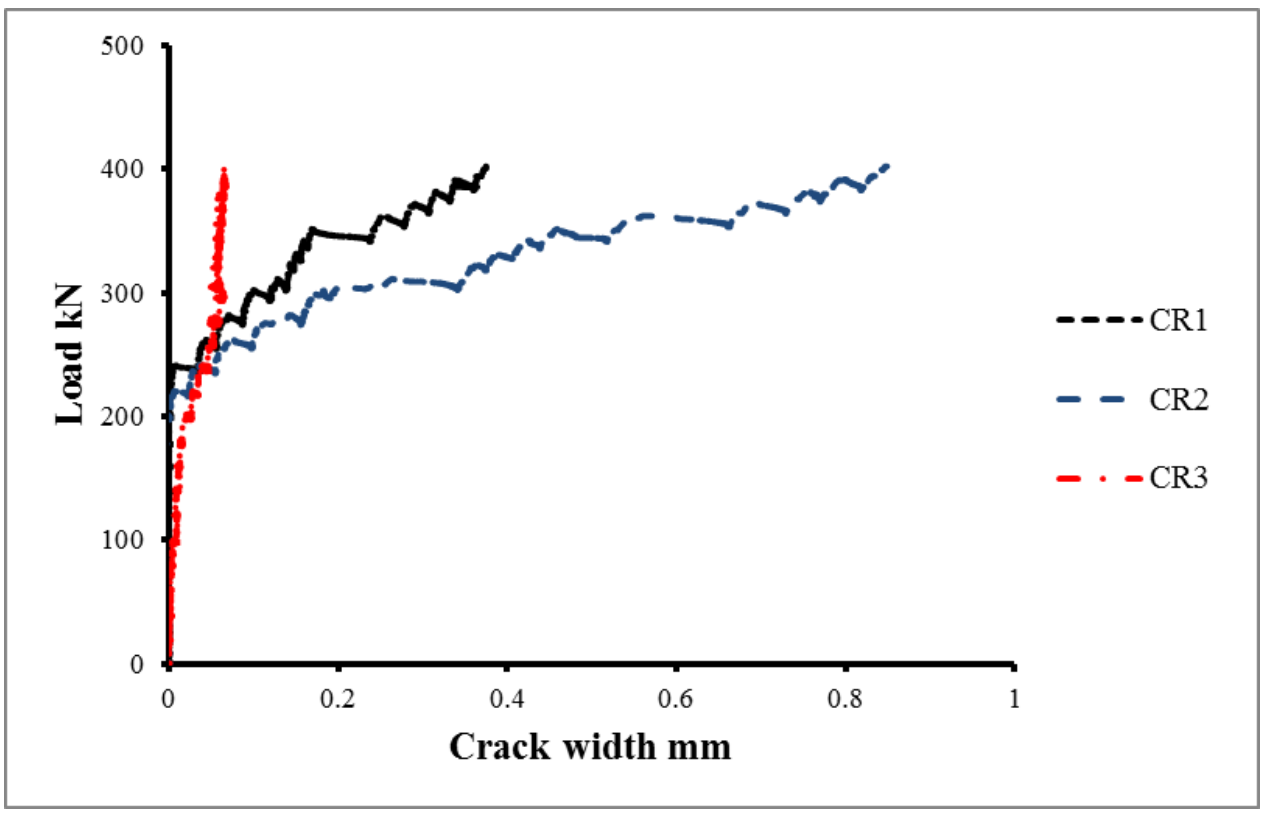

Figure 5.12 Load versus crack width relationship - Beam UNS3-1D 


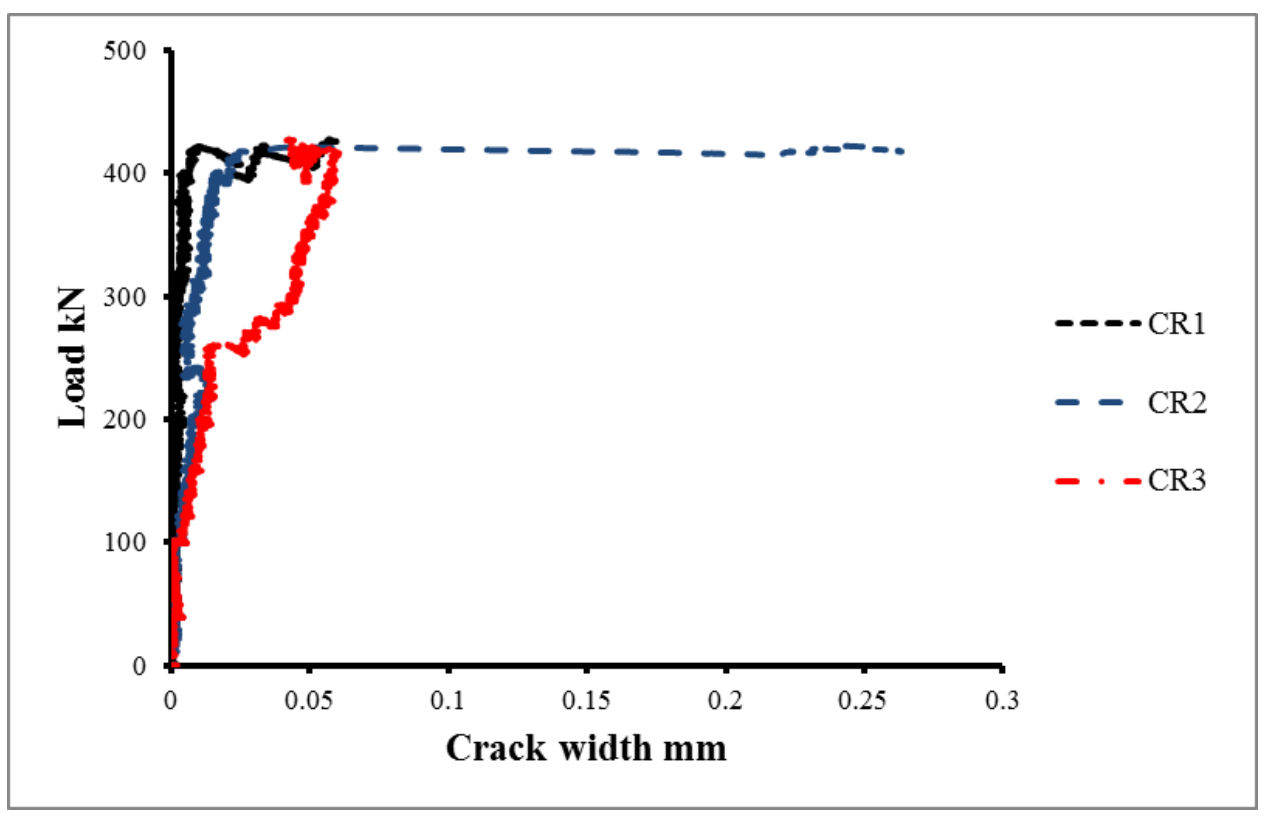

Figure 5.13 Load versus crack width relationship - Beam UNS3-1S

The load versus the reinforcement strain relationship for beams UNS3-1, UNS3-1D, and UNS3$1 \mathrm{~S}$ are shown in Figures 5.14- 5.16 respectively. It can be noted from Figures 5.14- 5.16 that most of the strain gauges increased linearly with the increase in the applied load excepting for S2 gauge as the strain increased suddenly at an applied load of 280 to $300 \mathrm{kN}$ due to the initiation of the inclined cracks at the NSC layer in the vicinity of the gauge. 


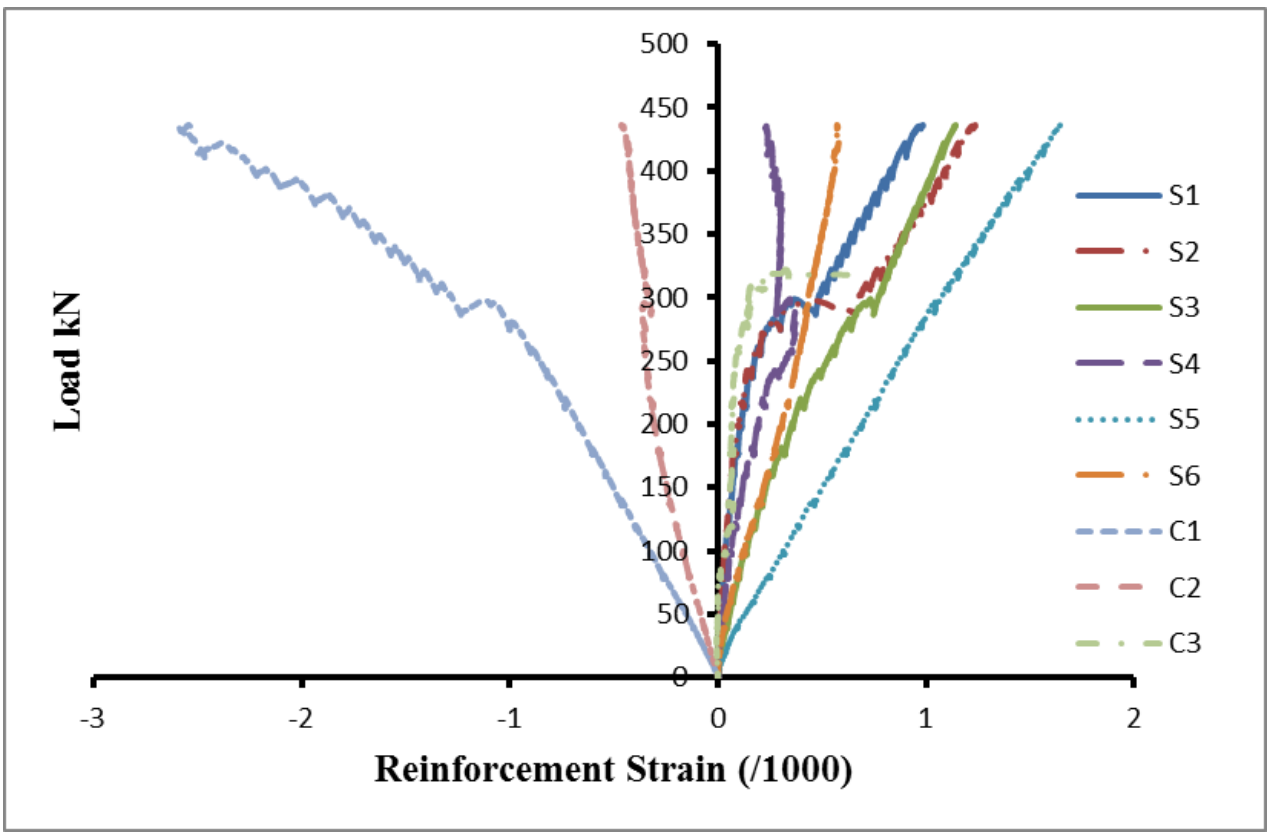

Figure 5.14 Load versus reinforcement strain - Beam UNS3-1

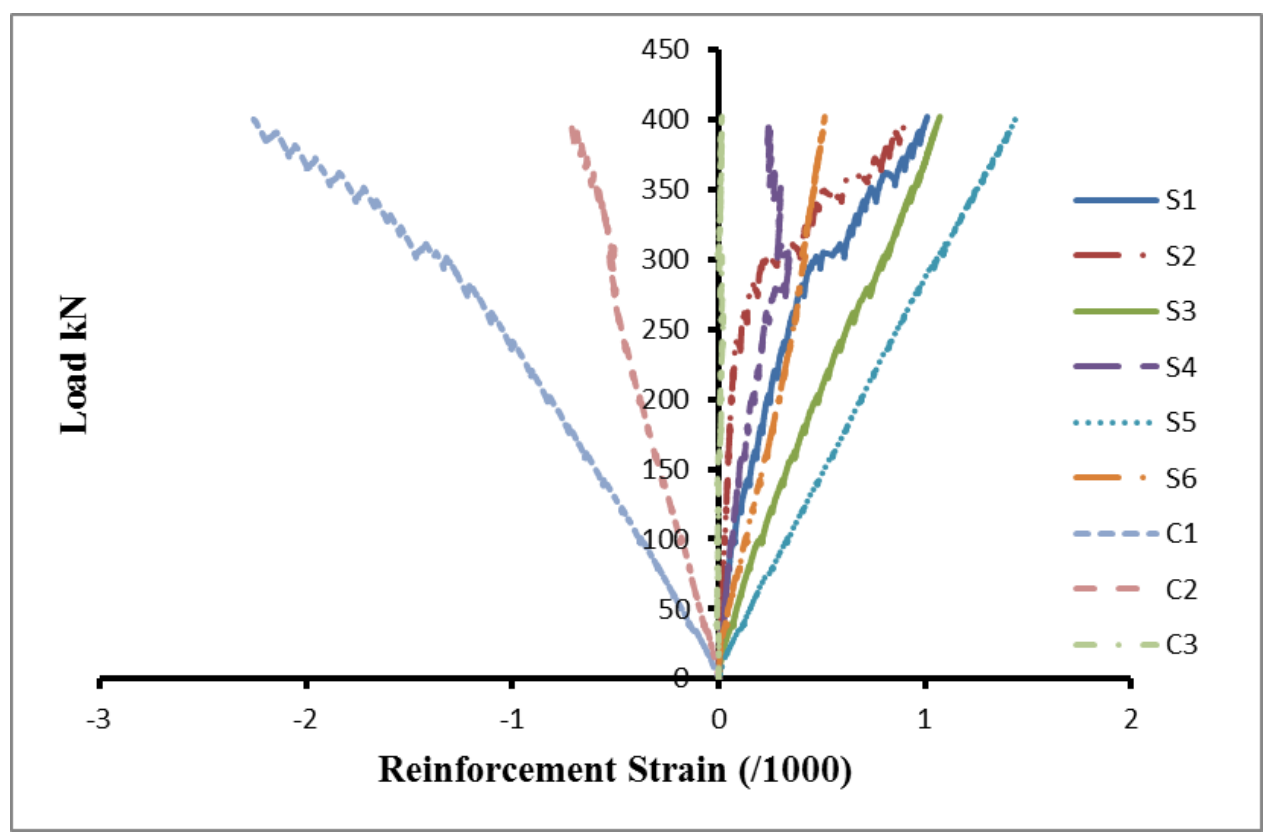

Figure 5.15 Load versus reinforcement strain - Beam UNS3-1D 


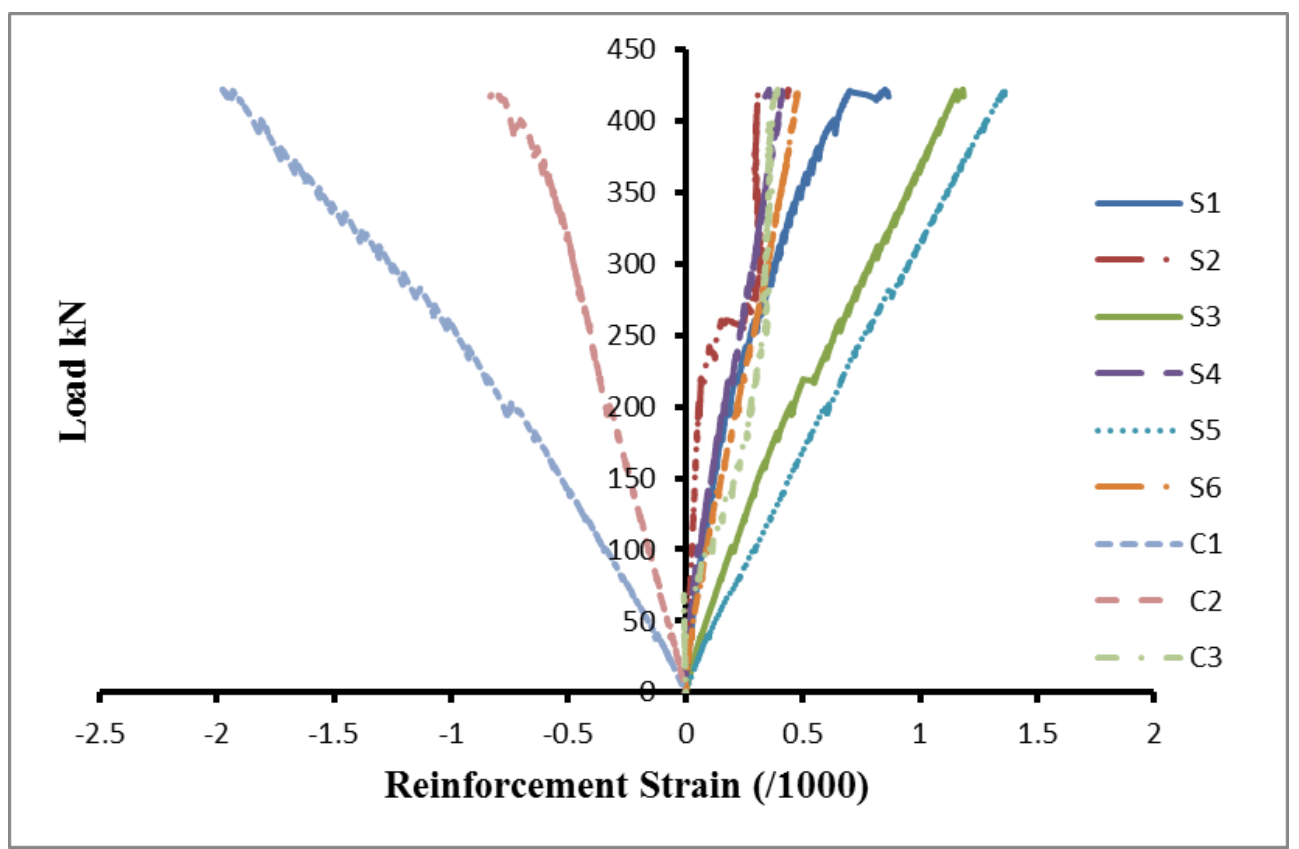

Figure 5.16 Load versus reinforcement strain - Beam UNS3-1S

\subsubsection{Beams UNS3-1.5, and UNS3-1.5D}

The load versus central deflection relationship and crack pattern after failure for Beams UNS31.5, and UNS3-1.5D were similar to beams UNS3-1, UNS3-1D and UNS3-1S, however, the shear capacity increased in UNS3-1.5D compared to beam UNS3-1.5 as shown in Figures 5.17 5.20 respectively. The initial cracking load, the ultimate load, and the maximum deflection at ultimate load of UNS3-1.5, and UNS3-1.5D are shown in Table 5.5. 


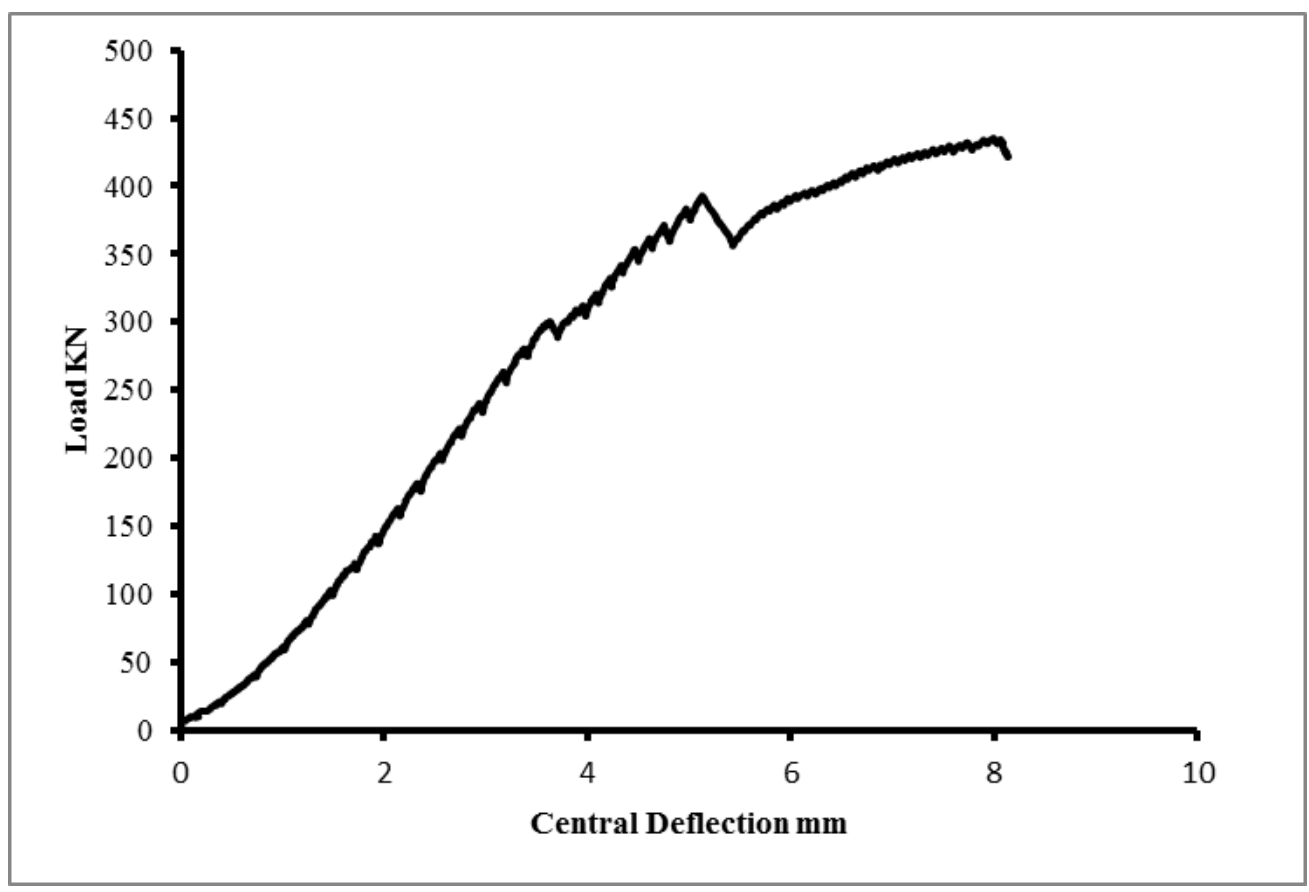

Figure 5.17 Load versus central deflection relationship - Beam UNS3-1.5

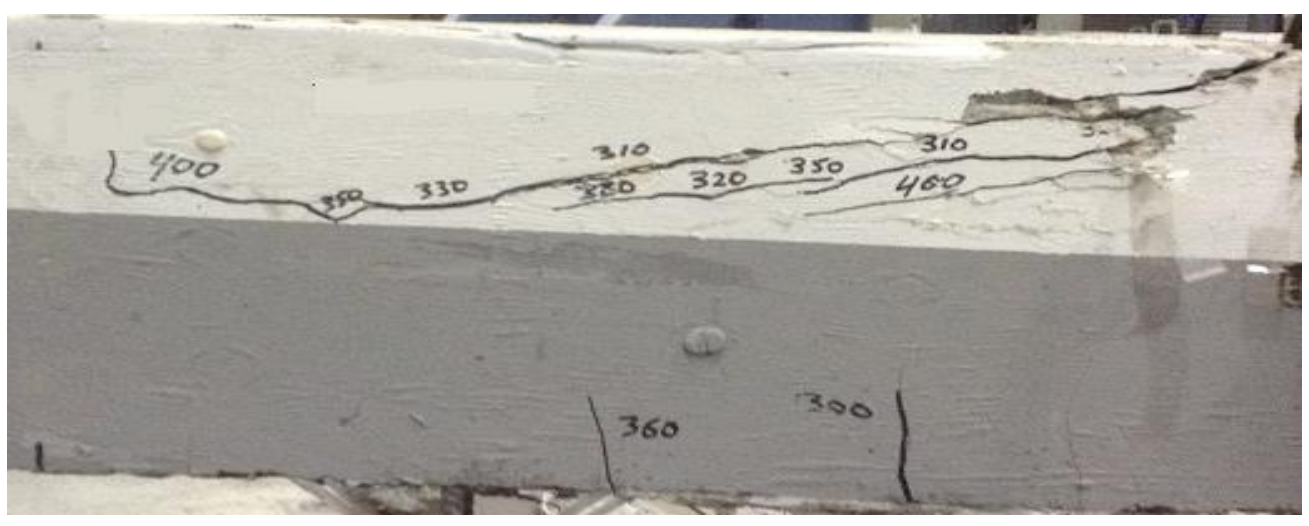

Figure 5.18 Crack pattern after failure - Beam UNS3-1.5 


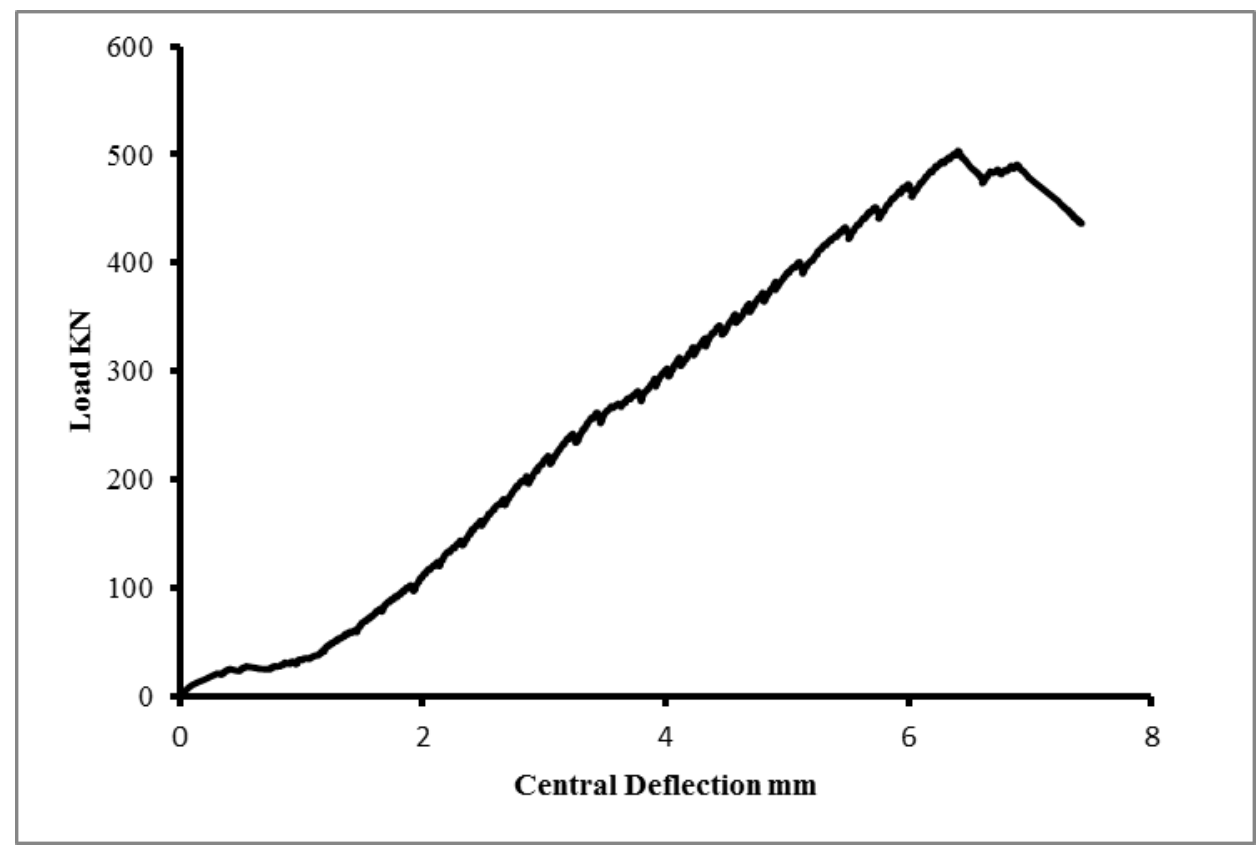

Figure 5.19 Load versus central deflection relationship - Beam UNS3-1.5D

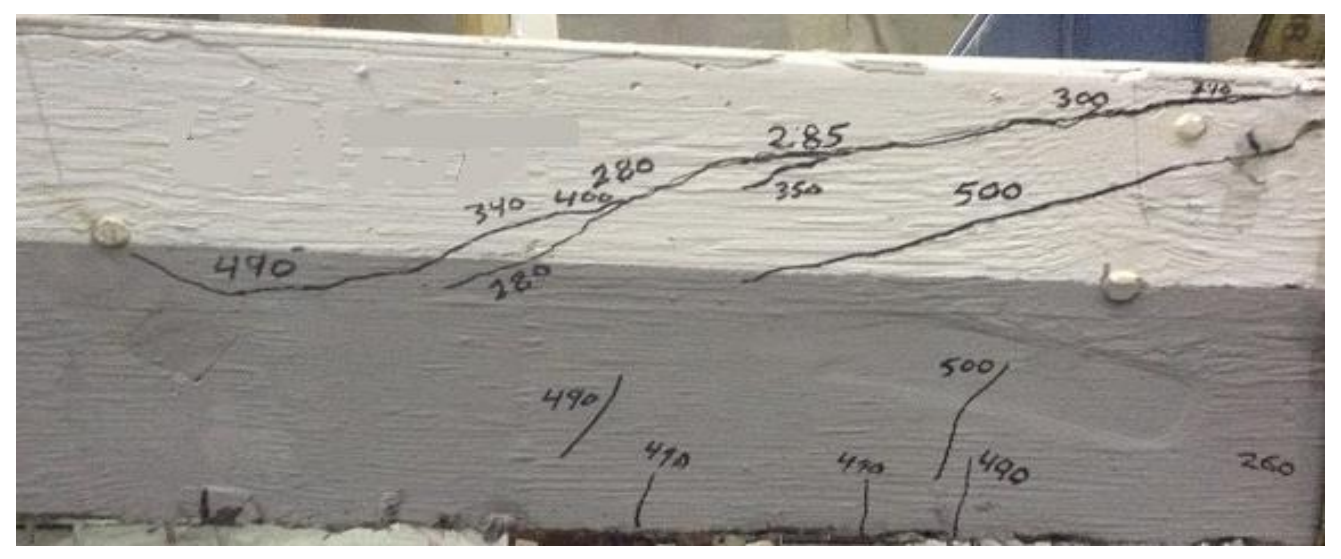

Figure 5.20 Crack pattern after failure - Beam UNS3-1.5D

Figures 5.21, and 5.22 show the load - crack width relationships for beams UNS3-1.5, and UNS3-1.5D respectively. It can be observed from Figure 5.21 that the crack width started to increase in gauges CR2 and CR3 at a load higher than $100 \mathrm{kN}$ while the crack width started to increase at gauge CR1 at a load higher than $300 \mathrm{kN}$ at the time that the inclined crack started to propagate between the UHPFRC and NSC layers. 


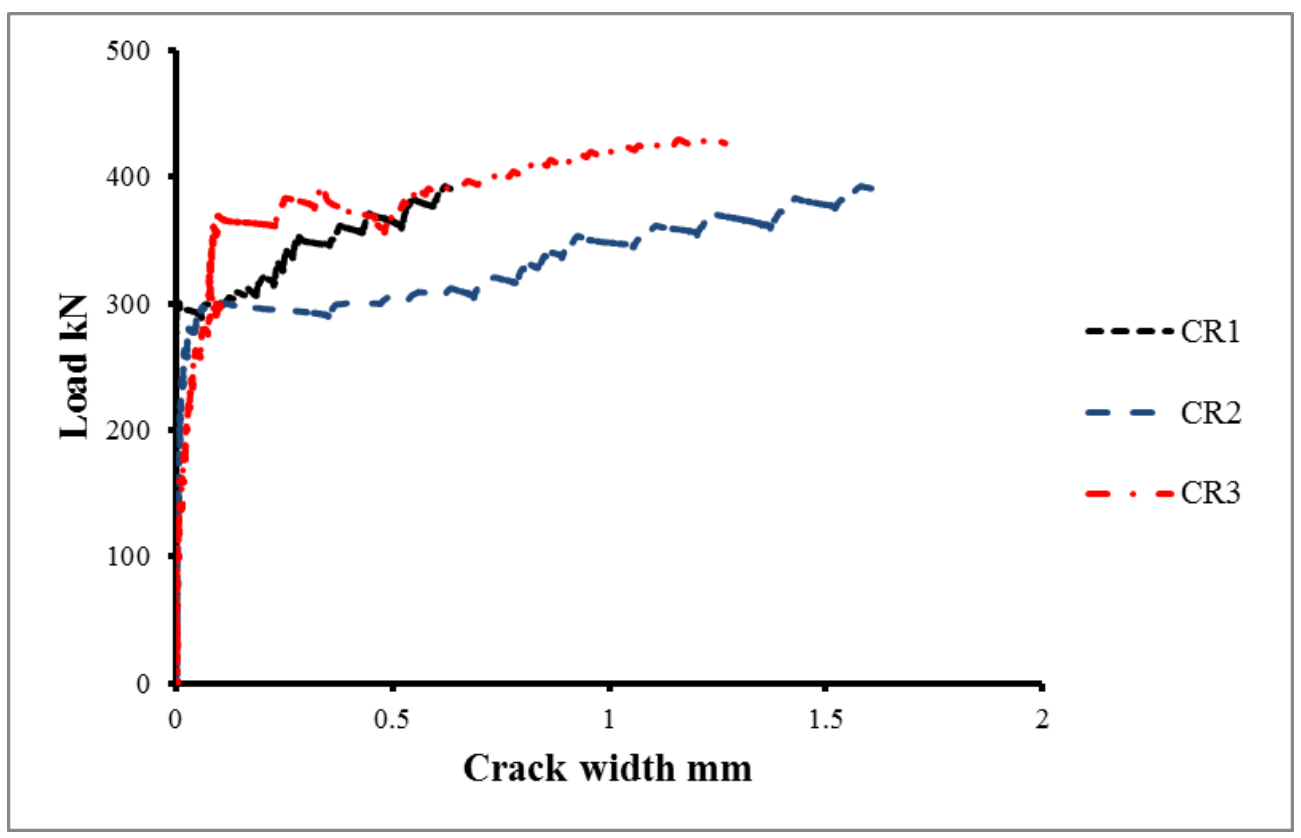

Figure 5.21 Load versus crack width relationship - Beam UNS3-1.5

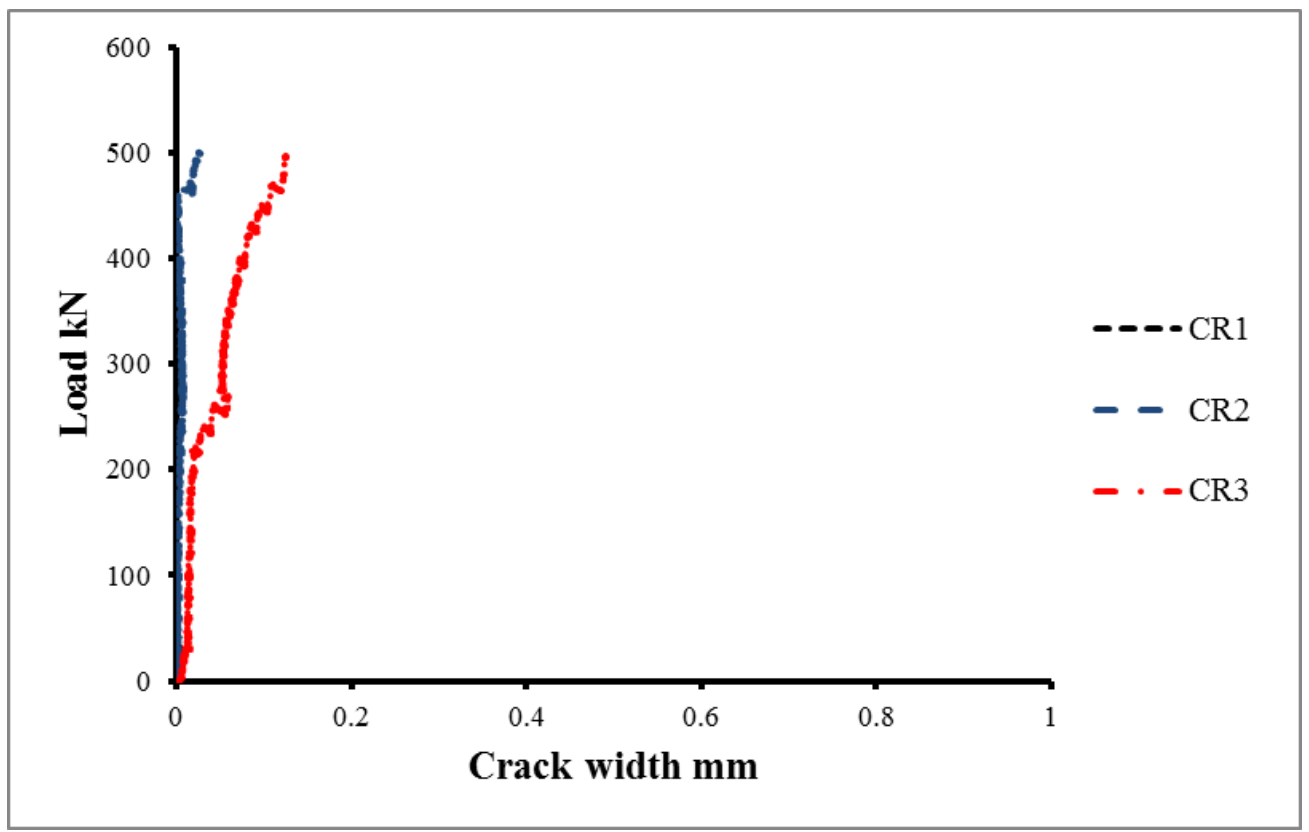

Figure 5.22 Load versus crack width relationship - Beam UNS3-1.5D 
The load versus the reinforcement strain relationship for beams UNS3-1.5, and UNS3-1.5D are shown in Figures 5.23 and 5.24 respectively.

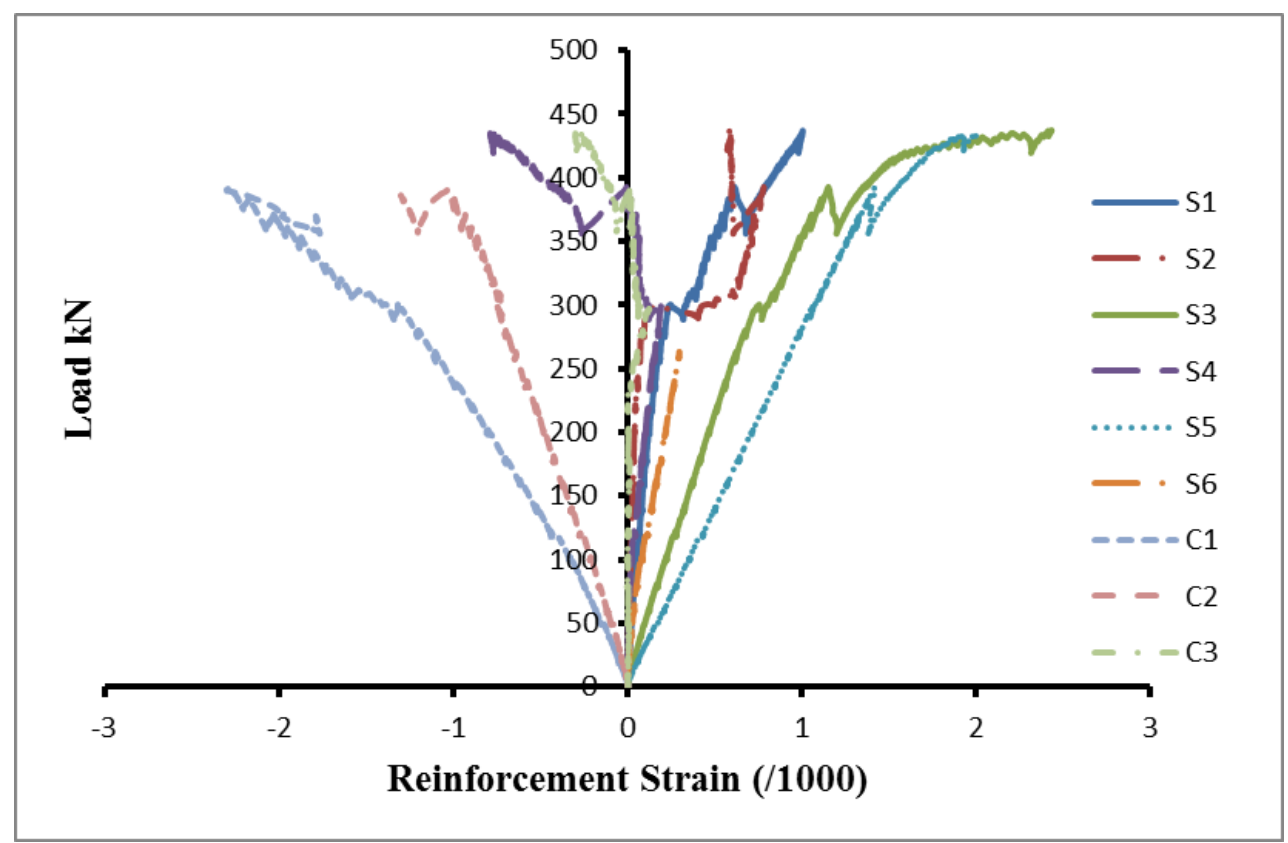

Figure 5.23 Load versus reinforcement strain - Beam UNS3-1.5

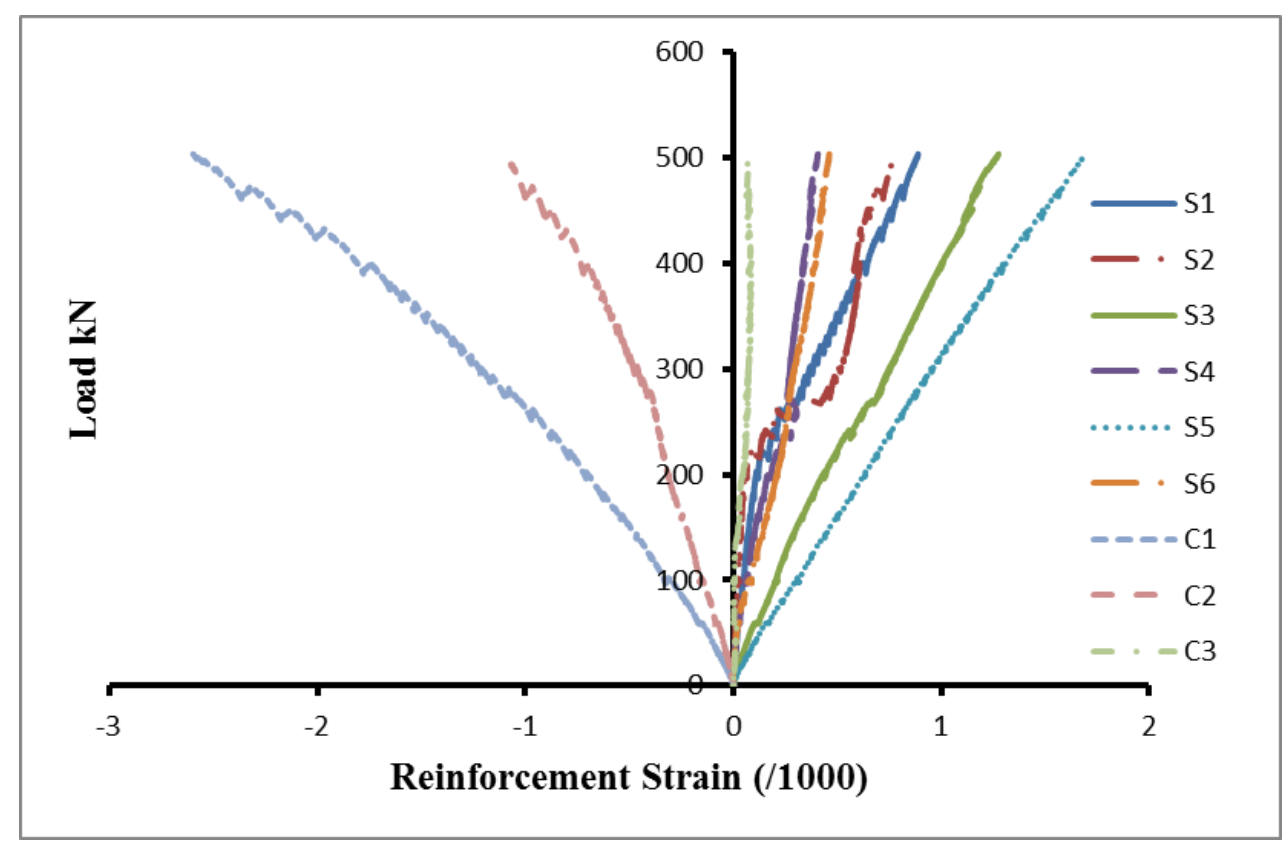

Figure 5.24 Load versus reinforcement strain - Beam UNS3-1.5D 


\subsubsection{Beams UNS3-2, and UNS3-2D}

The load versus central deflection relationship and crack pattern after failure for Beams UNS3-2 and UNS3-2D were similar to beams UNS3-1, UNS3-1D and UNS3-1S as shown in Figures 5.25 - 5.28 respectively. The initial cracking load, the ultimate load, and the maximum deflection at ultimate load of UNS3-2, and UNS3-2D are shown in Table 5.5.

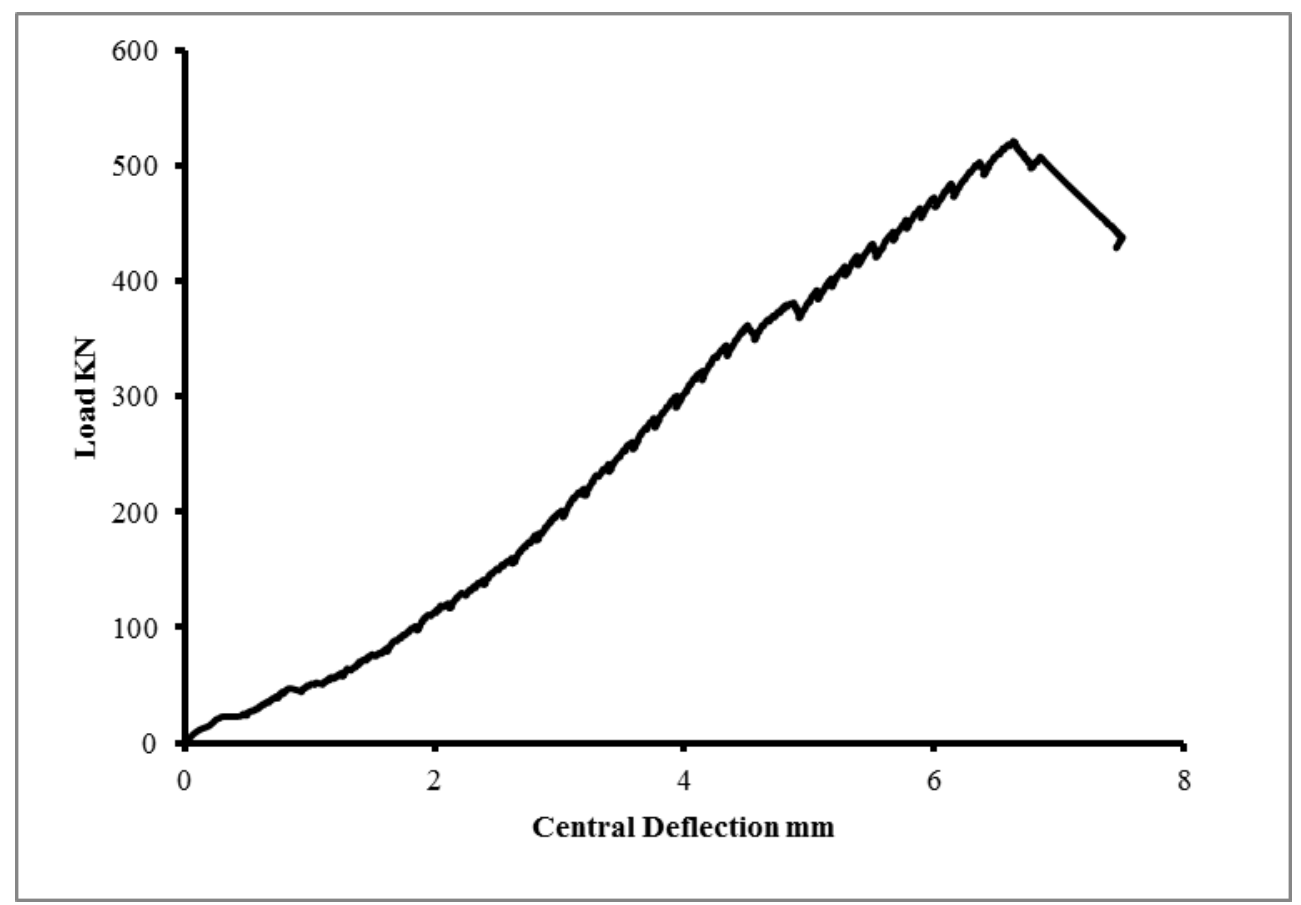

Figure 5.25 Load versus central deflection relationship - Beam UNS3-2

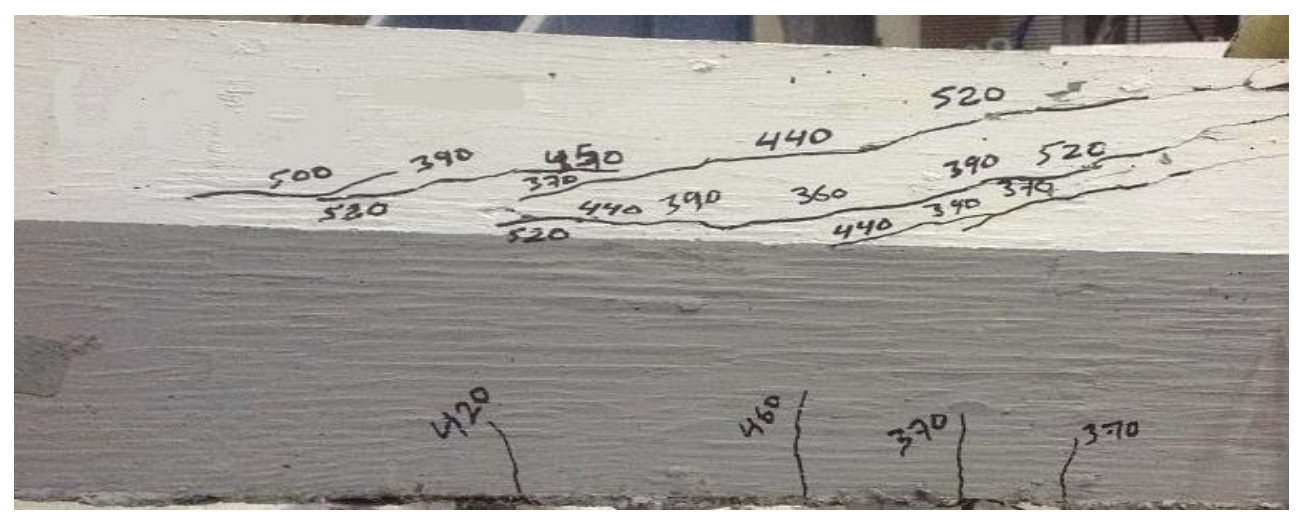

Figure 5.26 Crack pattern after failure - Beam UNS3-2 


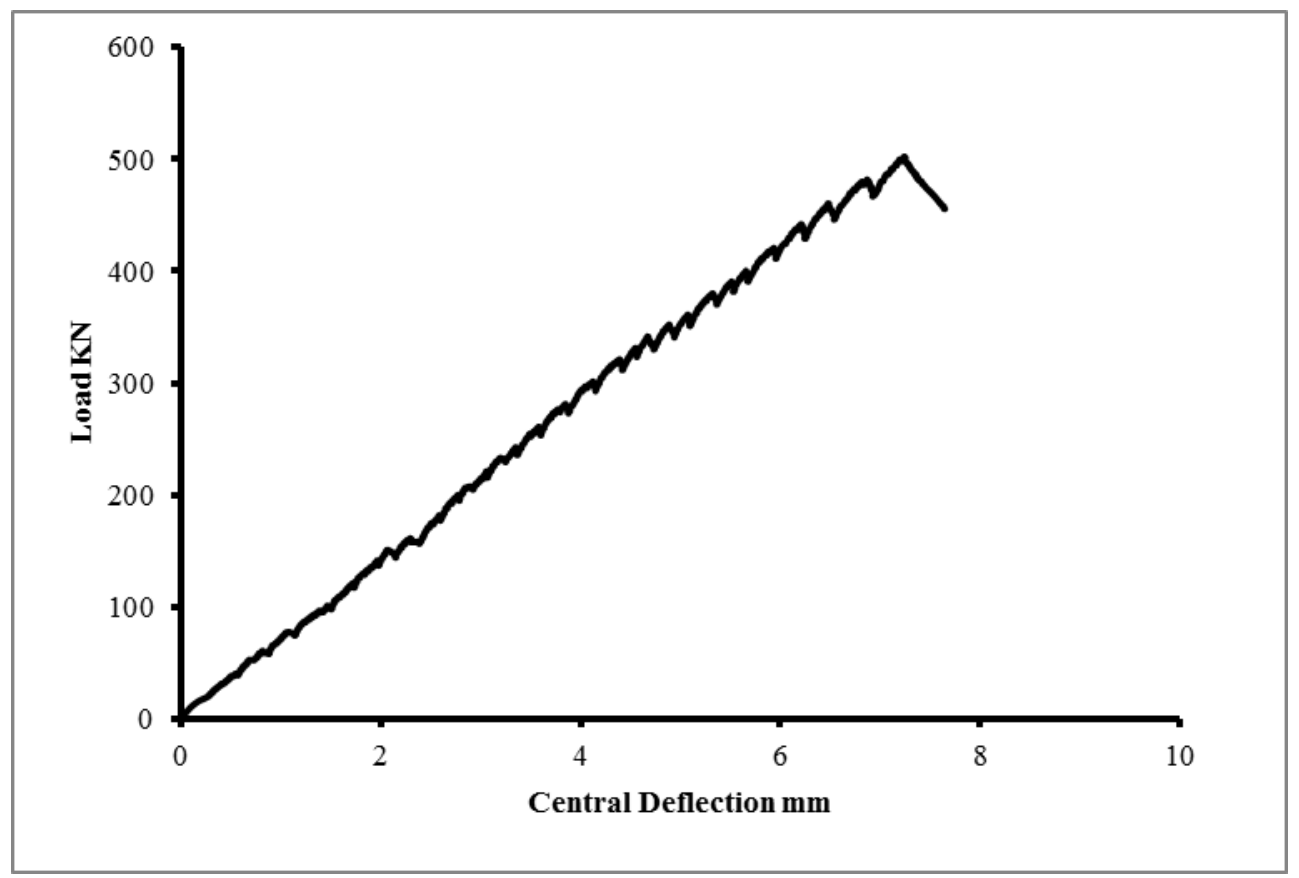

Figure 5.27 Load versus central deflection relationship - Beam UNS3-2D

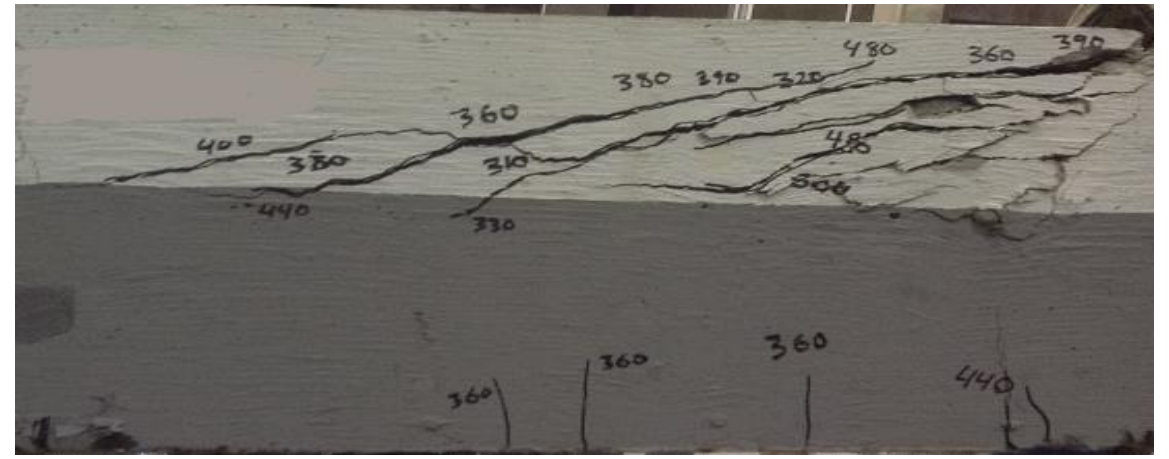

Figure 5.28 Crack pattern after failure - Beam UNS3-2D

Figures 5.29 and 5.30 show the load - crack width relationships for beams UNS3-2 and UNS32D respectively. It can be observed from Figures 5.29, and 5.30 that the crack widths started to increase at an applied load $250 \mathrm{kN}$ where the inclined cracks started to propagate between the UHPFRC and NSC layers. 


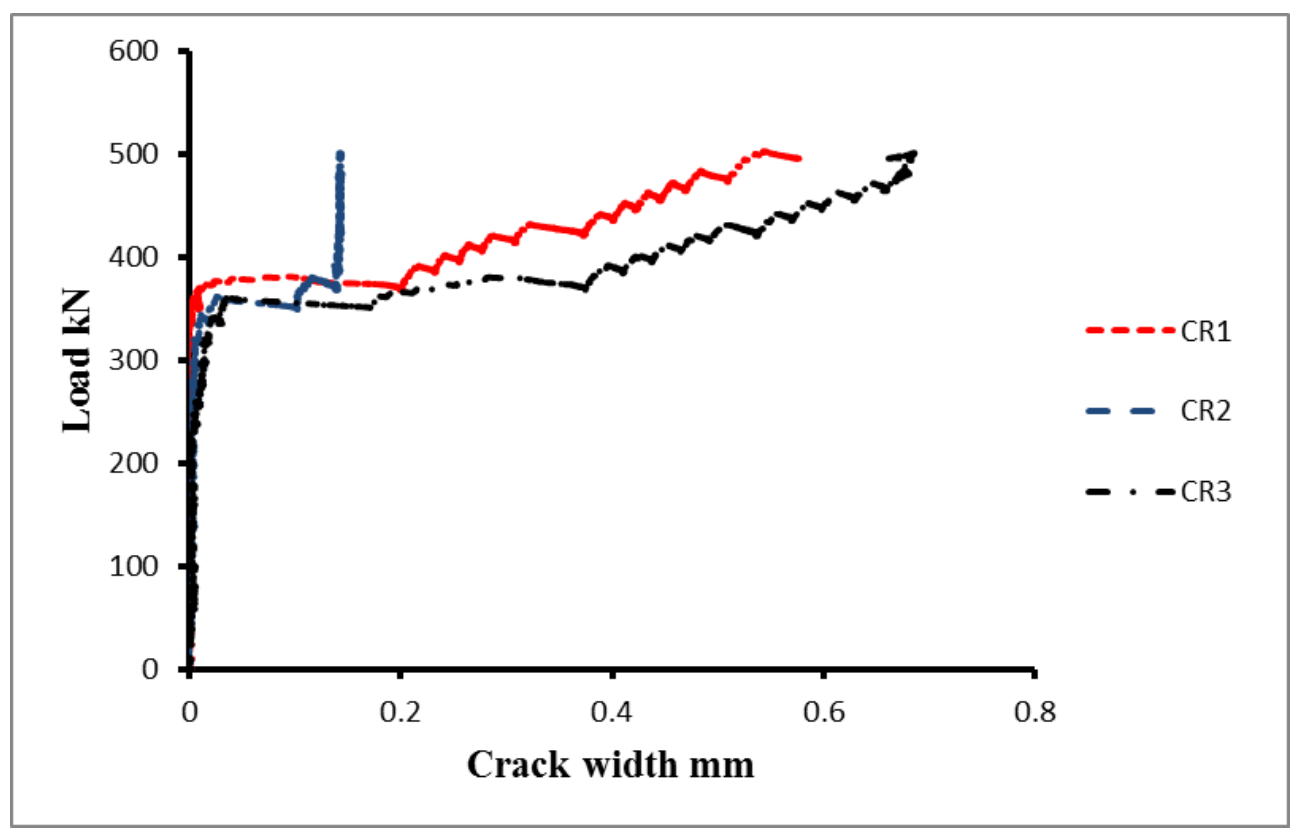

Figure 5.29 Load versus crack width relationship - Beam UNS3-2

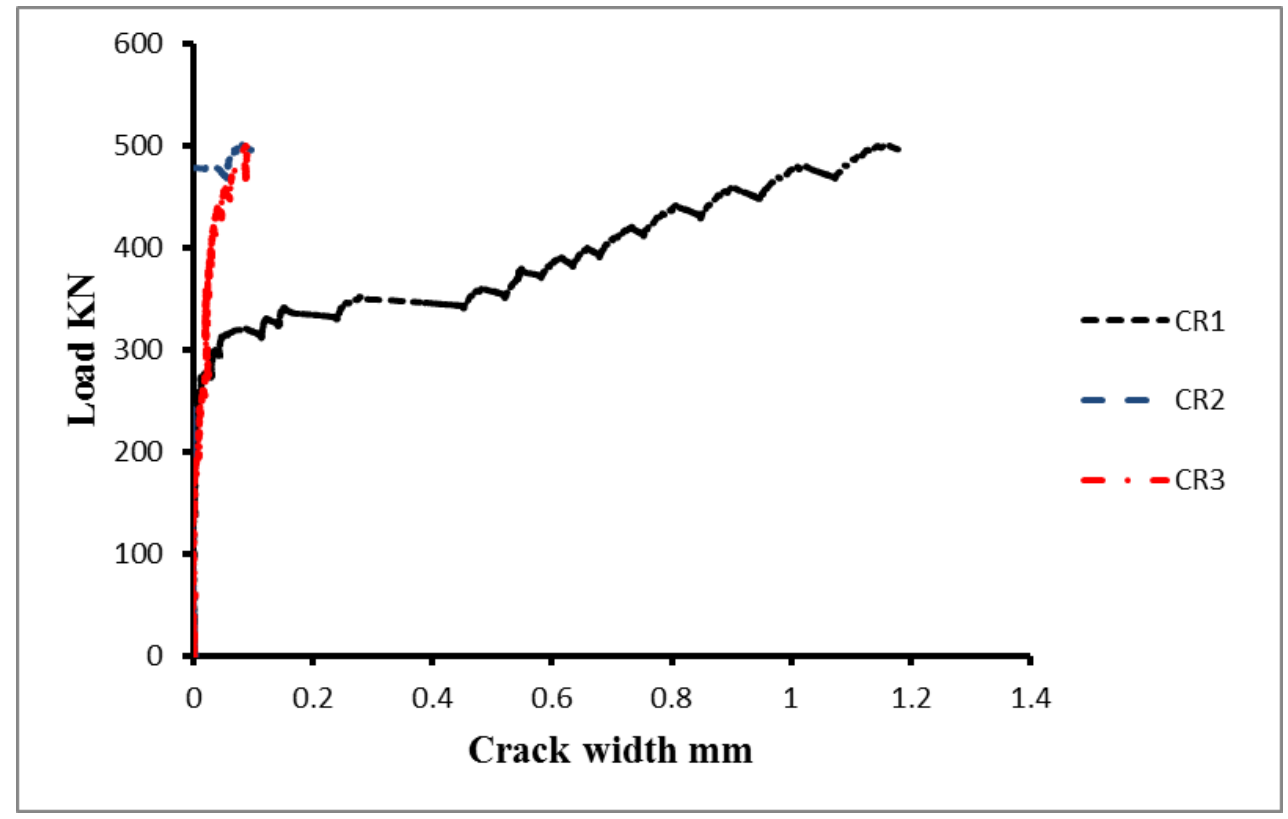

Figure 5.30 Load versus crack width relationship - Beam UNS3-2D 
The load versus the reinforcement strain relationship for beams UNS3-2 and UNS3-2D are shown in Figures 5.31 and 5.32 respectively.

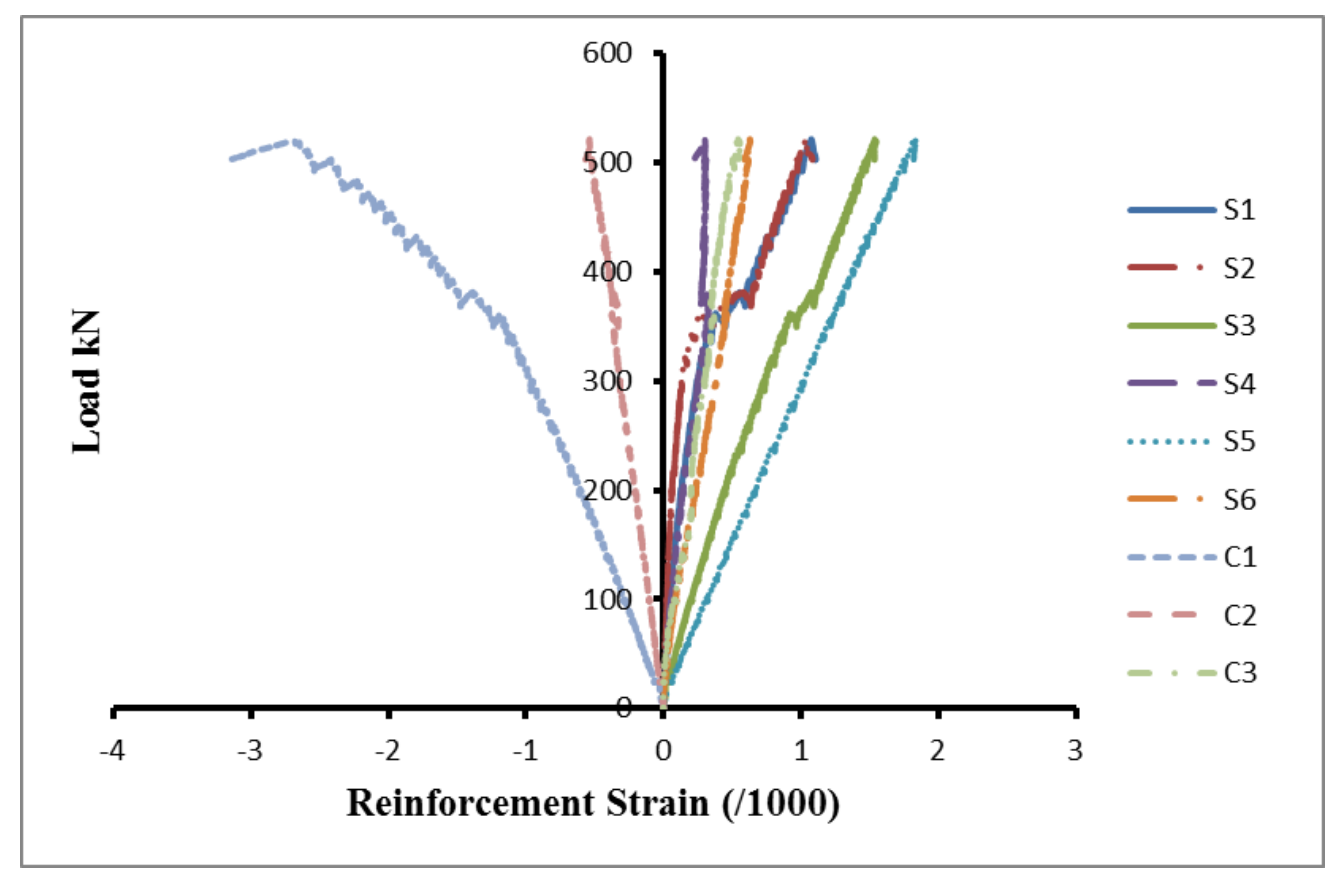

Figure 5.31 Load versus reinforcement strain - Beam UNS3-2

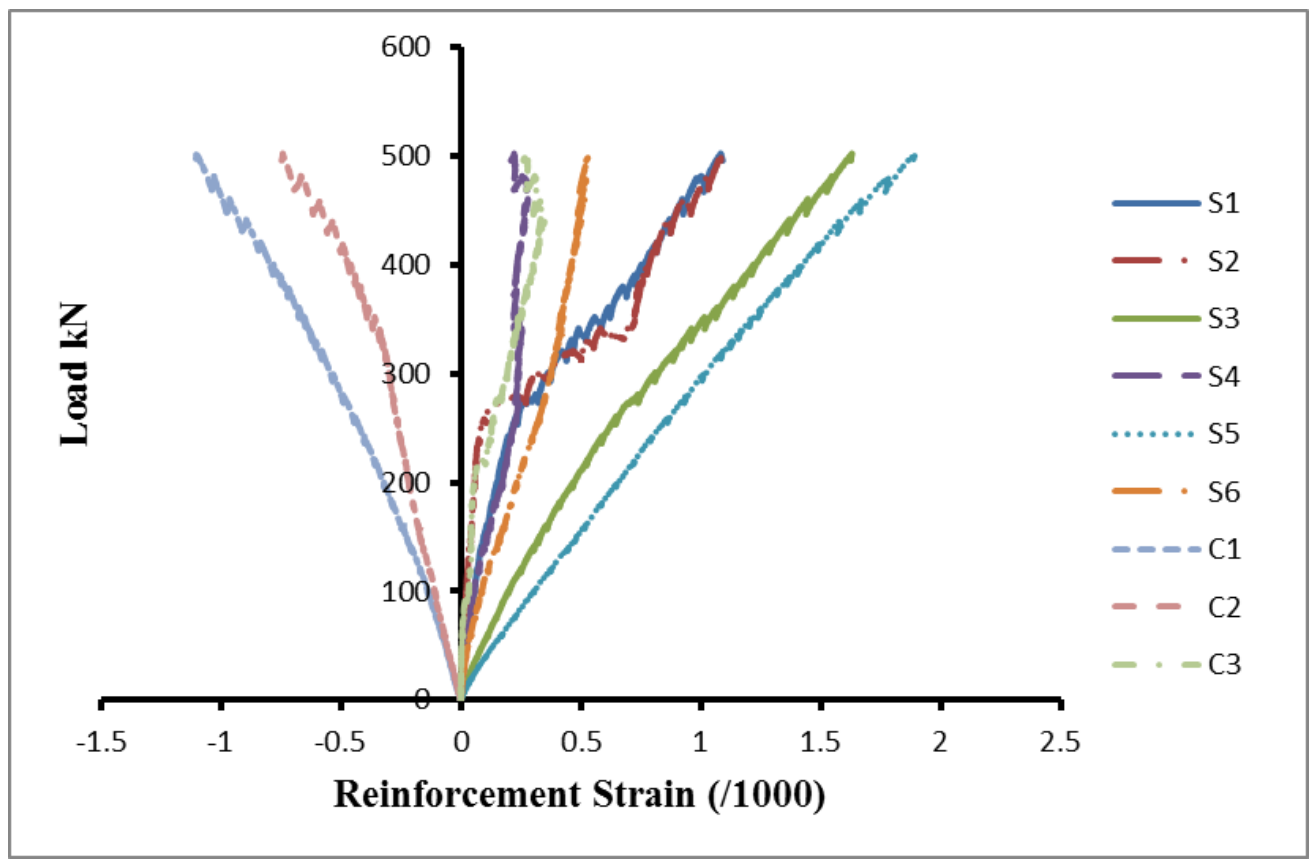

Figure 5.32 Load versus reinforcement strain - Beam UNS3-2D 


\subsubsection{Beams UHS3-1, UHS3-1D, UHS3-1S, UHS3-1.5, UHS3-1.5D, UHS3-2, and UHS3-2D}

The load versus central deflection relationship and crack pattern after failure for Beams UHS3-1, UHS3-1D, UHS3-1S, UHS3-1.5, UHS3-1.5D, UHS3-2, and UHS3-2D were similar to beams UN series as shown in Figures 5.33 - 5.46 respectively. The initial cracking load, the ultimate load, and the maximum deflection at ultimate load of UHS3-1, UHS3-1D, UHS3-1S, UHS3-1.5, UHS3-1.5D, UHS3-2, and UHS3-2D are shown in Table 5.5.

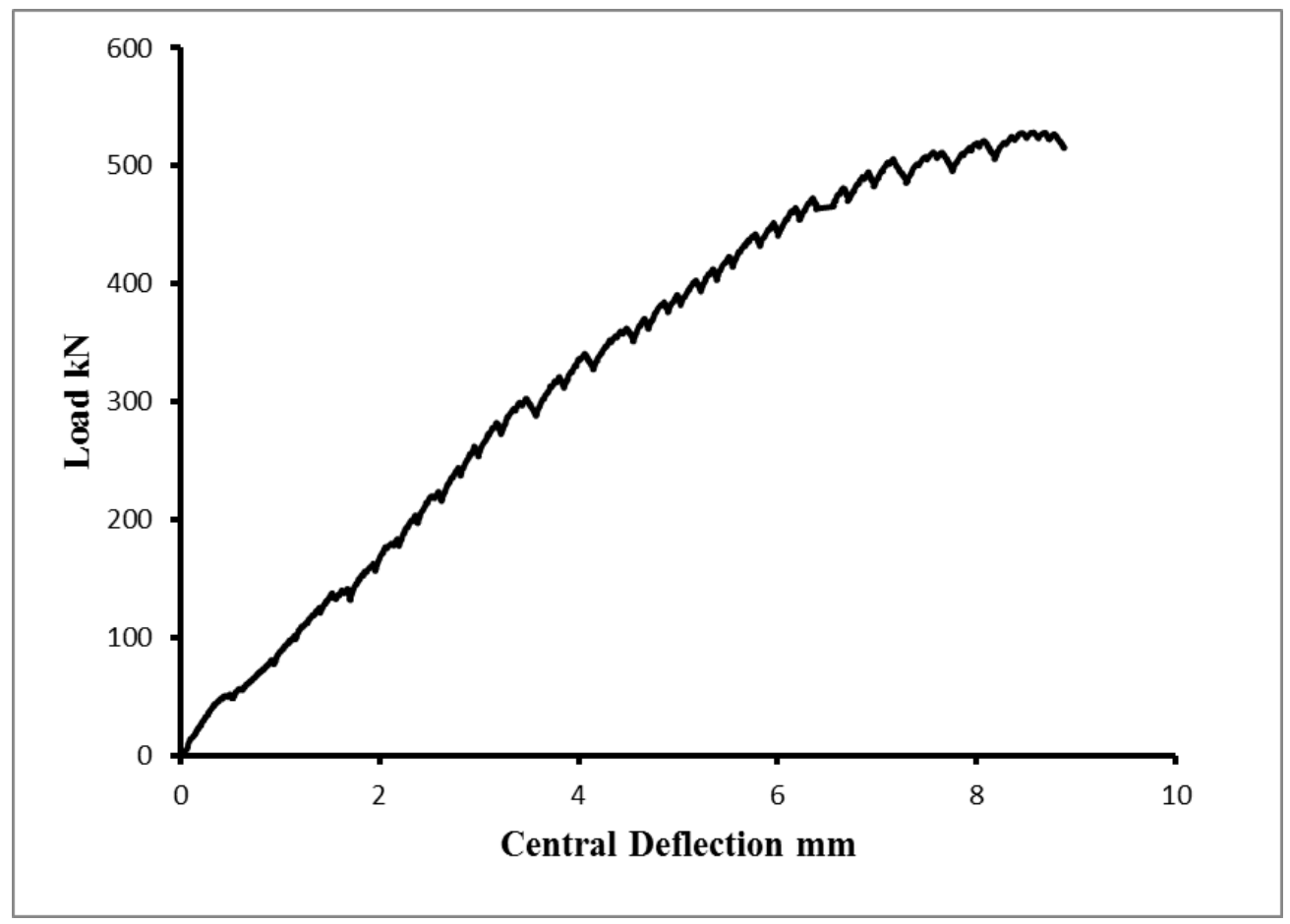

Figure 5.33 Load versus central deflection relationship - Beam UHS3-1

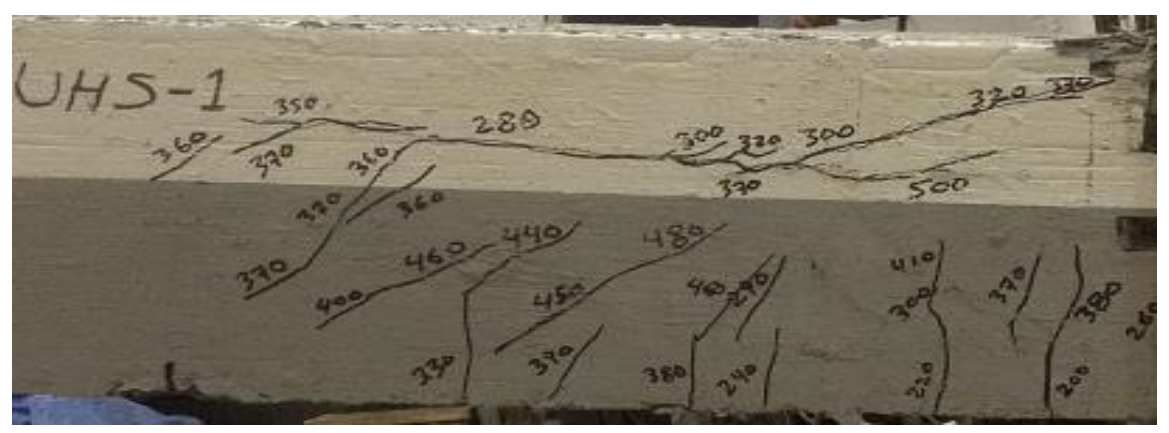

Figure 5.34 Crack pattern after failure - Beam UHS3-1 


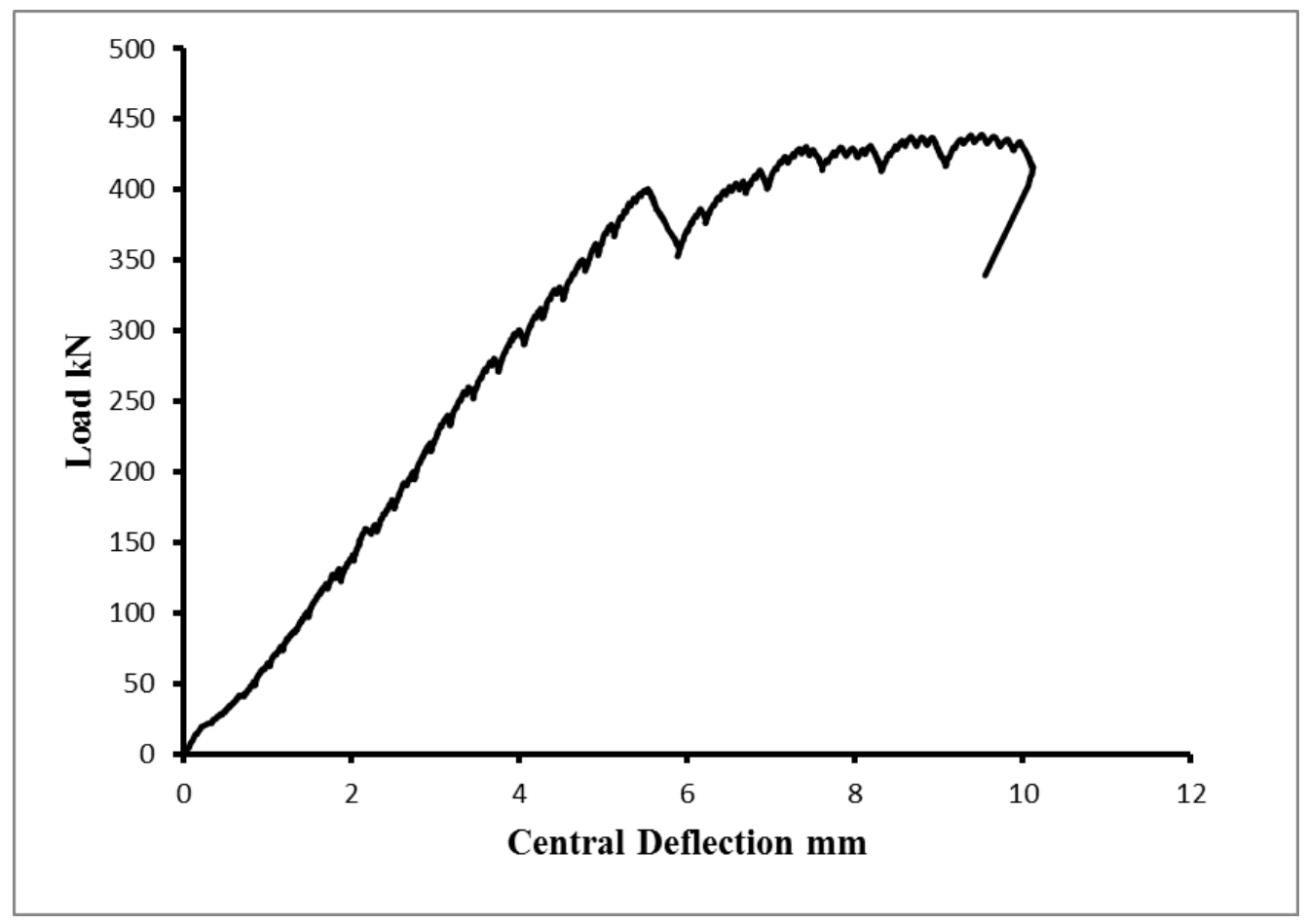

Figure 5.35 Load versus central deflection relationship - Beam UHS3-1D

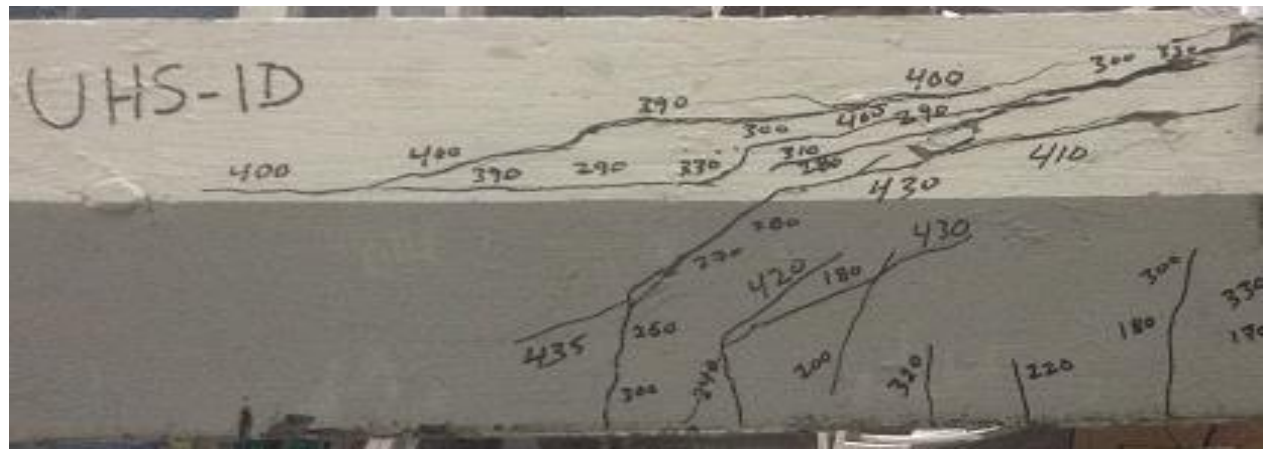

Figure 5.36 Crack pattern after failure - Beam UHS3-1D 


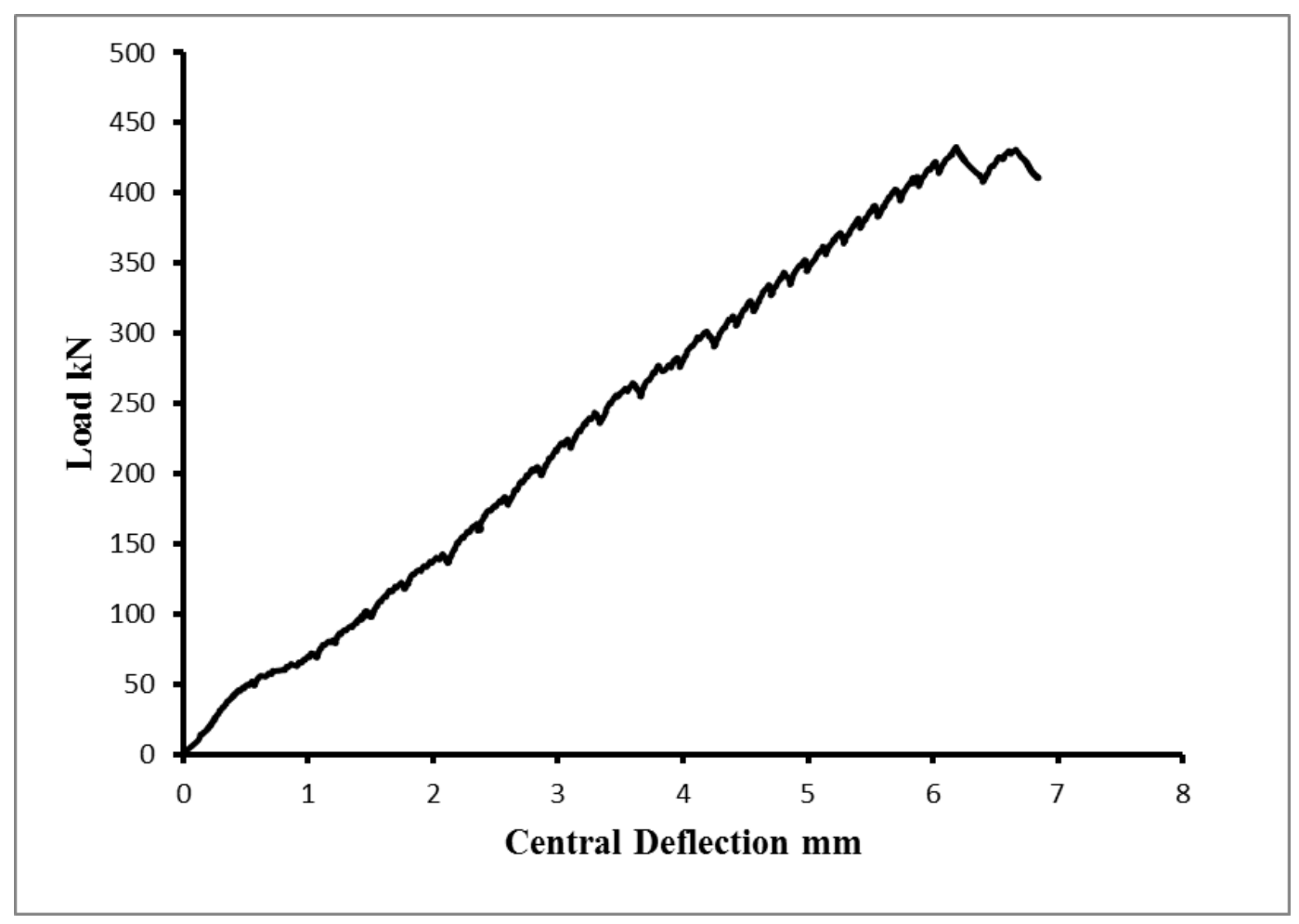

Figure 5.37 Load versus central deflection relationship - Beam UHS3-1S

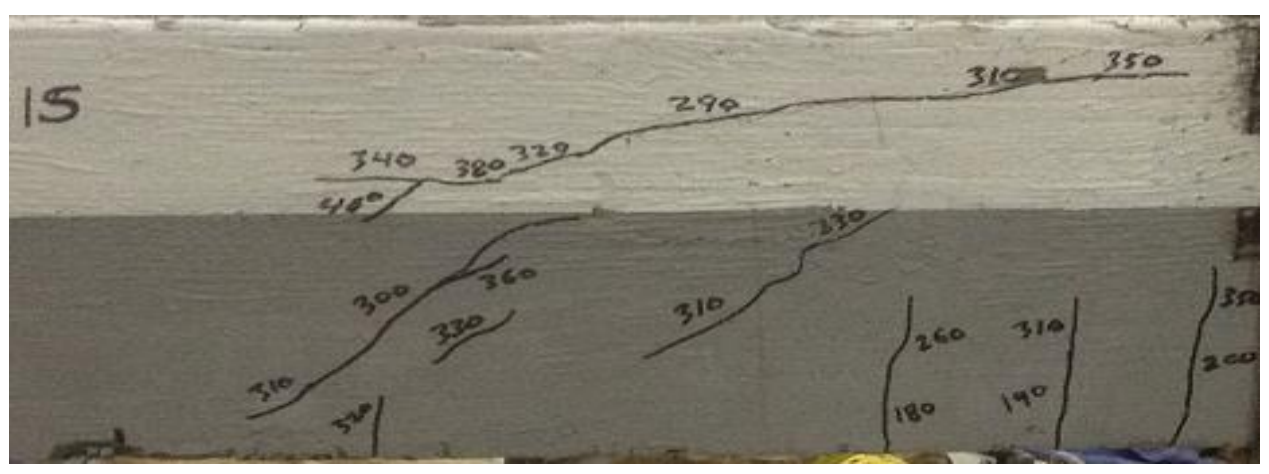

Figure 5.38 Crack pattern after failure - Beam UHS3-1S 


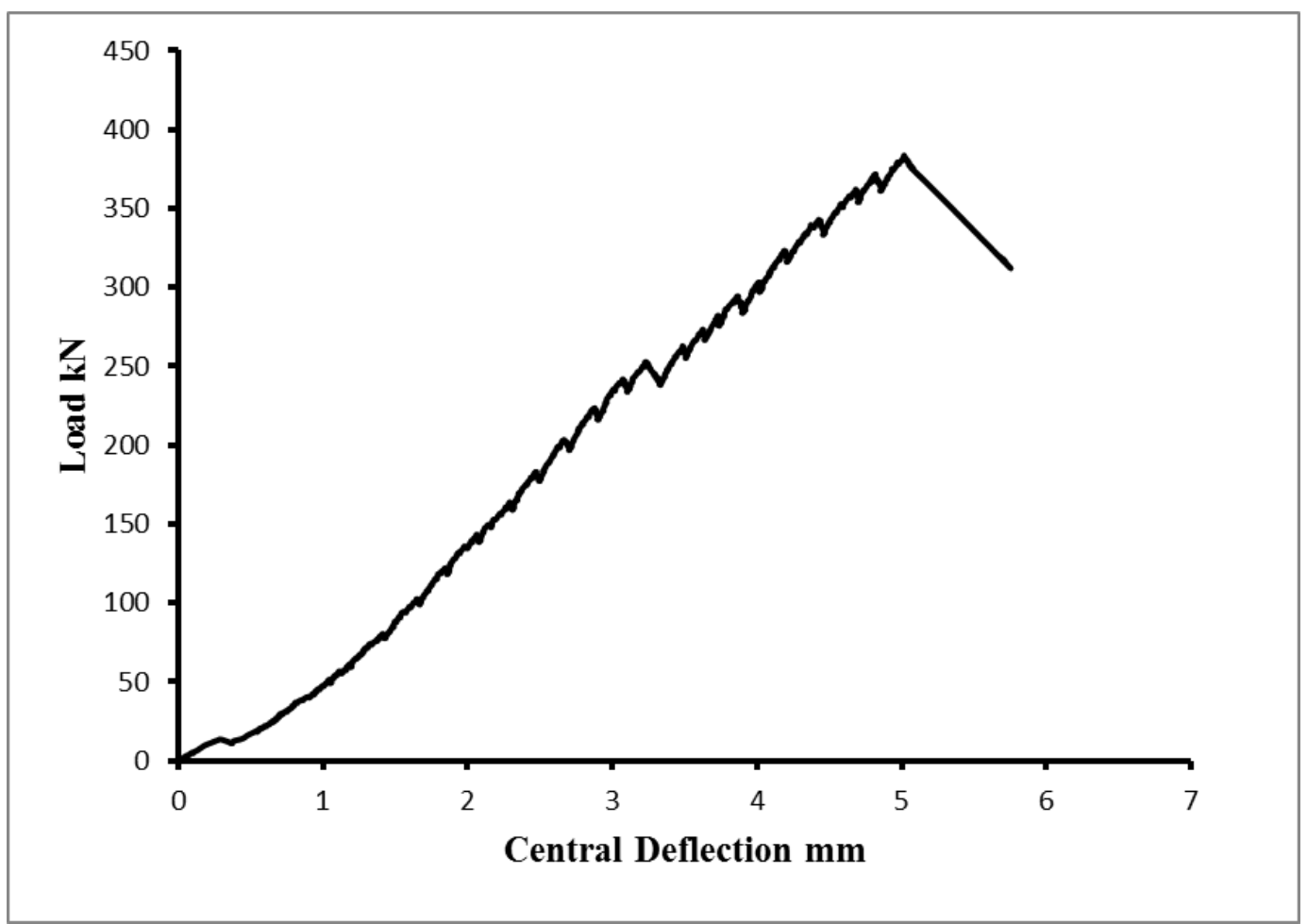

Figure 5.39 Load versus central deflection relationship - Beam UHS3-1.5

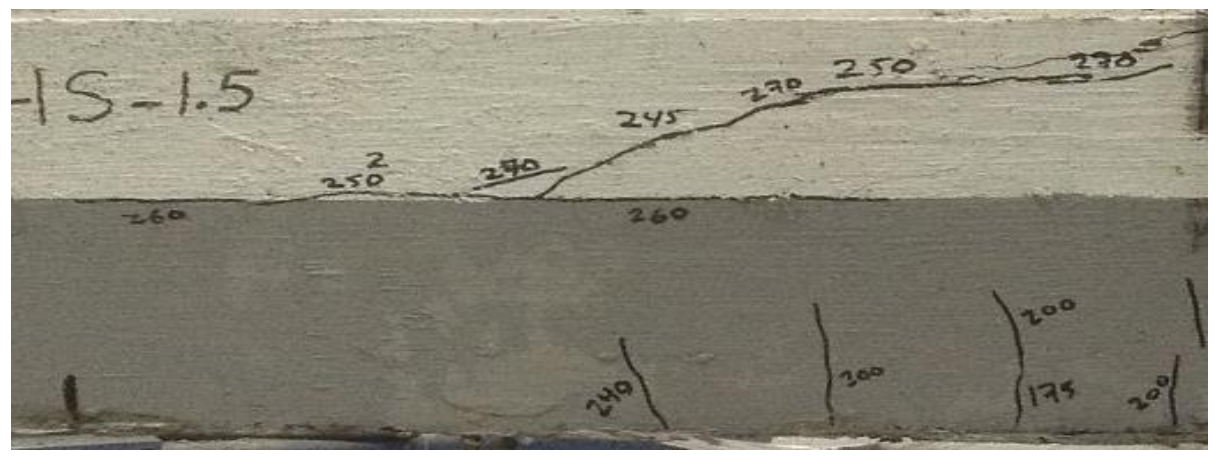

Figure 5.40 Crack pattern after failure - Beam UHS3-1.5 


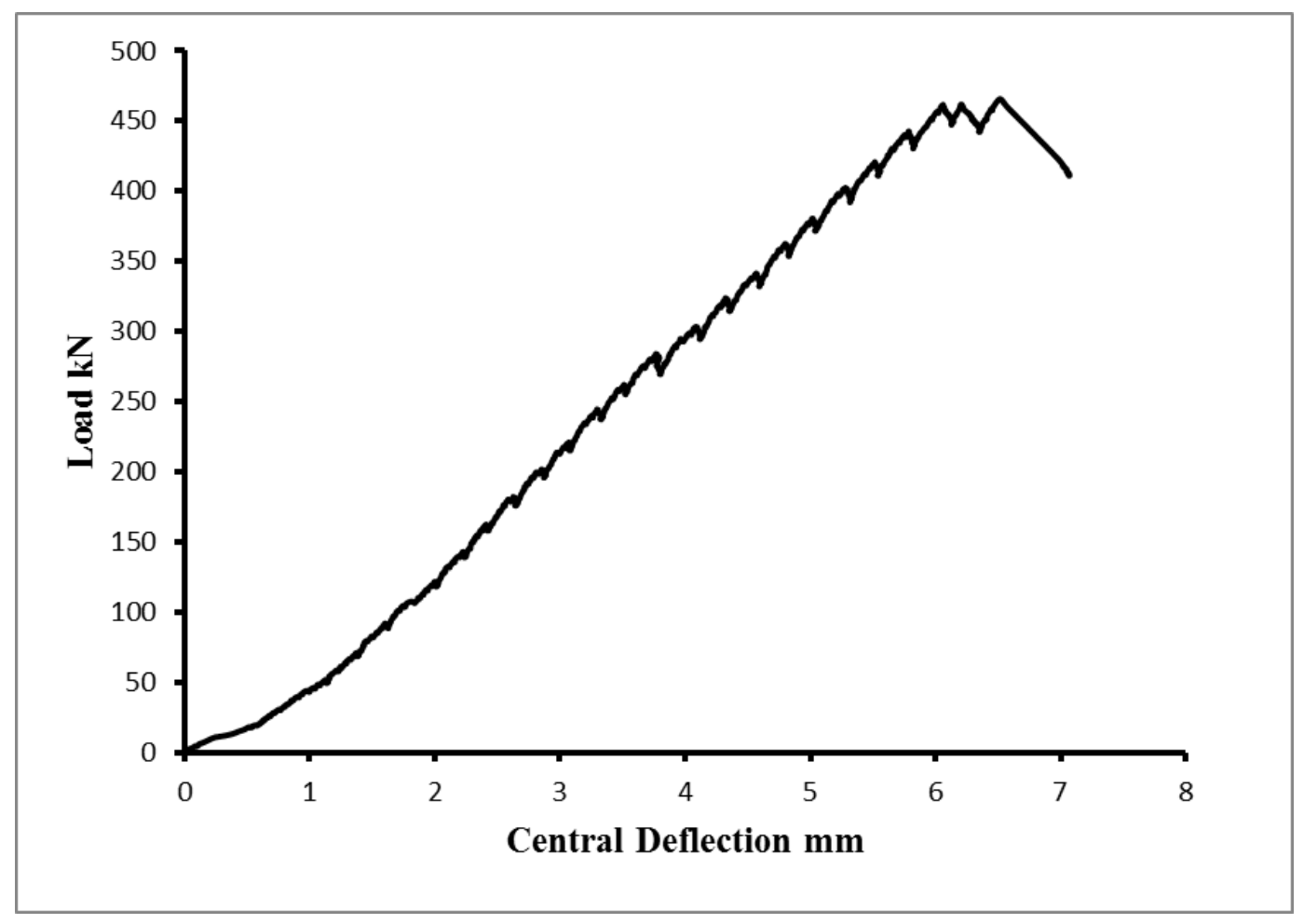

Figure 5.41 Load versus central deflection relationship - Beam UHS3-1.5D

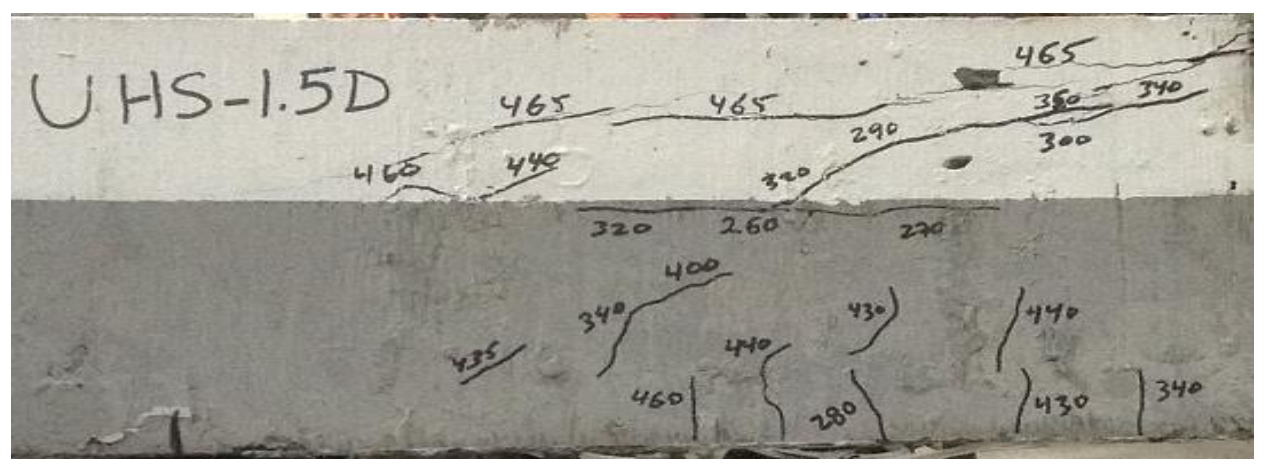

Figure 5.42 Crack pattern after failure - Beam UHS3-1.5D 


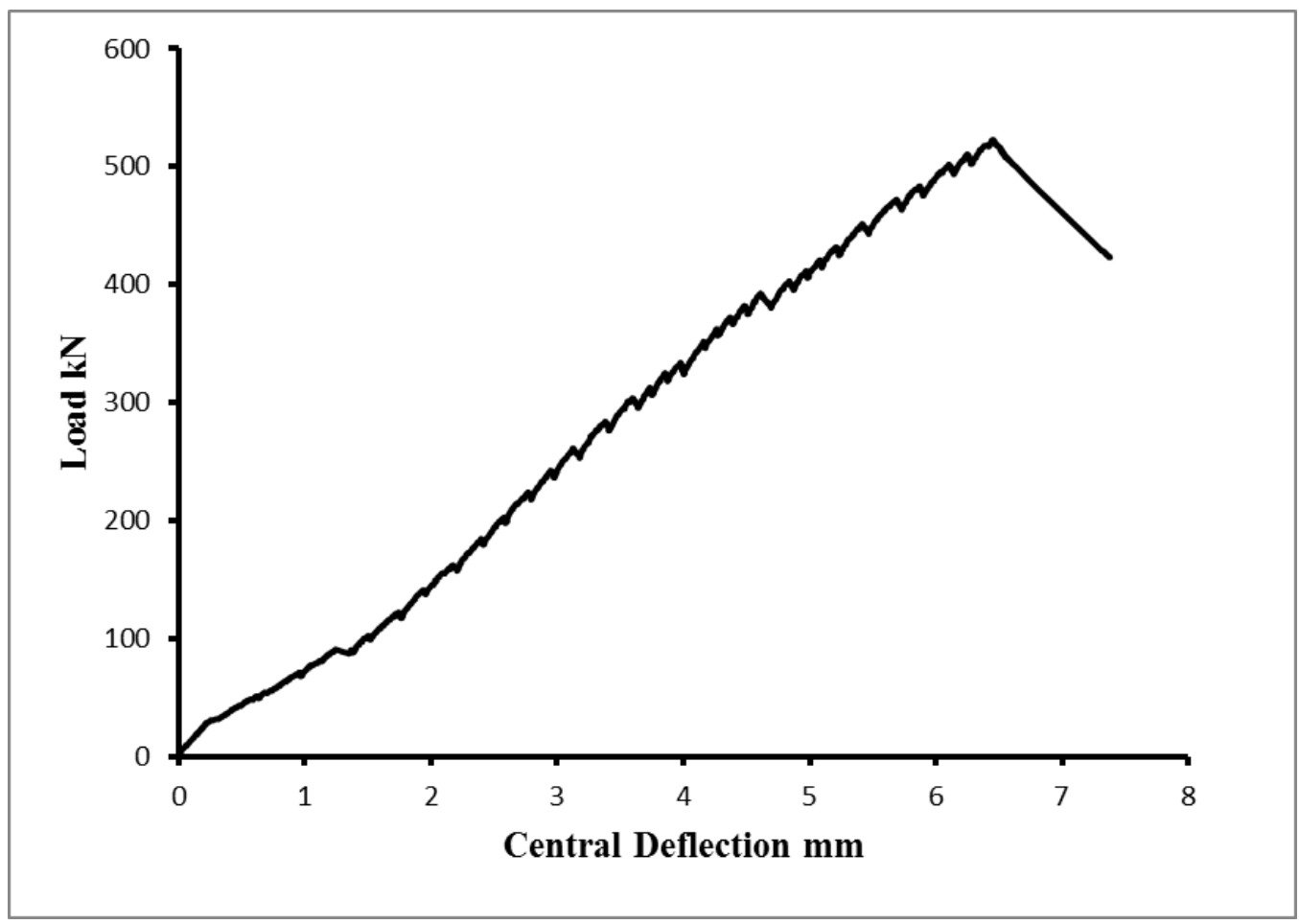

Figure 5.43 Load versus central deflection relationship - Beam UHS3-2

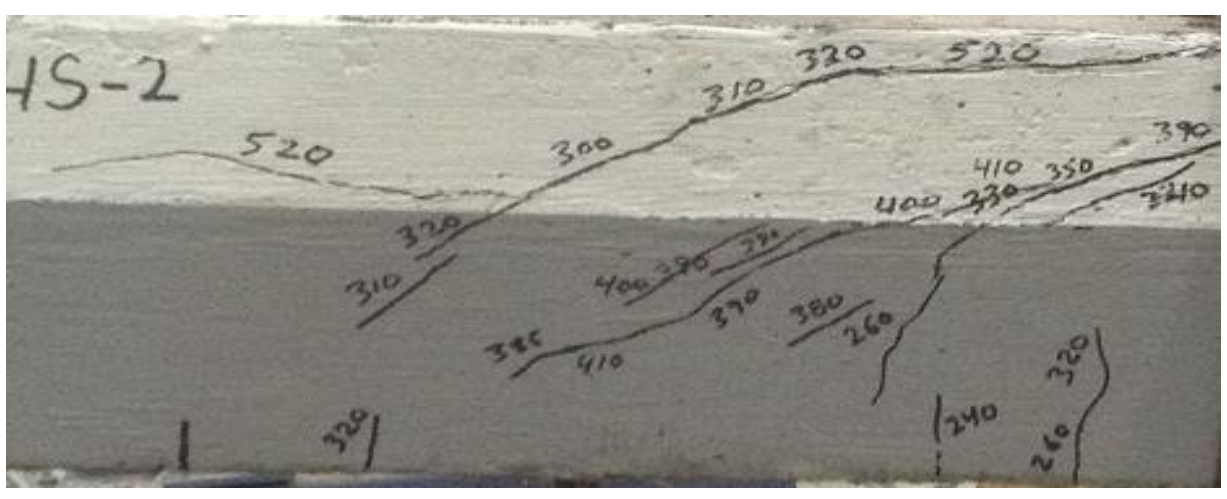

Figure 5.44 Crack pattern after failure - Beam UHS3-2 


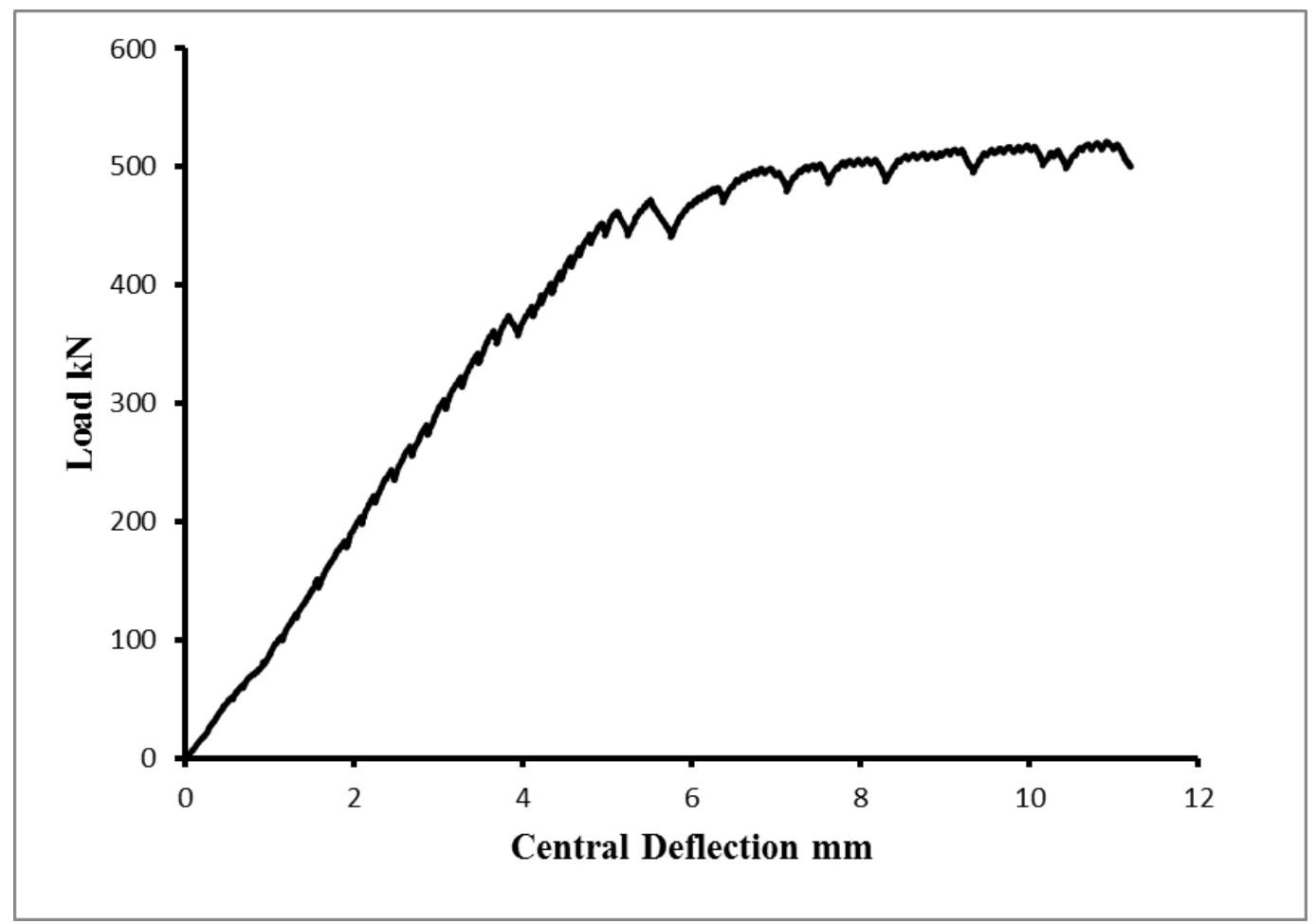

Figure 5.45 Load versus central deflection relationship - Beam UHS3-2D

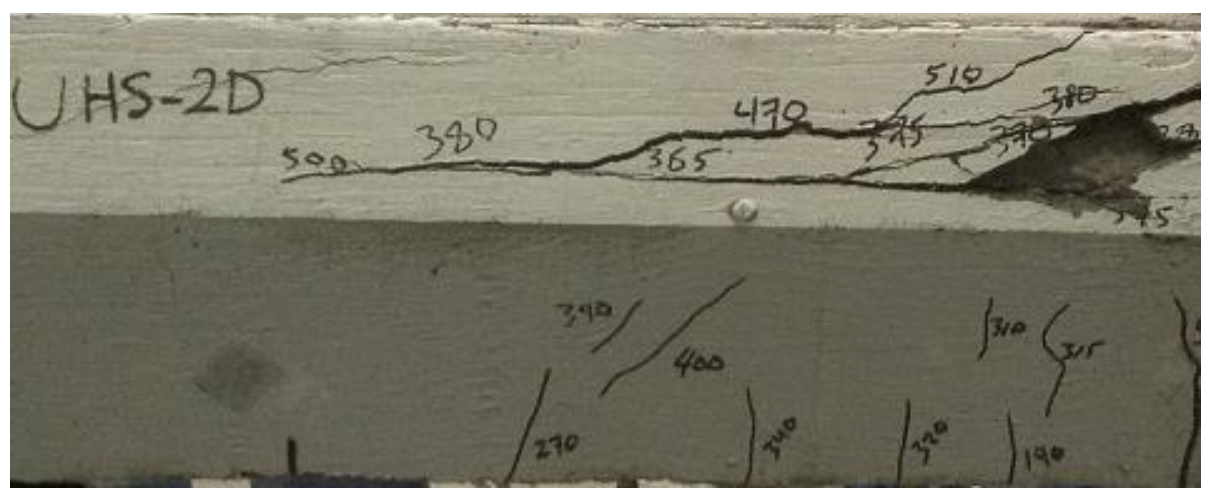

Figure 5.46 Crack pattern after failure - Beam UHS3-2D 
Figures 5.47, and 5.53 show the load - crack width relationships for Beams UHS3-1, UHS3-1D, UHS3-1S, UHS3-1.5, UHS3-1.5D, UHS3-2, and UHS3-2D UNS3-1.5, and UNS3-1.5D respectively.

The load versus the reinforcement strain relationship for beams UHS3-1, UHS3-1D, UHS3-1S, UHS3-1.5, UHS3-1.5D, UHS3-2, and UHS3-2D are shown in Figures 5.54 and 5.60 respectively.

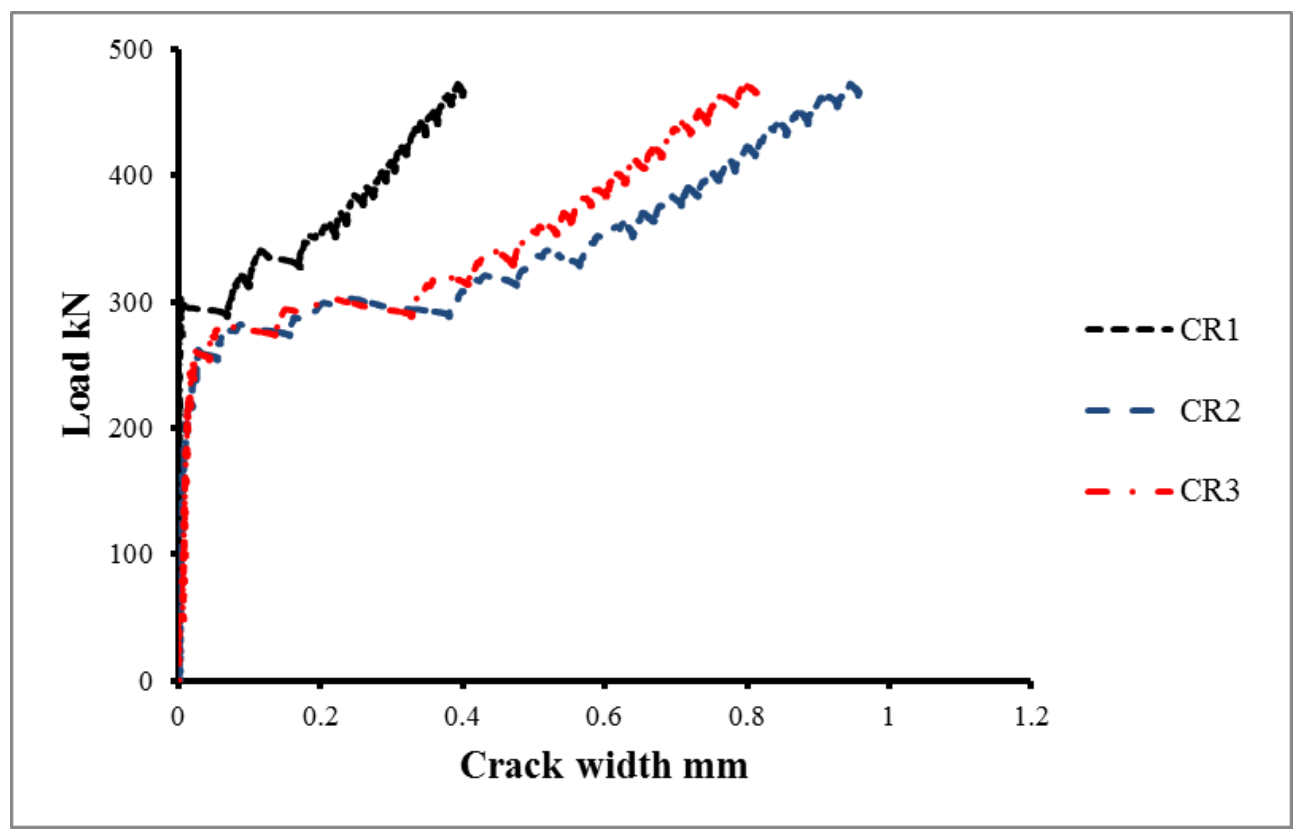

Figure 5.47 Load versus crack width relationship - Beam UHS3-1 


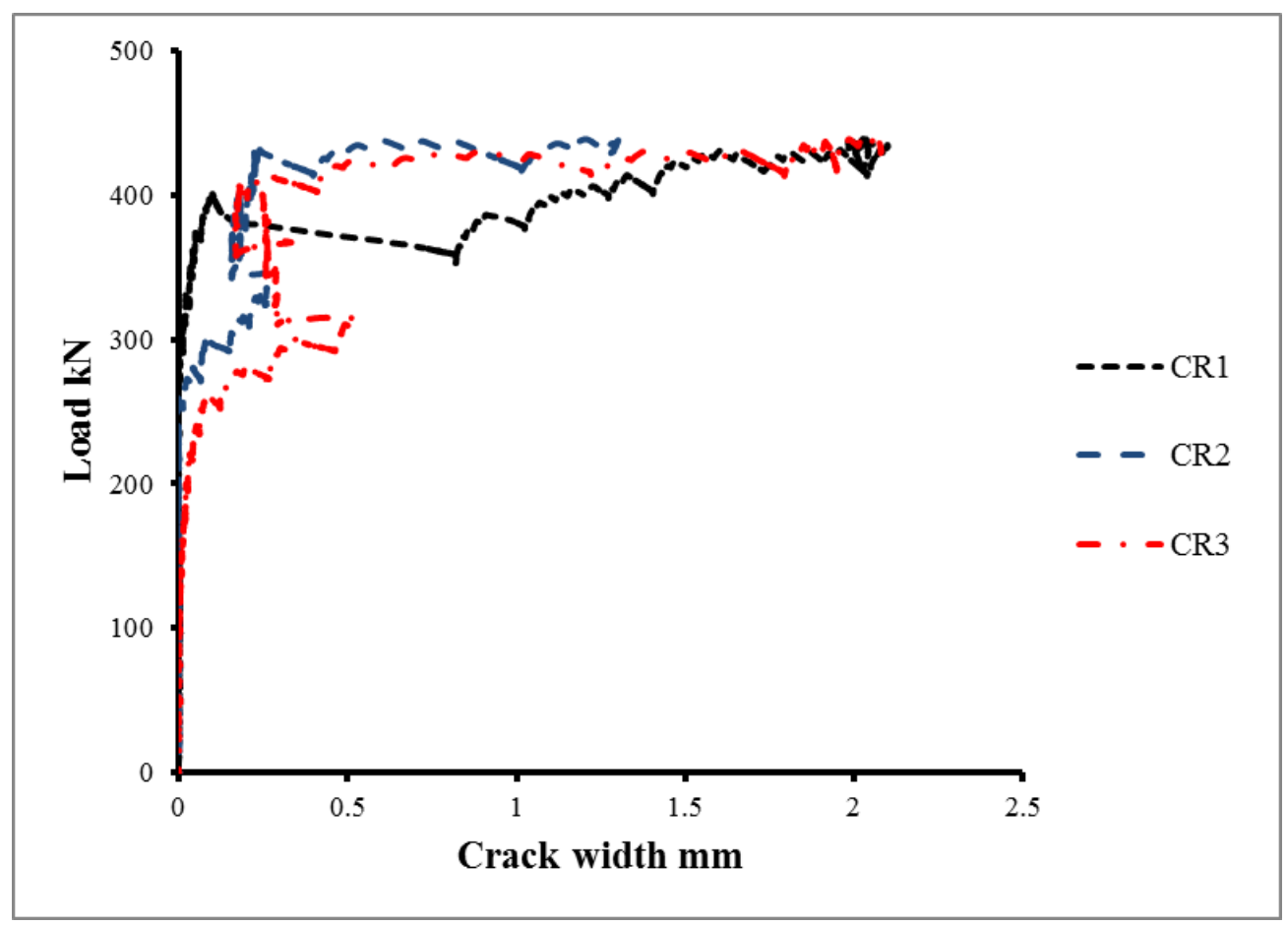

Figure 5.48 Load versus crack width relationship - Beam UHS3-1D

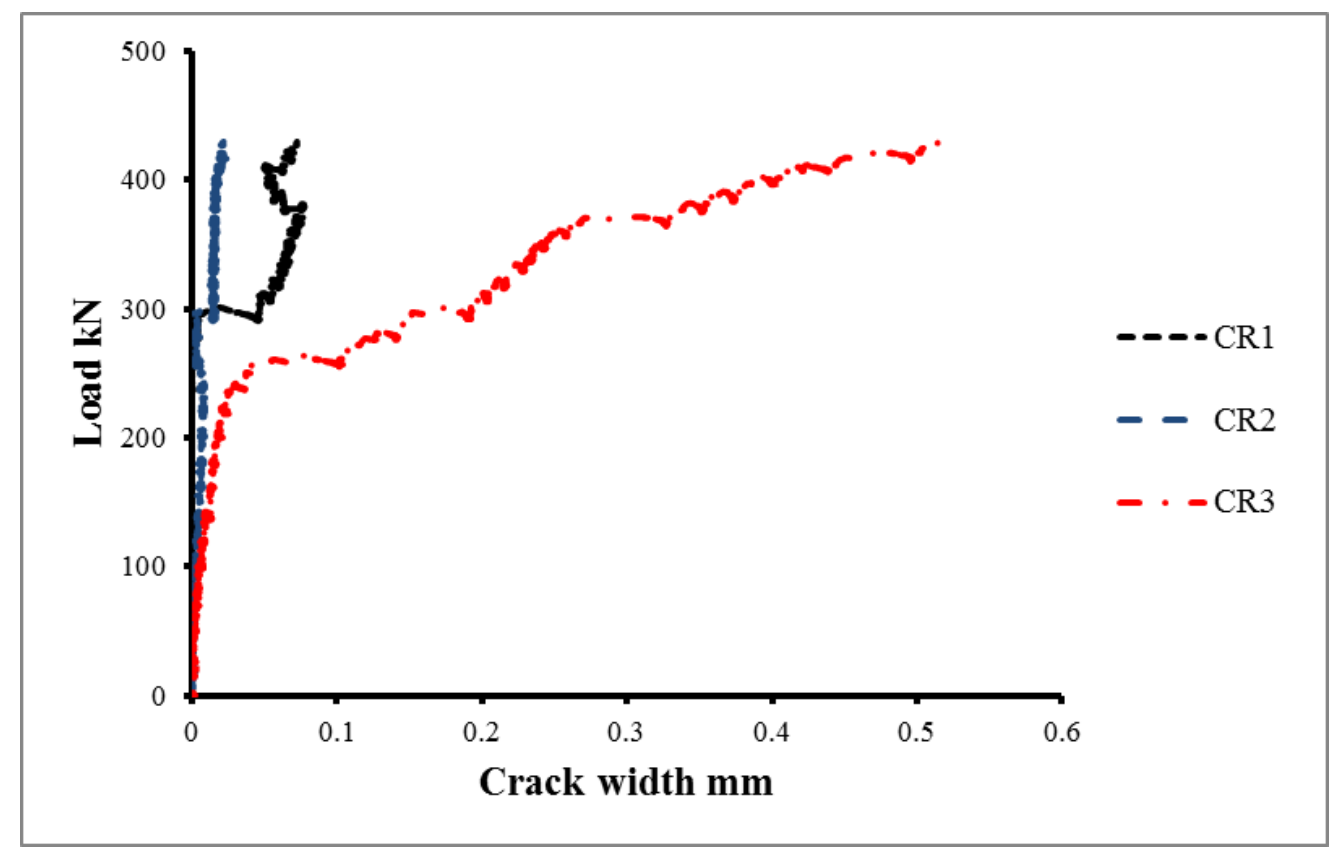

Figure 5.49 Load versus crack width relationship - Beam UHS3-1S 


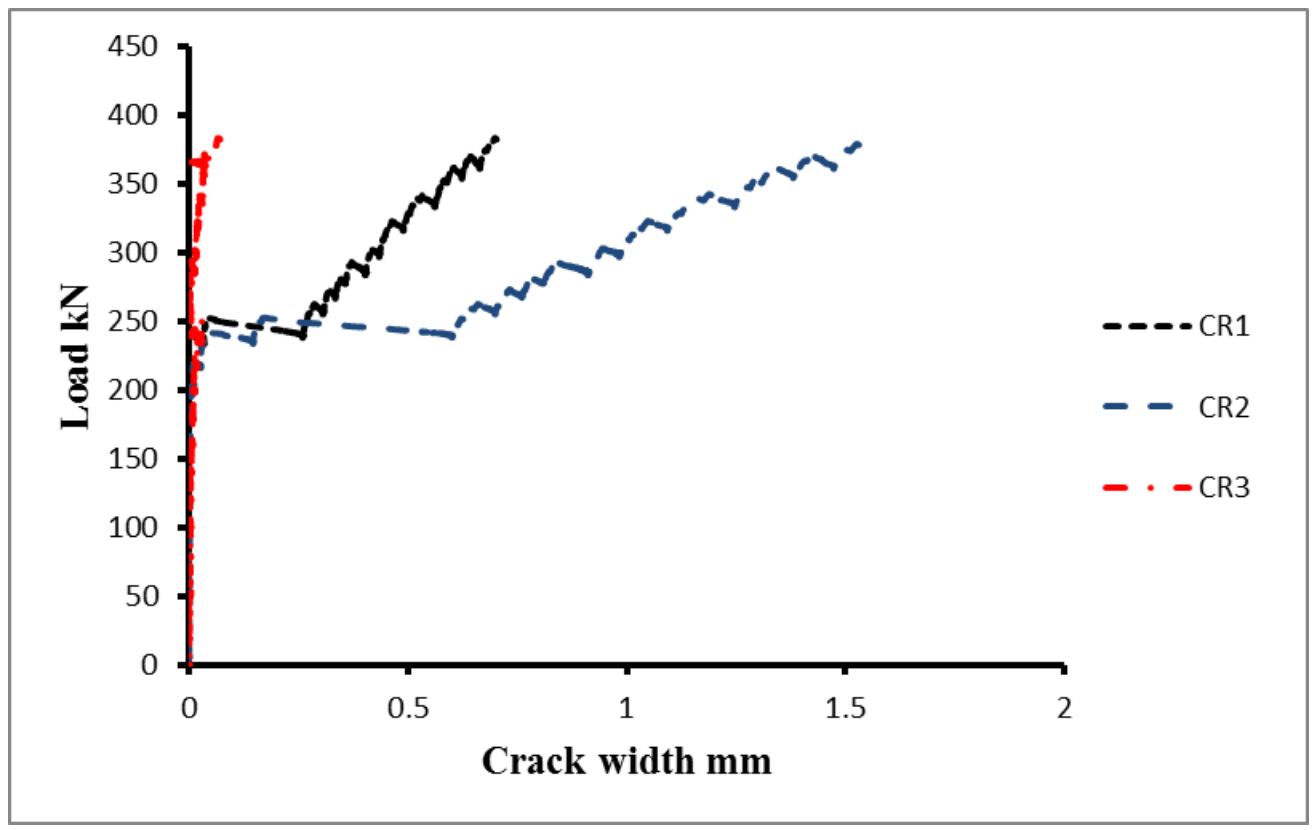

Figure 5.50 Load versus crack width relationship - Beam UHS3-1.5

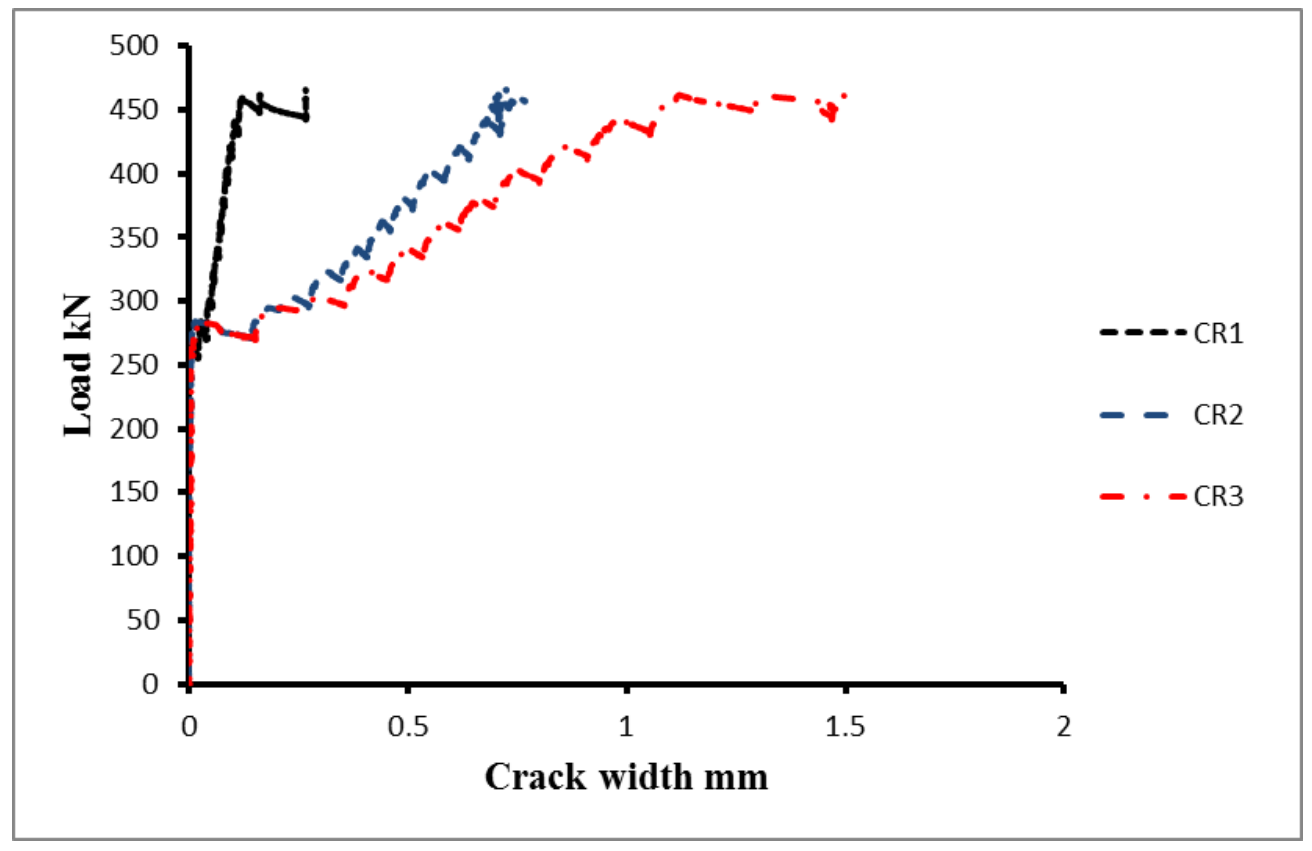

Figure 5.51 Load versus crack width relationship - Beam UHS3-1.5D 


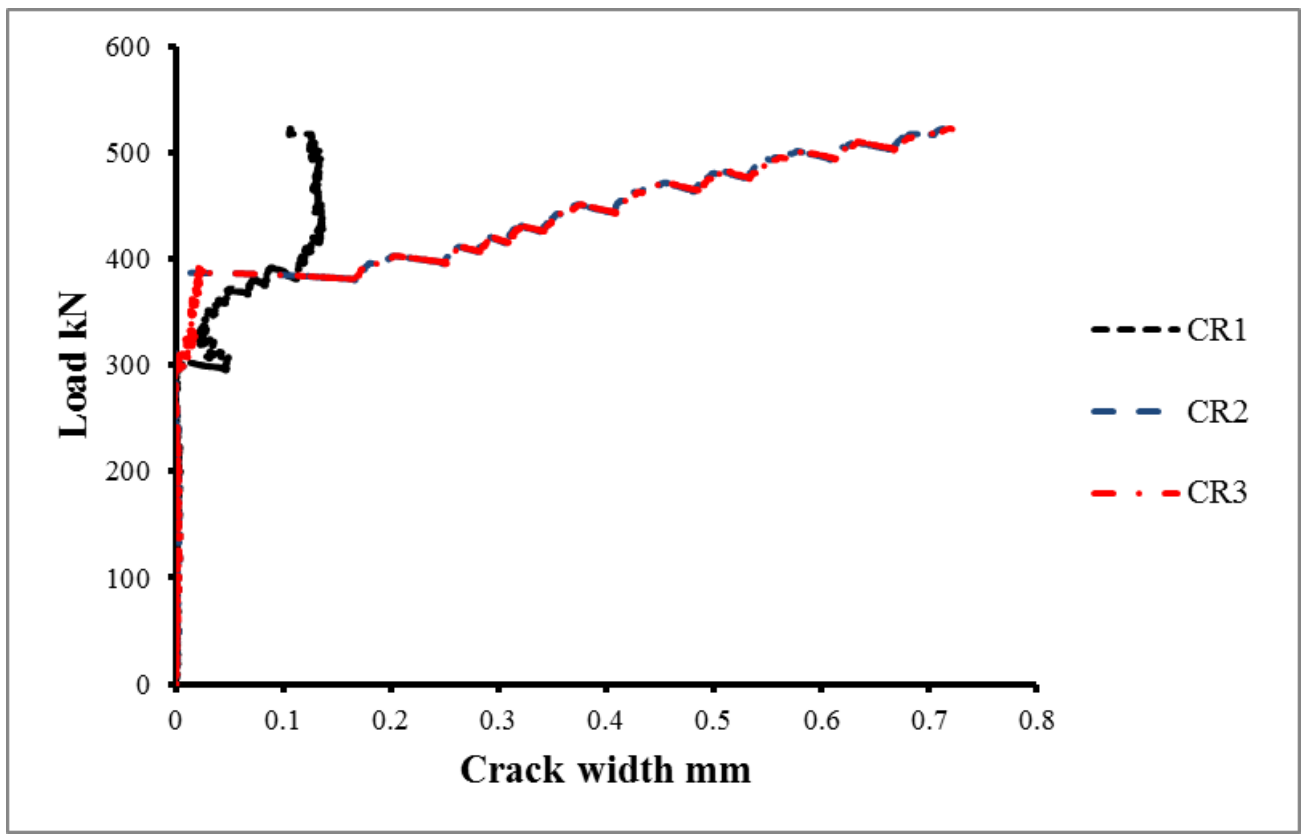

Figure 5.52 Load versus crack width relationship - Beam UHS3-2

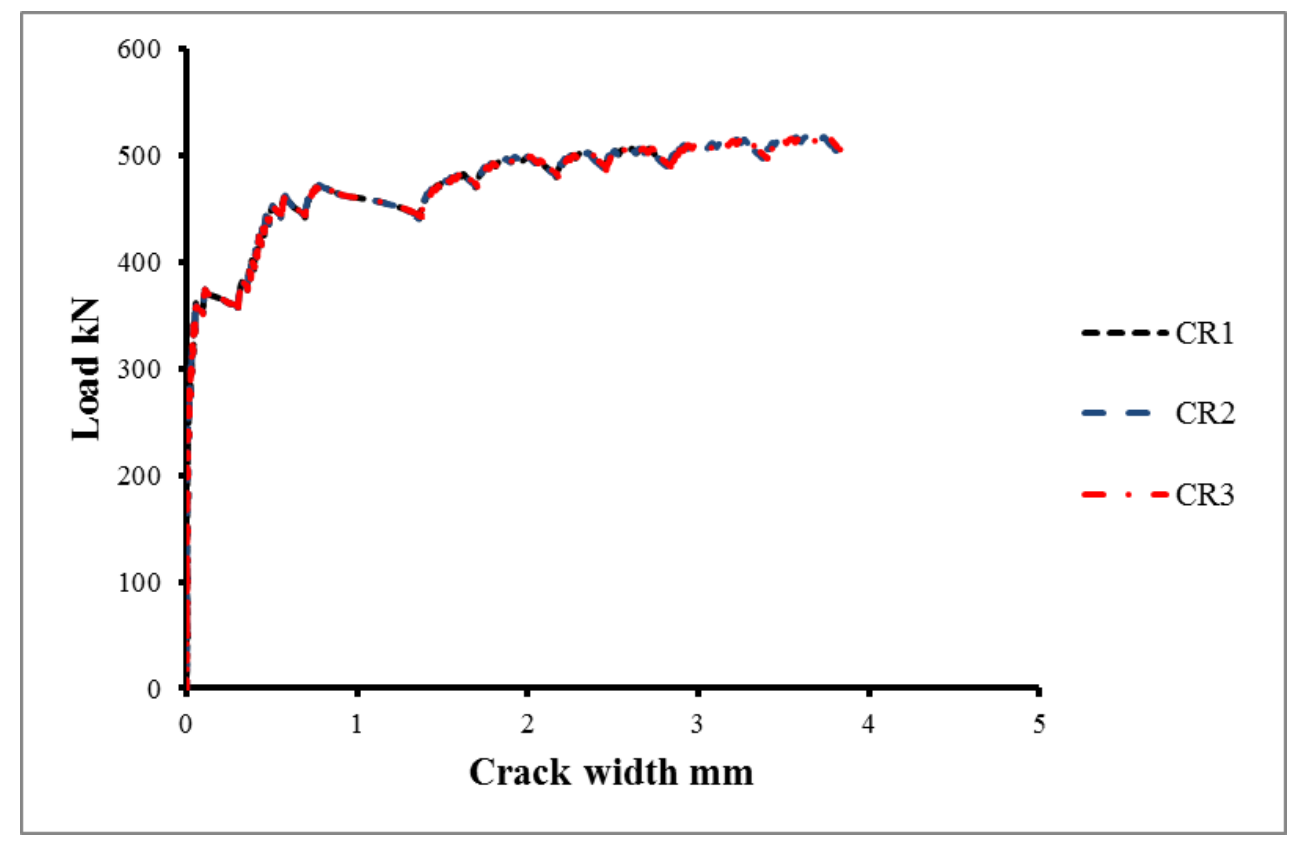

Figure 5.53 Load versus crack width relationship - Beam UHS3-2D 


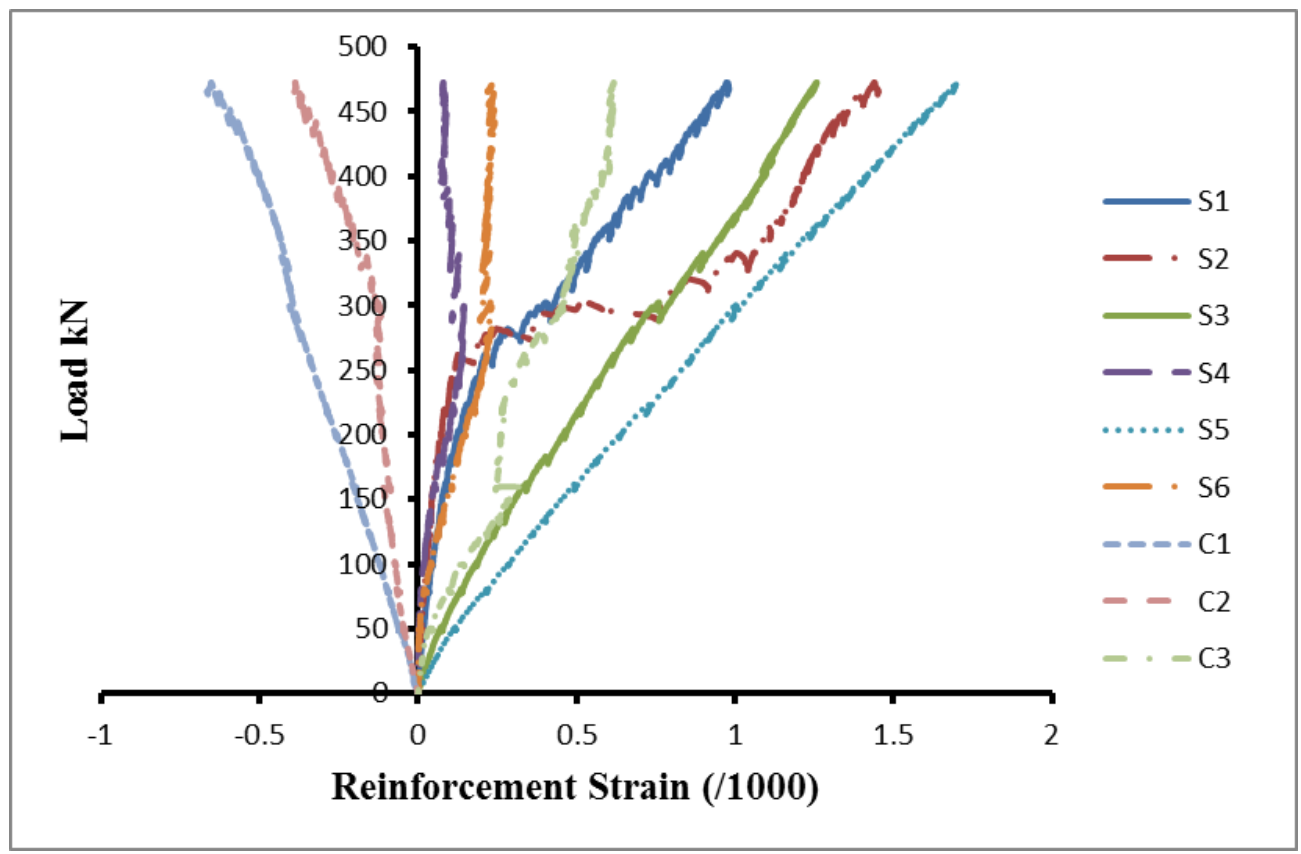

Figure 5.54 Load versus reinforcement strain - Beam UHS3-1

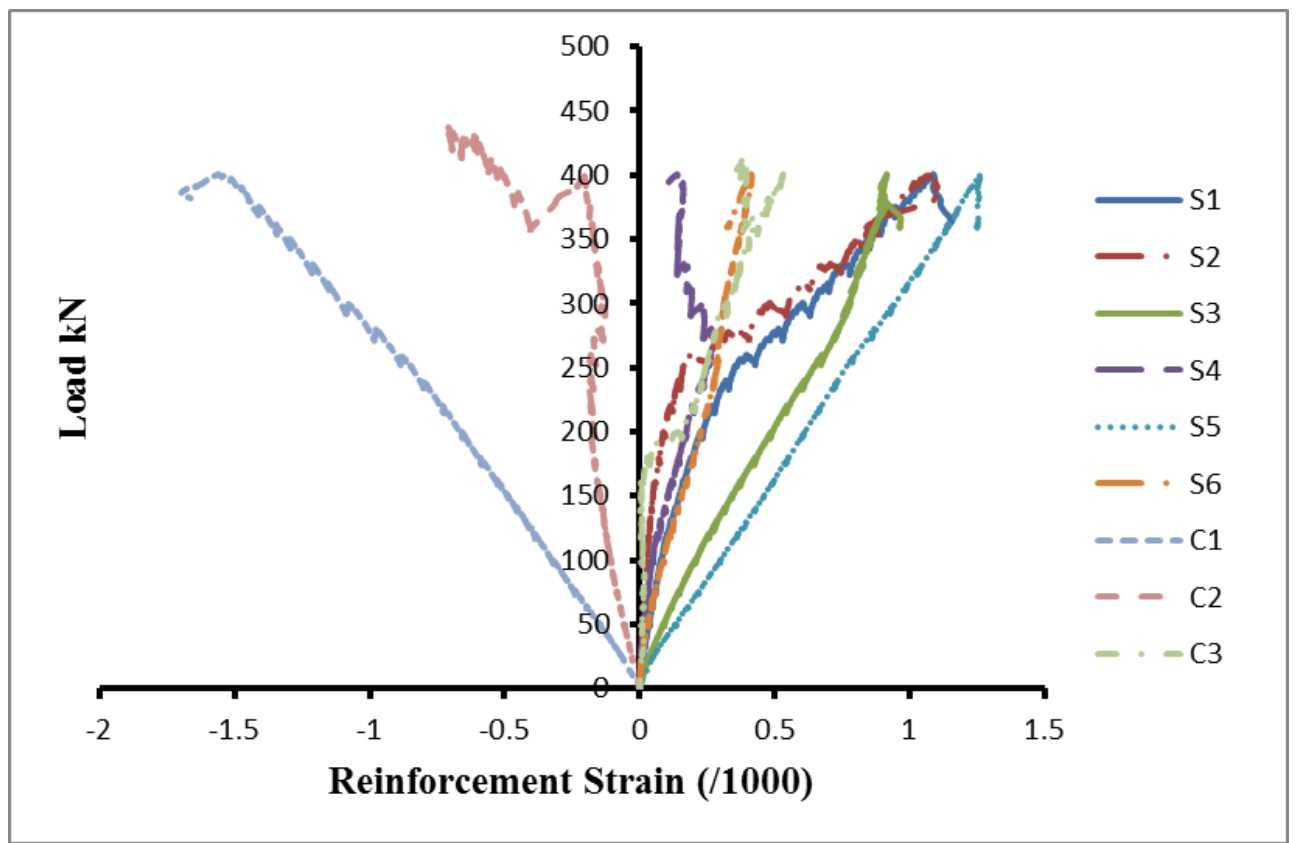

Figure 5.55 Load versus reinforcement strain - Beam UHS3-1D 


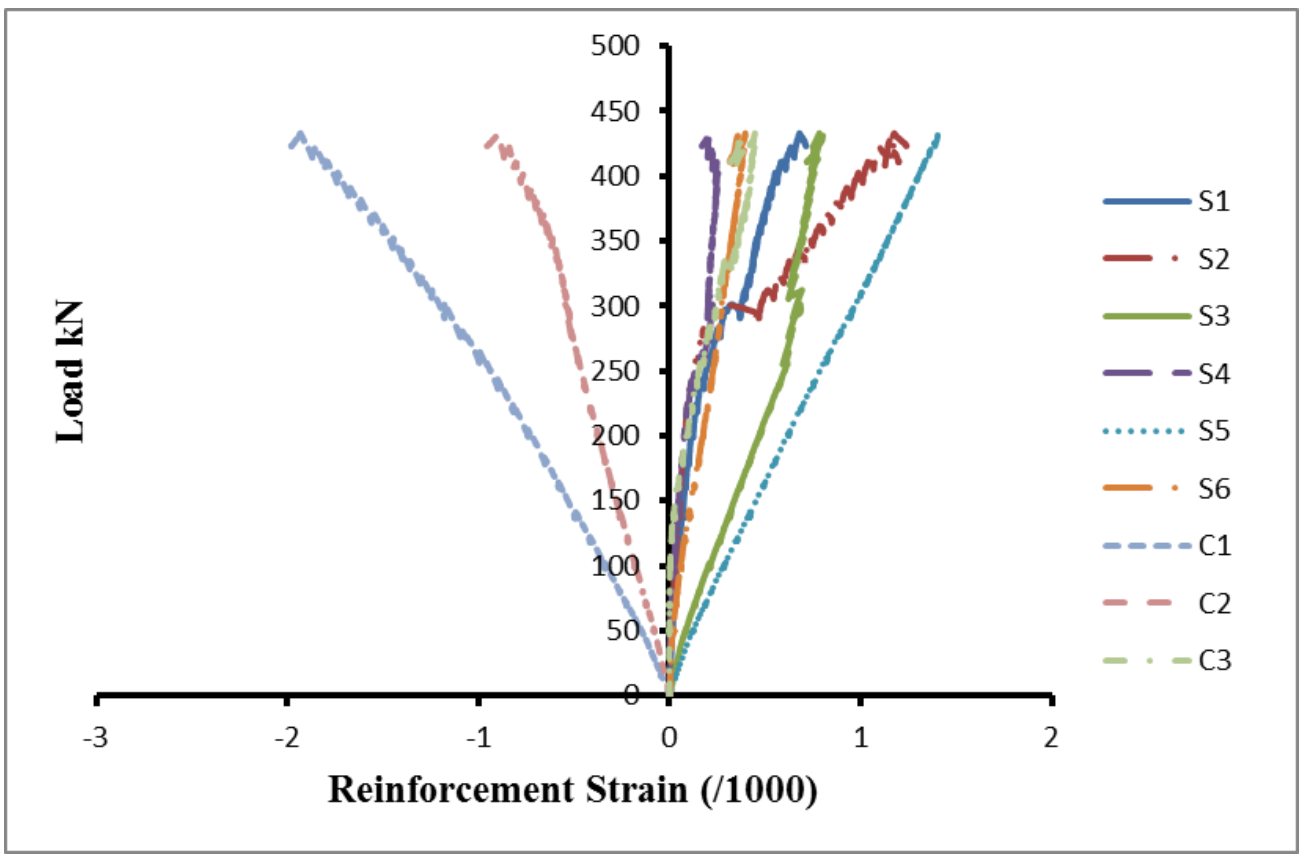

Figure 5.56 Load versus reinforcement strain - Beam UHS3-1S

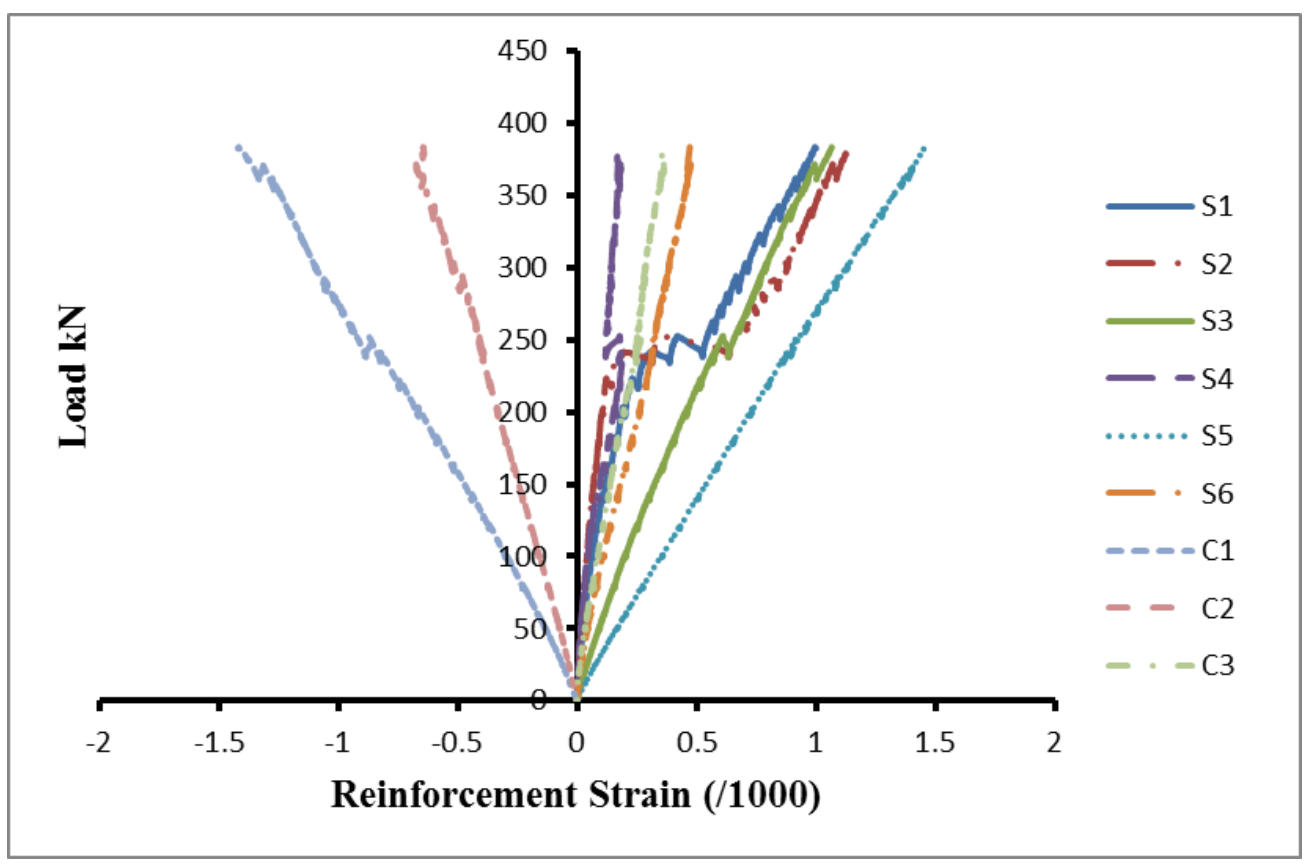

Figure 5.57 Load versus reinforcement strain - Beam UHS3-1.5 


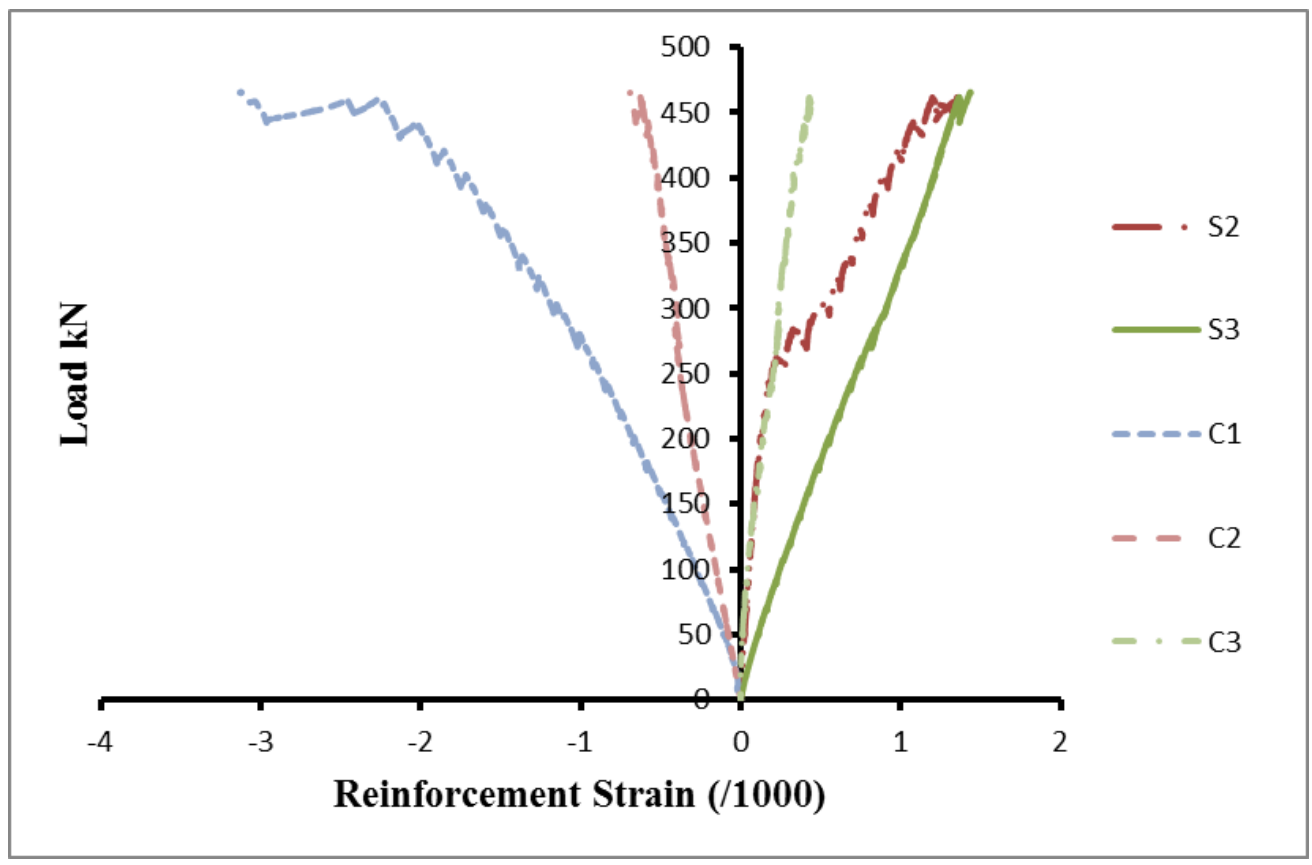

Figure 5.58 Load versus reinforcement strain - Beam UHS3-1.5D

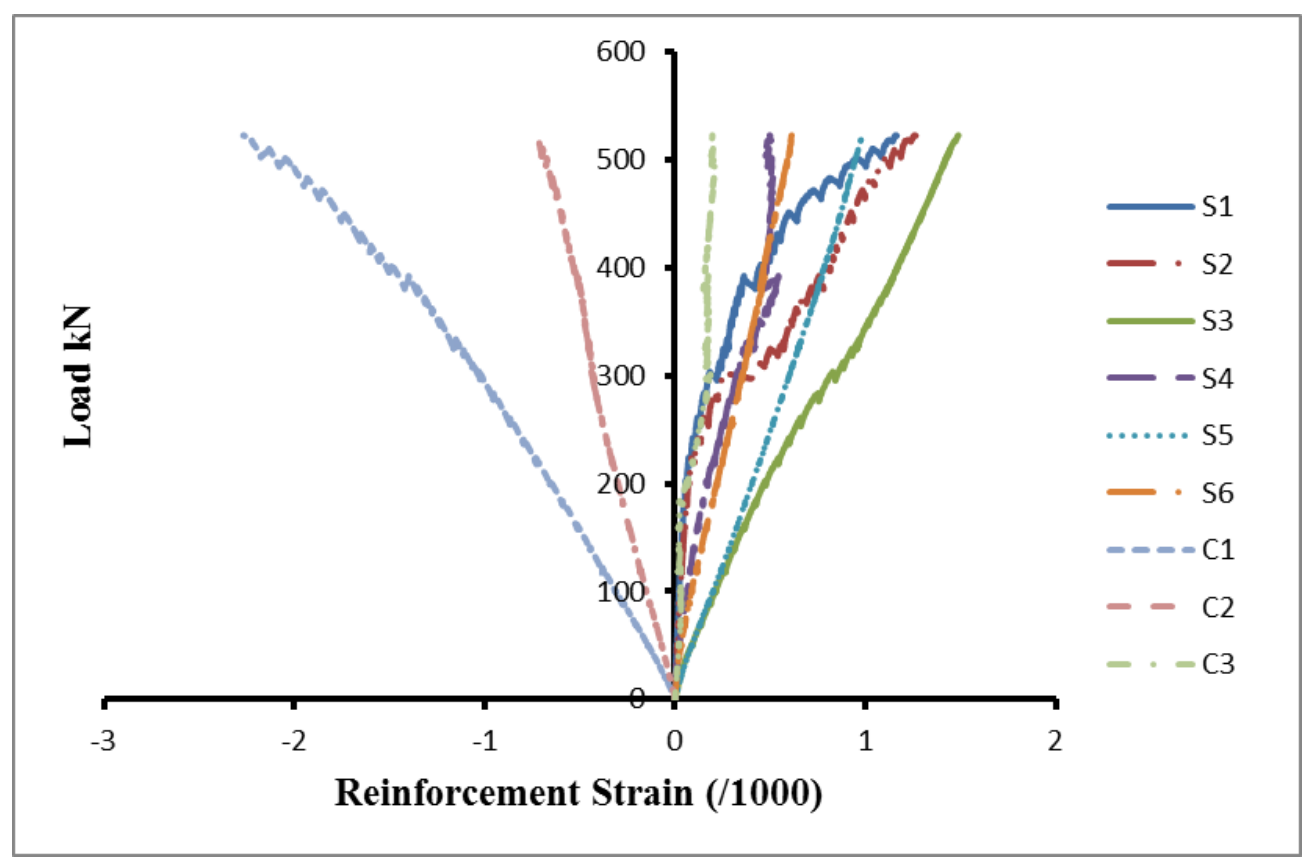

Figure 5.59 Load versus reinforcement strain - Beam UHS3-2 


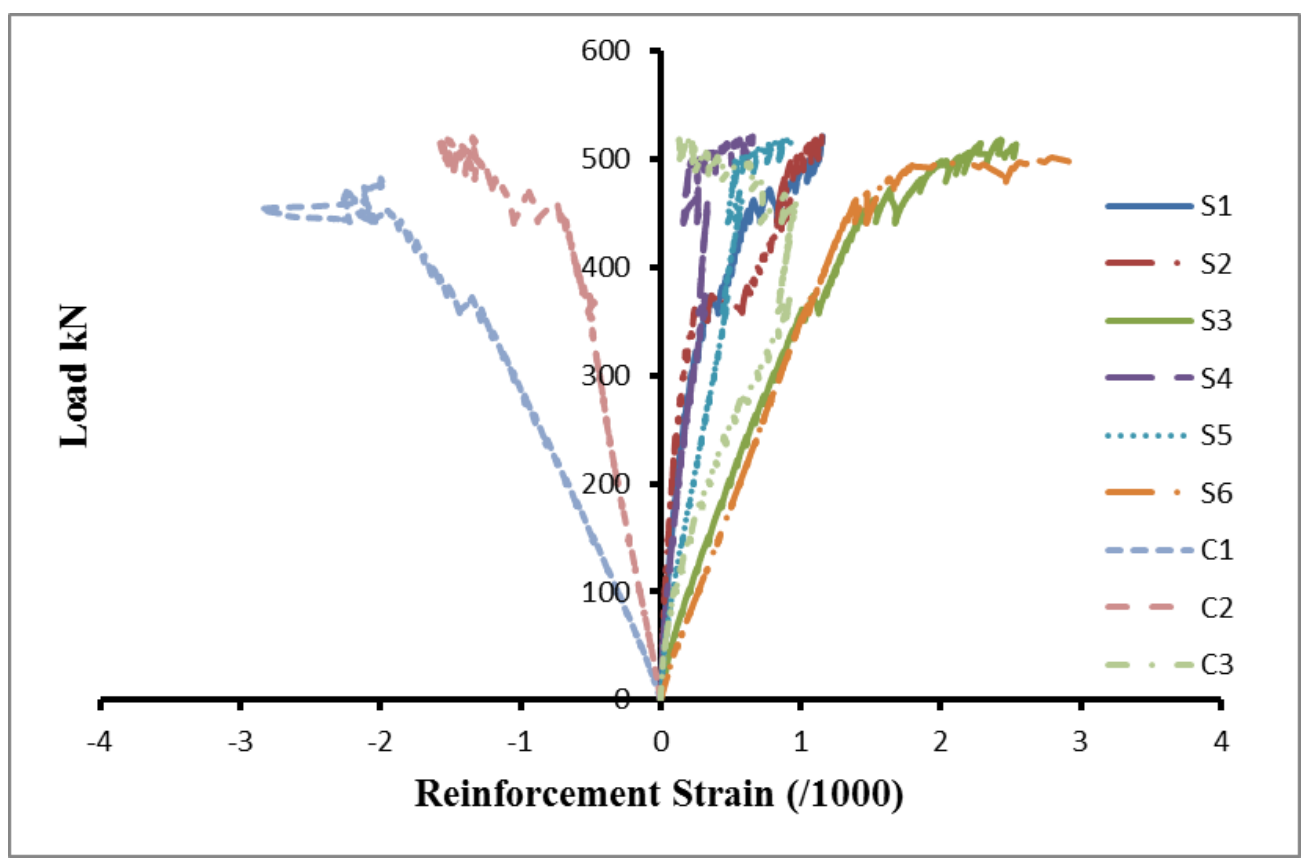

Figure 5.60 Load versus reinforcement strain - Beam UHS3-2D

\subsection{Bond between UHPFRC and NSC/HSC layers}

The bond between the two different layers of concrete (UHPFRC and NSC/ HSC) was examined using a split tensile test. Bond failure is characterized by failure along the interface surface. Some of the specimens failed in bond along the interface surface and others failed by the splitting the NSC or HSC layer. Bond stress is defined as the shear stress along the interface surface between two materials, and can be calculated from equation (3.3).

The average bond strength of composite cubes with $1 \%, 1.5 \%$, and $2 \%$ fibres volume fractions of UHPFRC-NSC were 11.62, 11.12, 11.97 MPa respectively, while the average bond strength of composite cubes with $1 \%, 1.5 \%$, and $2 \%$ fibres volume fractions of UHPFRC-HSC were 10.57, 12.32 and $12.86 \mathrm{MPa}$ respectively. It should be noted that bond strength at the composite interface is independent on the fibre volume content. Figure 5.61 illustrates failure mode of the composite splitting cubes. 
Out of all the UHPFRC-NSC specimens, only two specimens with $1.5 \%$ fibre volume content failed due to splitting failure in the NSC layer, the remainder of the specimens failed in bond at the UHPFRC-NSC interface. Out of all the UHPFRC-HSC specimens, two specimens with $1 \%$ fibre volume content and one specimen with $1.5 \%$ fibre volume content failed due to splitting failure in the HSC layer (as shown in Fig. 6d), the remainder of the specimens failed in bond at the UHPFRC-HSC interface. The failure load for the cubes that failed due to splitting failure in the NSC or HSC layer was lower than the failure load of the cubes that failed due to splitting along the UHPFRC-NSC/HSC interface. These cubes were thus eliminated from the calculation of average bond strength for the composite cubes.

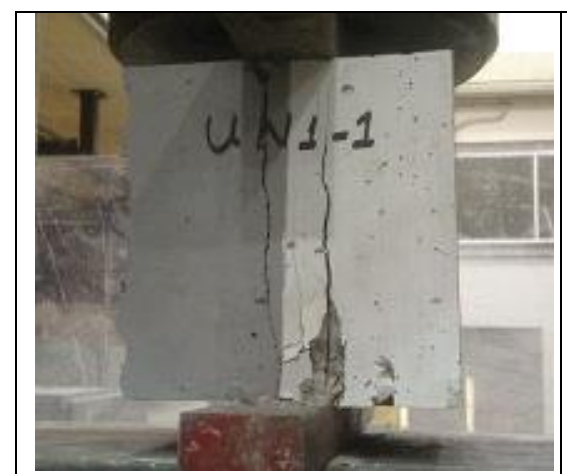

(a) UN1

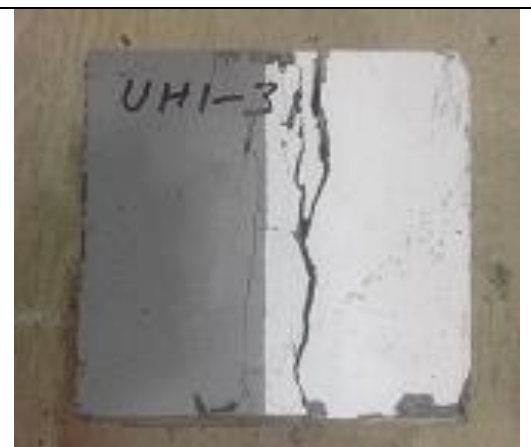

(d) UH1

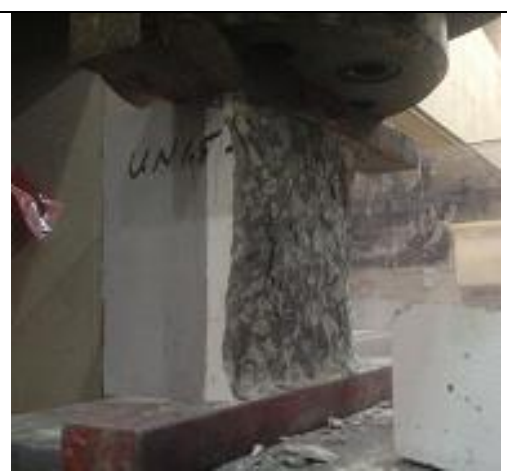

(b) UN1.5

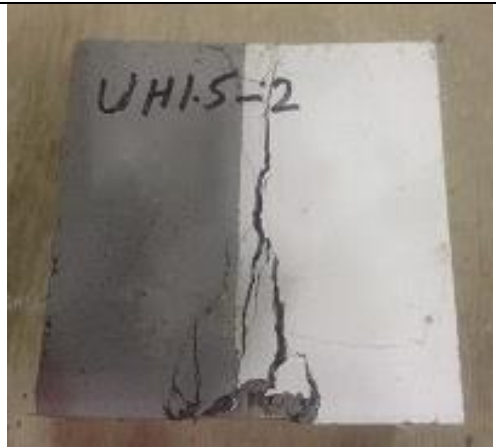

(e) UH1.5

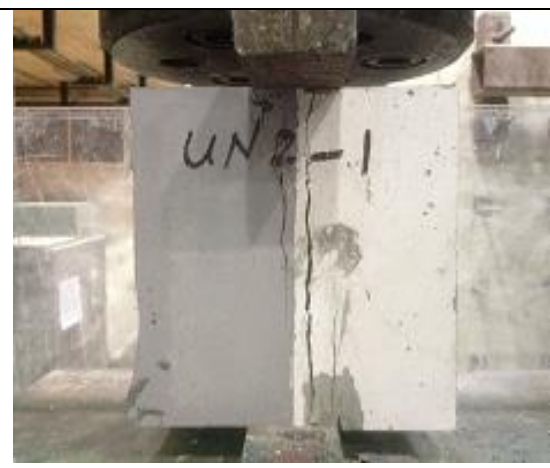

(c) UN2

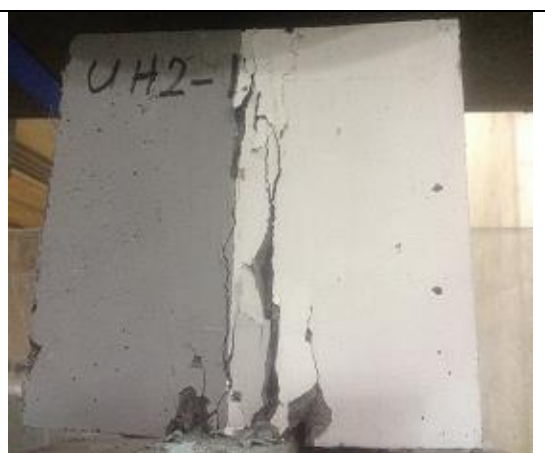

(f) $\mathrm{UH2}$

Figure 5.61 Splitting tensile tests of composite cubes 


\subsection{Comparison of response of UHPFRC members}

\subsubsection{Crack pattern and mode of failure}

All of the beams in series 3 failed in shear. All of the composite beams failed in shear due to the principal tensile stress in the NSC or HSC layer. The tensile stress in these layers exceeded the tensile strength of the concrete, leading to the development of a diagonal tensile crack in the direction perpendicular to the direction of the principal tensile stress.

The UHPFRC-NSC/HSC beams underwent three stages. The first stage was the linear elastic stage in which both layers behaved elastically. The second stage began with the appearance of a diagonal crack that started in the left span at the bottom of the NSC/HSC layer (mid depth of the beam) and propagated to the loading point as the load continued to increase. As the applied load increased, another inclined crack started to develop in the left span at the bottom of the NSC/HSC layer and the width of the cracks increased. The third and final stage took place when one or more cracks in the NSC/HSC layer caused the concrete to crush due to excessive strain, causing failure.

The UHPFRC-NSC beams failed at an applied load of 402 and $520 \mathrm{kN}$ which is 1.6 to 2.0 times higher than the failure load of NSC beam. Similarly, the UHPFRC-HSC beams failed at an applied load of 413 and $522 \mathrm{kN}$ which is 1.7 to 2.0 times higher than the failure load of HSC beam.

The results of the composite beam tests indicate that the compressive strength of the NSC or HSC concrete layer controls the ultimate shear strength of the composite beams. It was observed from the tests that the inclined cracks did not propagate into the UHPFRC layer due to high shear strength of this layer. In addition, the inclined cracks started to propagate higher into the NSC/HSC layer of the beams reinforced with dowels and shear stud. Tables 5.6 and 5.7 illustrate that the shear capacity of composite beams was not improved by the presence of dowels and shear studs with the exception of the composite beam with $1.5 \%$ fibre volume content. This can 
be attributed to the bond strength between the UHPFRC and NSC/HSC layers preventing the inclined cracks from propagating through the interface between the UHPFRC and NSC/HSC layers. It was observed from the load - crack width relationships for the composite beams that the crack width of all beams was significantly smaller between the UHPFRC and NSC/HSC layers and increased as the cracks began to propagate through the NSC/HSC layer. For example, in beam UNS3-2, the crack gauges was almost zero up to an applied load of $300 \mathrm{kN}$. When the inclined cracks began to develop in the NSC layer, the crack width began to increase. In addition, the crack width began to increase early on composite beams with $1 \%$, and $1.5 \%$ fibre volume content, while the crack width of the beams with $2 \%$ fibre volume content began to increase at loads above $200 \mathrm{kN}$.

\subsubsection{Load-deflection response}

The central deflection curves of the beams in series 2 and 3 can be seen in Figures 5.62-5.69. The central deflection of the UHPFRC-NSC/HSC composite beams was higher than the central deflection of the NSC/HSC beams due to the high ductility of the composite beams compared to NSC/HSC beams. In addition, the deflection of the beams increased in a linear fashion and was proportional to the applied load, even after the initiation of cracks.

The load-deflection curves of all the composite beams showed similar behaviour and were not significantly influenced by the fibre volume content or the presence of shear connectors, with the exception of the UHPFRC/HSC beams with $1.5 \%$ and $2 \%$ fibre volume content. The beams were able to carry the applied load and the stiffness was not degraded after the initiation of the inclined cracks. This behaviour can be attributed to the high stiffness of the UHPFRC layer supporting the NSC/HSC layer.

The maximum deflection of beams UNS3-1, UNS3-1D, UNS3-1S, UNS3-1.5, UNS3-1.5D, UNS3-2, UNS3-2D at failure were 6.15, 5.55, 6.46, 7.66, 6.41, 6.63, and 7.24 mm respectively, and for UHS3-1, UHS3-1D, UHS3-1S, UHS3-1.5, UHS3-1.5D, UHS3-2, UHS3-2D at failure were $8.81,9.69,6.84,5.75,7.06,7.34,11.14 \mathrm{~mm}$. It was observed from the test results that some 
beams were able to carry the load after the crushing of the NSC or HSC layer at the left side of the beam, and showed higher deflection. This can be attributed to the strut mechanism that the load transfer to the UHPFRC layer due to the fact that the right side of the beam was still able to carry the load and the NSC or HSC on the right side was still able to transfer the load to the UHPFRC layer.

A comparison between the UHPFRC beams with UHPFRC-NSC beams with different fibre volume contents are shown in Figures 6.70 - 6.72. It can be noted that the ultimate shear capacity of UHPFRC-NSC beams was $50 \%$ of the ultimate shear capacity of UHPFRC beams. However, the ductility of UHPFRC-NSC beams was similar to UHPFRC beams for beams with $1.5 \%$ and $2 \%$ fibre volume content. This shows that the addition of NSC or HSC layer significantly decreases the ultimate shear capacity of the UHPFRC beams due to the low shear capacity of NSC and HSC layers.

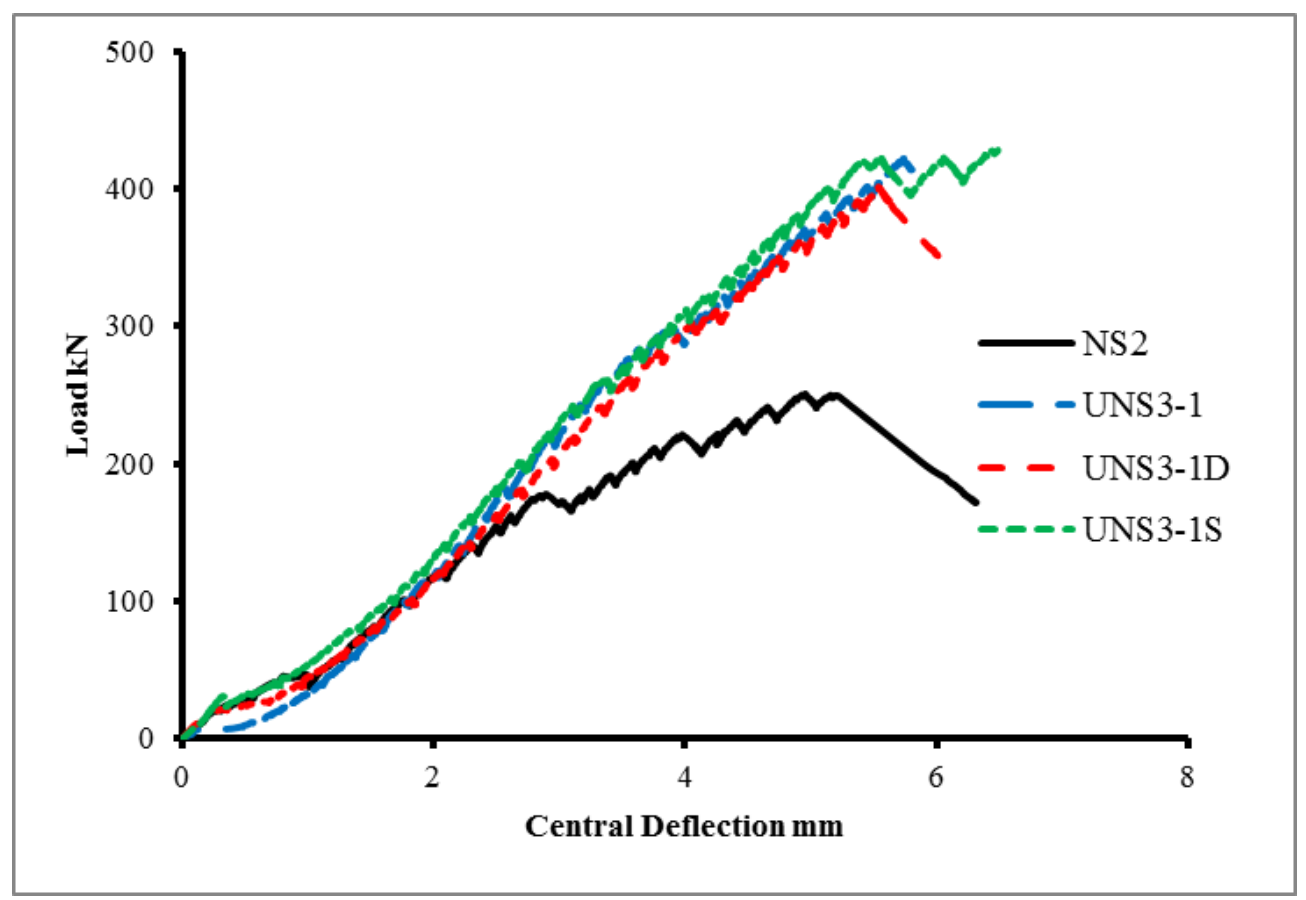

Figure 5.62 Load versus central deflection relationship comparison for UHPFRC-NSC beams with $1 \%$ fibre volume content 


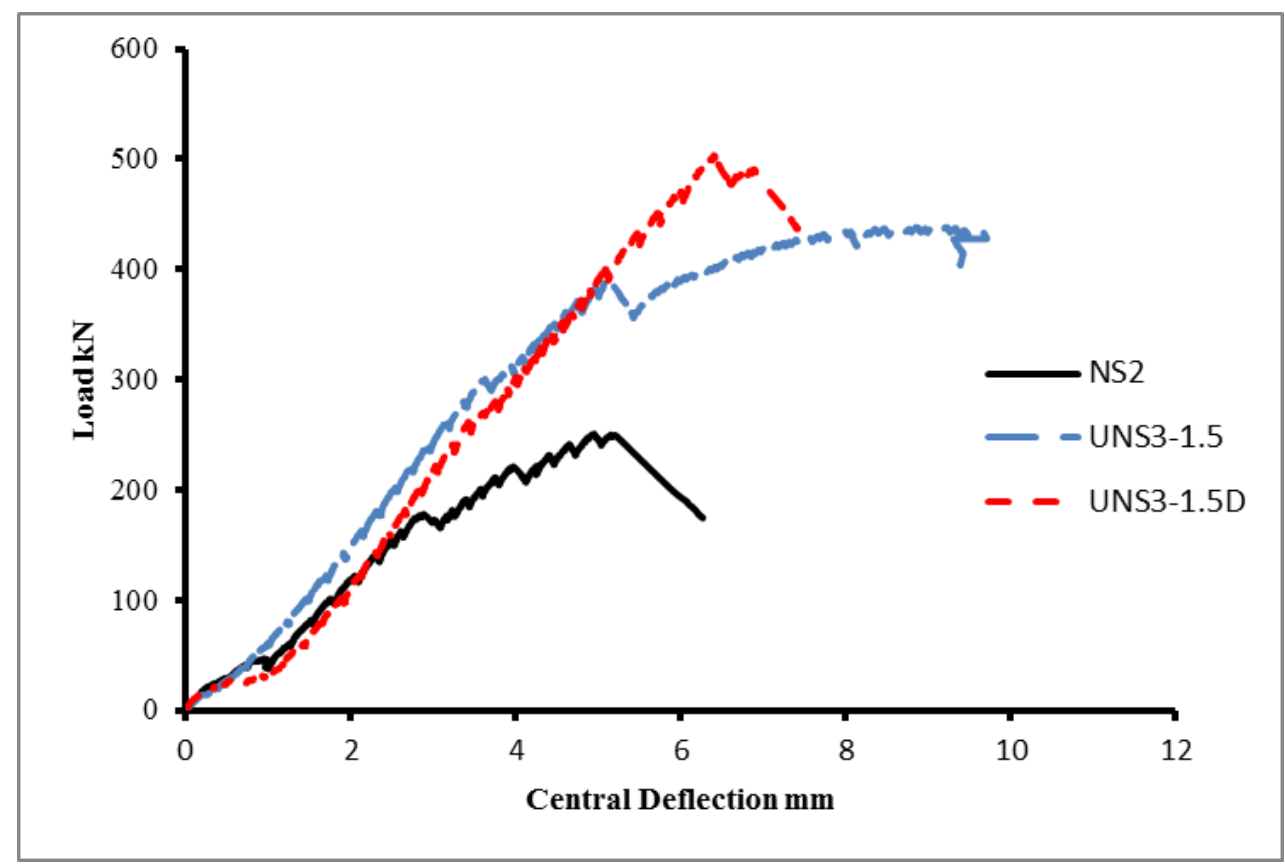

Figure 5.63 Load versus central deflection relationship comparison for UHPFRC-NSC beams with $1.5 \%$ fibre volume content

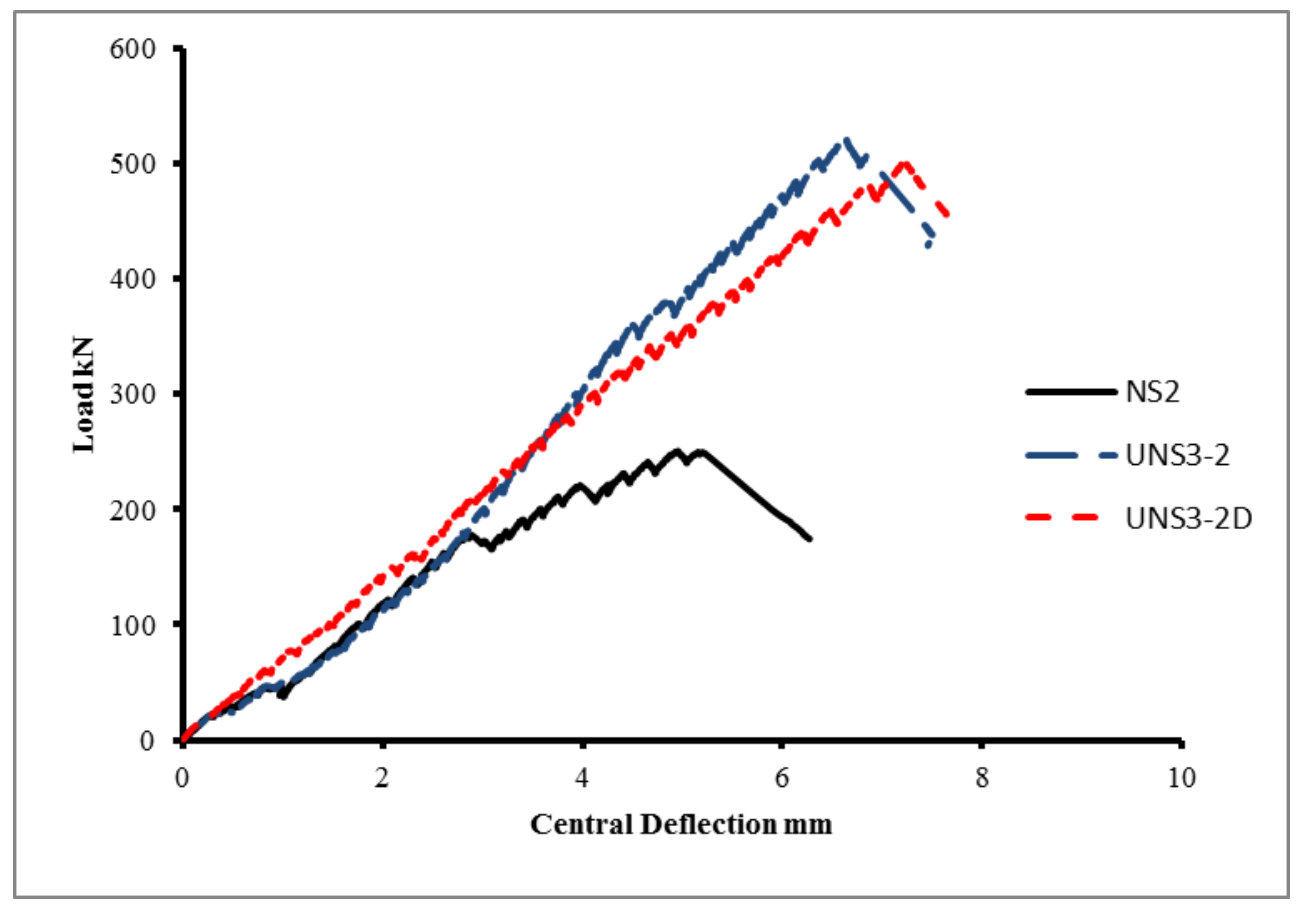

Figure 5.64 Load versus central deflection relationship comparison for UHPFRC-NSC beams with $2 \%$ fibre volume content 


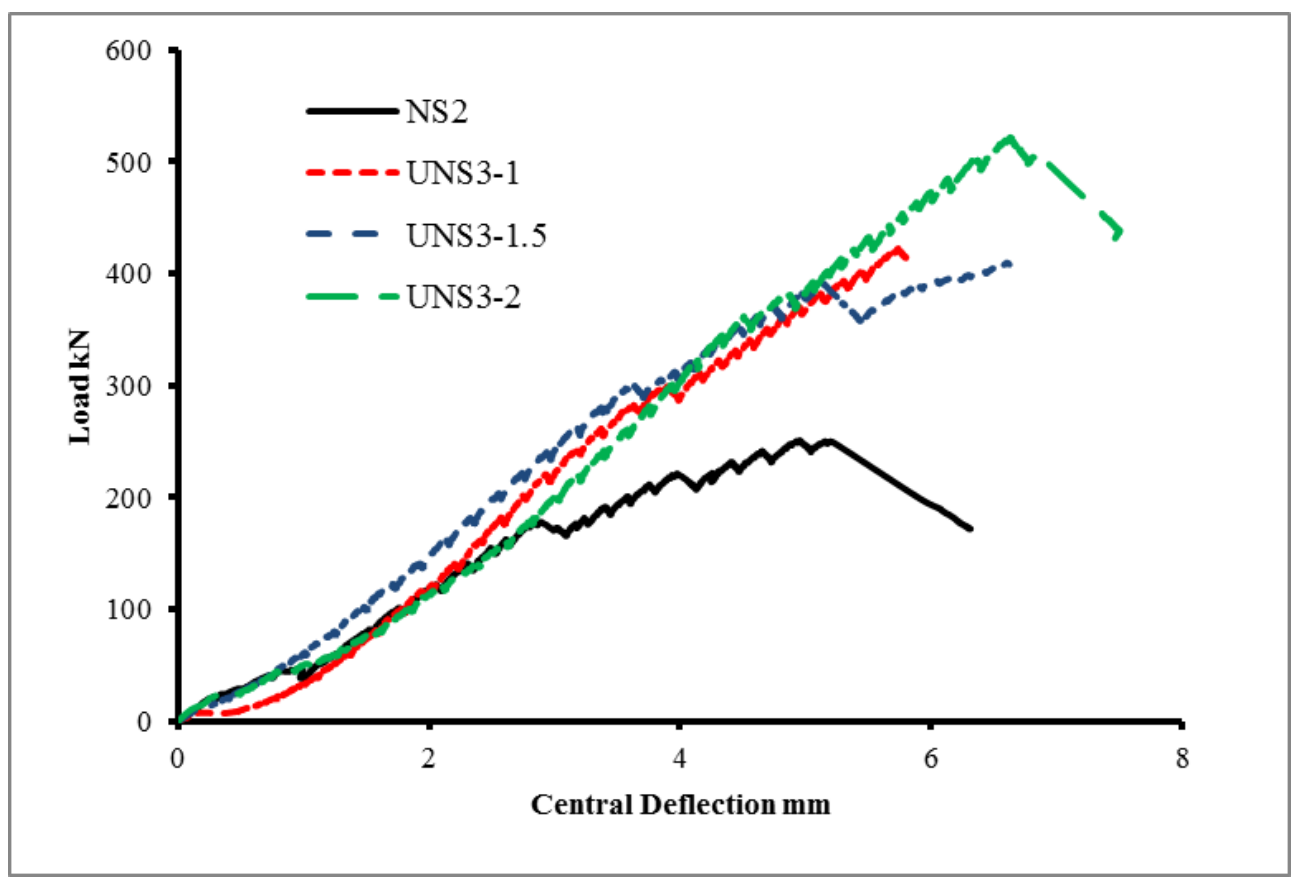

Figure 5.65 Load versus central deflection relationship comparison for UHPFRC-NSC beams without dowels or shear stud

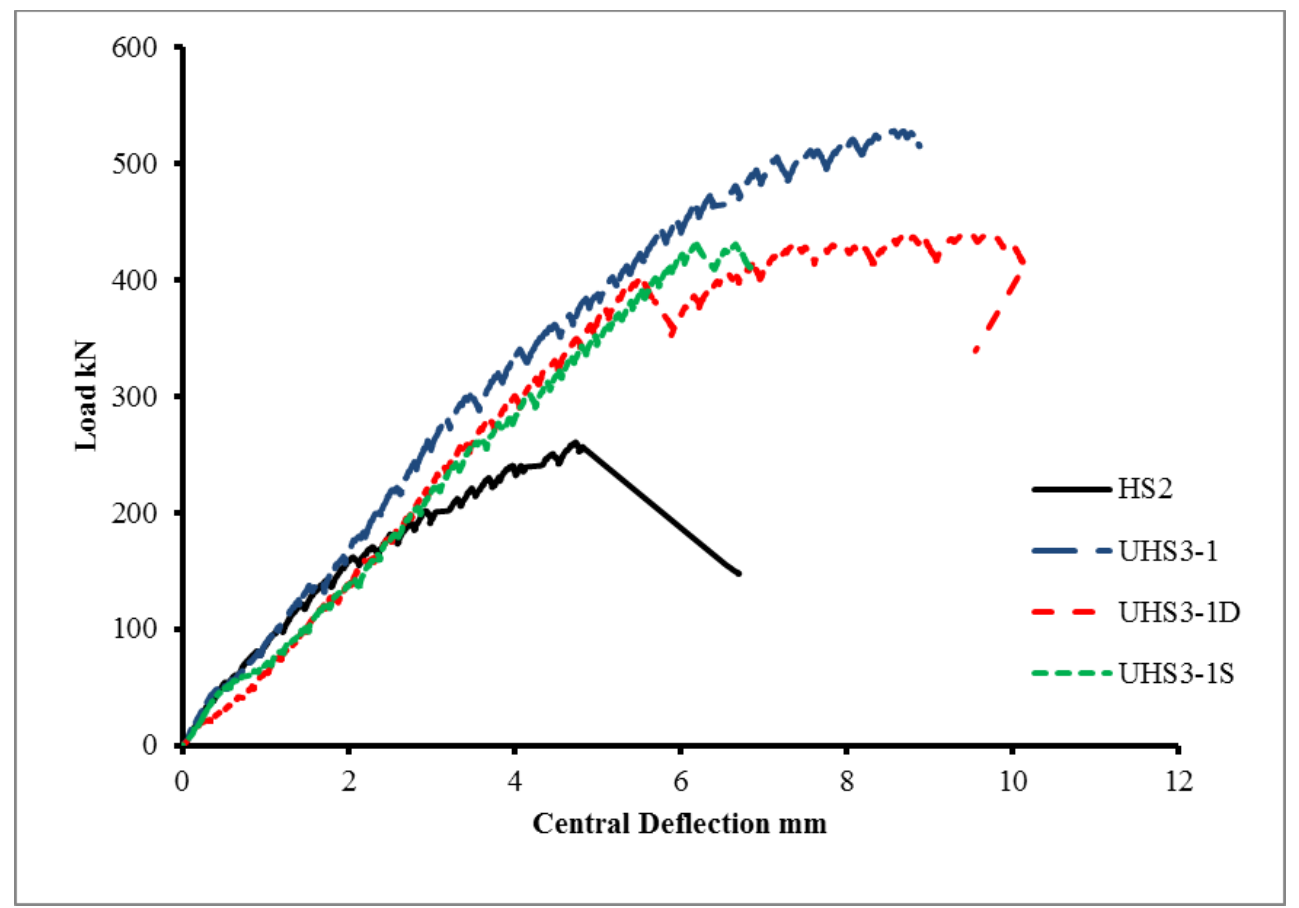

Figure 5.66 Load versus central deflection relationship comparison for UHPFRC-HSC beams with $1.0 \%$ fibre volume content 


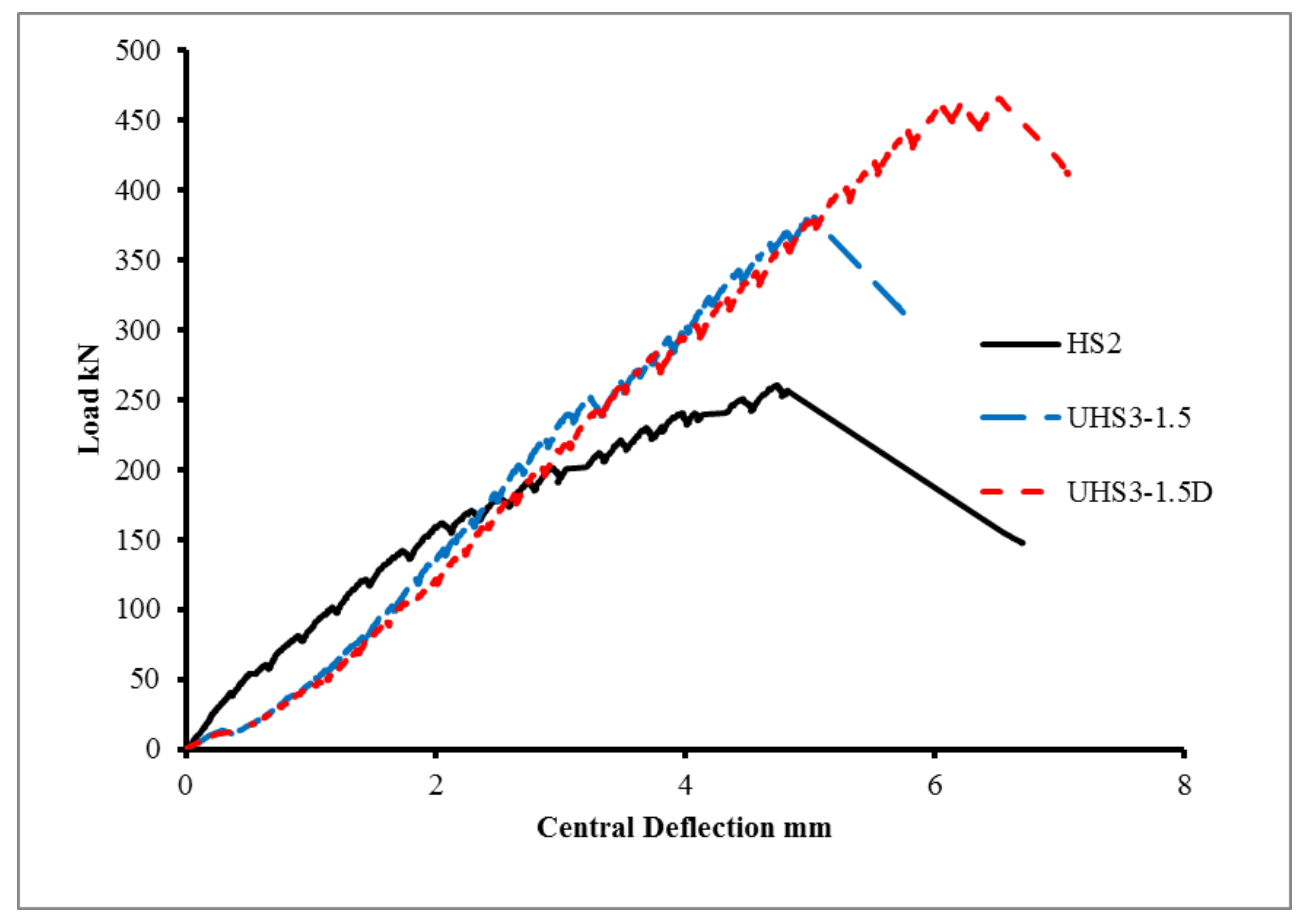

Figure 5.67 Load versus central deflection relationship comparison for UHPFRC-HSC beams with $1.5 \%$ fibre volume content

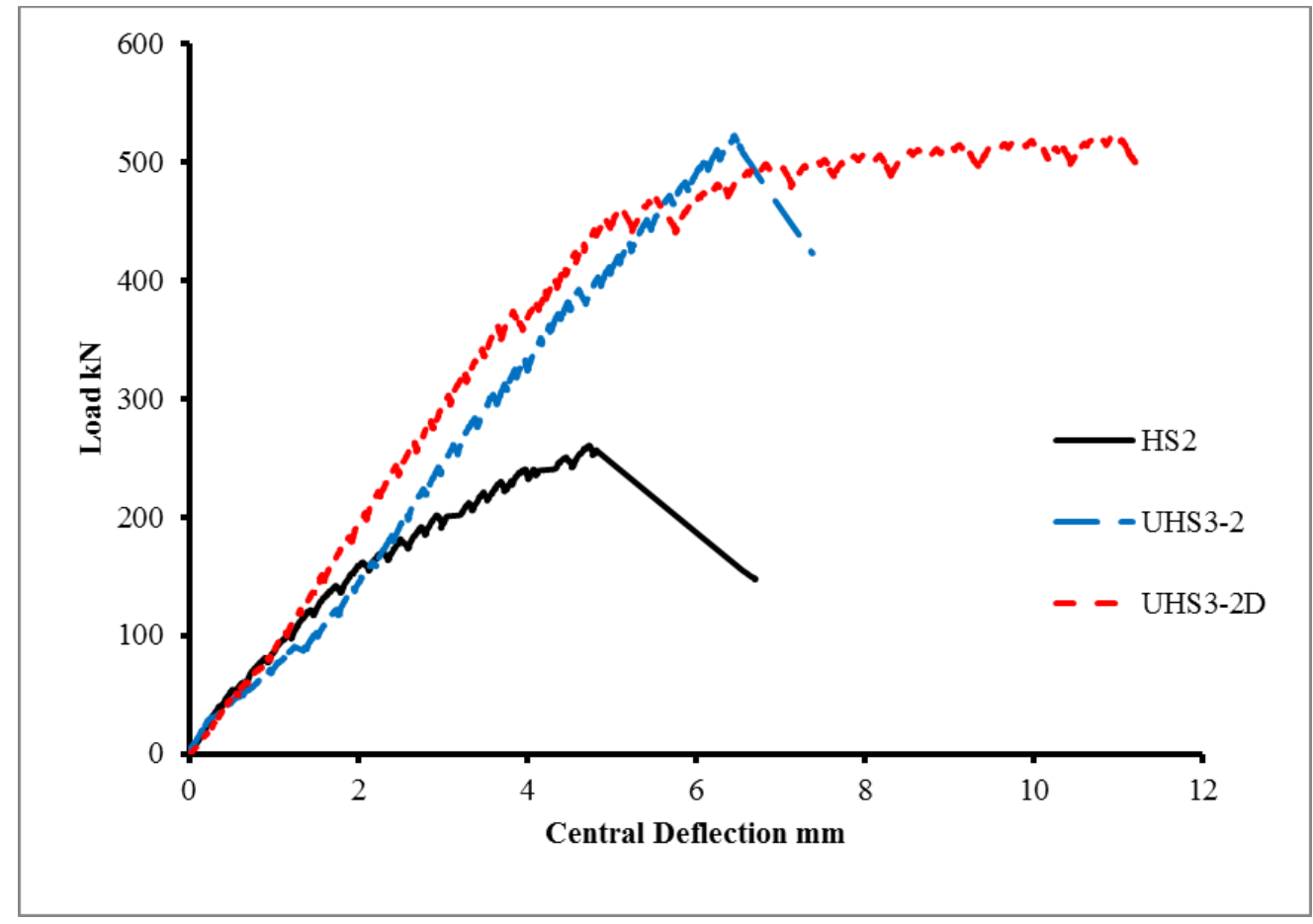

Figure 5.68 Load versus central deflection relationship comparison for UHPFRC-HSC beams with $2.0 \%$ fibre volume content 


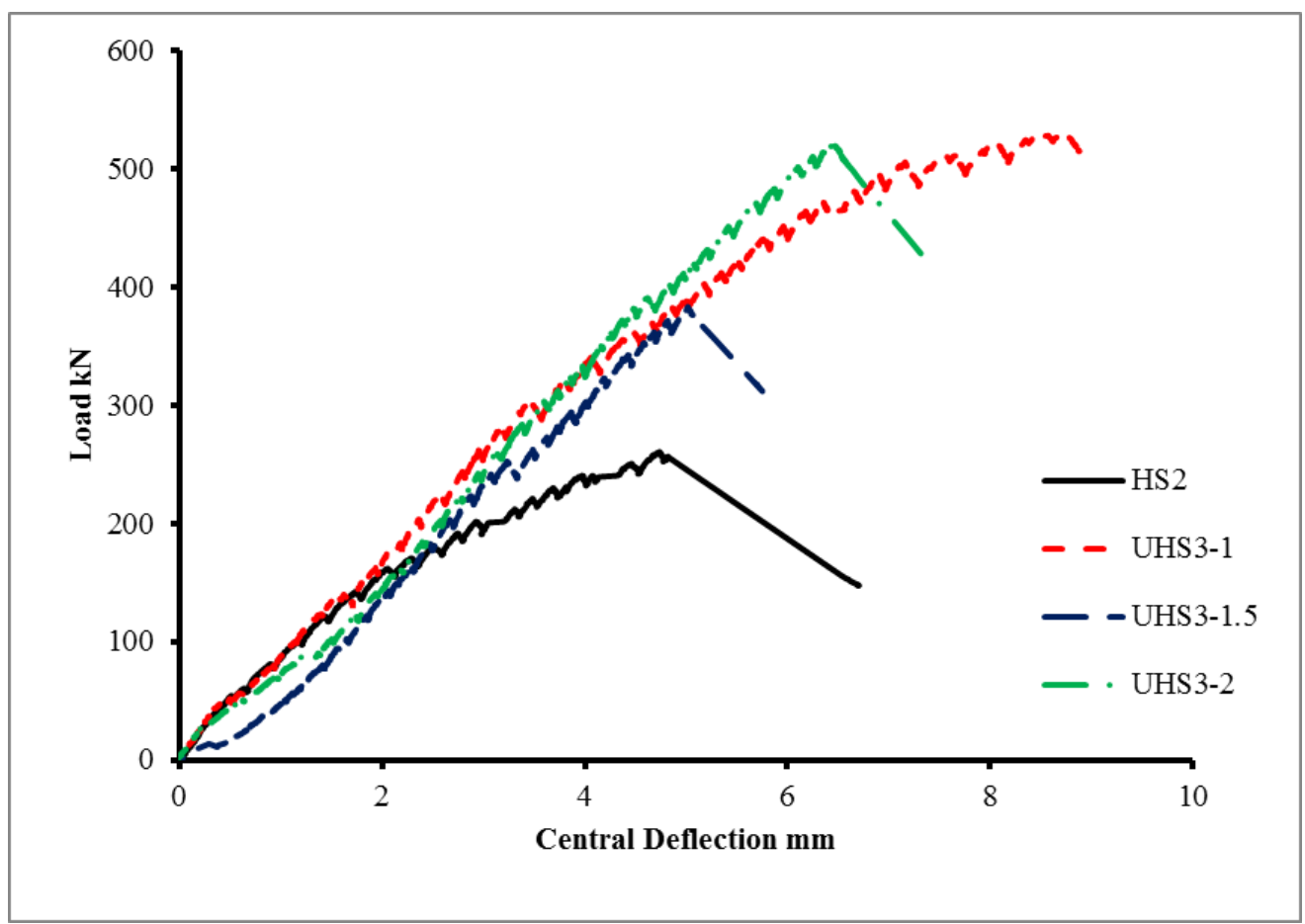

Figure 5.69 Load versus central deflection relationship comparison for UHPFRC-HSC beams without dowels or shear stud

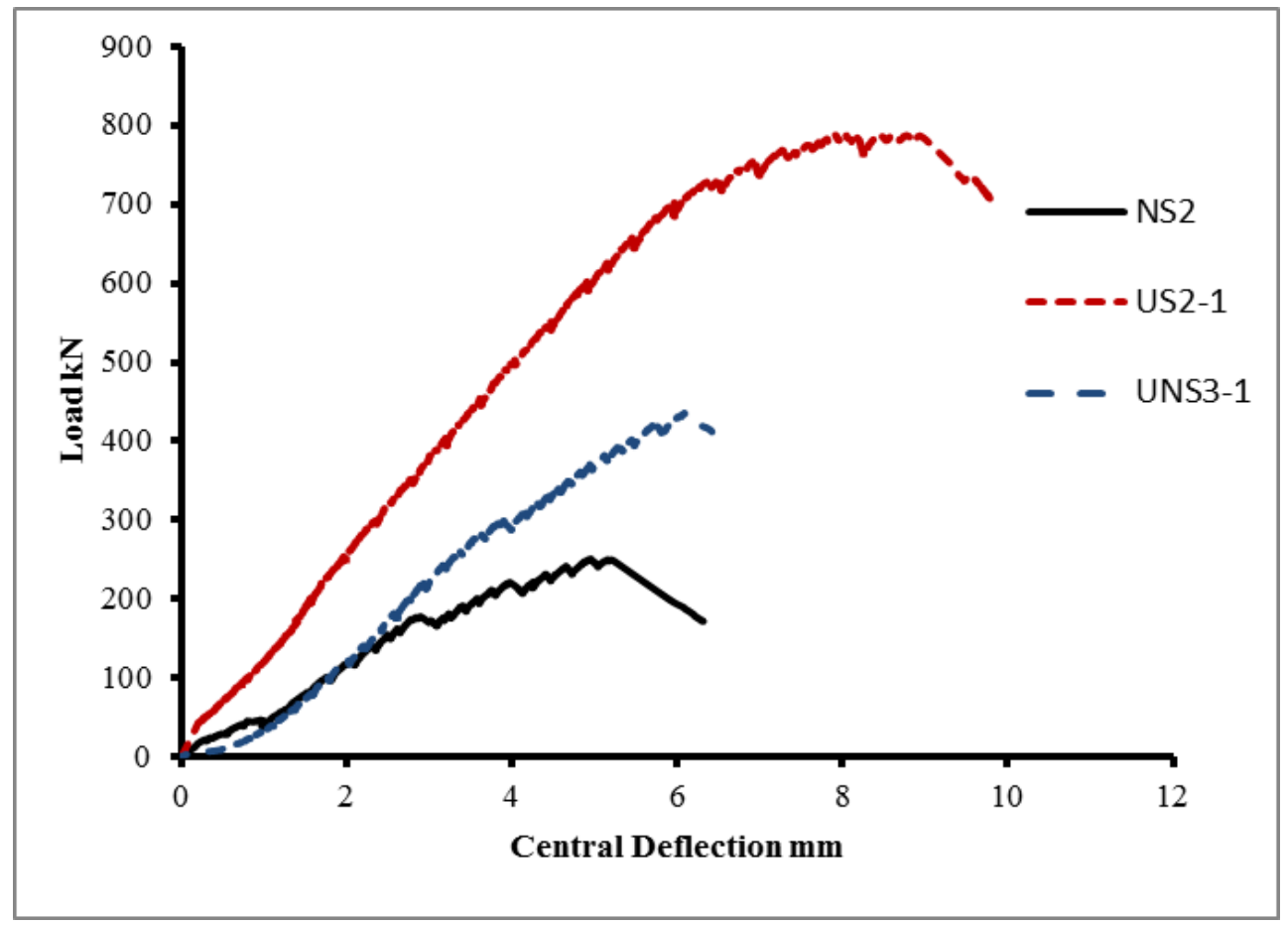

Figure 5.70 Load versus central deflection relationship comparison for beams with $1 \%$ fibre volume content 


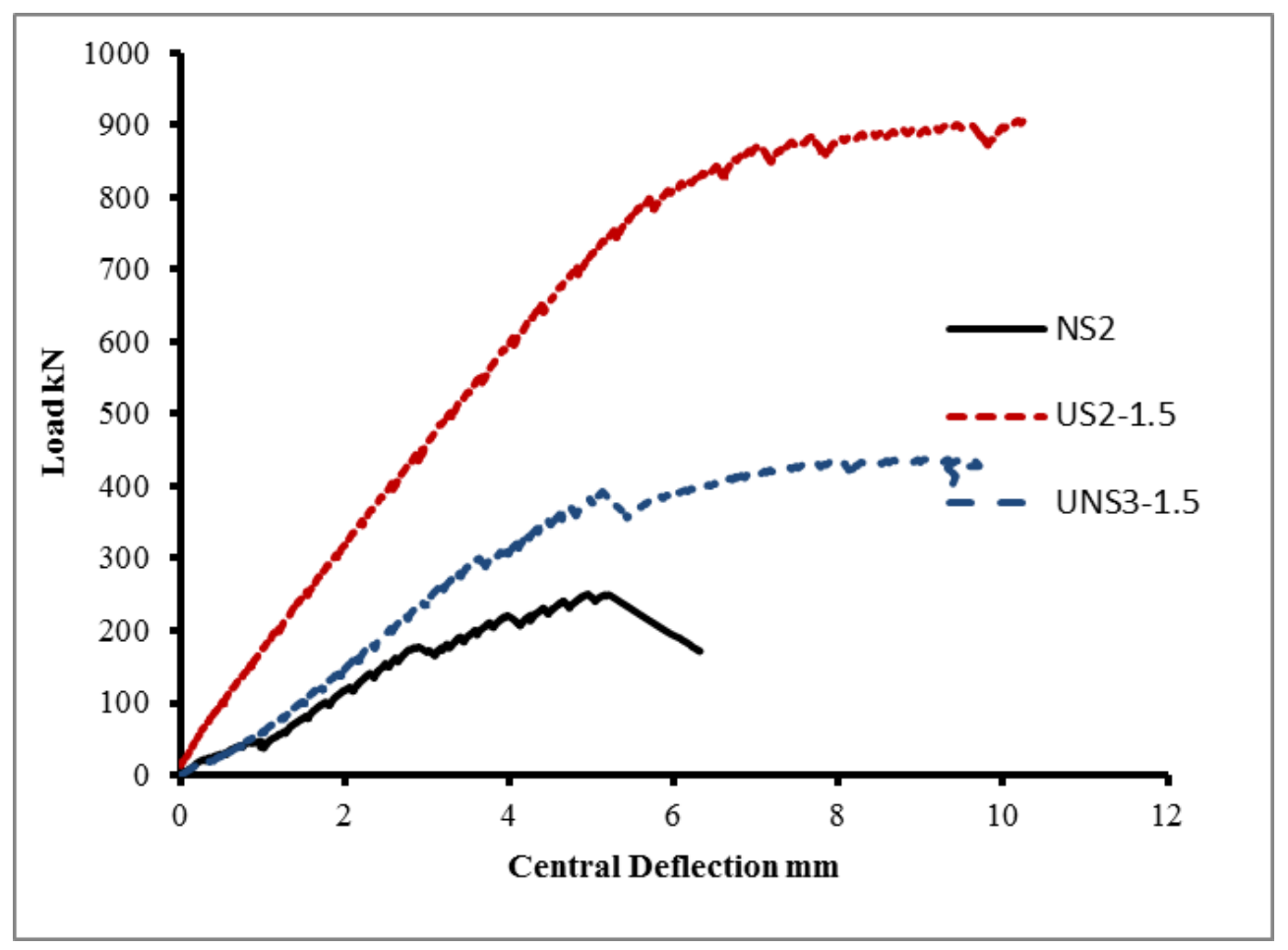

Figure 5.71 Load versus central deflection relationship comparison for beams with $1.5 \%$ fibre volume content

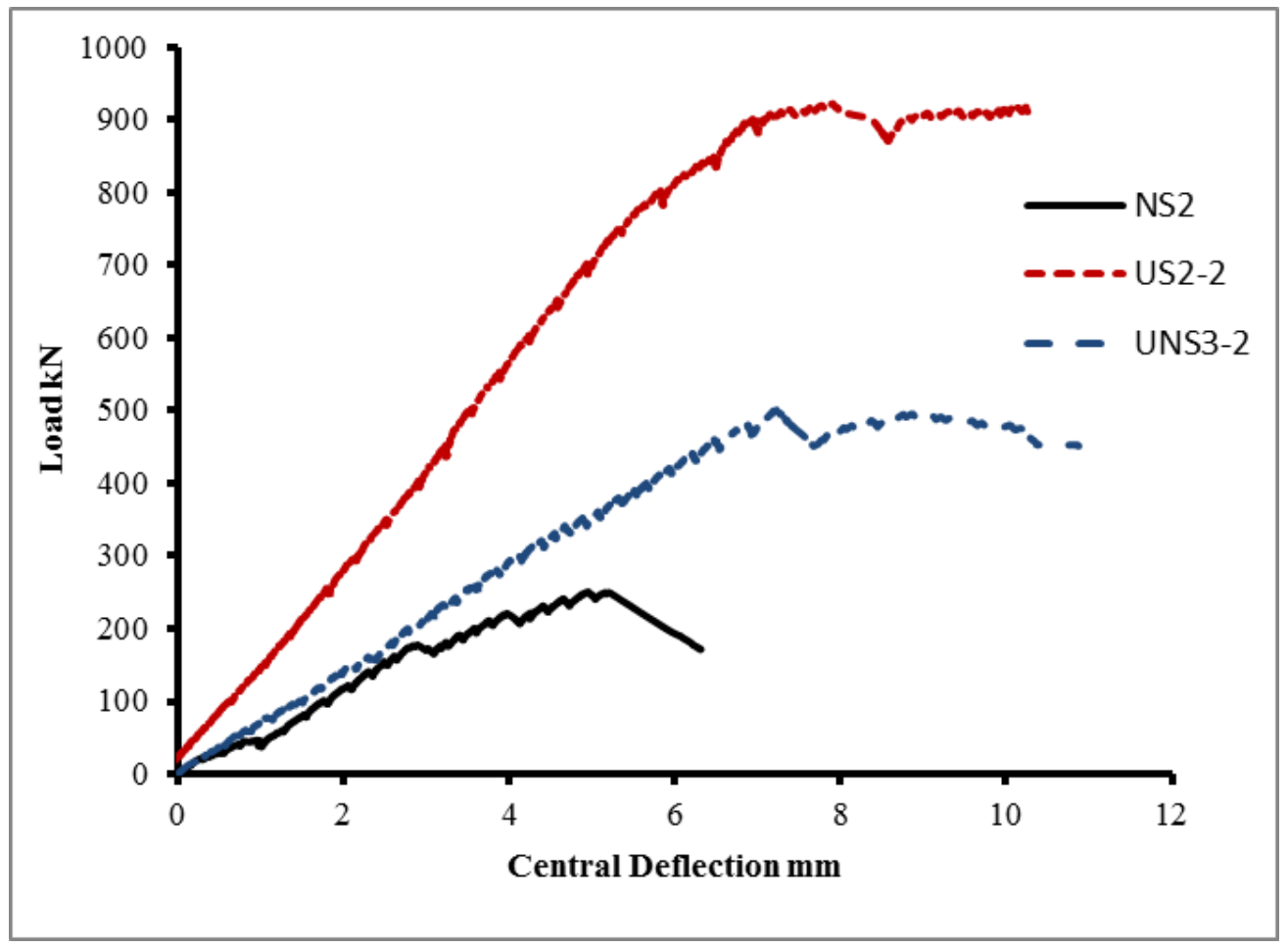

Figure 5.72 Load versus central deflection relationship comparison for beams with $2 \%$ fibre volume content 


\subsubsection{Shear capacity}

Tables 5.6 and 5.7 show the shear capacity of composite beams compared to NSC or HSC beam. It can be noted the ultimate shear capacity of UHPFRC/NSC beams is 1.6 to 2.0 times higher than the resistance of the NSC beam and the ultimate shear capacity of UHPFRC/HSC beams is 1.7 to 2.0 times higher than the resistance of the HSC beam. It is evident that the improvement in the shear behaviour of the composite beam was due to the addition of the UHPFRC layer in the tension zone. Even with a low fibre volume content of $1 \%$, the shear resistance of the UHPFRCNSC beam was $60 \%$ greater than the shear resistance of the NSC beam. Increasing the fibre volume content to $2 \%$ resulted in shear resistances that were at least double the resistance of the NSC/HSC beam.

The test results show that the addition of dowels or shear studs did not significantly enhance the ultimate shear capacity of the composite beams. This is due to high bond strength between the NSC/HSC and UHPFRC layers. The results also revealed that increasing the compressive strength from $51 \mathrm{MPa}$ to $70 \mathrm{MPa}$ did not enhance the shear capacity of the composite beams.

Table 5.6 Shear capacity of UHPFRC-NSC test specimens

\begin{tabular}{|l|c|c|c|c|}
\hline $\begin{array}{c}\text { Beam } \\
\text { specimen }\end{array}$ & \% Fibres & $\begin{array}{c}\text { Maximum } \\
\text { Shear } \\
\text { capacity } \\
V \text { exp } \\
(\mathbf{k N})\end{array}$ & $\left.\begin{array}{c}\text { Increase in } \\
\text { Resistance } \\
\left(\frac{V \exp -V \exp _{0}}{V \exp _{0}}\right.\end{array}\right)$ & $\begin{array}{c}\text { Deflection at } \\
\text { Maximum } \\
\text { Resistance } \\
\Delta \text { exp } \\
(\mathbf{m m})\end{array}$ \\
\hline NS2 & 0 & 125 & ---- & 4.63 \\
\hline UNS3-1 & 1 & 218 & 74.40 & 6.15 \\
\hline UNS3-1D & 1 & 201 & 60.36 & 5.55 \\
\hline UNS3-1S & 1 & 215 & 72.91 & 6.46 \\
\hline UNS3-1.5 & 1.5 & 220 & 76.07 & 7.66 \\
\hline UNS3-1.5D & 1.5 & 251 & 100.75 & 6.41 \\
\hline UNS3-2 & 2 & 260 & 107.93 & 6.63 \\
\hline UNS3-2D & 2 & 251 & 100.30 & 7.24 \\
\hline
\end{tabular}


Table 5.7 Shear capacity of UHPFRC-HSC test specimens

\begin{tabular}{|l|c|c|c|c|}
\hline \multicolumn{1}{|c|}{$\begin{array}{c}\text { Bpeam } \\
\text { specimen }\end{array}$} & \% Fibres & $\begin{array}{c}\text { Maximum } \\
\text { Shear } \\
\text { capacity } \\
V \exp \\
\mathbf{( k N )}\end{array}$ & $\left.\begin{array}{c}\text { Increase in } \\
\text { Resistance } \\
\left(\frac{V \exp -V \exp _{0}}{V \exp }\right.\end{array}\right)$ & $\begin{array}{c}\text { Deflection at } \\
\text { Maximum } \\
\text { Resistance } \\
\Delta \text { exp } \\
(\mathbf{m m})\end{array}$ \\
\hline HS2 & 0 & 128 & ---- & 4.62 \\
\hline UHS3-1 & 1 & 264 & 105.92 & 8.57 \\
\hline UHS3-1D & 1 & 219 & 71.16 & 9.52 \\
\hline UHS3-1S & 1 & 216 & 68.75 & 6.19 \\
\hline UHS3-1.5 & 1.5 & 201 & 57.03 & 5.15 \\
\hline UHS3-1.5D & 1.5 & 232 & 81.51 & 6.52 \\
\hline UHS3-2 & 2 & 261 & 103.77 & 6.45 \\
\hline UHS3-2D & 2 & 260 & 103.21 & 10.92 \\
\hline
\end{tabular}




\section{Chapter 6}

\section{Analytical Modeling of UHPFRC \& UHPFRC- NSC/HSC Members}

This chapter presents the proposed models to predict the structural behaviour of UHPFRC and UHPFRC - NSC/HSC members without shear reinforcement. Section 6.1 compares the experimental results with previous models and recommendations. Section 6.2 presents a method for predicting the shear strength of UHPFRC beams. Section 6.3 describes an analytical model to predict the flexural behaviour of UHPFRC members. Section 6.4 presents a method for predicting the shear strength of UHPFRC - NSC/HSC members without shear reinforcement.

\subsection{Comparisons with previous models and recommendations}

The experimental results of series 2 and the results obtained in previous research (Yang et al. 2012, Baby et al. 2010) were compared to the models proposed by other researchers in order to investigate their ability to adequately predict the shear strength of UHPFRC beams. The results indicate that the models proposed by Aouda et al. (2012), Khuntia et al. (1999), Kwak et al. (2002), Narayanan and Darwish (1987), Ashour et al. (1992), JSCE recommendation (2008), and French recommendation (2002) led to under prediction of the shear strength. In addition, the ACI-318-11, Eurocode 2 EN 1992-1-1:2004 and CSA A23.3-04 which is the same model proposed by Aouda et al. without fibres were unable to predict the shear capacity of UHPC beam without fibres.

\subsection{Predicting the shear strength of UHPFRC}

This section describes the proposed model to predict the shear strength of UHPFRC without shear reinforcement. In this model, an idealized crack represents a critical flexural-shear crack that often observed in fibre reinforced concrete beams that have failed in shear. This inclined

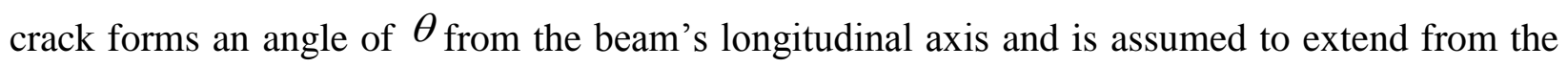
outer face of the tension surface to the location of the neutral axis. The present model ignores the shear deformation of the beam compression zone that causes sliding along the critical crack prior 
to failure. Therefore, the shear resistance along the inclined crack is resisted by the dowel action of the longitudinal steel reinforcement, and fibre tension. The contribution of dowel action to the shear capacity of reinforced concrete beams was investigated by previous researchers (Singh et al., 2012, Jeli et al., 1999). The results revealed that the diameter of the bar has no effect on the load-carrying capacity of the reinforced concrete members; therefore, the contribution of dowel action to shear resistance is unlikely to be a significant factor in the internal load-transfer mechanism leading to final collapse. Shear resistance along the inclined crack is thus assumed to be a result of fibre tension only.

Table 6.1 Comparison with previous Investigators and recommendations

\begin{tabular}{|c|c|c|c|c|c|c|c|c|c|c|c|}
\hline \multirow[t]{2}{*}{ Beam } & \multicolumn{10}{|c|}{$\begin{array}{l}V_{\text {pred }} \\
k N\end{array}$} & \multirow[t]{2}{*}{$\begin{array}{l}V u_{\exp } \\
k N\end{array}$} \\
\hline & $\begin{array}{l}\text { Aouda } \\
\text { et al. }\end{array}$ & N. \& D. & $\begin{array}{l}\text { Kwak } \\
\text { et al. }\end{array}$ & $\begin{array}{l}\text { Khunti } \\
\text { a et al. }\end{array}$ & $\begin{array}{c}\text { Ashour } \\
\text { et al. }\end{array}$ & $\mathrm{ACI}$ & Euro2 & French & JSCE & $\begin{array}{c}\text { Present } \\
\text { work }\end{array}$ & \\
\hline US1-0-3.5 & 72.28 & ------- & ----- & ----- & ------ & 51.14 & 71.66 & 71.81 & 89.73 & 99.39 & 99.4 \\
\hline US2-0-3-a & 73.23 & -------- & ----- & ---- & ----- & 56.49 & 79.74 & 69.64 & 99.10 & 106.35 & 142.0 \\
\hline US2-0-3-b & 79.39 & -------- & ----- & ----- & ------ & 56.49 & 85.29 & 85.93 & 106.2 & 115.92 & 147.2 \\
\hline US2-1-3 & 87.82 & 151.49 & 173.23 & 86.82 & 132.24 & ---- & ------ & ----- & ------ & 323.04 & 394.8 \\
\hline US2-1.5-3 & 102.33 & 161.73 & 183.53 & 103.46 & 144.93 & ----- & ------ & ----- & ------ & 428.70 & 455.2 \\
\hline US2-2-3 & 120.32 & 171.11 & 192.43 & 119.61 & 157.08 & ----- & ------ & 342 & 354.1 & 534.16 & $>475$ \\
\hline S34-F10* & 68.09 & 119.79 & 163.32 & 84.85 & 118.05 & ------ & ------ & ------ & ------ & 218.74 & 279 \\
\hline S34-F15* & 86.53 & 136.16 & 184.41 & 108.77 & 134.66 & ---- & ------ & ------ & ------ & 284.48 & 308 \\
\hline S34-F20* & 91.81 & 144.99 & 190.81 & 125.34 & 144.29 & ----- & ------ & 342.2 & 500.1 & 342.91 & 404 \\
\hline $\begin{array}{c}\text { Beam } 3 \mathrm{~A} \\
* *\end{array}$ & 82.69 & 319.94 & 238.99 & 99.92 & 156.78 & ----- & ------ & 218.72 & 230.1 & 413.34 & 461.5 \\
\hline $\begin{array}{c}\text { Beam 3B } \\
* *\end{array}$ & 70.77 & 317.59 & 242.78 & 83.66 & 151.54 & & ------ & 221.2 & 232.1 & 350.46 & 455 \\
\hline
\end{tabular}

N. \& D. is the model by Narayanan, and Darwish (1987)

*test beams by Yang et al. (2012)

** test beams by Baby et al. (2010)

The shear resistance of a UHPFRC beam $V_{u}$ can be equivalent to the expected shear resistance of a UHPC beam without shear reinforcement $V_{c}$ plus the additional shear resistance provided by the fibres $V_{f}$ due to the improved post-cracking resistance of the UHPFRC which is assumed to 
be uniform along the diagonal crack as shown in Fig. 6.1. The shear strength of UHPFRC beams can be calculated from equation (6.1) as shown in Fig. 6.1:

$$
V_{u}=V_{c}+V_{f}
$$

The shear resistance provided by the fibres, $V_{f}$, can be obtained as follows:

$$
V_{f}=b_{w} * L * f_{f i b} * n_{f i b} * \cos \theta
$$

where $b_{w}$ is the beam width or web width for I beam, $\theta$ is the angel of crack inclination, $f_{f i b}$ is the pullout strength of a single fibre, ${ }^{n}$ fib is the effective number of fibres per unit area that can be calculated from equation (6.3) (Hannant 1978, Lee 1990), and $L=\frac{h-c}{\sin \theta}$ as shown in Fig. 6.1.

$$
n_{f i b}=\frac{V_{s f}}{A_{s f}} * \alpha
$$




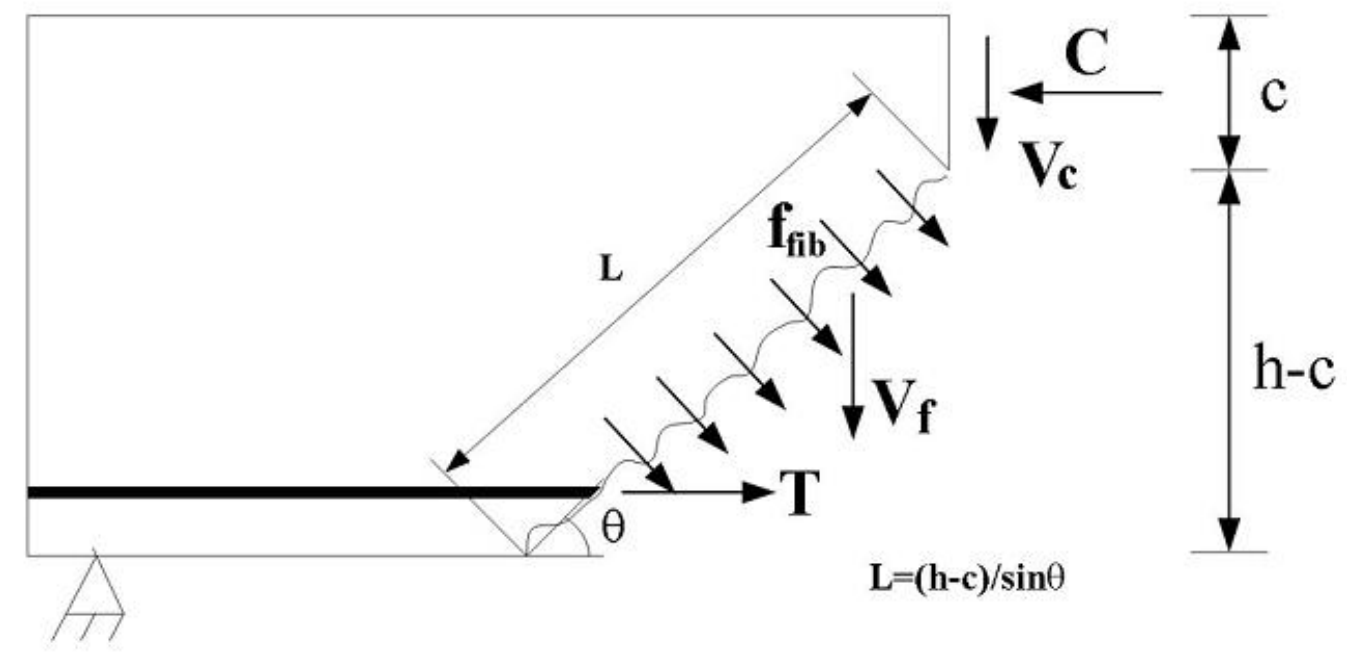

Figure 6.1 Fibre contributions to shear resistance

where $V_{s f}$ is the fibre volume content, $A_{s f}$ is the cross sectional area of single fibre, $\alpha$ is orientation factor accounts for the random orientation of the fibres in their orientation with respect to tensile direction that effect the amount of fibres crossing the failure plane.

The fibre orientation factor $\alpha$ for one, two (2D) and three dimensional (3D) fibre orientations was suggested by Naaman $(2008)$ as $1,2 / \pi$, and $\left(0.5,1 / \pi,(2 / \pi)^{2}\right)$ respectively. Soroushian and Lee (1990) reported $\alpha$ in the range from 0.41 to 0.82 depends on the dimensional orientation and specimen geometries. It was observed that the fibre orientation factor of concrete considering the boundary effect is dependent on the distance between the boundaries and normally ranges between 0.41 and 0.69 for 2D and 3D cases. Liu et al. (2011) have shown that specimens with dimensions larger than $50 \mathrm{~mm}$ are beneficial to the uniformity of fibre dispersion. For 3D rectangular sections without a boundary effect, the value of $\alpha$ was reported as 0.5 (Dupont et al. 2005). It was found that the fibre distribution of UHPFRC tend to align in the direction perpendicular to the direction of flow for panel specimens with small thickness (Barnett et al., 2010). The fibre will thus align in the direction perpendicular to the longitudinal axis of the beam. In the present model, $\alpha$ is assumed to be 0.5 for rectangular cross sections and $1 / \pi$ for I 
sections ( $b \leq 50 \mathrm{~mm}$ ) due to the narrow width of web in I sections. More research is necessary in order to determine the fibre orientation factor for I sections with a small thickness to height ratio. Thus, the "effective" number of fibres per unit area for rectangular sections is as follows:

$$
n_{f i b}=\frac{4 V_{s f}}{\pi d_{f}^{2}} * 0.5=\frac{2 V_{s f}}{\pi d_{f}^{2}}
$$

The pullout strength of a single fibre can be obtained from equation (6.5) assuming the maximum embedment length is $l_{f} / 2$.

$$
f_{f i b}=\eta \tau \pi d_{f} l_{f} / 2
$$

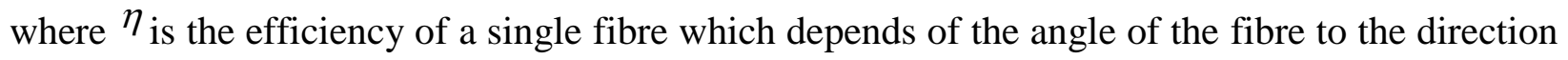
of fibre loading. This factor has been studied by numerous researchers Maage (1977); Naaman and Shah (1976); Rasmussen (1997). The results showed that the fibres are fully efficient at angles between $0^{\circ}$ and $75^{\circ}$; however, there is a significant decrease in efficiency when the angle is higher than $75^{\circ}$. The average fibre angle to the fibre loading direction for UHPFRC was reported to be between $40^{\circ}$ and $75^{\circ}$, depending on the distance from the base of the specimen and the casting procedure (Barnett et al., 2010). Therefore, in the present model, the fibre efficiency was assumed to be 1 . There was a promising correlation between this assumption and the experimental results obtained in this study (Table 6.1).

For UHPFRC beams, the contribution of concrete to ultimate shear strength is small. In addition, it is assumed that the contribution of the fibre in the concrete cover is negligible; therefore, it can 
be assumed that $(h-c)=d_{v}$. By substitute equation (6.4) and (6.5) into (6.2), the shear resistance provided by the fibres is:

$$
V_{f}=F * \tau * b_{w} * d_{v} \cot \theta
$$

where $F=\frac{V_{s f} l_{f}}{d_{f}}$ which represent fibre typology (Minelli, 2005), $d_{v}=\max (0.72 h, 0.9 d)(\mathrm{CSA}$ Standard A23.3-04, 2004), and $\tau$ is the average bond strength of fibres that can be obtained from tests on single fibre pullout. For UHPFRC, $\tau$ is between $9 \mathrm{MPa}$ and $10 \mathrm{MPa}$ depends on the particle packing density (Orange el al.1999, Wille and Naaman 2013). Thus, in the present model, the average bond strength $\tau$ is assumed to be $10 \mathrm{MPa}$. The critical inclined crack angle of beams that failed in shear $\theta$ was between $40^{\circ}$ and $45^{\circ}$. Yang et al. (2012) found that the critical angle $\theta_{\text {was around }} 45^{\circ}$; therefore, in order to be conservative, the average angle of the critical inclined cracks was assumed $45^{\circ}$. The shear contribution of the compression zone above the neutral axis can be determined from the experimental results obtained from UHPC beams. The ultimate shear force, $V_{u}$, resisted by the test beams in the left span can be calculated as follows:

$$
V_{u}=\frac{P_{u}(L-a)}{L}
$$

where, $\mathrm{L}$ is the length of the beam, a is the shear span, and $P_{u}$ is the ultimate applied load. The ultimate shear strength, $V_{u}$, resisted by the test beams without fibres in the left span is assumed due to the contribution of compression region only; therefore, $V_{u}$ in equation (6.7) is equivalent to $V_{c}$ in equation (6.1). As seen in Fig. 6.2, the behaviour of UHPC beam without the addition of fibre was similar to the behaviour of NSC beam with slightly higher strength due to the high compressive strength of UHPC material compared to NSC material. Thus $V_{c}$ proposed in the 
ACI code (ACI 318-11, 2011) can be modified based on the experimental results in this study as following:

$$
V_{c}=\left(0.24 \sqrt{f_{c}^{\prime}}+17.2 \rho_{w} * \frac{M * d}{V}\right) * b_{w} * d_{v}
$$

where, $f_{c}^{\prime}=$ concrete compressive strength, $\rho_{w}$ is the longitudinal steel reinforcement ratio, $d$ is the effective depth of beam, and $d_{v}$ is the effective shear depth .

The accuracy of the proposed model was verified using the experimental results obtained in this study as well as the experimental results obtained by Yang et al. (2012) and Baby et al. (2010) as shown in Table 6.1. As seen in this table, there is good agreement between the predicted shear capacities and the experimental results, with a standard deviation $V u_{\text {pred }} / V u_{\text {exp }}$ equal to 0.063 .

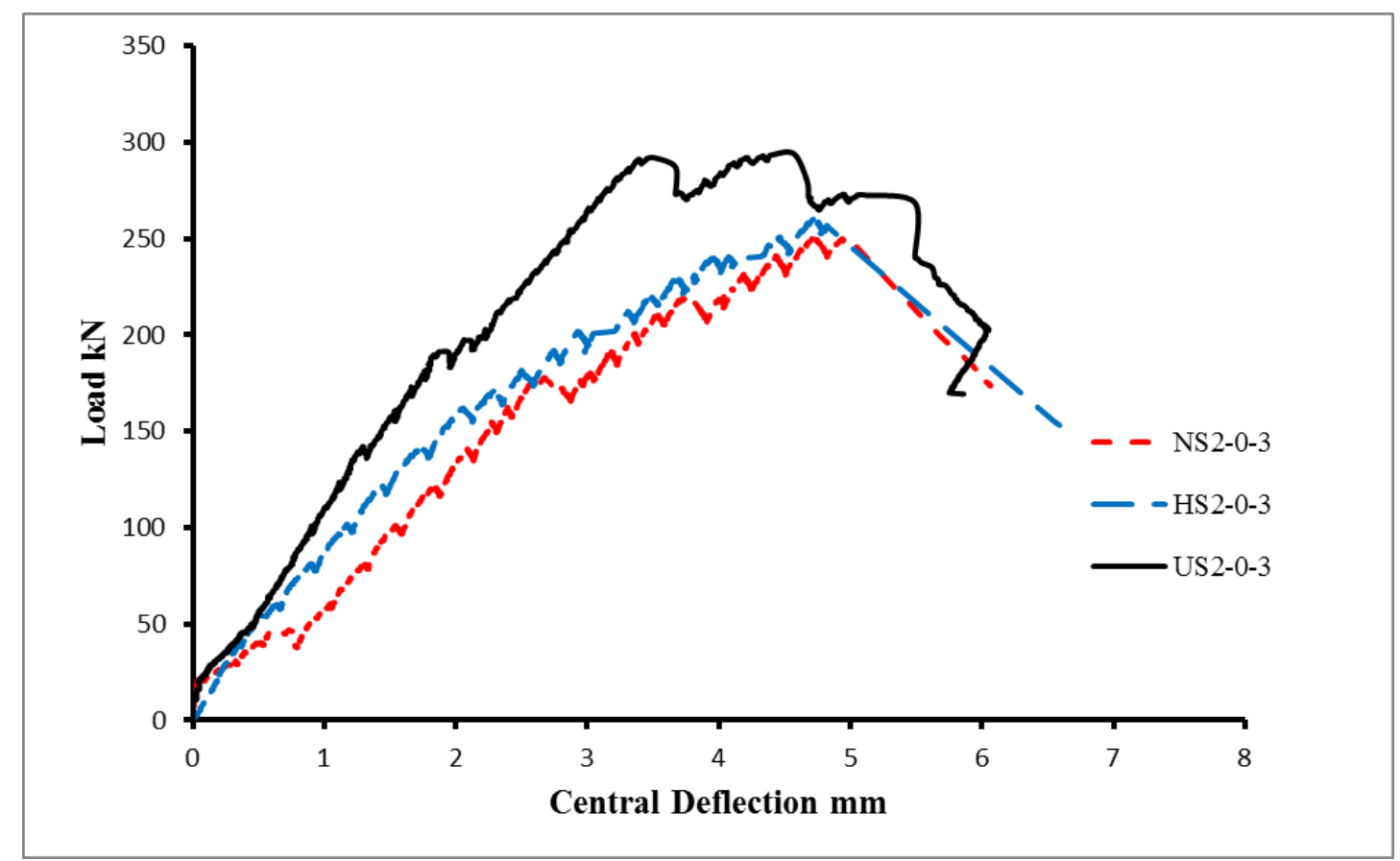

Figure 6.2 Load versus central deflection relationship for NSC, HSC and UHPC without fibre content with $\mathbf{a} / \mathbf{d}=\mathbf{3 . 0}$ 


\subsection{Predicting the flexural strength of UHPFRC}

The stress and strain distributions of reinforced concrete beam are shown in Fig. 6.3. The flexural strength of reinforced concrete beams can be calcualted from equation (6.9).

$$
M_{u}=A_{s t} * f_{y} *\left(d-\frac{\beta_{1} c}{2}\right)+f_{f t} * \frac{(h-c)^{2}}{2} * b+\alpha_{1} \alpha_{2} f_{c}^{\prime} \beta_{1} c b *\left(c-\frac{\beta_{1} c}{2}\right)
$$

where, $M_{u}=$ Ultimate moment of resistance, $f_{y}=$ steel yield strength, $d=$ depth of tensile steel reinforcement measured from top face of the beam, and $c=$ depth of neutral axis measured from the top face of the beam, $f_{f t}=$ uniform fibre reinforced concrete stress in tension, $A_{s t}=$ area of tensile steel reinforcement, $f_{c}^{\prime}=$ concrete compressive strength, $b=$ width of the beam, $h=$ height of the beam $\alpha_{1}, \alpha_{2}$ and $\beta_{1}$ are concrete stress block factors as shown in Fig. 6.3.

To determine the concrete stress block factors $\alpha_{1}, \alpha_{2}$ and $\beta_{1}$, Yang et al. (2013) developed equivalent stress block factors model for light weight and high strength concrete up to $120 \mathrm{MPa}$. Equations 6.10 to 6.12 show the calculation of the factors $\alpha_{2}$ and $\beta_{1}$, while the factor $\alpha_{1}$ assumed to be 0.85 similar to ACI code.

$$
\begin{aligned}
& \xi=\left(\frac{f_{c}^{\prime}}{10}\right)^{1.5} \\
& \alpha_{2}=0.96 * \exp (-0.0039 \xi) \\
& \beta=0.925 * \xi^{-.075} \leq 1
\end{aligned}
$$




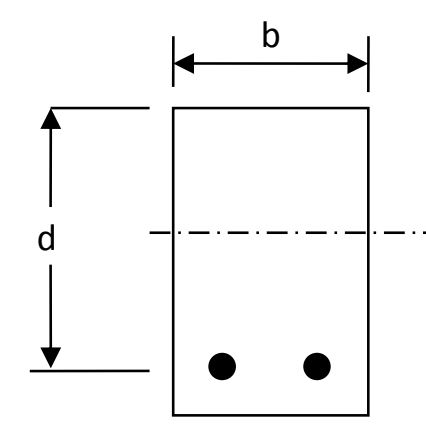

(a)

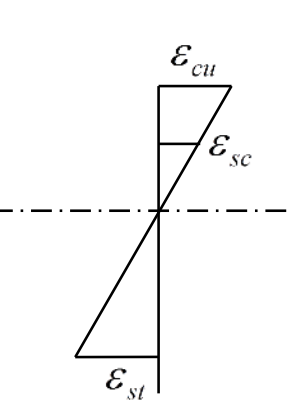

(b)

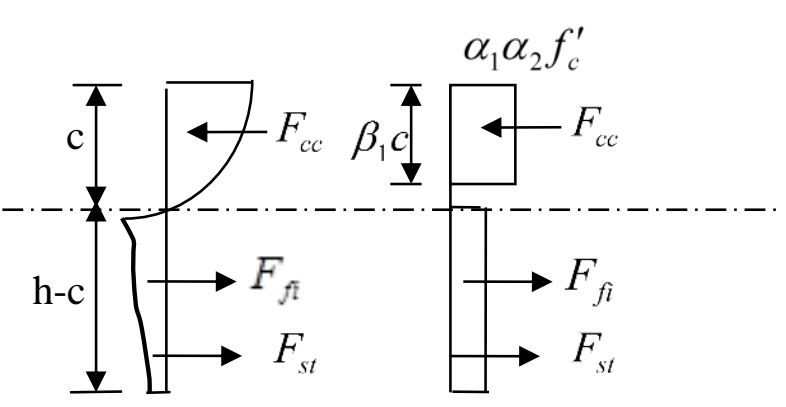

(c)

(d)

Figure 6.3 Vertical stress and strain distribution: (a) typical reinforced concrete beam section;(b) strain distribution; (c) actual concrete stresses with fibres; (d) equivalent concrete stresses with fibres

In order to determine the uniform fibre reinforced concrete stress in tension, $f_{f t}, 152 \times 152 \times 457$ $\mathrm{mm}$ fibre reinforced concrete prisms with different steel fibre volume percentages, $V_{s f}$ were tested. Sectional analysis for the prisms can be conducted using an iteration procedure to determine the location of the neutral axis and uniform fibre reinforced concrete stress in tension, $f_{f t}$, by satisfying the equilibrium of the horizontal forces and section moment for a given applied moment (as shown in equations 6.13 and 6.14).

$$
\begin{aligned}
& f_{f t} *(h-c) b=\alpha_{1} \alpha_{2} f_{c}^{\prime} \beta_{1} c b \\
& M_{u}=f_{f t} * \frac{(h-c)^{2}}{2} * b+\alpha_{1} \alpha_{2} f_{c}^{\prime} \beta_{1} c b *\left(c-\frac{\beta_{1} c}{2}\right)
\end{aligned}
$$

The results of sectional analysis revealed that the uniform fibre reinforced concrete stress in tension, $f_{f t}$, for Ductal mix at $1 \%$ and $2 \%$ fibre volume fractions were 2.93 and $4.00 \mathrm{MPa}$ 
respectively. The accuracy of the proposed model was verified using the experimental results obtained in this study as well as the experimental results obtained by Wahba et al. (2012) and Yang et al. (2010). The results can be seen in Table 6.2. As seen in this table, there is good agreement between the predicted flexural capacities and the experimental results, with a standard deviation $M u / M u_{\text {exp }}$ equal to 0.064 .

Table 6.2 Comparison with experimental results

\begin{tabular}{|c|c|c|c|c|c|c|c|c|c|}
\hline Specimen & $V_{s f}$ & $f_{c}^{\prime}$ & $\alpha_{2}$ & $\beta_{1}$ & $M_{s}$ & $M_{f}$ & $M_{u}$ & $M_{\exp }$ & $\frac{M_{u}}{M_{\exp }}$ \\
\hline US1-1 & 1 & 144.2 & 0.750 & 0.677 & 175.215 & 20.193 & 195.409 & 206.773 & 0.945 \\
\hline US1-2 & 2 & 158.6 & 0.775 & 0.685 & 173.723 & 14.525 & 188.248 & 190.75 & 0.986 \\
\hline US2-2 & 2 & 154.41 & 0.757 & 0.679 & 219.968 & 17.033 & 237.001 & 239.625 & 0.989 \\
\hline SB1* & 2 & 145.14 & 0.773 & 0.684 & 69.002 & 30.982 & 99.984 & 106.663 & 0.937 \\
\hline SB2* & 2 & 160.38 & 0.747 & 0.676 & 69.162 & 31.118 & 100.281 & 121.900 & 0.822 \\
\hline SB3* & 2 & 167.08 & 0.735 & 0.673 & 107.522 & 29.409 & 136.932 & 143.405 & 0.955 \\
\hline SB4* & 2 & 172.08 & 0.726 & 0.671 & 107.671 & 29.474 & 137.145 & 148.350 & 0.924 \\
\hline R12-1** & 2 & 190.9 & 0.693 & 0.663 & 29.032 & 35.618 & 64.650 & 79.100 & 0.817 \\
\hline R13-1** & 2 & 192.2 & 0.691 & 0.663 & 43.257 & 35.174 & 78.431 & 90.400 & 0.867 \\
\hline R14-1** & 2 & 196.1 & 0.684 & 0.661 & 57.306 & 34.741 & 92.047 & 97.180 & 0.947 \\
\hline R14-2** & 2 & 196.1 & 0.684 & 0.661 & 57.306 & 34.741 & 92.047 & 104.582 & 0.880 \\
\hline R22-1** & 2 & 190.9 & 0.693 & 0.663 & 52.246 & 34.713 & 86.959 & 93.677 & 0.928 \\
\hline R22-2** & 2 & 190.9 & 0.693 & 0.663 & 52.246 & 34.713 & 86.959 & 85.428 & 1.017 \\
\hline R23-1** & 2 & 196.1 & 0.684 & 0.661 & 77.249 & 33.820 & 111.069 & 109.328 & 1.015 \\
\hline R23-2** & 2 & 196.1 & 0.684 & 0.661 & 77.249 & 33.820 & 111.069 & 108.593 & 1.022 \\
\hline
\end{tabular}

*Test beams by Wahba et al. (2012)

**Test beams Yang et al. (2010)

\subsection{Predicting the shear strength of UHPFRC - NSC/HST composite beams} This section describes the proposed model to predict the shear strength of UHPFRC-NSC/HSC composite beams without shear reinforcement. In this model, an idealized crack represents a critical shear crack that develops in the NSC/HSC layer of fibre reinforced concrete composite beams that have failed in shear. This inclined crack forms at an angle of $\theta$ from the beam's longitudinal axis and is assumed to extend from the interface between the UHPFRC and NSC/HSC layers to the location of the neutral axis. The present model ignores the shear 
deformation of the beam compression zone that causes sliding along the critical crack prior to failure. In addition, the contribution of dowel action to shear resistance is neglected due to small contribution of dowel action to shear resistance. Therefore, The shear resistance of a UHPFRC$\mathrm{NSC} / \mathrm{HSC}$ beam can be equivalent to the expected shear resistance of a NSC/HSC beam without shear reinforcement, $V_{c}$, plus the additional shear resistance provided by the fibres, $V_{f}$, due to the improved post-cracking resistance of the UHPFRC layer as shown Fig. 6.4. The shear strength of UHPFRC-NSC/HSC composite beams can be calculated from equation (6.1) as shown in Fig. 6.4.

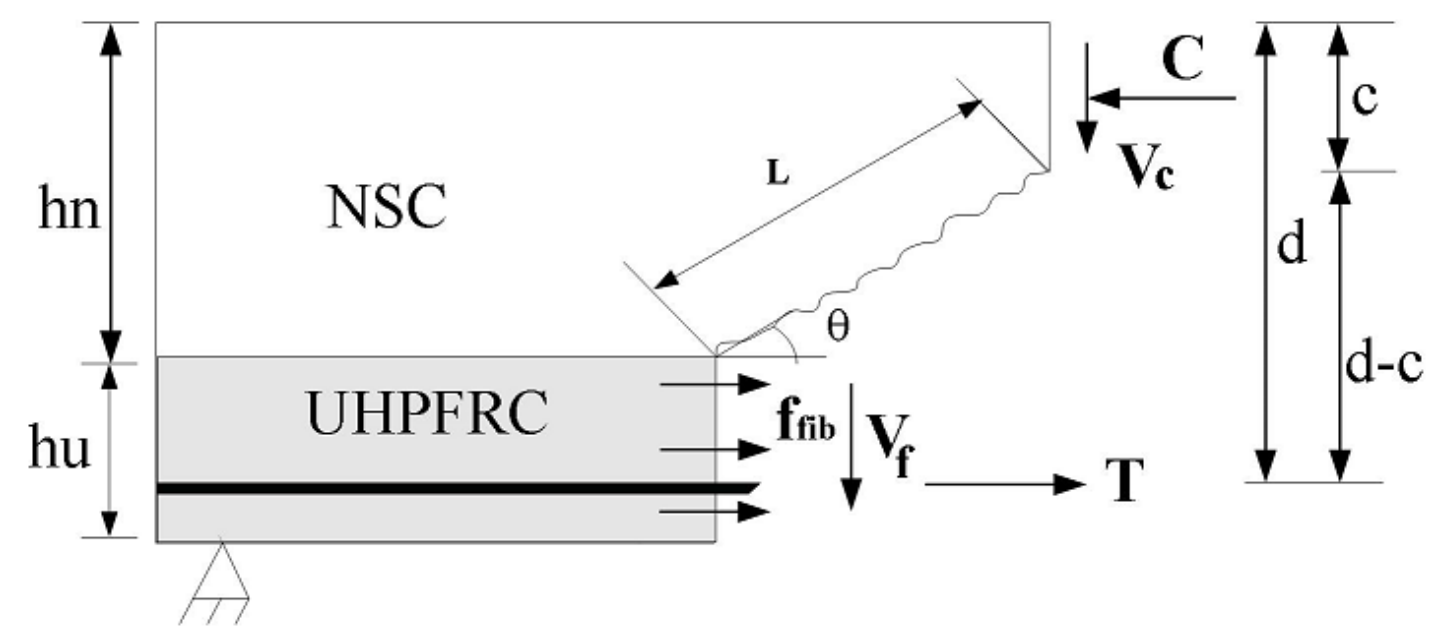

Figure 6.4 Fibre contributions to shear resistance

The shear resistance provided by the fibres, ${ }_{f}$, can be obtained as follows:

$$
V_{f}=b * h u * f_{f i b} * n_{f i b}
$$

where $h_{u}$ is the thickness of UHPFRC layer. 
The pullout strength of a single fibre can be obtained from equation (6.5) assuming the maximum embedment length is ${ }^{l_{f} / 2}$, and ${ }^{\tau}$ is assumed to be $10 \mathrm{MPa}$. The contribution of concrete to ultimate shear strength is small; therefore, it can be assumed that $(d-c)=d_{v}$ where $d_{v}=\max (0.72 h, 0.9 d)($ CSA Standard A23.3-04, 2004). In addition, it is assumed that the contribution of the fibre in the concrete cover is negligible. Thus, the shear resistance provided by the fibres is:

$$
V_{f}=F * \tau * b *\left(d-h_{n}\right)
$$

where $h_{n}$ is the thickness of NSC/HSC layer, and $F=\frac{V_{s f} l_{f}}{d_{f}}$. The shear contribution by compression zone above the neutral axis can be determined from the proposed equation by the ACI-318-11:

$$
V_{c}=\left(0.16 \sqrt{f_{c}^{\prime}}+17.2 \rho_{w} * \frac{M * d}{V}\right) * b * d_{v}
$$

The proposed model was verified with the experiment results obtained in this study. The results can be seen in Table 6.3. As seen in this table, there is good agreement between the predicted shear capacities and the experimental results, with a standard deviation of 0.85 for $V u_{\text {pred }} / V u_{\exp }$. 
Table 6.3 Material properties and experimental parameters of test beams

\begin{tabular}{|c|c|c|c|c|c|c|c|c|}
\hline Beam & $a / d$ & $\begin{array}{l}\rho \\
\%\end{array}$ & $\begin{array}{l}V_{s f} \\
\%\end{array}$ & $\begin{array}{c}f_{c}^{\prime} \\
\mathbf{M P a}\end{array}$ & $\begin{array}{c}f_{s p} \\
\mathbf{M P a}\end{array}$ & $\begin{array}{c}V u_{\exp } \\
\mathbf{k N}\end{array}$ & $\begin{array}{c}V u_{\text {pred }} \\
\mathbf{k N}\end{array}$ & $V u_{\text {pred }} / V u_{\exp }$ \\
\hline NS2 & \multirow{8}{*}{3.0} & \multirow{8}{*}{0.081} & 0 & 51.197 & 3.029 & 125 & 54.14 & 0.45 \\
\hline UNS3-1 & & & 1 & $\begin{array}{l}\text { N51.197 } \\
\text { U149.80 }\end{array}$ & $\begin{array}{l}\text { N3.029 } \\
\text { U11.17 }\end{array}$ & 201 & 135.07 & 0.67 \\
\hline UNS3-1.5 & & & 1.5 & $\begin{array}{l}\text { N51.197 } \\
\text { U162.83 }\end{array}$ & $\begin{array}{l}\text { N3.029 } \\
\text { U14.77 }\end{array}$ & 215 & 175.46 & 0.82 \\
\hline UNS3-2 & & & 2 & $\begin{array}{l}\text { N51.197 } \\
\text { U166.03 }\end{array}$ & $\begin{array}{l}\text { N3.029 } \\
\text { U15.54 }\end{array}$ & 251 & 215.99 & 0.86 \\
\hline HS2 & & & 0 & 70.078 & 4.216 & 128 & 59.705 & 0.46 \\
\hline UHS3-1 & & & 1 & $\begin{array}{c}\text { H70.078 } \\
\text { U181.907 }\end{array}$ & $\begin{array}{c}\mathrm{H} 4.216 \\
\text { U13.002 }\end{array}$ & 208 & 140.64 & 0.67 \\
\hline UHS3-1.5 & & & 1.5 & $\begin{array}{l}\text { H70.078 } \\
\text { U170.189 }\end{array}$ & $\begin{array}{l}\mathrm{H} 4.216 \\
\mathrm{U} 15.635\end{array}$ & 200 & 181.09 & 0.91 \\
\hline UHS3-2 & & & 2 & $\begin{array}{c}\text { H70.078 } \\
\text { U191.838 }\end{array}$ & $\begin{array}{c}\mathrm{H} 4.216 \\
\text { U16.275 }\end{array}$ & 260 & 221.59 & 0.85 \\
\hline
\end{tabular}




\section{Chapter 7}

\section{Finite Element Analysis}

To define the limits of the applicability of the proposed model, a wide range of experimental program is required. However, the material cost of UHPFRC is extremely expensive in comparison with normal and high strength concrete. Finite element (FE) methods serve as strong analytical tool to further investigate size effect and to calculate the response of composite members. Thus, FE method is used to perform further investigations on the parameters that affect the shear behaviour of UHPFRC members.

In this chapter, the material behaviour of UHPFRC is modeled by introducing a suitable tension stiffening model to simulate the tension behaviour of UHPFRC beams in tension. The finite element model is developed based on the smeared cracking approach adopting a plasticity-based concrete model. The validity of the proposed model was established through comparison with the results of the experimental test program in this study and with experimental results conducted by other researches.

\subsection{Description of finite element model}

Despite the significant amount of constitutive models that developed to represent the mechanical behaviour of reinforced concrete members (Chen 1982; Hillerborg et al. 1976; Lubliner et al. 1989; Lee and Fenves 1998), no accurate constitutive model of UHPFRC mechanical response is available in the finite element solutions for structural analysis of UHPFRC members. Therefore, a new model to represent the mechanical behaviour of UHPFRC is required.

In ABAQUS, two concrete constitutive models readily available; concrete smeared cracking (CSC) model and the concrete damaged plasticity (CDP) model. Chen and Graybeal (2012) 
showed that CDP is more suitable to simulate the mechanical behaviour of UHPFRC girders. Mahmud et al. (2013) showed that the CDP model is suitable to simulate the size effect of UHPFRC. Therefore, in this study, the CDP model is adopted to predict the actual behaviour of UHPFRC beams.

The concrete damaged plasticity (CDP) model in ABAQUS was proposed by Lubliner et al. (1989) for monotonic loading; then Lee and Fenves (1998) developed further the CDP model to consider the dynamic and cyclic loadings. The model assumes isotropic damaged elasticity combined with isotropic tensile and compressive plasticity to represent the inelastic behaviour of concrete. A softening stress-strain relationship is adopted to represent the formation of tensile micro cracks and a stress hardening followed by a strain softening beyond the ultimate compressive strength to represent the compressive plastic response. In addition, the tensile and compressive stiffness degradation of material and the recovery effects have been considered in this model.

The CDP model is smeared crack model which means the individual micro crack is not considered and the constitutive characteristic calculations are preformed independently at each integration point of the finite element analysis and the response in tension is described as a continuum in terms of stress-strain relations. This model include the compression hardening, tension stiffening, yield function and plastic flow of the material.

\subsection{Material properties}

\subsubsection{Material properties of steel}

In the present study, classical metal plasticity model in ABAQUS was adopted to define the behaviour of steel reinforcement up to failure. The stress-strain curve for steel was plotted based on the principles of strain hardening by Park and Paulay (1974). The young modulus $E_{s}$ and

Poisson's ratio $v_{s}$ for steel reinforcement was assumed to be $200 \mathrm{GPa}$ and 0.3 respectively. In 
ABAQUS, the true stress-plastic strain relationship must be used to define the plastic behaviour of metal plasticity. The nominal stress-strain diagram that can be obtained from uniaxial stressstrain test must be converted to true stress-strain diagram as shown in Fig. 7.1 and equation (7.1), then the plastic behaviour for the classical metal plasticity model must be used as an input in ABAQUS as shown in Fig. 7.2, and equation (7.2)

$$
\begin{gathered}
\sigma_{\text {true }}=\sigma_{\text {normal }}\left(1+\varepsilon_{\text {normal }}\right) \\
\varepsilon^{p l}=\ln \left(1+\varepsilon_{\text {normal }}\right)-\frac{\sigma_{\text {true }}}{E_{s}}
\end{gathered}
$$

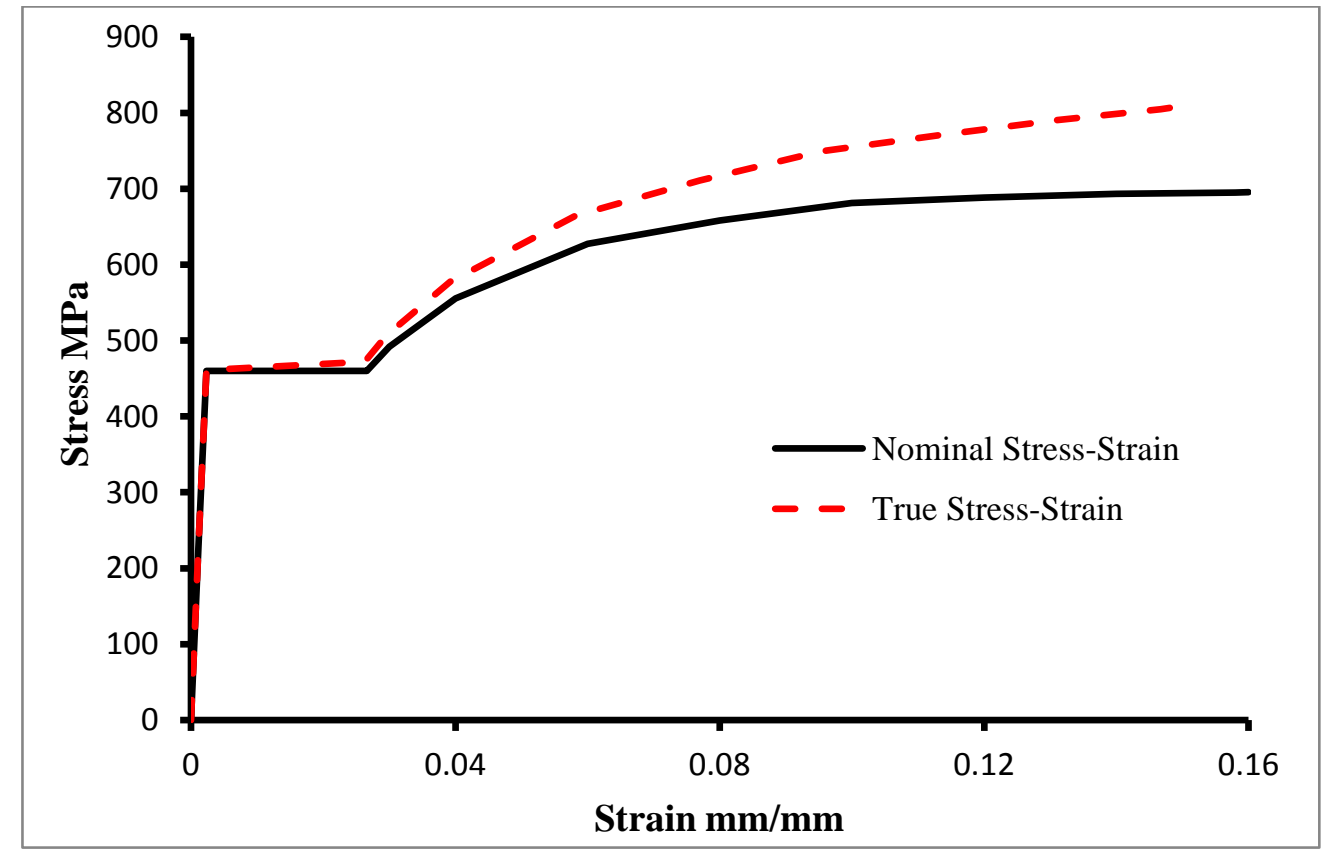

Figure 7.1 Nominal and true stress strain curve for steel reinforcement 


\subsubsection{Material properties of UHPFRC}

The nonlinear behaviour of UHPFRC is divided into two regions: compression and tension. The material property in compression is straightforward and was obtained from the compression cylinder tests data. The tension stiffening of UHPFRC was calibrated with the experimental

results in this study. The concrete density was assumed to be $2565 \mathrm{~kg} / \mathrm{m}^{3}$ (Chen et al., 2012). The Young's modulus and Poisson's ratio were assumed to be $47 \mathrm{GPa}$ and 0.20 respectively.

The uniaxial behaviour in ABAQUS must be defined as the stress-cracking strain or displacement for tensile behaviour and the stress-inelastic strain for compressive behaviour. The inelastic/cracking strains can be calculated according to ABAQUS user's manuals (2010) as follows:

$$
\begin{gathered}
\varepsilon_{c}^{i n}=\varepsilon_{c}-\frac{\sigma_{c}}{E_{c}} \\
\varepsilon_{c}^{c r}=\varepsilon_{t}-\frac{\sigma_{t}}{E_{c}}
\end{gathered}
$$

where $\varepsilon_{c}^{i n}$, and $\varepsilon_{c}^{c r}$ are inelastic strain in compression and cracking strain in tension respectively, $\sigma_{c}$, and $\sigma_{t}$ are compression and tensile stresses respectively, ${ }^{\varepsilon_{c}}$ and ${ }^{\varepsilon_{t}}$ compression and tensile

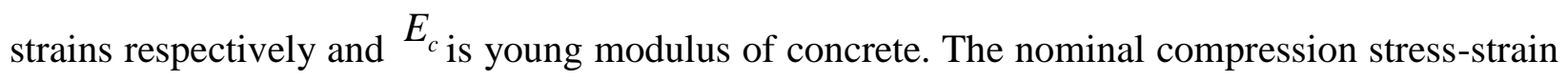
curve for UHPFRC is shown in Fig. 7.3, and the compression inelastic behaviour, compression damage parameter in CDP model are shown in Figs 7.4, and 7.5 respectively. 


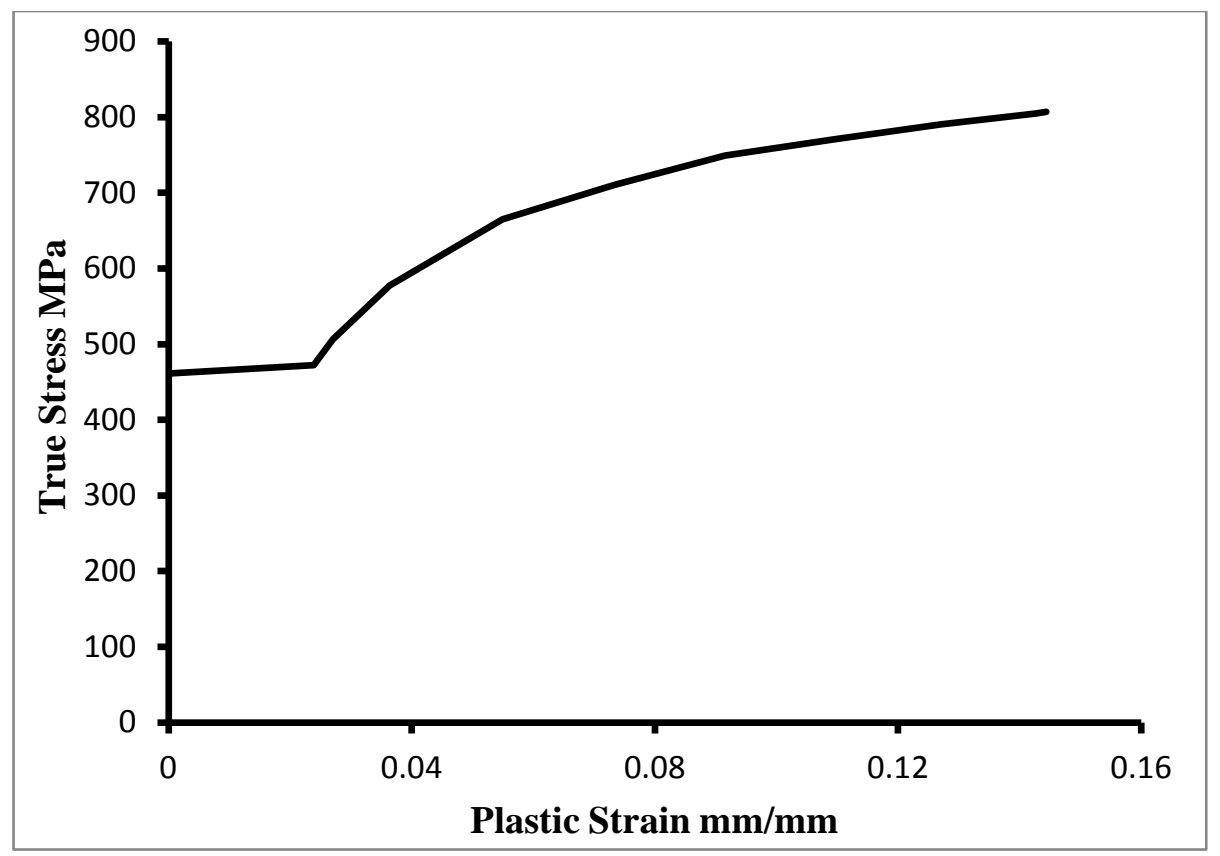

Figure 7.2 Plastic Strain- True Stress behaviour for Classical metal plasticity model

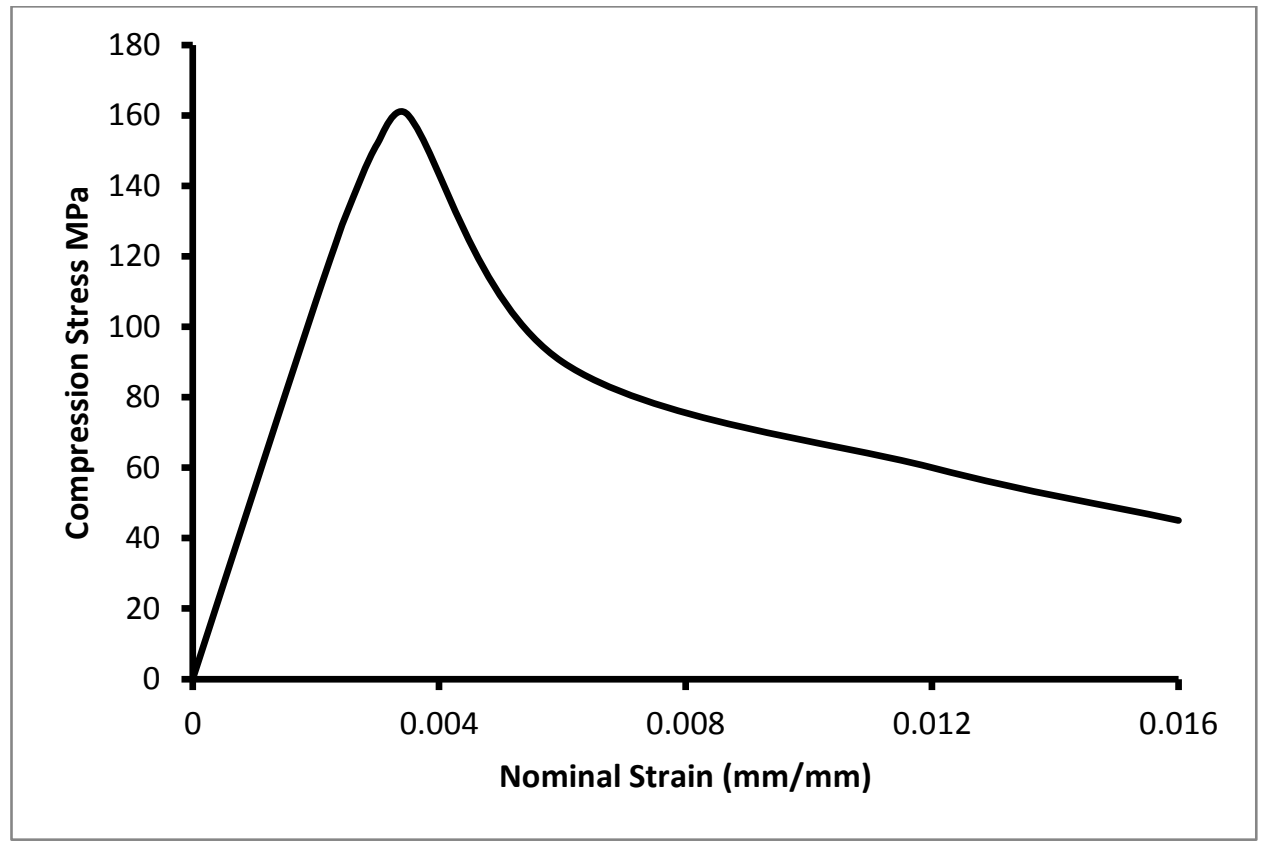

Figure 7.3 nominal compression stress-strain curve for UHPFRC 


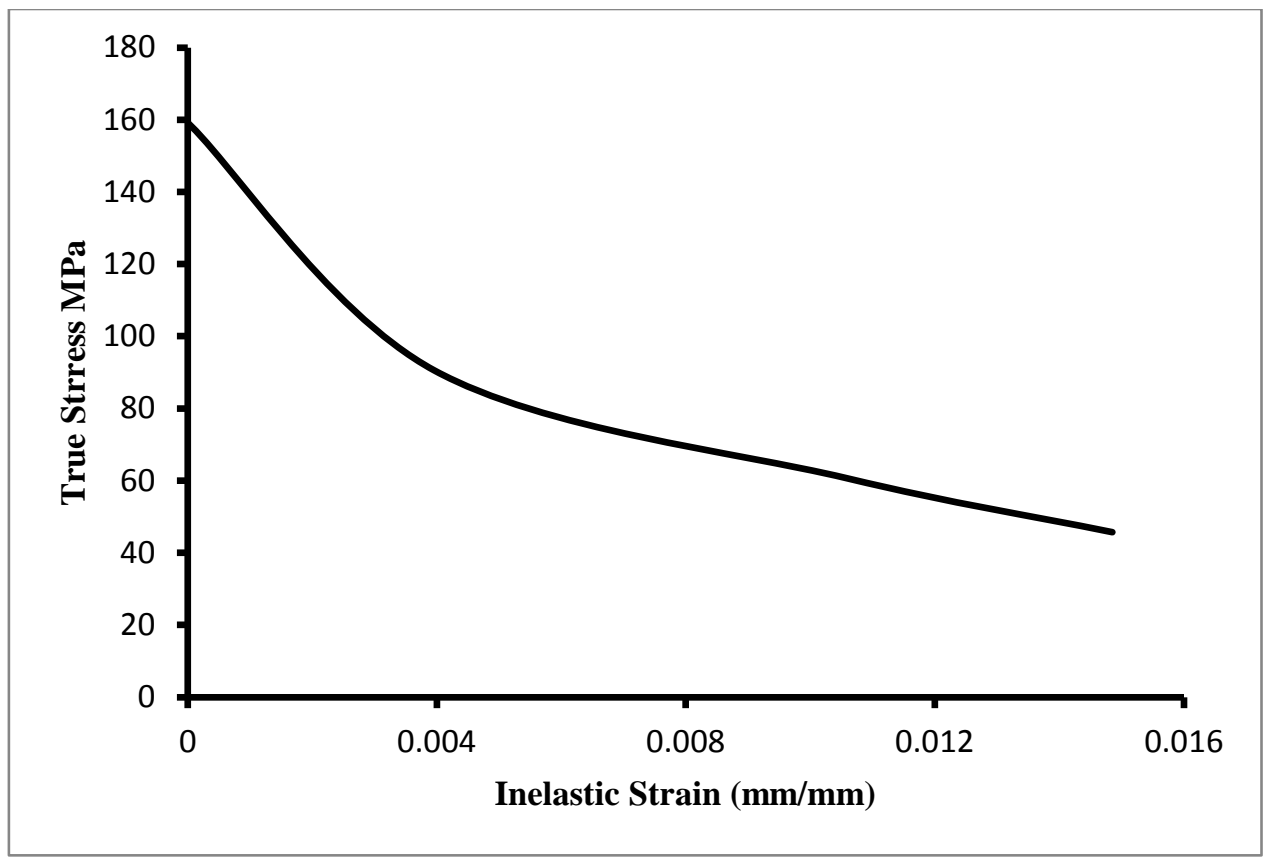

Figure 7.4 CDP model input for inelastic compression behaviour for UHPFRC

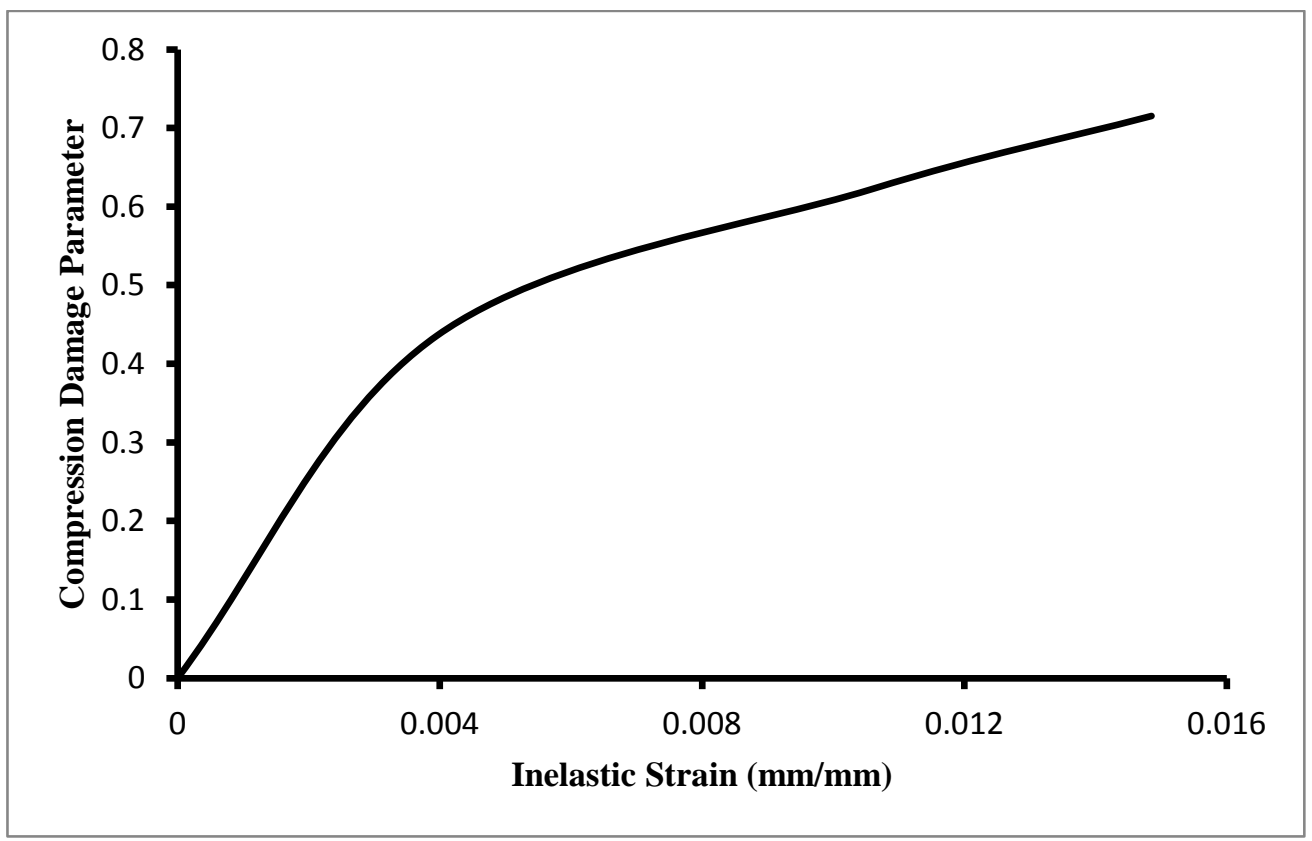

Figure 7.5 Compression damage parameter input for UHPFRC 


\subsubsection{Tension stiffening}

Cracking is one of prime importance in the nonlinear behaviour of reinforced concrete elements. When the tensile stress exceeds the tensile strength of concrete, a crack is formed in the direction normal to the direction of the tensile stress. At the crack the load is carried by the reinforcement only whereas between the cracks the load is shared between steel reinforcement and concrete. This ability of concrete between cracks to share the tensile load with the reinforcement is termed "tension stiffening". Thus, while the concrete stress is zero at the cracks, the average stress over a cracked region is not zero. Cracking occurs in the concrete when the tensile stress at a given location exceeds its tensile strength and it is manifested by a separation of the concrete at this location.

Tension stiffening in CDP can be defined as uniaxial stress-cracking strain relationship, stressfracture energy relationship or stress-displacement relationship. The experimental data obtained from dog-bone specimens by Mahmud et al. (2013) show that the complete fracture occurred at a strain $\varepsilon_{c u t}=0.04$. Based on dog-bone tests for UHPFRC specimens by Wille et al. (2011) and Mahmud et al. (2013), the tension stiffening in the present study was described as uniaxial stresscracking strain relationship, which is elastic-plastic with linear strain hardening to simulate the post cracking behaviour of UHPFRC, then softening occurs until complete fracture at a strain $\varepsilon_{\text {cut }}=0.04$. The input parameters for UHPFRC (with different fibre volume percentages) that includes inelastic tension behaviour and tension damage in CDP model are shown in Figs. 7.6 and 7.7 respectively. 


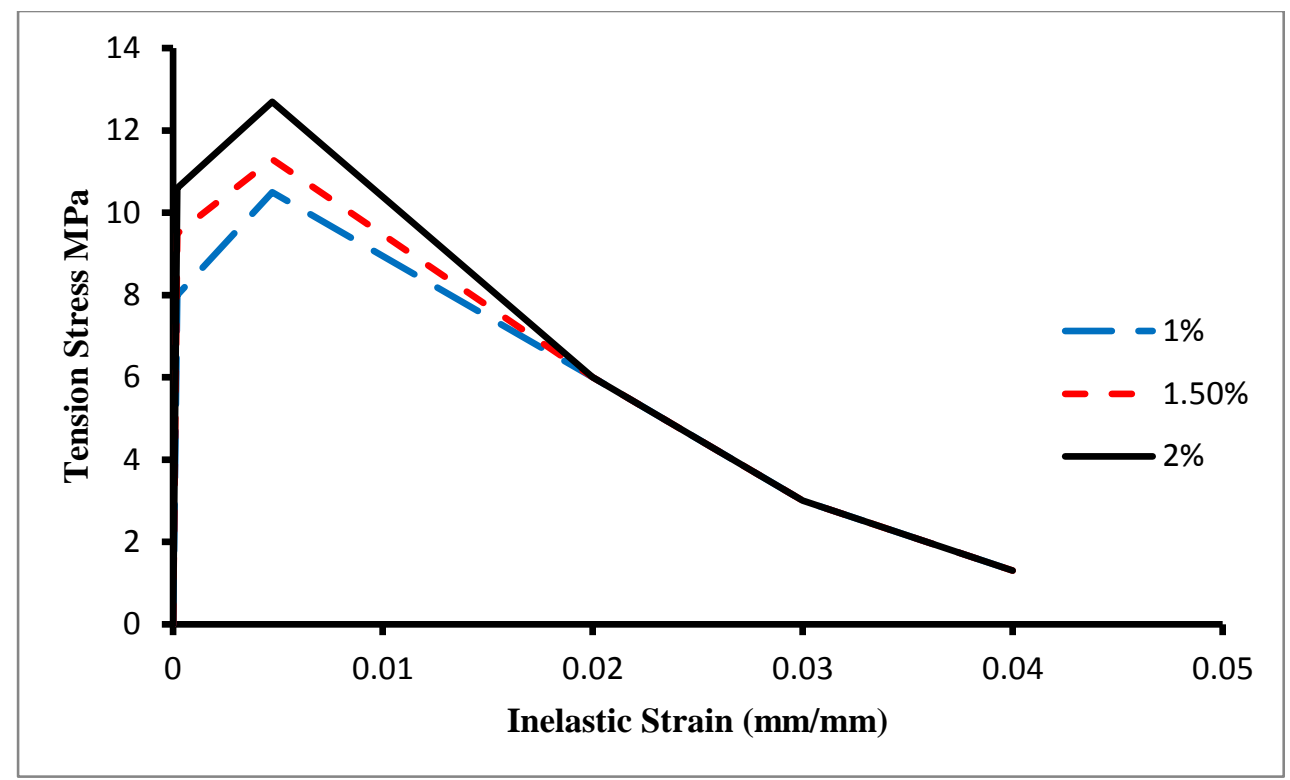

Figure 7.6 CDP model input for inelastic tension behaviour for UHPFRC for different fibre volume $\%$

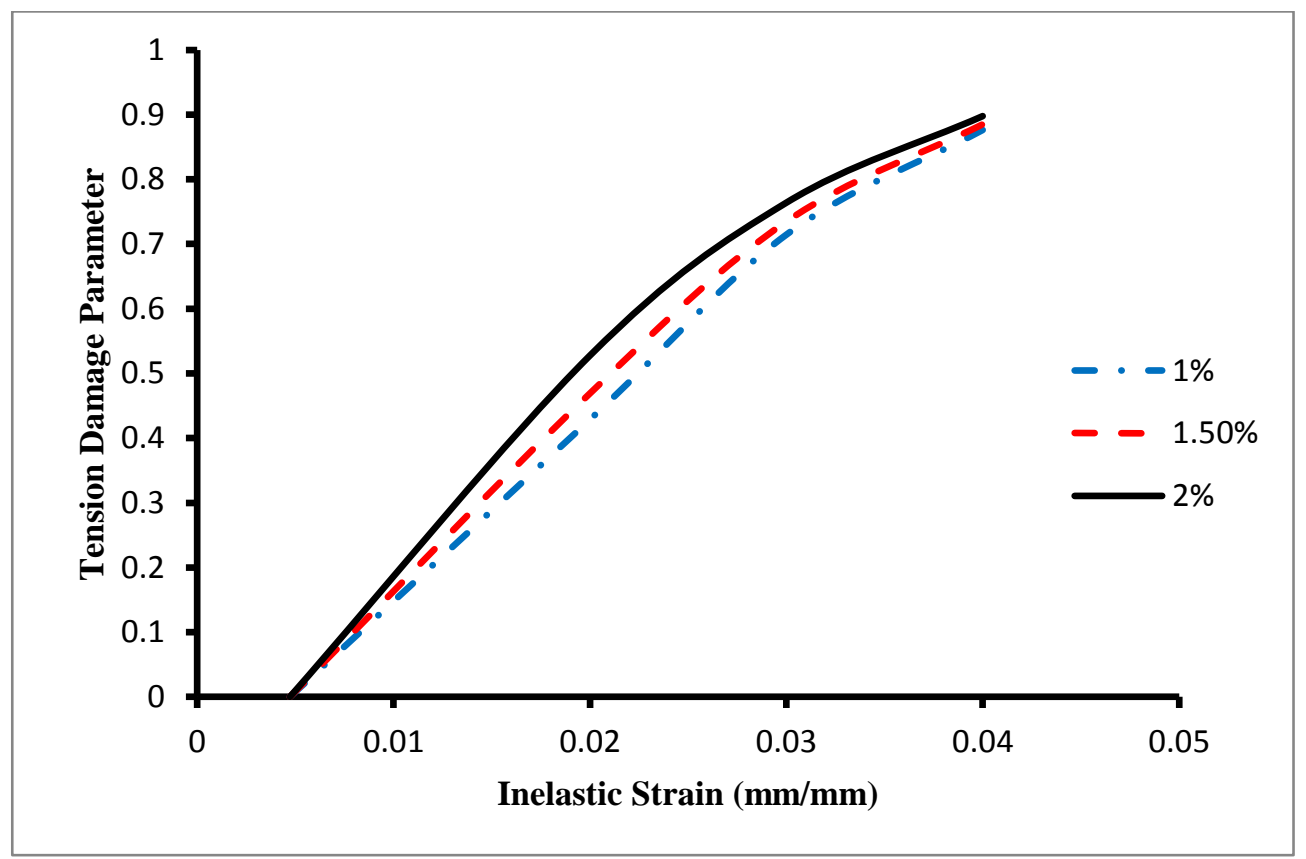

Figure 7.7 Tension damage parameter input for UHPFRC for different fibre volume \% 


\subsubsection{Yield surface definition}

The yield surface function in the CDP model is based on the Drucker-Prager yield criterion. This function was originally developed by Lubliner et al. (1989) for monotonic loading, and then modified by Lee and Fenves (1998) to consider the dynamic and cyclic loadings. In ABAQUS, the parameters that define the yield surface function is the ratio of initial equibiaxial compressive yield stress to the initial uniaxial compressive yield stress, ratio of the second stress invariant on the tensile meridian to that on the compressive meridian, and a viscosity parameter that defines viscoplastic regularization. These default values are set to $1.16,2 / 3$, and 0.0 respectively. The ratio of the second stress invariant on the tensile meridian to that on the compressive meridian $K_{c}$ by default is $2 / 3$ making the yield criterion approach Rankine's yield criteria (Pankaj 2010).

The maximum value of $K_{c}$ is 1.0 making the yield criterion approach Drucker-Prager yield criterion as shown in Fig 7.8. In the present study the default value of $K_{c}(2 / 3)$ was adopted in the analysis.

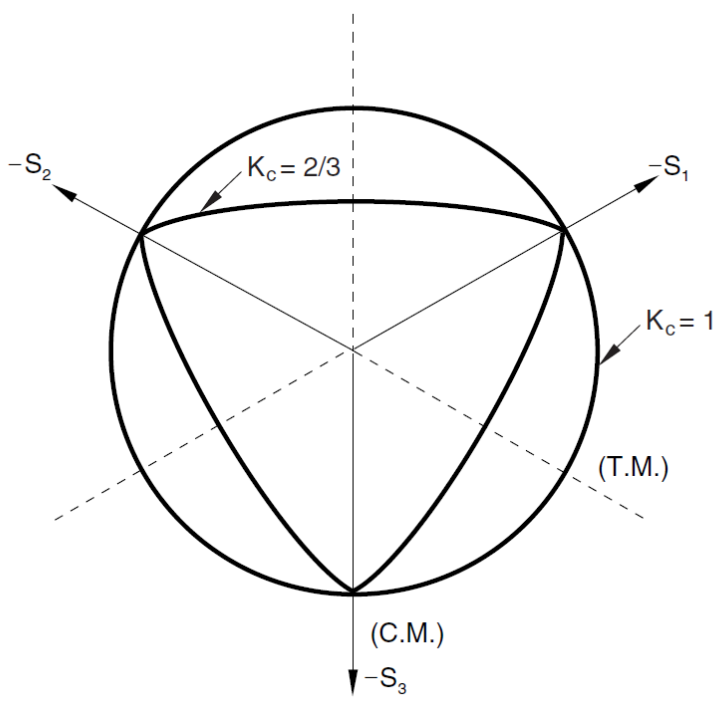

Figure 7.8 Drucker-Prager yield criteria for different values of ${ }^{K_{c}}$, (Hibbitt et al., 2011) 


\subsubsection{Plastic flow rule}

The plastic flow rule function in CDP model is a Drucker-Prager hyperbolic plastic potential function. The purpose of this function is to connect between the yield surface and the uniaxial stress-strain relationships (Malm 2009). In ABQUS, two parameters used to define the flow rule; dilation angle and eccentricity. The dilation angle controls the amount of plastic volumetric strain that can be developed during plastic shearing which is assumed to be constant during plastic yielding. The default value of the dilation angle is between $35^{\circ}$ and $40^{\circ}$ (Malm 2009). For ductile material, the value of dilation angle is high, while for brittle material the value of dilation angle is low. The eccentricity parameter defines the rate at which the flow rule function approaches the asymptote; the default value is 0.1 which implies the material has the same dilation angle over a wide range of confining pressure stress values. In the present study the dilation angle and eccentricity were assumed to be $39^{\circ}$ and 0.1 respectively.

The material properties of steel reinforcement and UHPFRC material models used in the FE model are presented in tables 7.1 and 7.2 respectively. For all other parameters, the default values have been used.

Table 7.1 Material properties of FE model for reinforcing steel

\begin{tabular}{|c|c|}
\hline Prosperity & Longitudinal Reinforcement 30M \\
\hline Elastic modulus $E_{s}$ & $200 \mathrm{GPa}$ \\
\hline Poisson's ratio $v_{s}$ & 0.3 \\
\hline Density & $7850 \mathrm{~kg} / \mathrm{m}^{3}$ \\
\hline Yield stress $f_{s y}$ & $468 \mathrm{MPa}$ \\
\hline Ultimate stress $f_{s u}$ & $688 \mathrm{MPa}$ \\
\hline Ultimate strain $\varepsilon_{s u}$ & $0.16 \mathrm{~mm} / \mathrm{mmm}$ \\
\hline
\end{tabular}


Table 7.2 Material properties of FE model for UHPFRC

\begin{tabular}{|c|c|}
\hline Prosperity & UHPFRC \\
\hline Elastic modulus $E_{c}$ & $47 \mathrm{GPa}$ \\
\hline Poisson's ratio $v_{c}$ & 0.2 \\
\hline Density & $2565 \mathrm{~kg} / \mathrm{m}^{3}$ \\
\hline Compressive cylinder strength & $160 \mathrm{MPa}$ \\
\hline Compressive strain at peak & 0.0035 \\
\hline Dilation angle & 39 \\
\hline Eccentricity & 0.1 \\
\hline
\end{tabular}

\subsection{Finite element mesh and geometry description}

The concrete in all the beams was modeled by eight node continuum elements with reduced integration (C3D8R), and the steel reinforcement was modelled by 3-node quadratic 3-D truss element (T3D3). The three dimension FE model is shown in Fig. 7.9. The load was applied as a pressure over the central area of the beam to avoid hourglass problem as shown in Fig. 7.10. To simulate the bond between steel reinforcement and surrounding concrete, reinforcement in concrete has been modeled as embedded discrete truss elements tied to the concrete region by assuming perfect bond between the reinforcement and the concrete. In the present analysis, no bond-slip model was considered. Mesh convergence was studied with three mesh sizes $40 \mathrm{~mm}$, $30 \mathrm{~mm}$ and $20 \mathrm{~mm}$ for beam US2-1.5-3.0. It was found that the latter two led to virtually identical results as shown in Fig. 7.11; therefore, $30 \mathrm{~mm}$ mesh size was adopted in this study. 


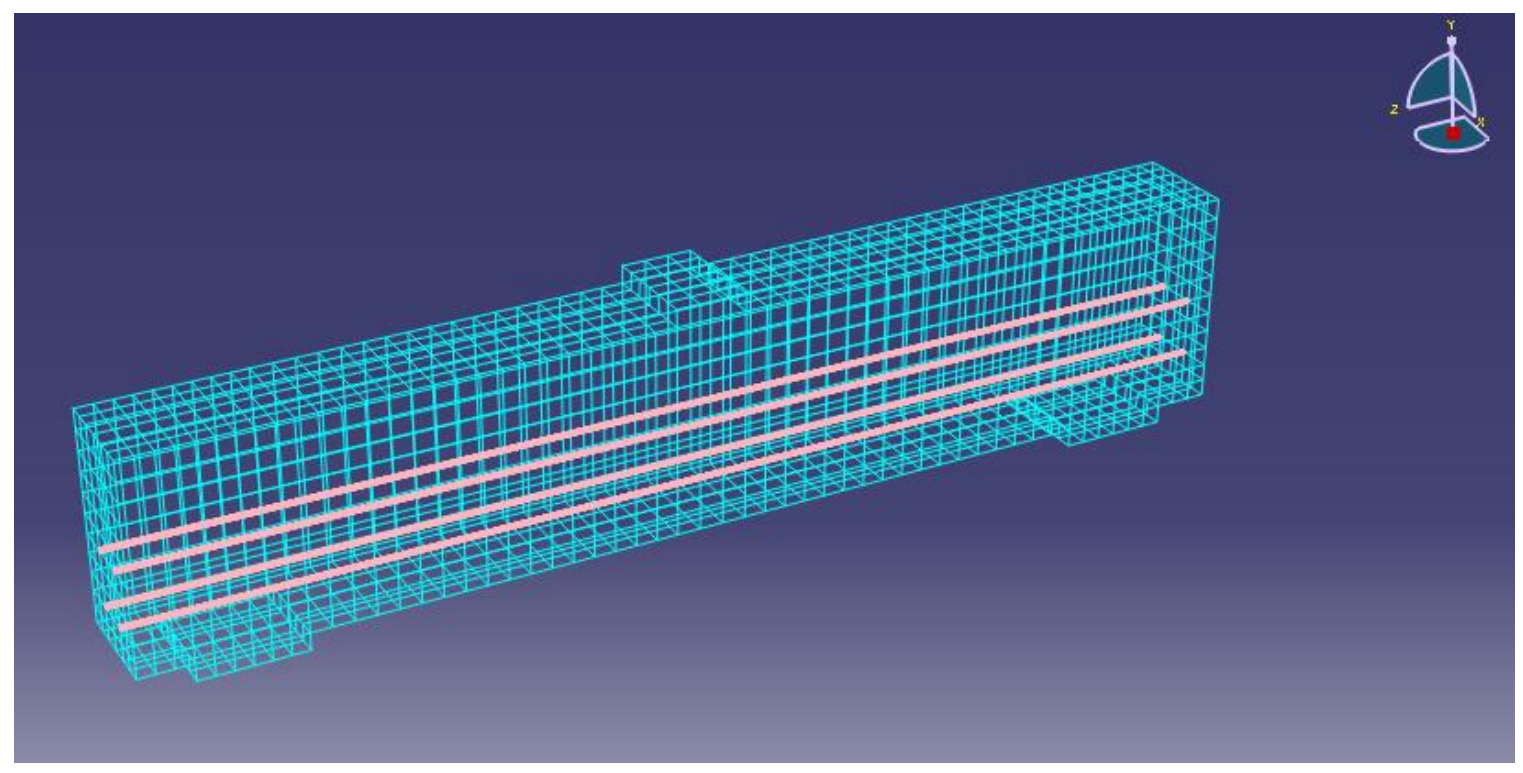

Figure 7.9 Generated FE mesh of beam US2-1.5-3.0 with element size $30 \mathrm{~mm}$

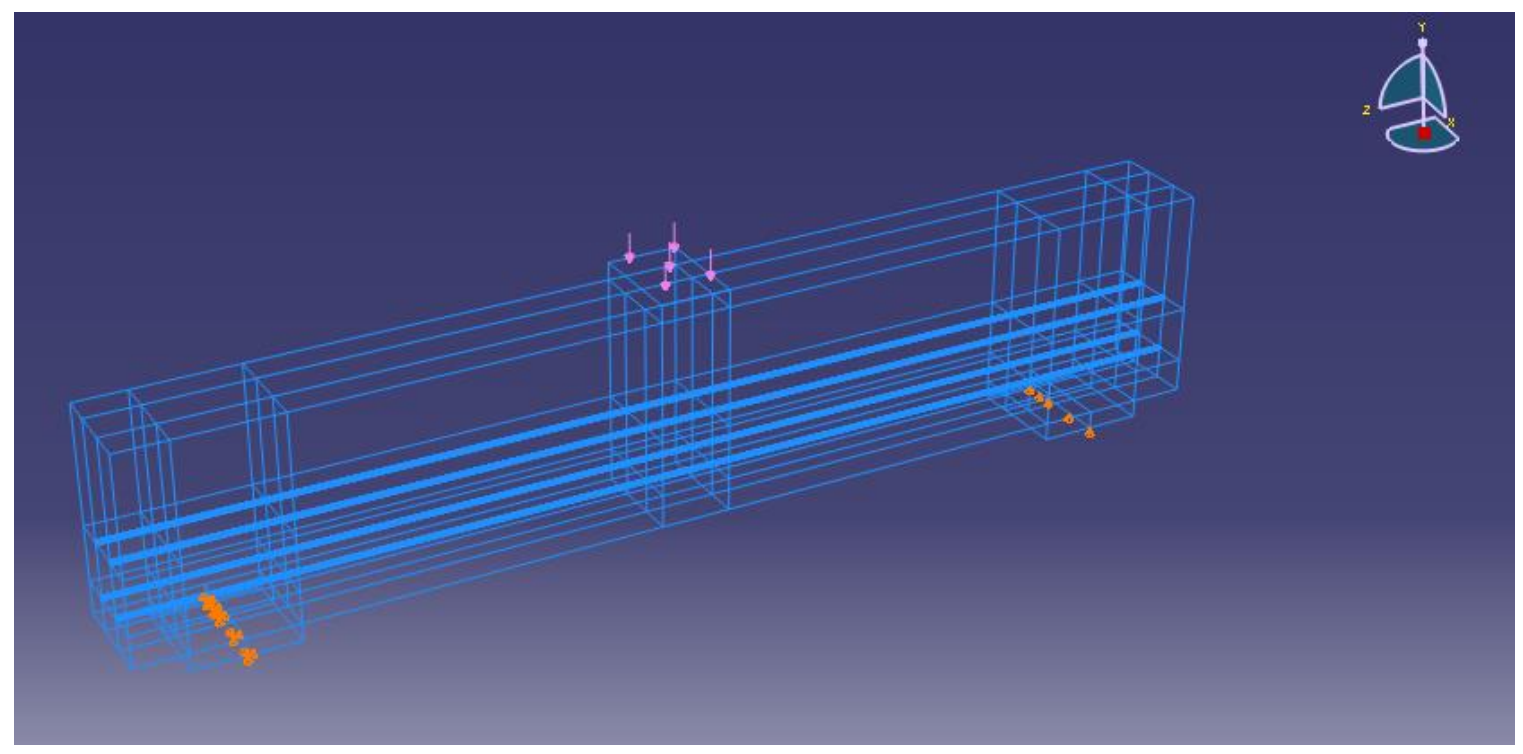

Figure 7.10 Load and boundary condition for FE model 


\subsection{Verification of FE model for UHPFRC beams}

To evaluate the capability of present FE model to simulate the shear behaviour of UHPFRC beams, the results of the model has been verified with the experimental program in this study and with the experimental investigation that was conducted by Yang et al. (2012)

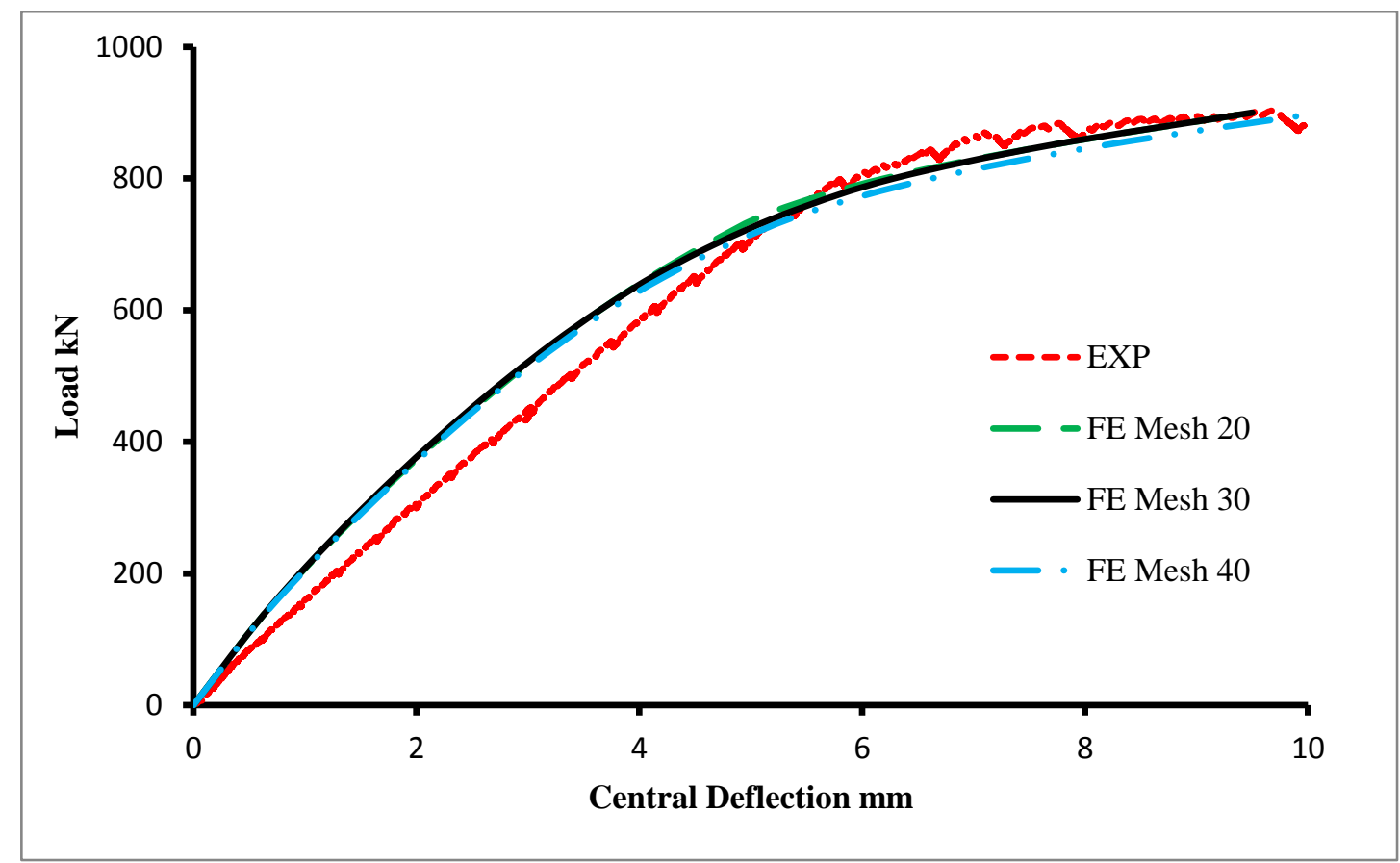

Figure 7.11 Load versus central deflection for different mesh sizes for beam US2-1.5-3

\subsubsection{Analysis of tested beam US2-1.5-3.0}

The results of the FE model were compared with the measured central deflection and strain measured from strain gauges 5 and 6 for beam US2-1.5-3.0 as shown in Figs. 7.11and 7.12 respectively. It can be noted from Figs. 7.11 and 7.12 that good agreement between the FE analysis based on the proposed tension stiffening model for $1.5 \%$ fibre volume content and the experimental results obtained in this study. The comparison of crack patterns obtained using CDP model with the experimental results also show close agreement as shown in Fig. 7.13. 


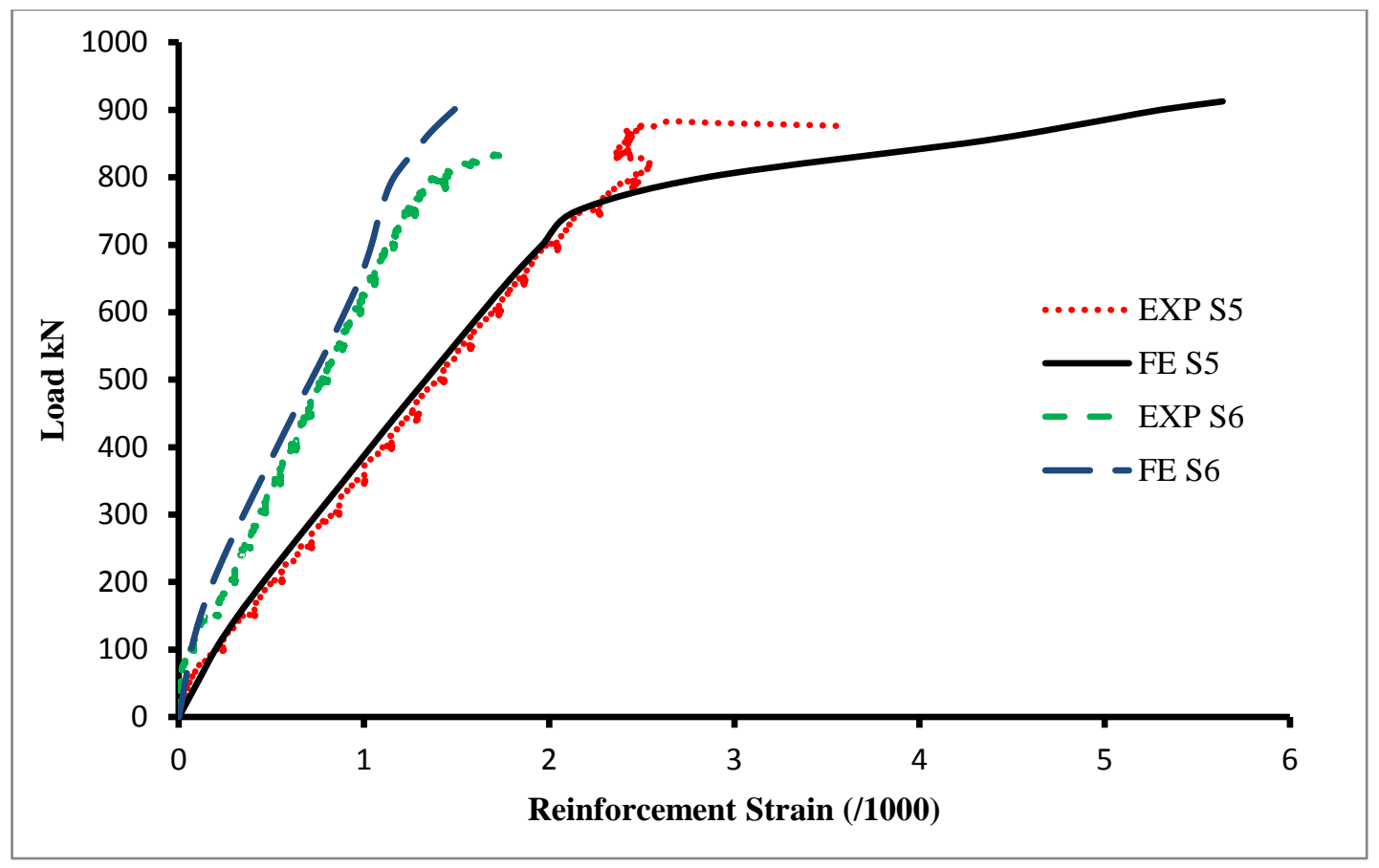

Figure 7.12 Load versus strain for beam US2-1.5-3

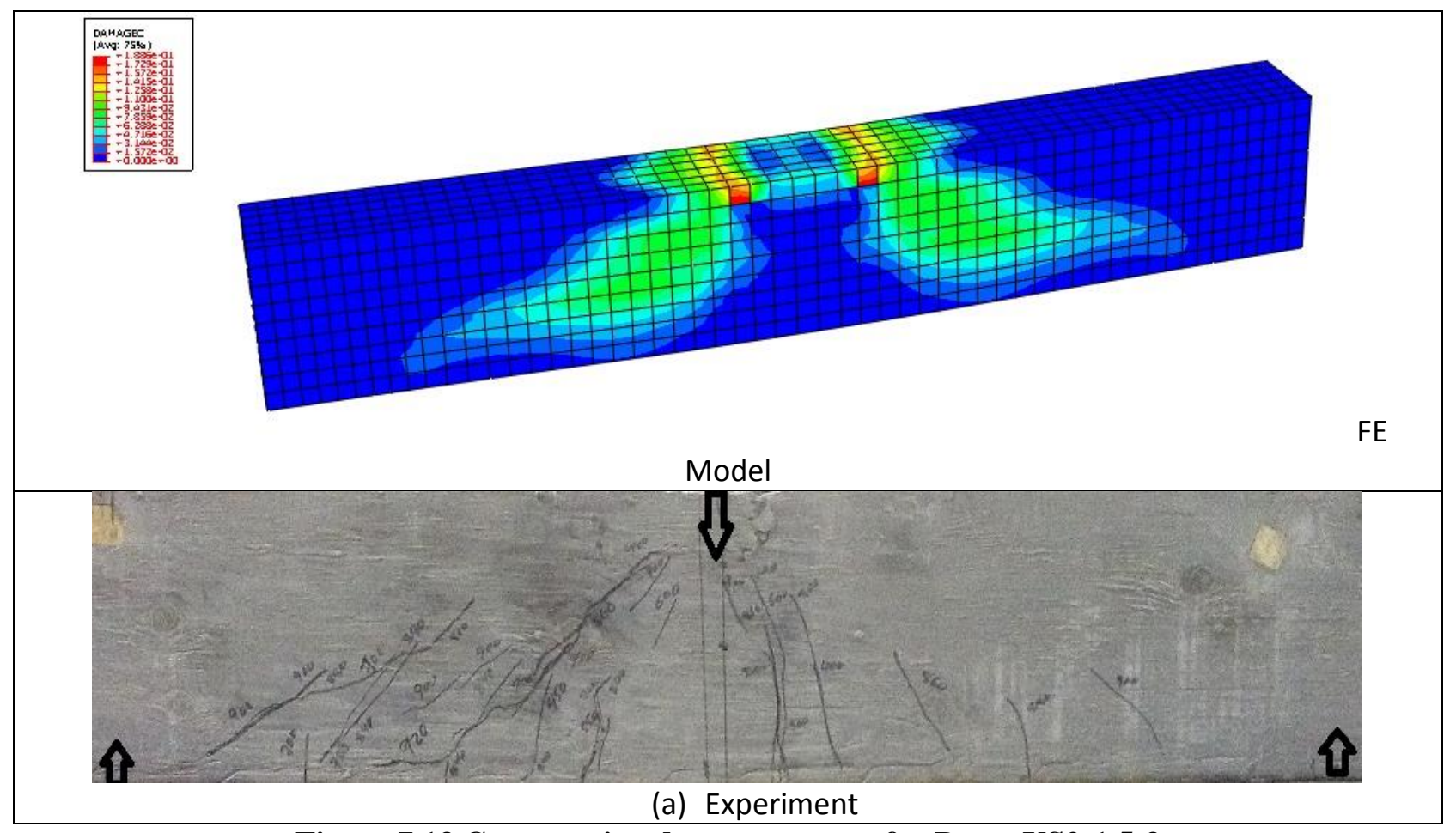

Figure 7.13 Compression damage pattern for Beam US2-1.5-3 


\subsubsection{Analysis of tested beam US1-2.0-3.5}

The results of FE model were compared with the measured central deflection for beam US1-2.03.5 as shown in Fig. 7.14. It can be seen from Fig. 7.14 that the present tension stiffening model for $2.0 \%$ fibre volume content shows good agreement with experimental results of UHPFRC beams with $2 \%$ fibre volume content.

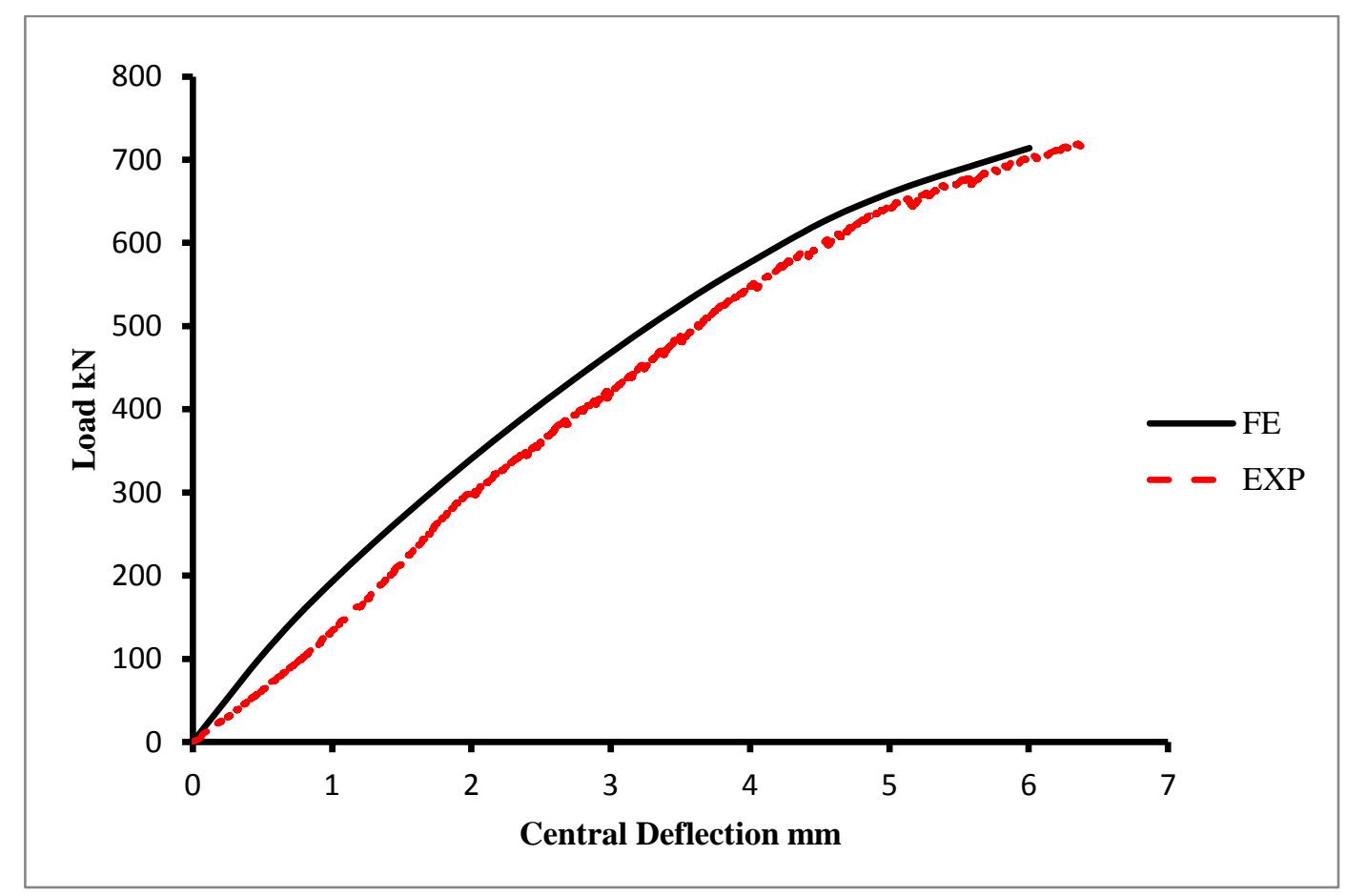

Figure 7.14 Load versus central deflection for beam US1-2.0-3.5

\subsubsection{Verification with experimental results of beam Yang et al. (2012)}

The measured central deflection and the crack patterns of beams S34-F15-P0 and S34-F20-P0 (Yang et al., 2012) for $1.5 \%$ and $2 \%$ fibre volume content were compared with the present FE model as shown in Figs 7.15 and 7.16 respectively. Good agreement between the FE model and the experimental results by Yang et al. was obtained in this study as seen in Figs 7.15 and 7.16. The comparison of crack patterns obtained using CDP model with the experimental result of beams S34-F20-P0 also show close agreement as shown in Fig. 7.17. This shows that the present model is capable of predicting the shear behaviour of I sections. 


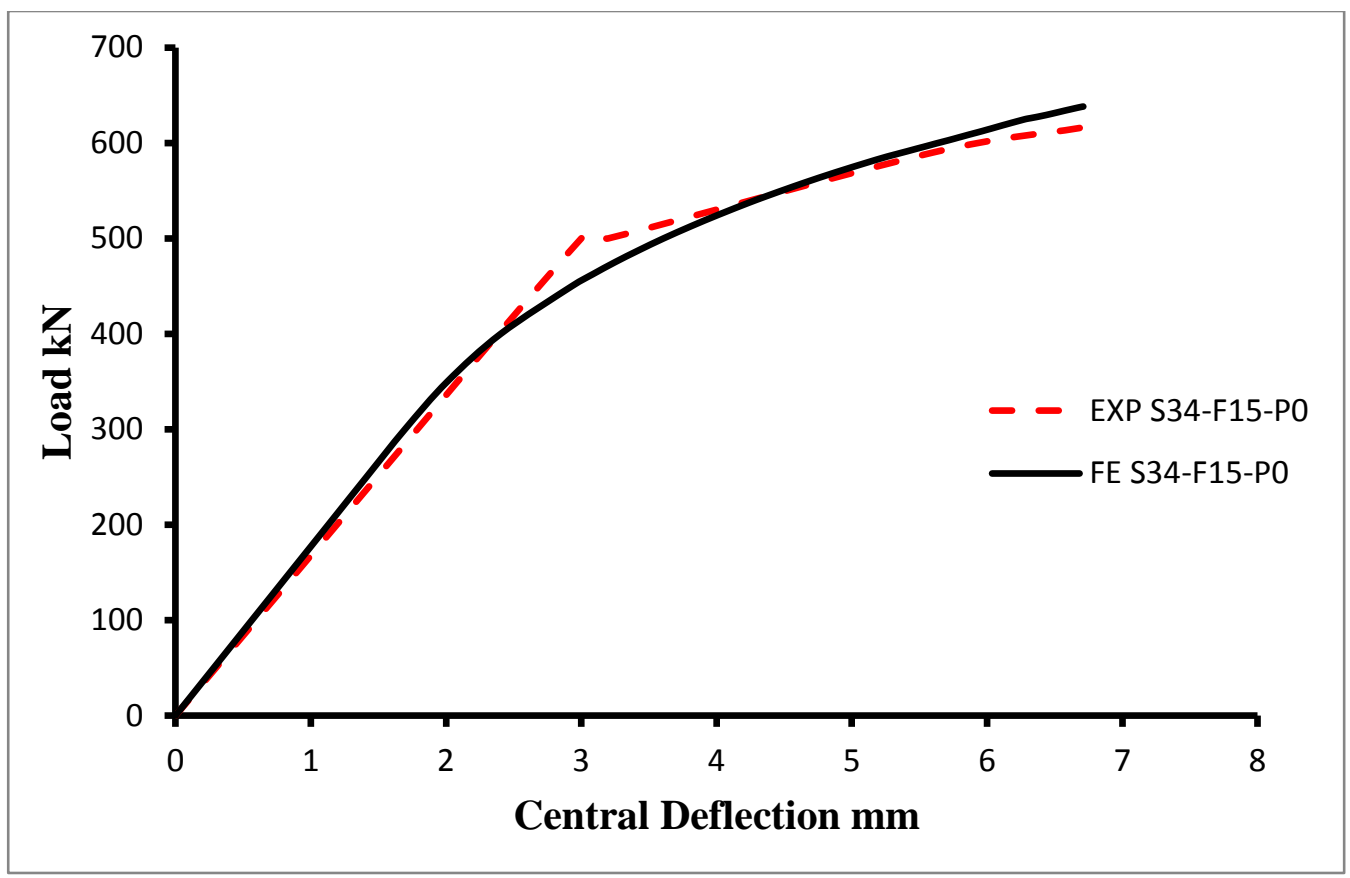

Figure 7.15 Load versus central deflection for beam S34-F15-P0 (Yang et al., 2012)

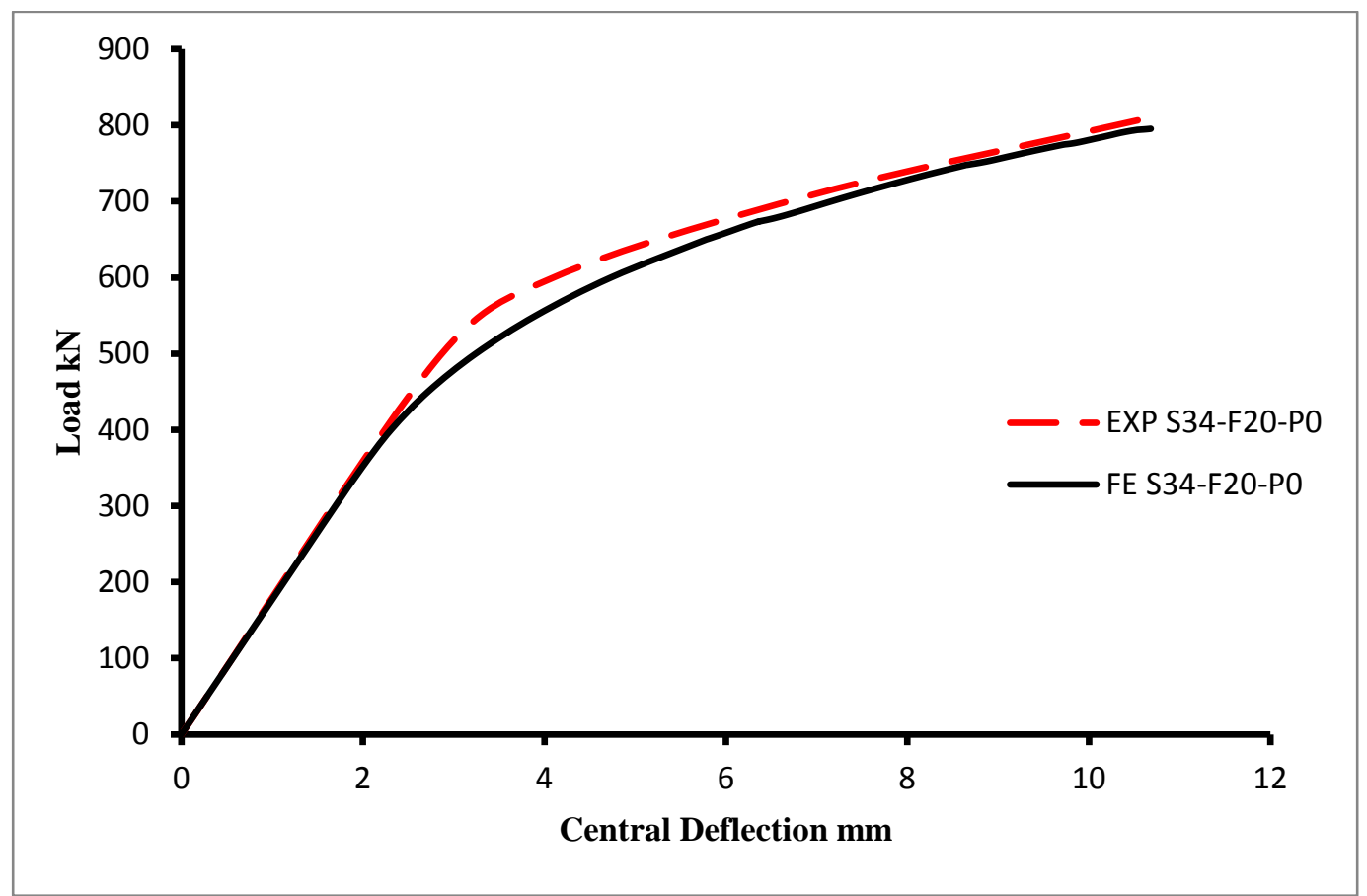

Figure 7.16 Load versus central deflection for beam S34-F20-P0 (Yang et al., 2012) 


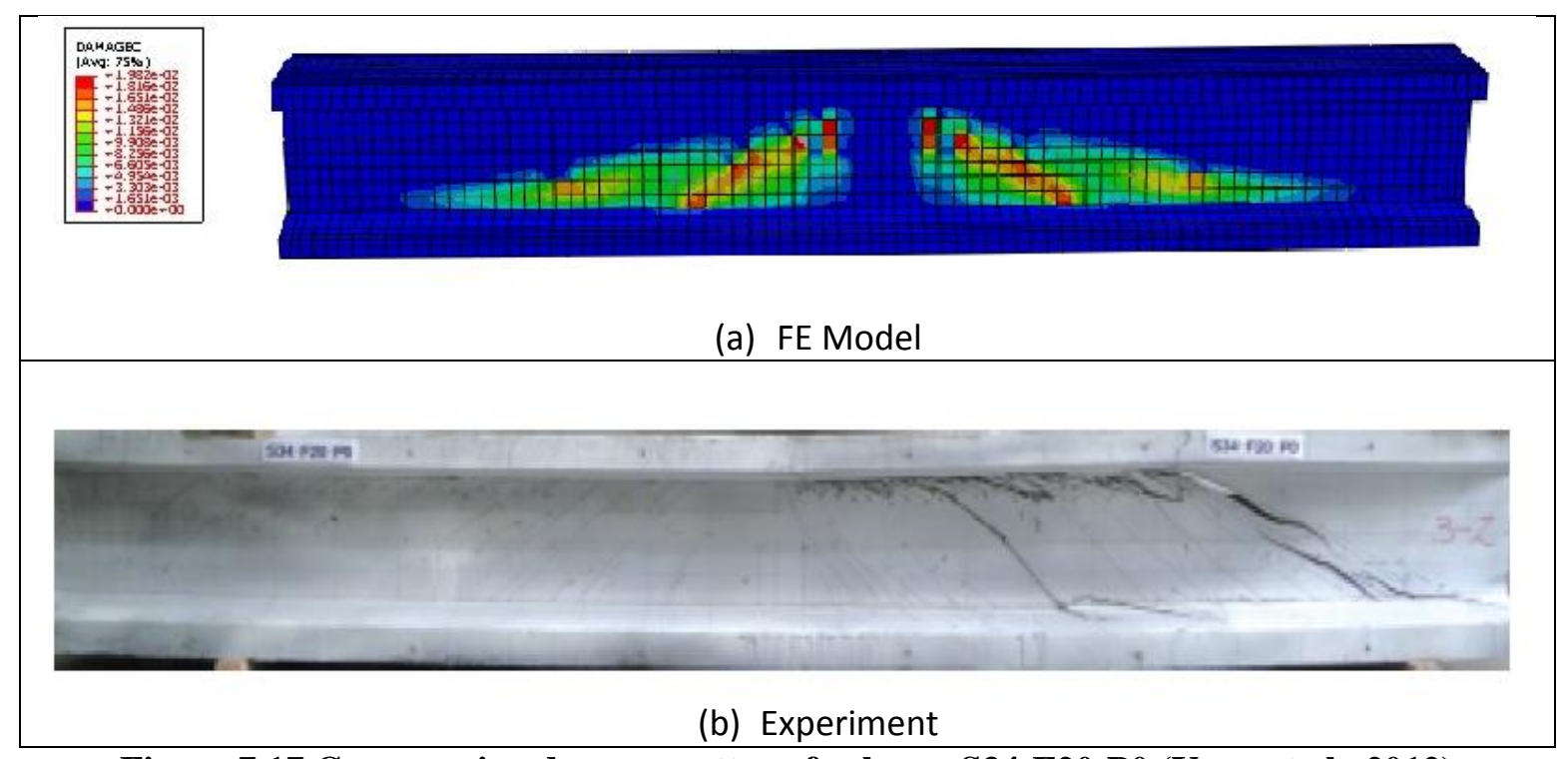

Figure 7.17 Compression damage pattern for beam S34-F20-P0 (Yang et al., 2012)

\subsubsection{Analysis of tested beam US2-1.0-3.0}

The results of the FE model were compared with the measured central deflection for beam US21.0-3.0 as shown in Fig. 7.18 to verify the tension stiffening of the model with $1 \%$ fibre volume content. It can be noted from Fig. 7.18 that good agreement between the FE analysis based on the proposed tension stiffening model for $1 \%$ fibre volume content and the experimental results obtained in this study. 


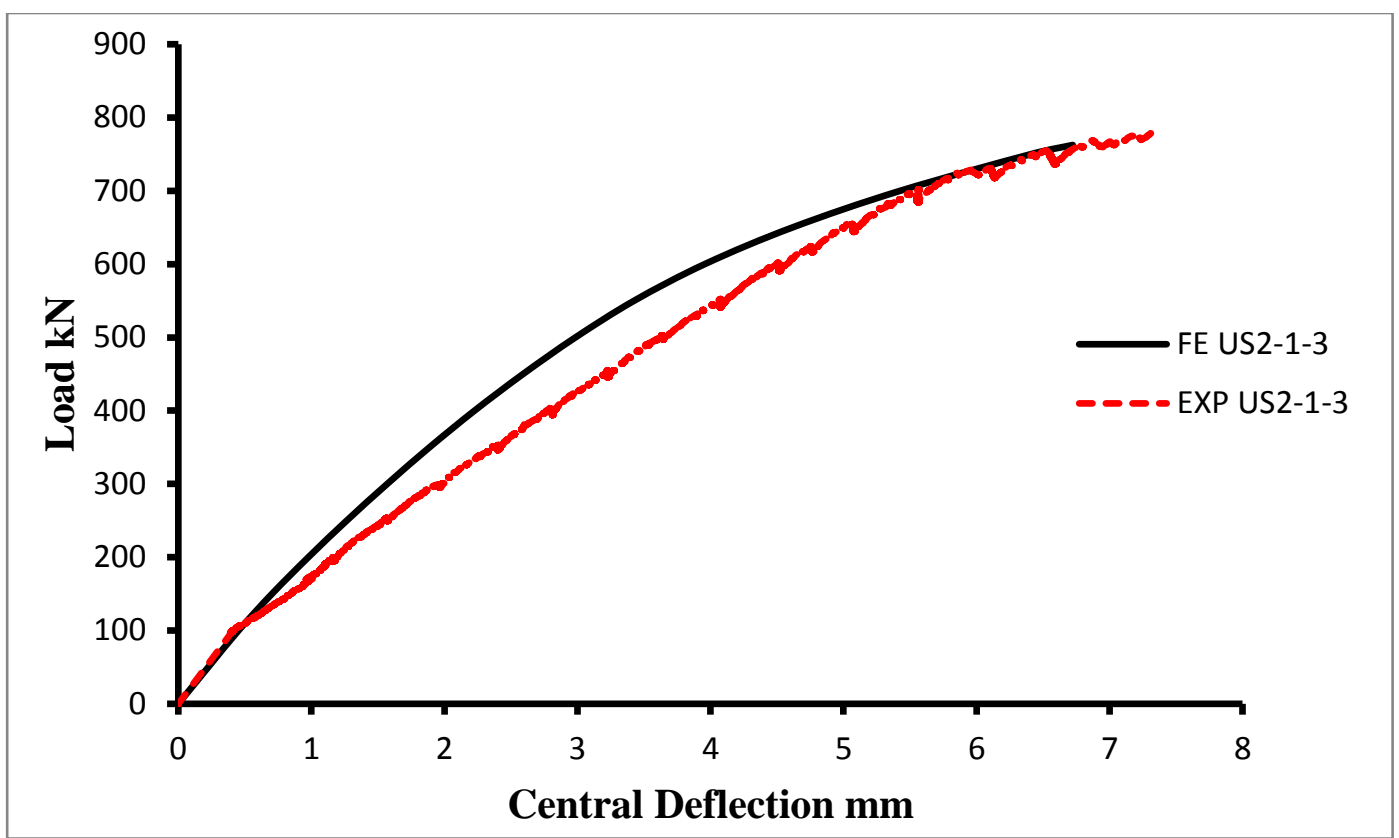

Figure 7.18 Load versus central deflection for beam US2-1.0-3.0

\subsection{FE model of UHPFRC-NSC/HSC beams}

The finite element model of UHPFRC-NSC/HSC beams was based on CDP model that was described earlier. Each UHPFRC-NSC/HSC beam is consisted of two materials: UHPFRC material in the lower layer of the beam and NSC or HSC material in the top layer of the beam. The UHPFRC material was described in section 7.2. This section will explain the nonlinear behaviour of NSC and HSC material.

The nonlinear behaviour of NSC or HSC is divided into two regions: compression and tension. The concrete density was assumed to be $2400 \mathrm{~kg} / \mathrm{m}^{3}$. The Young's modulus was obtained from the following equation Yang et al. (2013):

$$
E_{c}=8250\left(f_{c}^{\prime}\right)^{1 / 3}
$$


The Poisson's ratio was assumed equal to 0.20 .

\subsubsection{Compressive behaviour}

The relationship between concrete stress and strain can be obtained from equation 7.6 (Thorenfeldt et al., 1987).

$$
\frac{f_{c}}{f_{c}^{\prime}}=\frac{n\left(\varepsilon_{c} / \varepsilon_{c}^{\prime}\right)}{n-1+\left(\varepsilon_{c} / \varepsilon_{c}^{\prime}\right)^{n k}}
$$

where, $f_{c}^{\prime}=$ concrete compressive strength, $\mathrm{MPa},{ }^{\varepsilon_{c}^{\prime}}=$ strain when $f_{c}$ reaches $f_{c}^{\prime}, \mathrm{n}$ is a curve fitting factor $=E_{c} /\left(E_{c}-E_{c}^{\prime}\right), E_{c}=$ initial tangent modulus (when $\varepsilon_{c}=0$ ), $\mathrm{k}$ is a factor which control the slope of the descending branch of the stress-strain curve. The constants $\varepsilon_{c}^{\prime}, \mathrm{n}$, and $\mathrm{k}$ can be obtained from equations proposed by Yang et al. (2013).

$$
\begin{array}{ll}
\text { For } \varepsilon_{c} / \varepsilon_{c}^{\prime} \leq 1 & \mathrm{k}=1.0 \\
\text { For } \varepsilon_{c} / \varepsilon_{c}^{\prime}>1 & k=0.67+\frac{f_{c}^{\prime}}{62} \geq 1 \\
n=1.37 \exp \left[0.01 f_{c}^{\prime}\right] &
\end{array}
$$

For known $f_{c}^{\prime}, \mathrm{n}$, and $\mathrm{k}$, the strain at peak stress can be obtained from equation 7.10,

$$
\varepsilon_{c}^{\prime}=\frac{f_{c}^{\prime}}{E_{c}}\left(\frac{n}{n-1}\right)
$$


Concrete compressive stresses $f_{c}$ for different strains are calculated using the equation 7.11,

$$
f_{c}=\frac{n\left(\varepsilon_{c} / \varepsilon_{c}^{\prime}\right) f_{c}^{\prime}}{n-1+\left(\varepsilon_{c} / \varepsilon_{c}^{\prime}\right)^{n k}}
$$

The nominal compression stress-strain curve for NSC and HSC is shown in Fig. 7.19, and the compression inelastic behaviour, compression damage parameter in CDP model are shown in Figs 7.20 , and 7.21 respectively.

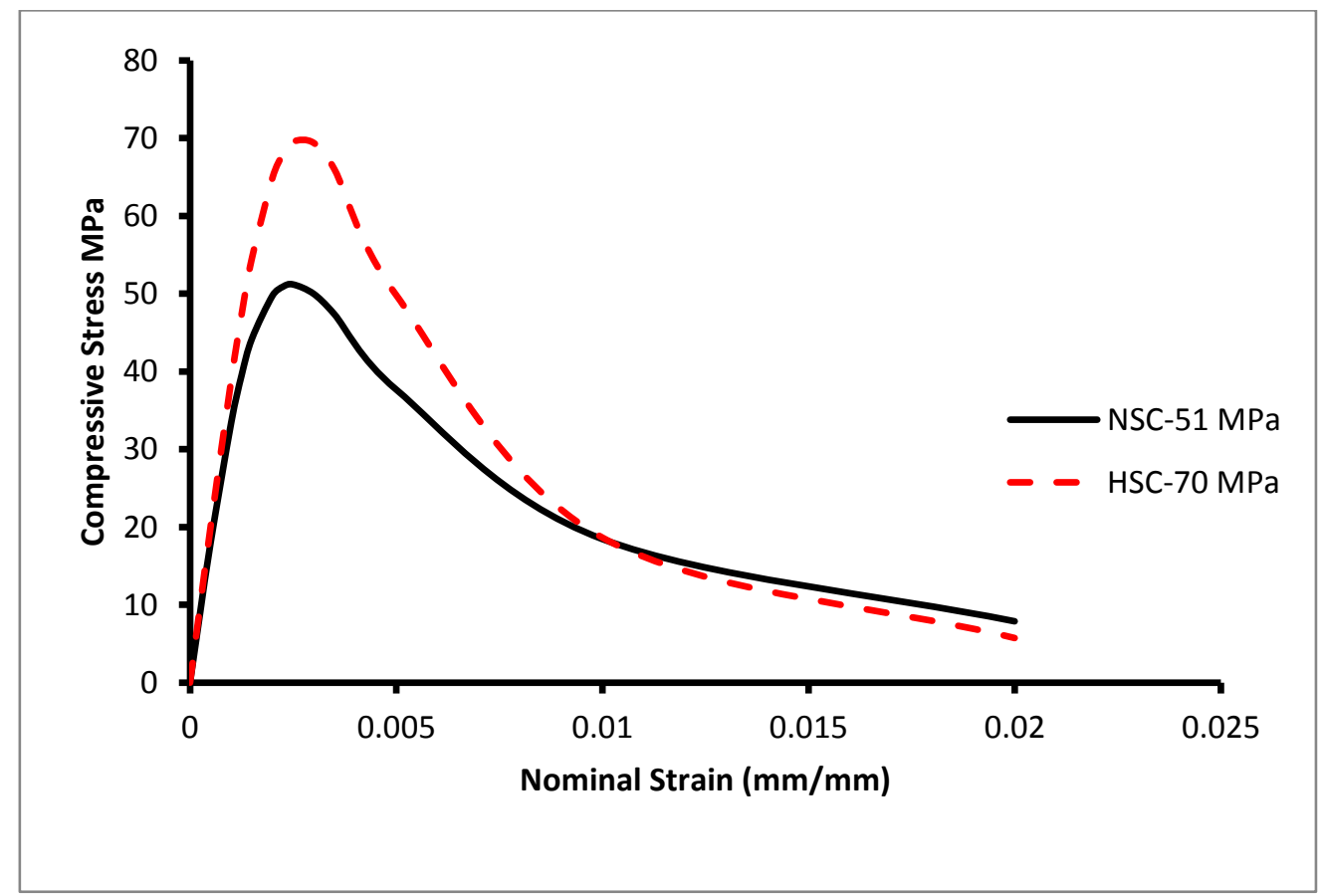

Figure 7.19 nominal compression stress-strain curves for NSC and HSC 


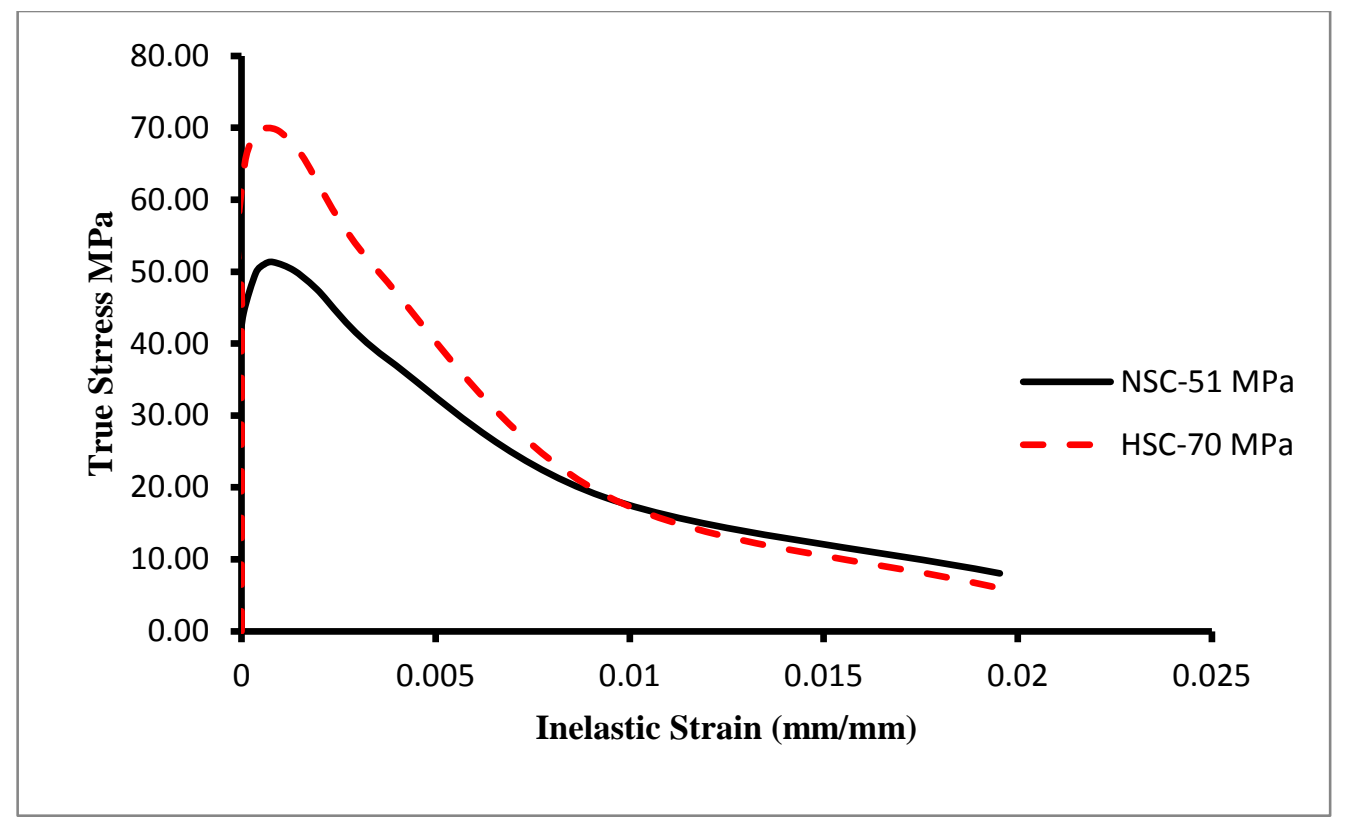

Figure 7.20 CDP model input for inelastic compression behaviour for NSC and HSC

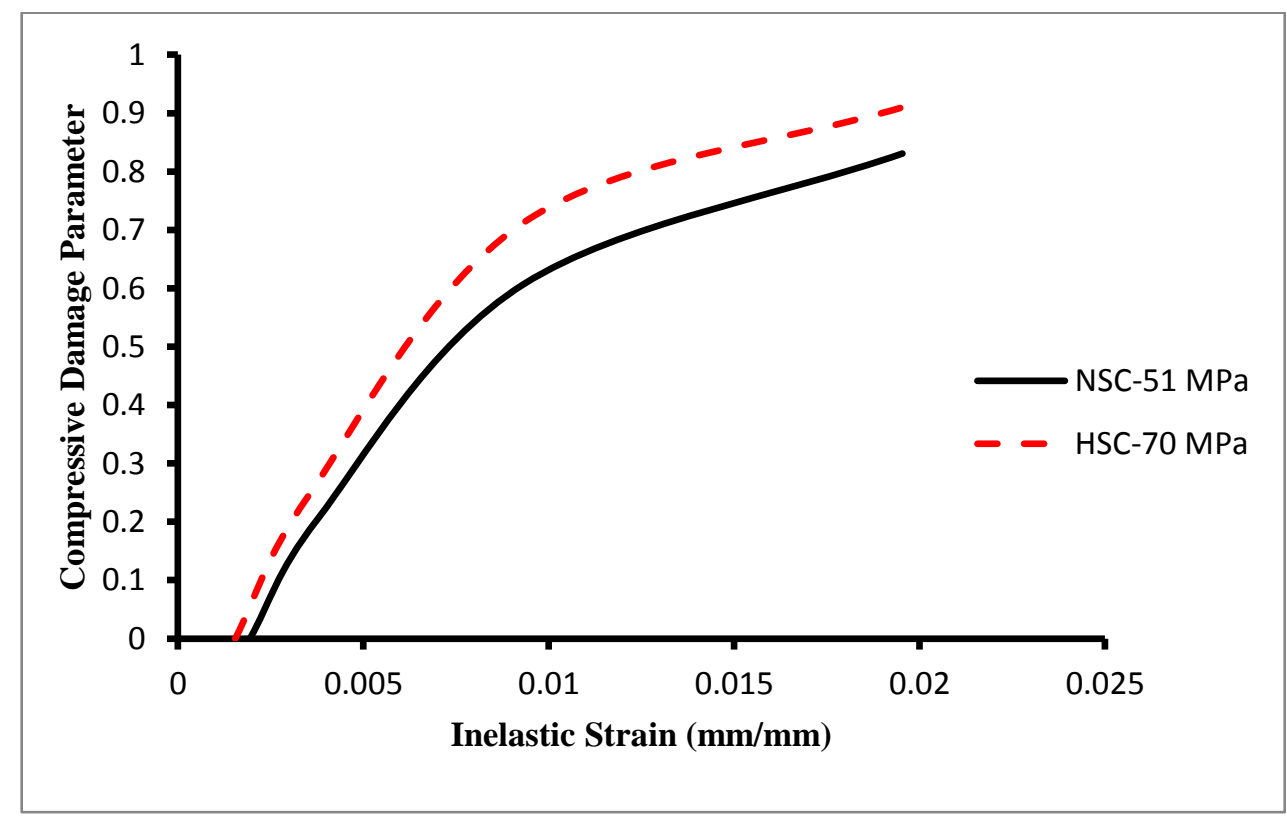

Figure 7.21 Compression damage parameter input for NSC and HSC 


\subsubsection{Tension behaviour}

The tensile behaviour of NSC and HSC materials was adopted from CEB-fib Model Code (2010). The nominal tensile stress-strain curve for NSC and HSC is shown in Fig. 7.22, and the inelastic tension behaviour in CDP model is shown in Fig 7.23. The NSC/HSC layer was placed in the compression region; therefore, the tensile damage parameter for NSC/HSC was neglected in the present model.

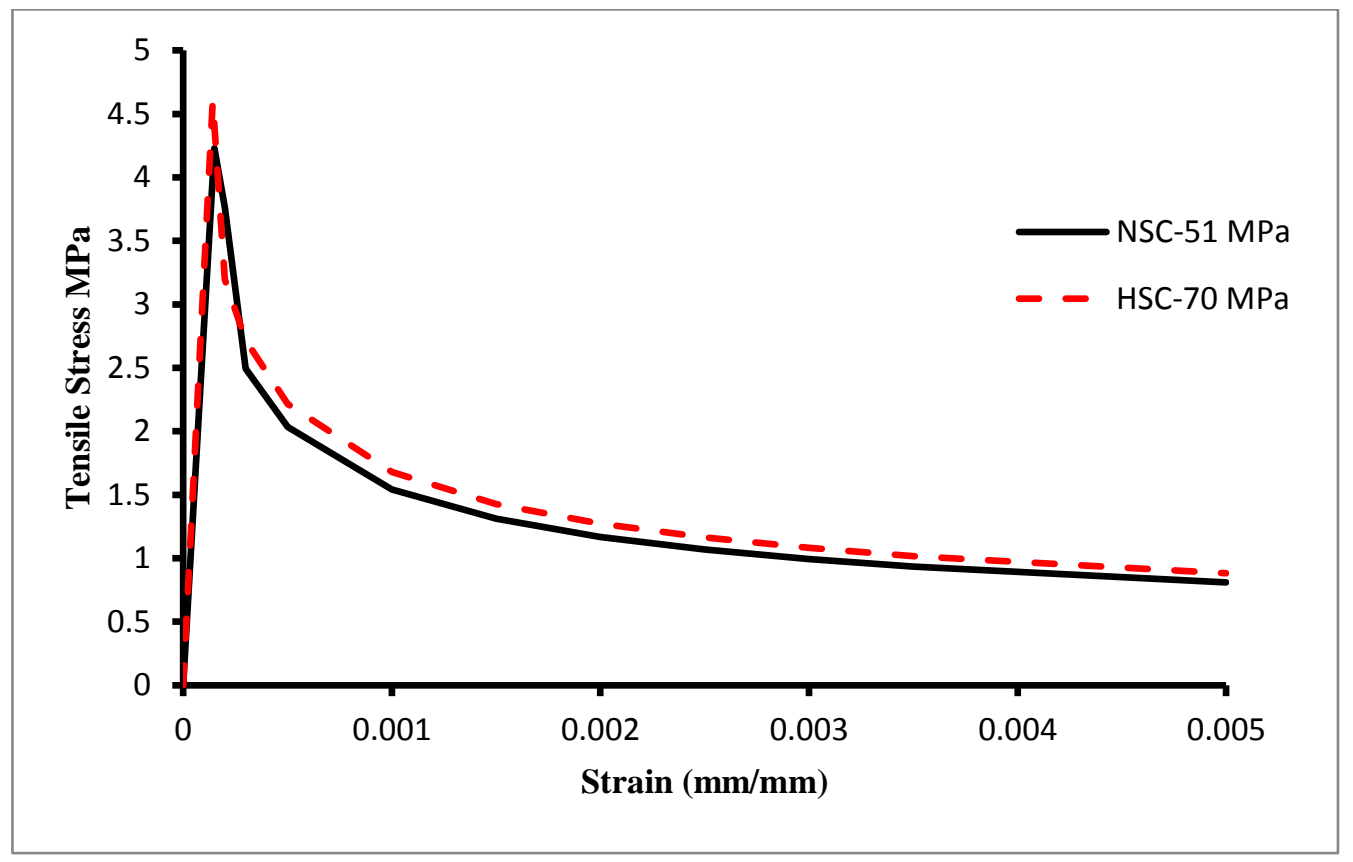

Figure 7.22 Nominal tensile stress-strain curves for NSC and HSC 


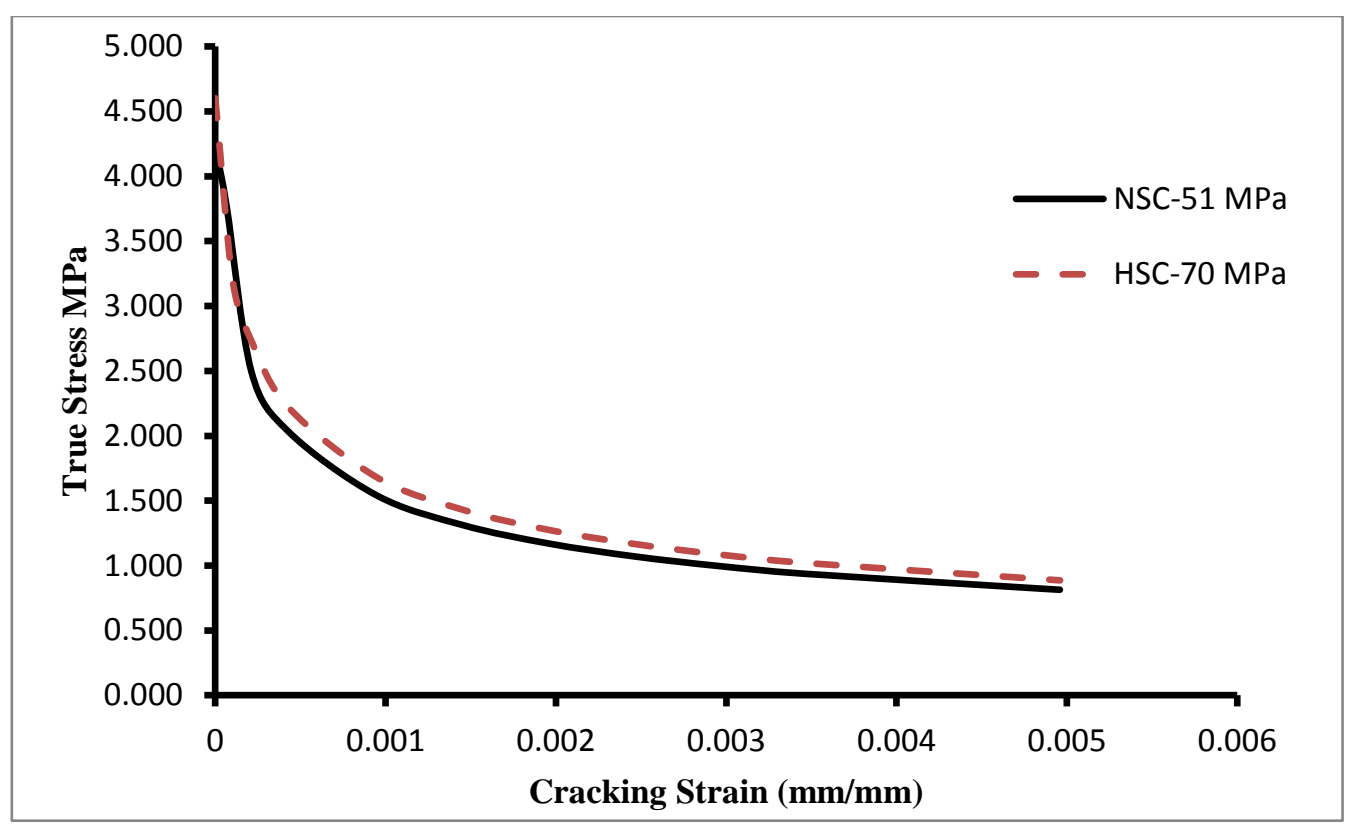

Figure 7.23 CDP model input for inelastic tension behaviour for NSC and HSC

\subsection{Verification of FE model for UHPFRC-NSC/HSC beams}

To evaluate the capability of the present FE model to simulate the shear behaviour of UHPFRCNSC/HSC beams, the results of the model has been verified with the experimental program in this study. The results of the FE model were compared with the measured central deflection of beam US3-2 as shown in Fig. 7.24. It can be noted from Fig. 7.24 that good agreement between the FE analysis and the experimental results obtained in this study. The comparison of crack patterns obtained using CDP model with the experimental results also show close agreement as shown in Fig. 7.25. 


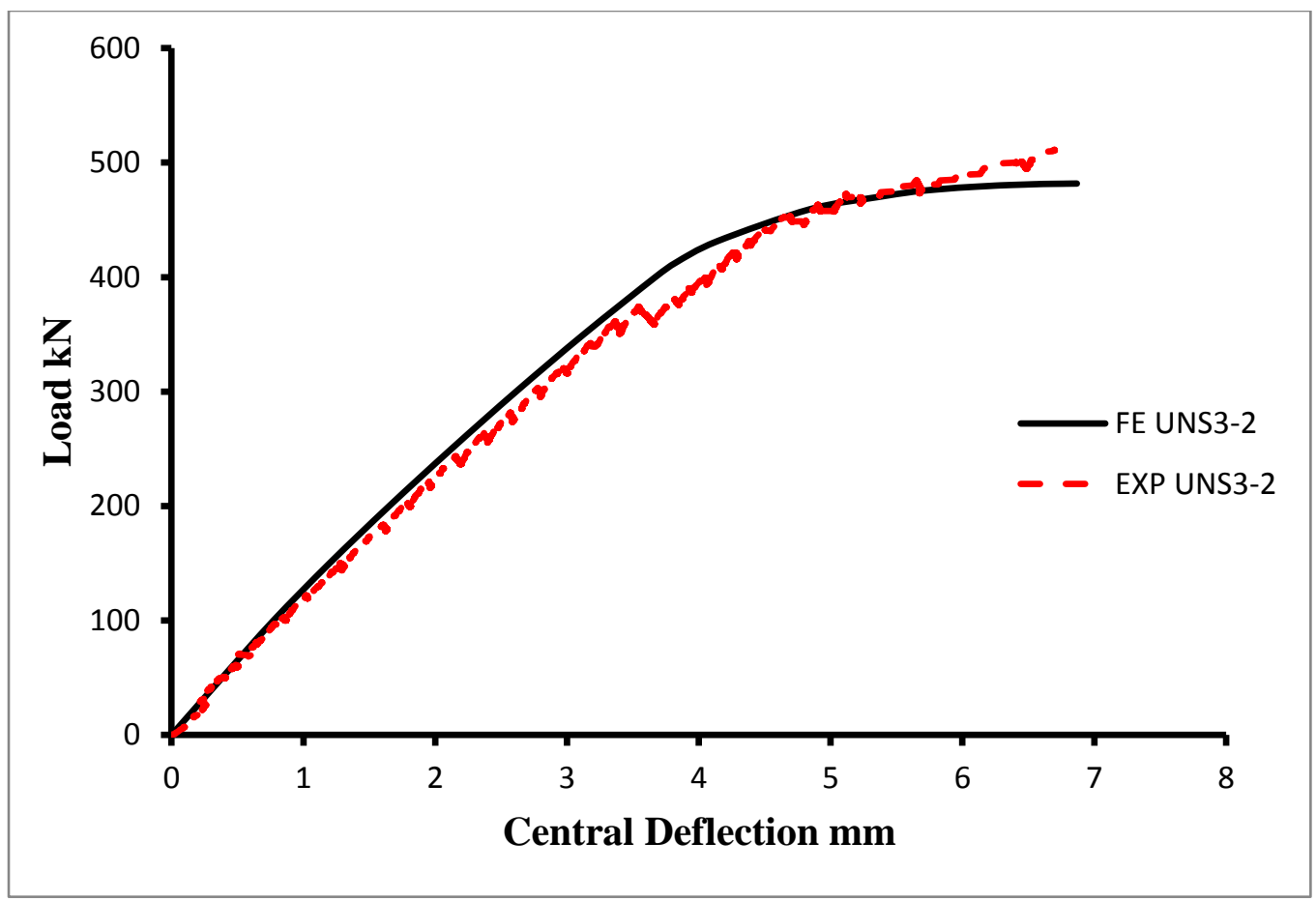

Figure 7.24 Load versus central deflection for beam UNS3-2 


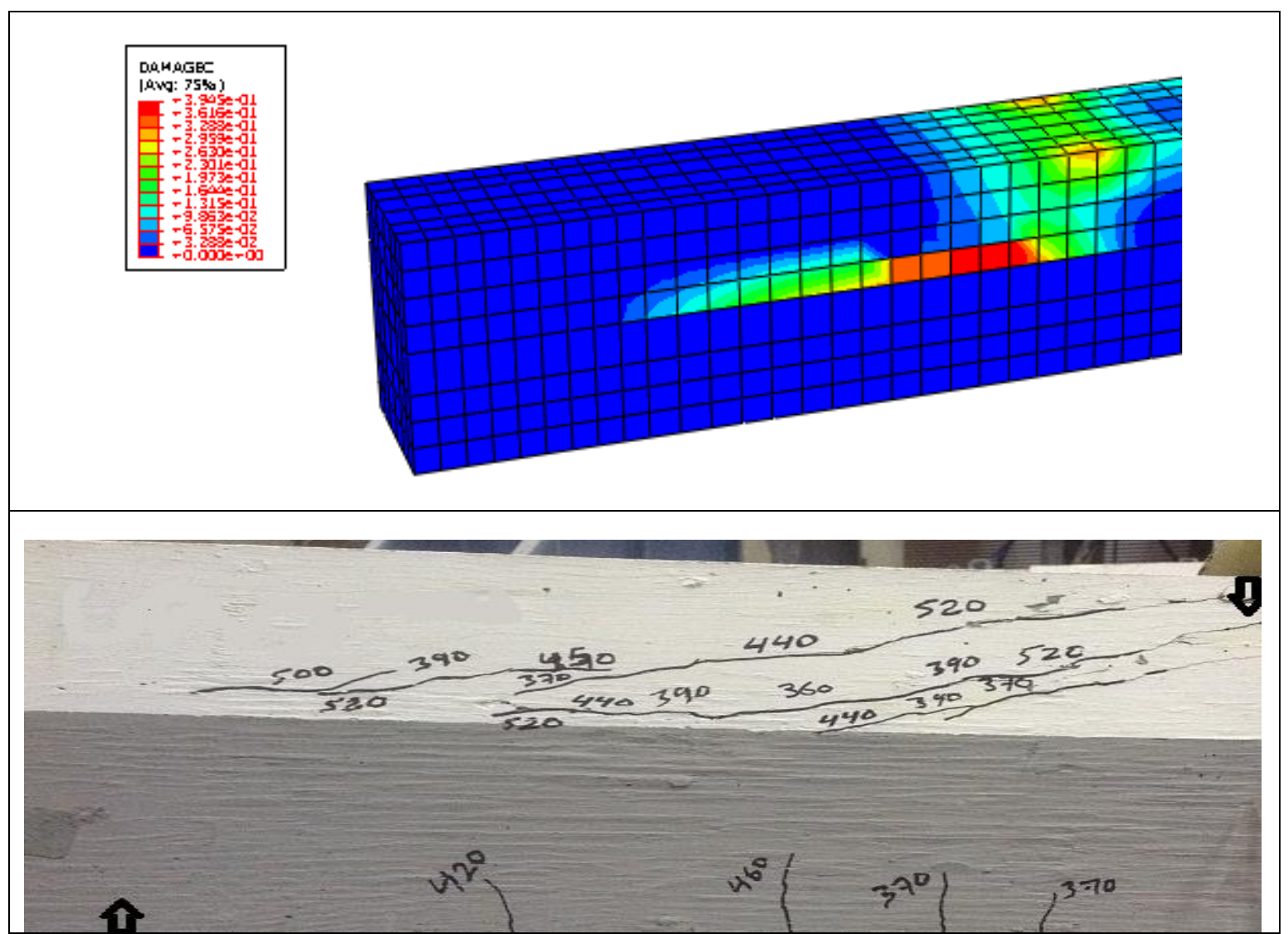

Figure 7.25 Compression damage pattern for Beam UNS3-2

\subsection{Parametric study}

\subsubsection{Size effect of UHPFRC beams}

To investigate the size effect of UHPFRC beams, FE simulations based on the present CDP model were carried out for beams with 150 x $300 \mathrm{~mm}, 250$ x $500 \mathrm{~mm}, 300$ x $600 \mathrm{~mm}$, and 400 x $1200 \mathrm{~mm}$ cross sectional areas. The FE analysis for beam with $150 \times 300 \mathrm{~mm}$ cross sectional area was verified with the experimental results for beam US2-1.5-3.0 as shown in Fig. 7.11. The steel reinforcement ratio was kept constant to study the effect of beam size on the shear behaviour of UHPFRC beams. The load versus central deflection was compared in Fig. 7.26. Fig. 7.26 shows that the central deflection could go up to $40 \mathrm{~mm}$ with beam size $400 \times 1200 \mathrm{~mm}$ due to high ductility of UHPFRC material. Table 7.3 shows shear capacity comparison for different beam sizes. It can be seen from Table 7.3 that shear capacity was reduced from 1.15 to 0.95 with increasing the beam depth from $300 \mathrm{~mm}$ to $1200 \mathrm{~mm}$. This result confirms that the size 
effect in structures made of UHPFRC material has little influence on the shear capacity. Similar results obtained by Mahmud et al. (2013) and Wille et al. (2012) that showed changes in beam sizes had little influence on the flexural strength.

Table 7.3 Shear capacity for UHPFRC for different beam sizes

\begin{tabular}{|c|c|c|}
\hline $\begin{array}{c}\text { Beam size } \\
\mathbf{m m}\end{array}$ & $\begin{array}{c}V u_{f e} \\
\mathbf{k N}\end{array}$ & Shear Capacity $\frac{V u}{b d \sqrt{f_{c}^{\prime}}}$ \\
\hline $150 \times 300$ & 455.00 & 1.15 \\
\hline $250 \times 500$ & 1282.50 & 1.03 \\
\hline $300 \times 600$ & 1850.00 & 1.01 \\
\hline $400 \times 1200$ & 4637.50 & 0.95 \\
\hline
\end{tabular}

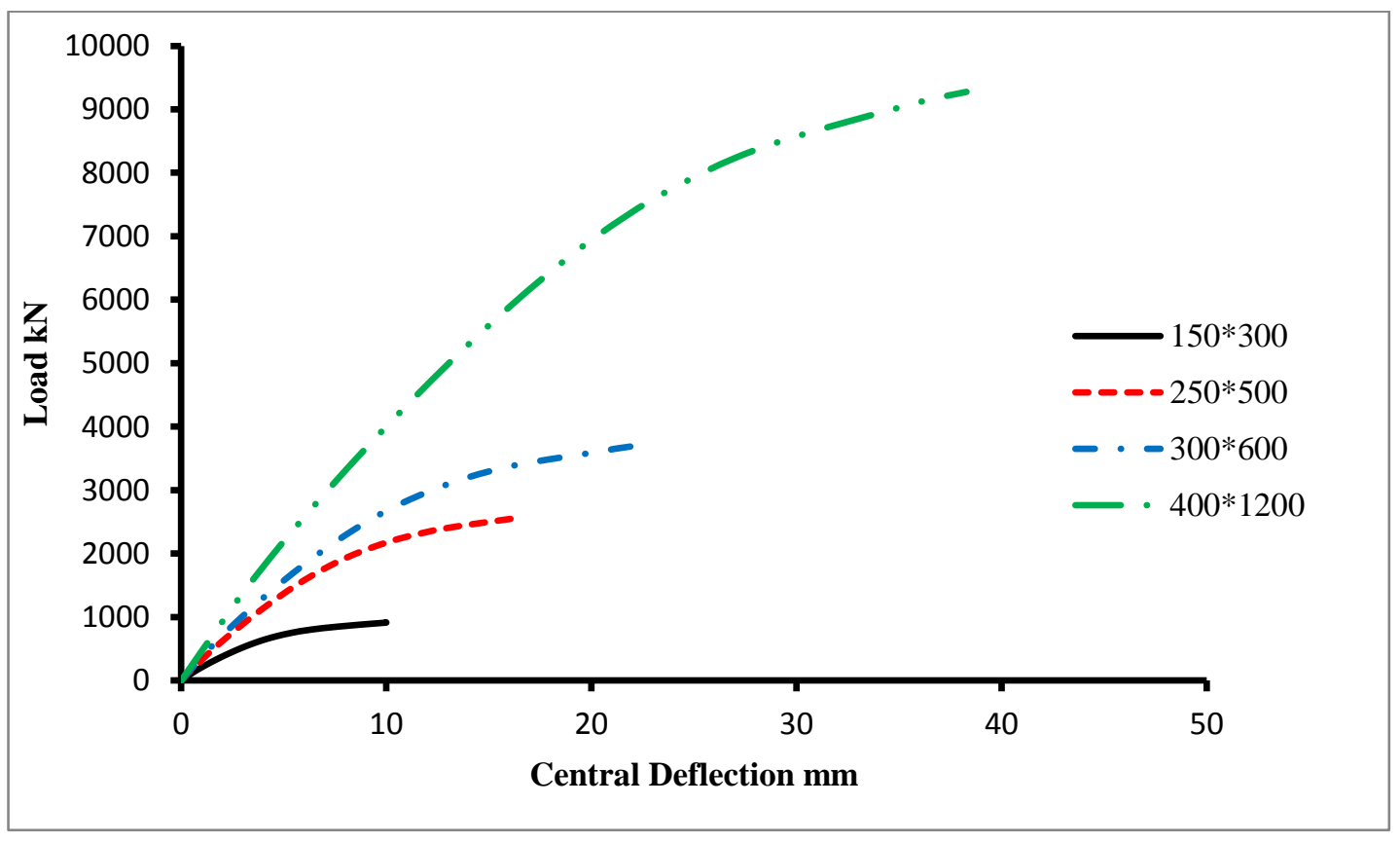

Figure 7.26 Load versus central deflection for UHPFRC for different beam sizes 


\subsubsection{Size effect of UHPFRC-NSC beams}

The FE simulations based on the present CDP model were carried out for beams with 150 x 300 $\mathrm{mm}, 300 \times 600 \mathrm{~mm}$, and $400 \times 1200 \mathrm{~mm}$ cross sectional area to investigate the size effect of UHPFRC-NSC beams. The FE analysis for beam with $150 \times 300 \mathrm{~mm}$ cross sectional area was verified with the experimental results for beam UNS3-2 as shown in Fig. 7.24. The steel reinforcement ratio was kept constant to study the effect of beam size on the shear behaviour of UHPFRC-NSC beams. It can be noted from the load versus central deflection relationship as shown in Fig. 7.27 that the central deflection could go up to $19 \mathrm{~mm}$ with beam size $400 \times 1200$ $\mathrm{mm}$ due to high ductility of UHPFRC material. Table 7.4 shows shear capacity comparison for different beam sizes. It can be seen from Table 7.4 that shear capacity was reduced from 0.60 for beam size $150 \times 300 \mathrm{~mm}$ to 0.43 for beam size $300 \times 600 \mathrm{~mm}$. however, increasing the beam size to $400 \times 1200 \mathrm{~mm}$ did not result in reduction of shear capacity of UHPFRC-NSC beams.

Table 7.4 Shear capacity for UHPFRC-NSC for different beam sizes

\begin{tabular}{|c|c|c|}
\hline $\begin{array}{c}\text { Beam size } \\
\mathbf{m m}\end{array}$ & $\begin{array}{c}V u_{f e} \\
\mathbf{k N}\end{array}$ & Shear Capacity $\frac{V u}{b d \sqrt{f_{c}^{\prime}}}$ \\
\hline $150 \times 300$ & 240.85 & 0.60 \\
\hline $300 \times 600$ & 803.00 & 0.44 \\
\hline $400 \times 1200$ & 2145.90 & 0.43 \\
\hline
\end{tabular}




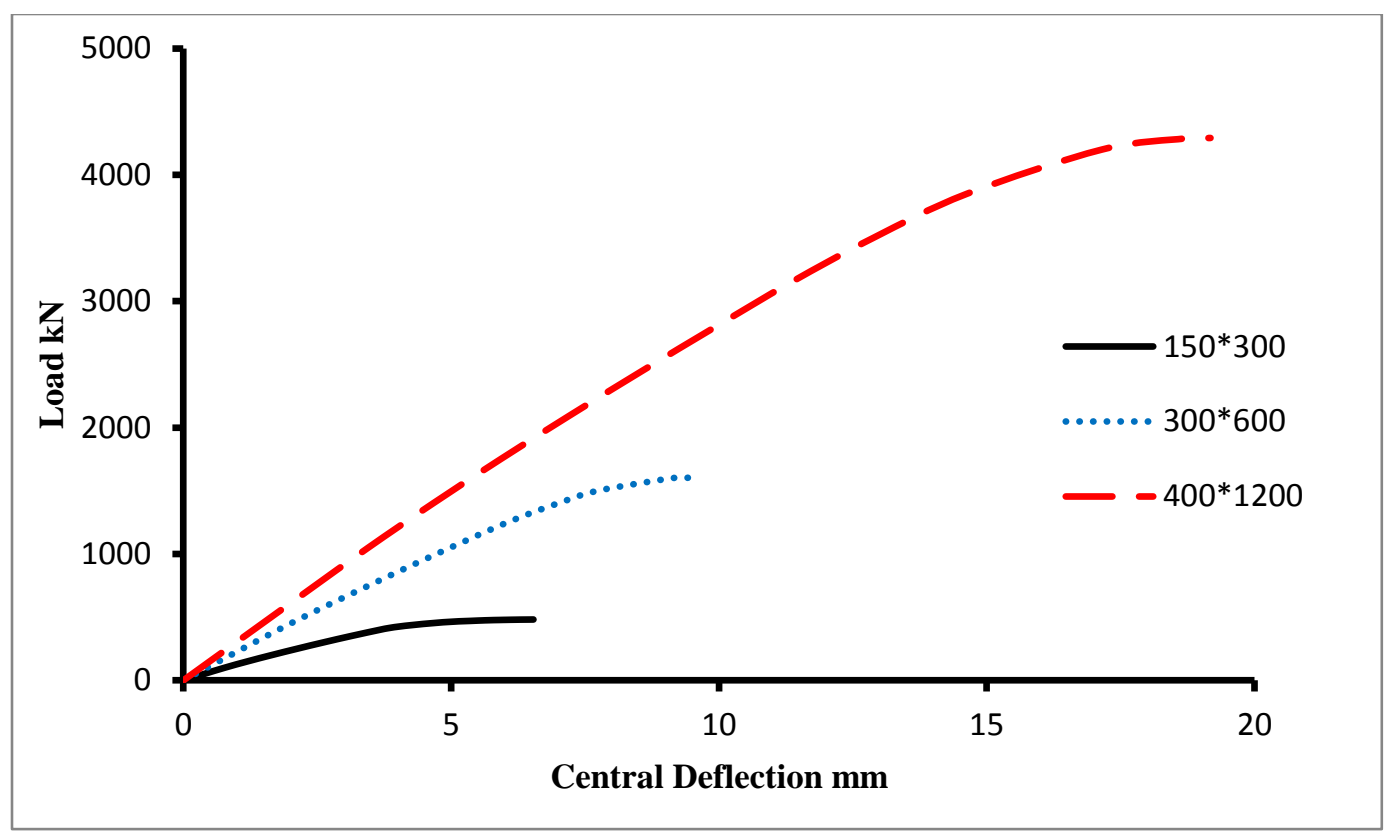

Figure 7.27 Load versus central deflection for UHPFRC-NSC for different beam sizes

\subsubsection{Compressive strength of NSC/HSC layer}

A FE analysis was carried on to study the effect of compressive strength of NSC/HSC layer on the shear behaviour of UHPFRC-NSC/HSC beams as shown in Fig. 7.28. The results show that increasing the compressive strength of concrete layer in compression beyond $51 \mathrm{MPa}$ did not enhance the shear capacity of UHPFRC-NSC/HSC beams. Furthermore, the beams with 100 MPa of HSC layer show less ductility and the load versus central deflection relationship was linear due the high compressive strength of the concrete in the compression zone. This indicates that using high compressive concrete strength in compression will reduce the ductility of UHPFRC-NSC/HSC beams due to the increase of the brittleness of concrete layer in compression. 


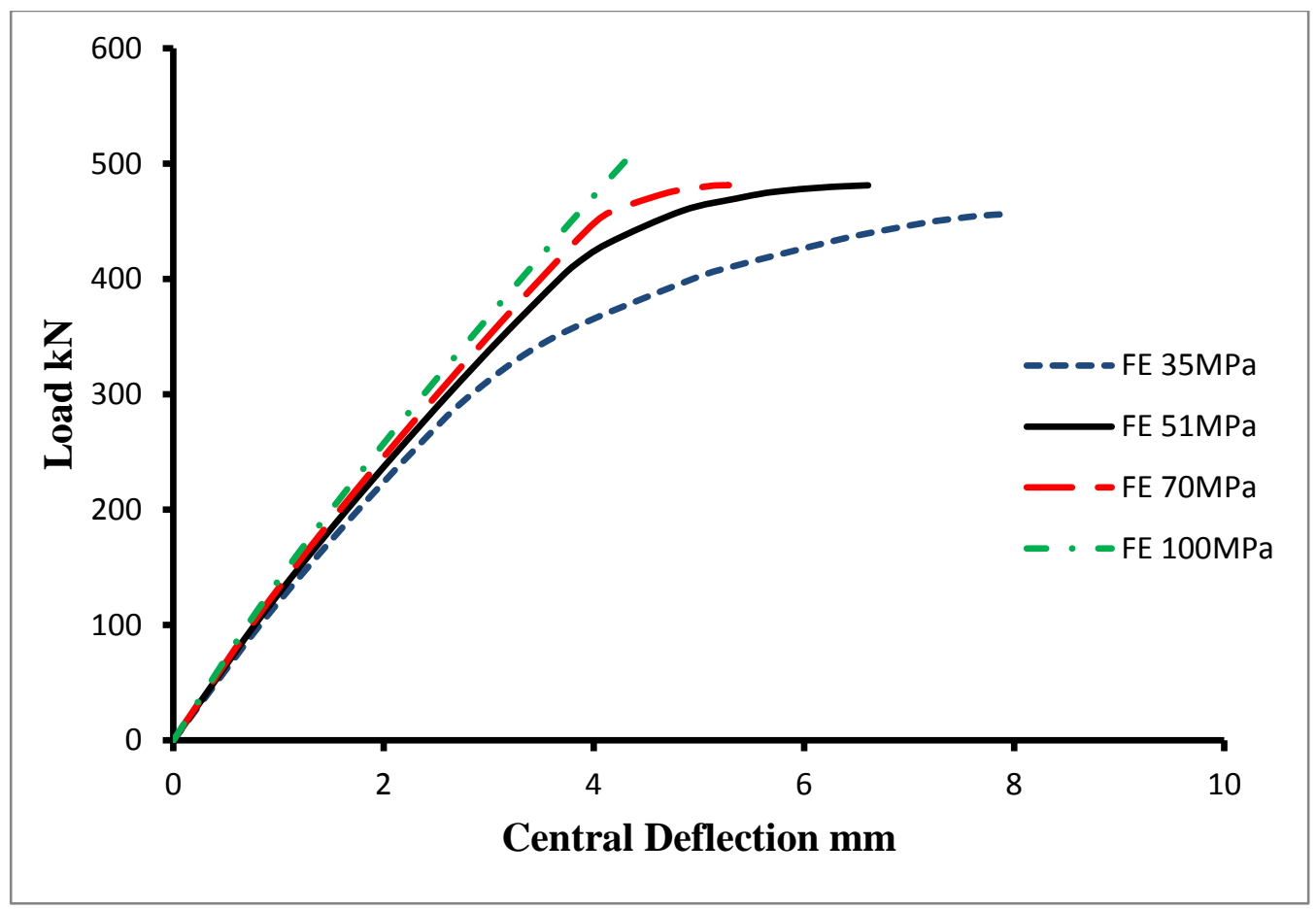

Figure 7.28 Load versus central deflection for UHPFRC-NSC/HSC beams for different NSC/HSC compressive strength

\subsection{Comparison between FE analysis and analytical model}

A FE analysis was carried out to verify the analytical model that developed in chapter 6 for UHPFRC and UHPFRC-NSC/HSC beams. Table 7.5 show comparisons between the finite element analysis and the analytical model for different UHPFRC beam sizes. Table 7.3 shows that the present FE analysis and analytical model show very close result with standard deviation of $V u_{c a l} / V u_{f e}$ is equal to 0.026 . 
Table 7.5 Comparison between FE Analysis and Analytical Model for different UHPFRC beam sizes

\begin{tabular}{|c|c|c|c|}
\hline $\begin{array}{c}\text { Beam size } \\
\text { mm }\end{array}$ & $\begin{array}{c}V u_{f e} \\
\mathbf{k N}\end{array}$ & $\begin{array}{c}V u_{c a l} \\
\mathbf{k N}\end{array}$ & $\frac{V u_{c a l}}{V u_{f e}}$ \\
\hline $150 \times 300$ & 455.00 & 428.699 & 0.942 \\
\hline $250 \times 500$ & 1282.50 & 1186.733 & 0.925 \\
\hline $300 \times 600$ & 1850.00 & 1720.037 & 0.930 \\
\hline $400 \times 1200$ & 4637.50 & 4599.158 & 0.992 \\
\hline
\end{tabular}

Table 7.4 shows comparisons between the FE analysis and the analytical model for different UHPFRC-NSC beam sizes. Table 7.6 also shows that the present FE analysis and analytical model show very close result with standard deviation of $V u_{c a l} / V u_{f e}$ is equal to 0.043 .

Table 7.6 Comparison between FE Analysis and Analytical Model for different UHPFRC-NSC beam sizes

\begin{tabular}{|c|c|c|c|}
\hline $\begin{array}{c}\text { Beam size } \\
\text { mm }\end{array}$ & $\begin{array}{c}V u_{f e} \\
\mathbf{k N}\end{array}$ & $\begin{array}{c}V u_{c a l} \\
\mathbf{k N}\end{array}$ & $\frac{V u_{c a l}}{V u_{f e}}$ \\
\hline $150 \times 300$ & 240.857 & 215.994 & 0.897 \\
\hline $300 \times 600$ & 803.004 & 671.830 & 0.837 \\
\hline $400 \times 1200$ & 2145.905 & 1698.056 & 0.791 \\
\hline
\end{tabular}

Table 7.7 shows comparisons between the results of the FE analysis with the analytical model for UHPFRC-NSC/HSC beams for different compressive strengths of concrete in compression zone. Table 7.7 also shows that the present FE analysis and analytical model show very close result with standard deviation of $V u_{c a l} / V u_{f e}$ is equal to 0.009 . 
Table 7.7 Comparison between FE Analysis and Analytical Model for UHPFRC-NSC/HSC with $2 \%$ fibre volume content

\begin{tabular}{|c|c|c|c|}
\hline $\begin{array}{c}\text { Compressive strength } \\
\mathbf{M P a}\end{array}$ & $\begin{array}{c}V u_{f e} \\
\mathbf{k N}\end{array}$ & $\begin{array}{c}V u_{c a l} \\
\mathbf{k N}\end{array}$ & $\frac{V u_{c a l}}{V u_{f e}}$ \\
\hline 35 & 228.042 & 208.855 & 0.916 \\
\hline 51 & 240.857 & 215.994 & 0.897 \\
\hline 70 & 241.382 & 221.559 & 0.918 \\
\hline 100 & 255.609 & 230.026 & 0.900 \\
\hline
\end{tabular}




\section{Chapter 8}

\section{Summary and Conclusions}

A comprehensive experimental, analytical and numerical study was carried out to investigate the various mechanical properties of UHPFRC members, and UHPFRC-NSC/HSC composite members. The finding can be summarized and conclusions drawn as follow:

\subsection{Experimental program}

\subsubsection{UHPFRC members}

Twelve prisms $152 \times 152 \times 533 \mathrm{~mm}$ in size constructed using UHPFRC material with different steel fibres content were tested under four-point un-notched bending tests. A total of twelve simply supported UHPFRC beams were tested to failure under a monotonically increased concentrated load. All of the beams have shear span to effective depth ratio between 1.5 and 3.5. These tests examined the influence of steel fibre content on the flexural and shear capacity of UHPFRC members. From series 1 and 2 test results, the following conclusions were made:

- Test results showed that the addition of $1 \%$ and $1.5 \%$ of steel fibres to concrete significantly improved the shear strength of UHPC by $77 \%$, and $120 \%$ respectively due to the stresses that develop across the crack surface.

- The cracking behaviour of UHPFRC beams in series 2 exhibited a similar pattern. The initial crack was observed to be diagonal in the mid-depth of the shear span. As the applied load increased, additional diagonal cracks were formed within the shear span. Finally, the failure occurred when the fibre pulled-out along the major diagonal crack.

- The behaviour of UHPC beam without fibre content shows similar behaviour to NSC beam with slight increase in the shear capacity due to the high compressive strength of UHPC.

- The increase of shear span to depth ratio decrease shear strengths. The beam with a shear span to effective depth ratio of 1.5 had more shear capacity than the ratio of 3.5. This 
could be attributed to the stability of the arch mechanism at lower shear span to effective depth ratios.

\subsubsection{UHPFRC-NSC/HSC members}

Twelve prisms 152 x 152 × $533 \mathrm{~mm}$ in size constructed using UHPFRC-NSC/HSC material with different steel fibres contents were tested under four-point un-notched bending tests. The composite UHPFRC-NSC/HSC prisms were made up of $101 \mathrm{~mm}$ NSC or HSC layer at the top, and $51 \mathrm{~mm}$ UHPC layer at the bottom. A total of fourteen simply supported UHPFRC-NSC/HSC composite beams were tested to failure under a monotonically increased concentrated load. All the beams have shear span to effective depth ratio of 3.0. These tests examined the influence of steel fibre volume percentage and the concrete compressive strength of the top layer on the flexural and shear capacity of UHPFRC-NSC/HSC composite members. From this series of tests the following conclusions were made:

- The addition of UHPFRC layer with $1.5 \%$ and $2 \%$ fibre volume content at the bottom of the NSC prisms significantly enhanced the flexural capacity by 54\%, and $90 \%$ respectively compared to NSC prisms.

- The average bond strength between the UHPFRC and NSC/HSC layers were between 10.57 and $12.86 \mathrm{MPa}$. Test results showed that the content of steel fibres in UHPFRC layer did not affect the bond strength at the interface between the UHPFRC and NSC/HSC layers.

- Test results showed that the ultimate shear capacity of the composite beams were significantly higher than the NSC/HSC beams.

- The behaviour of UHPFRC-NSC/HSC composite beams in series 3 exhibited similar failure mode. The initial crack was observed to be diagonal in the mid-depth of the shear span in the NSC/HSC layer. As the applied load increased, additional diagonal cracks were formed within the shear span. Finally, the failure occurred when the tensile stresses in the NSC/HSC layer exceeds the tensile strength of concrete in the NSC/HSC layer.

- The addition of dowels and shear stud was not very effective in enhancing the shear capacity of the composite beam.

- The composite beams exhibit high ductility compared to NSC/HSC beam. 


\subsection{Analytical program}

Analytical models to predict the flexural and shear behaviour of UHPFRC beams and shear behaviour of UHPFRC-NSC/HSC composite beams were developed as shown in Table 8.1.The following conclusions were drawn:

- The results of proposed model for predicting the shear capacity based on the average bond strength $\tau$ for UHPFRC calculated from a single fibre pullout test show good agreement with the experimental tests in this program and by other researchers.

- A procedure for predicting the flexural capacity of UHPFRC beams was presented. This method shows good agreement with the experimental test results of this program investigation and with experiments conducted by other researchers.

- A model for predicting the shear capacity of UHPFRC-NSC/HSC composite beams shows good agreement with the experimental test results of this program.

- The proposed model allows evaluating the effect of fibre volume content $(1 \%, 1.5 \%$, and $2 \%$ ) on shear capacity of fibre reinforced concrete beams.

- A finite element model was developed based on the smeared cracking approach adopting a plasticity-based concrete model. The validity of the proposed model was established through comparison with the results of the experimental test program in this study and with experimental results conducted by other researchers.

- The FE model was then carried out for size effect analysis. The results of finite element analysis show that the size effect in structures made of UHPFRC material has little influence on the shear capacity.

- Similar to the experimental results, the finite element analysis results show that increasing the compressive strength of HSC concrete layer in compression beyond 51 MPa did not enhance the shear capacity of UHPFRC-NSC/HSC composite beams. Furthermore, the beams with $100 \mathrm{MPa}$ of HSC layer show less ductility and the load versus central deflection relationship was linear due the high compressive strength of the concrete in the compression zone. This indicates that using high compressive concrete strength in compression will reduce the ductility of UHPFRC-NSC/HSC composite beams due to the increase of the brittleness of the concrete layer in compression. 
- A comparison between the finite element analysis and the analytical model for the different UHPFRC and UHPFRC-NSC/HSC composite beam sizes show that the present finite element analysis and the analytical model have very close results. This indicates that both finite element model and the analytical models developed in chapter 6 are capable of predicting the shear behaviour of UHPFRC and UHPFRC-NSC/HSC beams.

Table 8.1 Summary of proposed models

\begin{tabular}{|c|c|c|}
\hline Material & Failure & Model \\
\hline UHPFRC & Shear & $\begin{array}{l}V_{u}=V_{c}+V_{f} \\
V_{c}=\left(0.24 \sqrt{f_{c}^{\prime}}+17.2 \rho_{w} * \frac{M * d}{V}\right) * b_{w} * d_{v} \\
V_{f}=F * \tau * b_{w} * d_{v} \cot \theta \\
F=\frac{V_{s f} l_{f}}{d_{f}}\end{array}$ \\
\hline UHPFRC & Flexure & $M_{u}=f_{f t} * \frac{(h-c)^{2}}{2} * b+\alpha_{1} \alpha_{2} f_{c}^{\prime} \beta_{1} c b *\left(c-\frac{\beta_{1} c}{2}\right)$ \\
\hline UHPFRC-NSC/HSC & Shear & $\begin{array}{l}V_{u}=V_{c}+V_{f} \\
V_{c}=\left(0.16 \sqrt{f_{c}^{\prime}}+17.2 \rho_{w} * \frac{M * d}{V}\right) * b * d_{v} \\
V_{f}=F^{*} \tau * b *\left(d-h_{n}\right) \\
F=\frac{V_{s f} l_{f}}{d_{f}}\end{array}$ \\
\hline
\end{tabular}

\subsection{Future research}

Suggestions for future research are given below:

1- Investigating composite actions with other reinforced concrete members. It was evident that bond strength between UHPFRC and NSC/HSC layers was high; therefore, this composite system can be extended to other structural members such as slabs. 
2- An experimental program to investigate the reversed cyclic loading response of UHPFRC and UHPFRC-NSC/HSC beams.

3- An experimental program to investigate the durability of UHPFRC-NSC/HSC beams such as chloride test, freeze and thaw cycles.

4- Determine the resistance factors of UHPFRC materials through probability study based on experiments to support the analytical data.

5- Determine an effective moment of inertia model that accurately models the behaviour of UHPFRC composite members subjected to shear and bending.

6- Further fibre types could be used to examine the influence of fibre geometry on the structural behaviour of UHPFRC members. 


\section{REFERENCES}

ABAQUS Standard User's Manual, (2008), “ABAQUS User's Manuals” Hibbitt, Karlsson and Sorensen Inc. Dassault Systèmes Simulia Corporation, Version 6.9, 2011.

ACI-ASCE Committee 426, (1973), "Shear Strength of Reinforced Concrete Members" Proceedings, Vol. 99, ST6, pp. 1091-1187.

ACI-ASCE Committee 445, (1998), "Recent Approaches to Shear Design of Structural Concrete," ASCE Journal of Structural Engineering, Vol. 124, No. 12, pp. 1375-1417

Adebar, P., Mindess, S., St.-Pierre, D., and Olund, B., (1997), "Shear Tests of Fibre Concrete Beams without Stirrups,” ACI Structural Journal, Vol. 94, No. 1, pp. 68-76.

AFGC Groupe de travail BFFUP, (2002), «Ultra High Performance Fibre Reinforced Concretes: interim recommendations", Scientific and Technical Committee, Association Française de Genie Civil

Ahlborn, T.M., Peuse, E.J., and Msson, D.L, (2008), "Ultra-High Performance Concrete for Michigan bridges material performance -phase I", in Report. No. CSD-2008-11, Michigan Tech Transportation Institute, Houghton, Michigan.

Almansour, H., and Lounis, Z., (2010), "Innovative Design Approach of Precast-Prestressed Girder Bridges Using Ultra High Performance Concrete", Canadian Journal of Civil Engineering, Vol. No. 4, pp. 511-521 
Al-Ta'an, S. A., and Al-Feel, J. R., (1990), "Evaluation of Shear Strength of Fibre-Reinforced Concrete Beams", Cement and Concrete Composites, Vol. 12, No. 2, pp. 87-94

Allen, H. G., (1972), “The Strength of Thin Composite of Finite Width, with Brittle Matrices and Random Discontinuous Reinforcing Fibres”, Journal of Physics, Vol. 5, pp. 331-343

American Concrete Institute, (2011), "Building Code Requirements for Structural Concrete", ACI Standard 318-11

Alwan, J. M.; Naaman, A. E., and Guerrero, P., (1999), "Effect of Mechanical Clamping on the Pull-Out Response of Hooked Steel Fibres Embedded in Cementitious Matrices," Concrete Science and Engineering, Vol. 1, pp. 15-25.

Aoude, H., (2007), "Structural Behaviour of Steel Fibre Reinforced Concrete Members", PhD thesis, McGill University, Montreal, Canada

Aoude H., Belghiti M., Cook W.D., and Mitchell D., (2012), "Response of Steel FibreReinforced Concrete Beams with and without Stirrups", ACI Structural Journal Vol. 109, No. 3, pp. 359-367

Ashour, S.A., and Hasanain, G.S., and Wafa, F.F., (1992), "Shear Behaviour of High-Strength Fibre Reinforced Concrete Beams”, ACI Structural Journal Vol. 89, No. 2, pp. 176-184 
ASTM C39/C39M, (2010), "Standard Test Method for Compressive Strength of Cylindrical Concrete Specimens", American Society for Testing and Materials, West Conshohocken, PA, PP.7

ASTM C1609/C1609M-05, (2005), "Standard Test Method for Flexural Performance of FibreReinforced Concrete (Using Beam with Third-Point Loading" ASTM International, West Conshohocken, PA, pp. 9

ASTM C496/C496M, (1996), "Standard Test Method for Splitting Tensile Strength of Cylindrical Concrete Specimens" ASTM International, West Conshohocken, PA

ASTM C882, (1999), "Standard Test Method for Bond Strength of Epoxy-Resin Systems Used With Concrete by Slant Shear", ASTM International, West Conshohocken, PA

ASTM A615/A615M-12, (1972), "Standard Specification for Deformed and Plain Carbon-Steel Bars for Concrete Reinforcement", ASTM International, West Conshohocken, PA

ASTM C143/C143M, (2012), "Standard Test Method for Slump of Hydraulic-Cement Concrete, concrete, concrete slump, cone, consistency, plasticity, slump, workability", ASTM International, West Conshohocken, PA

Aveston, J., Mercer, R.A., and Sillwood, J.M., (1974), "Fibre Reinforced Cements - Scientific Foundation for Specifications", Proceeding of National Physical Laboratory Conference, UK, pp. $93-103$ 
Baby, F., Billo J., Renaud J.C., Massotte, C., Marchand, P., and Toultemond, F., (2010), "Shear Resistance of Ultra High Performance Fibre-Reinforced Concrete I-beams", Fracture Mechanics of Concrete and Concrete Structures, Korea Concrete Institute ISBN 978-89-5708-182-2, pp. $1411-1417$

Barnett, S.J., Lataste, J., Parry, T., Millard, S.G., and Soutsos M.N., (2010), “Assessment of Fibre Orientation in Ultra High Performance Fibre Reinforced Concrete and its Effect on Flexural Strength", Materials and Structures, Vol. 43, pp. 1009-1023

Bache, H.H., (1987), "Introduction to Compact Reinforced Composite", Nordic concrete research, No. 6, pp. 19-33

Banthia, N., and Trottier, J. F., (1994), "Concrete Reinforced with Deformed Steel Fibres, Part 1: Bond Slip Mechanisms", ACI Material Journal, Vol. 91, No. 5, pp. 435-446

Batson, G., Jenkins, E., and Spatney, R., (1972), "Steel Fibres as Shear Reinforcement in Beams", ACI Journal Proceedings, Vol. 69, No. 10, pp. 640-644

Bierwagen, D., and Abu-Hawash, A., (2005), "Ultra High Performance Concrete Highway Bridge", Proceed of the 2005 Mid-Continent Transportation Research Symposium, Ames, Iowa, pp.1-14

Birchall, J.D., Howard, A.J., and Kendall, K., (1981), "Flexural Strength and Porosity of Cements", Nature, Vol. 289, pp. 388-390 
Buitelaar, P., (2004), "Ultra High Performance Concrete: Development and application during 25 years", Plenary Session international Symposium on UHPC

Canadian Standard Association, (2004), "Design of Concrete Structures”, CSA Standard A23.304

Canadian Standard Association, (1983), "Deformed Steel Wire for Concrete Reinforcement". (CSA) Standard G30.14-M83, Rexdale, Ontario, 1983

CEB-fib, (2010), “CEB-FIP Model Code”, 1st Draft, Vol. 1,” Lausanne, Switzerland

Chan, Y.W., and Chu, S.H., (2004), "Effect of Silica Fume on Steel Fibre Bond Characteristics in Reactive Powder Concrete," Cement and Concrete Research, Vol. 34, No. 7, pp. 1167-1172

Chen, L., and Graybeal, B., (2012). "Modeling Structural Performance of Ultrahigh Performance Concrete I-Girders", Journal of Bridge Engineering, Vol. 17, No. 5, pp. 754-764.

Collins, M. P., Mitchell, D., Adebar, P.E.; and Vecchio, F.J., (1996), “A General Shear Design Method," ACI Structural Journal, Vol. 93, No. 1, pp. 36-45.

Cunha, V.M. C.F., Barros, J.A.O., and Sena-Cruz, J. M., (2010), "Pullout Behaviour of Steel Fibres in Self-Compacting Concrete," Journal of Materials in Civil Engineering, ASCE, V. 22, No. 1, Jan., pp. 1-9. 
De Larrard, F., (1999), "Concrete Mixture Proportioning - A Scientific Approach", Modern concrete technology Vol. 9, E \& FN SPON, London, England, pp. 421

De Larrard, F., Sedran T., (1994), "Optimization of Ultra-High-Performance Concrete by the Use of a Packing Model", Cement and Concrete Research, Vol. 24, No. 6, pp. 997-1009

Dinh, H.H., (2009), "Shear Behaviour of Steel Fibre-Reinforced Concrete Beams without Stirrup Reinforcement", PhD thesis, University of Michigan, Ann Arbor, MI, pp. 285

Dinh, H.H., Parra-Montesinos, G. J., and Wight, J. K., (2010), "Shear Behaviour of Steel FibreReinforced Concrete Beams without Stirrup Reinforcement” ACI Structural Journal, Vol. 107, No. 5 , pp. $597-606$

Dupont, D., (2003), "Modelling and experimental validation of the constitutive law and cracking behaviour of Steel Fibre Reinforced Concrete", Department of Civil Engineering. Heverlee, Catholic Universty of Leuven.

Dupont, D., and Vandewalle, L., (2005), "Distribution of Steel Fibres in Rectangular Sections", Cement and Concrete Composite, Vol. 27, No. 3, pp. 391 - 398.

Eurocode 2, (2004), "Design of Concrete Structures”, EN1992-1-1

European Concrete Committee, (1993), "CEB-FIB model code 1990", Thomas Telford Ltd, London 
Foster, S.J., (2001), “On Behaviour of High-Strength Concrete Columns: Cover Spalling, Steel Fibres, and Ductility,” ACI Structural Journal, Vol. 98, No. 4, pp. 583-589.

Graybeal, B.A., (2005), "Characterization of the Behaviour of Ultra-High Performance Concrete", PhD thesis, University of Maryland, College Park, ML, pp. 383

Graybeal, B.A., (2006), "Material Property Characterization of Ultra-High Performance Concrete", FHWA, U.S. Department of Transportation, Report No. FHWA-HRT-06-103, McLean, VA

Graybeal B.A., and Baby, F., (2013), "Development of Direct Tension Test Method for UltraHigh-Performance Fibre-Reinforced Concrete,” ACI Material Journal, Vol. 110, No. 2, pp. 177186

Graybeal, B.A., and Davis, M., (2008), “Cylinder or Cube: Strength Testing of 80 to $200 \mathrm{MPa}$ (11.6 to 29 ksi) Ultra-High-Performance Fibre-Reinforced Concrete”, ACI Material Journal, Vol. 105, No. 6, pp. 603-609

Graybeal B.A., Tanesi, J., (2007), “Durability of an Ultra-High Performance Concrete”. ASCE, Journal of Materials in Civil Engineering Vol. 19, No. 10, pp. 848-854

Habel, K., Denarie, E., Brühwiler, E., (2006), "Structural Response of Elements Combining Ultra High-Performance Fibre-Reinforced Concretes (UHPFRC) and Reinforced Concrete", ASCE Journal of Structural Engineering, Vol. 132, No. 11, pp. 1793-1800 
Hajar, Z., Lecointre, D., Simon, A., and Petitjean, J., (2004), "Design and Construction of the World First Ultra-high Performance Concrete Road Bridges", Proceedings of the International Symptom on UHPC, Kassel, Germany, pp.39-48

Hannant, D. J., (1978), "Fibre Cements and Fibre Concretes”, John Wiley and Sons, New York

Johnston, C., (2001), "Fibre-reinforced Cements and Concretes", Gordon and Breach, Amsterdam

Hillerborg, A., Modeer, M., and Petersson, P.E., (1976), “Analysis of Crack Formation and Crack Growth in Concrete by Means of Fracture Mechanics and Finite Elements" Cement Concrete Research, Vol. 6, No. 6, pp. 773-782.

Jeli, I., Pavlović, M.N., and Kotsovos, M.D., (1999) “A study of Dowel Action in Reinforced Concrete Beams”, Magazine of Concrete Research, Vol. 51, No. 2, pp. 131 -141

JSCE, (2006), "Recommendations for Design and Construction of Ultra High-Strength Fibre Reinforced Concrete Structures (draft)", JSCE Guidelines for Concrete No. 9

JSCE, (2008), "Recommendations for Design and Construction of High Performance Reinforced Cement Composites with Multiple Fine Cracks (HPFRCC)”, JSCE Guidelines for Concrete No. 82 
Kamen, A., Denarié, E., Sadouki, H., and Brühwiler, E., (2008), “Thermo-mechanical Response of UHPFRC at Early Age - Experimental Study and Numerical Simulation", Cement and Concrete Research, Vol. 38, No. 6, pp. 822-831

Kaufmann, W., and Marti, P., (1998), "Structural Concrete: Cracked Membrane Model”, Journal of Structural Engineering, ASCE, Vol. 124, No. 12, pp. 1467-1475

Khuntia, M., Stojadinovic, B., and Goel, S.C., (1999), "Shear Strength of Normal and HighStrength Fibre Reinforced Concrete Beams without Stirrups", ACI Structural Journal, Vol. 96, No. 2, pp. 282-289

Kim, D., El-Tawil, S., and Naaman, A. E., (2008), "Loading Rate Effect on Pullout Behaviour of Deformed Steel Fibres,” ACI Materials Journal, Vol. 105, No. 6, pp. 576-584

Kwak, Y.K., Eberhard, M.O., Kim, W.S., and Kim, J., (2002), "Shear Strength of Steel FibreReinforced Concrete Beams without Stirrups”, ACI Structural Journal, Vol. 99, No. 4, pp. 530538

Lee, J., and Fenves, G. L., (1998), "Plastic-damage Model for Cyclic Loading of Concrete Structures", Journal of Engineering Mechanics, Vol. 124, No. 8, pp. 892-900.

Lee, C.D., (1990), "Constitutive Modelling and Flexural Analysis of Steel Fibre Reinforced Concrete for Structural Applications", Department of Civil and Environmental Engineering, Ann Arbor, Michigan State University. 
Lubliner, J., Oliver, J., Oller, S., and Oñate, E., (1989), “A plastic-damage Model for Concrete”, International Journal of Solids and Structures, Vol. 25, No. 3, pp. 299-326.

Loukili, A., Khelidj, A., and Richard P., (1999), "Hydration Kinetics change of the Relative Humidity and Autogenous Shrinkage of Ultrahigh Strength Concrete", Cement and Concrete Research, Vol. 29, No. 4, pp. 577-584

Magureanu, C., Sosa, I., Negrutiu, C., and Heghes, B., (2010), "Bending and Shear Behaviour of Ultra-high Performance Fibre Reinforced Concrete", High Performance Structures and Materials Journal, Vol. 112, pp. 79-89

Mahmud, G. H., Yang, Z., and Hassan A.M.T., (2013), "Experimental and Numerical Studies of Size Effects of Ultra High Performance Steel Fibre Reinforced Concrete (UHPFRC) beams", Construction and Building Materials Vol. 48, pp. 1027-1034

Mansur, M.A., Ong, K.C.G., and Paramasivam, P., (1986), "Shear Strength of Fibrous Reinforced Concrete Beams without Stirrups", ASCE Journal of Structural Engineering, Vol. 112, No. 9, pp. 2066-2079

Mansur, M.A., Chin, M.S., and Wee, T.H., (1999), "Stress-strain Relationship of High-strength Fibre Concrete in Compression", ASCE, Journal of Materials in Civil Engineering, Vol. 11, No. 1, pp. 21-29. 
Minelli, F., (2005), "Plain and Fibre Reinforced Concrete Beams under Shear Loading: Structural Behaviour and Design Applications," PhD thesis, Department of Civil Engineering, University of Brescia, Starrylink Editrice, Brescia, Italy, pp. 429

Markovic, I., (2006), "High-Performance Hybrid-Fibre Concrete Development and Utilisation" $\mathrm{PhD}$ thesis, Delft University of Technology, Delft, the Netherlands, pp. 228

Meda, A., Rosati, G., (2003), "Design and Construction of a Bridge in very High Performance Fibre Reinforced Concrete”, Journal of Bridge Engineering, Vol. 8, No. 5, pp.281-287

Momayez, A., Ehsani, M.R., Ramezanianpour, A.A., and Rajaie,H. , (2005), "Comparison of Methods for Evaluating Bond Strength between Concrete Substrate and Repair Materials", Cement and Concrete Research, Vol. 35, p. 748-757.

Moretto, O., (1945), "An Investigation of the Strength of Welded Stirrups in Reinforced Concrete Beam", ACI Journal Proceedings, Vol. 42, No. 11, pp. 141-162

Mahmud, G.H., Yang, Z., and Hassan, A.M.T., (2013), "Experimental and Numerical Studies of Size Effects of Ultra High Performance Steel Fibre Reinforced Concrete (UHPFRC) Beams", Construction and Building Materials Vol. 48, pp. 1027-1034

Martinola, G., Meda, A., Plizzari, G., and Rinaldi, Z., (2010), "Strengthening and Repair of RC Beams with Fibre Reinforced Concrete", Cement and Concrete Composites, Vol. 32, No. 9, 2010, pp. 731-739 
Naaman, A. E., (1987), "High-Performance Fibre Reinforced Cement Composites" Proceedings of the IABSE Symposium on Concrete Structures for the Future, Paris, France, pp. 371-376.

Naaman, A.E., (2008), "High performance fibre reinforced cement composites", Caijun S, Mo YL (eds) High-performance construction materials. Science and Applications, pp. 91-153

Naaman, A.E., and Najm, H., (1991), "Bond-Slip Mechanisms of Steel Fibres in Concrete," ACI Materials Journal, Vol. 88, No. 2, pp. 135-145.

Naaman, A.E., and Reinhardt, H.W., (1995), "Characterization of High Performance Fibre Reinforced Cement Composites-HPFRCC", proceedings of High Performance Fibre Reinforced Cement Composites 2 (HPFRCC2), International Union of Testing and Research Laborat International Workshop, Ann Arbor

Naaman, A.E., Wille, K, (2010), "Some Correlation between High Packing Density, Ultra-high Performance, Flow Ability, and Fibre Reinforcement of a Concrete Matrix", BAC2010 - 2nd Iberian congress on self-compacting concrete, University of Minho, Guimaraes

Narayanan, R., and Darwish, I.Y.S., (1987), "Use of Steel Fibre as Shear Reinforcement", ACI Structural Journal, Vol. 84, No.3, pp. 216-227.

Narayanan, R., and Kareem-Palanjian, A.S., (1984), "Effect of Fibre Addition on Concrete Strengths", Indian Concrete Journal (Bombay), Vol. 58, No.4, pp. 100-103. 
Nataraja, M.C., Dhang, N. and Gupta, A.P., (1999), "Stress-strain Curves for Steel-Fibre Reinforced Concrete under Compression", Cement and Concrete Composites, Vol. 21, No. 5, pp. 383-390.

Nawy, E.G., (1996), "Reinforced Concrete: A Fundamental Approach", 3rd Edition, Prentice Hall Canada Inc., Toronto, Canada, pg. 415.

Noghabai, K., (2000), "Beams of Fibrous Concrete in Shear and Bending: Experimental and Model", ASCE Journal of Structural Engineering, Vol. 126, No. 2, pp. 243-251

Noshiravani, T. and Brühwiler, E., (2010), "Behaviour of UHPFRC-RC Composite Beams Subjected to Combined Bending and Shear", Proceedings of the 8th fib International $\mathrm{PhD}$ Symposium in Civil Engineering, Kgs. Lyngby, Denmark: DTU Byg.

Orange G., Acker P., and Dugat J., (1999), "Damage Resistance and Micromechanical Analysis of Ultra High Performance Concrete", Proceeding of the 3rd International RILEM Workshop on High Performance Fibre Reinforced,

Orange G., Dugat J., Acker P., (2000), "DUCTAL: New Ultra High Performance Concretes: Damage, Resistance and Micromechanical Analysis", Fifth RILEM Symposium on Fibre- Reinforced Concretes (FRC) (BEFIB 2000), Ed. by P. Rossi and G. Chanvillard, Lyon, France, pp 781-790.

Park, R., and Paulay, T., (1974), "Reinforced Concrete Structures," John Wiley \& Sons, Inc. New York, USA. 
Parra-Montesinos, G.J., (2006), "Shear Strength of Beams with Deformed Steel Fibres", Concrete International Journal, Vol. 28, No. 11, pp. 57-66

Places, A. , and Regan, P.E. , (1971), "Shear Failure of Reinforced Concrete Beams", ACI Journal, proceeding, Vol. 68, No. 10, pp. 763-773

Rahman, S., Molyneaux, T., and Patnaikuni, I., (2005), "Ultra high performance concrete, recent applications and research", Australian Journal of Civil Engineering, Vol. 2, No. 1, pp.13-20

Reineck, K.H. and Frettlohr, B., (2010), "Tests on Scale Effect of UHPFRC Under Bending and Axial Forces," Proceedings of the Third International fib Congress and Exhibition Incorporating the PCI Annual Convention and National Bridge Conference, Washington, DC, Compact Disc, Paper 54.

Richart, F.E., (1927), "An Investigation of Web Stresses in Reinforced Concrete Members", Bulletin 166, University of Illinois Engineering Experiment Station, Urbana, IL

Richard, P., Cheyrezy, M., (1995), “ Composition of Reactive Powder Concretes”, Cement and Concrete Research, Vol. 25, No. 7, pp. 1501-1511.

Robins, P., Austin, S., and Jones, P., (2002), "Pull-Out Behaviour of Hooked Steel Fibres", Materials and Structures, Vol. 35, pp. 434-442. 
Romualdi, J. P., and Mandel, J. A., (1964), "Tensile Strength of Concrete Affected by Uniformly Distributed and Closely Spaced Short Lengths of Wire Reinforcement", ACI Journal, Proceedings Vol. 61, No.6, pp. 657-671.

Rosenbusch, J., and Teutsch, M., (2002), “Trials Beams in Shear (Series 1 and 2)”, Brite/Euram Project 97-4163, Final report, sub task 4.2, Technical University of Braunschweig, Braunschweig, Germany

Rosenbusch, J., and Teutsch, M., (2002), "Trials Beams in Shear (Test Programme 3)", Brite/Euram Project 97-4163, Final report, sub task 4.2, Technical University of Braunschweig, Braunschweig, Germany

Rossi, P., (1997), "High Performance Multimodal Fibre Reinforced Cement Composites (HPMFRCC): The LCPC Experience”, ACI Materials Journal, Vol. 94, No. 6, pp 478-483.

Rossi, P., (2002), "Development of new Cement Composite Material for Construction, Innovations and Developments in Concrete Materials and Construction", Proceedings of the International Conference, University of Dundee, Ed. by R. K. Dhir, P. C.Hewlett and L. J. Csetenyi, Dundee, Scotland, pp. 17-29.

Roy, D. M., Gouda, G. R., Bobrowsky, A., (1972), "Very High Strength Cement Pastes prepared by Hot Pressing and other High Pressure Techniques”, Cement and Concrete Research, Vol. 2, No. 3, pp. 349-366. 
Saucier, F., Bastien, J., Pigeon, M., and Fafard, F., (1991), “A Combined Shear-Compression Device to Measure Concrete to Concrete Bonding”, Experimental Techniques, Vol. 15, No. 5, pp. $49-55$

Schantz, B.A., (1993), "The Effect of Shear Stress on Full Scale Steel Fibre Reinforced Concrete Beams", MS thesis, Clarkson University, Potsdam

Schmidt, M. and Fehling, E., (2004), "Ultra-High-Performance Concrete: Research, Development and Application in Europe", American Concrete Institute, Vol. 228, pp. 51-78

Shah, S., and Rangan, B.V., (1971), "Fibre Reinforced Concrete Properties", ACI Journal Proceedings, Vol. 68, No. 2, pp. 126-135

Sharma, A. K., (1986), "Shear Strength of Steel Fibre Reinforced Concrete Beams," ACI Journal, Proceedings Vol. 83, No. 4, pp. 624-628.

Shin, S.W., Oh, J., and Ghosh, S. K., (1994), "Shear Behaviour of Laboratory-Sized HighStrength Concrete Beams Reinforced with Bars and Steel Fibres," Fibre Reinforced Concrete Developments and Innovations, SP-142, American Concrete Institute, Farmington Hills, pp. 181200.

Spasojević, A., (2008), "Structural Implications of Ultra-High Performance Fibre-Reinforced Concrete in Bridge Design," Ph.D. Thesis NO 4051. Ecole Polytechnique Fédérale de Lausanne (EPFL). Switzerland, p. 285. 
Stengel, T., (2009), "Effect of Surface Roughness on the Steel Fibre Bonding in Ultra High Performance Concrete (UHPC)," Proceedings of NICOM3 (Nanotechnology in Construction 3), pp. 371-376

Sujiravorakul, C., (2001), "Development of High Performance Fibre Reinforced Cement Composites Using Twisted Polygonal Steel Fibres" PhD thesis, University of Michigan, Ann Arbor, MI, pp. 230

Suleiman, M., Sritharan, S., and Vande Voort, T.L., (2008), "Design and Performance Verification of UHPC piles for deep foundations", Center for Transportation Research and Education Iowa State University

Susetyo, J., Gauvreau, P., and Vecchio , F. J., (2011), "Effectiveness of Steel Fibre as Minimum Shear Reinforcement”, ACI Structural Journal, Vol. 108, No. 4, pp. 488 - 496

Swamy, R. N., and Al-Taan, S.A., (1981), "Deformation and Ultimate Strength in Flexure of Reinforced Concrete Beams Made with Steel Fibre Concrete", ACI Journal Proceedings, Vol. 78, No. 5, pp. $395-405$

Swamy, R.N., and Bahia, H.M., (1985), "Effectiveness of Steel Fibres as Shear Reinforcement", Concrete International: Design and Construction, Vol. 7, No. 3, pp. 35-40

Swamy, R.N., Jones, R., and Chiam, A.T.P., (1993), "Influence of Steel Fibre on the Shear Resistance of Lightweight Concrete I-Beams”, ACI Structural Journal, Vol. 90, No. 1, pp. 103 114 
Swamy, R.N., and Mangat, P.S., (1976), "The Interfacial Bond Stress in Steel Fibre Cement Composites", Cement and Concrete Research, Vol. 6, No. 5, pp. 641 - 649

Swamy, R.N., Mangat, P.S., and Rao, C.V.S.K., (1974), "The Mechanics of Fibre Reinforcement of Cement Matrices", Fibre Reinforced Concrete, SP-44, American Concrete Institute, Detroit, pp. 1-28.

Singh, B., and Chintakindi, S., (2012), "An Appraisal of Dowel Action in Reinforced Concrete Beams", Proceedings of the ICE - Structures and Buildings, Vol. 166, No. 5, pp. $257-267$

Soroushian, P., and Lee, C., (1990), "Distribution and Orientation of Fibres in Steel Fibre Reinforced Concrete", ACI Materials Journal Vol. 87, no. 5, pp. 433-439.

Tomas, J., and Ramaswamy, A., (2007), "Mechanical Properties of Steel Fibre Reinforced Concrete", ASCE Journal of Materials in Civil Engineering, Vol. 19, No. 5, pp. 385-392

Wahba, K., Marzouk, H., and Dawood, N., (2012), "Structural Behaviour of UHPFRC Beams without Stirrups", 3rd International Structural Specialty Conference, Edmonton, Alberta

Wafa, F.F., and Ashour, S.A., (1992), "Mechanical Properties of High-Strength Fibre Reinforced Concrete", ACI Material Journal, Vol. 85, No. 5, pp. 449-455 
Wall, J.S., and Shrive N.G., (1988), "Factors Affecting Bond between New and Old Concrete", ACI Materials Journal, Vol. 85, No.2 pp. 117-125.

Wight J.K., and MacGregor J.G., (2012), "Reinforced Concrete: mechanics and design”, 6th ed., Pearson, Toronto

Wille, K., Kim, D.J., and Naaman, A.E., (2011), "Strain-hardening UHP-FRC with Low Fibre Contents", Materials and Structures, No. 44, pp. 583-598

Wille, K., and Naaman, A. E., (2012a), "Ultra-High Performance Concrete and Fibre Reinforced Concrete: Achieving Strength and Ductility without Hear Curing”, Materials and Structures, No. 45, pp. 309-324

Wille, K., and Naaman, A. E., (2012b), "Pullout Behaviour of High-Strength Steel Fibres Embedded in Ultra-High-Performance Concrete”, ACI Materials Journal, Vol. 109, No. 4, pp. $479-487$

Wille, K. and Naaman A. (2013), "Effect of Ultra-High-Performance Concrete on Pullout Behaviour of High-Strength Brass-Coated Straight Steel Fibres”, ACI Materials Journal, Vol. 110, No. 4, pp. 451-461

Wille, K. and Parra-Montesinos, G., (2012), "Effect of Beam Size, Casting Method, and Support Conditions on Flexural Behaviour of Ultra-High-Performance Fibre-Reinforced Concrete," ACI Materials Journal, Vol. 109, No. 3, pp. 379-388. 
Winter, G., and Nilson, A.H., (1979), "Design of concrete structures", 9th ed., New York, McGraw-Hill

Write, P.J.F., (1955), “Comments on Indirect Tensile Test on Concrete Cylinders”, Magazine of Concrete Research, Vol. 7, No. 20, pp. 87-96

Yang, I., Joh, C., and Kim, B. (2010), "Structural Behaviour of Ultra-high Performance Concrete Beams Subjected to Bending”, Engineering Structures, Vol. 32, pp. 3478-3487

Yang, I., Joh C., and Kim, B. (2012), "Shear Behaviour of Ultra-high Performance FibreReinforced Concrete Beams without Stirrups", Magazine of Concrete Research, Vol. 64, No. 11, pp. 979-993

Yang, K., Sim, J., and Kang, T., (2013), "Generalized Equivalent Stress Block Model Considering Varying Concrete Compressive Strength and Unit Weight”, ACI Structural Journal Vol. 110, No. 5, pp. 791-799

Yudenfreund, M., Skalny, J., Mikhail, R.S., Brunauer, S., (1972), "Hardened Portland Cement Pastes of Low Porosity, II. Exploratory Studies, Dimensional Changes", Cement and Concrete Research, Vol. 2, No. 3, pp. 331-348.

Zsutty, T., (1971), "Shear Strength Prediction for Separate Categories of Simple Beam Tests”, ACI Journal, proceeding, Vol. 82, No. 2, pp. 138-143 
